\title{
PAISAJES SONOROS DEL RETORNO Palma de aceite, despojo y culturas de paz en el postconflicto colombiano
}

María del Pilar Ramírez Gröbli 


\section{Nexos y Diferencias \\ Estudios de la Cultura de América Latina}

\section{8}

F nfrentada a los desafíos de la globalización y a los acelerados procesos Cde transformación de sus sociedades, pero con una creativa capacidad de asimilación, sincretismo y mestizaje de la que sus múltiples expresiones artísticas son su mejor prueba, los estudios culturales sobre América Latina necesitan de renovadas aproximaciones críticas. Una renovación capaz de superar las tradicionales dicotomías con que se representan los paradigmas del continente: civilización-barbarie, campo-ciudad, centro-periferia y las más recientes que oponen norte-sur y el discurso hegemónico al subordinado.

La realidad cultural latinoamericana más compleja, polimorfa, integrada por identidades múltiples en constante mutación e inevitablemente abiertas a los nuevos imaginarios planetarios y a los procesos interculturales que conllevan, invita a proponer nuevos espacios de mediación crítica. Espacios de mediación que, sin olvidar los nexos que histórica y culturalmente han unido las naciones entre sí, tengan en cuenta la diversidad que las diferencia y que existe en el propio seno de sus sociedades multiculturales y de sus originales reductos identitarios, no siempre debidamente reconocidos y protegidos.

La colección Nexos y Diferencias se propone, a través de la publicación de estudios sobre los aspectos más polémicos y apasionantes de este ineludible debate, contribuir a la apertura de nuevas fronteras críticas en el campo de la cultura de América Latina.

\section{Directores}

Fernando Aínsa (Zaragoza); Marco Thomas Bosshard (Europa-Universität Flensburg); Oswaldo Estrada (The University of North Carolina at Chapel Hill);

Luis Duno Gottberg (Rice University, Houston); Margo Glantz (Universidad Nacional Autónoma de México); Beatriz González-Stephan (Rice University, Houston); Gustavo Guerrero (Université de Cergy-Pontoise); Jesús Martín-Barbero

(Bogotá); Andrea Pagni (Friedrich-Alexander-Universität Erlangen-Nürnberg);

Mary Louise Pratt (New York University); Friedhelm Schmidt-Welle (IberoAmerikanisches Institut, Berlin) 


\section{PAISAJES SONOROS DEL RETORNO}

Palma de aceite, despojo y culturas de paz en el postconflicto colombiano

María del Pilar Ramírez Gröbli

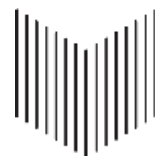

Iberoamericana • VerVuert • 2020 
Publiziert mit Unterstützung des Schweizerischen Nationalfonds zur Förderung der wissenschaftlichen Forschung.

Publicado con la ayuda del Fondo Nacional Suizo para la Investigación Científica.

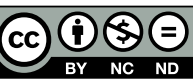

Esta obra está bajo una licencia de Creative Commons Reconocimiento-

No Comercial-Sin Obra Derivada 4.0 Internacional. Para más

información consulte https://creativecommons.org/licenses/by-nc-nd/4.0/.

Cualquier forma de reproducción, distribución, comunicación pública o transformación de esta obra solo puede ser realizada con la autorización de sus titulares, salvo excepción prevista por la ley. Diríjase a CEDRO (Centro Español de Derechos Reprográficos) si necesita fotocopiar o escanear algún fragmento de esta obra (www. conlicencia.com; 917021970 / 9327204 47)

(C) Iberoamericana, 2020

Amor de Dios, 1 - E-28014 Madrid

Tel.: +34914293522

Fax: +34914295397

(C) Vervuert, 2020

Elisabethenstr. 3-9 - D-60594 Frankfurt am Main

Tel.: +49695974617

Fax: +49695978743

info@iberoamericanalibros.com

www.iberoamericana-vervuert.es

ISBN 978-84-9192-104-2 (Iberoamericana)

ISBN 978-3-96456-904-2 (Vervuert)

DOI: https://doi.org/10.31819/9783964569059

Diseño de cubierta: Rubén Salgueiros

Depósito legal: M-13362-2020

The paper on which this book is printed meets the requirements of ISO 9706

Este libro está impreso íntegramente en papel ecológico sin cloro Impreso en España 
Hoy es su canto un azadón que le abre surcos al vivir, a la justicia en su raíz y a los raudales de su voz. En su divina comprensión luces brotaban del cantor

Violeta Parra, "Cantores que reflexionan"

Cuando los libros están de veras vivos, respiran; y uno se los pone al oído y les siente la respiración y sus palabras son contagiosas, peligrosamente, carińosamente contagiosas...

Eduardo Galeano 

Dedicado a quien es la más pura expresión del amor, la ternura y la razón: a mi madre, Soledad Leuro, jmi solecito!

A Héctor Miguel, mi hermano y entrañable amigo A Natalia, Samuel y Sebastian, mis hijos, que son la más hermosa prolongación de mi existencia

A Roland mi esposo y compañero, con quien "codo a codo somos mucho más que dos" 



\section{Índice}

Agradecimientos........................... 13

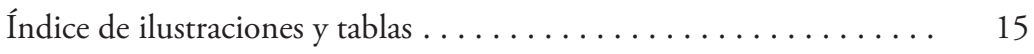

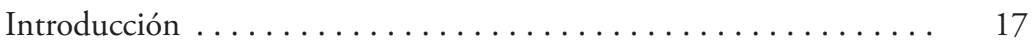

\section{Primera PARTE}

Capítulo i. Industria palmera, postconflicto y culturas de convivencia33

Capítulo ir. Cultura, conflicto y medio ambiente: aproximaciones . . 63

Capítulo int. El arte musical en el conflicto . . . . . . . . . . . . 105

Capítulo iv. Marco contextual. Agrocombustibles, conflicto y tierra. . 159

\section{Segunda PARTe}

Capítulo v. Casos de estudio. . . . . . . . . . . . . . . . . . . . . 199

Capítulo vi. Manejo del conflicto. Acciones comunitarias, convivencia y construcción de paz. Análisis comparativo ..... 259

Capítulo vir. Representación en la lírica musical: contenidos y dinámicas del conflicto . .................. 331

Capítulo viri. Conclusiones ...................... 367

Discografía y bibliografía ............................ 377

Anexo. Corpus de cantos recopilados ............... 403 



\section{Agradecimientos}

Gracias a los contactos que me proporcionó Stefan Suhner, del Grupo de Trabajo Suiza Colombia (ASK, por sus siglas en alemán), pude ponerme en comunicación, desde Suiza, con la organización Pensamiento y Acción Social. Luego, al llegar a Colombia, he logrado establecer vínculos también con la Comisión Eclesial de Justicia y Paz. Gracias a la valiosa colaboración y guía de personas muy comprometidas, como Alexandra Loaiza, de la organización Pensamiento y Acción Social, y Abilio Peña, de la Comisión Eclesial, entre otras, pude llegar hasta las zonas en combate abierto. Agradezco a los miembros de la Zona de Reserva Campesina del Valle del Río Cimitarra por haber compartido conmigo sus proyectos y obsequiarme el CD fruto de su trabajo musical. Mis agradecimientos también para Ariel Castillo, por contactarme con otros cantores del Caribe. A mi estimado colega José Manuel Camacho, por sus valiosos comentarios y su apoyo para que este proyecto se hiciera realidad. Agradezco de igual manera al profesor José Manuel López de Abiada los enriquecedores diálogos respecto al contenido de este libro. A Mercedes Jaramillo, por la lectura del texto preliminar, su aporte y contribución. Mis agradecimientos también a Mario Rodríguez, quien desde los inicios de mi investigación doctoral fue un valioso interlocutor que le ha proporcionado luz a este proyecto. Agradezco muy cariñosamente a Cristina Carmona Egler su dedicación y trabajo en la revisión textual y a Esmeralda Mora, gran amiga, sus cuidadosos y detallados aportes en la corrección del texto. Agradezco muy especialmente a Ladys Margarita Rúa, mi cuñada, quien ha colaborado 
también con diligencia y dedicación para realizar el trabajo de edición del manuscrito original.

Mis más profundos agradecimientos para las personas de las comunidades Las Pavas, El Garzal y las zonas humanitarias, quienes me permitieron conocer sus mundos y mirar con otros ojos aquellas realidades, hasta entonces desconocidas para mí. Les agradezco por haber compartido conmigo, con tanta cercanía, sus composiciones musicales, sus historias de vida y sus historias comunitarias. Para todos y cada uno de ellos y para muchas otras comunidades que están en la misma situación, expreso mi entera admiración por la valentía que los caracteriza y porque con su compromiso llevan procesos de construcción de paz ejemplares, no solo para otras comunidades en Colombia, sino para muchas comunidades del Sur Global que se ven sometidas al desplazamiento forzado de sus territorios a causa de los monocultivos de palma de aceite, la extracción y otras formas de usurpación de tierras. 


\section{Índice de ilustraciones y cuadros}

1. Las ZIDRES y el cultivo de palma de aceite....................... 46

2. Dimensiones de observación para el análisis........................ 113

3. Tipología del relato lírico en los cantos .............................. 142

4. Países con inversión en tierras de América Latina y el Caribe 170

5. Registro del área cultivada en hectáreas en América del Sur y Centro América .............................................................. 173

6. Estructura de tenencia de la tierra en Colombia signos de porcentaje ............................................................... 182

7. Regiones palmeras de Colombia ....................................... 183

8. Producción de aceite de palma crudo por zonas ................... 184

9. Instrumentos de diagnóstico y análisis ............................... 201

10. Comunidad Las Pavas...................................................... 202

11. Ubicación geográfica: comunidad Las Pavas........................ 212

12. Cuerpos de agua de la región y los cultivos de palma............ 214

13. Mapa detallado de las características geográficas de Las Pavas 217

14. Cambuches fabricados por los miembros de ASOCAB......... 221

15. Cartografía general del caso Las Pavas ................................ 223

16. Ubicación geográfica de la comunidad El Garzal................. 230

17. Ubicación geográfica de las zonas humanitarias.................. 252

18. Roles de una misma causa: desplazamiento forzado para producción de palma de aceite .................................... 267 
19. Relación de actores en el conflicto..................................... 277

20. Prospecto de casa para trabajadores de la industria palmera.. 283

21. Acciones comunitarias específicas en cada comunidad.......... 293

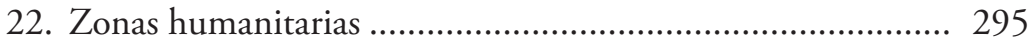

23. Circunstancias del retorno .............................................. 296

24. Reapropiación del espacio local........................................ 303

25. La casa de la memoria ..................................................... 307

26. Reterritorialización ASOCAB ...................................... 308

27. Habilitar las tierras: permanencia y resistencia..................... 310

28. Distribución de una finca campesina en El Garzal .............. 311

29. Zonas de reserva campesina ….......................................... 323

30. Temas transversales en los cantos....................................... 338

31. Resignificación del actor: las palmeras............................... 354

32. Resignificación del Estado............................................... 356

33. Resignificación del concepto campesino-campesinado ......... 361 


\section{Introducción}

Escuchar cantos y cuentos ha despertado en mí un particular interés desde muy temprana edad. Esa profunda afinidad con la música y con la literatura oral fue el motivo primero que me impulsó a emprender este proyecto de investigación. De forma paralela, la constante inquietud sobre el fenómeno de desplazamiento forzado que había convertido a Colombia en un país marcado por el destierro ocupaba recurrentemente mis reflexiones y cuestionamientos sobre esa temática. Por coincidencia, o tal vez "porque así lo quiso el destino", empecé a adentrarme en el territorio de la oralidad y a escuchar con trémulo asombro cantos y cuentos que relataban despojos y desplazamientos forzados. Ese fue mi primer acercamiento a las líricas campesinas, en las que descubrí que las voces que escuchaba provenían no solo de individuos, hombres y mujeres, sino de colectividades, quienes a través de esas melodías cantaban y contaban sus experiencias del destierro. Es admirable y fascinante confirmar que la producción oral en Colombia, así como en muchos otros países latinoamericanos, es abundante, rica y espléndidamente variada. La oralidad y la lírica musical son parte del acervo cultural, un legado heterogéneo y diverso. Esas voces se han constituido en lugar enunciativo desde donde se recuperan diversas memorias: históricas, campesinas, étnicas, ecológicas, entre muchas otras. De manera simultánea, es a través del ámbito de la oralidad en donde se sistematizan procesos comunitarios y colectivos sobre la construcción de paz, incluso en medio de los desafiantes escenarios de confrontación. 
Si bien el fenómeno del desplazamiento forzado en Colombia se ha exacerbado en la última década a lo largo y ancho de todo el país, lo han experimentado con mayor dureza las poblaciones rurales. Los desplazamientos forzados están estrechamente relacionados con el ejercicio del control y poder territoriales. No son solamente los actores armados, quienes tienen una responsabilidad ante las situaciones del despojo, sino también las aparentes estrategias de desarrollo han acarreado el desplazamiento forzado de algunas poblaciones rurales. El contexto actual, la creciente extensión de monocultivos de palma de aceite, ha transformado gran parte del paisaje agrícola en las diversas regiones y ha incidido en el desarraigo de los asentamientos rurales. Si bien la migración interna forzada ha caracterizado parte de la dinámica sociopolítica en la historia del país, sus causas son múltiples y han ido cambiando durante las décadas del conflicto armado e imponiendo patrones de violencia que son sensiblemente distintos entre el espacio rural y el espacio urbano. De acuerdo con Ana María Ibáńez (2008), los actores armados han usado el desplazamiento forzado como una forma de violencia deliberada. En el contexto colombiano, tal desplazamiento es una estrategia efectiva para ejercer el control y el dominio territoriales, usurpar activos valiosos y explotar los recursos naturales. La otra estrategia es evitar la resistencia civil, que es lo que viene sucediendo con mayor intensidad, tras la firma del Acuerdo de Paz en 2016.

La literatura que documenta la dinámica, las causas y la intensidad del desplazamiento es copiosa. Asimismo, las narrativas sobre los desplazados han sido y siguen siendo consignadas, en su gran mayoría, en el universo ficcional. En la literatura escrita, personajes de diversa índole narran las experiencias del destierro; algunos títulos como El día del odio (1952), de José Antonio Osorio, Los parientes de Ester (1978), de Luis Fayad, u obras más recientes como La multitud errante (2003), de Laura Restrepo, son producto de esta temática del desarraigo en la literatura. Otros autores como Alfredo Molano, en obras como Siguiendo el corte: relatos de guerras y de tierras (1989), o Arturo Álape, en Ciudad Bolivar: La hoguera de las ilusiones (1995), recurren a la literatura testimonial para dar voz a las víctimas de la violencia. Mientras la producción escrita sobre el desplazamiento forzado como fenómeno ha ganado gran despliegue, sea en el marco de análisis sociológico o 
político o en la creación ficcional, la literatura oral producida en los diversos contextos de la guerra ha quedado, en su mayoría, desatendida o poco estudiada. Asimismo, se desconoce que esos relatos orales tematizan no solo el desplazamiento forzado, sino que también contienen imaginarios del retorno a los territorios.

Incontables son las historias que surgen, especialmente en los espacios rurales, sobre las formas como el desplazamiento ha transformado e impactado la cultura comunitaria y campesina. Una extensa variedad de literatura oral, como el canto, la décima, los romances, las coplas, la poesía popular, entre otras, ha sido la herramienta primera del relato rural. Las comunidades que enfrentan el desplazamiento consignan experiencias y saberes en la literatura oral, que por su fuerza e inmediatez ha prevalecido a la escritura. Estas formas de la literatura oral proveen una visión de mundo en cuyos relatos no solo se muestran las dinámicas internas de las poblaciones, sino que revelan historias alternativas y, al mismo tiempo, subalternas. Además, la tradición oral constituye un pilar para la comprensión de los significados sociales, políticos y culturales que caracterizan el ambiente rural y campesino. Las manifestaciones orales que surgen desde las poblaciones campesinas recogen las cosmologías y los conceptos de espacialidad y temporalidad que han sido amenazados a causa de las confrontaciones. Por ello, no solo se encuentran consignadas las escenas y circunstancias del desplazamiento forzado, sino que se reconstruye la perspectiva futura del retorno y se recupera la historia comunitaria, el pasado y el origen.

Ese es el caso de las composiciones inéditas que he recolectado para este estudio, en las que a través del canto se narran los procesos de desplazamiento forzado ocasionados por la industria de la palma de aceite en Colombia durante las últimas dos décadas. Comunidades de pescadores y campesinos de los litorales del Atlántico y del Pacífico le cantan al ayer, al hoy y al mańana; recuperan temporalidades míticas que recrean en la melodía vallenata o en el rap - o en otros ritmos - y reproducen en los cantos nuevos significados del habitante rural, de la tierra y del territorio. Este análisis abarca el periodo a partir de la segunda mitad de la década de los años 1990 hasta finales del año 2018 y examina las acciones locales y comunitarias que inciden en la transformación del conflicto, la construcción de espacios de paz 
y la reafirmación de la subjetividad comunitaria. El análisis consta de dos ejes: el primero investiga qué mecanismos y estrategias emplean las poblaciones rurales para retornar a sus territorios de origen. El segundo examina la dimensión política de la música en los procesos de desplazamiento y retorno. Las comunidades de enfoque son Las Pavas y El Garzal, de la zona del Caribe colombiano, y las comunidades afrodescendientes de las zonas humanitarias ${ }^{1}$ de la región del Pacífico. Estas comunidades han experimentado consecuencias devastadoras, en concreto, la usurpación de tierras destinadas a los monocultivos de palma de aceite. Se trata de un análisis complementario que busca, por un lado, explorar cómo se reconstruyen los procesos de desarraigo y la representación de la historia comunitaria, y asimismo cómo se plasman los significados culturales de la naturaleza, de la tierra y el territorio en la producción oral y musical campesinas. Por otro lado, examina qué respuestas y propuestas nacen en los ámbitos comunitarios y cómo gestionan las comunidades diversos recursos, culturales, sociales y económicos, para hacer posibles los retornos. Estos dos ejes integran una reflexión complementaria que es útil para poder visibilizar los procesos de retorno y lucha por el territorio que llevan a cabo estas tres comunidades mencionadas. Estas reflexiones intentan ser un aporte para la inclusión de las gestiones comunitarias en el contexto actual del país y en la construcción de paz. La transformación hacia la convivencia en el espacio rural exige la inclusión y el reconocimiento de las comunidades campesinas, sus saberes, sus conocimientos y

1. Las zonas humanitarias son espacios de reasentamiento poblacional en la región del Pacífico colombiano. La organización Justicia y Paz, que acompańa el proceso de esas comunidades, define las zonas Humanitarias y las zonas de biodiversidad de la siguiente manera: "Las Zonas Humanitarias y las Zonas de Biodiversidad son lugares específicos de protección de la vida en el territorio. Las Zonas Humanitarias son lugares perfectamente visibilizados y habitados por un grupo humano que afirma sus derechos como población civil y cuyos miembros comparten libremente un Proyecto de Vida para defenderse de la militarización y de la confrontación armada. Las Zonas de Biodiversidad son áreas de protección y de recuperación de ecosistemas de Territorios Colectivos o privados y de afirmación del derecho a la alimentación de grupos familiares cuyos predios han sido arrasados o están en riesgo de ser destruidos por agronegocios, obras de infraestructura, o explotación de recursos naturales" (Bouley y Rueda 2009: 3). 
su ineludible participación en la toma de decisiones sobre los bienes naturales.

En el proceso de selección de los casos a estudiar una condición imprescindible era que fueran exclusivamente comunidades rurales. Aunque también se encuentran procesos de migración forzada en las ciudades, no se puede constatar que los procesos de retorno comunitarios sean duraderos. Los procesos de dispersión y pérdida de la identidad comunitaria fuera del hábitat lugareño impiden la cohesión colectiva de las poblaciones. Otro criterio importante fue registrar las dinámicas comunitarias en relación a los cultivos de palma. Por un lado, en la región del Pacífico han venido ocurriendo diversos episodios de violencias y masacres, especialmente hacia la población afrodescendiente. Este hecho se ha recrudecido en los primeros meses del año 2017 y, con mayor intensidad, tras la entrada en vigencia del Acuerdo de Paz firmado en el 2016. ${ }^{2}$ Los atropellos contra los afrocolombianos en el paro de Buenaventura fueron una muestra más de esa situación. Además, existe aún un proceso legal en que se denuncia a empresarios palmeros por ocupar territorios colectivos de las comunidades afrocolombianas. Por otro lado, en la zona del Atlántico se han incrementado excesivamente los cultivos de la palma de aceite y existen diversos procesos de resistencia local. Un tercer criterio - indispensable - era examinar comunidades que hayan sido afectadas por los cultivos de palma de aceite a larga escala. En este sentido, se consideraban varios niveles de desterritorialización, que van desde la amenaza del desplazamiento y el desplazamiento de hecho hasta el retorno al territorio. Estos tres criterios anteriores hubieran sido insuficientes para los propósitos de este estudio si no se hubiesen elegido comunidades que poseen material narrativo y/o musical relacionado con la problemática de los monocultivos de aceite de palma, pues esta última condición es absolutamente necesaria porque solo así es posible escudriñar a fondo la reconstrucción y representación de las realidades sociales a través de la creación lírica. En este estudio se opta por el uso del término 'agro-

2. Para contextualizar la situación de los pueblos afrocolombianos en el Pacífico, se puede consultar Melva (2016). 
combustible'3 y no 'biocombustible', pues el prefijo 'agro-' se relaciona con la actividad agrícola y su uso en la industria de carburantes.

Comparto con Adrián F. Freja de la Hoz, en su publicación La literatura oral en Colombia. Romances, coplas y décimas en el Pacífico y el Caribe colombianos (2015), que la literatura oral ha quedado al margen de la historia colombiana. Las diferentes expresiones orales de los espacios locales, especialmente aquellas de las zonas rurales, han sido desvirtuadas de injusta manera. Como este autor afirma, "la noción de literatura adoptada en las historias, teorías y críticas literarias en Colombia ha estado mediada siempre por la tradición letrada" (Freja 2015: 13). Los estudios académicos han dado primacía a la literatura escrita, olvidando — deliberadamente- que existe un importante legado cultural presente y preponderante en el terreno de la oralidad. Así es que gran parte de las composiciones que emergen de los espacios rurales locales están aún por ser exploradas e incluidas en la historia y en la construcción de la nación colombiana pluriétnica y multicultural. La producción musical de las comunidades campesinas —objeto de este estudio- no solo revela historias inéditas de nuestro pasado colombiano, sino que contiene huellas imprescindibles para conocer esa Colombia que ha estado ausente. Sin ser ajenas a los procesos de una globalización imperante, esas manifestaciones líricas y musicales participan en la reestructuración y en el intercambio de lenguajes que componen el conjunto semiótico de los contextos lugareños del campo, en donde surgen.

En el proceso de transición hacia la convivencia pacífica que se ha estado negociando en la sociedad colombiana, en especial, durante los últimos cuatro años, se hace ineludible redescubrir la Colombia rural. En consecuencia, es necesario dar voz a los habitantes del campo, reconocerlos, comprender qué están reivindicando y cuáles son

3. El uso del prefijo "bio"' se utiliza para indicar productos cuyo proceso de producción se basa en métodos ecológicos. El material combustible, que en su gran mayoría, proviene de productos agrícolas cultivados a gran escala a partir de la materia prima vegetal no es acorde con los métodos de producción ecológica, por lo tanto el uso del prefijo 'bio' es erróneo. Por agrocombustible se entiende, en esta investigación, los productos agrícolas que han sido sembrados en extensiones de monocultivos, especialmente de palma de aceite, y que están destinados a ser utilizados para la producción de combustibles energéticos. 
sus valoraciones del territorio; en suma, conocer sus prácticas locales. Si bien las historias de rupturas y desplazamientos, hasta ahora dominantes en el universo de las literaturas en Colombia, nos acercan al contexto del desarraigo, no siempre abordan la reconstrucción comunitaria ni tematizan las acciones colectivas emprendidas para retornar a los territorios. Por el contrario, en las composiciones musicales sí se relatan esos anhelos y se convierten, justamente, en ese puente vehicular de transición y comunicación social. La producción oral y musical induce a desenmarańar no solo conceptos, sino también afectos vinculados con la construcción cultural colectiva en la ruralidad. Asimismo, incitan a develar conocimientos y saberes locales sobre la naturaleza y la cultura rural. En este sentido, esos cantos inéditos que relatan las vivencias colectivas, el desplazamiento forzado y la utopía del retorno - tanto en estas comunidades como en otras que no se incluyen en este estudio- se convierten en signo y significado a la vez. Por un lado, son signos porque están anclados dentro de un contexto general en el cual su función estética es representar musicalmente la visión del mundo de las comunidades. En este caso específico, la música vallenata no cumple una función puramente representativa de una realidad específica, sino que devela el sentir y lo que es emotivamente relevante para la memoria cultural e histórica propia de ámbitos rurales, en este caso, ruralidades de los litorales. Por otro lado, esas composiciones son portadoras de nuevos significados, o significados modificados, ya que la relación entre las composiciones y el mundo extra artístico configura un conjunto heterogéneo de sentido. Allí se conjuga la estructura sonora no verbal con los textos líricos, reproduciendo así el mundo de sentido que caracteriza a las poblaciones locales.

Óscar Hernández Salgar (2016) llama a esos conjuntos heterogéneos "ensamblajes multimodales". Esta referencia conceptual es un valioso aporte para situar el análisis musical, o, más específicamente, a las prácticas sonoras dentro de un conjunto de lenguajes en cuya matriz existe un campo de fuerzas y significados que se encuentran, y donde el eje musical "como cualquier otro medio expresivo tiene la capacidad de generar significados. Más aún tiene la capacidad de privilegiar unos significados por encima de otros, y éste solo hecho la convierte en instrumento político” (Hernández, 2016: 43) 
Si aceptamos que el canto opera como instrumento para la acción política local, es necesario comprender de qué manera la obra estética musical guarda una relación con el contexto extra artístico y, por tanto, cómo puede la música asumir una connotación política que modifique o cuestione las formas de poder establecido. El presente análisis está guiado a partir de ese interrogante y se propone indagar la dimensión política de los cantos surgidos en el contexto comunitario que emergen como reto a los impactos de la industria de palma de aceite en Colombia; de igual manera, investiga qué significados privilegian esas composiciones y cuáles inducen a acciones de empoderamiento de las comunidades. Las hipótesis que plantea este estudio son por una parte, que la música producida en los contextos rurales contemporáneos canaliza la reconstrucción sociocultural colectiva y dota de nuevos significados tanto a la cultura local como a la naturaleza del lugar. Y por la otra, que la música de los entornos rurales recrea sensaciones y afectos que se emparentan con acciones de reivindicación por el territorio y tienen efectos en la distribución de las relaciones de poder con incidencia social y política.

El vínculo entre las acciones políticas y las emociones ha sido especialmente estudiado en Colombia por Peter Wade, Ana María Ochoa y Óscar Hernández. Si bien estos análisis constituyen meritorias contribuciones para la comprensión del significado de lo musical en lo político, mi propuesta aquí se orienta más hacia la necesidad de explorar cómo las prácticas sonoras y las manifestaciones orales nacidas de y desde localidades rurales construyen epistemologías alternativas en cuyos discursos se perfilan nuevas formas de participación política y de empoderamiento. En este caso específico, esa participación, por una parte, tiene que ver con la reivindicación de ontologías y significados locales para relacionarse con la naturaleza, la comunidad y la sociedad $y$, por otra, se cristaliza en el diseńo de estrategias de gobernanza de la tierra y el territorio desde el acervo comunitario.

Por tratarse de un estudio interdisciplinario, lo que se busca es poder hacer uso de planteamientos de diferentes ámbitos. Respecto a las proposiciones desde los estudios culturales, se toman aportes de autores como Homi K. Bhabha, Jesús Martín Barbero, Eduard Said y Stuart Hall, entre otros. Atendiendo a lo planteado por Stuart 
Hall y Mellino (2011) ${ }^{4}$ sobre la labor de los estudios culturales, en específico, en lo que se refiere a la complejidad para comprender las relaciones entre cultura y poder, este estudio opta intencionalmente por no convertirse en un análisis mono-dimensional. Si bien las teorías sobre conflicto armado y recursos naturales brindan algunos aportes respecto a la duración del conflicto (Ross 2003) y a la participación de los recursos en la financiación del conflicto (Collier y Hoeffler 1998), carecen de elementos decisivos para explicar la relación entre desplazamiento forzado y recursos naturales, en este caso, los monocultivos de aceite de palma en Colombia. Este análisis se sustenta, particularmente, en los planteamientos sobre conflictos socioambientales y retoma contribuciones significativas de la ecología política, como, por ejemplo, las formas de valoración de la naturaleza propuestas por Joan Martínez Alier, así como también los aportes de Arturo Escobar respecto a la cultura ecológica y los significados de lo local en contraposición a lo global. Se abordan de igual forma los planteamientos sobre manejo y transformación de conflictos que aporta John Paul Lederach; conceptos como "la genialidad artística" y "la sanación social" ("the artist's genius and the social healing") amplían el análisis desde la perspectiva cultural. Este autor brinda un marco de análisis fundamental para analizar la función de la creatividad artística — musical — en la construcción de la paz.

Tal como viene sucediendo actualmente, en gran parte del hemisferio sur, las plantaciones de larga escala imponen modelos de producción que afectan las dinámicas de economía regional, inciden en los patrones de organización social y transforman, abruptamente, las culturas locales. Los monocultivos de aceite de palma han crecido de manera exponencial, causando fuertes impactos en distintas regiones tropicales en América Latina, Asia y África. Muchos estudios insisten en que el aceite de palma tiene ventajas comparativas en términos de

4. Los estudios culturales, como señala Eduardo Restrepo (s. f.) no son "solo estudios”, son algo más, porque están orientados hacia una acción transformadora del mundo, es decir, se interrogan por el para qué y por ello no atienden solo a planteamientos teóricos, sino que están articulados con las complejas realidades y contextos. 
rentabilidad y utilidad, lo que lo ha convertido en el aceite vegetal usado en diversas industrias. Así, se puede encontrar como parte de los ingredientes más usados a nivel mundial en la industria de alimentos, como materia prima de la industria de cosméticos, como componente importante en la industria de transporte y, pese a lo controvertido de sus efectos medioambientales, sigue siendo promovido en la industria energética para producir biodiésel: los llamados agrocombustibles. Las grandes extensiones de tierra que demanda la producción de aceite de palma a larga escala reproduce los sistemas de concentración de tierra en pocas manos y, por sus características, se podría enmarcar en lo que se conoce como fenómeno global de usurpación de tierras (Haller et al. 2019). En este contexto, la palma de aceite que se produce en Colombia ha estado destinada específicamente para producir biodiésel. Las políticas energéticas diseñadas por el gobierno colombiano, especialmente a partir del 2000, han apostado por camino de la agroindustria. Por ser un cultivo de larga extensión, la palma de aceite afecta sensiblemente la diversidad de cultivos locales y tradicionales, y exacerba las proporciones asimétricas, ya existentes, en los patrones de distribución agrícola. En Colombia, el monocultivo de palma de aceite se ha promovido como programa gubernamental en varias administraciones y, tras una historia de transformaciones como entidad, la Federación Nacional del Cultivadores de Palma de Aceite (FEDEPALMA) se institucionalizó como gremio líder en el país. La implementación de los cultivos se introdujo de forma sistémica con diferentes niveles de intensidad en cuatro de las cinco regiones geográficas del país, como se verá posteriormente. En el ámbito nacional, los efectos de los monocultivos de palma de aceite se perciben en las dinámicas de producción y de consumo que se derivan de la actividad agrícola. En términos locales se manifiestan en los impactos sociopolíticos, ambientales y económicos que alteran la vida de muchas poblaciones rurales; en muchos casos la producción de palma de aceite a larga escala guarda una relación directa con el desplazamiento forzado ${ }^{5}$ de las poblaciones, como se tiene evidencia en Las Pavas y Maria Baja, departamento de Bolívar;

5. En otros sitios de América Latina la agroindustria se puede ver en plantaciones extensas de caña de azúcar y de soja, entre otras. 
Cuencas del Curvaradó, departamento del Chocó; San Martin, departamento del Cesar; Zona Bananera, departamento de Magdalena, entre otros (Goebertus, 2008, Hurtado et al., 2017).

La expansión de cultivos agroindustriales de palma de aceite tanto en Colombia como en otros países del Sur Global —en Asia: Malasia, Indonesia y Tailandia; en África: Nigeria y Costa de Marfil; en América Latina: Honduras, Costa Rica, Guatemala y Nicaragua, entre otros- sigue abarcando vastas extensiones de tierra y generando fuertes impactos en las prácticas de uso y distribución de la tierra y el territorio.

Es preciso recalcar que las reflexiones de este análisis se apoyan en procedimientos metodológicos de investigación cualitativa. Durante mis visitas y mi estadía en los lugares donde habitan las comunidades seleccionadas, pude recolectar gran parte del material de estudio. Se llevó a cabo una estancia con los integrantes de las poblaciones, algo cercano a lo que se denomina "una etnografía". En el caso de las comunidades del litoral pacífico, he permanecido menos tiempo en la región porque las condiciones de seguridad me lo impidieron debido a la presencia de actores armados. Eso no quiere decir que las conversaciones y los intercambios con los habitantes hayan sido menos intensos en esa zona, por el contrario, las entrevistas y gran parte de los relatos que grabé fueron fruto de largas conversaciones durante las caminatas por los senderos silvestres de las cuencas de Curvaradó y Jiguamiandó. Se trataba de una caminata ecuménico-ecológica que fue organizada por la Comisión Intereclesial de Justicia y Paz, y en la cual yo pude participar como visitante. Fue una semana de recorridos por varias de las zonas de la región y en la que participaron integrantes de otras comunidades campesinas, afrocolombianas e indígenas, incluso de diferentes zonas del país. También hubo presencia internacional, y delegados de organizaciones de Canadá, España y Estados Unidos se sumaron a las jornadas. En nuestro recorrido, paralelo a la verificación de cultivos de palma, en territorios colectivos también observamos cultivos de coca. No solo las visitas y las entrevistas con los campesinos o con miembros de organizaciones de acompańamiento forman parte de la estructura metodológica en que se sustenta esta reflexión, a ello se suman la indagación en documentos elaborados por las comunidades, 
textos redactados por las organizaciones de base y acompañamiento, entrevistas con empleados del Ministerio de Agricultura en Bogotá, entrevistas a miembros de la Embajada Suiza en Colombia, artículos de prensa y documentos legales, especialmente en lo relacionado a la titulación de tierras. El análisis hubiera sido sesgado si no se hubiera tomado en cuenta al gremio FEDEPALMA, así que también se entrevistó a algunos empresarios palmeros. Realicé entrevistas con representantes de los directivos de ese gremio y consulté una cantidad suficiente del material que publican para escudriñar a fondo cuál es la narrativa que se construye desde esa otra perspectiva sobre la industria de la palma de aceite. Si bien el empleo de datos cuantitativos puede arrojar resultados novedosos, la complejidad que presentan los conflictos sobre recursos naturales requiere investigaciones más exhaustivas, por eso son necesarios estudios que indaguen acerca de la epistemología que fundamenta la acción comunitaria y sus acciones en defensa de los recursos naturales, especialmente en los países del Sur Global. En este análisis se emplean algunos datos secundarios, extraídos de estudios cuantitativos. Se utilizan especialmente cifras sobre los impactos medibles relacionados con el fenómeno del desplazamiento forzado y estadísticas sobre cultivos de palma.

El libro está compuesto de dos partes. En la primera se encuentran los capítulos I al IV. En el capítulo I se introduce el contexto global en el que se enmarca la producción de agrocombustibles provenientes del agro. Aquí se hace una traslación a lo que está sucediendo en la actualidad en los ambientes rurales en Colombia. En este sentido, se hace un énfasis especial sobre los aportes que podría hacer este trabajo en relación con el escenario de postconflicto que se ha empezado a gestar en el ambiente nacional. En esa misma línea se hace referencia al concepto del buen vivir, noción que caracteriza a las culturas andinas y que aparece en el Acuerdo de Paz de 2016, con el fin de visibilizar prácticas locales que han resguardado culturas de paz. Estas prácticas de y por la convivencia social deben empezar, ahora, a salir del mutismo; además, por haber sido opacadas por los preponderantes discursos sobre la violencia. En el capítulo II se encuentra una selección de planteamientos teóricos que desde la ciencia y la academia iluminan el 
análisis y que conforman ese caleidoscopio transdisciplinario del que se alimenta toda la reflexión. Se toman consideraciones de los estudios culturales, así como también de los estudios de conflicto, conflicto socioambiental y de construcción de paz. En el capítulo III se presenta una reflexión sobre el arte musical, su función y representación en relación con la conflictividad y la construcción de la paz. Se narra el proceso de recolección de los cantos y se ofrece una tipología del corpus recolectado en las tres comunidades. Se hace una distinción que ilustra cómo las composiciones que emergen de contextos del conflicto mantienen espacios para narrar la convivencia, las prácticas comunitarias, la cohesión y las acciones colectivas, así como también los imaginarios del retorno. En este capítulo se expone un breve recorrido por los territorios musicales del vallenato en Colombia y la conquista del rap en territorios rurales, finalizando con algunas consideraciones sobre cómo se reproducen esos ritmos en los ambientes locales y comunitarios. Posteriormente, el capítulo IV se ocupa nuevamente del contexto nacional, pero en relación a la producción de agrocombustibles. En especial, se presenta en detalle la estrategia gremial y estatal que promueve la industria de palma de aceite en el contexto nacional de Colombia. Se brinda una reflexión sobre los lineamientos generales del panorama global, así como también el negocio de tierras y la situación energética en América Latina.

La segunda parte del libro se compone del capítulo V al VIII. En el capítulo $\mathrm{V}$ se presentan los tres casos que se seleccionaron: comunidad Las Pavas, comunidad El Garzal y las zonas humanitarias. En cada uno de ellos, se presenta una muestra de su producción musical, en la que se ilustra la problemática de la agroindustria. Se hace un análisis detallado sobre las singularidades y especificidades que el conflicto muestra en cada una de las comunidades; se exploran las características ambientales y sociales de cada uno de los casos. El capítulo VI ofrece un análisis comparativo que recoge las reflexiones de cada uno de los casos. A través de un ejercicio de comparación se distinguen, en primer lugar, las formas de recepción de la incursión de la palma, la composición de actores involucrados y los detonantes y catalizadores del conflicto. Se analizan de manera exhaustiva los diversos escenarios que se han construido en las acciones comunitarias y en las estrategias 
de retorno, especificando las incidencias en la dimensión sociopolítica y cultural. En el capítulo VII, el corpus lírico es la fuente principal a través de la cual se examinan los significados, la experiencia y el sentido de los impactos ocasionados por la agroindustria palmera en el tejido social comunitario. Se analiza cómo en el canto se representan y se resignifican los efectos de la extensión de los monocultivos. El análisis del discurso lírico se realiza al establecer una analogía con las características del testimonio en la literatura. A partir de esa analogía, se propone que los cantos del corpus son manifestación de una lírica testimonial que reconstruye las categorías de valoración del acervo campesino y la ontología rural. El análisis lírico examina la simbología contenida en los cantos, en la que se reconfiguran conceptos de espacialidad, territorialidad y ancestralidad. En este sentido, las reflexiones conducen a articular las diferentes estrategias en las que las comunidades locales redefinen la subjetividad campesina y su relación con el proyecto nación. El capítulo VIII finaliza este estudio con reflexiones en torno a las incidencias en la transformación del conflicto derivadas de las estrategias y los mecanismos utilizados por las comunidades. Para finalizar aparecen las conclusiones y las aproximaciones sobre las especificidades del manejo del conflicto y la dimensión política de la música desde las acciones comunitarias. 


\section{Primera PARTe}





\section{Capítulo I}

\section{Industria palmera, postconflicto y culturas de convivencia}

\section{La industria de la palma de aceite}

Si nos ubicamos en el contexto regional del continente latinoamericano, Brasil es el país pionero en la producción de agrocombustibles, especialmente de etanol. ${ }^{1}$ Otros países del continente, entre ellos Colombia, Argentina, Guatemala y Uruguay, han optado también por incursionar en el negocio de los combustibles extraídos del agro con el propósito de posicionarse como exportadores a nivel mundial. La mayoría de los gobiernos nacionales en América Latina han acogido con gran receptividad esta estrategia y han introducido incentivos

1. La producción de etanol se deriva especialmente de los cultivos de caña de azúcar, localizados en su gran mayoría en la región del Cerrado. En 2006 era de cerca de dieciocho millones de litros y con las subvenciones del Gobierno se esperaba que para el ańo 2010 subiera a los veinticuatro millones (Fritz 2008). El informe anual de la Global Renewable Fuels Alliance (GRFA) prevé una producción de más de noventa mil millones de litros para el 2014. 
en sus programas políticos para promover la producción de agrocombustibles. ${ }^{2}$ Este entusiasmo se refleja también en la modificación de disposiciones normativas y legislativas para facilitar las gestiones jurídicas requeridas por la industria de hidrocarburos. Estos y otros procedimientos, utilizados para el fomento del agronegocio, son elegidos como nuevos derroteros que contribuyen al llamado 'desarrollo' y 'bienestar' nacionales.

La ambiciosa agenda por la producción de agrocombustibles ha influido en la expansión de los monocultivos en la región. El factor institucional ha sido determinante, en especial a partir del 2006 en el contexto de la crisis financiera global, pues varios países han introducido iniciativas en sus políticas energéticas para el uso de biodiésel, paralelamente a la imponente producción de etanol que se extrae de la caña de azúcar. Países como Colombia, Brasil, Perú, Costa Rica y Ecuador tienen iniciativas nacionales para seguir incrementando el área de expansión de los monocultivos de palma de aceite. Sin embargo, hay diferencias en el uso que le da cada país a su producción, en el caso de Colombia la mitad de su producción se utiliza para producir biodiésel ${ }^{3}$.

La deforestación y el cambio de los usos de la tierra relacionados con los cultivos de palma de aceite ${ }^{4}$ afectan cada vez a más países en el continente latinoamericano. De acuerdo con Forumo y Aide, "en América Latina, la producción de aceite de palma se ha duplicado desde 2001, la mayor parte de la expansión parece estar ocurriendo en tierras no boscosas" (Forumo y Aide 2017). En ese mismo estudio, se estima que entre 1989 y 2013, en América Central y el Caribe, los niveles de

2. En algunos casos, se han cambiado acuerdos regionales o nacionales previos a conveniencia de los grandes consorcios.

3. La promoción y el consumo de biodiésel se formuló a través de la ley 939 del 2004 y la resolución 1289 del 2005. Se preveían incrementos paulatinos en el consumo de biodiésel en el transporte. A partir del 2012, el 60\% de todos los vehículos que se vendieran en Colombia deberían usar la tecnología "E85 flexi fuel".

4. De acuerdo estudios recientes, los altos niveles de deforestación que se han evidenciado en los países del sudeste asiático como Indonesia y Malasia a causa de los monocultivos de palma de aceite son mucho más severos que lo que sea registrado en América Latina. 
deforestación a causa de las plantaciones de palma correspondieron al 2\%, mientras que en América del Sur, entre el 2000 y el 2010, cerca del 30\% de áreas sembradas con palma de aceite eran zonas forestales. Si bien las cifras de desforestación de los cultivos de palma en América Latina no alcanzan los niveles de los países del sudeste asiático, los impactos se hacen sentir en el cambio de cultivos que son desplazados y son parte del abastecimiento de las poblaciones locales, la presión en la extensión de la frontera agrícola y el mercado de tierras. En términos de mercado comercial, la mayoría de los países productores de la región son exportadores, sin embargo, el 80\% del aceite de palma producido en América Latina se exporta dentro del área continental. En esa dinámica, México es el mayor importador con un 61\%. Brasil, México y Colombia son los mayores consumidores de aceite de palma en la región, convirtiéndose Brasil en el país latinoamericano que más aceite de palma importa de fuera de la región, especialmente de Indonesia, y se destina para la industria alimenticia. Colombia es, por su parte, el mayor exportador de la región, cuyos destinos son Holanda, Reino Unido y Alemania, y de forma recíproca Europa capta cerca del 93\% de todo el aceite que se exporta de América Latina y el Caribe.

Existe una gran controversia en torno a los aportes reales, las oportunidades y los desafíos que plantea esta forma de extracción energética. Los asuntos que suscitan mayor polémica están relacionados con efectos que causan los monocultivos en el medio ambiente, las repercusiones que acarrea en la población local, la utilidad en términos prácticos y de uso, la extensión de las plantaciones dedicadas a los combustibles, así como también los costos de transacción para sustituir los fósiles no renovables. Estos aspectos los analizan autores como Giampietro y Mayumi (2009), Cotula, Dyer y Vermeulen (2008), Dworack et al. (2008), Hill et al. (2006), Oosterkamp, De Bruin y Barrón (2007), Peskett et al. (2007), Rajagopal et al. (2007), Roa (2007), Fritz (2008), Toasa (2009) y Franco et al. (2010), entre muchos otros.

Así como muestran diversos estudios, las dinámicas de cambio en la vocación agrícola, los usos y el acceso a la tierra que se derivan de la introducción de cultivos perennes para el uso industrial recrudecen la disparidad estructural, ya arraigada, en la distribución agraria e inciden en el aumento de la desigualdad y precariedad del acceso a 
la tierra para los campesinos. Para los propósitos agroindustriales, la tierra es considerada, exclusivamente, un recurso para efectos de productividad; además, el acceso a la propiedad agrícola sigue siendo un instrumento de poder para quienes ya poseen grandes extensiones de tierra o para quienes disponen de los medios económicos para adquirirlas. La recepción de los monocultivos de palma de aceite a nivel local tiene diferentes escenarios que varían según la región y la historia poblacional de las comunidades que se vinculan o se ven obligadas a vincularse a esa actividad. La problemática del acceso a la tierra y el cambio en los usos de la producción agrícola son efectos directos que enfrentan las poblaciones rurales en todas las regiones. Otros efectos, tales como el desempleo, el cambio en las prácticas alimentarias, la alteración de las formas de organización colectiva, la fragmentación social, la pérdida de saberes compartidos, los hostigamientos y las agresiones al campesinado son consecuencias que experimentan, en mayor proporción, algunas poblaciones específicas que han sido despojadas de sus territorios.

En algunos estudios se ha analizado la relación que guardan las plantaciones de cultivos de palma de aceite con el conflicto armado en Colombia y el desplazamiento. Juanita Goebertus (2008), Camilo Rey (2008), Mónica Hurtado, Catherine Pereira Villa y Edgar Villa (2017), entre otros, aportan importantes reflexiones sobre la relación entre los desplazamientos forzados en algunas regiones y el aumento en las extensiones de cultivo de palma de aceite. Asimismo, en los análisis de Sebastián Ocampo (2009) sobre la relación entre agroindustria y conflicto armado se tematiza la relación entre recursos naturales y la financiación del conflicto armado. De acuerdo con sus hallazgos, en el caso de la palma de aceite, aunque no se muestran correlaciones directas, sí hay incidencias indirectas, especialmente en relación a la tenencia de la tierra a nivel local. Este es un asunto crucial que pone desafíos a la implementación del Acuerdo Final y a los propósitos de restitución de tierras y ordenamiento territorial. 


\section{El postconflicto o la transición a la paz: reflexiones} y aportes de este estudio

¿Cómo reconstruir el poder público y disminuir la violencia? Como señala Hannah Arendt (1970), el poder y la violencia no son idénticos. El poder está en riesgo cuando aparece la violencia, esta es potencialmente un instrumento para la destrucción del poder, pero no puede crear un nuevo poder, sino reproducir más violencia. En el contexto colombiano, la historia de violencias ha impedido la reconstrucción del poder público; se han impuesto fuerzas de combate y lucha armada apropiándose de diversos instrumentos para ejercer el control. El uso de la violencia tanto armada como no armada ha ido destruyendo los espacios de poder social y político generando una forma de confrontación permanente. Con la firma del Acuerdo Final, Colombia ha querido entrar en una nueva fase post-conflicto, lo que significa la finalización de la confrontación armada entre los actores enfrentados. Esta nueva etapa de transición va a ser un proceso probablemente largo y seguramente exigente. Exigente no solamente para los que han sido azotados por la violencia armada, sino para quienes la han propiciado. Pues, una vez se silencian los fusiles se hace necesario volver la mirada hacia los conflictos sociales que las armas y la violencia habían congelado en el olvido.

Los acuerdos propician espacios para frenar las hostilidades de la guerra abierta y abren posibilidades para desempolvar los temas que han dado origen a los conflictos y así poder avanzar en la búsqueda de viabilidades para transformación social. En el proceso de transacción de las disputas empiezan a darse espacios para diseñar una arquitectura del entendimiento y la convivencia, y redefinir los roles de los actores sociales y la reconstrucción del andamiaje del poder público. Ese diseńo, de gran envergadura, debe crear catalizadores que encausen la movilización social e instauren un ambiente de prácticas democráticas. Esa fase de transición en la que se han desmovilizado actores armados acontece paralelamente con la movilización de fuerzas sociales latentes. Es urgente que esas fuerzas no correspondan a la reproducción de los esquemas de violencia previos, sino que reactiven esquemas de nuevo 
poder colectivo, de acciones y beneficios sociales. Por ello, de igual forma, es urgente que se generen espacios que legitimen actores y agentes de movilidad social, que se conviertan en espacios de empoderamiento. Parte de esa reconstrucción del rompecabezas del poder público está en los actores que han venido imponiendo los diversos tipos de violencia, a quienes la ejercen con las armas y, también, a quienes la administran utilizando recursos económicos para reproducirla. Este estudio examina tanto el desplazamiento como el emplazamiento de tres comunidades que se han visto afectadas a causa de los monocultivos de palma aceite en Colombia y que son agentes que a través de mecanismos de resiliencia han querido construir historias de convivencia creando espacios para la justicia social, política y ambiental.

No es una sorpresa que el primer punto del Acuerdo Final para la Terminación del Conflicto y la Construcción de una Paz Estable y Duradera se titule "Hacia un nuevo campo colombiano: Reforma Rural Integral", pues gran parte de las sociedades que habitan en las áreas rurales han sido dispersadas a causa de los desplazamientos forzados. Las culturas rurales en Colombia y muchos lugares del Sur Global tienen una historia de repetitivos despojos. No solo las diferencias partidistas desde las primeras décadas del siglo $\mathrm{xx}$ han violentado fuertemente al campesinado colombiano, sino también la formación de grupos armados como las guerrillas a partir de los años sesenta y posteriormente los grupos paramilitares han ocasionado la devastación en amplias zonas del país rural. El discurso desarrollista a través de los megaproyectos ha producido casos severos de desterritorialización, comprometiendo en buena parte el uso de los recursos naturales locales. El despojo que causan los monocultivos de palma de aceite, como veremos en las comunidades de enfoque está ocurriendo también en el contexto de la minería. Los megaproyectos para la explotación minera causan descomposición en los tejidos sociales de las poblaciones y afectan la supervivencia de las culturas autóctonas. Uno de los casos más severos es la actual situación que enfrenta la cultura wayuu en el departamento de la Guajira. ${ }^{5}$ Diversas comunidades de esa etnia han

5. En el documental La buena vida, cuya producción es del año 2015, se puede apreciar parte del proceso de despojo que han sufrido algunas de las comunidades. 
sido desplazadas por los grandes consorcios que están a cargo de la explotación de carbón en las minas del Cerrejón. La minería es motivo de una de las composiciones del CD producido por cantautores de la Zona de Reserva Campesina del Cimitarra, titulada "Pa' Guamocó", donde se tematiza así:
Miles de colombianos: indios, blancos y negros
Trabajamos la tierra para poder subsistir (bis)
El monstruo de los yanquis nos quiere quitar la tierra
Que hemos trabajado desde hace mucho tiempo atrás (bis).
(Mauricio Sánchez, Relatos musicales para la memoria histórica).

Guamocó $^{6}$ es una región de historia de explotación minera en donde el mineral de oro ha significado el desplazamiento de muchos de sus pobladores, que practicaban la minería artesanal. La presencia de grupos armados ha facilitado el control territorial de la zona y el ingreso de las empresas transnacionales, para que sean ellas quienes exploten el oro, así como lo expresa la estrofa anterior: "El monstruo de los yanquis nos quiere quitar la tierra”. Como el caso Guamocó se podría enumerar una larga lista de despojos por el extractivismo minero. Los cultivos extensivos para agrocombustible son una de formas de extracción o neoextractivismo.

De acuerdo al texto de la Reforma Rural que se consigna en el Acuerdo Final, el territorio se define de la siguiente manera:

Un escenario socio-histórico con diversidad social y cultural en el que las comunidades - hombres y mujeres - desempeñan un papel protagónico en la definición del mejoramiento de sus condiciones de vida y en la definición de desarrollo del país dentro de una visión de integración urbano-rural (Nuevo Acuerdo Final 9).?

6. "La tierra es muy rica en recursos naturales, lo que significa que la población, en su mayoría, se dedica a la minería artesanal, sobre todo, a la explotación del oro. Este trabajo, bastante peligroso, se realiza en el sector informal del mercado laboral de Colombia y está criminalizado por parte del Estado colombiano, puesto que los mineros tienen que pagar obligatoriamente impuestos a la guerrilla o a grupos neoparamilitares en la región como ejemplo del poder que tienen estos grupos" (Peace Brigades Colombia 2016).

7. Las cursivas son mías. 
El territorio y, no solo la tierra, deben ser apreciados en toda su complejidad. Existe un componente sociohistórico que caracteriza tanto a las regiones como a las comunidades locales y se hace visible a través de las prácticas del habitante rural. Este acervo histórico-cultural se ha visto impactado por las prácticas extractivistas a gran escala, que se pueden evidenciar en diferentes momentos de la historia rural y se han llevado a cabo especialmente en los países del Sur Global. Si hacia comienzos del siglo xx se impusieron en Colombia los monocultivos de banano, en las últimas décadas del siglo pasado y en las primeras dos décadas que han transcurrido del siglo XxI, se pueden observar las enormes dimensiones territoriales que ha abarcado el cultivo de palma de aceite en diferentes regiones del país. Los cultivos extensivos avalados e impulsados por las élites nacionales, incluso han sido parte del programa de desarrollo nacional en la administración de Álvaro Uribe. El surgimiento de las naciones en América Latina se gestó en burguesías sin identidad nacional y las reformas agrarias han seguido las estructuras de la herencia colonial. Como bien lo señala Eduardo Galeano, "las burguesías de estas tierras habían nacido como simples instrumentos del capitalismo internacional, prósperas piezas del engranaje mundial que sangraba a las colonias y a las semicolonias" (Galeano 2015: 152).

Desde los años noventa se han intensificado en Colombia los monocultivos con una marcada internacionalización de la agroindustria. Imponer usos de la tierra que son completamente ajenos a las prácticas locales obliga a cambiar drásticamente la vocación agrícola lugareña. Por otra parte, la ocupación de grandes extensiones de tierra que están destinadas al cultivo industrial se ha llevado a cabo sin incluir a las poblaciones rurales en los procesos de consulta ni en los procesos de decisión sobre el uso de los territorios. Gran parte de las dinámicas de transformación del agro en Colombia han estado guiadas por modelos que se ajustan mucho más a las tendencias y demandas globales y toman el sello del mejoramiento y del desarrollo, pero, en la práctica, siguen ignorando por completo las decisiones de las comunidades rurales, aun cuando los procedimientos jurídicos para el uso territorial aparezcan en las disposiciones legales. 
A pesar de los escasos instrumentos jurídicos y políticos que poseen las comunidades rurales para incidir en la dinámica de usurpación de tierras y el neoextractivismo, muchas de ellas logran activar y movilizar recursos para construir narrativas y acciones de la interlocución y convivencia. Las consultas populares, que son un mecanismo de participación ciudadana, han sido el instrumento utilizado para manifestar la posición comunitaria frente a la presencia de megaproyectos de minería. Sin embargo, la Corte Constitucional atendiendo a una "Acción de Tutela instaurada por Mansarovar Energy Colombia Ltda., contra el Tribunal Contencioso Administrativo del Meta" emitió una sentencia en octubre del 2018 en la cual las consultas populares no pueden frenar proyectos de minería ni explotaciones petroleras porque las decisiones sobre explotación de los recursos del subsuelo deben ser tomadas por autoridades nacionales en coordinación con autoridades regionales. Este hecho marca un retroceso en las posibilidades de participación local y comunitaria y es un claro revés a la gobernanza de los recursos naturales de las regiones. En las composiciones líricas analizadas en este estudio, los pobladores rurales construyen desde el canto un discurso lírico cuyo propósito es crear espacios de coexistencia y entendimiento que superen el dolor, instauren la confianza y sirvan como instrumento de inclusión y participación. Uno de los cantautores de la comunidad de Las Pavas proyecta el anhelo de la convivencia a través de una composición en ritmo de vallenato con motivo de las votaciones del plebiscito sobre el Acuerdo de Paz en el mes de octubre de 2016:

\title{
El PLEBisCito
}

\author{
Sé que mañana sale un sol distinto \\ Una nueva luz a mi país, yo veo llegar \\ Feliz me siento al ver correr mis hijos \\ Y que una mina no escuche explotar \\ Toda mi gente tiene la esperanza \\ Que ahora las cosas sí pueden cambiar \\ Sólo pongamos un poco de confianza
}

8. El texto que emite la sentencia se puede consultar en el siguiente enlace: $<$ http:// www.corteconstitucional.gov.co/relatoria/2018/SU095-18.htm>. 


\author{
Y al plebiscito, sí, hay que votar \\ Y al plebiscito, sí, hay que votar (bis) \\ ¡Ay! de Las Pavas, hay un grano de arena \\ Por esa paz que ha luchado ASOCAB \\ ¡Ay! Acabemos esta bendita guerra \\ Llegó el momento de perdonar \\ Y al plebiscito, sí, hay que votar \\ Y al plebiscito, sí, hay que votar (bis) \\ ¡Ay! Mi país ya se encuentra cansado \\ Por esta guerra que tocó librar \\ Pero si hay unos que han aprovechado \\ Y a los del campo nos toca llorar \\ Y al plebiscito, sí, hay que votar \\ Y al plebiscito, sí, hay que votar (bis) \\ (Etni Torres, ASOCAB, Las Pavas).
}

En esta composición, antes que narrar o describir el despojo al que han sido sometidos los campesinos de Las Pavas a causa de la industria palmera, el cantautor reafirma el proceso de la comunidad y de la asociación campesina ASOCAB y la urgente necesidad de transitar hacia escenarios de convivencia pacífica y entendimiento social. En la tercera estrofa, se recalca el aporte comunitario que han venido construyendo las asociaciones campesinas. Así como lo expresa Etni Torres: “Ay! de Las Pavas, hay un grano de arena / Por esa paz que ha luchado ASOCAB”. Ese grano de arena es simiente de esta comunidad que, por más de una década, sigue manteniendo un proceso de resiliencia y edificando el proyecto del retorno territorial, como lo veremos más adelante. No es legítimo que se siga diseñando desde los centros de negocios urbanos lo que debe ser el futuro de las poblaciones rurales. Fallidas son las predicciones econométricas para un simulado progreso. La asimétrica distribución de las tierras en Colombia es un claro indicador de que las riquezas quedan en unos pocos, en quienes se concentra el poder, mientras paralelamente se disminuye el bienestar de muchos y se van descomponiendo valiosos segmentos de la población rural y semiurbana. La mayoría de poblaciones rurales siguen supeditadas a 
marcos de acción dispuestos por alianzas entre gobiernos y empresarios (que en muchos casos son los mismos) en donde los campesinos no disponen de instrumentos de poder, y, cuando existen, reducen al máximo la participación popular, como el reciente fallo de la Corte Constitucional sobre las Consultas Populares. El documento final del Acuerdo de Paz se refiere al papel que tienen las comunidades sobre la gobernanza de su territorio; allí se recalca la necesidad de promover la participación comunitaria y se indica que se deben abrir espacios de participación: "mediante la generación de espacios institucionales, participativos y democráticos donde éstas (las comunidades) tengan capacidad de transformación e incidencia en la planeación, implementación, seguimiento y los diferentes planes y programas acordados" (Nuevo Acuerdo Final 9).

Si bien en la Constitución colombiana de 1991 ya se insiste en la necesidad de ampliar los mecanismos de participación ciudadana y abarcar procesos de decisión que vayan más allá del sufragio político, en la práctica, el paso de una democracia representativa que genere espacios decisivos de participación no se da por el solo hecho de consignarlo dentro de las disposiciones legales de la carta magna. Esos espacios de participación son visibles, casi siempre, recién después de recorrer largos caminos de lucha, como los que han tenido que seguir las comunidades rurales, conquistándolos y haciéndolos propicios en la interacción social. Es decir, que las nuevas formas de participación que llegan a ser legalmente establecidas en el contrato legal constitucional, en muchos casos, han sido el resultado de procesos de reivindicación social. Un ejemplo de ello son las Zonas de Reserva Campesina (ZRC) y el derecho de los territorios colectivos. ${ }^{9}$ Las comunidades desplazadas de sus entornos originales no solo reclaman el retorno a los territorios físicos de su hábitat, sino que demandan también la posibilidad de reconstruir su cultura territorial local. En Colombia existen seis

9. Tanto las Zonas de Reserva Campesina como los Territorios Colectivos son modelos de ordenamiento territorial que han significado largos caminos de lucha para los pobladores rurales. En el caso de las primeras, la gestión y el trabajo de muchas asociaciones campesinas han derivado en la vinculación en el marco legal. En el caso de los segundos, las comunidades afrocolombianas del Pacífico han liderado importantes procesos para su consolidación territorial como Comunidades Negras. 
Zonas de Reserva Campesina, ZRC, que abarcan 831.111 hectáreas; entraron en vigencia con la ley 160 de $1994 .{ }^{10}$ La imposición del modelo neoliberal y extractivista va en detrimento de las ZRC, figuras de gobernanza territorial que no han sido impulsadas debidamente por el Gobierno. De impulsarse las Zonas de Interés de Desarrollo Rural, Económico y Social (ZIDRES) se seguirán fomentando los beneficios de los empresarios y poca incidencia tendrán las economías campesinas en la transformación del sector rural, lo cual reproduce una vez más la asimetría de poderes. Esto afecta no solamente a las comunidades, sino que compromete otros segmentos de la economía, así como también la soberanía alimentaria del país. Resulta preocupante que, en el marco de propuestas por la construcción de paz, el Gobierno apoye la implementación de figuras de administración territorial que llevarían a exacerbar la concentración de tierras y la pauperización del campesinado. Ese es el caso de las ZIDRES. De acuerdo con Carmenza Castiblanco y Juan Carlos Rojas Bustos (2016), se trata de una figura creada en la ley 1776 de 2016, cuya formulación de desarrollo no guarda ninguna relación con el bienestar de las comunidades campesinas, sino que, por el contrario, se basa en el mismo modelo neoliberal que beneficia a los grandes empresarios y a través del cual se concentra la tierra en muy pocas manos. Se trata de un mecanismo con el que los grandes latifundistas podrán seguir accediendo de manera fácil a las tierras, ahora con el beneplácito legal para apropiarse de bienes, usos y servicios ambientales. Además, con la excusa del modelo agroexportador, se promueve el acaparamiento de tierras utilizando diversas modalidades como concesión de tierras y arrendamiento o la adquisición de baldíos de la nación, entre otras. Por otra parte, esa ley cristalizada en las ZIDRES actúa completamente en contra de las comunidades campesinas, pues las sigue marginalizando porque no contempla sus economías agrícolas locales ni las involucra en procesos de consulta popular para decidir

10. "Hoy en día el Estado nos ha limitado y nos ha puesto un poco de trabas a pesar de que las ZRC ya están legalmente constituidas. Entonces, en este momento el Estado no quiere cumplir la ley porque hay 54 organizaciones solicitando Zonas de Reserva Campesina pero no ha sido posible que se constituya una nueva, solo quedaron las 6 que ya teníamos" (<http:/www.reliefweb.int/report/colombia/zonas-de-reserva-campesina-alternativa-de-desarrollo-rural-solidario $>$ ). 
sobre sus territorios; tampoco incide positivamente en los proyectos de desarrollo rural locales. De acuerdo con las investigaciones realizadas por Mingorance (2018), como se observa en los mapas, justamente las zonas en las que se prevé desarrollar las ZIDRES, son aquellas que se señalan como aptas para el cultivo de palma de aceite. De igual manera, la expansión de los cultivos ha tenido mayor despliegue en la región oriental en departamentos como Meta, Vichada y Casanare, en donde, según las narrativas del gobierno, las ZIDRES serían lo más propicio, ya que por ser zonas alejadas no se puede generar el desarrollo endógeno. En realidad, la aprobación de las ZIDRES para poder dar rienda suelta al agronegocio, anda a mayor velocidad que los puntos pactados en el primer capítulo de Reforma Rural Integral. Las ZIDRES favorecen los mecanismos para dar en concesión a los empresarios las tierras de la nación que antes fueron terrenos baldíos y así ampliar la frontera agrícola; lo que significa que los campesinos que fueron desplazados por la violencia en esos territorios seguirán siendo invisibles para la agroindustria que se concentra en la expansión del cultivo de la palma de aceite. La extensión equivale a cerca de "de las 7,2 millones de hectáreas que, según la Unidad de Planificación Rural Agropecuaria (UPRA), están en malas condiciones y son susceptibles de desarrollar ZIDRES, el 75,5\% (5,5 millones de hectáreas) corresponden de forma milimétrica con las áreas aptas para el cultivo de palma africana” (Colombia Plural, 2018). El Consejo Nacional de Política Económica y Social (CONPES) reimpulsó, a través del proyecto 3917, la creación de las ZIDRES en territorios que no son aptos para ello. Por un lado, el CONPES 3917 quiere desconocer conscientemente los derechos de las comunidades ancestrales, cuyas demandas por derechos de tierra llevan mucho tiempo sin resolver y, por otra parte, ignoran el proceso de formación en el que están muchas comunidades campesinas para constituir las Zonas de Reserva Campesina (ZRC). 

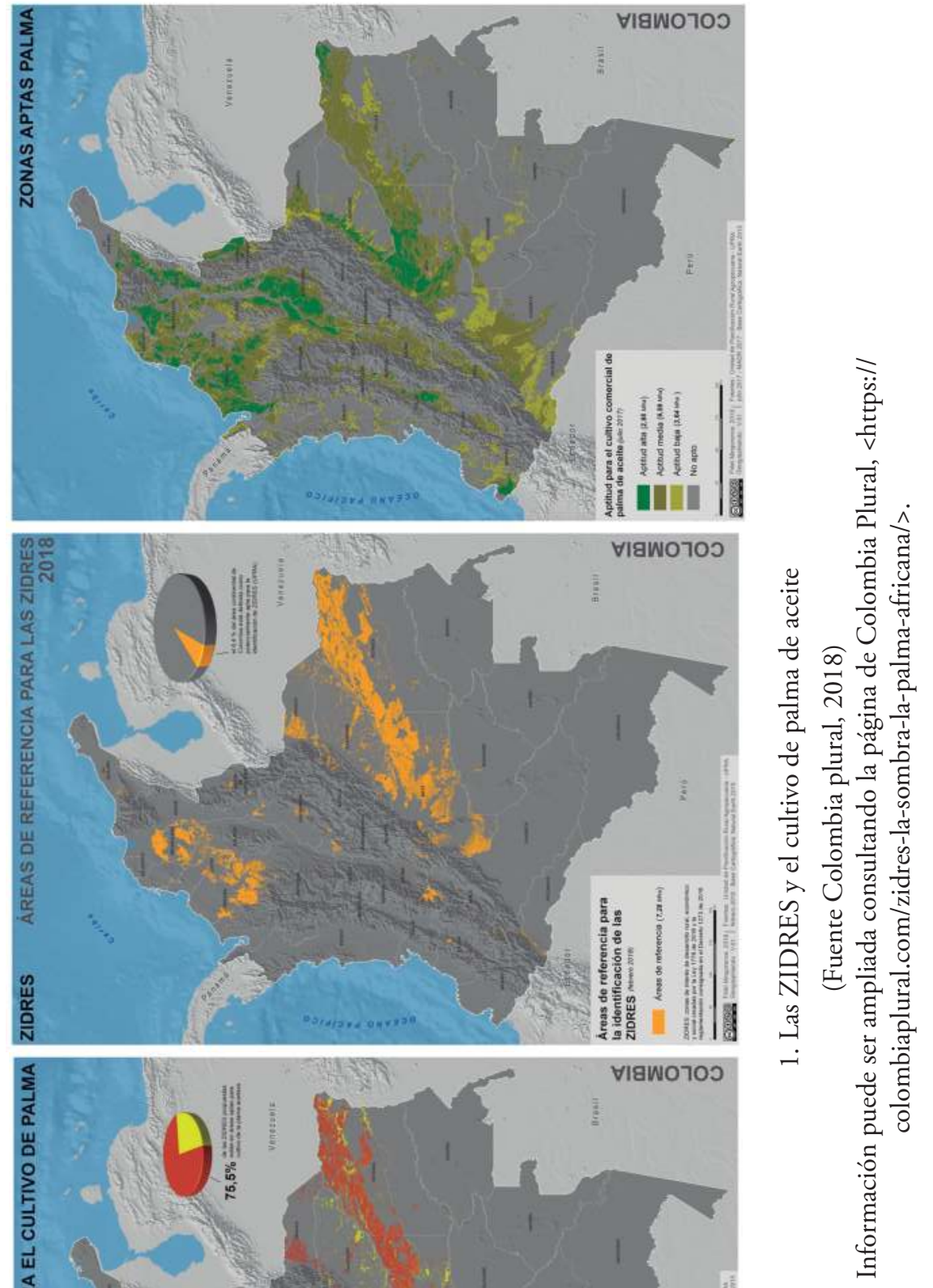
Lo que resulta más nocivo en términos de construcción de equidad es el mecanismo de alianzas productivas que salvaguarda los mismos patrones de relación asimétrica entre campesinos y empresarios y que conduce a la pérdida de los territorios de los habitantes rurales. Como señaló Darío Fajardo, se trata de "asociación del zorro y las gallinas", y, tal y como lo expresó Alejandro Reyes Posada, asesor del ex ministro Juan Camilo Restrepo, los beneficios serán para los empresarios:

El efecto es que los empresarios "ambiciosos" podrán descargar costos y riesgos en sus socios campesinos, que además le demandarán bienes públicos al Estado, como en cualquier región de colonización, para que así sea éste quien termine pagando el costo de instalar la mano de obra para las plantaciones agroindustriales (Reyes 2015).

Los monocultivos de palma están concebidos dentro de ese modelo agroexportador que responde a las demandas nacionales e internacionales. De acuerdo con los informes recientes de la Revista Palmas 39, de 2019, el aceite de palma producido en Colombia se está fomentando en el uso local, especialmente en la industria alimenticia y del agrocombustible a través del Programa Nacional de Biodiésel. En diferentes zonas del país la imposición de ese modelo ha mostrado fuertes impactos en la dinámica de adquisición de territorios y ha generado conflictividad por vincular actores armados; esto ha ocurrido en territorios colectivos en las cuencas del Curvaradó y Jiguamiandó en el Urabá chocoano, en la Orinoquía, en Montes de María y en muchos otros lugares. El estudio de Sánchez-Ayala y Cindia Arango-López (2015) ilustra el impacto de los monocultivos de la palma de aceite en el asentamiento de San Cristóbal, en Montes de María. En la dinámica de la tenencia de tierras se evidencia la vinculación de actores ilegales para apropiarse de los lotes de los afrocolombianos y así ejercer mayor control sobre los territorios. En otros estudios sobre el impacto de los monocultivos de palma de aceite y su relación con el desplazamiento (Rey 2013, Goebertus 2008, Hurtado 2017) se documenta la incidencia de los grupos paramilitares ya sea por la presión y la violencia que ejercen sobre la población para expulsarla o por la cooperación conjunta con algunas de las empresas de industria palmera. 
Dentro de los trece principios que rigen el marco del Acuerdo Final definitivo, la participación es uno de ellos, una participación integral que refuerce las prácticas de una gobernanza democrática basada en fundamentos de transparencia y rendición de cuentas, veeduría ciudadana y vigilancia. En la práctica rural, es sabido que muchas de las comunidades que han querido poner en ejercicio esos mecanismos han experimentado duras reacciones y se han visto involucradas, incluso, en disputas violentas. Además, han soportado diferentes formas de hostigamiento por parte de grupos que ostentan poder. Tal es el caso de las comunidades que se han pronunciado en contra de los monocultivos de palma africana en las regiones del Atlántico y del Pacífico colombiano. A pesar de las profundas asimetrías de poder, las comunidades han recurrido a mecanismos de resistencia para poder hacer visibles sus modos de convivencia que nacen de las racionalidades comunitarias. Así mismo han recurrido a sus lenguajes rurales y auténticos, como son las músicas regionales, para negociar espacios de participación y empoderamiento. El indagar qué mecanismos utilizan y cómo construyen los discursos para interactuar ante estructuras asimétricas de poder, se convierte en un eslabón imprescindible para aportar en la construcción de la paz desde una inclusión y participación que incida en la transformación de las estructuras de inequidad vigentes.

En últimas, no se trata solo de generar espacios de participación en el marco legislativo, ya que existe un buen número de códigos en la normatividad legal. Lo fundamental es incluir esas otras racionalidades como parte de la transformación de relaciones de poder y en espacios concretos: la producción agrícola, la gestión organizativa y la administración de los bienes naturales, entre otras. El impulsar esa transformación implica cuestionarse cómo y qué instrumentos pueden ser efectivos para ese propósito. La respuesta al cómo no es, ni puede ser, una respuesta homogénea, sin duda existen muchas y variadas herramientas que emergen desde diversas organizaciones de base. Una de esas búsquedas la intenta formular este estudio, específicamente en lo que compete a los instrumentos que usan las colectividades rurales desde su acervo comunitario para recobrar su tierra y los modos de vida de sus culturas territoriales. Abordaré a continuación dos aspectos que son fundamentales para considerar el aporte de este análisis en 
relación a la coyuntura nacional y regional del continente en el proceso y búsqueda de construcción de la paz.

\section{Los principios: el bienestar y el buen vivir}

El concepto del buen vivir y el concepto del bienestar aparecen como directrices que deben guiar la implementación del Acuerdo Final. Es significativo ver que esos dos términos se acercan al planteamiento que han venido defendiendo las culturas andinas durante los procesos de Estados plurinacionales, en especial en los países de Ecuador y Bolivia durante las últimas dos décadas. En el contexto del Acuerdo de Paz en Colombia resulta particularmente atrayente examinar qué especificidades y matices caracterizan esos conceptos dentro de los ambientes locales rurales. Es urgente, además, poder diferenciar y distinguir los significados que le atribuyen las comunidades rurales a la naturaleza y observar qué paradigmas de las prácticas agroindustriales entran en contraposición con la ontología local. Asimismo, es necesario comprender cuáles son las valoraciones respecto a los recursos naturales y en qué se diferencian de las narrativas construidas por la agroindustria. Por otra parte, se hace apremiante poder examinar si existen ejes de intersección entre esas racionalidades, al parecer inconmensurables. De acuerdo con lo consignado en el texto del Acuerdo Final, el buen vivir y el bienestar están relacionados, por un lado, con "la erradicación de la pobreza y la satisfacción plena de la ciudadanía de las zonas rurales", lo que fomenta(ría) el ejercicio pleno de los derechos de los campesinos y de las comunidades étnicas, y, por el otro, estos conceptos macro se relacionan con el logro de la convergencia en la calidad de vida entre los dos ambientes, el rural y el urbano. Esos dos aspectos que aparecen como enunciados fundamentales en el texto del Acuerdo Final de paz constituyen una parte primordial del presente análisis. Tanto en las entrevistas que se han llevado a cabo con los miembros de las comunidades de enfoque de este estudio como también en los materiales de su producción musical se rastrea cuáles son los significados que las comunidades les atribuyen a los conceptos bienestar y desarrollo desde su cosmovisión comunitaria y colectiva. De igual manera, se examina qué 
lógicas constituyen y han formado parte de la cultura y las prácticas ecológicas de las comunidades. Existe una historia inédita sobre la gobernanza comunitaria de los recursos naturales locales que no está consignada en el universo escrito o que ha sido poco documentada en la literatura, pero que se encuentra depositada en la riqueza de la creación oral, entre otros productos culturales. Las composiciones líricas que surgen de experiencias comunitarias son una creación artística y política en donde se encuentra almacenado un cúmulo de sabiduría de las poblaciones campesinas. Es allí donde, también, aparece representada la experiencia rural, en cuya simbología se reproducen y se representan las interacciones de los pobladores rurales en los ambientes agrestes y las tácticas de convivencia entre diversos espacios que se entrecruzan. A través de la producción oral, se pueden rastrear también estrategias de resiliencia y resistencia comunitarias, como se verá más adelante.

Existen diversas investigaciones que contribuyen a la reconstrucción de un marco de análisis sobre las circunstancias, las causas y los efectos/impactos de los monocultivos de palma de aceite y que, además, brindan también elementos para la comprensión de la problemática medioambiental derivada de la industria agrícola. Sin embargo, muchos de esos estudios revelan poco sobre cómo y cuáles han sido los procesos en el interior de las comunidades mismas. En la coyuntura de la construcción de paz, por la que ha apostado parte de la sociedad colombiana actualmente, es preciso conocer qué instrumentos locales y culturales han sido puestos al servicio de esa perspectiva de (re)construcción desde las experiencias comunitarias. El actual Acuerdo Final de paz contiene un compendio ambicioso cuyo primer principio se denomina "Transformación estructural". La estructura sistémica existente, que subyace en el entramado sociopolítico y económico nacional, está arraigada en un paradigma de economía capitalista cuyos modelos de producción y consumo son insostenibles en términos ecológicos. Implementar procesos de transformación estructurales será un trabajo de transformación a largo plazo, lo que indica que sería osado esperar que las estructuras de ese sistema que han guiado las prácticas sociales desde hace más de medio siglo vayan a reformarse de la noche a la mañana. 
Cualquier sociedad que haya experimentado los efectos de la confrontación armada habrá aprendido de su propia experiencia que el camino y la búsqueda de una convivencia justa y en paz se recorre en medio de un cúmulo de emociones y heridas abiertas que necesitan del tiempo y de la disposición de los actores involucrados para la sanación social. El cambio de esas estructuras profundas donde se acaparan diversas formas de poder puede ser posible si somos capaces de visibilizar y dar voz a procesos locales rurales que proponen paradigmas distintos para el bienestar común. Asimismo, si comprendemos que lo que está teniendo lugar, no es exclusivamente la finalización de la confrontación abierta entre la guerrilla más antigua del continente latinoamericano, las Fuerzas Armadas Revolucionarias de Colombia (FARC), y las fuerzas militares nacionales, sino un proceso social inaplazable. Colombia es una sociedad en proceso de reconstrucción que puede habilitar espacios de convivencia con equidad. Se trata, entonces, de un proceso que va más allá de las ideologías partidistas o las filiaciones políticas. Esto es lo que John Paul Lederach llama la "sanación social”, que empieza en las instancias domésticas, locales, lugareñas. Ahora bien, no solamente la transformación a escala local puede garantizarnos que la transición hacia una sociedad sin conflicto armado sea efectiva; John Paul Lederach (2005) también señala que es necesario realizar un diseño estratégico de procesos de cambio a diferentes niveles y con diferentes grupos sociales y agrega que "ese marco requiere de la capacidad de comprender los patrones actuales, imaginar y desear el futuro y diseñar procesos de cambio"11 (2005: 138).

Aproximarse a la comprensión sobre cuál es y cuál ha sido, durante más de medio siglo, el modus operandi de los diferentes grupos que componen la sociedad colombiana exige una reflexión profunda acerca de lo que aceptá(ba)mos como parte de la cotidianidad. Es necesario traspasar lo que nos lacera y nos violenta como sociedad, porque, además, esas formas de transgresión no son exclusivas de las armas, sino que están presentes tanto en las estructuras del sistema vigente como

11. La traducción del inglés al español es mía. El texto en inglés es el siguiente: “The framework therefore required a capacity to understand the patterns of the present, imagine a desired future, and design change processes". 
en los patrones de comportamiento e intercambio social anclados en nuestras prácticas culturales. Esa comprensión exige, además, conocer y reconocer las diversas Colombias que cohabitan la nación y en especial comprender cómo es la Colombia rural, aquellas poblaciones de las que no conocemos sus realidades ni sus verdades ni sus sueños.

Mi experiencia al visitar y conversar con los habitantes de las comunidades de Las Pavas y El Garzal y de las zonas humanitarias de las cuencas del Curvaradó y Jiguamiandó me mostró cuán poca es nuestra comprensión acerca de lo que está sucediendo en el campo, conocemos muy poco las realidades que coexisten en la nación y las diversas idiosincrasias de las zonas rurales. El imaginario del conflicto y la opinión que se forman gran parte de la sociedad colombiana y la sociedad internacional está vinculado con los propósitos de medialidades sensacionalistas. A los colombianos, tanto los residentes en el país como a los de las diásporas, se nos ha informado sobre quiénes son los agentes en combate armado, pero la gran mayoría de nosotros no conocemos cuáles y quiénes son los actores no armados. No tenemos pleno conocimiento de cómo han reconstruido sus vidas, cómo han consignado sus historias, cómo han enfrentado el despojo o cómo han logrado retornos colectivos. Tampoco tenemos conocimiento de cómo han cultivado culturas de convivencia resilientes que les permiten seguir existiendo aún. Esas historias de las Colombias diversas son inéditas aún. Parte de ese proceso de acercamiento implica explorarlas, y este estudio quiere ser una modesta contribución hacia ese recorrido. Si bien el proceso de paz se inició con las conversaciones de los actores armados, los temas de la negociación abordan problemáticas fundamentales que han aquejado al pueblo colombiano y se han discutido en diferentes momentos históricos. Sin ser caso exclusivo en el subcontinente, en Colombia la concentración de tierras en manos de unos pocos ha sido uno de los motivos por los que surge el movimiento armado de las FARC. Las negociaciones en torno a la tierra les competen en gran parte a quienes ocupan territorios campesinos y colectivos a través de las armas, pero también a quienes ocupan esos territorios con otras estrategias, en nombre del 'desarrollo' y el 'progreso'. Las alteraciones y los efectos que se derivan de esa transformación en el paisaje rural son solo unos de los muchos interrogantes que la academia debe 
abordar. Es de trascendental importancia explorar cómo las comunidades locales construyen y reconstruyen la Colombia rural que aún les queda. Si bien, lo acoto en singular, no quiere decir que sea una realidad rural homogénea, pues las prácticas campesinas son múltiples y variadas dependiendo de los matices étnicos y regionales. Escudriñar esos procesos significa poder comprender qué elementos intervienen en la (re)construcción de las subjetividades campesinas y étnicas de los pobladores rurales; además, permite identificar elementos fundamentales de la gestión de las poblaciones rurales en relación a la transformación de un proyecto nacional de convivencia social, ciudadana y rural con justicia y paz.

\section{La tenencia y el uso de la tierra}

La historia de la tenencia de la tierra en América Latina muestra constantes estructurales que se han mantenido y se siguen manteniendo desde los tiempos coloniales En Colombia, en particular, el destierro de las poblaciones y el control territorial han estado gobernadas por una violencia sistemática y de acuerdo con los análisis de Reyes el impacto al que dio lugar la ocupación colonial espańola derivó en dos procesos complementarios que están vigentes de alguna manera en la estructura agraria y han sido semilla para conflictos violentos:

El mestizaje de indígenas, españoles y africanos [...] originó una ocupación minifundista en las tierras de los altiplanos y valles andinos del sur y del occidente del país [...] La secular expansión de haciendas ganaderas de la costa atlántica y de los grandes valles interandinos del Magdalena y del Cauca, que subordinó a la población campesina a las tareas del desmonte de bosques y siembra de pastos (20106: 45-46).

Los heredados modelos de administración agraria y propiedad territorial con la figura de los hacendados no han sido transformados en su esencia. La formación de los partidos políticos de antaño fue parte importante en ese proceso, pues en ellos estaban los caudillos regionales o los gamonales que formaban parte del aparato democrático, y de la administración del poder público, centralizada en Bogotá, se ha 
nutrido de estas estructuras. La titulación de la tierra, hasta antes del año 1936, estaba basada en un sistema patrimonialista, en el cual los titulares debían contar con títulos desde "el original, emanado desde la corona espańola, y luego del gobierno nacional para demostrarla" (Reyes 2016; 48). Las reformas agrarias en Colombia no han logrado modificar las amañadas estructuras que regían antes de la independencia. Si bien el gobierno de Carlos Lleras Restrepo apoyó en 1969 las luchas gremiales del campesinado y la creación de la Asociación Nacional de Usuarios Campesinos (ANUC), en la década de los setenta, el movimiento pierde fuerza y entra a disputar las tierras con las guerrillas y los paramilitares, momento en que, una vez más, la violencia debilita la organización campesina. La estructura de fragmentación de actores que domina el control territorial tiene grandes efectos en la complejidad del conflicto en Colombia. La violencia armada y las estructuras señoriales que se mantienen hoy en día reducen de forma importante el espacio de acción y de constitución del Estado de derecho. De ahí que la presencia estatal se haya asociado a la militar, es decir, al ejercicio de la violencia legitimada. La violencia y el conflicto no tienen una causalidad directa con las crisis, como se tiende a pensar. Las dinámicas de apropiación de tierras no son hijas de los tiempos de crisis, sino, más bien, herederas de los tiempos de prosperidad, como lo plantea Eduardo Galeano:

La apropiación privada de la tierra siempre se anticipó, en América latina, a su cultivo útil. Los rasgos más retrógrados del sistema no provienen de la crisis, sino que han nacido durante periodos de mayor prosperidad; a la inversa, los períodos de depresión económica apaciguaron la voracidad de los latifundistas por la conquista de nuevas extensiones (2015: 170).

En los rigurosos análisis sobre la estructura de tenencia de tierras en Colombia, que ha abordado en profundidad Darío Fajardo, hay dos asuntos cruciales que considero de suma relevancia para este estudio. Por un lado, las proporciones de la concentración de tierras y, por otro, las dos velocidades en las políticas sociales

Muchos países de América Latina, y especialmente Colombia, se caracterizan por presentar altos niveles de concentración de la propiedad territorial en manos de pocos propietarios. De acuerdo con 
los estudios realizados por Darío Fajardo (2002), en Colombia, la relación entre el área predial rural y los propietarios - ya hace una década - confirmaban esas marcadas desproporciones en la distribución de la tierra: el 0,4\% de los propietarios posee el $61,2 \%$ de la superficie rural predial, cuya extensión es superior a las quinientas hectáreas (5). En el Informe Nacional de Desarrollo Humano 2011, "Colombia rural. Razones para la esperanza", realizado por el Programa de las Naciones Unidas para el Desarrollo (PNUD), se confirma que los niveles de concentración de tierra han seguido en ascenso en la última década y la estructura de poseedores de extensas hectáreas se mantiene inmodificable. Dario Fajardo afirma que "la concentración repercute en los niveles de producción: mientras que las fincas menores de 5 ha destinan a usos agrícolas el 38,6 por ciento de su superficie, las mayores de 200 ha solamente destinan a este uso el 2,5 por ciento de su superficie" (Fajardo 2002: 5). El fomento de la capacidad de transformación consignada en el texto del Acuerdo Final, anteriormente citado, tiene que pasar por un proceso de reconocimiento de los actores rurales como agentes fundamentales en los procesos de transición. Intentar dar reverso a esas abrumantes desproporciones en la distribución de la tierra en Colombia implica empoderar los espacios de participación y toma de decisiones de las poblaciones rurales; en específico, en temas relacionados con la gobernanza de los bienes naturales.

La estructura de utilización y apropiación de tierras propia de los monocultivos exacerba la violencia agraria y el control territorial fragmentado, pues allí confluyen la apropiación de la tierra en pocas manos y el aumento de la violencia. La estructura de los monocultivos busca expandir cada vez más su espacio agrícola, con lo cual se pretende concentrar extensas porciones con un solo cultivo para alcanzar la producción agroindustrial que se caracteriza por tener una vocación, fundamentalmente, exportadora. Si en los siglos anteriores, el trabajo del campesinado estaba obligado a aumentar el capital de los hacendados y las élites regionales, hoy en día, el campesinado está supeditado a las estructuras de agricultura extensiva y está incrustado a los propósitos de élites transnacionales. En el contexto nacional de transición que busca la paz y la convivencia, la formulación de las políticas agrícolas inclusivas exige reconsiderar los modelos de producción vigentes y 
revaluar los sistemas de alianzas en la cadena de productividad agroindustrial. Esto implica recuperar la soberanía territorial y reconstruir - o como lo llama B. de Souza "refundar"- el Estado. Si bien posibilitar el acceso a la tierra y legitimar los derechos de las comunidades campesinas que han sufrido los vestigios del despojo no garantiza ese logro per se, sí podría contribuir a la transformación de las estructuras asimétricas de distribución de la tierra por un lado, porque los reasentamientos generan una nueva dinámica del mercado de predios y tienen una clara incidencia en la democratización de la economía agraria $y$, por otro, porque es urgente no solo restituir tierras, sino restaurar estilos de vida, marcos de organización y regulación comunitarios que generan espacios de conservación de las diversas especies naturales y los ecosistemas. La reparación es un proceso que tiene que orientarse a la recuperación del sentido de la vida, de las prácticas comunitarias, es una restitución de la cultura territorial. Eso quiere decir admitir que las culturas rurales tienen otros parámetros de equivalencia que no son necesariamente mercantiles-utilitaristas, y no lo son en absoluto respecto a los bienes agrícolas. Los marcos del pensamiento rural comunitario asignan valor a la adquisición, distribución y producción colectiva de diversos tipos de bienes, mientras el racionalismo individual da valor al poder adquisitivo del sujeto individual y a la acumulación.

Respecto a las dos velocidades, es necesario considerar aquí la temporalidad y la ligereza en el marco de la transición hacia el postconflicto. En el sentido que lo plantea Fajardo, las velocidades se refieren al ritmo con el que avanzan las políticas públicas de implementación en el campo en comparación al tiempo de avance del conflicto. Existe una clara diacronía en la velocidad con que ocurren los procesos, y es allí, en esos mismos desencuentros temporales, en donde la conflictividad adquiere mayor fuerza. En el espacio político, esa disparidad se manifiesta con mayor evidencia en los procesos de implementación —quizá menos que en la formulación de las políticas-. Mientras los tiempos para poner en marcha los programas han sido largos y dispendiosos, el curso de las confrontaciones se ha acelerado de manera exponencial. Asimismo, las temporalidades entre los espacios rurales y los espacios urbanos muestran ritmos profundamente disonantes. Esa variación indica que la construcción de realidades lleva su ritmo propio y está en 
consonancia con los espacios de los cuales emerge. Desde otra perspectiva, esa disonancia y asimetría temporales no son nocivas si se aceptan como parte diferencial de la composición multicultural de la nación, ya que hay realidades paralelas en el concierto nacional que suceden a destiempo, y considerar esa simultaneidad es un desafío de cómo articular intersecciones de la convivencia social y comunitaria, también a ese nivel.

El desequilibrio se produce cuando las velocidades persiguen propósitos antagónicos, que parece ser el caso en los procesos de titulación territorial. Los procesos migratorios de desplazamiento forzado o no forzado no solo resultan de la confrontación armada, sino también de la falta de oportunidades para los habitantes del campo. Lo que apunta Fajardo en su reflexión, y es una idea que se reitera en el informe de desarrollo humano de 2011, "Colombia rural", es que somos una sociedad más rural de lo que nos consideramos. Tanto los planteamientos de Fajardo como el informe y otros documentos enfatizan en la necesidad de una articulación equitativa y equilibrada entre la distribución de oportunidades en cuanto a la participación política, la acción y gestión social y los niveles económicos entre campo y ciudad. En sus conclusiones, Fajardo señala que es necesario "reconocer que la vida rural es el punto de partida de un equilibrio efectivo en las relaciones campo-ciudad, y condición de una sociedad colombiana viable" (2001: 36).

\section{Rescatar las culturas de convivencia}

La convivencia de lo colectivo debe ser restablecida no solo para quienes habitan en comunidades administrativamente definidas, sino para toda la sociedad civil. Esto quiere decir reintegrar en nuestra visión del mundo relaciones menos hostiles con nuestros semejantes, con nuestro entorno natural y social. Ahora, más que nunca, es necesario considerar y ponderar las valoraciones de la acción local, colectiva y comunitaria y las cosmovisiones étnicas y campesinas en las alternativas de gobernanza territorial; es decir, existe una profunda necesidad de valorar los bienes naturales, públicos y comunitarios. Es desde allí 
donde es posible plantearse qué prácticas y saberes aportan a la creación de espacios sustentables. Hildebrando Vélez (2007) insiste en la necesidad de establecer la diferencia entre las sociedades sustentables y las sostenibles: la acepción de sustentable sería, en su opinión, mucho más adecuada para poder referirnos a prácticas no degradables para el medio ambiente, mientras que la noción de sostenibilidad está asociada al potencial rentable de un recurso natural. De acuerdo con este autor, la sustentabilidad se podría definir como "la capacidad de un ecosistema para nutrir y sostener continuamente una población, incluyendo la población humana, sin destruir la capacidad de supervivencia del ecosistema conforme a los límites de resiliencia"12 (Vélez 2007: 8). La lógica sustentable incorpora la coexistencia de los bienes naturales como sistemas vivos con los que el hombre tiene que interactuar y considerar prácticas de intercambio en cuyas relaciones prime el valor de la reciprocidad. Desde esa perspectiva, se puede plantear una construcción de pautas de convivencia que amparan las relaciones no solamente entre grupos humanos y sus respectivas singularidades, sino entre especies vitales que cohabitan y forman parte de la naturaleza. Esta visión de lo sustentable transciende la idea de tolerancia y transita hacia la noción de bienestar en términos no solamente de conveniencia económica, sino, y sobre todo, de convivencia ecopolítica.

Las actividades de las comunidades rurales ponderan el uso y la intervención de agentes naturales en sus diversas actividades, creando verdaderos nichos de la cultura bio. Además, generan tecnologías sustentables como la producción a pequeña escala, los procesos de diversificación y variabilidad de cultivos, los manejos integrales en condiciones precarias, tecnologías limpias o amigables con la naturaleza, la adecuación de su sistema de producción a los ciclos de la naturaleza y las condiciones locales de su contexto, etc. Es decir, existen diferentes prácticas que desde lo local/rural nos muestran modos de convivencia que han construido y resguardado las comunidades y que no están

12. La traducción es mía. El texto en inglés es el siguiente: "To the capacity of an ecosystem to continually nourish and sustain population, including the human population, without destroying the ecosystem's capacity self-preservation by conforming to the limits of resilience" (Vélez 2007: 8). 
exclusivamente en cohabitación con lo humano, sino también con lo inmaterial y espiritual. De tal manera que la forma de extracción agroindustrial que se deriva de los cultivos extensivos, en este caso de palma de aceite y que en gran parte se destina para para producir agrocombustibles, no solo desplaza poblaciones agrícolas, sino también desplaza racionalidades campesinas, incluso más eficientes - aunque precarias- y más sustentables en el plano local, pero desafortunadamente tienen poca capacidad de desplegarse por ausencia de políticas que las promuevan.

Las culturas de convivencia que han intentado conservarse en muchos de los espacios rurales están relacionadas también con las consideraciones sobre los ritmos de vida y las temporalidades tanto de los seres naturales como de los seres humanos. Si los procesos de modernización no son revaluados con el fin de promover el bienestar del campo agrícola -lo que va más allá de la acumulación y el utilitarismo-, los resultados políticos seguirán siendo incipientes. Ahora bien, la revisión de la modernización en el campo tiene que ser congruente con los conceptos de bienestar y buen vivir que hemos mencionado anteriormente. Eso quiere decir que de la modificación de las políticas agrícolas en Colombia o, mejor, los procesos de reforma agraria deben estar orientados a consolidar culturas ecopolíticas que incorporen las historias agrarias comunitarias y potencien formas de intercambio económico y político en donde la agricultura campesina conserve su esencia ontológica. Pero, a su vez, esas reformas deben verse también favorecidas por técnicas y una tecnologías agrícolas para el fortalecimiento de los pobladores rurales, de sus economías, de su producción, de su consumo, etc. En este sentido, la convivencia está contemplada desde la coexistencia y la inclusión de prácticas locales y de modos de tecnificación en la economía agrícola que aportan en las visiones de bienestar basadas en valores de la administración comunitaria de los recursos tanto naturales como no naturales. 
LOS SERES HUMANOS Y LA NATURALEZA

Hay valiosos ejemplos de procesos de construcción pacífica a nivel local: las redes de paz, el mandato campesino, las comunidades de tejedoras, los grupos por la paz, etc. Esos procesos, y otros, que existen en diferentes regiones del país - aunque hasta ahora no se hayan dado a conocer - han contribuido a cambiar el cauce de los ríos y de los ruidos de la guerra y han incidido en la construcción de espacios de paz en medio del conflicto. Podríamos denominarlos escudos silenciosos que han mitigado las confrontaciones o han llegado, incluso, a neutralizarlas. Los gestores de esos blasones contra la violencia han librado muchas batallas y se han protegido de la desidia y la desolación a las que la guerra ajena ha querido condenarlos. Esas armas a las que me refiero son los esfuerzos por la paz que han venido tejiendo diferentes grupos de las sociedades tanto urbanas como rurales usando diversos medios y canales para difundir su patrimonio cultural. En este sentido, las investigaciones existentes siguen dejando una amplia brecha con relación a aquello que acontece en el interior de las poblaciones afectadas, a los mecanismos que las comunidades han desarrollado y a las herramientas culturales de las que hacen uso para enfrentar el despojo y la violencia en sus diversas formas. Existen pocos estudios que se hayan ocupado de examinar exhaustivamente la representación cultural de la conflictividad, la acción proactiva de las comunidades rurales y, en suma, tanto la capacidad resiliente como las estrategias de convivencia que emergen a nivel local en los espacios rurales. En los análisis sobre las experiencias agroecológicas en el departamento del Meta realizados por Carmenza Castiblanco y Juan Carlos Rojas, los autores señalan que la agroindustria se impone como modelo de desarrollo rural sin tener un mínimo de conocimiento sobre las economías agrícolas productivas en los entornos locales:

La apuesta de desarrollo rural agroindustrial y agroexportador, desconoce de manera tajante las experiencias organizativas y agroecológicas que han llevado a cabo comunidades campesinas durante los últimos 10 años, beneficiarias de los 
procesos de adjudicación de baldíos por parte del INCODER ${ }^{13}$ en los municipios de Puerto Gaitán y Puerto López (Meta) (2016: 11).

Existen pocas reflexiones que dediquen su análisis a las narrativas que surgen de comunidades rurales o que examinen la producción cultural y artística en la que se recrea la estética rural y a través de la cual se reconstruyen los efectos que ocasionan diversas formas de despojo y cómo se manifiestan en el arte. Sin embargo, recientes análisis (Forero, Rodríguez y León 2015) en los que se documentan los valiosos aportes de la agricultura familiar en la altillanura colombiana confirman que el modelo de agricultura familiar es más sustentable que el de agricultura a gran escala no solo ecológica sino también económicamente. Estas economías generan, además, un valor adicional en términos culturales porque se convierten en fuentes de la transferencia de saberes de campesino a campesino. Asimismo, se preocupan por desarrollar y adquirir técnicas para el trabajo agrícola que atienden a las necesidades de sus espacios comunales, colectivos y locales, ejerciendo influencia en el aumento del bienestar en el ambiente rural. Esto confirma que este tipo de economías basan sus relaciones con la naturaleza en intercambios de aprovechamiento mutuo y generan dinámicas de convivencia con la misma y la conservación medioambiental.

El contexto de transición y la coyuntura de un acercamiento entre los actores armados en disputa en Colombia requieren un compromiso decidido de parte de los diversos ámbitos sociales para propiciar espacios de reflexión y comprensión en torno a las prácticas ecológicas locales y a los significados de lo local sobre la naturaleza, la tierra y el territorio. Los procesos comunitarios que se manifiestan contra la usurpación de tierras, ya sea por la actividad de los agrocombustibles o por otras modalidades de extractivismo, están teniendo lugar en diversos países de Asia, África y América Latina. Muchas de las acciones colectivas que se oponen a esa tendencia se muestran como derroteros

13. El INCODER se liquidó como institución a finales del año 2015, cuando se crearon seis dependencias del Ministerio de Agricultura: la Agencia Nacional de Tierras, la Agencia de Desarrollo Rural, la Agencia para la Renovación del Territorio, el Consejo Superior de Uso del Suelo, el Consejo Superior de Restitución de Tierras y la Dirección de Mujer Rural. 
hacia la transformación de los escenarios de conflicto y han llegado a incidir en marcos políticos y jurídicos para el beneficio de los habitantes rurales. Hay procesos inéditos de vindicación comunitaria; dos de ellos de ámbito nacional, los más recientes, son los defensores de los páramos (Censat 2016) ${ }^{14}$ y la consulta popular en Cajamarca. En el primero, varias organizaciones de diversas regiones de Colombia construyen rutas de trabajo para protección de la montaña andina. En el segundo, las poblaciones del municipio de Cajamarca del departamento de Tolima se opusieron al proyecto minero la Colosa a través de una consulta popular (Dietz 2018). ${ }^{15}$ Estas dos iniciativas evidencian que existen mecanismos legales que abren un panorama de participación democrática para que las acciones gestadas en las localidades rurales logren generar reformas exitosas en favor de la recuperación y gobernanza de sus territorios. Esos procesos de lucha por la participación en la gestión de los recursos naturales y las vidas de generaciones dedicadas a la defensa del territorio se convierten en caminos viables para democratizar la tierra y el territorio.

14. Crónica del Tercer Encuentro Nacional de Defensores de Páramos "Territorio y Soberanía”, en Tasco, Boyacá, del 13 al 15 de agosto 2016. Se puede ampliar la información en Censa: <https://censat.org/es/noticias/declaracion-politica-iii-encuentro-nacional-de-defensores-y-defensoras-de-paramos-territorios-y-soberania>.

15. Dietz (2018) toma este caso para analizar transformaciones en el marco institucional y los procesos de la democracia participativa. 


\section{Capítulo II}

\section{Cultura, conflicto y medio ambiente: aproximaciones}

Existen diversos marcos de análisis que examinan las disputas por recursos naturales o que analizan la relación entre estos y el surgimiento de conflictos (Ross 2003, 2004; Collier y Hoeffler 1998). El marco teórico de las ciencias políticas proporciona aproximaciones para analizar los estudios sobre conflictos, su manejo y su transformación (Lederach 1995, 2010; Miall 2001; Walker y Daniels 1997; Pendzich et al. 1991). Si bien algunos estudios sobre la relación entre conflictividad y medio ambiente usan análisis cualitativos, parece que una amplia mayoría prefiere recurrir a los instrumentos cualitativos para el análisis. Metodológicamente, ese tipo de análisis aplica procedimientos que buscan validar las hipótesis propuestas para luego aproximarse a elaborar interpretaciones que puedan alcanzar un valor universal o planteamientos generalizadores sobre el conflicto. Aunque el marco teórico para investigar la confrontación como fenómeno social y político sí arroja pistas sobre el origen y los impactos de los conflictos por los recursos naturales, los resultados se convierten en narrativas que 
leen —interpretan — desde fuera el contexto de las disputas. Hay una tendencia aún muy positivista para explicar causalidades entre variables, cuyas determinaciones pretender ser lo más cercanas a las ciencias exactas. Aunque los análisis que intentan explicar relaciones de causalidad son necesarios, no son suficientes para acceder a una comprensión robusta e integral sobre la confrontación ni sobre otras inquietudes sociales. Es necesario, pues, acercarse al análisis de las especificidades contextuales y las historias que marcan y determinan la caracterización de los agentes involucrados en las disputas. Asimismo, es imprescindible repensar cómo hacer investigación y cómo ponerla al servicio de la transformación social. He aquí la importancia de aproximarse a identificar y desglosar de fondo tanto los entornos en los que surgen las disputas como también los ambientes, las identidades y los atributos que definen a los actores en conflicto. Esta necesidad de ahondar en el conocimiento de un actor específico es inherente a la urgencia de observar los procesos sociales superando los planteamientos mecanicistas y recurriendo a un panorama científico que nos permita explorar respuestas sobre las acciones humanas, en este caso en el contexto de la confrontación. Al respecto, Orlando Fals Borda (2009) aporta una reflexión acerca de lo que determina un efecto y pone en tela de juicio la consideración de causalidad aplicada también para las ciencias sociales:

Como en lo social el antecedente inmediato de la acción es volitivo, la acción no va determinada en un sentido único, sino que tiene una determinación múltiple dentro del proceso o marco en el cual adquiere sentido. La determinación múltiple, con ese abanico de opciones dentro de una coyuntura (posibilidades que se cierran al abrirse otras), explicaría por qué la historia no se repite, por qué sus procesos no son inevitables, excepto quizás en formas muy largas y lentas (2009: 260).

El carácter volitivo al que se refiere Fals Borda, es decir, la voluntad con la que actúan los actores en situaciones de conflicto, no puede ser analizado desde conceptos hermenéuticos. Lo que esas determinaciones teóricas sí nos pueden aportar es un panorama de reflexiones sobre cómo interpretar las realidades. Además, esos planteamientos pueden ser puentes para aproximarse a la lectura de los contextos que construyen los actores. A continuación, se presentan algunos planteamientos tanto de los estudios culturales como de los de conflicto. Los aportes 
teórico-reflexivos sobre conflicto y medio ambiente que aparecen a continuación corresponden a una selección rigurosa que permite abordar la complejidad de los contextos geográficos del estudio. Se trata de construir una reflexión ecléctica compuesta por fundamentos teóricos que conjuguen elementos complementarios y aporten visiones largas y anchas para comprender las realidades que manifiestan las confrontaciones. Este propósito responde a las limitaciones que puede generar para cualquier investigación el ceñirse exclusivamente a la selección de un planteamiento teórico o a una determinada rigidez metodológica, pues de lo que se trata es de poder explorar una dialéctica metodológica que nos permita el intercambio y la ampliación entre los conceptos necesarios en el análisis y a través de la cual se puedan contrastar esos conceptos con las realidades de las comunidades en cuestión. Este proceso es de alto valor porque posibilita conceptualizar o revaluar lo dogmático y revalidar o resignificar lo teorizado en el marco de lo local.

\section{Estudios culturales y sus discursos}

Las percepciones de espacio y tiempo modifican la relación con el mundo y a su vez dan origen a nuevas formas de interacción. A través de la relación trilógica hombre-tiempo-espacio se crean significados de la naturaleza y la sociedad que son representados a través de sistemas de símbolos. La representación simbólica no solo da cuenta de esa relación trilógica, sino que también actúa en el proceso de resignificación de los acontecimientos y las interacciones colectivas. El repertorio simbólico, el conjunto de valores, las prácticas y los juicios compartidos por una colectividad podrían ser entendidos como un engranaje sistémico, que podría denominarse cultura. La definición de cultura, sin embargo, parece constituir un debate en sí mismo. Existen una multiplicidad de aproximaciones que, partiendo desde diferentes perspectivas, disciplinas y corrientes de pensamiento integran elementos diversos o contradictorios para conceptualizar y teorizar la cultura. Sin adentrarme en una reflexión extensa sobre lo que significa este término, tomaré algunos aportes y planteamientos relevantes para este análisis que emergen de las reflexiones de los estudios culturales, 
en específico, aquellos planteamientos que se refieren a la producción cultural en América Latina.

Los estudios culturales hacen un aporte de las realidades latinoamericanas en tanto que "su formación se puede pensar como un proceso de retroalimentación constante entre diferentes grupos de la sociedad civil, modos culturales populares, instituciones culturales, estados nacionales, corrientes de pensamiento internacionales y continentales" (Szurmuk y Mckee 2009: 12). El término 'retroalimentación' conduce a la idea de un compartir simultáneo y equitativo entre diferentes grupos sociales. En las realidades latinoamericanas, se ha suscitado la búsqueda por redefinir lo que es la cultura nacional y la lucha por propiciar espacios de representación que revelen la heterogeneidad y la diversidad como partes constitutivas en la construcción de las narrativas nacionales. En términos de representatividad tanto política como social, muchos grupos sociales han quedado al margen de la llamada 'cultura nacional'. La tendencia a rotular de homogéneo lo que define a la cultura nacional ha obviado las diferencias, ambivalencias y disyunciones que socialmente conforman la nación y las narrativas que emergen de muchos grupos que han quedado al margen de esa representatividad nacional. Sus planteamientos fueron relegados en el terreno de lo subalterno y sus prácticas culturales quedaron desplazadas mientras se pretendía construir la idea de cultura nacional con una supuesta identidad homogeneizante y exclusivamente mestiza e inalterable. Homi K. Bhabha señala que en el entramado de esas diferencias y en la diversidad de los grupos sociales se actualizan procesos dialécticos de la nación, como lo indica el siguiente fragmento:

Es justo desde la inestabilidad de la significación cultural donde la cultura nacional venga a articularse como una dialéctica de varias temporalidades — moderna, colonial, postcolonial, nativa- que no puede ser un saber que se estabiliza en su enunciación (Bhabha 2004: 218-219). ${ }^{1}$

1. La traducción es mía. El texto original en inglés es el siguiente: "It is just from the instability of cultural significance that national culture comes to articulate itself as a dialectic of various temporalities - modern, colonial, postcolonial, native - that cannot be a knowledge that stabilizes in its enunciation". 
Esa multitemporalidad es incluso uno de los criterios imprescindibles para el proceso actual de postconflicto en el contexto colombiano. La reconstrucción de la nación debe ser entendida como la posibilidad de incluir, reconocer e incorporar como válidos y legítimos discursos, prácticas y narrativas, así como también distintas valoraciones en las prácticas sociopolíticas y económicas. En consecuencia, sería la posibilidad de reconocer que el quehacer político, la convivencia y las propuestas democráticas no tienen un solo formato de presentación. En esa misma línea, las ideas de nación emergen de diferentes representaciones y lenguajes. Las subjetividades comunitarias en la ruralidad, sus procesos de consolidación y reconstrucción en el contexto del postconflicto deben ser vistas como actores y engranajes fundamentales de lo nacional. Los procesos comunitarios que reivindican los recursos naturales no buscan exclusivamente invertir el balance de poderes, sino que se orientan con mayor énfasis a la resignificación y las valoraciones de la naturaleza desde su acervo campesino en el marco de la diversidad nacional. Así, y como lo señala Bhabha, se trata de "redefinir el proceso simbólico a través del cual el imaginario social —nación, cultura y comunidad - se convierte en sujeto del discurso y en objeto de la identificación psíquica” (Bhabha 2004: 220). ${ }^{2}$

Ese imaginario social en el contexto rural lo redefinen algunas comunidades a través de la creación lírica, entre otras formas de expresión cultural. En las composiciones se deposita un cúmulo de significaciones con las que las poblaciones campesinas comprometidas en la lucha por el territorio dan forma a la historia agraria en la temporalidad del presente, situándola en una contemporaneidad dinámica. Lejos de simbolizar una realidad idílica, apenas conectada con el pasado, la representación que emerge desde las comunidades intenta mostrar y posicionar sus preceptos, que, arraigados en una epistemología nativa y rural, revelan también las contradicciones sociales con el propósito de aproximarse a plantear prácticas de articulación entre las posiciones

2. La traducción es mía. El texto original en inglés es el siguiente: “To redefine the symbolic process through which the social imaginary - nation, culture or Community - becomes the subject of discourse, and the object of physic identification". 
discordantes de los diferentes grupos sociales. Más allá de aceptar la disonancia como realidad en la interacción social, es necesario e indispensable comprender que el contexto y las condiciones de la construcción de la nación deben diseñar sistemas políticos, económicos y sociales que resulten en la creación de una arquitectura cultural incluyente y participativa.

\section{La oralidad y la lírica: equidad en la diferencia}

Si bien la producción oral — también llamada literatura oral — en los estudios culturales ha tenido un espacio de representación, existe aún una marcada tendencia a otorgarle a la escritura y al universo gráfico un lugar especial y preponderante en la investigación académica. ¿Acaso olvidamos que el mundo gráfico emerge de la producción oral? ¿O quizás se desconoce que la producción oral ha jugado un papel fundamental en la construcción de las culturas latinoamericanas? Así como también ha sido primordial en la emergencia de otras literaturas, como lo señala Adrián F. Freja de la Hoz, quien realizó un trabajo de investigación sobre las diversas formas de 'literatura oral':

Tuvo que transcurrir mucho tiempo para que los estudiosos de la literatura clásica tuvieran en cuenta el carácter oral de los textos fundacionales y por tanto el problema de la oralidad [...]. Algo similar sucede con la literatura de la Edad Media. Solo hasta los años cincuenta los medievalistas descubren la existencia de la poesía oral medieval (2015: 28).

Y es que el reconocimiento que se debe dar a la literatura oral empieza por explorar ese enlace — casi continuo - entre literatura escrita y literatura oral que se encuentra presente en gran parte de los textos producidos en diversas zonas del continente. Tal y como afirmó Gabriel García Márquez, uno de los escritores colombianos más brillantes y quien ha sabido combinar de manera grandiosa los discursos de la oralidad y de la escritura en sus obras: "Cien años de soledad, no es más que la tentativa de un vallenato de más de 450 páginas" (Williams 1991). En esta aseveración, este gran escritor y premio Nobel de Literatura en 1982 pone al descubierto que, en la literatura 
latinoamericana y específicamente en la colombiana, se encuentra inherente un valioso sustrato de la tradición oral. En una gran parte de las obras literarias, ese legado de oralidad aflora en la creación de la palabra escrita y convierte el texto en un universo polifónico y con dinamismo perlocutivo. Muchas obras literarias contienen en su construcción narrativa diversos elementos que provienen del lenguaje hablado. La elaboración discursiva del lenguaje hablado le proporciona al texto narrado un giro temporal, pues las marcas del habla tienen un efecto en la reactualización de los hechos que se relatan. En relación a este aspecto, Paul Ricoeur considera que "en el discurso hablado, esta habilidad del discurso para remitirse de vuelta al sujeto hablante presenta un carácter de inmediatez porque el hablante pertenece a la situación de interlocución: Está ahí, en el sentido genuino de estar-ahí de Da-sein" (2011: 42). La riqueza de la literatura oral es copiosa y abundante, esto se puede identificar de forma especial en los litorales del Pacífico y el Atlántico colombianos; sin embargo, existe también una gran producción que florece en diferentes regiones del país: la andina, la llanera, la selvática. Esa predilección por las literaturas orales no está necesariamente vinculada con la errónea percepción de que las comunidades rurales sean iletradas. La preferencia por la oralidad para construir relatos colectivos guarda una estrecha relación, en primera instancia, con las tradiciones regionales en las que se han construido las historias comunitarias. Y en muchos sitios se puede detectar que la construcción de las historias comunitarias acontece, particularmente, a través de la consolidación de las identidades musicales en espacios de oralidad que se han ido generando a lo largo de los años y que se han ido transformando, también, regionalmente por flujos tanto locales como internacionales.

La producción y formación de discursos y metadiscursos sobre las identidades y culturas nacionales están enmarcados en una diferencia cultural que, dependiendo de la categorización social que se le haya otorgado a lo diferente, tiene repercusiones en los procesos de aceptación o negación de la diferencia; es decir, una diferencia racial, por ejemplo, sería valorada a partir de los discursos que se han impuesto históricamente sobre las valoraciones de inferioridad y superioridad. Esta construcción social de la diferencia en términos raciales, así como 
también en términos de género, sigue dominando la reproducción del imaginario colectivo respecto a la concepción de pertenencia a los espacios de participación política y al acceso a las oportunidades. El cuestionamiento y la consciencia de la diferencia son una temática presente en los debates sobre las identidades nacionales. Los grupos que reclaman participación en la arena social, política y económica consideran necesaria la resignificación de la diferencia en el diálogo social, pues es un requisito imprescindible para empoderarse y reconstituirse como comunidades. La diferencia es un valor suplementario que en la cotidianidad se manifiesta a través de las prácticas y los conocimientos particulares de las poblaciones y las hace esencialmente singulares como colectivo. Esa diferencia debe recategorizarse desde otras dimensiones distintas a las valoraciones de lo fenotípico, por ello la diferencia contiene un carácter marcadamente distintivo y deber ser contemplada desde una epistemología de complementos y reciprocidades. Bajo esa perspectiva, el complemento y la correspondencia entre grupos sociales propiciarían el surgimiento de nuevos espacios de acción, gestión y ejecución en las dimensiones de lo político, lo social y lo económico. Los espacios emergen a menudo en zonas liminales y aparecen como alternativas a las barreras puestas para disgregar o marginalizar las posibilidades de acceso y comunicación entre los grupos sociales. Bhabha (2004) llama a esos espacios los in-between spaces. Son ambientes recreados en donde se construye esa posibilidad de representar simbólicamente las singularidades que caracterizan a los grupos que han quedado al margen. En el arte se puede identificar la construcción de este tipo de representación, como es el caso de las comunidades afrodescendientes, indígenas o campesinas en Colombia. Esas poblaciones reivindican relaciones de equidad social y política a partir del reconocimiento de la diferencia en sus prácticas ancestrales, territoriales, ecológicas, sociales, etc. Sucede que muchas veces esos espacios son prohibidos o vetados hasta que logran consolidarse como instancias de acción, y, en el contexto colombiano, muchos de esos espacios han fortalecido y le han dado visibilidad a las propuestas de transición también en las fases del postconflicto hacia la construcción de la paz. 
La búsqueda de equidad en la diferencia tiene efectos en la deconstrucción de las prácticas coloniales que siguen vigentes en el contexto contemporáneo. La constitución de jóvenes repúblicas en América Latina no tuvo como resultado cambios significativos en las estructuras sociopolíticas y económicas heredadas de la época colonial. Sin entrar en mayores detalles, es preciso mencionar que el sistema seńorial implantado desde los inicios de la colonización española se mantuvo durante más de tres siglos. Una nueva era postcolonial en cuyos núcleos vertebrales se mantenían sistemas coloniales cambiaron en su apelación nominal, pero sus referentes semánticos no se transformaron en su esencia. En realidad, el tránsito se hizo hacía un neo y no hacia un postcolonialismo. Las confrontaciones entre diversos grupos sociales se cultivan, en gran parte, desde esa transición, que no ofrecía mecanismos que acabaran con el orden social colonial impuesto por varios siglos. En este ámbito de relaciones de colonialidad y postcolonialidad, otros estudios como los de Stuart Hall (2002), quien dedica especial atención a la formación discursiva sobre lo postcolonial, plantean que los conceptos que subyacen a los discursos opuestos también emergen de una construcción que está caracterizada por la creación de fronteras tanto materiales como simbólicas. Este autor hace énfasis en las posiciones de polarización entre dualidades colonizadores/ colonizados y centro/periferia y señala que deben ser vistas desde una óptica más amplia que contemple los procesos locales en los que sucede la descolonización. Su propuesta coincide con los planteamientos hechos por Ella Shohat (1991), pues ambos autores sugieren que es necesario considerar que las trasformaciones se dan a diferentes ritmos, dependiendo de las dinámicas sociales. En torno a los ritmos del cambio en la sociedad colombiana, Orlando Fals Borda, en su libro $\mathrm{La}$ subversión en Colombia. El cambio social en la historia (2008), presenta un riguroso análisis sobre la historia colombiana, diferenciando cuatro órdenes sociales. El término subversión se refiere a las tensiones y los conflictos que se pueden identificar antes y después de cada periodo clasificado, que Fals Borda llama los condicionantes. La distinción entre las diferentes fases guarda relación con los periodos históricos que las caracterizan: 
La distinción entre ellos guarda relación con los periodos históricos de la siguiente manera: en la época de la conquista, la primera subversión moral es la "cristiana". Posteriormente en el periodo de la ilustración es la "liberal" con valores burgueses, después una subversión socialista a comienzos del siglo xx y hacia mediados del siglo xx una subversión "neoclasista” anticipando un quinto orden (2009: 443).

Declarar la finalización de un sistema colonial y el ingreso en la era de la independencia fue una razón que impulsó a creer en la inminente necesidad de abandonar los patrones bajo los que funcionaban las sociedades tradicionales y transitar hacia las puertas del progreso. La modernidad entrante en una América Latina, supuestamente republicana, pasó solo por algunas de las esquinas del continente, y, mientras algunos de sus grupos sociales atisbaban su llegada, en otras orillas del subcontinente muchos de sus pobladores ni siquiera tuvieron la oportunidad de percatarse de ello. Una modernidad que parece asociarse de forma exclusiva a lo que se entiende por comunicación tecnológica y, como bien lo señala Jesús Martín-Barbero, una modernidad devoradora:

Una modernización cuya racionalidad, al presentarse como incompatible con su razón histórica, legitimó la voracidad del capital y la implantación de una economía que tornó irracional toda diferencia que no fuera recuperable por la lógica instrumental del mal llamado desarrollo (2001: 9).

La orientación hacia la modernidad equiparada con los fundamentos del paradigma utilitarista ha socavado otras dimensiones de lo moderno, tanto en el terreno político como en el terreno social. Como propone Mary L. Pratt en su ensayo La modernidad desde las Américas, la modernidad no es un proyecto acabado sino en plena realización. "La modernidad aparece, entonces, no como un proceso que otorga libertad, sino como un proceso que pone en movimiento ciertos conflictos, y que está constituido a su vez por esos conflictos. Esta formulación obviamente demanda también una relectura de la emancipación en el centro" (2000: 833).

Sin ahondar más en las transiciones hacia otros posts, lo que debe quedar claro es que la oralidad ha sido el canal de resguardo de las culturas rurales, marginadas o periféricas y que, dependiendo del 
momento histórico, esas expresiones de la diferencia han enfrentado la censura, la subordinación o el desprecio. Allí, los relatos orales y líricos han consignado no solo el dolor, sino también sus contras. En ellos se encuentran depositados artefactos para la convivencia local en una polifonía de voces sobrevivientes y una sinfonía de acciones por la paz. Una enriquecida porción de la historia de cómo crear resiliencia y resistencia comunitaria se encuentra consignada en la memoria oral, especialmente aquella que emerge en ámbitos del dominio comunitario. Se podría asegurar que el lenguaje artístico y musical ha promovido escenarios de conciliación, de negociación y de perdón entre las víctimas y los victimarios.

\section{La música popular: objeciones}

La música, el canto y la lírica que emergen de las colectividades rurales se nutren del repertorio histórico-cultural que no solo funciona como representación de las prácticas comunitarias, sino como práctica de la representación de esas subculturas. Las prácticas orales y musicales son reveladoras de historias rurales étnicas, campesinas, locales, regionales; es decir, son portadoras de múltiples discursos polifónicos. La gran mayoría de esos relatos hasta ahora inéditos, que se materializan en el canto y en el cuento, revelan los trazos de una estética renaciente que emerge para la creación de escenarios de entendimiento y, en el contexto actual de Colombia, son fuentes imprescindibles para la transición del postconflicto, tanto por su constitución argumentativa como por su configuración estructural. Algunas de las composiciones que nacen en una comunidad campesina se van convirtiendo en símbolos de representación y se convierten en herramienta de participación popular. Sin embargo, es preciso observar que también la oralidad popular ha sido instrumentalizada por la industria musical o discográfica, derivando en algunos casos en interpretaciones desvinculas de la herencia local o tradicional.

Respecto al origen de la música 'popular', Jacques Gilard, gran investigador, plantea reflexiones muy acertadas sobre la relación entre la cultura y el poder político durante la conformación de la modernidad 
en Colombia hacia las décadas de los cuarenta y cincuenta. Este autor establece una analogía entre lo que caracteriza a la poesía popular gauchesca en Argentina y el origen de la música vallenata para esa época y asegura que las versiones populares son fórmulas estandarizadas. En palabras de Egberto Bermúdez (2009), lo popular deja de serlo "cuando miembros de la elite provinciana costeña tomaban la voz de sus propios jornaleros y 'concertados' para reafirmar su poder sobre ellos" (Bermúdez 2009: 35). Como lo advierte Jorge Luis Borges y lo confirma Jacques Gilard, se da una forma de popularización tratando de imitar el estilo popular pero creado por las élites nacionales. Así, Martín Fierro es la creación de hombres de la ciudad y no el fruto de la poesía popular campesina. La mayoría de las actuales composiciones no ilustran los relatos ni las vivencias rurales en torno a las problemáticas que han experimentado las comunidades campesinas en términos agrícolas. Este hecho se explica porque los intereses comerciales de la industria musical han priorizado otros ejes temáticos para la expresión vallenata.

Situar la producción musical de ambientes específicos dominados por la confrontación armada y en asimetrías de poder supone reubicar también el lugar que se le confiere a la lírica, al canto y a la música misma como mecanismos y medios de reflexión. Me refiero a la reterritorialización de la oralidad dentro de los análisis académicos de la cultura, pues esta contiene un acervo que revitaliza y reconstruye las realidades históricas y locales. Mientras la escritura y el texto gráfico se han venido reafirmando como instrumentos que marcan un sistema predominante de poder, la oralidad, lejos de convertirse en expresión arcaica, sigue reafirmándose y es lugar de práctica y práctica de lugar, en donde se pueden explorar aportes desde los grupos sociales menos privilegiados. La literatura oral en América Latina recupera un amplio universo no solo de las tradiciones, sino de las percepciones que ponen en relación al hombre con sus mundos — materiales, espirituales y ficticios- Los discursos orales no pueden ser reducidos a una performance vocal, se apoyan más bien en un sistema complejo de comunicación en el que los gestos, el ritmo, la coreografía y otros elementos complementan a la palabra para construir y recomponer las realidades locales. Y es que la oralidad se convierte en práctica semiótica que da 
la estructura al universo colectivo, transciende la temporalidad, dinamiza y revive los significados de lo real y no cae presa de la expresión petrificada. La articulación de los sistemas comunicativos entre los sectores hegemónicos y los sectores subalternos es analizada por Martín Lienhard en su ejemplar ensayo La voz y su huella, en donde afirma lo siguiente:

En el contexto de los procesos de enfrentamiento étnico-social, los textos "alternativos" resultan, de hecho, verdaderos campos de batalla semiótica, espacios donde se redefinen, ficticia o ficcionalmente, los lugares respectivos de los "vencedores" y de los "vencidos" (2003: 33).

Los textos alternativos, como señala Martín Lienhard, no solo son campos de batalla, sino que se han convertido en fuente misma para hallar los eslabones de una historia de marginalidad y resiliencia de las subculturas latinoamericanas. La oralidad constituye una de esas piezas vitales de la reconstrucción social que puede proporcionar herramientas para llevar a cabo los procesos que emergen de las comunidades y busca aportar reflexiones que emanan desde la convivencia, los conceptos y los preconceptos de los agentes marginados. Las confrontaciones por la tierra y el territorio están relacionadas, por un lado, con la noción espacial de terreno geográficamente demarcado, pero también con una construcción cultural que rebasa lo puramente material.

Hermann Herlinghaus (2009), desde una perspectiva más transnacional, observa cómo a través de diferentes tipos de música se manifiesta la crudeza social causada por el sistema económico global. Este autor realizó un notable análisis sobre la música, el canto y la relación de las composiciones de los corridos y las realidades mexicanas. Considera que las narrativas producidas por grupos sociales que quedan al margen del llamado 'progreso económico' no solamente relatan las transformaciones locales, sino, especialmente, ilustran cómo se manifiestan los efectos de desterritorialización derivados de los procesos de globalización y del libre mercado. A diferencia de las zonas de contacto que propone Pratt, Herlinghaus considera, por el contrario, que el uso de mecanismos que transgreden fronteras ni construyen ni se constituyen en puentes de comunicación. También señala que los procesos de 
hibridación cultural están relacionados con la estética, más de lo que aparentemente se cree. ${ }^{3}$ Las configuraciones estéticas que emergen en los años noventa del pasado siglo, como el narcocorrido, las telenovelas y las historias de sicarios, entre otros, son muestras de ese orden, como lo expresa Herlinghaus (2009) en el siguiente fragmento:

Antes que ser aberrantes representaciones artísticas transnacionales, estas narrativas son, en sí mismas, parte de un cambio en las sensibilidades estéticas y conceptuales. Pueden ser percibidas como figuraciones de la ubicuidad de la violencia en términos de la experiencia (2009: 6). ${ }^{4}$

Herman Herlinghaus (2009) reprocha la poca reflexión entre el planteamiento de lo híbrido y el poder: "Se trata muy poco sobre la práctica del poder del centro desenmascarada en el inconsciente colonial y mucho más sobre el desencantamiento de la 'Periferia' misma y de sus condiciones propias" (24).

\section{Cartografías comunitarias de la nación}

Homi K. Bhabha, en su obra Lugares de la cultura (1994), se acerca a la inquietud investigadora en torno a una nueva cartografía espacial. Se refiere a la representación compleja de las dualidades presente/pasado e inclusión/exclusión, en las que se crean lugares de articulación entre culturas y prácticas culturales diferentes. Los in-between spaces (espacios intermedios), que Bhabha considera sitios de reformulación sobre la representación de la diferencia, pueden devenir en espacios de la negociación y articulación de las oposiciones o, por el contrario, ser proclives a convertirse en áreas de conflicto. Bhabha retoma las posibles

3. La producción simbólica que se gesta en los procesos de hibridación cultural es interpretada por García Canclini y Bhabha como resultados de procesos migratorios. En este sentido, la interpretación de Herlinghaus emerge desde una perspectiva diferente: la exclusión sistemática.

4. La traducción es mía. "Rather than aberrant transnational artistic representations, these narratives are themselves part of a change in aesthetic and conceptual sensibilities. They can be perceived to be singular figurations of the ubiquity of violence in terms of experience". 
tensiones que se puedan generar en estos espacios y los presenta como análogos a los discursos entre modernidad y tradición. Una de las premisas relevantes, y que lo diferencia en su carácter constitutivo de las reflexiones que hace García Canclini, es la noción de comunidad, pues Bhabha (1994) la considera un proyecto en construcción:

Las diferencias sociales no son simplemente dadas a una experiencia a través de una tradición cultural ya autenticada, sino que se constituyen en signos de la emergencia de una comunidad contemplada como proyecto — al mismo tiempo una visión y una construcción- (1994: 3).

En este planteamiento aparece tanto la percepción temporal como espacial en una articulación simbólica entre el ir y venir. Se alude a una transición que permite circular a través de las fronteras de lo cultural y a partir de allí reconstruir el presente, el cual se compone de las "discontinuidades, desigualdades, y minorías" (4). La epistemología de lo postmoderno se orienta hacia el reconocimiento del vaivén, los límites y extra-límites, the beyond, en los cuales se sitúan las nuevas narrativas y las nuevas voces que antes no eran dignas de ser representadas; relatos emergentes e inéditos que se revelan en el lugar interfronterizo de transición. En la apreciación, antes citada, Bhabha no se refiere a las comunidades rurales, sino al concepto mismo de comunidad como proyecto. Sin embargo, esta idea es transferible también a las comunidades que conciben como proyecto la unión con lo territorial y que reivindican en primer lugar su historia cultural campesina o étnica.

Es quizás en esos espacios o umbrales de una simbología emergente en donde la construcción de lo nacional ha adquirido nuevas perspectivas. En esos planos se visibiliza no solo la representación de las minorías étnicas, sino también las grandes mayorías marginalizadas por el sistema capitalista. Si esas nuevas representaciones forman parte de la comunidad proyecto nacional es preciso preguntarse cómo se conciben, se construyen y se incluyen las diferencias en este constructo de comunidad. Benedict Anderson (1991) señala que tanto los mecanismos a través de los cuales se erigen las naciones-Estado como la construcción discursiva de la nación están llenos de simbologías y procesos culturales que refuerzan los conceptos de comunidad imaginada limitada 
y soberana. Este autor se refiere a la nación y al nacionalismo como artefactos que han sido creados por una clase particular. El debate de cómo definirse como nación y de cómo definirla se reconstruye desde la misma dialéctica desde la cual emergen sus contradicciones. Se trata de dialécticas en el sentido hegeliano, en las que se enfrentan discursos opuestos que son tesis o antítesis, que son afirmaciones o negaciones de una misma construcción.

La formación de los nacionalismos en el continente latinoamericano se ha caracterizado por imaginar una comunidad mestiza y homogénea idealizando estos atributos como marcadores absolutos de la identidad y pertenencia nacionales. En la construcción simbólica de la nación prevalecía - y todavía hoy en día persiste- la iconografía de un patriotismo de los vencedores y, con ello, el ímpetu de entrar en una modernidad importada. Para mantener vivos esos ideales, se han aceptado tácitamente sistemas y prácticas que enmascaran el racismo y la marginalización con gran complacencia, como si estas fuesen condiciones heredadas y perpetuas. A otras formas de representación, en cuyas simbologías se mostraban facetas menos mestizas, no les fue posibilitado el acceso a circuitos de difusión nacional; tampoco fueron tomadas en consideración si no se ajustaban al ideal de mestizaje propagado por los grupos de poder. Una variedad heterogénea de culturas, lenguas y prácticas ha ido emergiendo y consolidándose para redefinir la nación. Diversos grupos sociales reivindican su participación y lo hacen desde sus identidades, que les habían sido negadas, identidades de género, étnicas y territoriales, entre otras. Más que la creación de espacios intermedios que propone Bhabha es necesario escudriñar quiénes se apropian de esas nuevas dimensiones de lo político, de lo social, de lo económico. Asimismo, es importante contrastar las formas de representación que surgen con los grupos que buscan ser representados. A través de la creación artística se manifiestan acciones políticas de grupos en el espacio rural que cuestionan y, a la vez, resignifican las formas de incorporación en la vida social, política y económica de la nación. Es imprescindible conocer no solo la construcción de significados, sino la composición de significantes presentes en las simbologías de los actores sociales, antes totalmente invisibilizados. Las voces campesinas son portadoras de nuevas semánticas de la gestión, 
administración y comprensión de lo público. Los proyectos de una nación pluriétnica y multicultural deben, asimismo, tener una orientación plural y diversa. Esa diversidad debería constituirse en base a su esencia fundacional. ${ }^{5}$

Las burguesías y élites que han impuesto formas de representar lo nacional han hecho uso de símbolos regionales, étnicos y locales para alimentar una idea de pertenencia nacional que está ligada a la conservación del poder económico y político de un reducido grupo de familias que se pueden identificar en cada país latinoamericano. Quienes han creado un discurso nacional no están interesados en un verdadero desarrollo nacional, no conocen las realidades del campo y son ajenos a las realidades pluriétnicas, su mayor preocupación es poder estar en consonancia con la demanda internacional y competir con el mercado foráneo, como se ha seńalado anteriormente.

\section{De la comunidad imaginada a la vida en la comunidad rural}

Gran parte de los debates académicos centran su atención en la representación nacional y, para analizar la construcción simbólica y discursiva, toman como punto de partida los espacios urbanos y su devenir. Pareciera que hay una marcada tendencia a considerar los ambientes rurales aún como espacios arcaicos, tradicionales y monolíticos. Así, cuando se plantea la idea de diversidad, se piensa casi automáticamente en una sociedad urbana en la cual pueden estar representados una cantidad variopinta de 'ciudadanos' con carácter cosmopolita, pero donde no se incluye necesariamente lo campesino ni las poblaciones rurales. Esta práctica urbanocéntrica y 'moderna' ha pretendido, incluso, hacer una representación de la ruralidad resaltando la tradición como un atributo máximo y singular de la vida campesina.

5. El reconocimiento de Estados plurinacionales con autonomía en la ejecución política y administrativa son modelos del naciente quehacer político que han sido constitucionalmente reconocidos en Estados como Bolivia y Ecuador, países donde las culturas autóctonas llevan sufridos largos procesos de luchas y empoderamiento. 
Muchas representaciones visuales de lo rural apelan a las celebraciones rituales y reconstruyen un ambiente casi excéntrico de lo agreste. La vida rural ha sido representada en los medios masivos, en gran parte, por grupos que desconocen la cotidianidad de los pobladores rurales $y$, pese a ello, se empeñan en producir visiones romantizadas o simplemente banales sobre el ambiente campesino. Incluso las representaciones de lo rural suelen aparecer aún como mera simbología de retratos folclóricos que refuerzan la idea de nación. Muchas de las formas y de los símbolos de representación campesina, como, por ejemplo, el sombrero y el poncho, han sido instrumentalizadas con fines comerciales o para posicionar un producto en el mercado internacional; la comercialización de Juan Valdez como muestra de la excelencia del café colombiano es solo uno de ellos.

La comunidad política imaginada es un proyecto en construcción, la vida en la comunidad rural es una construcción proyectada. Mi propuesta es examinar cómo se autorrepresenta la vida comunitaria, acceder a ese metalenguaje para comprender cómo se posiciona la comunidad como entidad, cuál es su memoria y cómo reconstruye el tejido fracturado. En los espacios locales hay un amplio repertorio de material que representa la estética y la semántica del poblador campesino y su vida en el ambiente rural. A través de la comunidad, como instancia nuclear de la identidad campesina, se producen formas de representación que simbolizan la organización grupal y espacial, la gestión de los recursos y la interacción social, así como también las relaciones con los diversos mundos que coexisten o forman parte de la comunidad. Las comunidades campesinas instituyen normas de adhesión, pertenencia y acción que difieren de las nociones contractuales urbanas. La comunidad y las organizaciones campesinas se convierten en agencias que, conscientes de las diferencias y contradicciones, deciden gestionar los recursos a partir de lógicas basadas en una epistemología social colectiva. Existen diversas formas de producción cultural que emergen desde el seno comunitario, la música y las literaturas orales son dos de ellas. Los registros orales consignados en la música propician espacios intermedios (in-between spaces) en los cuales se representa la cultura rural, que ha sido injustamente desvirtuada. Las composiciones musicales y líricas de los habitantes rurales son no solo 
lugares del hacer cultural, sino también espacios con alcance político que interpelan por esa inclusión y aportan en la ampliación de mecanismos que definan la nación en tanto acción política de reivindicación de la equidad y la justicia.

Es interesante observar que las nociones de sustentabilidad, propiedad y beneficio, entre muchas otras, que provienen de la vida y la cotidianidad del entorno rural, difieren ontológicamente de la racionalidad moderna. Tanto los significados como los significantes de esos conceptos emergen de valoraciones epistemológicas fundadas en relaciones de reciprocidad, entre los seres humanos y los seres naturales, entre lo material y lo inmaterial. Esa aproximación no se debe confundir con la apología de un campo sin industria ni tecnología ni tampoco se debe confundir con un rechazo de los beneficios que los avances tecnológicos pueden proporcionar en las labores agrícolas o a la reorganización territorial. Se trata más bien de poder acceder a esos beneficios manteniendo una relación de reciprocidad y complementariedad entre hombre y naturaleza, entre industria y economías de producción local, entre lo privado y lo colectivo, etc. Un magnífico trabajo realizado por Rafael Bautista plantea el reconocimiento de un sujeto comunitario como una alternativa real del pensamiento descolonizador. Ese sujeto comunitario brinda una acción política para rescatar las sociedades sometidas a la modernidad. Bautista señala que:

La insistencia se traduce en la forma de inserción de lo indígena en la lucha política: la defensa de la comunidad ante la expansión sistemática de las relaciones "sociales" provenientes de la ciudad. La insurgencia de lo comunitario es lo que interpela al sistema político en su conjunto (2014: 24).

Al referirnos al concepto comunidad hay una porfiada tendencia a asociar la comunidad con un grupo homogéneo de personas que se definen por rasgos culturalmente idénticos o por las mismas tradiciones. Lejos de ser así, las comunidades son entramados interculturales que se componen de visiones del mundo cercanas, pero que se distinguen entre sí. Es verdad que hay denominadores comunes a todos los miembros de un grupo comunitario y valoraciones sobre la naturaleza, conceptos de espiritualidad y sentidos de pertenencia que marcan una 
pauta de identificación común, pero es necesario tener presente que hay singularidades que hacen a las comunidades distintas entre sí, aunque siempre son proclives a la búsqueda del bienestar común y colectivo. Los ambientes comunitarios conviven también con la disensión y no existe un concepto de comunidad que anule al individuo, se trata de ejercer la individualidad desde una perspectiva colectiva. Así lo señala la Fundación Wayna Tambo en su publicación Procesos educativos para la crianza de lo comunitario:

La comunidad produce una intersubjetividad muy poderosa que nos permite sentirnos parte de, ser parte de, estar en. [...] Tres elementos que componen la comunidad:

El que tiene que ver con el funcionamiento de la red de amparo y protección.

La comunidad que permite la reproducción, el brotar permanente de la vida del colectivo en todas sus dimensiones: económicas, sociales, culturales, éticas, estéticas, políticas, organizativas, etc.

El que la comunidad produce una energía, un nivel de afecto, cariño, de intersubjetividad poderoso en términos de pertenencias colectivas que nos atraviesan la vida entera (2016: 28).

Muchas comunidades campesinas se ven enfrentadas a grandes desafíos por no tener acceso a la tierra y porque se les impide gobernar sobre sus territorios. Diversos factores son detonantes de esas situaciones: las irregularidades en los procesos de titulación, los manejos fraudulentos de los grandes terratenientes y el control territorial que es ejercido tanto por la industria agrícola como por los actores armados, instaurando regímenes de conflicto y terror para generar desplazamientos forzados. Se podrían mencionar muchas más causas que ocasionan conflictos por la tierra y el territorio. Las racionalidades comunitarias brindan valiosos elementos de concertación, distribución, administración y conservación de los recursos naturales que surgen desde las lógicas de lo colectivo. Tal vez se encuentre allí uno de los aportes más apremiantes para implementar el Acuerdo Final de paz, en las constelaciones de ruralidades que aprehendan las prácticas comunitarias y las integren en la diversidad nacional. 


\section{Conflictos medioambientales: enfoque y planteamientos}

En los aportes de los estudios sobre conflictos por recursos naturales, Guillaume Fontaine (2004) y Pablo Ortiz (1999) argumentan que existe una clara relación entre las disputas ecológicas y el impacto comunitario. He decidido muy conscientemente no trabajar únicamente sobre la base teórica propuesta por el ENCOP (Bächler et al. 1996) en torno a los conflictos medioambientales porque sus análisis tratan poco los matices sociales o políticos. Como lo indica el mismo Bächler, "las variables socioeconómica, institucional y centradas en el agente, las cuales afectan la relación causal entre conflicto y medio ambiente, tienden a ser subestimadas"6 (1999: 82). Desde la perspectiva del conflicto medioambiental, las discusiones sobre ecología y medio ambiente tienen un punto de partida diferente al social. Además, una de las presunciones es que la consciencia ecológica corresponde a valores que se manifiestan en las sociedades postmaterialistas. Este postulado se inspira en los estudios sobre valores y niveles de desarrollo realizados por Ronald Inglehart (1977). ${ }^{7}$

Los planteamientos desarrollados por Thomas Homer-Dixon (1999), Günther Bächler (1999) y Stephan Libiszewski (1992) construyen una base teórica que explica la relación entre conflicto y medio ambiente desde una perspectiva multicausal. Estos enfoques consideran por un lado, que el crecimiento poblacional en los países del hemisferio sur es un factor que ejerce presión sobre los recursos naturales y que da origen a conflictos; por otra parte, argumentan que la competencia por los recursos naturales y su escasez se derivan de ese

6. La traducción es mía. El texto original en inglés es el siguiente: "The socio-economic, institutional, and actor-oriented variables which affect the causal relationship linking environment and conflict tend to be underestimated".

7. Inglehart presenta la jerarquía de valores sociales, que explica a partir de las necesidades satisfechas. De acuerdo con este autor, las necesidades de la humanidad se modifican según los niveles de desarrollo que vayan alcanzando. Sus reflexiones han sido usadas para encontrar explicaciones sobre el comportamiento político de los ciudadanos a través del análisis cultural. Existe un estudio más reciente en el que Marita Carballo y Ronald Inglehart (1997) indican que la modernización no sigue un curso lineal, sino que se distinguen dos niveles de desarrollo en ella. 
motivo. Dicha escasez, en sus distintos matices, aparece como otro factor desencadenante de los conflictos. El planteamiento de Bächler integra otros elementos dentro de una interpretación estructural y sus propuestas en las hipótesis de causalidad retoman consideraciones subyacentes a la teoría de la dependencia, de geografía política, de la antropología y de la sociología del desarrollo. Stephan Libiszewski propone el concepto 'conflictos medioambientales' y lo define de la siguiente manera:

Los conflictos medioambientales se manifiestan como conflictos políticos, sociales, económicos, étnicos, religiosos o territoriales; o como conflictos por recursos o por interés nacional o cualquier otro tipo de conflicto. Existen conflictos tradicionales inducidos por degradación medioambiental (1992: 13) ${ }^{8}$

A pesar de que Libiszewski ofrece una definición técnica, en su reflexión posterior él mismo es consciente de que la mayor dificultad reside en encontrar la causa que da origen a este tipo de conflictos. ${ }^{9}$ Para mitigar ese dilema propone una reconsideración del concepto de lo medioambiental a partir de los fenómenos sociales:

Normalmente el cambio medioambiental tiene que ser "trasladado" a alguna forma de fenómeno social [...]. En este contexto, incluso el valor de los bienes naturales como recursos tienen que ser visto como un hecho social que varía en el tiempo y en el espacio dependiendo de los contextos socioeconómicos y culturales. $(12)^{10}$

8. La traducción es mía. El texto original en inglés es el siguiente: "Environmental Conflicts manifest themselves as political, social, economic, ethic, religious or territorial conflicts, or conflicts over resources or national interest, or any other type of conflict. They are traditional conflicts induced by an environmental degradation".

9. "This wide concept of cause is what makes our field broad and complex" (Libiszewski 1992: 12).

10. La traducción es mía. El texto original en inglés es el siguiente: "Normally environmental change has to be 'translated' into some kind of social phenomenon [...] In this context even the value of natural goods as resources must be seen as a social fact varying over space and time depending on the cultural and socio-economic context". 
Siguiendo detenidamente las consideraciones hechas por Libiszewski y por otros autores, los conflictos medioambientales estarían supeditados a un componente esencial: el factor social. Al parecer, el aspecto social está siempre presente, por ello es preciso examinar el planteamiento que aporta otro grupo de investigadores que denominan la relación entre conflicto y medio ambiente como conflictos socioambientales. Para esta investigación no es relevante el aspecto de causalidad, sino el de interacción, por ello, tomo elementos reelaborados por Bächler (1999), quien retoma el estudio hecho antes por David Dessler (1994) y lo adapta para el caso de Ruanda y África oriental. Se trata en primera instancia de la identificación sistemática de los roles que puede adoptar un evento concreto para un autor definido. En su análisis distingue los siguientes elementos:

1. Las razones: combinación de acciones percibidas por un actor como 'problemas históricos'.

— Los desencadenantes de las acciones: son aquellos eventos que llevan a determinar la viabilidad de una actuación.

2. Un desencadenante de una acción es un evento que hace que cada acción se convierta en la alternativa más favorecida en el conjunto de viabilidad de alguien. 3. Los objetivos: son las metas o los propósitos del conflicto. Se sitúan más en el contenido que en la dinámica del conflicto.

4. Los canales: son las líneas de división o fisura en los diferentes ámbitos: político, social, económico.

5. Los catalizadores: son los factores que controlan la intensidad y la duración del conflicto una vez éste ha iniciado (Bächler 1999: 106-107). ${ }^{11}$

En el capítulo sexto se encuentra una tabla comparativa en la que se desglosan los elementos antes descritos para los tres casos de este estudio. Las dinámicas de interacción de las comunidades tienen lugar en el marco del conflicto socioambiental que compromete bienes

11. La traducción es mía. El texto en inglés es el siguiente: 1. "A reason is a combination of actions that are perceived by an actor as 'historical problems' [...] 2. A trigger of an action is an event which causes that every action to become the most favoured alternative in someone's feasibility set. [...] 3. A target is an actor's objective, aim or goal [...] 4. A channel is a line of political, social, economic or national cleverage... [...] 5. A catalyst is any factor that controls the rate or intensity and the duration of a conflict, once initiated". 
naturales comunitarios. A través del acompañamiento, las comunidades han ido desarrollando capacidades para el manejo de conflictos y para los espacios de negociación y han fortalecido poco a poco sus recursos para avanzar hacia la transformación de las disputas. Sin embargo, en los contextos de hostigamiento, amenazas y desplazamientos forzados, los encuentros entre los actores se tornan en alcances muy complejos que impiden acuerdos concretos o puntos de encuentro, incluso irrealizables a medio plazo. En los estudios de conflicto, en general, se plantea la evolución del conflicto en términos de transformación. ${ }^{12}$ Este, a su vez, puede derivar en escenarios de reproducción o de cooperación. Ese deslinde representa de entrada un cuestionamiento si se contempla exclusivamente cómo evolucionan las relaciones entre los actores implicados. Más que atender puramente a las tendencias de evolución o finalización del conflicto, es necesario observar su contenido y considerar qué valores entran en disputa o qué valoraciones son conmensurables y cuáles no. Si la transformación del conflicto deviene en un contexto de cooperación, es imprescindible tener claro qué premisas, valores y estructuras se están validando en ese escenario. En muchos casos de conflictos por recursos naturales en América Latina se ha constatado que la cooperación se puede convertir en un falso estandarte y, en vez de contribuir a corregir la asimetría de poderes, ha favorecido a actores con mayores instrumentos de poder. En los peores casos, puede significar la adherencia a un discurso o posición imperantes que reproduce o exacerba las estructuras de inequidad que han desencadenado las disputas. De la misma manera, al hablar de reproducción no solo podemos centrarnos en las interacciones de los actores, sino que es necesario identificar las características del contexto en que tiene lugar la confrontación. Es imprescindible no perder de vista que un escenario de reproducción de un conflicto medioambiental se puede dar por la inconmensurabilidad de valoraciones sobre la naturaleza o puede tener lugar, incluso en una aparente reconciliación,

12. En lo que se refiere al manejo del conflicto, se suelte también usar el término resolución. Para el propósito de este análisis esa aproximación se desvincula, a mi parecer, del proceso central, que es transformar la estructura en la que se ha gestado la confrontación, por ello, opto preferiblemente por la noción de transformación. 
cuando las estructuras de asimetría e inequidad permanecen inalterables. Es esencial observar si en el proceso y en la dinámica de la confrontación se identifican espacios de construcción de paz. Las acciones por la paz son diversas y se van propiciando paralelamente al conflicto. Además, sería también necesario considerar cuáles son los significados de paz para los actores en un contexto de desplazamientos forzados en donde la población campesina ha estado sometida a la disgregación de su esencia rural. Volveré a este aspecto al analizar las composiciones musicales de estas comunidades.

Resulta imprescindible, a todas luces, hacer una valoración sobre el desarrollo de las confrontaciones. J. Paul Lederach (1995) propone una matriz de análisis — tomada de Curle (1971) — que puede ser un instrumento para estimar cómo va evolucionando el conflicto y para reflexionar sobre cuáles serían los potenciales pasos a seguir en miras a propiciar espacios de entendimiento. No solamente es importante identificar cómo se desarrolla el conflicto, sino y, sobre todo, es de vital importancia conocer qué instrumentos usan los actores en esa dinámica. Si los instrumentos jurídicos, políticos y sociales no son lo suficientemente eficaces para poder construir espacios de comunicación, se debe explorar qué otros elementos se convierten en dispositivos para generar espacios de conciencia y reflexión. Las comunidades campesinas hacen uso del acervo cultural para construir lugares de deliberación sobre sí mismas y sobre las formas de interacción con los actores en desacuerdo. En ese sentido, en cuanto a los bienes culturales y los casos de enfoque de este estudio, el lenguaje musical cumple una función importante tanto para movilizar recursos que incidan en los procesos de transformación local y nacional como para reactivar canales de comunicación que se han destruido por el uso de la violencia armada.

\section{Conflictos socioambientales}

En primera instancia, es importante mencionar que este segundo grupo de investigadores considera los conflictos medioambientales como confrontaciones en las que la atención se concentra exclusivamente en el daño que se causa a los recursos naturales — los representantes de 
esta tendencia son particularmente los grupos ecologistas o ambientalistas-, mientras que los conflictos socioambientales se relacionan principalmente con las comunidades afectadas y los cambios en el medio ambiente. Su argumento no dista en esencia del planteamiento hecho por el primer grupo en cuanto a que no existe conflicto medioambiental sin dimensión social (Fontaine 2004).

Las confrontaciones por los recursos naturales, ya sea por uso, suministro, distribución o acceso, presentan en su mayoría escenarios multicausales de cierta complejidad. El tratamiento comunitario de conflictos socioambientales, como lo expone Pablo Ortiz y Lizi Ernst (2007), supone tener una comprensión de diferentes niveles y escenarios de incidencia y de interacción; es decir, que es necesario examinar el papel de los actores en el plano local para poder determinar sus alcances en relación con el desarrollo sustentable. Para Ortiz (1999) los "conflictos en torno a los recursos naturales son fenómenos sociales que involucran condiciones mínimas como: la escasez, el deterioro y la privación" (10). De acuerdo con los planteamientos de este autor, en las confrontaciones de esa índole reside un componente ideológico importante, en el cual se distingue tanto el nivel normativo (las reglas) como el operativo (las prácticas). Entre estos dos niveles suele haber incompatibilidades que se manifiestan en los intereses, las percepciones, las lógicas y las visiones del mundo de los actores involucrados.

La multicausalidad de los conflictos socioambientales implica que exista más de una variable que influye en las tendencias: cooperación o reproducción. De acuerdo con el Centro de Investigación y Planificación del Medio Ambiente (CIPMA) (1995), citado por Acevedo et al. (2009), el concepto conflicto socioambiental se podría definir como "aquel donde la controversia de información, intereses o valores se refieren a aspectos relacionados con el acceso, disponibilidad y calidad de los recursos naturales y de las condiciones ambientales del entorno que afectan la calidad de vida de las personas" (12). Algunas de las condiciones bajo las cuales se gestan los conflictos son suficientes pero no necesarias para su erupción. En ese sentido, Bächler señala lo siguiente:

El análisis causal es, por lo tanto, necesario pero no suficiente. [...] El rastreo de los trayectos que siguen los conflictos tiene que estar combinado con un enfoque 
centrado en los agentes que conceptualice posición, intereses (metas) y percepciones de los actores tanto individuales como colectivos. (1999: 104). ${ }^{13}$

Los planteamientos en cuanto a la relación conflicto/recursos naturales que sugieren una correspondencia con los nuevos valores en sociedades postmaterialistas son objetadas por parte de varios académicos —entre los están Joan Martínez Alier (2011); Joan Martínez Alier e Inge Ropke (2008); Boaventura de Sousa Santos (2010, 2012); Arturo Escobar (2000, 2006); Arturo Escobar y Susan Paulson (2005); Rolain Borel (2005), e Iokiñe Rodríguez y Hernán Darío Correa (2005)—, pues suponer que la conciencia medioambiental es el resultado de una visión lineal de desarrollo económico es desconocer culturas ancestrales que fueron en gran parte destruidas durante la colonización y en cuyos principios fundacionales prima, aún hoy en día, el cultivo de las relaciones de equilibrio entre seres humanos y naturaleza. Además, se cuestiona en qué medida los modelos de desarrollo económico fomentan un mejoramiento contundente de la calidad de vida de todos los grupos sociales; es decir, que la consecución de un estadio de desarrollo — desarrollo desde la lógica occidental— no conduce necesariamente a establecer una relación ecuánime con los recursos naturales ni con el medio ambiente.

Visto desde una dinámica global, en gran parte de los países del hemisferio sur hay una movilización de conflictos de orden medioambiental que surgen como resultado del crecimiento económico y los hábitos de consumo de los países llamados industrializados. Al respecto, Mariana Walter señala que, como consecuencia de ello, se da "la extracción de recursos, la expansión de vertederos y riesgos de contaminación para quienes el ambiente es la base material del sustento" (2009: 4). Joan Martínez Alier aporta algunas reflexiones sobre medio ambiente y conflicto y lo denomina "ecologismo de los pobres" o "ecologismo popular". Su propuesta no rechaza una aproximación

13. La traducción es mía. El texto original en inglés es el siguiente: "Causal analysis is therefore necessary but not sufficient. [...] The tracing of pathways of conflicts has to be combined with an actor-oriented approach that conceptualizes position, interest (aims) and perceptions of both individual and collective actors". 
ecologista derivada de sociedades postmaterialistas, pero tampoco contempla la idea del ecologismo como un bien exclusivo surgido de ellas. Sugiere que existen tres corrientes del ambientalismo; ${ }^{14}$ de ellas, podemos resaltar la tercera, que se refiere a la justicia ambiental y ecologismo de los pobres. En esta tendencia se advierte sobre los fuertes impactos que causa el sistema económico imperante en el medio ambiente y en las poblaciones rurales con pocos instrumentos de poder. También "llama la atención sobre el desplazamiento geográfico de fuentes de recursos y de sumideros de residuos" (Martínez Alier 2011: 34). Siguiendo esta misma perspectiva global, este autor se propone ver los dilemas con el medio ambiente en relación al concepto de distribución, lo que llama conflictos ecológico-distributivos.

\section{Conflictos ecológico-distributivos}

Los conflictos ecológico-distributivos hacen referencia a la alta demanda de recursos naturales por parte de los países del hemisferio norte. Los patrones de consumo de las sociedades industrializadas ocasionan el desplazamiento geográfico de comunidades y de la frontera agrícola para satisfacer su abastecimiento. El argumento de esta propuesta se basa conceptualmente en la ecología económica. Las interpretaciones sobre conflicto, medio ambiente y recursos naturales han sido analizadas también por Martínez Alier (Alier y Ropke 2008) a través de las múltiples dimensiones que son consideradas cuando se trata de asignar valor a la naturaleza. Este autor señala que la valoración de los recursos naturales en términos económicos es tan solo una de las muchas otras posibilidades que existen para otorgarles un significado.

14. En esta clasificación las otras dos corrientes son el culto a lo silvestre, en la que se proclama la preservación de la naturaleza sin tomar posición sobre la industria ni tampoco sobre la urbanización, y el evangelio de la ecoeficiencia, que se preocupa por los efectos del crecimiento económico: "Dirige su atención a los impactos ambientales y a los riesgos para la salud de las actividades industriales, la urbanización y también la agricultura moderna. Cree en el desarrollo sostenible, la modernización ecológica y el buen uso de los recursos" (Martínez Alier 2011: 27). 
La multiplicidad de valoraciones sobre el agua, la tierra y otros recursos está determinada por la confrontación de distintas narrativas que no siempre se manifiestan, pero que permanecen latentes. Martínez Alier (2011) ha trabajado el tema de la ecología distributiva y su acercamiento a los análisis sobre tópicos medioambientales a través de una perspectiva diacrónica en el área ecológica. Sus planteamientos coinciden con los de Bächler respecto a la importancia de volver la mirada sobre las causas. Otro punto de encuentro entre ellos es la germinación de los conflictos sociales ligados al medio ambiente, incluso antes de haberlos denominado socioambientales. Al referirse a los problemas de contaminación a principios del siglo xx, Martínez Alier ilustra el siguiente caso:

El mercurio fue el origen de famosos casos de enfermedades en el Japón desde la década de los cincuenta en adelante. Que en la época no se empleaban las palabras ecología o medio ambiente es indudable, pero eso no impide interpretar esos conflictos sociales como conflictos ecológicos. En la historia social se procede habitualmente así. (2011: 98)

En la amplia gama teórica sobre los conflictos en torno al medio ambiente, la interpretación de la distribución ocupa un puesto central. La ecología política retoma los conflictos sobre el orden distributivo de los recursos, que está especialmente relacionado con los conflictos sobre recursos o servicios ambientales, comercializados o no comercializados. La distribución ecológica también involucra la normatividad social, ya que en ella se crean patrones de reparto en el orden espacial y temporal para obtener determinados beneficios derivados de los recursos naturales. De acuerdo con Martínez Alier, "la Ecología Política se superpone a la economía política que, en la tradición clásica, es el estudio de los conflictos de distribución económica" (2011: 112). Sin embargo, la ecología política transciende los parámetros de valoración económica y va más allá para formular interrogantes sobre las escalas y los sistemas de valoración de donde ellas nacen, de tal manera que, mientras las respuestas de la economía política intentan explicar algunos desaciertos como externalidades o fallas del mercado, los economistas ecológicos hablan de la translación de costes del mercado a costos sociales y ambientales. 
Consideraciones transversales: escenarios de regulación social

La historia nacional en Colombia ha obviado las identidades campesinas y étnicas en el entramado nacional y se les ha negado el acceso tanto a los recursos como a las posibilidades de distribución equitativa y digna. La lucha por la transformación de estructuras excluyentes la han emprendido muchas comunidades campesinas y étnicas, desembocando en disputas generacionales y en algunos casos generando reformas constitucionales. A pesar de los importantes logros que se ven reflejados en la Constitución de 1991, los procesos de inclusión y participación en las prácticas políticas y económicas concernientes a la gobernanza de los recursos naturales son socavados. En el contexto de postconflicto en el actual panorama nacional en Colombia no solo es imprescindible incluir y dar participación a las poblaciones más afectadas por el conflicto armado, sino que deberían introducirse mecanismos que tengan efectos vinculantes. Dar reconocimiento a las subjetividades comunitarias implica propiciar espacios de decisión en el marco de la construcción democrática, especialmente en la función que tienen las comunidades en la transformación de la ruralidad productiva. Asimismo, es apremiante conocer las racionalidades comunitarias que guían los procesos de producción y distribución de los recursos naturales. Muchas de ellas proponen prácticas alternativas y plausibles ante el sistema avasallador que compromete los bienes naturales como objetos, exclusivamente, para maximizar ganancias económicas.

A pesar de que existen mecanismos legales y jurídicos para el ejercicio de su derecho, las prácticas de clientelismo y corrupción obstaculizan los procesos que emprenden las comunidades por la lucha territorial, convirtiéndose en largos y tediosos caminos con resultados estériles en la gobernanza territorial. Mientras el marco de regulación legal es deficiente y está amañado, los bienes culturales que poseen las comunidades campesinas, étnicas, se convierten en material que instaura un marco de regulación social alternativo, vivo y dinámico. $\mathrm{Y}$, en este sentido, se estarían creando instrumentos que se orientan a modificar prácticas arraigadas en la asimetría del poder y, en este caso 
específico, que se proponen sancionar social y moralmente las formas de despojo a través de las expresiones artísticas y culturales. Como las normatividades dispuestas en la ley, es decir, lo estrictamente legal, no tienen una capacidad de regulación social, las prácticas que emergen de la racionalidad comunal incorporan un marco alternativo que aporta a la transformación de los comportamientos sociales; es decir, que, más que ser meras manifestaciones culturales, las composiciones musicales y la producción oral de las comunidades resilientes se convierten en mecanismos con potencial para incidir en la distribución e interacción de los poderes en distintas dimensiones. La regulación social no se da exclusivamente por el sistema de leyes, existen otros circuitos de regulación que son sumamente eficaces en el estímulo o la sanción de comportamientos y emociones. La construcción de imaginarios es uno de esos canales que pueden modificar las percepciones de los actores sociales. En este sentido, un circuito cultural que contribuye a regular las percepciones, los imaginarios, las emociones y, tal vez a largo plazo, los comportamientos sociales es la música. Visto desde esa perspectiva, las composiciones musicales comunitarias se posicionan más allá del canto de denuncia ante tal o cual actor. Los cantos comunitarios, además de tener funciones muy claras en el entramado local en el que nacen, también son instrumentos de comunicación ante la sociedad civil, en este caso, colombiana.

Las prácticas de convivencia y los marcos de sustentabilidad de los recursos naturales que buscan las comunidades rurales, desplazadas o no desplazadas, implican acciones concretas que tienen efectos en el desequilibrio de poderes. En este sentido, en ese material musical se gestan también reflexiones sobre el quehacer político, las nociones de equidad, los conceptos de ciudadanía y las valoraciones de ecología, entre otras, de tal forma que las representaciones musicales exhortan a reconstruir una sociedad de ciudadanos con conciencia comunitaria, independientemente de si habitan en el campo, en una comunidad establecida o de si son campesinos o no. Aquí no se trata de la comunidad imaginada a la que se refiere Anderson, sino de incorporar racionalidades comunitarias tanto en la práctica social como en la institucional que recompongan los tejidos fracturados y reconstruyan una verdadera transición hacia la convivencia. 
Pensar en la construcción de un sistema de regulación social que incorpore las racionalidades comunitarias en su totalidad es quizá demasiado utópico, pero lo que sí logran las manifestaciones musicales y gran parte de la producción cultural es propiciar plataformas para concebir prácticas de convivencia alternativas a la maximización del beneficio individual; es decir, los signos y símbolos que se recrean a través de la música resignifican la dimensión de lo comunitario en la sociedad y, en especial, en la acción comunitaria en la gobernanza de los recursos naturales desde el paradigma comunocéntrico. Podemos entonces sugerir que el material cultural que proviene de los procesos de colectividades rurales no solo contiene importantes elementos de reivindicación social y política, sino que constituye un invaluable repertorio de simbologías fundamentales para edificar una transición cultural hacia la construcción de la paz, entendida como la búsqueda de transformar asimetrías a diversas escalas. A continuación, algunas reflexiones sobre las lógicas que caracterizan el concepto de la subjetividad comunitaria de las poblaciones rurales.

\section{Expresiones de la racionalidad comunitaria}

La simbología contenida en las composiciones líricas o cualquier otro tipo de expresiones culturales representa un sistema de conceptos que hacen de las comunidades rurales entidades portadoras de una nueva comprensión de lo político y que las distinguen de las entidades hasta ahora establecidas en la sociedad moderna. Esa distinción está dada esencialmente en el seno de un marco conceptual de donde nacen las premisas y los significados que definen lo comunitario. Se trata de un cúmulo de sentidos que se concretiza en las relaciones que se establecen entre los distintos mundos: humano, natural y espiritual. De allí son identificables dos conceptos indispensables que representan alternativas de acción política: la subjetividad comunitaria y la intersubjetividad, que veremos más en detalle a continuación. Estos dos conceptos son definitivos para comprender los procesos sociopolíticos y las proposiciones para una nueva institucionalidad que emergen 
desde lo local comunitario. ${ }^{15}$ Lo comunitario rural concibe la reciprocidad y la complementariedad como pautas para el uso, la distribución, la producción y el consumo de los diversos recursos, sean estos materiales, cognitivos o espirituales. Desde esa perspectiva, las instituciones no solo serían entes de control y absorción del poder, sino que deberían ser agentes dinámicos que tuvieran influencia en las sociedades y reconstruyesen y reprodujesen modelos cognitivos y normativos acordes a los significados comunitarios. En el caso concreto del acceso y uso de los recursos naturales y las fuertes luchas comunitarias ante la lógica neoextractivista, las instituciones deberían ser parte del entramado sociocultural que representa también la racionalidad y las prácticas comunales relacionadas con la distribución de recursos. La incorporación de marcos de referencia comunitaria en la distribución y gobernanza de los recursos naturales propiciaría espacios de una nueva cultura política institucional.

La subjetividad comunitaria está caracterizada por la comprensión de ambientes interconectados, complementarios y recíprocos. Esta interconexión se construye a partir de un sistema de valoraciones y preferencias que se derivan del conocimiento generacional adquirido en el intercambio comunal. Las comunidades históricamente reconocen la coexistencia de vínculos inquebrantables entre diferentes formas de vida. Esta concepción dista tajantemente de la racionalidad individual en la sociedad moderna. Mientras la racionalidad comunitaria se orienta hacia la reproducción del bienestar para todos sus miembros y la búsqueda de una unidad común, la racionalidad individual está orientada a la optimización y ganancia máxima del individuo. En las comunidades rurales, la convivencia y cercanía con el mundo natural y otros mundos ha devenido en conocimiento, generando saberes que orientan las relaciones de interacción hacia horizontes de reciprocidad. La racionalidad moderna ha establecido sistemas de preferencias $\mathrm{y}$ creencias que basan las relaciones humanas y las relaciones con el

15. En esta aproximación del institucionalismo, debe pensarse en los planteamientos del que proviene de las teorías de la sociología de la organización y cuya base son las reflexiones sobre el papel de la cultura en el quehacer político (Hall y Taylor 1996). 
entorno ambiental en la práctica de la supremacía y la explotación. Se trata de diferentes formas de dominación que validan esta racionalidad, $y$, en este sentido, el principio de maximizar los beneficios individuales ${ }^{16}$ se convierte en hilo conductor de los intercambios sociales en casi todos los ámbitos: la economía, la política, la ecología, la sociedad, etc.

La intersubjetividad es el reconocimiento de que un individuo está vinculado a una comunidad formada no solo por lo material y lo humano, sino también por lo espiritual. El prefijo inter- significa que el hombre se siente cohabitante de un sistema de mundos relacionados. Desde esa perspectiva, se sitúa en una relación horizontal o circular pero no vertical. De ese locus deviene la comprensión de un mundo recíproco y complementario que es necesario retroalimentar permanentemente. La búsqueda de la unidad común forma parte también de esos procesos de retroalimentación. En ese sentido, hay una autoconciencia que alerta de las repercusiones que ocasionará el actuar individualmente sobre los otros sujetos y los impactos que tendrá en su conservación y el equilibrio comunitario. Esa conciencia intersubjetiva posibilita la acción de un ejercicio político donde prima lo comunal, lo colectivo. Esto quiere decir que las acciones humanas están abocadas a gestar actuaciones de servicio que devengan en circunstancias de bienestar del grupo. Mientras en la racionalidad comunitaria lo político se asume como ejercicio del poder, entendido como ministerio, la racionalidad social individual entiende el poder como acción de dominación y dominio para obtener el máximo beneficio. Los procesos de interacción que se dan en la sociedad moderna están basados en el cálculo estratégico a partir de las expectativas que se tengan de los otros actores sociales. De acuerdo con la corriente del institucionalismo de la teoría racional, son las instituciones las encargadas de estructurar esas interacciones. En términos prácticos, la estructuración o regulación de las interacciones acontecen desde la normatividad impuesta por los grupos sociales que han mantenido el poder; esto es recurrente en los países latinoamericanos donde la representación del poder

16. Aquí el término 'individual' se puede referir a una empresa o una persona que se rige por órdenes de ganancia y lucro. 
democrático está dominada por la oligarquía. La interacción entre individuos supone, además, la construcción y el aporte a los saberes desde la experiencia, la convivencia y la reflexión compartida en lo comunitario. Sin ser relaciones perfectas, los ambientes comunitarios son mayormente proclives a producir categorías de valoración —en la dimensión política, social y económica - guiadas primeramente por la voluntad, entendida como actitud de esfuerzo, cooperación, y no solo por la facultad, entendida como la habilidad para actuar o como superioridad.

El sistema de preferencias de la racionalidad comunitaria está basado en valores deontológicos como la pertenencia (versus la propiedad), la reciprocidad (versus la no reciprocidad) o la complementariedad (versus la reducción). Sin ser los únicos componentes de la racionalidad comunitaria, estos son parámetros fundamentales que caracterizan la cotidianidad de muchas poblaciones tanto en el campo como en las ciudades latinoamericanas. La subjetividad comunitaria es a su vez reivindicativa y propositiva: reivindicativa porque se presenta y reconstruye lecturas de las realidades que la sociedad moderna y la racionalidad individualista no reconoce, realidades políticas, medioambientales y económicas que afectan tanto a las sociedades como a las comunidades y que están encubiertas bajo el rótulo del beneficio. Un ejemplo de ello es la economía verde, en la que la explotación desmedida de los fósiles y recursos no renovables aún sigue apareciendo como sinónimo de sostenibilidad ambiental. $Y$ es propositiva porque crea un ambiente de reflexión sobre las relaciones del colectivo, de la comunidad con su entorno. El pensamiento propositivo de la racionalidad comunitaria se configura dentro de prácticas de complementariedad y reciprocidad en las cuales se cultiva lo que liga a los individuos a la comunidad y lo que los hace o no pertenecientes a ella. El pensamiento propositivo supone una actitud analítica en la que se instaura un marco de acciones que determinan aquello que nutre a la comunidad y aquello que la fragmenta. En las comunidades andinas, por ejemplo, la actitud del servicio a los demás es una de las características que incrementa y revitaliza las relaciones de lo comunitario. Por eso, el compartir, el servir y el dar se entienden como valores prácticos que traen beneficios a la vida comunitaria. A continuación, señalo algunos temas concretos en 
los que se pueden identificar valoraciones inconmensurables entre la racionalidad comunitaria y la racionalidad de la sociedad moderna.

\section{Valoraciones inconmensurables: seguridad, desarrollo, sostenibilidad y gobernanza}

Las diferentes valoraciones sobre el acceso a la tierra y el territorio y la administración de los recursos naturales entran en contraposición cuando las epistemologías que las constituyen corresponden a paradigmas diferentes, no solamente en los procesos de reclamación de tierras, sino también en las decisiones sobre las reformas agrícolas y la estipulación de códigos administrativos y legales, entre otros. En las prácticas industriales del agro, en América Latina y la mayor parte del hemisferio sur prevalecen los paradigmas de la economía de mercado liberal. Esos discursos son respaldados por agentes o instituciones en los que los ciudadanos han delegado el poder, pero, paradójicamente, muchos de ellos representan intereses económicos de las empresas transnacionales y de poderosos conglomerados foráneos, de tal manera que los procesos políticos y electorales se han convertido en dispositivos al servicio de lo privado, incluso, subvencionados, muchas veces, con dinero público. Las extensas plantaciones de palma de aceite contempladas como plan nacional de desarrollo en Colombia han afectado a las comunidades locales. Casos en Montes de María, Las Pavas, El Garzal y otras comunidades de la Región del Atlántico muestran la ineficiencia institucional en los procesos de litigio por la tierra y el territorio. En este mismo sentido, los casos de corrupción durante los últimos periodos de administración de los gobiernos de turno en Colombia han crecido asombrosamente: El uso de dinero público ha estado relacionado con casos de corrupción, el más conocido, Agro Ingreso Seguro", y otros recientes como Odebrecht, "mermelada", Interbolsa y Navelena, empresas españolas (Torres 2017). Conceptos como la seguridad, el desarrollo, la sostenibilidad y la gobernanza se han convertido en significantes que pueden ser utilizados e instrumentalizados en diferentes discursos. 
'Seguridad y medio ambiente'. El tema del medio ambiente y su relación con la emergencia de conflictos ha sido analizado desde diversos enfoques. Algunos planteamientos sugieren una relación de causalidad entre estas dos variables y examinan condiciones suficientes y necesarias para explicar su correspondencia. De acuerdo con las reflexiones que aporta Bächler (1999), el tema del medio ambiente ha sido abordado dentro del marco discursivo de seguridad o seguridad medioambiental y es acogido por distintas disciplinas y comunidades científicas: ambientalistas, sociólogos y analistas de conflictos, entre otros. De acuerdo con este autor, los cuestionamientos surgidos en torno al medio ambiente han estado camuflados o han sido acomodados por la necesidad que tienen los gobiernos, especialmente los de los países industrializados, de asegurar un horizonte para sus carencias energéticas, de tal manera que las temáticas medioambientales a nivel nacional siguen los lineamientos de estrategias transnacionales ${ }^{17}$ impuestas por los actores más influyentes en la arena política y económica.

Por otra parte, Bächler considera que existe un gran sesgo en el debate entre conflicto y medio ambiente. Hay una tendencia a descubrir reiteradamente nuevos asuntos a los que se les atribuyen características esencialistas de la emergencia del conflicto. Sin embargo, se olvida a menudo que el contenido histórico y local de los actores puede ser un determinante mayor en la erupción de las confrontaciones. Persiste también una tendencia a caer en una forma de determinismo medioambiental que sobreestima las estructuras geopolíticas existentes e intenta encontrar — a todas luces — relaciones de causalidad lineal y directa entre conflicto y medio ambiente. La relación entre el deterioro de los ecosistemas - lo que se conoce como conflictos inducidos- y violencia es un ejemplo de esa tendencia.

'Desarrollo'. Otro planteamiento — cuestionable — para explicar las relaciones entre conflicto y medio ambiente es el discurso sobre

17. No es un secreto que la mayor parte del carbón que se extrae de la mina del Cerrejón, en el departamento de la Guajira, en Colombia, va destinado a suplir las necesidades energéticas en Alemania. 
desarrollo. Su definición ${ }^{18}$ y sus diversas variantes constituyen un punto de partida determinante. Uno de los postulados centrales concibe el desarrollo socioeconómico como un elemento decisivo para comprender el papel que juega el medio ambiente en la erupción de conflictos. En consecuencia, el surgimiento de los escenarios de confrontación por los recursos naturales guarda estrecha relación con las regiones, geográficamente situadas, donde hay menor desarrollo económico; es decir, este tipo de conflictos es exclusivo en una cartografía del llamado 'subdesarrollo'. Esta idea sugiere que, en dichas regiones, en términos socioeconómicos, existirá mayor probabilidad de emergencia de conflictos y confrontaciones violentas. Por el contrario, el desarrollo es planteado por Arturo Escobar (1984, 1988, 1995a, 1995b) en un sentido más amplio y se refiere a él como una invención. Lo cataloga como un discurso de las sociedades modernas occidentales desde la posibilidad que estas han creado para ejercer control sobre el llamado Tercer Mundo. Si el desarrollo se examina como una construcción discursiva, es posible reinterpretar las diferentes estrategias desarrollistas más como mecanismos de control sistemático a través de diferentes ámbitos: social, político, cultural y económico. Desde esta perspectiva, el discurso del desarrollo es considerado como un proceso que se pone en práctica para articular el poder y el saber, de tal manera que se puedan acoplar tanto formas de dominación como posibilidades de conocimiento. Ese ajuste permite crear narrativas que den forma a la dominación y a los términos de regulación entre lo permitido y lo prohibido; es decir, se aplica casi una línea positivista que pueda domesticar las conductas sociales y dirija las acciones hacía el logro del llamado desarrollo. Abordaré, más adelante, el punto sobre comportamientos y acción social a través de la música.

'Sostenibilidad y sustentabilidad'. El conocido debate sobre sostenibilidad debe ser entendido en el marco de procesos sociales orientados a la acción pública y social. Hildebrando Vélez (2007) sugiere diferenciar conceptualmente entre sostenibilidad y sustentabilidad. En

18. Sven Engel (2001) presenta algunas reflexiones críticas sobre el concepto de desarrollo, al que señala como un "régimen discursivo" en relación con los postulados de postmodernidad y postdesarrollo. 
español, se pueden hacer las dos acotaciones, pero Vélez los deslinda de la siguiente manera:

Sostenibilidad está relacionada al crecimiento económico permanente y no necesariamente con la conservación de los ecosistemas dentro de los límites de resiliencia. ${ }^{19}$

Sustentabilidad se refiere a la capacidad de un ecosistema para nutrir y sostener continuamente una población, incluyendo la población humana, sin destruir la capacidad de supervivencia del ecosistema conforme a los límites de resiliencia (Vélez 2007: 8) ${ }^{20}$.

La capacidad de un ecosistema para mantener una población sin autodestruirse está regulada por la intervención de los seres humanos. La sustentabilidad extiende la significación e integra la noción de armonía de la acción humana en relación a los hábitos de consumo. Un significado profundo que subyace en el concepto de sustentabilidad es el reconocimiento a la autorregulación y preservación de otros sistemas de vida, diferentes a la vida humana. Justamente, al mencionar "el sostenimiento de otras poblaciones" se hace referencia a otras estructuras ecosistémicas que existen paralelas a los seres humanos. En las reflexiones sobre sostenibilidad y desarrollo, ambos conceptos aparecen a menudo relacionados entre sí como ideas complementarias. De acuerdo con Stephan Rist et al. (2007), el carácter normativo que enmarańa el concepto de desarrollo sostenible se convierte en una de sus mayores limitaciones. Transcender ese impedimento significa poder compatibilizar el concepto dentro de los procesos socio-locales específicos, de tal manera que esa traslación se visibilice en cambios en las estructuras sociales para el beneficio de los actores más desfavorecidos y en la protección medioambiental.

19. La traducción es mía. El texto original en inglés es el siguiente: "Is related to permanent economic growth and not necessarily with the conservation of ecosystems within the borders of resilience".

20. La traducción es mía. El texto original en inglés es el siguiente: "Refers to the capacity of an ecosystem to continually nourish and sustain a population, including the human population, without destroying the ecosystem capacity off self-preservation by conforming to the limits of resilience". 
'Gobernanza'. En el análisis del manejo y la transformación de conflictos por recursos naturales, uno de los conceptos esenciales es la gobernabilidad o gobernanza. No se puede afirmar que estos términos se hayan convertido en sinónimos, pero en sus definiciones se encuentran elementos comunes que los vinculan. Los conceptos sobre la gobernanza surgen en relación a dos procesos fundamentales: la liberación económica y la democratización y el papel del Estado dentro de un nuevo orden político global. En el curso de esos procesos se revaluaron las concepciones de las gestiones pública y privada en un marco político con nuevos actores. Los conceptos que se proponen sobre gobernanza contienen planteamientos que provienen de la teoría política, teorías sobre la administración pública y la gestión pública. Respecto a la definición de gobernanza, la autora Renate Mayntz (2005) anota que

recientemente el término "gobernanza" ha sido utilizado de otras dos maneras, ambas diferentes de la dirección o la guía política [...]. Distinguir estos distintos significados no es sólo importante a fin de evitar malentendidos, sino también porque un cambio semántico refleja normalmente un cambio en la percepción, tanto si éste refleja o no, a su vez, cambios en la realidad (2005: 83).

Si hay un cambio de percepción sobre la gobernanza, como lo indica Mayntz, lo que se puede constatar en muchos procesos de administración de recursos naturales en América Latina es, por un lado, que la gestión de esos recursos sigue muy anclada a los patrones de la gobernanza corporativa. Si bien en el papel están consignados los principios, en la práctica los procedimientos están sujetos a los intereses económicos y políticos y, lo que es aún peor, incluso existiendo diversos mecanismos jurídicos y legales para que las comunidades rurales gobiernen sobre sus recursos naturales, estos son violados o manipulados por los agentes y las instituciones gubernamentales en complicidad con la economía privada. Ejemplos de ello son el consentimiento de plantaciones de palma de aceite en territorios colectivos de los afrodescendientes en el Chocó; otorgar licencias para la exploración o explotación de minerales fósiles tanto en resguardos indígenas como en comunidades campesinas, y, tal vez uno de los hechos más recientes en Colombia, proponer mecanismos para deslegitimar las consultas populares y las 
consultas previas (Torres 2017: s. p.). Ante este avasallador panorama, las comunidades rurales han buscado establecer alianzas y unirse en redes para movilizar recursos y ejercer gobernanza territorial. ${ }^{21}$ Respecto a la movilización en un entramado de agrupaciones sociales, Fritz Scharpf (2006) considera que se teje una red de decisiones entre lo privado y lo público que involucra tanto al Estado como a las instituciones. La gobernanza es para él un modo institucional de coordinar las acciones sociales que se deciden y se implementan a través de regulaciones vinculantes de lo colectivo. ${ }^{22}$

21. Un ejemplo sobre el manejo comunitario del agua se puede encontrar en Urrea (2013: 71-74).

22. Esto quiere decir que la interacción se convierte en una característica decisiva de la gobernanza. Jan Kooiman (2003) propone la idea de una "gobernanza interactiva o sociopolítica" y advierte que la respuesta a los problemas sociopolíticos que surjan de esa interacción debe derivar también de una plataforma de interacción entre respuestas colectivas que articulen lo público y lo privado. 



\section{Capítulo III}

\section{El arte musical en el conflicto}

\section{Oralidad rural para el postconflicto}

En los cantos se reconstruye una versión que relata la experiencia de lo acontecido y que se ensambla a través del texto y la melodía. En este estudio, la expresión artística, en particular la lírica, constituye un componente central porque ofrece la posibilidad de identificar elementos intrínsecos al conflicto y permite explorar singularidades de los procesos sociales comunitarios relacionados con la agroindustria. La procedencia oral de los cantos es una particularidad esencial que revela la construcción de relatos multitemporales y multiespaciales. Esto significa que se articulan vivencias pasadas y presentes que reconstruyen los imaginarios tanto del futuro como del pasado de las historias comunitarias. Los hallazgos que se puedan extraer de la fuente musical son determinantes para la formulación de posibles explicaciones a por qué una comunidad elige unos mecanismos y unas estrategias para manejar el conflicto y no otros; es decir, que la indagación a través del plano de lo representado desvela visiones colectivas del mundo que han sido construidas desde la experiencia conjunta y aparecen codificadas en la creación lírica. Además, la creación musical amplía los códigos de comunicación y constituye un mecanismo de interlocución ante las disputas. 
Las composiciones musicales que emergen de los procesos locales asediados por los monocultivos de palma de aceite en Colombia — como en otros lugares del Sur Global- son productos político-artísticos. En la lírica se manifiestan lógicas comunitarias relacionadas con acciones e interacciones en diferentes instancias: la acción pública, la acción social y la acción legal. Asimismo, allí se hace referencia a niveles de poder, estructuras organizativas, percepciones y cosmovisiones. A través de las expresiones musicales se puede explorar tanto la producción de sentido como la construcción de significados locales. En el procedimiento del análisis sobre el texto lírico, se considera el texto como construcción propia, como creación artística dotada de significado, pero que establece un vínculo con una experiencia referencial. A este respecto Paul Ricoeur señala:

La dialéctica entre significado y referencia es tan original que puede ser tomada como una guía independiente [...]. El lenguaje no es un mundo propio. No es ni siquiera un mundo. Pero porque estamos en el mundo, porque nos vemos afectados por las situaciones, y porque nos orientamos comprensivamente en esas situaciones, tenemos algo que decir [...]. Esta noción de traer la experiencia al lenguaje, es la condición ontológica de la referencia (2011:35).

Cuando se afirma que el texto lírico es una experiencia colectiva, se quiere decir, primero, que surge dentro de un grupo específico en el cual existen vínculos de identidad común, como lo son las comunidades rurales de este estudio. Eso implica que la autoría de estas composiciones no le pertenece a un autor individual, sino que, por el contrario, le pertenece a la comunidad o a la colectividad en donde ellas nacen. Esta es una de las características principales de la oralidad. Aunque sí se identifican las voces que interpretan los cantos, sea que los reciten o los canten, no hay rasgos que le atribuyan propiedad de un bien común a una única persona. La segunda característica exclusiva de la oralidad o de las literaturas ${ }^{1}$ orales es que son creadas para ser transmitidas oralmente. Sin duda puede existir un intento de llevar las composiciones al plano escrito, pero seguirán teniendo una esencia fundamentalmente

1. En el capítulo anterior, se ha explicado la necesidad de reconocer como literatura oral a lo que se llama sencillamente oralidad. 
oral. Indagar las temáticas que las comunidades rurales componen y llevarlas al universo escrito es uno de los válidos esfuerzos por rescatar la oralidad rural, sin embargo, seguirán difundiéndose y reproduciéndose en el universo oral. Los cantos que se presentan en este estudio son solo una pequeña muestra de un extenso material de la producción campesina en Colombia, la tarea de recopilación del material existente está aún por hacer. Sobre la música en comunidades indígenas se han hecho investigaciones con enfoques desde la antropología y la lingüística. De acuerdo con una recopilación bibliográfica realizada por Carlos Miñana Blanco (2009) titulada "Problematizando el concepto de 'música indígena”, el autor señala que los conceptos de música, canto y baile se entienden de diferente forma en los pueblos indígenas y anota lo siguiente:

Por ejemplo, "el lenguaje kuna no emplea términos que correspondan directamente a los conceptos castellanos de 'música', 'canto', 'canción', y 'baile'. La mayoría de los géneros vocales kuna se asocian directamente con el término igar (también igala) que puede ser traducido como 'camino', 'sendero, camino orientado a la comunicación con el mundo de los espíritus (Miñana Blanco 2009: 6).

Los cantos recopilados para este estudio forman un conjunto de composiciones inéditas que nos trasportan a los universos de la oralidad campesina, que puede ser étnica a la vez. Walter Ong (1982) señala que la oralidad posee un carácter originario previo a la escritura y que la expresión oral habría sido capaz de existir sin que hubiese existido ninguna escritura antes. No obstante, la escritura ha logrado imponerse como sistema de comunicación con pretensión de superioridad. Incluso gran parte de la investigación sobre producción oral ha sido integrada en los estudios de la creación literaria. Al parecer, como lo asegura Adrián F. Frejade la Hoz, "hasta el momento en que escribo este trabajo, nadie ha hecho una teoría de la literatura oral como tal" (Freja de la Hoz 2015: 24). Lo que sí existe son teorías sobre la oralidad que han desarrollado significativos aportes para interpretar las manifestaciones orales.

En los relatos líricos que surgen en y desde la oralidad rural, nos encontramos con una riqueza retórica que construye un universo de sentido para representar al habitante rural y su entorno. Las letras de 
los cantos que se analizan en este proyecto se abordan desde dos planos, el de la expresión y del contenido. Desde la expresión se realiza un análisis poético-lírico para acceder al tejido semántico y para descubrir el andamiaje estructural que le da forma al texto; es decir, en la expresión se enfatiza lo semántico-emotivo y las reflexiones se orientan hacia la búsqueda de la experiencia humana, tanto colectiva como individual, y los rasgos que activan la experiencia sensorial que producen y transmiten los cantos.

Las reflexiones en el plano del contenido permiten elaborar un análisis de símbolos, paralelismos, metáforas y otras figuras retóricas presentes en los cantos, es decir, se analiza lo semántico-conceptual con el propósito de comprender valores, juicios y conceptos propios del repertorio cultural comunitario. Además, a través de la sustancia conceptual se pueden rastrear estructuras subyacentes en las cuales se fundamenta la esencia cognitiva y normativa de lo comunitario. La creación lírica, examinada desde ese compuesto binario, permite analizar de qué manera la expresión y el contenido líricos revelan la experiencia y la significación comunitaria ante la conflictividad. Es allí en donde se pueden explorar esos elementos invisibles a los que se hizo referencia en el capítulo anterior.

\section{Rescatar la oralidad}

Si me referí anteriormente al rescate de la oralidad rural es porque, como lo reconocen Ana María Ochoa (2002, 2006), Peter Wade (1998, 2003, 2005), Adrián F. Freja de la Hoz (2015) y muchos otros autores, esos discursos inéditos han sido desplazados y marginalizados tanto o más de lo que han estado sus poblaciones. Ese desplazamiento está estrechamente relacionado con la preferencia por la literatura escrita, en un cierto fetichismo en el que se ampara el discurso del poder. Como sugiere Lienhard, desde los inicios de la invasión colonial en el continente americano, la escritura ha sido un mecanismo para establecer casi un ritual del prestigio con el que se instalaban en el territorio representantes de las sociedades grafocéntricas: 
A los ojos de los conquistadores, la escritura simboliza, actualiza o evoca —en el sentido mágico primitivo- la autoridad de los reyes españoles, legitimada por los privilegios que le concedió a raíz de la conquista cristiana (Lienhard 2003: 47).

Independientemente de la importancia que tenga la escritura y sin desconocer todos los beneficios que se le ameritan, el problema —en últimas - no es la presencia impuesta de la misma, sino la marginalización de la oralidad y su exclusión en muchos campos de la investigación. Y, más aún, y lo que es peor, la poca o nula valoración de las narrativas orales, hasta el punto de llegar a ser consideradas como piezas folclóricas tanto en la academia como en muchos otros ámbitos. Considero que es preciso mencionar que la literatura escrita impuesta durante la conquista y colonización españolas se encargó no solo de asignarle a ese universo gráfico funciones de poder político, que se siguen perpetuando hasta hoy en día, sino también de liquidar toda suerte de sistemas de comunicación más cercanos o más lejanos a la escritura que pudieran haber existido en la época precolombina, pues no se puede afirmar que las culturas precolombinas, postcoloniales o tradicionales, por el hecho de ser mayormente culturas de expresión oral, no posean o no hayan poseído otros sistemas de anotación que se han alternado con la oralidad. Un ejemplo de ello son los conocidos códices mayas, los glifos y los quipus andinos, sistemas autóctonos que registraban esferas específicas de la memoria colectiva, en lo político, administrativo y religioso, entre otros. Lo que es necesario resaltar aquí es que tanto la literatura escrita como la literatura oral forman parte de un sistema más complejo de signos y que ninguno puede revelar en su totalidad una visión integral del universo del que proceden, sino que, por el contrario, estos sistemas, en su conjunto, nos hacen conscientes de la complejidad y, al mismo tiempo, de la riqueza que estos mundos —en sus matices y diversidad- representan.

En consecuencia, de lo anterior debemos deducir que las culturas rurales que siguen conservando un acervo profundamente oral poseen también la escritura, entre otros sistemas, como vehículo de comunicación. Los campesinos de las regiones rurales de América Latina han sido injustificadamente tildados de ignorantes o analfabetas. No solo el cúmulo de conocimientos que poseen, en especial sobre la naturaleza 
y sobre las diversas formas de relacionarse con el medio ambiente, sino también las variadas formas de transmisión de esta información entre generaciones han sido sumamente desvalorizadas. Tales consideraciones están relacionadas justamente con la supremacía que se le ha otorgado al sistema gráfico.

Tal vez estas breves pero ilustrativas aclaraciones posicionen el canto dentro de un conjunto de lenguajes que no solo son complementarios en los discursos sociales, sino que nos revelan visiones del mundo que en la escritura no siempre están presentes. En últimas, para realizar el análisis sobre los escenarios de disputa, es necesario indagar cómo se representan en las narrativas líricas las lógicas, los saberes, los conocimientos y los principios locales. Rastrear esos repertorios en la producción musical permite también registrar las transformaciones y los cambios tanto en la selección de los sistemas de expresión cultural elegidos por las comunidades como sus contenidos y estructuras. Estamos llamados, y es nuestra tarea como académicos, a recuperar lo que aún sea posible de las estructuras comunicativas que, al margen de las estructuras hegemónicas, han estado condenadas a la extinción o a la subordinación.

La producción oral forma parte de un importante proceso de reconstrucción social. Gran parte de los conflictos por la tierra, entre otros, generados por la producción de agrocombustibles en Colombia, han causado rupturas en el tejido social de las poblaciones rurales. Los procesos de restablecimiento del ambiente comunitario conducen a la producción de nuevas realidades dentro de estructuras sociales y políticas aún incipientes para reparar la cohesión colectiva. La música y la oralidad creadas en medio de esos ambientes de tensión se convierten en eslabones de la arquitectura para la reconstrucción del futuro. El cúmulo de conocimientos, experiencias y significados compartidos socialmente ejerce una influencia en las acciones — no solo individuales, sino también grupales - para reactivar de nuevo la vida comunitaria. Además, en el contexto de disputa, el repertorio cultural se convierte en dispositivo funcional que incide también en la transformación del conflicto. 


\section{Cantarle al retorno}

Si bien muchos de los estudios sobre el conflicto documentan con detalle y gran rigor el fenómeno del desplazamiento, existen también procesos de retorno emprendidos por comunidades con alto grado de organización colectiva. En la Colombia de hoy, es necesario - sino urgente- elaborar una cartografía del retorno tanto en el contexto nacional como en la producción artística y musical que surge de esa temática. Si aceptamos el retorno, la restitución de tierras y la reparación a las víctimas del conflicto como estrategias válidas de la justicia transicional, tenemos que aceptar el regreso de las expresiones orales como instrumentos para restituir y reparar las voces y las memorias vetadas. Eso exige acercarse a examinar y comprender las prácticas locales, la historia colectiva y las especificidades de las formas de organización en cuya matriz ocurre la producción cultural. Para lograr esa comprensión es indispensable identificar cómo se da de facto la (re)construcción de sentido y la experiencia del sinsentido. A ese respecto, Flick señala:

El saber se construye en procesos de intercambio social, descansa en el papel de la lengua en las relaciones sociales y tiene, ante todo, funciones sociales. [...] La producción de textos contribuye a esta construcción social de los mundos que investigamos (2010: 104). ${ }^{2}$

El rescate, al que me referí anteriormente, debe acontecer de dos formas, o en forma simultánea, desde dos frentes. Por un lado, es necesario recuperar importantes componentes de los sistemas de comunicación que han sido desvalorados y denigrados y, por el otro, reconstruir los significados que esos sistemas han venido preservando en sí durante ańos. No solamente mundos gráficos y letrados, sino universos visuales, verbales y acústicos que han formado parte de un conjunto semiótico de comunicación entre las poblaciones marginadas, así como también entre ellas y otros grupos sociales. En el contexto del

2. La traducción es mía. El texto original en alemán es el siguiente: "Wissen wird in Austauschprozessen konstruiert, basiert auf der Rolle von Sprache in sozialen Beziehungen und hat vor allem soziale Funktionen. [...] Die Herstellung von Texten trägt zu dieser sozialen Konstruktion der Welten, die wir untersuchen”. 
conflicto armado y la violencia dirigida, estos sistemas han estado no solo expuestos al deterioro, sino también en riesgo de desaparecer. Las condiciones extremas de violencia destrozan los tejidos sociales, lo que hace que los símbolos y gran parte del repertorio cultural sufra fuertes fracturas. Esta fragmentación causa graves repercusiones en la función que cumple la producción cultural porque destruye aquello que en la cotidianidad asigna sentido y significado a la vida y a las prácticas comunitarias. De forma paradójica, muchas veces es justamente ese mismo universo simbólico el que puede volver a reconstruir el sentido y elaborar razonamientos para el sinsentido. En el caso de algunas comunidades, las expresiones musicales, la oralidad y la narrativa que visualizan una temporalidad cíclica han sido una de las armas/herramientas más poderosas para reconstruir la esencia comunitaria. Considero fundamental detenerse a observar el proceso de (re)producción en el que se sitúa la creación de un producto cultural: si consideramos los productos o manifestaciones culturales como textos de las realidades, entonces su proceso de producción es análogo al de cualquier otro texto que puede ser interpretado como proceso cultural.

\section{(Re)construcción de la memoria colectiva}

El proceso de producción de las composiciones musicales pasa por un estadio de visualización en el que se producen imágenes que forman un caleidoscopio óptico de la experiencia. Aquí aparecen tanto las experiencias de violencia como las de no violencia. Esas representaciones entran en un espacio compartido con lo emotivo en donde se explora el significado de la emoción ante lo vivido. En ese espacio se comparte también lo cognitivo, se busca el significado de la razón y asimismo se indaga por el significado de lo ético y lo moral. La imagen se reconstruye en la oralidad a través de la materia textual del canto. En la melodía se refuerza la expresión de esas diversas valoraciones que provienen de tres campos diferentes. De esa manera podría resumirse, muy brevemente, cómo se elabora parte de la historia en un canto que reconstruye la memoria colectiva. 
La estrategia metodológica integra tres estadios: la experiencia, la construcción y la interpretación. Esta es la base trilógica sobre la cual se apoya el proceso analítico que subyace a la creación de un texto cultural, pero también se puede aplicar para la producción de un texto documental, académico, etc. Flick señala que "las ciencias sociales producen una visión más sobre el conocimiento científico y la representación del ensamblaje comprende procesos diversos de producción de la realidad" (2010: 110). En la figura que se ve a continuación se representa la relación triangular de esas tres fases:

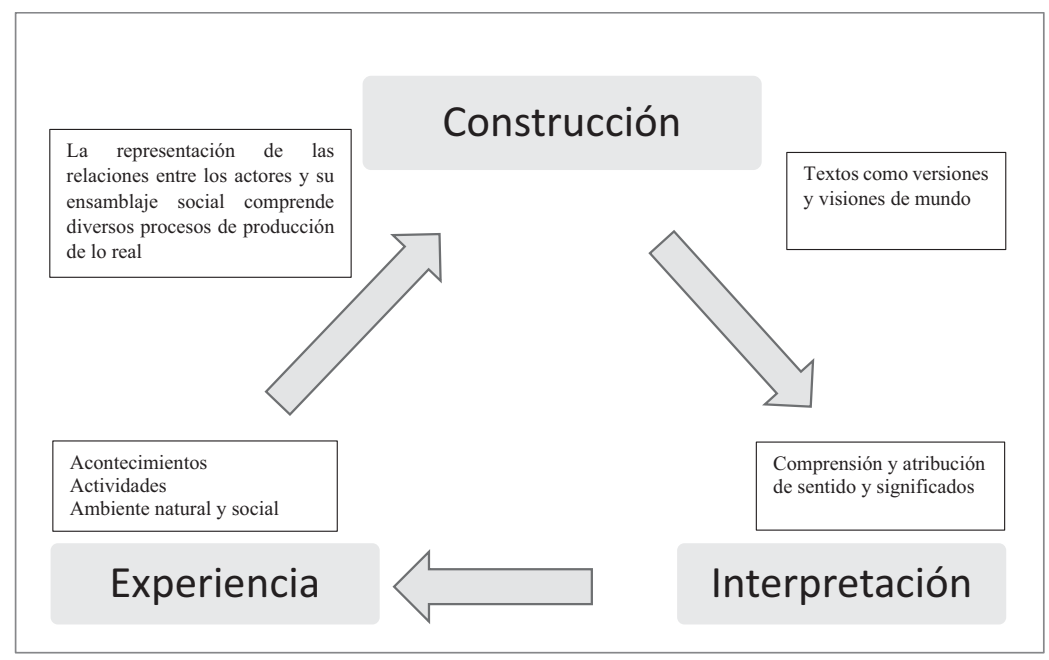

2. Dimensiones de observación para el análisis Fuente: diagrama tomado de Flick (2010: 111).

Al observar el procedimiento que propone Flick, vemos que el proceso de análisis para acercarse al entendimiento o a la interpretación de una realidad no es muy diferente al que se sigue para crear un texto cultural,

3. La traducción es mía. La versión en alemán es la siguiente: "Sozialwissenschaft produziert eine weitere Version der Welt. Wissenschaftliche Erkenntnis und Darstellung von Zusammenhängen umfasst damit verschiedene Prozesse der Konstruktion von Wirklichkeit”. 
ya sea un escrito u oral. Si bien estos procesos no son idénticos, comparten entre sí los tres rasgos matizados en la singularidad de la creación; es decir, la creación de una composición musical — para ilustrar el tipo de corpus con el que se trabaja en este estudio- pasa también por la experiencia, que en este caso es la del desarraigo, por una fase de construcción o reconstrucción. En esta fase el proceso de remembranza se activa de manera especial porque vincula eventos recientes y eventos pasados acumulados en la memoria, entre otros, gracias a la tradición. La tercera fase de interpretación es la que da origen al texto. Allí aparecerán elementos relevantes que han sido extraídos tanto de la experiencia como de la relectura de esa experiencia, es decir, la reconstrucción.

Las piezas musicales que surgen como textos líricos del despojo contienen - tanto en su constitución textual como en su constitución sonora- versiones del mundo y de las experiencias de quienes las componen. En este sentido, es necesario hacer énfasis en que las experiencias que se representan en la oralidad y en la lírica campesina no son abstracciones individuales. En las composiciones líricas, la creación artística consigna la experiencia comunitaria y se recrea en ella dando forma a un discurso histórico inédito que se revela a través de la oralidad y la melodía. Allí se hace visible un diálogo que establece la voz creadora con lo vivido, es decir, primero con su historia propia y luego con quienes son destinatarios de esta. Se manifiesta no solo la experiencia de la realidad circundante, sino, de manera especial, los significados y el sentido que tiene la experiencia misma del proceso de creación de la pieza artística; es decir, las reflexiones sobre los cantos, que aparecen con más detalle en los capítulos V y VII, componen en su lectura historias de reconstrucción de las realidades contextuales y, a su vez, son una reelaboración del ejercicio artístico como tal. Podría decirse que se trata casi de una metainterpretación — reflexión - que reivindica el arte lírico comunitario como elemento relevante del sistema comunicativo que debe ser recuperado para la interacción y participación sociales. Se sigue un camino de desglose para acercarse a la realidad creada, se inserta ese texto representativo de la realidad en el diálogo con un intertexto y se examina cómo ocurre el proceso de construcción. En ese proceso tiene lugar también la interpretación de ese producto textual y su relación no solamente con otros textos, sino con los contextos en los que se origina. 
Tal vez la diferencia en la creación de los distintos tipos de texto, los culturales, artísticos y científicos, es que en este último tipo de textos se reinterpretan esas creaciones a la luz de diversos enfoques y posturas teóricas, se elabora una versión que interroga, cuestiona y a su vez trata de acercarse a un constructo argumentativo de por qué se originan esas visiones de mundo plasmadas en los textos.

La producción lírica y musical que nace en contextos comunitarios tiene peculiaridades que la distinguen fundamentalmente de la producida para la industria musical. Una de las mayores particularidades es su génesis: el ambiente comunitario en el que se origina la práctica músico-lírica emerge de procesos sociales colectivos, en la creación lírica se materializa la experiencia del entramado colectivo. Una segunda característica es la configuración ideológica y la estética del cuerpo textual. El universo lírico de los cantos contiene un concepto de ruralidad alternativa como opción en donde se descubren principios sobre las relaciones entre ser y espacio que se contraponen a ideas de los sistemas feudales y pseudofeudales —incluso señoriales_ que aún gobiernan el discurso y las políticas agrarias contemporáneas. Sus letras representan estéticamente una axiología campesina que pone énfasis en la relación dialógica de una cultura rural desde la base.

Los cantos que se han recolectado para el estudio están compuestos por algunos de los líderes de las comunidades Las Pavas y El Garzal y de las zonas humanitarias. En las conversaciones que sostuve con varios de los cantautores, afirmaban que el cantar era una necesidad que habitaba en ellos y que los temas de composición siempre se inspiraban en las experiencias más cercanas, relacionadas con el conflicto. Sin embargo, no todos los cantos se convierten en lírica sobre la violencia. Esos impactos que ha causado la lucha por la tierra eran motivos de inspiración también para recordar el camino y los motivos que los agrupan y los identifican como comunidad campesina. El proceso de producción de los jóvenes que componen rap se genera de una actitud totalmente decidida por reivindicar no solo su cultura campesina, sino también su identidad étnica de descendencia africana. La relación entre la africanidad y la reivindicación como grupo social marginado se ajusta a los matices contextuales de la Región del Pacífico. A este respecto, Peter Wade señala que, con respecto a la construcción discursiva 
de la nación en Colombia, el concepto de negritud tiene mucho más impacto en el panorama político y cultural en comparación con la influencia que tiene África (2005: 354).

\section{Músicas y conflicto}

John M. O'Connell y Salwa Castelo-Branco, en su libro Music and Conflict (2010), analizan el rol de la música y los procesos de interacción en escenarios de conflicto. En su volumen se constata que el arte musical ha estado presente en la historia de confrontación de muchos países y que ha jugado un claro papel en casos de conflictos interestatales como los de Corea del Norte y Corea del Sur (Howard 2010) o en la antigua Yugoslavia (Pettan 2010), así como también en las profundas diferencias ideológicas en Indonesia (Rasmussen 2010). La expresión artística constituye un componente vital del análisis sobre el conflicto, su manejo y transformación. La comunicación melódica y musical posibilita identificar elementos intrínsecos al conflicto y permite explorar singularidades de los procesos sociales comunitarios que no se registran en documentos oficiales. Los hallazgos que se puedan extraer de la fuente musical son determinantes para profundizar en el saber sobre la sustancia que contiene el discurso, sea este de índole nacional o comunal.

John Paul P. Lederach y Angela Lederach, en su obra When Blood and Bones Cry Out, también examinan el conflicto y su transformación desde perspectivas culturales. En su análisis integran las expresiones narrativas y líricas que emergen de comunidades locales que han experimentado episodios y periodos de violencia. Su propósito "se enfoca en el desarrollo del concepto curación social como fenómeno que se sitúa entre la curación microindividual y la reconciliación colectiva" (2010: 6). ${ }^{4}$ Su propuesta es examinar aspectos escondidos

4. La traducción es mía. El texto original en inglés es el siguiente: "Our purpose focuses on the development of the concept of social healing as an intermediary phenomenon located between micro-individual healing and wider collective reconciliation". 
en la construcción metafórica y simbólica que surge de comunidades en contextos de conflicto en Somalia, África Occidental y Colombia. Según estos autores, es necesario prestar atención a las metáforas que se revelan en la dinámica en la cual se desarrolla el conflicto. Su interés primordial es acercarse a la comprensión sobre cómo las comunidades negocian significados en contextos de confrontación violenta. A este respecto indican lo siguiente:

A través de la exploración del fenómeno de la metáfora como el sonido, la música, la poesía y el cuidado maternal buscamos ideas, indicios y cualidades que estimulen la imaginación acerca de los cambios y mecanismos por los cuales la sanación social puede ser observada y comprendida (Lederach y Lederach 2010: 13).

\section{Música, cultura y paz}

Las investigaciones sobre el conflicto que toman como fuente el material lírico examinan la producción musical para indagar la creación discursiva y simbólica y los significados de las letras y del lenguaje musical. Algunos de esos estudios exploran también rasgos de la construcción sociocultural e histórica para estimar en qué medida esas composiciones artísticas retratan, en los paisajes sonoros, las realidades de las que emergen. Héctor D Fernández L'Hoeste (1998), Ana María Iglesias (2011) y Óscar Hernández Salgar (2016), por ejemplo, analizan la creación musical como parte de la composición discursiva en la construcción del concepto nación.

Fuera del enfoque geopolítico que les confieren algunos estudios a las expresiones musicales, existen otras reflexiones sobre la producción lírica que indagan la música en relación a la generación de conocimientos y las transformaciones sociales. Aunque un poco extensa, presento esta lista de estudios que abordan la música en relación a fenómenos sociopolíticos y culturales: Peter Wade (1998), sobre la identidad y la raza; Ángela López (1998), las manifestaciones del arte de la calle; Héctor D. Fernández L'Hoeste (1998), ciudad y rock nacional; Wivian Weller (2000), el hip hop y el rap en Brasil; Herlinda Ramírez Barrados (2000), el corrido en México; Ruth Finnegan (2002), ¿por 
qué estudiar música?; Ana María Ochoa (2002, 2006), la música y la violencia/discursos de autenticidad; Gabriel Correa (2002), el rock argentino; María L. Figueredo (2002), el retorno en el canto popular en Uruguay; Derek Pardue (2004), el hip hop en la educación; Roberto Torres (2005), la canción de protesta; Silvia Ramos (2006), el afroreggae en Brasil; Óscar Hernández Salgar (2007), la colonialidad y postcolonialidad musical en Colombia; Tomás Sánchez y Alejandro Acosta (2008), la música popular campesina; Arlene Tickner (2008), el hip hop en Colombia, Cuba y México; Ana María Arango y Leónidas Valencia (2009), la chirimía chocoana en el Pacífico colombiano; Krista Thompson (2009), la cultura visual del hip hop; Hermann Herlinghaus (2009), el corrido mexicano; Ariel Castillo (2010), la música vallenata; James L. Morgan (2010), el significado y la función de la cultura industrial en Argentina, y muchos otros más.

Existe una mirada, a mi parecer un poco sesgada, de que la música se instaura como instrumento terapéutico de catarsis para liberarse de los traumas ocasionados por la confrontación. Aunque la creación musical y la música misma sí contribuyen a mitigar los traumas, sus efectos están mayormente relacionados con procesos de autorreparación comunitaria, que tienen incidencia en puntos de intersección claves dentro del marco político y social. Además, al hacer uso de los recursos culturales, los miembros de la comunidad se conciben a sí mismos como hacedores de paz, lo cual significa que toman un rol activo en la construcción de la misma. Lederach y Lederach enfatizan en la importancia del uso de ese bien cultural que coactúa en la transformación o induce a ella e indican que "se debe dar especial consideración a la construcción de la paz que proviene de los recursos culturales para la resolución del conflicto y que existen dentro del contexto" ( 2010: 97). ${ }^{5}$

Desde esta perspectiva, el cruce de significados representados en la creación lírica se aleja del planteamiento dicotómico de opuestos, referidos específicamente a paz o conflicto. Si explorásemos más en

5. La traducción es mía. El texto original en inglés es el siguiente: "Considerable attention must be given to discovering and building on the cultural resources for conflict resolution that exist within the context". 
profundidad los recursos culturales en las manifestaciones artísticas, podríamos encontrar que existen unos espacios de recreación transitoria tanto del concepto de paz como del concepto de conflicto. Si aplicamos en este sentido, y una vez más, el planteamiento propuesto por Bhabha (2004), los in-between spaces se manifiestan también en la creación lírica, a través de un panorama de relaciones transversales. Eso quiere decir que las significaciones que forman parte importante de la construcción de realidades sociales, políticas, ecológicas y de otras índoles aparecen paralelamente en la construcción transversal del relato lírico y se orientan a cuestionar y a resaltar los efectos que ocasionan las relaciones asimétricas de poder en los distintos ámbitos. La lucha por la tierra, razón fundacional de la contienda de las comunidades, es uno de los motivos más antiguos del conflicto colombiano que se manifiesta con fuerza en el canto. En especial se hace un reclamo por la gobernanza local sobre los recursos naturales y contra la imposición de lógicas dominantes. Parte de los textos líricos que conforman el corpus de este proyecto incluyen en su discurso lírico consideraciones alternativas a la distribución y el uso de la tierra. En ellos se recalca la importancia de trascender la idea mercantil del territorio y sugieren la necesidad de establecer una correspondencia entre prácticas y espacialidades locales, lo que quiere decir darle antelación y prioridad a la cultura ecológica de las poblaciones locales.

Los cantos — se pueden ver las transcripciones en el apéndice- no solo relatan historias de desplazamiento y desarraigo originados por la confrontación, sino que también construyen líricamente conceptos que resignifican la noción de naturaleza, sociedad y campesinado. Esa distinción es perceptible en la mayoría de composiciones, y el lugar-hábitat aparece como núcleo vital para el bienestar comunitario. Arturo Escobar insiste en la necesidad de recuperar la perspectiva del lugar como antítesis de la tendencia globalizante y apunta que "el lugar, en otras palabras, ha desaparecido en el 'frenesí de la globalización de los últimos años' y este desdibujamiento del lugar tiene consecuencias profundas en nuestra comprensión de la cultura, el conocimiento, la naturaleza y la economía." (2000: 114). Además, en el caso de las comunidades, se trata de un lugar-territorio físicamente determinado y con fronteras definidas. Esta resignificación del espacio local aparece 
como una antítesis a lo que se concibe como tal en los lentes de la globalización, desde cuya perspectiva las espacialidades se tornan en una mezcla de intercambios y cruces que se derivan de los flujos migratorios. El espacio adquiere un carácter trashumante, diluido y difuso.

Los relatos de la experiencia de estas culturas campesinas consignadas en el canto replantean esos conceptos. Y, por el contrario, lejos de ser una simbiosis espacio-temporal con fronteras abiertas, las comunidades amenazadas por el despojo reclaman la defensa del territorio y el lugar local y piden la demarcación de fronteras como mecanismos de protección de su cultura y de su existencia.

En varias de las disputas tanto intranacionales como internacionales, la música ha sido un instrumento de acercamiento entre las partes en desacuerdo, como lo he referido anteriormente. Las narrativas sobre la confrontación y la producción lírica pueden tener un efecto conciliador para mitigar el conflicto. Sin embargo, hay otro tipo de producción lírica cuyo propósito está orientado a desenmascarar un sistema de legitimidades ficticias o a reconstruir el tejido social impactado por el conflicto. Tanto la narrativa oral como la lírica que emergen de ambientes campesinos podrían situarse en una base fundamental que alimenta lo que Paul Ricoeur (2001) llama la "filosofía de la acción", porque allí se reconstruye un repertorio memorable sobre cómo se interpretan desde el interior de las comunidades los avatares, los aciertos, las victorias, las derrotas y las esperanzas. Esa reconstrucción incentiva los motivos de la acción, la existencia y las razones de lucha de los movimientos sociales. En el universo musical, dichos espacios plasman una cartografía figurativa de la acción que se debate entre el desplazamiento forzado y el retorno deseado del yo lírico.

\section{Cantos y décimas}

Los cantos recogidos durante mi visita de campo corresponden a las regiones del Caribe y del Pacífico colombiano. Especialmente en el Pacífico, muchas poblaciones han sido gravemente afectadas por el desplazamiento forzado. Estas dos regiones son tradicionalmente diversas y ricas en producción lírica. Uno de los géneros musicales más 
conocidos y que quizá haya adquirido mayor difusión es el ritmo del vallenato, primero a nivel internacional y después a nivel nacional. Sin embargo, además de encontrar composiciones en este estilo musical, existe una variedad sonora que incluye otros ritmos como el porro, la cumbia, el paseo, el bullarengue, el bunde, el merengue y la gaita, los cuales han transitado a lo largo y ancho de todo el país y algunos dedican su relato a narrar el desplazamiento forzado. El género poético también constituye un paraje fundamental de la producción oral, especialmente en las regiones atlántica y pacífica, en donde es posible encontrar una gran producción de décimas; las que aparecen a continuación, aunque no pertenecen a los cantos recopilados, ejemplifican la forma en la que expresan los pobladores rurales la situación del campesinado ante las confrontaciones armadas:

\section{Región del Caribe}

Hemos vivido violencia

Hemos vivido secuestro

Pero este país tan nuestro

Salvémoslo con decencia

Hoy se acude a la indulgencia

En una forma muy sana

Este pueblo se engalana

Y de ustedes soy amigo

Vengan y pidan conmigo

Para la paz colombiana.

(Alfredo Martelo, "Pie Forzado

para la paz colombiana”)

\section{Región del Pacífico}

De nuevo ahora le toca

Al campesino sufrir,

Con tanto "pájaro grande"

Que en los cielos ve crujir.

De nuevo ven revivir

La horrible pesadilla,

De ver cómo se acuchilla

Sin compasión el destino.

Atropello y la amenaza

Para el pobre campesino.

(El Diablo)

En su trabajo sobre la literatura oral en Colombia, Adrián F. Freja de la Hoz recoge diferentes composiciones orales en copla, romance y décima de los dos litorales colombianos. Su trabajo es un excelente punto de partida para la recuperación de la literatura oral colombiana. Coincido con ese autor en que es necesario enfatizar y visualizar esa enorme y exquisita producción de la literatura oral campesina y la deuda que tenemos con las historias inéditas de nuestra Colombia rural. Este autor afirma que "la décima propone una reflexión respecto al oficio de campesino en medio de un conflicto armado" (2015: 155) y 
más adelante agrega que "las décimas desarrollan, de igual manera, una problemática generalizada: la violencia y el desplazamiento forzado. Es decir, el poeta se comporta como un sujeto colectivo" (2015: 155). El manifestar un sentir colectivo a través de una sola voz resalta nuevamente una característica fundamental de la literatura oral: la creación de autoría se deposita en el bien simbólico, inherente a la convivencia comunitaria. En el contexto del dolor causado por la violencia, el relato que transmite en la décima esa voz sentipensante es herencia colectiva, una racionalidad de lo comunitario, de lo colectivo y del sentir común.

Solemos decir que se nace con la vena artística o la vena musical. Y es que, aunque no sea mi intención equiparar las variables de heredabilidad de los estudios cuánticos, lo que sí se puede afirmar es que, tanto en lo puramente biológico como en lo social, esa heredabilidad está influenciada por las transformaciones sociales que inciden en la modificación de las características peculiares de una especie con el transcurrir del tiempo. De una forma análoga, esa vena musical o artística, que es característica de la creación oral en los litorales colombianos del Atlántico y del Pacífico, ha sido transmitida generacionalmente como valor cultural que se ha arraigado en el ambiente sociocultural de las regiones costeras y ribereñas en particular. La confluencia de la variedad poblacional y étnica se puede evidenciar, especialmente, en algunos asentamientos de esas regiones de Colombia. Esa convergencia ha derivado en un flujo de intercambios entre diversas visiones del mundo, prácticas de organización y expresiones artísticas, entre otras. En algunas ocasiones, se ha producido un cruce de elementos y procesos de representación de los grupos involucrados, incluso la casi integración de algunos elementos culturales, y, aunque podría verse como una simbiosis de elementos, lo que ha surgido es una reafirmación de las diferencias en un entorno de participación conjunta; es decir, la expresión singular de cada subcultura se hace más evidente en los espacios compartidos de representación colectiva. La singularidad, lejos de entrar en contradicción, se convierte en elemento de reciprocidad e intercambio grupal. Esto es perceptible especialmente en el arte. En el arte musical, por ejemplo, se puede apreciar esa combinación representativa de las culturas que coexisten; se hace evidente a través de los aportes melódicos y la combinación de los respectivos instrumentos 
musicales. En gran parte de la producción musical de las zonas litorales, los instrumentos de percusión son el aporte de lo afrodescendiente, traído por los grupos humanos que en ese entonces llegaron al continente como esclavos. Estos instrumentos, como el tambor y el alegre, entre otros, marcan la relación entre sonoridad y cuerpo, relación que aglutina variadas formas de expresión tanto en el lenguaje verbal como en el no verbal. Este nexo se adopta en los ámbitos locales con diversos matices, troquelando la producción musical regional.

\section{Proceso: recopilación de los cantos y comunidades cantoras}

El procedimiento de recopilación tuvo lugar durante mis visitas a las zonas rurales de Las Pavas y El Garzal, en el departamento de Bolívar, y en Jiguamiandó y Curvaradó, en el departamento del Choco. En Las Pavas, desde la recopilación de los cantos que aparecen en el CD hasta el cierre de la edición final de este texto, se han podido recolectar algunos pocos cantos más gracias al contacto permanente con algunos miembros de estas comunidades. Existen otras fuentes líricas adicionales recogidas durante mi segunda estadía de campo: las canciones de Ceferina Bánquez en el CD Cantos ancestrales de Guamanga (2012), a quien pude contactar gracias a Ariel Castillo, y Cantos sobre la tierra y el campesinado, en el CD Relatos musicales para la memoria histórica que he recibido directamente de miembros de la Zona de Reserva Campesina del Valle del Río Cimitarra, una producción del año 2012. En el marco de este análisis, esas piezas musicales adicionales tendrán el propósito de complementar y ampliar el estudio de la producción lírica proveniente de las comunidades de enfoque. Existe un campo inexplorado de producción inédita que debería ser objeto de estudios posteriores: se trata de una gama musical que contribuye a la reconstrucción del tejido cultural y refuerza la articulación entre el territorio sonoro-cultural en transición hacia la conciliación y la construcción de la paz, en especial aquellas que surgen de los espacios comunitarios. El Centro Nacional de Memoria Histórica lleva un excelente trabajo orientado hacia ese propósito. Una de las producciones más recientes 
es la producción de tres CD, titulados Tocó cantar. Travesía contra el olvido (2014), en los que se recogen diferentes tipos de ritmos y en los que varias personas reconstruyen en sus melodías algunas de las experiencias de la guerra y sus visiones hacia la transformación social y la construcción de la paz.

El corpus total de este estudio se compone de treinta y siete cantos (véase Apéndice), la mayoría transcritos por mí, excepto la versión del CD Les voy a cantar la historia. ${ }^{6}$ Casi todas las composiciones las he recolectado o grabado durante las charlas que sostuve con los habitantes de las comunidades en mis visitas a las zonas de enfoque de este proyecto. Existe otro disco compacto producido por el grupo de jóvenes cantantes Los Renacientes titulado también Los Renacientes y lanzado en el año 2008. Interpretan rap y fusión de músicas autóctonas de la región del Pacífico colombiano. El reciente CD Les voy a cantar la historia recopila cantos a capela con ritmo vallenato compuestos por los campesinos de la comunidad Las Pavas y se lanzó en julio del 2013 en Bogotá; todas sus composiciones nacen en el ambiente rural. Quienes las componen se ven enfrentados a condiciones de extrema violencia, no solamente dentro del marco de la confrontación armada, sino también dentro del sistema estructural de marginalización en la que se encuentra gran parte de la población rural en Colombia. Los cantautores, que son casi siempre los compositores de los temas que se presentan en el corpus, inician el proceso de difusión de forma intracomunitaria, mayormente en las tertulias que se realizan en las comunidades, durante reuniones o en los encuentros en las asociaciones campesinas o entre diversas asociaciones.

En la comunidad Las Pavas, la cual se detalla más adelante, la Fundación Chasquis y la Fundación Connat, ${ }^{7}$ realizaron un reportaje sobre el retorno de la comunidad a la hacienda durante el mismo tiempo de mi visita a las comunidades en los años 2012 y 2013 que fue convertido en documental y se titula Algún día es mañana. En algunas

6. Existe un cuadernillo de transcripciones de los cantos de Las Pavas que he tomado como base, introduciendo algunos cambios ortográficos necesarios.

7. La Fundación Connat, en Suiza, y la Fundación Chasquis, en Colombia, llevan a cabo todo el trabajo de difusión. 
escenas se puede ver cómo los cantos compuestos por los paveros se interpretan en las reuniones, y se convierten en instrumentos que vitalizan la dinámica comunitaria. Ese reportaje se presentó en el festival Pantalla Latina en San Gallen, Suiza, en el año 2012 y la nueva versión del mismo fue convertida en documental y presentada en el año 2015. Esa posibilidad de difusión está, naturalmente, articulada con el intenso compromiso y el trabajo que llevan a cabo las dos fundaciones antes mencionadas, promotoras de la idea, así como también con la decidida colaboración y el seguimiento por parte de las organizaciones no gubernamentales que apoyan a la comunidad desde la capital de país, desde las ciudades intermedias del territorio nacional y en el ámbito internacional. También existe una página virtual en la que se actualiza la situación de la comunidad Las Pavas $^{8}$ y en la que se consigna periódicamente la memoria de sus actividades. Allí se encuentran especialmente documentos oficiales, tanto eventos significativos para el proceso comunitario como diferentes informaciones sobre la diacronía de los desplazamientos y retornos.

Cada una de las comunidades de enfoque del presente análisis ha sido —o siguen siendo - acompañadas por diferentes organizaciones nacionales. Las comunidades de las zonas humanitarias de la Región Pacífico, por ejemplo, cuentan con el apoyo de la Comisión Intereclesial de Justicia y Paz, que tiene su sede en Bogotá. Esa organización les brinda un acompańamiento de forma permanente a las poblaciones que han constituido las zonas humanitarias en las cuencas de Curvaradó y Jiguamiandó. En las composiciones musicales, los habitantes de la zona de Cacarica, Comunidades de Autodeterminación Vida Dignidad de Cacarica (CAVIDA) expresan sus experiencias del desplazamiento violento y de su cohesión comunitaria afianzada en su identidad étnica afrodescendiente. El disco se ha dado a conocer en sectores que apoyan los motivos e intereses de esas poblaciones, tanto en el ámbito nacional como en el internacional.

La comunidad El Garzal muestra un matiz diferente porque gran parte de su producción musical tiene motivos religiosos y los cantos

8. La dirección electrónica de la Asociación de Campesinos de Buenos Aires (ASO$\mathrm{CAB}$ ) es la siguiente: <https://www.retornoalaspavas.wordpress.com/>. 
son interpretados en las celebraciones de la iglesia. En los relatos proporcionados durante mi visita de campo, los miembros de la comunidad me explicaban que los versos se componen, se van agrupando y posteriormente se empiezan a difundir durante las celebraciones eclesiásticas. En una pequeña población que se llama Vijagual se ha instalado una emisora cuyo propósito principal es la difusión de mensajes religiosos, pero también ofrece servicios de información a las comunidades del municipio. Pude observar que estas canciones se interpretaban en los oficios religiosos de la comunidad El Garzal y, si bien existen algunos cantos compuestos por los campesinos, la mayoría de ellos no son producciones propias de la comunidad, sino que han sido tomadas del repertorio de feligreses de la congregación religiosa a la que pertenecen: la Iglesia Internacional del Evangelio Cuadrangular.

La difusión de las letras es una cuestión sujeta al proceso de consolidación de las comunidades y se concibe desde la idea de reapropiación territorial. Si bien los cantautores se convierten en personajes especiales, no se representan a sí mismos, su función es representar las vivencias comunitarias, cantar y contar sus testimonios, ya que las experiencias de desarraigo pertenecen al drama comunitario. El repertorio se conecta con el sentimiento de filiación colectiva e interpela por la búsqueda de alternativas y estrategias que generen espacios de participación y acción comunitarias, en este caso a través del arte musical. No hay certeza de si la difusión tendrá gran eco en el marco nacional, pero lo que se observó en la segunda mitad del año 2013 es que el tema agrario sale con vigor al escenario público, especialmente a través de las manifestaciones y protestas, como el paro campesino en el año 2014, el trabajo colectivo y en red de diferentes comunidades rurales a lo largo y ancho del país y las actuales consultas populares. Algunos de los temas de la protesta actual aparecen en los cantos, pero hay otras temáticas como la entrada en vigor de los Tratados de Libre Comercio (TLC) firmados por el Gobierno que no aparecen referidas directamente, aunque en el CD Relatos musicales para la memoria histórica de la Zona del Reserva Campesina del Valle del Cimitarra sí se manifiestan tópicos relacionados con esa estrategia comercial, así como se aprecia en la siguiente estrofa del canto "Hablando sin rodeos": 
El macabro ejecutivo ha trazado una meta

Amedrantar a los campesinos,

Vivos o muertos sacarlos de sus parcelas

Daremos la lucha hasta el final,

De nuestro territorio no nos sacarán

Las empresas extranjeras,

Las llamadas multinacional

(Guillermo Macías, "Hablando sin rodeos")

\section{Ejes temáticos de los cantos}

\section{TiERRA Y TERRITORIO}

Las temáticas de la composición oral son variadas. En el caso de los cantos en ritmo vallenato, dichos temas están ligados a las actividades que realizaban los trabajadores en sus jornadas de agricultura u otras labores relacionadas con el campo o con la pesca. Los cantos que conforman el corpus de este proyecto manifiestan las problemáticas sobre el acceso a la tierra, al agua y a otros recursos naturales. De esos tópicos centrales se derivan varios subtemas que se analizan en detalle más adelante, como el manejo de los recursos naturales, los mecanismos de gobernanza de la tierra y el territorio, los derechos sobre la tierra como hábitat, los actores interesados por ella, los perjuicios sobre sus abusos y el negocio que se hace con ella, entre otros. Estos tópicos no son nuevos en la producción oral ni corresponden solo a las realidades de los litorales en Colombia, pero surgen con más frecuencia en los contextos regionales en donde se han exacerbado las disputas por la imposición de prácticas industriales neoextractivistas en el espacio agrario. En la lírica de las comunidades en cuestión, gran parte de los relatos ensambla una dinámica de interacción en su constitución enunciativa, pues se revelan con más determinación los actores en disputa y los factores de disentimiento. Además, en la mayoría de los versos subyace una formación discursiva reivindicativa de la acción colectiva, particularidad fundamental de la razón comunitaria, como lo veremos más adelante.

Jorge Artel, uno de los grandes poetas reconocidos por resaltar la poesía afrocaribeña, dedica también gran parte de la temática de sus 
composiciones a la tierra y a los campesinos que habitan en el Caribe colombiano. En la literatura, las voces que resaltan de forma particular las tradiciones orales y populares se pueden encontrar incorporadas ya en las novelas costumbristas que empiezan a dar espacio a las expresiones populares.

Las temáticas sobre tierras y conflicto se pueden encontrar en la lírica de comienzos del siglo xx. Observemos los siguientes fragmentos: el primero es parte de un poema de la primera década de siglo xx y el segundo es una estrofa de uno de los cantos de las comunidades en las zonas humanitarias:

\begin{tabular}{|c|c|}
\hline Esta chispa hizo del Boche & El cultivo de la palma \\
\hline El campesino trovero & Es un cultivo ilegal \\
\hline Empezó a soltar amarras, & Por eso los campesinos \\
\hline Y este pueblo con sus garras & Allá fuimos a mochar \\
\hline Fue reventando linderos. & \\
\hline Linderos ensangrentados & (E. Cuadrado, "La palma” \\
\hline Con un afán extranjero. & (Comunidad Las Pavas) \\
\hline Una chispa fue el principio & \\
\hline Que impone el explotador. & \\
\hline Para mostrar la vergüenza & \\
\hline La antorcha que ardió en la noche. & \\
\hline Compaegoyo) & \\
\hline
\end{tabular}

Guillermo Valencia Salgado, conocido como Compaegoyo (citado por Jaramillo 2010), ilustra los estragos que el sistema feudal ha causado en la clase campesina. Los dos fragmentos anteriores tematizan asuntos de orden político-social irresolutos en torno a la tierra y en ambos se observa que los temas de la rebelión y de la resistencia son análogos. En el primero, Boche quiere descubrir las acciones vergonzosas de un explotador y, en el segundo, el nosotros - tácito- muestra la acción del explotado. Estas dos perspectivas se dirigen a un mismo núcleo temático: la desposesión de la tierra. La construcción perlocutiva en los dos pasajes atina a revelarle al oyente un efecto de tensión y acción a la vez, pero mostrado desde diferentes ángulos.

La narrativa latinoamericana de comienzos del siglo $\mathrm{xx}$ se torna más regionalista y durante ese tiempo se producen gran cantidad de 
obras cuyo motivo central es el conflicto de fuerzas entre hombre y naturaleza. De acuerdo con Fernando Aínsa, "las novelas de la tierra no crean únicamente un paisaje literario, sino que integran personajes colectivos, verdaderos arquetipos de grupos representativos de la sociedad en los que reconocerse" (2003: 13). Sin embargo, en esas representaciones no hay una reivindicación de la situación de marginalidad y subordinación de esos grupos, más bien se trata de presentarlos como un conjunto de actores agregados con la intención de "redondear la identificación colectiva”. Como señala Aínsa en ese mismo ensayo, "el indio, el cholo, el gaucho y el emigrante entran en una narrativa como grupos sociales homogéneos" (2003: 13).

En la historia musical de Colombia, especialmente en las composiciones que han sido difundidas por la industria disquera, la figura del campesino aparece como parte del segmento social, sin embargo, las problemáticas de destierro, explotación y concentración de la tierra no se han tematizado rigurosamente. En composiciones muy conocidas, como son "Campesina santandereana", "Mi casta" y "La ruana", entre otras, la figura del campesino no se cristaliza a través de esa dualidad conceptual de tierra-territorio. Son valiosos lo aportes que hace Óscar Hernández Salgar al respecto, pues señala que el uso de esas letras referidas al campesino - y en melodías propias de las regiones andinas de Colombia, como el bambuco, el pasillo y otros ritmos- han sido utilizadas estratégicamente por la industria para exaltar especialmente el orgullo regional. En la canción "La ruana", por ejemplo, el texto musical enfatiza la herencia española mucho más que la identidad local, de tal manera que la ruana se parangona a la capa de un hidalgo, como se dice en la misma: "La capa del viejo hidalgo se rompe para hacer ruana". De acuerdo con Óscar Hernández, ese elemento de la vestimenta campesina resalta el valor de patria, el cual también se menciona en la canción pero está limitado solo a las regiones en donde se usa esa prenda. La selección de esa simbología no es aleatoria, sino que, como lo indica este autor, corresponde a otros intereses:

En pleno auge de la industria fonográfica en Medellín y en el momento más fuerte de la violencia partidista, una buena parte de la producción musical abordaba contenidos que buscaba exaltar el orgullo por la región o el país en una clara respuesta 
al interés de la industria de fomentar un nacionalismo que redundara en un mayor consumo interno. El tema de la violencia brilla por su ausencia en toda esta producción musical y sólo aparecen algunos comentarios al respecto en canciones muy posteriores como "A quién engañas abuelo", de Arnulfo Briceńo (ca. 1967) (Hernández Salgar 2016: 165). ${ }^{9}$

Tanto en la poesía y en la literatura como en las composiciones musicales se evidencia la figura campesina en su contenido textual. Este personaje aparece representado de diversas formas y se reconstruye discursivamente, con énfasis y enfoques distintos. En la industria musical, a la que hace referencia Hernández Salgar, la mención al campesino se ha difundido en ritmos propios de las zonas centrales que se ubican geográficamente en los altiplanos Cundi-Boyacenses o en la región de Antioquía. Esto se ha dado así, entre otras cosas, porque el atuendo de la ruana ha sido y sigue siendo un elemento de identidad campesina nacional. Sin embargo, siendo la ruana una prenda exclusiva de las tierras de la altiplanicie, pareciera que gran parte de la población campesina que habita en las zonas costeras quedara por fuera del marco simbólico de la representación de los pobladores rurales. ${ }^{10}$

Como indica Óscar Hernández Salgar en el fragmento arriba citado, la violencia como fenómeno que lacera al campesino parece ser una temática vetada por los circuitos de difusión musical. Lo que se puede constatar es que gran parte de la producción de esta industria se aferró por largo tiempo a propagar una visión un tanto romántica tanto del campesino como del espacio rural propiamente dicho, a excepción de Jorge Velosa y su grupo, quienes en sus composiciones de música carranguera le cantan al origen campesino y resaltan los valores de los pobladores rurales y, sobre todo, tematizan en sus letras las migraciones forzadas y las disparidades entre el ambiente rural y el urbano.

La industria musical colombiana ofrece una visión muy parcial que no retrata auténticamente la idiosincrasia de los habitantes rurales. Lo más probable es que la población campesina, que en su gran mayoría ha sido amenazada y se ha enfrentado a las diferentes oleadas de violencia,

9. Las cursivas son mías.

10. Existe una reflexión de la música carranguera sobre el discurso ecológico (Cárdenas y Montes 2009). 
no se identifique con esa visión romántica poco transcendente y que nada tiene que ver con las realidades rurales. No hay que perder de vista que la mayoría de los compositores de estas canciones emblemáticas sobre el campo y el campesino no conocían las realidades de las que escribían, irónicamente, muchos conocían mejor a autoridades políticas o eran sencillamente fieles a los pedidos de la industria en auge. Aquí se confirma una vez más la afirmación de Adorno y Bielsa (2002) respecto a que la poesía gauchesca no fue hecha por los gauchos. Esas formas de representación idealizada de nuestros habitantes rurales se alejan de las realidades de las poblaciones de carne y hueso, como lo describe Galeano en el siguiente fragmento:

El gaucho de las estampas folklóricas, tema de cuadros y poemas, tiene poco que ver con el peón que trabaja, en la realidad, las tierras anchas y ajenas. Las alpargatas bigotudas ocupan el lugar de las botas de cuero; un cinturón común, o a veces una simple piola, sustituye los anchos cinturones con adornos de oro y plata (2015: 157).

Durante los años posteriores al inicio de la violencia en Colombia, es decir, después de la década de los cincuenta, las zonas rurales prefirieron adoptar otro tipo de melodías, diferentes al bambuco y al pasillo, con el propósito de expresar sus experiencias y lo que ellas significaron en su entorno de penurias. La música guasca, o de carrilera, como se conoce en Colombia, fue la que más tomó los espacios locales en las ruralidades. Así, y de acuerdo con Hernán Restrepo Duque, los campesinos se sentían más cercanos a las melodías que llegaban del extranjero, que eran las que se escuchaban en tiendas del pueblo. Se "prefirió la tristeza ecuatoriana, la añoranza cubana, todo eso que nos llegaba enlatado del norte o del sur y que solemos denominar como música guasca" (Restrepo Duque, citado por Hernández Salgar 2016: 166).

Como podemos ver, las composiciones de la industria musical seleccionan las temáticas que puedan tener mejor acogida en la audiencia y, además, se eligen aquellas que cumplan con los propósitos claros de productividad o estén relacionados con ellos. El gran trabajo que han realizado estos autores mencionados y muchos otros que aparecerán en este estudio se constituyen en valiosos aportes que permiten, por un lado, escudriñar la radiografía de la historia musical y su difusión en 
Colombia y, por el otro, indagar composiciones inéditas para cuestionar el por qué las músicas que retratan e ilustran las realidades rurales no han tenido difusión.

DESPLAZAMIENTO Y RETORNO: CONTEXTOS NARRATIVOS Y MUSICALES

En el repertorio seleccionado para este estudio existen dos temas vertebrales en las letras de los cantos que reconstruyen momentos importantes y trascendentales para las comunidades: las experiencias de desplazamiento forzado y las experiencias de retorno a los territorios.

Respecto a las causas contextuales del desplazamiento se puede establecer una relación diferente sobre los motivos que producen el desplazamiento en Colombia, como se mencionó en el capítulo I. En el campo de la producción musical, las composiciones comunitarias reconstruyen el significado de lugar y de hogar tras haber sufrido el desarraigo violento de sus territorios. A este respecto, John Paul Lederach (Lederach y Lederach) considera que

La idea que la canción crea un sentido de significación de lo local y del lugar no es del todo nueva, aunque no ha sido probablemente explorada en términos de lo que tiene lugar a través de la fenomenología de la sanación (2010: 31). ${ }^{11}$

Mientras en la literatura y la narrativa colombiana uno de los motivos principales de la producción ha sido la temática alrededor de diferentes formas y efectos de la violencia, el tema del desplazamiento forzado ha quedado consignado solo por unos pocos autores. Respecto a la violencia como fenómeno gestor de una tradición literaria, Augusto Escobar (1996) señala que existe un tipo de literatura sobre la violencia en sí, mientras que existe otra clase de literatura que más bien propone una reflexión sobre de la violencia. Desde esa perspectiva, las narrativas que desarrollan la temática del desplazamiento forzado

11. La traducción es mía. La versión en inglés es la siguiente: “The idea that song creates a sense of meaningful location and place is not entirely new, though is perhaps not fully explored in terms of what takes place through the phenomenology of healing". 
tendrían la intención de propiciar un discurso narrativo de reflexión. $\mathrm{Al}$ respecto, Escobar indica lo siguiente:

Una y otra novelística muestra, por medios literarios o paraliterarios, el testimonio vivo, la cosmovisión de una comunidad desgarrada y la historia de sus protagonistas. Cuando decimos que es una literatura de la violencia y otra que hace una reflexión literaria sobre ella, lo hacemos para distinguir su doble carácter. ${ }^{12}$

Algunos autores, como Alfredo Molano en Crónicas del desarraigo. Desterrados (2005); Laura Restrepo en La multitud errante (2001); Gustavo Álvarez Gardeazábal en Las mujeres de la muerte (2003), y muchos otros, han construido en sus universos narrativos versiones sobre personajes que han experimentado las vicisitudes del destierro. A partir del relato testimonial, se retoma el tópico del desplazamiento forzado para crear universos ficcionales en los que se narra la complejidad de este fenómeno.

Es preciso preguntarse si esa apariencia binaria entre las novelísticas de la violencia puede ser análoga a las composiciones musicales. Tal vez no sea pertinente establecer una comparación en los mismos términos, incluso me atrevería a afirmar que la composición musical que nace de las comunidades enfrentadas a contextos de violencia armada tiende a ser un resultado del proceso de reflexión sobre la violencia más que una retórica de la violencia. Esa reflexión es ofrecida en una forma lírico-musical que conjuga las funciones pensantes y sensitivas de quien las compone, por ello sugiero considerar esas composiciones como lírica testimonial; es decir, como un discurso que se reconstruye a través de la fuente poética para deliberar sobre la agresión causada, así como también sobre lo que han causado las agresiones. Esta lírica hace cómplice a diversos ritmos musicales para crear en su estética una función representativa de la racionalidad rural y se contrapone a la estética creada por las ideologías, ya sean de tipo político, religioso o de otra índole.

Gran parte de la música que se ha venido difundiendo actualmente, a través de conocidos artistas colombianos, escenifica en sus relatos

12. Se puede consultar de forma virtual en: <http://www.javeriana.edu.co/narrativa_colombiana/contenido/bibliograf/violencia.htm>. 
episodios de contención en los cuales se describe la manera en que el caos social mantiene atrapada a la población civil en un callejón sin salida. En algunos textos musicales de artistas famosos — como Juanes y Totó la Momposina- la retórica lírica se compone de ruegos, peticiones por un alto a la violencia y al derramamiento de sangre. Estas composiciones son creaciones individuales sobre el malestar que ocasionan las circunstancias de conflicto a nivel nacional y, si bien se convierten en formas de expresión de la inquietud colectiva por la paz y la no violencia, aún no aportan una reflexión de fondo a la brecha existente sobre el quehacer comunitario por la paz y el uso del material musical local. Lo que quiere decir que, si nos atenemos exclusivamente a ese tipo de composiciones, esto presentaría grandes limitaciones a realizar el análisis sobre la problemática de la población rural. Exceptuando las composiciones de la banda colombiana ChocQuibTown, que tiene en sus letras temas sobre la identidad étnica y regional del Pacífico chocoano, la mayoría de producciones de la industria musical que tematizan el conflicto proporcionan poca o muy escasa información para los propósitos de este estudio. La mayoría de las letras con amplia difusión se alejan de las semánticas que emergen de las estrategias de sobrevivencia y conflicto y la construcción de paz en los escenarios rurales/locales. Por ello es fundamental recurrir al repertorio que surge desde las comunidades que están avocadas a la lucha cotidiana y nos revelan esos significados.

\section{Los cantautores}

Respecto al uso de la terminología, es pertinente advertir que me refiero no al cantante, sino al cantautor, concepto que el Diccionario de la Real Academia de la Lengua define como: "Cantante, por lo común solista, que suele ser autor de sus propias composiciones, en las que prevalece sobre la música un mensaje de intención crítica o poética” (Real Academia Española 2001, s. v.). También utilizo el término canto y no canción, pues la definición que proporciona esa misma fuente denomina el canto como "composición de música vocal" y "composición poética especialmente de tono elevado y solemne" (Real Academia Española 2001, s.v.). 
En las entrevistas realizadas a los miembros de las comunidades fue posible constatar que cada una de las composiciones reconstruye una experiencia traumática de la expulsión y el desplazamiento forzado. De la misma manera, cada uno de los compositores exterioriza en el preámbulo de la composición la necesidad imperante de plasmar a través del canto el impacto causado por la experiencia vivida. La lírica, sin embargo, no expresa solamente la captación de hechos aislados, sino que configura un entramado narrativo en el cual es posible detectar las formas de interacción de la comunidad antes, durante y después de las experiencias del desarraigo.

\section{Estructuración del programa lírico: tipología}

Una de las particularidades más sorprendentes al hacer el análisis de la lírica de los cantos recolectados en esas poblaciones, para mí, ha sido descubrir que la creación que emerge en contextos de conflicto no conduce necesariamente a relatos que describan en sus letras la confrontación; es decir, el relato no solo está constituido por las circunstancias violentas, sino que contiene abundantes elementos que hacen referencia a prácticas que ilustran el panorama diacrónico comunitario. En sus repertorios, la díada tiempo-espacio juega un papel central y acompańa todo el programa lírico de la dialéctica tópica: desplazamiento y retorno. La razón de este hecho no tiene que ver solo con el mutismo que crea la guerra o el miedo que puedan generar el agresor o la agresión, pues, a mi parecer, está también relacionado con una necesidad intensa de simbolizar la pertenencia al lugar y de representar el desarraigo como una pérdida enorme, casi inconmensurable, del hábitat propio, del hogar territorial. Asimismo, esa diada ilustra en gran medida la percepción de la sociabilidad que se recrea en la música: las relaciones sociales que se gestan con el entorno natural y el entorno social del colectivo y que además están mediadas a través del lenguaje no verbal y las prácticas sonoras, entre otras.

En la reconstrucción lírica están depositados discursos que constituyen bases fundamentales de la filiación local y que representan en el canto la función vital que cumplen en la recomposición del tejido 
comunitario. El discurso lírico-musical articula los diversos mecanismos que en el arte se conjugan para mostrar un intento de recuperación de lo social y lo culturalmente construido. Ese proceso se nutre de figuras y agentes concretos, como el campesino, las plantas, el terruño y la asociación, entre otros, que forman parte del universo comunitario y están presentes en el repertorio melódico. La asociación campesina es una figura sumamente importante y significativa en el discurso lírico, ya que, en las composiciones, se constituye en motivo central a partir del cual se hilvana el relato cantado, aparece como agente social con carácter de institución. En el canto, la asociación ostenta un valor imprescindible para la consolidación y afianzamiento de la cohesión y acción comunitarias.

Obsérvese que la reconstrucción del relato en el marco de la lírica es presentada de manera diferenciada. Por una parte, existen cantos en los cuales se muestra un retrato casi radiográfico de sucesos con fuerte carga agresiva en los que se narra el ataque a una población o a una comunidad específica, mientras que, por otra parte, existen otras composiciones que no se refieren a eventos determinados, sino que construyen el núcleo narrativo a partir del objeto de contiendas; es decir, deliberan sobre temas como la tierra y el territorio o subtemas relacionados con esos conceptos. En otros cantos, el motivo principal se consagra a la comunidad y a sus miembros. Estas dos entidades se convierten en el texto lírico en cuerpo indisoluble atemporal, pero con espacio definido. A continuación, se presentan en mayor detalle sus características y al final de la caracterización tipológica se puede encontrar un listado con todos los cantos del corpus y su correspondencia con la clasificación propuesta.

\section{Caracterización Tipológica}

Focalización de la contienda como eje central

Los cantos que plasman la confrontación como eje central en su lírica lo hacen en su gran mayoría partiendo de un hecho concreto sucedido en la comunidad, apelan de manera recurrente a una incursión o una 
arremetida inesperada que ha sido ejecutada por un actor armado. El carácter testimonial del relato se puede distinguir aquí con mayor insistencia, pues el portavoz de la historia proporciona en el canto datos sobre fechas y lugares existentes que son revelados sin alteración en el texto lírico. Por otra parte, las acciones que tienen que ver con la declaración de percepción sensitiva del acto de agresión siempre están descritas: me refiero a actos concretos como ver, escuchar o sentir, que conforman una amplia gama del mundo sensorial que transmite la experiencia de testigo y testimonio en el canto.

En este tipo de relato sobre la disputa, aparecen otras figuras que se podrían sugerir como la antítesis del campesinado. En este sentido, no quiero referirme a una posición maniquea entre campesinado y otros actores, sino a una forma de jerarquización en los personajes representados en el canto, como los paramilitares, el Ejército, el Estado y la industria palmera. Estas figuras actorales son quienes, al imponer su poderío y fuerza en el campo de disputa, producen un efecto de negación del campesinado, denigrando los atributos constitutivos de su naturaleza. Además, esas otras figuras tienen características explícitamente opuestas a las que posee el cuerpo del campesinado. Podríamos afirmar que, en este tipo de composiciones, el énfasis está puesto en los actores en disputa y sus acciones. Sin embargo, no se trata de narraciones que ilustran los mecanismos de interacción, sino de acciones que se concentran en la acción/reacción. Su contenido está mayormente dominado por las circunstancias del combate.

\section{Focalización del objeto de contienda}

Aquellos cantos que focalizan el tópico narrativo en la tierra y otros recursos naturales se alejan de la confrontación central como tema en su relato. La mayoría de estas composiciones expresan aspectos sobre la cosmovisión campesina, ya que en ellas está contenida una construcción tanto racional como emotiva que vincula de manera estrecha el aspecto religioso. En este tipo de relato, el eje central está en los efectos de la conflictividad, pero se refiere con vehemencia a los significados 
de valoración sobre la tierra y se ponen de relieve las discrepancias sobre otras formas de estimación de los recursos naturales.

Dos personajes centrales que sobresalen en este tipo de composiciones son la figura del campesino y la del creador. El relato lírico en esos cantos retoma el territorio como epicentro sistémico del discurso, conectándolo con tres entidades: el campesino, la tierra y el creador. De esta manera se escenifica un panorama supranatural en las historias cantadas, en el que actores no humanos entran a formar parte de los procesos de acción-reacción y se manifiestan ante las disputas. Esa interacción se ve materializada concretamente en las transformaciones que se revelan en el elemento tierra. Una de las peculiaridades de estas composiciones es que muestran una tendencia a enclaustrar las nociones de espacio y de tiempo dentro del concepto mítico-arquetípico; es decir, el relato desvela consideraciones sobre las construcciones temporales y espaciales que apelan al lugar fundacional y originario de las comunidades. Asimismo, ese relato se inserta en la cosmovisión de estas colectividades campesinas, pero no se presenta como un atributo exclusivo para ellas, por el contrario, las composiciones exhiben una conciencia colectiva que va más allá de la identidad regional y que tiende más hacia la construcción de la subjetividad comunitaria y campesina, por ello se hace mención a los trabajos, las creencias y las prácticas de los espacios rurales en Colombia.

Esa dimensión temporal-espacial, antes mencionada, sitúa la circunstancia de la confrontación en un marco más amplio e integra el aspecto histórico como parte vertebral para acceder a la comprensión sobre las disputas. Este aspecto es indispensable para dilucidar dos cuestiones fundamentales:

1) la forma en la que las comunidades representan y tematizan las generaciones de luchas y despojos de la tierra;

2) la manera en la que reconstruyen en la lírica los sistemas y mecanismos dentro de los cuales tales luchas han tenido lugar.

Adicionalmente, estas dos cuestiones coaportan respuestas ante la inquietud de constituir un nuevo estatuto campesino ante el contexto de la expulsión. 


\section{Focalización del agente colectivo: asociación campesina}

Una tercera forma de estructurar el relato de los cantos es la construcción de textos en cuya lírica prevalece una apología dirigida, en mayor medida, a la fundación y existencia de la asociación campesina y, en menor grado, al material lírico. En esta forma de relato son casi inexistentes las escenas de confrontación entre actores armados $\mathrm{u}$ otro tipo de agentes. Se hace mención a las diferentes formas de identificación campesina y se exaltan, sobre todo, los logros comunitarios que han tenido lugar. La dimensión temporal tiene un matiz fundacional, pero el énfasis está puesto explícitamente en la condición futura, es decir, en el retorno y en la reconstrucción comunitaria tras el desplazamiento. Esa visión utópico-realista que se manifiesta en el texto expresa la magnitud del significado colectivo que adquirió la gestión asociativa, sin embargo, también se hace un llamado permanente a convocar la unión como fortaleza del tiempo presente. Además, la unidad grupal se instituye como talante dinamizador que refuerza el sentido de la existencia rural y soporta la resistencia campesina.

Se puede afirmar que en este tipo de composiciones se confecciona una oda a la constitución campesina, presentándola como agente promotor y actor de ejecución que amortigua los embates ante la violencia. En este tipo de composiciones es posible escudrińar de manera más amplia el rol, la posición, las acciones y la representación de las asociaciones campesinas en el marco del conflicto, es decir, aquí el énfasis está puesto en los rasgos colectivos. Los cantos que pertenecen a esta forma de relato se convierten, algunas veces, en himnos asumidos por los integrantes de las comunidades y expresan el carácter constitutivo de su agrupación con plena convicción de la victoria.

\section{SimilitudES Y DIFERENCIAS EN LA TIPOLOGÍA}

Es importante señalar que, si bien cada una de las composiciones muestra más rasgos afines a una de las tres tipologías, en cada uno de los cantos se pueden encontrar matices de los otros dos. 
Para los efectos de este análisis es útil realizar una diferenciación en la estructuración del programa lírico que puede servir como marco inicial para identificar acciones comunitarias sobre el manejo del conflicto y las acciones de construcción de la paz. Las manifestaciones sobre estas acciones son perceptibles en la construcción lírica y muestran una dimensión de la acción comunitaria en la gobernanza política por el territorio. Las lecturas que se hacen del texto lírico aportan claramente a la indagación sobre la reconceptualización que surge de la ontología campesina sobre su entorno y el manejo de los recursos naturales, así como también sobre la identidad campesina.

Especialmente a través de la segunda tipología es posible deslindar una gama de significados asociados al objeto de disputa, la tierra y otros recursos naturales, y hacer una lectura sobre las diferentes perspectivas de valoración por parte de otros actores con respecto al mismo. A través de las interpretaciones que se extraigan de la tercera tipología es factible proponer planteamientos sobre cómo la composición lírica se convierte en un instrumento que refuerza procesos de agrupación social, su rol como catalizador del conflicto, su importancia en relación a las acciones colectivas y su dimensión política.

Es importante también observar el rol del canto en el proceso de consolidación comunitaria: las asociaciones campesinas se convierten en piedra angular, con influencia contundente en la transformación del conflicto. Además, los efectos que tiene la creación lírica en el seno de la asociación campesina pueden poner de relieve la incidencia en las tendencias globales y las respuestas locales. Por un lado, se revelan dinámicas transareales ${ }^{13}$ — más allá de las fronteras nacionales- que confluyen en las demandas globales relacionadas con la producción de palma de aceite y los desbalances locales que genera la estrategia de los monocultivos. Por otra parte, se pueden distinguir las diferentes formas de respuesta y recepción locales ante los imperantes globalizantes del mercado, los cuales en este caso afectan gravemente los entornos agrícolas locales.

13. Este término lo proporciona Ottmar Ette (2016) y se refiere a los flujos entre espacios que se constituyen en áreas, cuya formación va mucho más allá de lo geopolíticamente delimitado. 
Acercarse a examinar las formas de estructurar los relatos puede contribuir a determinar los niveles de descripción que aparecen en ellos, pero, sobre todo, permite identificar unidades de sentido claves para comprender el relato y el correlato que subyace en los cantos. De gran utilidad son los postulados de Roland Barthes (1977) en esta materia. Aunque propone una distinción de tres niveles de descripción para la obra narrativa, podemos identificarlos en los textos líricos también: nivel de la función, nivel de la acción y nivel de la narración. Esa categorización nos permite identificar las unidades de sentido que aparecen en los textos y sirve como instrumento para establecer su funcionalidad y su relación con el resto del relato.

El nivel de la función atiende a la interpretación de por qué se hace uso del género lírico como el canto para comunicar. Sobre la elección de las formas líricas entraré en detalle posteriormente, porque hay todo un sustrato histórico-cultural propio de esas dos regiones que es pertinente abordar de forma rigurosa.

El segundo nivel, el de la acción, describirá el análisis de una instancia, meta que examina no solo las acciones que se relatan en el discurso lírico, sino las que convoca esa lírica musical como instrumento comunitario en los procesos de consolidación como agente social rural. En este sentido se resemantiza y se reconstruye el significado de comunidad.

El tercero, el de la narración, tratará la construcción en sí y la estructura narratológica en el texto lírico, es decir, la forma en que se articulan las unidades allí presentadas y cómo entre ellas se crean vínculos integrativos o signos de fragmentación que impregnan a la lírica de ese rasgo testimonial que antes se ha mencionado. 


\begin{tabular}{|c|c|c|}
\hline Contienda como eje central & $\begin{array}{l}\text { Objetos y sujetos de contienda como } \\
\text { eje central }\end{array}$ & $\begin{array}{l}\text { Agente colectivo y entidad religiosa } \\
\text { como eje central }\end{array}$ \\
\hline Canto 1: Sin título & Canto 4: "La palma" & $\begin{array}{l}\text { Canto 17: "Homenaje a nuestros } \\
\text { mártires" }\end{array}$ \\
\hline Canto 2: "El 2 de junio" & Canto 5: "Negros en palenque" & Canto 19: "Algún día es mańana" \\
\hline Canto 3: "Ciento veinte muertos" & Canto 6: Sin título & Canto 20: "Bonarences de ASOCAB" \\
\hline Canto 10: "Violencia brava" & Canto 7: "Óyeme Chocó" & Canto 22: “Llegó la hora” (retorno) \\
\hline \multirow[t]{15}{*}{ Canto 11: "Cómo fue" } & Canto 8: "El sofoco" & Canto 23: "Los dioses de la tierra" \\
\hline & Canto 9: "El sufrimiento" & Canto 26: "Pueblito bello" \\
\hline & Canto 12: "El gobierno de la gente" & Canto 27: "Lamento por mi pueblo" \\
\hline & Canto 13: "El señalamiento" & Canto 28: "Sentimiento de mi pueblo" \\
\hline & Canto 14: "Llanto" & Canto 31: "De aquí no nos vamos a ir" \\
\hline & Canto 15: Vaguay (origen, tierra, etnia) & Canto 32: "Campesino de verdad" \\
\hline & Canto 16: "Tierra querida” & Canto 33: "Los veinte años de lucha" \\
\hline & $\begin{array}{l}\text { Canto 18: Sin título (tierra, origen, } \\
\text { naturaleza, etnia) }\end{array}$ & Canto 34: Sin título \\
\hline & Canto 21: "Historia de vida" & Canto 37: "Creación universal" \\
\hline & $\begin{array}{l}\text { Canto 24: "Martín Valiente y su mata } \\
\text { de cańa" }\end{array}$ & \\
\hline & Canto 25: "Palo de letras" & \\
\hline & Canto 29: "El mico desplazado" & \\
\hline & Canto 30: "La voz de la montańa" & \\
\hline & Canto 35: "Los comentarios" & \\
\hline & Canto 36: "Don Carmelo" & \\
\hline
\end{tabular}

\section{Tipología del relato lírico en los cantos}

Cerca del $51 \%$ de los cantos dedican su relato lírico a los objetos y sujetos involucrados en la contienda

Cerca del 35\% de los cantos dedican su relato lírico al agente colectivo o a la figura religiosa

Cerca del 14\% de los cantos dedican su relato lírico a narrar la contienda 


\section{Ritmos musicales de los cantos}

Reiterando la afirmación que se ha formulado al comienzo de este apartado, la riqueza de los litorales colombianos abunda, entre otras, en variedad de ritmos y melodías musicales. En mi última visita de campo a las comunidades, en agosto de 2013, pude encontrar que la creación lírica que tematiza la expulsión de la población es amplia y está aún por explorar.

Existen ritmos como el bullarengue, en sus diferentes variantes en la zona Caribe: el fandango, la chalupa y el bullarengue sentado, que incorporan en sus letras experiencias individuales del desarraigo. Asimismo, en el litoral Pacífico la producción de ritmos emblemáticos como la chirimía, el sexteto y el conjunto de voces, entre otros, no solo siguen consignando en sus letras un repertorio simbólico cultural ancestral, sino que integran la experiencia del desplazamiento como motivo del relato lírico. Para la presente reflexión no solo es de vital importancia la composición que tematiza el despojo del territorio, sino también aquellas letras musicales en las que se tratan los procesos de retorno. La riqueza musical y rítmica del Pacífico colombiano ha empezado a ganar mayor difusión en el plano nacional, así como también en el internacional, con la banda ChocQuibTown, que incorpora en sus sonidos funk, hip hop y reggae jamaiquino y los mezcla con sonidos autóctonos del Pacífico como el bunde o el currulao, entre otros, en cuyas letras se reivindica el carácter étnico y el nexo territorial en el marco de la gobernanza.

Respecto de los ritmos musicales en los que componen las comunidades de enfoque para este estudio, hay dos que son predominantes: el vallenato y el rap. La mayoría de cantos están compuestos en ritmo de vallenato, incluso en las comunidades que habitan en el litoral Pacífico. El ritmo preferido de la composición guarda relación con la diferencia generacional: mientras los más jóvenes escogen el rap, otros grupos generacionales optan por componer en vallenato o ritmos autóctonos. Ante este panorama musical, surge la inquietud sobre si la preferencia del vallenato corresponde a los ejes musicales que caracterizan la región o si más bien tiene que ver con su predominancia como el ritmo actual emblemático en Colombia. Tal vez no es preciso decantarse por una $\mathrm{u}$ 
otra opción exclusivamente, quizá sea más certero escudriñar si existe un vínculo entre estas dos aproximaciones.

\section{EL RITMO VALLENATO, HISTORIA Y REPRESENTACIÓN}

El vallenato es un ritmo típico nacido en la región Caribe de Colombia, en la cual el mestizaje se hace realidad en la música, pues se combinan instrumentos como el acordeón, de origen europeo, la guacharaca, ${ }^{14}$ de origen indígena, y la caja, de origen africano. Al parecer, la incorporación del acordeón se da posteriormente, pues las primeras composiciones vallenatas fueron tocadas con guitarra y no con acordeón (Posada 2002). De acuerdo con José Antonio Figueroa (2009), la génesis del vallenato se remonta a las llamadas colitas, que eran fiestas de los empleados del servicio y tenían lugar después de las celebraciones de los dueños de la casa —oficiadas con música europea— al ritmo de vals. A las colitas solían adherirse los señores o patrones, quienes, ebrios, querían hacer uso de sus derechos sexuales sobre sus empleadas. La Fundación del Festival de la Leyenda Vallenata caracteriza las colitas de la siguiente manera:

En estos tiempos, la música, como el vestido y las costumbres, dividía verticalmente las clases sociales. De un lado la aristocracia criolla se divertía al son del piano, la guitarra y el acordeón que acompañaban los valses, cuadrillas y lanceros, mientras que el pueblo se divertía bailando al son del tambor y la flauta. Las Colitas eran una prolongación de las diversiones de los ricos en el ambiente de la gente del pueblo, mezclándose momentáneamente unos y otros. (Fundación Festival de la Leyenda Vallenata 2014)

Hay diferentes voces críticas que cuestionan tanto el origen geográfico del vallenato como el evento del festival. Una de ellas es Consuelo

14. Luis Carlos Ramírez señala en su artículo "Vallenato, ¿etiqueta para una moda?" que en las investigaciones de Egberto Bermúdez en su ensayo de 2004 ¿Qué es el Vallenato? Una aproximación musicológica se pueden encontrar suficientes argumentos que deniegan la trietnicidad instrumental del vallenato porque las guacharacas se encuentran en los contextos afrocolombianos y no en los ambientes indígenas. 
Posada, quien afirma que el Festival de la Leyenda Vallenata atiende a propósitos diferentes y da menos importancia a lo cultural: "Estos intereses han impuesto el predominio de lo mercantil sobre lo artístico y han conducido al Festival a una comercialización incontrolada" (2002: 75). Por otra parte, la existencia del acordeón como instrumento originario de la interpretación del ritmo vallenato es cuestionada también por algunos expertos como Jaques Gilard (1986, 1993). Este autor sostiene que nadie puede asegurar totalmente que el acordeón haya sido adoptado en Valledupar ni tampoco que de esa región se derive la influencia del nombre del ritmo. Según sus indagaciones, antes de la década de los treinta, los grandes acordeoneros realizaban las interpretaciones sin acompañamiento instrumental. En cuanto a las controversias respecto al nombre de este ritmo musical, algunos piensan que existe efectivamente una relación entre este y el origen geográfico, el Valle de Upar. Los que se oponen a esa consideración afirman que no se pueden marcar fronteras definidas a los nacimientos musicales y favorecen la idea de que es toda la región la que da lugar a la aparición de ese ritmo. Jacques Gilard considera, además, que la élite de Valledupar adoptó el ritmo vallenato como exclusivo de su zona, desconociendo que en toda la región del Caribe colombiano predomina la interpretación musical acompañada del acordeón.

Otras críticas que se le hacen al Festival de la Leyenda Vallenata van dirigidas a los criterios de selección para elegir las temáticas en el certamen. Al parecer, eso criterios están vinculados con lo que se considera el canon vallenato, en donde las variaciones instrumentales son vetadas. Algunos argumentos relacionados con esas apreciaciones sugieren que muchas de las composiciones son expresiones del descontento de las poblaciones caribeñas ante las estructuras de poder y su imposición en la cultura musical. Ariel Castillo, excelente conocedor y especialista en la temática, comparte la posición crítica frente al Festival de la Leyenda Vallenata y se refiere a su reglamento y a sus procedimientos poco transparentes para elegir a los reyes vallenatos, considerando que se asimilan más a un andamiaje de favoritismos y desafectos que refleja más los beneficios de quienes son jurado que la calidad de los elegidos. 
El VALLENATO Y LA ORALIDAD

Las letras de las canciones vallenatas se componen tanto de historias insólitas como de relatos cotidianos extraídos de las vivencias de los pueblos en la región del Caribe: "Hacer música es solamente una forma diferente de percibir la vida", afirmaba Monchi, compositor de Las Pavas, durante las conversaciones que mantuve con él en la hacienda de Las Pavas. Esta forma exclusiva de percepción sobre la creación musical también ha sido integrada al universo escrito y aparece ilustrada de forma brillante por Gabriel García Márquez en muchas de sus reconocidas obras literarias. A este respecto, Ariel Castillo (1986) afirma que algunos compositores de vallenato que se han hecho conocidos a nivel nacional aparecen en fragmentos de Cien años de soledad (1994) y El coronel no tiene quien le escriba (1986). Uno de esos personajes es el gran compositor Rafael Escalona.

Castillo (1986) señala que una de las similitudes entre la narrativa de García Márquez y la canción vallenata es la existencia de una relación de "afinidad genérica" entre ellas. Para él, "ambas formas relatan historias, constituyen acontecimientos, y poseen una estructuración narrativa" (52). La canción vallenata emerge de la tradición oral en la costa Atlántica de Colombia y, gracias a la representación de personajes importantes en el ámbito tanto literario como musical, ha logrado ganarse un lugar relevante en la herencia cultural colombiana. Dentro de las temáticas de la composición vallenata se encuentran numerosas leyendas sobre figuras de la mitología y la religiosidad popular, cuyas historias han sido conservadas a través de generaciones y retratan parte de las convicciones del pueblo caribeño.

Jacques Gilard (1993) reitera que en las letras vallenatas se halla la presencia de una sola matriz: "La poesía oral hispánica que se reconoce bajo variaciones siempre identificables (el papel de las condiciones locales) desde los Estados Unidos hasta la Patagonia” (32). En cuanto a la herencia hispánica, Consuelo Posada (2002) ha investigado 
exhaustivamente las relaciones entre los versos populares del romance y las canciones vallenatas, con un importante trabajo comparativo en el cual "se encontraron en las coplas colombianas y latinoamericanas nuevas relaciones con los versos populares del romance, heredado de la influencia española: vigencia de temas, moldes, formas, y aparecieron estrofas y versos sueltos integrados a la canción popular y en general a la canción vallenata en particular" (70). Sus hallazgos indican que, además de la organización estrófica que comparte con el romance español, en el vallenato hay similitudes también en otros aspectos como el "paralelismo, repetición de una misma palabra a comienzo de estrofa" (70). El vallenato se nutre de la tradición y la historia orales y se construye a partir de las vivencias colectivas, los imaginarios y las creencias de los habitantes de las comarcas. La similitud no es solo temática, sino también a nivel de su estructura textual, pues muchos de los cantos están compuestos en octosílabos y en ellos parecen mezclarse tanto la herencia colonial como la ancestral. Sin embargo, la apreciación que hace Gabriel García Márquez a este respecto es que en las interpretaciones de Rafael Escalona y otros compositores se puede observar una nueva trova vallenata que se aleja del esquema tradicional y se convierte en canto en construcciones isométricas y diseños asimétricos. ${ }^{15}$

En sus trabajos sobre la difusión del Romancero en ultramar, George List (1973) y Gisela Beutler (1985) señalaron la proliferación de romances religiosos en el litoral Pacífico de Colombia. Susana Friedmann (1989) retoma esos estudios y considera que existen también romances en los cantos festivos. De acuerdo con Antonio Sánchez Romeralo (1989), la tradición oral hace una selección temática en la cual los temas que logran conservarse son los tópicos vitales para la preservación de la memoria. Este género sigue la tradición de los antiguos romances españoles en los que se tematizaba también el destierro; en Colombia la temática del desarraigo es más que actual como temática de las composiciones. Este trabajo sobre la presencia del romancero en la literatura contemporánea en Colombia lo ha retomado Adrián F. Freja de la Hoz para mostrar que "existe un campo de la literatura oral

15. Algunas consideraciones de Gabriel García Márquez sobre la música vallenata las menciona González (2014). 
poco estudiado y conocido en los ámbitos académicos". Las composiciones en romance, si bien surgen de la época medieval o aun antes, siguen estando vigentes en diversas regiones del continente latinoamericano, como sucede en Colombia, y se verá en detalle en el análisis de los cantos.

\section{Tradición TRANSCULturaLIZADORA EN EL VALLENATO}

La construcción narrativa de la lírica vallenata recupera los acontecimientos pasados y se convierte en multiplicadora de historias locales que adquieren trascendencia en el ámbito tanto nacional como internacional. ${ }^{16}$ No es necesario un evento excéntrico para dar rienda suelta a la construcción de la oralidad popular, es justamente la historia cotidiana del caribeño, campesino, pescador o habitante de las pequeñas ciudades intermedias, la que aparece como protagonista en el universo lírico de las canciones. Gabriel García Márquez (1950), citado en Castillo (1986), llama a esa actitud lírica "estirpe juglaresca" y comenta al respecto:

Quien haya tratado de cerca a los juglares del Magdalena [...] podrá salirme fiador en la afirmación de que no hay una sola letra en los vallenatos que no corresponda a un episodio cierto de la vida real, a una experiencia del autor. Un juglar del río Cesar no canta porque sí ni cuando le viene en gana, sino cuando siente el apremio de hacerlo después de haber sido estimulado por un hecho real. Exactamente como el verdadero poeta (1986: 50).

El posicionamiento del vallenato como ritmo emblemático de lo nacional en Colombia se da con la dinámica continental de la década

16. Luis Carlos Ramírez Lascarro (2017) presenta una reflexión en la que sugiere que en la historia del vallenato existe una manifestación recurrente a la protesta. En su ensayo cita compositores muy conocidos como Rafael Escalona, con la canción "El hambre del Liceo", Gildardo Montoya, con "Plegaria Vallenata", y otros menos conocidos como Horacio Mora y Lucho Cobo. Según Ramírez, estos y otros compositores han sido relegados y dejados al margen de la industria musical por tratar temáticas que denuncian abiertamente los poderes — gobernantes y éliteslocales y regionales. 
de los años cuarenta, especialmente en el tópico literario, cuando las vanguardias que se habían gestado desde principios de siglo querían darle una nueva orientación a la producción literaria del continente.

La vanguardia cosmopolita se acercó a modelos más europeos, mientras que la otra, realista-crítica, apeló a lo llamado auténtico y tradicional. Esta última optó decididamente por las prácticas y los valores culturales que habían sido mantenidos durante siglos y que habían pasado de generación en generación por medio de la tradición oral.

Como se mencionó antes, Jacques Gilard, Consuelo Posada y otros autores consideran que el vallenato que se difunde a través de los medios masivos y de la industria musical no es la música originalmente popular. Se podría decir que sus críticas se refieren al estilo popularizante apropiado por las élites del Valle de Upar para crear otro que se acercara tanto a lo cortesano como a lo moderno. Sin embargo, no se puede negar que, pese a todos los usos que se le han querido dar a la música vallenata, sigue conservando su atributo inicial de ser poesía oral. Así, tal y como lo presenta Jacques Gilard, el elemento popularizante de las composiciones recreadas por las élites tomó mayor fuerza y se difundió con propósitos vinculados a lo económico y lo político, pero presentados como tradición e identidad cultural regional. Egberto Bermúdez asegura que para Gilard "la única continuidad que observaba en el vallenato para considerarlo una tradición era aquella de la permanencia en el poder de la clase política que siempre lo ha auspiciado" (Bermúdez 2009: 36). Para ejemplificar esa continuidad, el autor menciona algunas familias que controlan el poder económico y político en la región Caribe, como los Dangond, Celedón, Castro, De la Spriella y Villazón, que forman parte de las actuales figuras vallenatas. Además, y no por mera casualidad, algunas de esas familias hayan tenido alguna relación con actividades y negocios en la industria de la palma.

Si bien las composiciones musicales autóctonas de la costa Caribe de Colombia, el vallenato, los paseos, las pullas, los bullerengues y las cumbias, entre otros, conforman un abanico musical portador de la cultura caribeña colombiana, tienen un acervo predominantemente africano. Tanto la evolución como el entramado de las músicas caribeñas han recibido la influencia de los flujos migratorios de otras músicas del Caribe antillano y afroamericano. De acuerdo con Bermúdez, las 
composiciones en cinquillo y tresillo, ${ }^{17}$ que son variaciones típicas del vallenato, se pueden encontrar en muchos otros ritmos del Caribe insular. Peter Wade (2003) coincide con la apreciación de Bermúdez y señala que atribuir a la música caribeña en Colombia una pertenencia exclusivamente ligada al origen territorial sería desconocer las influencias musicales que ha recibido, no solo en el ámbito de intercambios migratorios, sino también en la formación y los conocimientos de músicas europeas que tuvieron destacadas figuras de la música caribeña, como lo fue el maestro Lucho Bermúdez.

$\mathrm{Si}$ se toma un corpus de las composiciones en ritmo vallenato paralelo a aquellas que participan en el Festival de la Leyenda Vallenata, se puede apreciar que en muchas de ellas se manifiesta el sentir del poblador marginal que se enfrenta a los desequilibrios del sistema a nivel económico, social y político. La estructura de esas temáticas varía entre textos narrativos, descriptivos y líricos. Jacques Gilard —según Bermúdez (2009) — no solo cuestiona, sino que también refuta que la narración sea la técnica más extendida en los textos vallenatos. Por otra parte, Ismael Medina Lima (2003) también se muestra escéptico ante esa aseveración y lo deja claro en el análisis que realiza sobre la obra musical de Rafael Escalona. Conocidos expertos en los análisis de la música vallenata como Ariel Castillo y Julio Escamilla coinciden en afirmar que existe una preponderancia lírica y descriptiva en las letras vallenatas. Ese carácter narrativo y un tono descriptivo es predominante en los cantos que se recolectaron en este estudio, pues la técnica narrativa permite elaborar un discurso que conecta temporalidades. Además, la creación vallenata de las comunidades logra rescatar la esencia de lo colectivo resaltando la vinculación multitemporal que vincula el carácter comunitario, la acción común ante el despojo de tierras y la proyección en un escenario futuro de retorno. En este sentido, las medialidades y sus mediaciones tienen un papel preponderante. Las expresiones musicales son portadoras de mensajes y simbologías, antes latentes pero no explícitas ni difundidas, como lo indica Jesús Martín-Barbero.

17. Cinquillo y tresillo son grupos de valoración especial dentro del lenguaje musical; el cinquillo se caracteriza por tener cinco notas musicales y el tresillo, tres. 
Hasta hace unos cincuenta años las composiciones vallenatas no tenían la importancia que han adquirido hoy en día en el plano nacional, y mucho menos en el escenario internacional. Su difusión y auge a nivel global se debe a varios factores y los procesos de difusión de lo que se considera popular. Por lo general, esos procesos han estado dominados por los intereses lucrativos de la industria discográfica y han sido sometidos a juicios de reconocimiento para tener la aprobación como ritmos dignos de ser escuchados. Óscar Hernández Salgar (2007) señala que la incorporación de algunos ritmos pasa por un proceso de blanqueamiento para poder ser aceptados dentro de los estándares deseados de la industria musical. Ritmos como el vallenato y otros, provenientes de las culturas litorales, han sido rechazados durante muchos ańos y mantenidos al margen de lo musicalmente consumible en el ámbito social y juzgados con desprecio en las representaciones de la identidad nacional.

Muchas de las melodías emergentes de los sectores socialmente marginados estaban supeditadas a una expresión que estuvo ligada a la cuestión racial, factor determinante de aceptación o rechazo en el sistema colonial. Hernández Salgar considera que las relaciones de poder se expresan precisamente a través de las formas de exclusión de la producción musical de las comunidades afrocolombianas o indígenas; esto hace parte del sistema de exclusión en el que están subordinados diversos grupos sociales. En sus palabras:

Tanto para los nacionalismos europeos como para la construcción de la música nacional colombiana a partir de géneros andinos en la segunda mitad del siglo XIx, es la raza y su ubicación en una escala de clasificación social, la que sigue determinando las relaciones de poder en el mundo eurocentrado (2007: 253)

\section{VALLENATO Y PODER EN LA INDUSTRIA MUSICAL}

Se ha señalado antes la gran controversia y los dominios del poder local en torno a las temáticas, los cantantes y el canon en los procesos de selección para el Festival de la Leyenda Vallenata. Óscar Hernández Salgar (2007) y Ana María Ochoa (2002) señalan que el poder se percibe no solo en eventos locales o regionales, sino sobre todo en el 
tratamiento de la difusión. En especial, existe un interés de grupos de la élite por incorporar ritmos de esencia popular, pero adaptándolo a las tendencias musicales de la industria global. Ochoa señala que el vallenato ha sido incorporado dentro de la gama de ritmos que tienden a difundirse a escala global y de la categoría world music a través de la figura de Carlos Vives, conocido cantante de vallenato. Desde la perspectiva de esta autora, sucede el fenómeno del cross-over, mediante el cual un artista de un origen racial diferente al de la música tiene gran influencia en clases medias y altas para la aceptación y difusión de melodías tradicionales que antes no fueron valoradas. A este fenómeno Peter Wade, Óscar Hernández Salgar y otros autores lo denominan blanqueamiento. Ana María Ochoa, por su parte, argumenta que se da un proceso de redefinición de la industria musical en los años ochenta e indica al respecto:

La música del mundo, lo es de la imaginación y tecnologías que caracterizan a la modernidad-mundo y a las nuevas relaciones entre procesos de globalización y regionalización. De hecho, una categoría como esta depende exclusivamente de los modos como las nuevas tecnologías han posibilitado el posicionamiento de las regiones a nivel global. (2002)

Aunque los dos autores citados anteriormente enfatizan aspectos diferentes en su argumentación, Hernández sobre la cuestión racial y Ochoa sobre el concepto de autenticidad, ambos coinciden en señalar que la industria musical transnacional ha tenido un papel protagónico en la difusión del vallenato e impone parámetros transformacionales que responden en primera instancia a rasgos determinados por el aparato industrial musical. Esto implica muchas veces dejar de lado la intención original de la creación oral vallenata: expresar las problemáticas de las realidades locales de las cuales emerge. Hernández también agrega al respecto que ese fenómeno se da en el marco de un discurso postcolonial que se diferencia de los preceptos de la modernidad porque intenta ser incluyente, pero en realidad solo lo es en apariencia, pues se enmascara una forma de participación, mientras que los procesos de selección siguen modelos estandarizados que buscan lo popular, como se ha señalado anteriormente. Si bien los procesos de hibridez cultural han procurado espacios de encuentro de la diversidad en las 
sociedades latinoamericanas, esos espacios siguen estado administrados por los mismos poderes y sus representantes: las élites.

\section{El rap: historia y difusión}

En este estudio, las composiciones en ritmo de rap y hip hop las realizan grupos de jóvenes de las zonas humanitarias de Cacarica y Las Camelias. Uno de ellos, cuya agrupación musical se llama Los Renacientes, ha logrado lanzar una producción de tres CD y ha visitado Europa con el apoyo de Amnistía Internacional. Esta agrupación forma parte de la organización Comunidades de Autodeterminación, Vida Dignidad del Cacarica (CAVIDA). Junto con otros músicos del Cacarica grabaron tres compilaciones, una en 1999, titulada Óyeme Chocó; otra en 2002, A nuestros mártires, y la tercera, Los Renacientes 97, en 2008.

El segundo grupo de jóvenes se ubica en la Zona Humanitaria Las Camelias y es un grupo naciente que compone rap como parte de su acción comunitaria. La difusión de sus cantos es uno de sus actuales proyectos, pero hasta ahora no han logrado llevarlo a cabo. Sin embargo, las canciones que interpretan son conocidas y cantadas por los miembros de la comunidad y son también difundidas en la página web de la Brigada de Paz. Existe un lazo de apoyo mutuo entre estas dos agrupaciones musicales porque están conformadas por jóvenes que han estado expuestos a circunstancias de desplazamiento forzado y que encuentran en la música un catalizador. Respecto al origen del rap, que es esencialmente la expresión rítmica que eligen los jóvenes para manifestarse, veremos que se trata de una zona de contacto en creación, porque allí se articula una simbología que emerge de dos categorías de representación social, por un lado, lo étnico y, por otra parte, lo campesino.

\section{Historia Y SURGIMIENTO}

El rap pertenece a lo que se conoce como cultura del hip hop. Su origen tuvo lugar en las comunidades afroamericanas y latinas que habitaban en los barrios del Bronx en Nueva York durante la década de los 
años sesenta. Una de sus manifestaciones fue el grafiti, que empezó a inundar las paredes de las ciudades, del metro y de gran parte del mobiliario neoyorquino. La cultura del grafiti estuvo acompańada por las figuras de los disc jockey (DJ) y maestro de ceremonias y también por los breakdancers.

La producción de la música rap estuvo muy influenciada por las particularidades culturales que caracterizaban a los pobladores de los guetos en la ciudad de Nueva York. En las formas de celebración que tenían lugar en ellos se fueron integrando prácticas tradicionales de sus países de origen. Este es el caso de la música $d u b$, técnica que se usaba en Jamaica con la cual se podía extender el sonido de la percusión para hacer el ritmo más bailable. En sus albores, la música hip hop se gesta en las fiestas callejeras y se va transformando en las décadas posteriores. A finales de los años ochenta se extiende a varios países de América Latina y alcanza niveles de difusión también en otros continentes.

Los ritmos iniciales que caracterizaban al hip hop fueron el funk y el soul, que se han transformado paulatinamente debido a las diversas mezclas de audio como el scratching y las interrupciones del breakdance. Asimismo, los motivos del texto lírico han cambiado, pues, al principio, las letras se caracterizaban por enfocarse en temas sexuales o escatológicos y luego adoptaron los retos de desafío y contrapunteo conocidos como the dozens, confrontaciones de creación improvisada entre cantantes en cuyos repertorios el insulto hacia la familia era el tema central, nutrido de la fortaleza emocional de los contrincantes para responder a los retos. El perdedor era quien primero se encolerizaba a causa del ultraje.

\section{ÁmBITO NACIONAL}

En Colombia, el hip hop y el rap han tenido una gran acogida, en especial, por parte del público joven. Incluso, desde hace algunos ańos, tiene lugar un evento anual llamado Hip Hop al Parque y, de acuerdo con las estimaciones de Arlene Tickner, "en Colombia el hip hop ha disfrutado relativamente de amplia cobertura de los medios a nivel nacional, pero ha fallado en atraer los mismos niveles de atención a nivel 
internacional y en ganar atención de los sellos discográficos" (2008: 133). ${ }^{18}$ De acuerdo con la misma autora, algunos grupos como La Etnia fueron pioneros en el proceso de internacionalización del hip hop colombiano y su éxito fue reconocido por las distribuidoras nacionales, logrando crear su propio sello discográfico.

Otra de las producciones conocidas es el mixtape titulado Esto es Colombia, que ya ha alcanzado su quinto volumen. Los productores son DJ Impereal y Demolition Men. DJ Impereal es un colombiano que reside en Estados Unidos y tiene una gran trayectoria y conocimiento del género y de la industria musical. Apoya y promueve la producción nacional de hip hop y agrupa en sus mixtapes voces de diferentes regiones. En el último volumen participan grupos de Medellín, Bogotá, Cúcuta, Manizales y Cali, entre otras ciudades. Uno de los grupos que ha alcanzado mayor difusión tanto nacional como internacionalmente en el hip hop es ChocQuibTown. Este grupo compone temas en ritmos hip hop y funk, pero sus composiciones también abarcan otros ritmos colombianos como el currulao, el bunde y la cumbia. Es un grupo originario de la región Pacífico y su nombre se compone de la abreviación de la capital, Quibdó, y el departamento, Chocó.

\section{Sensaciones alternativas en lo rítmico: visiones críticas}

Los productores de la world music consideran de gran importancia que las músicas que se difundan desde sus estudios lleven el sello de lo global, es decir, que su música sea de carácter supranacional, lo cual supone que distintos ritmos contengan y transmitan esencialmente el lenguaje de las emociones. Al parecer, la tendencia es convertir la experiencia musical en un ente portador de sensaciones, en un espacio aterritorial dislocado y con posibilidad de reubicación en cualquier lugar. De hecho, los desarrollos tecnológicos, aplicados también en la industria musical, han hecho posible este desplazamiento sonoro.

18. La traducción es mía. El texto original en inglés es el siguiente: "In Colombia hip hop has enjoyed relatively ample media coverage nationally but has failed to attract similar levels of international press and record label attention". 
Pero ¿qué sucede con las músicas que no han entrado en el sistema industrial? En términos de difusión, hay muchos ritmos que seguirán quedando reducidos a lo local y tal vez nunca den el salto de lo regional a lo transnacional, pero es justo allí donde se engendran nuevos puntos de anclaje y expresión que en algunos casos parecen seguir una dinámica diferente a las músicas del mundo. Por otra parte, un ritmo local como el vallenato — versión autóctona — crea a partir de su filiación con el contexto lugareño producciones en las se revelan realidades que afrontan las comunidades del Caribe. En el caso de los cantos compuestos por las poblaciones rurales se expresan los impactos de la industria de la palma y otras actividades de la extracción minera. Las temáticas corresponden, entonces, a una denuncia sobre las carencias estructurales, los abusos a los campesinos y la discriminación racial, entre otros.

Algunos temas logran difundirse, sirviéndose de las ventajas del universo medial, en especial, de las redes que ofrece el mundo virtual, pero sin pasar por la industria musical. Veremos más adelante cómo los aires vallenatos y otras músicas locales no solo representan la conflictividad, sino que recorren la memoria histórica agraria. La dinámica de esa difusión musical opera de forma contraria a como lo hacen las disqueras, pues nace desde lo local y no tiene el propósito de unificar, sino justamente de pluralizar la creación discursiva a través de la lírica y, a su vez, de singularizar las experiencias del lugar. Este hecho se puede, incluso, rastrear en los diversos canales de la red virtual, en donde también es posible ver cómo un mismo evento o fenómeno de tendencia global tiene diferentes formas de recepción y causa diferentes impactos en los espacios locales, así como ocurre con la producción musical que tematiza sobre la tierra y el territorio. Por otra parte, esas producciones se diferencian de la música popular en tanto que no tienen el propósito central de generar emociones exclusivamente. Si en la música popular parecen suscitarse formatos emotivos que estén relacionados con lo placentero, el hedonismo, las experiencias individuales intensivamente efímeras y las sensaciones polarizadas entre lo dramático y lo espectacular, en las composiciones locales, la sensación que produce la lírica musical se orienta a transmitir una impresión, una huella anclada en una temporalidad que supera lo espontáneo o lo fugaz. 
Es interesante, además, ver cómo en la música popular los temas que contienen diversos ritmos reflejan casi una banalización de la vida, se convierten en apologías de lo superficial. Así, un hecho insignificante es reconstruido melódica y textualmente con el propósito de dar la sensación de magnificencia, de modo tal que lo trivial impera en nuestro sentir - como se observa en muchas de las canciones populares en ritmos de reguetón, merengue e incluso en los vallenatos actuales, entre otras-, mientras que las composiciones musicales de las comunidades tematizan asuntos cruciales y contienen elementos trascendentes de la vida local, donde aparecen vínculos temporales y multidimensionales de la ruralidad. Sin embargo, esas composiciones no tienen, ni en lo melódico ni en lo textual, la ambición de presentar ese formato sensacionalista — que se percibe tanto en la música popular como en la prensa escrita-, en la dimensión temporal, lo que intentan transmitir es lo sustancial, lo profundo, y, a diferencia del formato industrial, lo que allí se evoca son tanto las experiencias como la acción comunitarias. Es por esta razón que las composiciones narran los significados, los sentires y la construcción de la vida colectiva. Si bien el relato de lo comunitario y de lo colectivo es de gran importancia para el eje temático de la construcción de la paz, también se singularizan las acciones de personajes importantes en la cotidianidad del colectivo. 



\section{Capítulo iv}

\section{Marco contextual Agrocombustibles, conflicto y tierra}

Antes de abordar los casos de estudio de las comunidades y sus diversos impactos a nivel socioambiental en Colombia, en este capítulo se presenta el contexto actual de los agrocombustibles y el negocio con la tierra en América Latina. Los temas de las composiciones en los cantos relatan las experiencias de diferentes comunidades que se han visto afectadas y han llegado a sufrir el desplazamiento forzado de sus territorios. La lírica testimonial que nace de esas comunidades es una expresión que nos acerca a las lecturas que hacen los campesinos sobre las tendencias globales y la forma como estas afectan su vida familiar y comunitaria. Estos cantos son narrativas que documentan cómo reciben algunas de las poblaciones rurales los impactos de las políticas globales, en nuestro caso, aquellas que se derivan de la agroindustria de la palma de aceite. En otros casos, se trata de denunciar las estrategias ilegales que se utilizan para implementar localmente las demandas de los países industrializados.

La producción de palma de aceite es una tendencia que se sigue imponiendo en los paisajes de diversos países del hemisferio sur y que, en algunos casos, como en Malasia e Indonesia, países con mayor producción a nivel mundial, ha alcanzado niveles alarmantes de extensión, 
con altas repercusiones socioambientales. En Indonesia los alarmantes niveles de deforestación han ido de la mano de la implementación de políticas gubernamentales que favorecen las concesiones para la agroindustria impidiendo el acceso a la tierra a las comunidades campesinas (Znoj et al. 2018); un cuarto del total de su bosque ha sido deforestado a causa de la industria de la palma. Eso corresponde a 31 millones de hectáreas $^{1}$ (un área cercana al tamaño de Alemania). Diversos grupos locales presentan a través del video ¿Proceso o retroceso? testimonios de desplazamientos forzados y agresiones contra comunidades indígenas. ${ }^{2}$

A continuación, se describen algunos lineamientos de la agroindustria que se identifican a nivel global. Se plantean algunas reflexiones sobre la situación de la tierra en América Latina, así como también las tendencias energéticas en el subcontinente. En la tercera parte, se presenta el contexto de los agrocombustibles, con énfasis en la producción de palma de aceite en Colombia.

\section{Aproximaciones a los agrocombustibles: diferentes perspectivas}

La dominante expansión del cultivo de palma de aceite, especialmente en las regiones tropicales del planeta, guarda estrecha relación con la industria de los agrocombustibles. Existe una gran controversia con respecto a los beneficios como también a los riesgos que se derivan de esta actividad. La literatura que tematiza ese debate es diversa y representa distintos paradigmas. Gran número de estudios, especializados en los elementos técnicos y tecnológicos para la obtención de agrocombustibles, centran sus argumentos en las ventajas del costo-beneficio que representa la agroindustria, como por ejemplo los de autores como Hazell y Pachauri (2006); Fischer y Schrattenholzer (2001);

1. Para más información al respecto, se puede consultar la página de Greenpeace: <http://www.greenpeace.org/international/Global/international/publications/forests/2015/Under-Fire-Eng.pdf>.

2. Disponible en <http://www.lifemosaic.net/esp/recursos/video/progreso-o-retroceso-1era-parte/>. 
Hall y Scrase (1998), y Speight (2011). Otras reflexiones se ocupan menos de la parte técnica y ponen mayor énfasis en las repercusiones de los agrocombustibles en el medio ambiente. Esos estudios evalúan las alteraciones producidas en los ecosistemas y las repercusiones a nivel medioambiental. Por otra parte, existe también un gran número de informes en los que se analizan las dimensiones sociales y políticas de la producción de agrocombustibles en distintos lugares, en particular en países del hemisferio sur. De especial interés son los estudios de Saturnino y Franco (2012) y de Cotula, Dyer y Vermeulen (2008). En los análisis tanto cuantitativos como cualitativos se revelan enfoques diferentes en los que domina el énfasis en el tema energético, algunos de ellos son los de Lal y Stewart, que en su volumen Soil Quality and Biofuel Production (2010) y a través de datos empíricos y modelos matemáticos se analiza la relación entre las cosechas de producción de granos y el comportamiento del agua y la tierra para producir la cantidad de biomasa esperada. Blum et al. (2010) examinan las posibles consecuencias de los agrocombustibles en relación a la intensidad de los cultivos y a los requerimientos climáticos y ecológicos. Estos autores hacen referencia a lo que llaman los "juegos de manejo", y su reflexión también indaga si la estructura del diseño para la producción de monocultivos puede perjudicar a algunas especies de animales, suelos o incluso a los mismos cazadores dentro del territorio europeo.

LOS AGROCOMBUSTIBLES EN EL ESCENARIO GLOBAL

La seguridad en términos energéticos ha ido adquiriendo mayor importancia en las agendas políticas nacionales y a nivel global. La escasez de combustibles obtenidos de materiales fósiles — estrechamente relacionada con los patrones de consumo de sociedades industrialesempezó a hacerse evidente en las últimas décadas del siglo pasado y en la primera década del presente siglo. La finitud de los combustibles fósiles, la rápida demanda del crudo, precipitada — entre otras razonespor la emergencia de países como China e India, la volatilidad de los precios del petróleo y los patrones de consumo de las sociedades con altos niveles industriales y tecnológicos conforman un escenario en el 
que pareciera ser urgente la diversificación de las fuentes energéticas. La obtención de energía a través de la utilización de material extraído del agro es una de las alternativas que se exploran con mayor interés a nivel global. Los argumentos que se tejen a su favor se relacionan tanto con el consumo energético a nivel mundial como con los supuestos efectos de la reducción del efecto invernadero. Los actores globales que promueven y lideran la industria del combustible extraído del agro justifican la necesidad de continuar incrementando los niveles de producción. Sus argumentos sugieren que las circunstancias de esa demanda son de orden global, y entre ellos se encuentran los siguientes:

— las fuentes de petróleo en la superficie terrestre están alcanzando el punto máximo de su capacidad de extracción; ${ }^{3}$

- la reducción de gas de dióxido de carbono, producido especialmente por los combustibles fósiles, debe ser menguada a través de otras formas de extracción;

— el crecimiento del sector del transporte a nivel global es altamente dependiente del combustible fósil;

- el transporte de larga distancia tanto de bienes como de personas implica un gran gasto de energía y está estrechamente vinculado con el mercado de importaciones y exportaciones.

Hazell y Pachauri señalan que, según las metas propuestas por la Unión Europea en materia energética, para el año 2020 los países miembros deberían ser capaces de abastecer el 10\% de su consumo de combustible para transporte con materias provenientes de energías renovables (2006: 3). ${ }^{4}$ De acuerdo con el informe de la Comisión Económica

3. Las recientes exploraciones sobre hallazgos de petróleo en el Ártico no parecen representar una opción. Por un lado, se estiman los efectos medioambientales que ello pueda tener y, por otro, la existencia del Tratado Antártico, refrendado en el Protocolo de Madrid, prohíbe hasta 2041 la explotación de sus recursos naturales, excepto que se trate de fines científicos.

4. De acuerdo con Hebebrand y Laney (2007), el consumo energético de Estados Unidos y la Unión Europea excede en mucho sus recursos energéticos autóctonos. Estados Unidos necesitó cuatro mil ochocientos millones de barriles de petróleo en el 2004 para el sector de trasportes y se estima que en 2030 será superior a los seis mil ochocientos millones de barriles. En la Unión Europea se usaron dos mil cuatrocientos millones de barriles de petróleo en el 2005 y se cree que en el año 2020 serán dos mil novecientos millones. 
para América Latina y el Caribe (CEPAL) del año 2013, el impulso de los agrocombustibles continuó en ascenso: "En el año 2010, la producción mundial de agrocombustibles alcanzó un récord de ciento cinco mil millones de litros, incrementándose en un $17 \%$ respecto al 2009 " (2013: 44). La caña de azúcar y las oleaginosas tendrán gran demanda porque el consumo en China aumenta a gran velocidad. Según las perspectivas del mercado mundial de los agrocombustibles, "hacia el 2023 se espera que el $12 \%$ de la producción mundial de cereales secundarios, así como el 28\% de la producción mundial de caña de azúcar y el 14\% del aceite vegetal sean utilizados para la producción de agrocombustible" ${ }^{5}$

\section{La PaLma de aCeite}

La palma de aceite pertenece al grupo de las oleaginosas que crecen en zonas de hasta $500 \mathrm{~m}$ de altitud; es conocida también como palma africana por ser originaria de ese continente (golfo de Guinea, en el África centro-occidental). La mayor producción de la palma de aceite a nivel mundial procede de Malasia e Indonesia, países que proveen el 85\% de la que se comercializa en el mundo. De acuerdo con la información de la red virtual LifeMosaic (2013), "Indonesia sola cultiva más allá de 20 millones de hectáreas de plantaciones para el 2020, un área del tamaño de Inglaterra, Holanda y Suiza juntas". ${ }^{6}$ Las estadísticas del índice mundial de producción (Indexmundi) muestran que Colombia ocupa el cuarto puesto de producción de palma de aceite, después de Indonesia, Malasia y Tailandia. Entre los primeros once países productores se encuentran cinco del subcontinente latinoamericano: Colombia,

5. Consultado en: <http://www.prospectiva2020.com/sites/default/files/report/files/82_i2020_biocombustibles_persp_merc_mundial_sit_argentina_lima_web. pdf>. [consultado: 22.4 2013].

6. LifeMosaic es una organización que trabaja con las comunidades afectadas por la palma de aceite y coordina el proyecto "Impacto de las plantaciones de palma aceitera en Indonesia". Además, ha realizado la película Voces de las plantaciones de palma, en la cual se recogen los testimonios de veinte comunidades indígenas de Indonesia que narran los efectos de la agroindustria palmera. Para mayor información, consultar en: <http://www.lifemosaic.net/esp/proyectos/palma-de-aceite/>. 
Ecuador, Honduras, Brasil y Costa Rica. Guatemala y México aparecen también entre los veinte primeros.

El término genérico para indicar el material biológico del cual se extrae el combustible es biomasa, y existen diversas razones por las que se incentiva su uso; mientras que el petróleo y el gas son recursos minerales propios de ciertos subsuelos y, por lo tanto, no los poseen todos los países, la biomasa puede ser obtenida por cualquier país dentro de sus límites territoriales, lo que representa independencia energética. De acuerdo a los datos proporcionados por Sasson (2011), la biomasa se utiliza de manera distinta en porcentaje y modalidad en los países industrializados y en los países en desarrollo: los primeros la utilizan especialmente para la generación de electricidad y energía calorífica, mientras que los segundos hacen uso de ella en el ámbito doméstico, como combustible o para el calentamiento de viviendas.

\section{AlianZas EN La PRODUCCión GLOBAL}

La producción de agrocombustibles se ha convertido en muchos lugares del planeta en una de las alternativas más usadas para sustituir el consumo de hidrocarburos. Muchos gobiernos han incluido en sus agendas políticas la promoción de este tipo de energía como bandera emblemática para el suministro energético. No solo el sector público, sino también el sector privado, así como organizaciones internacionales e intergubernamentales se muestran cada vez más interesadas en el crecimiento de la industria de los agrocombustibles. La marcada tendencia que se encamina a nivel global está caracterizada por los siguientes aspectos:

1. El desarrollo e investigación tecnológica se pone al servicio de la agroindustria. En muchos países se destinan fondos tanto públicos como privados para el desarrollo de investigaciones en torno a los agrocombustibles: variedades, cultivos transgénicos, nuevos recursos potenciales para la explotación y exploración de combustibles de segunda y tercera generación. ${ }^{7}$

7. Se habla de una segunda y hasta de una tercera generación de combustibles que no involucran de forma directa cultivos utilizados originalmente para la alimentación 
2. La creación de diferentes instituciones locales que se encargan de la promoción y al mismo tiempo ejercen presión para adelantar y poner en marcha las políticas agrícolas e instaurar los marcos jurídicos que amparen las leyes de producción. En este sentido, las instituciones están concebidas como entes reguladores de conductas, pero también actúan como instancias de inclusión o exclusión dentro de las cuales se puede acoger o sancionar la participación de un actor determinado. Tales instituciones representan normas de funcionamiento que no están en consonancia con una sociedad empresarial local, sino con patrones exógenos, regidos por principios económicos y con incidencia en la acción pública, los sistemas políticos y los sistemas económicos. Esta concepción de la creación de nuevas instituciones posee algunas de las características atribuidas al nuevo institucionalismo; desde esa perspectiva, estas adquieren rasgos en los que el quehacer sociopolítico es la base fundamental de la interacción institucional en una sociedad. ${ }^{8}$

3. La cooperación tecnológica entre países y entre grupos empresariales internacionales se basa en la rentabilidad que proporcionen las inversiones en este campo. Es interesante observar que las fusiones y la cooperación entre dichos grupos no está supeditada a las áreas de competencia originales de cada uno, sino que se articulan con filiales de otros ámbitos de producción y ejercen gran influencia más allá de sus campos de dominio originales. En esa composición se encuentran desde consorcios especializados en informática hasta empresas especialistas en producción de oleaginosas.

Respecto a las tendencias que se vislumbran en torno al uso de los recursos energéticos, De Greiff anota:

El auge de los gases anuncia ya las transiciones que se vislumbran para la primera mitad del siglo xxi. El advenimiento de las celdas de combustible y de la energía de los combustibles ecológicos, biocombustibles y demás derivados del reciclaje masivo de los desechos orgánicos de los centros urbanos y de la biomasa (metanos solares); y la de la hidroelectricidad verde (2009: 29).

y que hacen uso de técnicas que toman como base los residuos dejados por la producción agrícola.

8. Para ver más al respecto, consultar Hall y Taylor (1996). 
El panorama energético está dominado por los patrones de grupos poderosos de las naciones industrializadas y que es presentado como global. Los desafíos que se exportan al mundo se derivan de las demandas energéticas, en especial para satisfacer las necesidades que generan los centros más industrializados, localizados en los dos hemisferios. Entre las posibles alternativas evaluadas se encuentran las diferentes generaciones de agrocombustibles, pero también la producción de energía a través de la fusión termonuclear. Las nuevas tecnologías apuntan al hallazgo de fuentes inagotables de energía, como parece ser la que se obtiene a través del hidrógeno y de fusiones termonucleares. La composición de nuevas realidades energéticas se da de forma recíproca entre los actores consumidores y productores y además se transforma según la demanda. La conformación de la Organización de Países Exportadores de Petróleo (OPEP), por ejemplo, ha dado lugar a comportamientos en la arena política tanto nacional como global que evidencian claramente una geo-estrategia en torno al abastecimiento. Asimismo, la acelerada búsqueda de alternativas para el combustible a través del uso agrícola genera una nueva cartografía energética, da origen a otras alianzas en la organización interestatal e interinstitucional y también genera modificaciones en el interior de los tejidos sociales, tanto en el espacio urbano como en el rural, especialmente, ocasionando impactos en detrimento del bienestar de conjuntos poblacionales rurales, quienes experimentan los efectos de manera más directa y drástica.

ACAPARAmiento DE TIERRAS O LAND GRABBinG

De acuerdo con los estudios preliminares que han realizado Saturnino Borras et al. $(2012)^{9}$ entre otros, existen ciertos rasgos afines que

9. En este estudio se examina el fenómeno land grabbing desde tres dimensiones específicas: "i) una parte significativa de las recientes adquisiciones de tierras a gran escala; ii) la participación de gobiernos extranjeros en estos acuerdos sobre tierras; y iii) el impacto negativo de estas renovadas inversiones en tierras en la seguridad alimentaria del país receptor”. La traducción es mía. El texto original en inglés es el siguiente: "i) significant extent of recent large-scale land acquisitions; 
parecen tener un carácter transversal y que conducen a deducir que se trata de una anomalía que se propaga a nivel global. El fenómeno se conoce con el nombre de land grabbing, lo que en espańol se conoce como usurpación de tierras. Según con Borras et al. (2011), esta situación está estrechamente vinculada al uso de tierras para agrocombustibles, sin embargo, no es su única causa, como afirman:

La usurpación de tierras ha emergido como una frase comodín para referirse a la explosión de transacciones comerciales de tierra (trans)nacionales y a la especulación de la tierra, principalmente en los ańos recientes, pero no solamente a los relacionados con producción a larga escala y a la exportación de alimentos y agrocombustibles (2011: 1). ${ }^{10}$

En otros informes que siguen las dinámicas del acaparamiento de tierras se confirma que la tendencia muestra rasgos similares a nivel global. Se observa que existen vínculos entre los gobiernos y el sector privado que derivan en asociaciones público-privadas con el propósito de desarrollar proyectos que van etiquetados con sellos de sustentabilidad o de inversiones responsables. En realidad, se trata de procedimientos simulados para apropiarse de tierras fértiles y desplazar comunidades campesinas. De acuerdo con el informe de la organización no gubernamental Grain (2016), se observa un cierto descenso en la dinámica de apropiación de tierras para producción agrícola, en la cual algunos países compraban extensiones en territorios extranjeros para asegurar la producción de sus países de origen. Sin embargo, se comprueba un aumento en la adquisición de tierras para el negocio de los agrocombustibles. Este informe afirma que "las plantaciones de palma por sí solas son responsables de la mayor parte del acaparamiento de tierras en el sector de alimentos y agrícola en los últimos ańos" (Grain 2016: 7). El sector financiero, por su parte, tiene una corresponsabilidad en

ii) involvement of foreign governments in these land deals; and iii) negative impact of such renewed land investments on food security of the recipient country" (Borras et al. 2012: 4).

10. La traducción es mía. El texto original en inglés es el siguiente: "Global land grab' has emerged as a catch-all phrase to refer to the explosion of (trans)national commercial land transactions and land speculation in recent years mainly, but not solely, around the large-scale production and export of food and biofuels". 
ese fenómeno y se identifica la participación de nuevos actores que aparecen en escena. Por un lado, están algunos fondos de pensiones que optan por invertir en el negocio de la tierra para poder aumentar su capital. Por otra parte, las instituciones de financiamiento para el 'desarrollo', cuyas inversiones deberían estar destinadas al mejoramiento del sector agrícola, también pasan a engrosar los capitales privados. De una manera menos evidente, los paraísos fiscales ayudan a que el financiamiento ilícito pueda ser usado para el negocio y el acaparamiento de tierras. Una de las recientes tendencias que se vislumbra es "una repartición colonial en las inversiones" (Grain 2016: 9). De acuerdo con los datos que proporciona el informe de Grain, hay zonas geográficas en las que el despliegue de esta práctica es mayor: por ejemplo, compañías japonesas se concentran en Brasil y Mozambique para producir soja y empresas chinas están más interesadas en Nueva Zelanda, Australia y en la zona oriental de Rusia. Mientras algunas compañías europeas han comprado tierras en el occidente de Rusia, las compañías indias se inclinan más por las tierras de Etiopía. Países como Francia y Portugal prefieren adquirir terrenos en sus antiguas colonias en el continente africano y Estados Unidos y el Reino Unido, por su parte, están presentes en muchos lugares de forma simultánea.

\section{El negocio de la tierra en América Latina y el Caribe}

Como lo sugieren Borras et al. (2011), la transacción de tierras que se ha disparado en los últimos ańos está causada por diferentes factores. Uno de los motivos más importantes es la introducción de monocultivos destinados a la obtención de combustibles cuyo uso final suele ser el sector del transporte. En ese estudio se analiza el fenómeno en la región de América Latina y el Caribe y se datan hallazgos específicos, dos de ellos, de especial interés para este análisis.

1. La transacción de tierras no se da principalmente por la vocación agrícola para consumo de alimentos, sino que obedece a varias categorías, entre las que se encuentran la adquisición de terrenos para sectores distintos al alimentario, la plantación industrial de árboles y la conservación de terrenos a larga escala. 
2. Hay escenarios de usurpación de tierras en América Latina: el desplazamiento poblacional y la incorporación. Respecto al primero, no se indican casos de desplazamientos masivos, excepto en Colombia. Con relación al segundo, se involucra a los pequeños agricultores en proyectos ventures en las plantaciones de nuevos enclaves. Si bien en América Latina la problemática del desplazamiento de la población rural no alcanza la dimensión que adquiere en otros continentes (por ejemplo, en África), sí se produce a través de mecanismos que mantienen enmascarado ese fenómeno. En Colombia, es de carácter forzado —en la mayoría de casos-y no muestra una relación monocausal con la actividad del agrocombustible; sin embargo, ese nuevo marco de usurpación acentúa la confrontación por la tierra, tornándose en una causa recurrente.

En ese mismo análisis de tierras, Borras et al. (2011) señalan que se observa un cambio en la estructura del poder y la gobernanza de la tierra, en el que se distinguen categorías de uso y diversas incidencias en la distribución y la concentración. Por una parte, las corporaciones transnacionales están involucradas en diversos sectores de la economía de manera simultánea: en el área alimenticia, en el área energética y en la ecológica, entre otras. La tendencia que se observa en América Latina, en términos de actores involucrados en ese fenómeno, son las inversiones de transnacionales regionales que están buscando cobertura regional y quieren alcanzar una extensión a nivel continental. Un aspecto singular que llama la atención es que algunos países de la región son simultáneamente inversores en territorios foráneos y a la vez experimentan una gran oleada de inversiones extranjeras en sus territorios nacionales, y uno de ellos es Brasil. De acuerdo con las cifras que provee este estudio, en la región continental, Brasil es un país receptor de inversiones e inversionista a la vez. La siguiente tabla muestra la tendencia de inversiones en tierra que está en marcha en América Latina. 


\begin{tabular}{|c|c|}
\hline $\begin{array}{l}\text { Países de origen } \\
\text { de inversores extranjeros }\end{array}$ & Países activos en \\
\hline \multicolumn{2}{|l|}{ Internacional } \\
\hline Estados del Golfo & Argentina, Brasil \\
\hline China & Argentina, Brasil \\
\hline EE UU & Colombia, Perú, México \\
\hline Europa & Colombia, Perú, Uruguay, México \\
\hline Corea del Sur & Argentina, Brasil \\
\hline Japón & Brasil, Colombia, Ecuador \\
\hline \multicolumn{2}{|l|}{ América Latina } \\
\hline Argentina & Brasil, Uruguay, Paraguay \\
\hline Brasil & $\begin{array}{l}\text { Bolivia, Colombia, Paraguay, Uru- } \\
\text { guay, Chile }\end{array}$ \\
\hline Chile & $\begin{array}{l}\text { Argentina, Brasil, Uruguay, Colom- } \\
\text { bia, Ecuador, Perú }\end{array}$ \\
\hline Colombia & Bolivia, Perú \\
\hline
\end{tabular}

4. Países con inversión en tierras de América Latina y el Caribe

Países inversores en América Latina y el Caribe

(Fuente: FAO Seventeen country studies, plus the summary paper, 2011. Tomado de Borras et al. 2011: 24).

La emergencia de las translatinas en el negocio de adquisición de tierras en el continente responde a dos procesos: por un lado, se ha generado una configuración sistémica global en la cual se perfila una dinámica policéntrica y multidimensional — policéntrica, pues, si bien se sigue constatando una marcada influencia de la relación Norte-Sur, aflora con ímpetu una relación Sur-Sur que replica los modelos y los mecanismos en el interior de la región-y, por otra parte, las nacientes translatinas están concebidas dentro de los planes de integración energética que han venido promoviendo los gobiernos más progresistas, en cuyo grupo, el rol de Brasil y los objetivos que persigue no son claramente visibles. Me referiré a este asunto de la integración continental 
en materia energética más adelante. Es de notar que la relación Sur-Sur no se restringe a la esfera continental en América, sino que se extiende hacia los países asiáticos, con quienes existen intereses especiales - por lo menos así se observa- en llevar a cabo intercambios de transferencia tecnológica.

\section{La gobernanza y la adquisición de la tierra}

La producción de agrocombustibles en los países del hemisferio sur muestra similitudes. De acuerdo con los estudios de caso que reportan Fritz (2008) y Franco et al. (2010), los mecanismos de promoción para diferentes cultivos como la palma de aceite, la soja, el maíz y otros productos destinados para los hidrocarburos son estructuralmente homogéneos. Esto quiere decir que se utilizan instrumentos normativos para reducir las tasas fiscales para las empresas, se facilitan los porcentajes de inversión y, en algunas ocasiones con dinero del Estado, se suavizan o transforman las legislaciones medioambientales para desplazar a poblaciones rurales, especialmente indígenas y campesinas. Los impactos locales que causa la producción de esta clase de cultivos también se asemejan entre sí, especialmente en el ámbito medioambiental y en el social. Las consecuencias que afrontan las poblaciones son similares, sin embargo, y como se ha reiterado antes, la recepción a nivel local tiene algunas variaciones dependiendo de las especificidades de los contextos particulares.

Un factor preocupante de las relaciones Sur-Sur es el discurso de cooperación al desarrollo (en términos occidentales) que se ha instaurado, especialmente, entre las relaciones de Brasil con otros países del sur continental y hemisférico. La recepción del Gobierno brasilero ha sido de plena acogida hacia las políticas propuestas por los dos bloques económicos — la Unión Europea y Estados Unidos—para terminar a medio y largo plazo con la dependencia de los recursos minerales. El rol que tiene Brasil en el plano continental se puede ver en la dinámica de tierras - antes expuesta- y su desempeño en las relaciones tanto Sur-Sur como Norte-Sur. 
En cuanto al cambio en los usos agrícolas, se constata que los suelos que estaban destinados anteriormente a cultivos de alimentación básica para los habitantes de las zonas rurales se han sustituido paulatinamente por los sembrados de cańa de azúcar, soja y palma de aceite. La concentración de grandes expansiones para la producción de un solo cultivo lleva consigo implicaciones no solo de orden medioambiental, sino, y sobre todo, fuertes implicaciones en los requerimientos alimentarios de las poblaciones, pues los sembrados de pancoger son desplazados o disminuidos. La extensión de la frontera agrícola es un hecho que se detecta en varios de los países productores, y la deforestación de bosques tropicales y Zonas de Biodiversidad se reporta por parte de varias organizaciones de derechos humanos y por las comunidades afectadas. También existe una gran contradicción con respecto a políticas propuestas por la Unión Europea y Estados Unidos para mitigar las emisiones de gas. A pesar del potencial reductor que parecen tener cultivos como la palma de aceite o la caña de azúcar, se desestiman los efectos que tienen los monocultivos a larga escala, como lo afirman Franco et al.: "El ahorro energético se ve perjudicado por las plantaciones de caña de azúcar que destruyen los sumideros de carbono en la sabana del Cerrado y el bosque Amazonas, así como también por su considerable daño ambiental que ocasionan" (2010: 689). ${ }^{11}$

Por otra parte, es necesario tener en cuenta los efectos directos del cambio de uso de la tierra en la población rural. La gráfica que se ve a continuación muestra la evolución de los monocultivos de caña en Brasil y las cifras de extensión de palma de aceite en Colombia, así como el caso de Argentina (periodo 1995-2009, donde los cultivos de soja crecieron un $287 \%$ ), revelan un aumento de estas plantaciones. El drástico cambio en el uso de la tierra incidió en la crisis por alimentos que se presentó en el 2009 y, si bien no se ha comprobado la competencia entre la producción de alimentos básicos y los cultivos para carburantes,

11. La traducción es mía. El texto en inglés es el siguiente: "But savings are undermined by sugarcane plantations destroying carbon sinks in the Cerrado savannah and Amazon rainforest, as well as by wider environmental harm”. 
sí hay evidencias de las desproporciones y dominio en la extensión de cultivos industriales y sus efectos en la soberanía alimentaria. En lo que a Colombia se refiere, se sabe que ha pasado de ser un país altamente productor de bienes primarios a ser importador de ellos, así como lo revela este fragmento de un artículo en el diario El Pais:

Eso nos indica que el $28,5 \%$ de todo lo que consumimos en cada comida diaria es importado. [...] Lamentablemente las compras agrícolas desde Estados Unidos pasaron de representar el 24\% al 58\%, es decir, que se duplicaron (García 2015).

\begin{tabular}{|c|c|c|c|}
\hline & Soja & Cańa de azúcar & Palma de aceite \\
\hline \multicolumn{4}{|c|}{ América del Sur } \\
\hline 1961 & 259,534 & $2,124,775$ & 38,700 \\
\hline 1970 & $1,443,590$ & $2,485,528$ & 57,081 \\
\hline 1980 & $11,467,985$ & $3,623,922$ & 83,088 \\
\hline 1990 & $17,725,284$ & $5,290,929$ & 210,906 \\
\hline 2000 & $24,156,087$ & $5,995,162$ & 341,709 \\
\hline 2009 & $42,792,479$ & $9,878,744$ & 448,313 \\
\hline \multicolumn{5}{|c|}{ América Central } \\
\hline 1961 & 9943 & 500,207 & 22,910 \\
\hline 1970 & 111,844 & 761,258 & 21,986 \\
\hline 1980 & 155,287 & 882,750 & 35,447 \\
\hline 1990 & 309,996 & 875,047 & 57,197 \\
\hline 2000 & 85,992 & $1,071,684$ & 109,430 \\
\hline 2009 & 83,444 & $1,231,025$ & 239,204 \\
\hline \multicolumn{5}{|c|}{} & & \\
\hline Fuente: FAOSTAT (2012) & \multicolumn{5}{|}{} \\
\hline
\end{tabular}

5. Registro del área cultivada en hectáreas en América del Sur y Centro América (tomado de Borras et al. 2012: 853)

Modalidades DE ADQUisición

Las grandes proporciones de monocultivo de caña de azúcar, palma de aceite y soja están relacionadas con la concentración de tierra y el aumento en el mercado de precios de los terrenos. En Brasil, la expansión de la caña de azúcar ha sido posible porque se ha hecho uso de tierras que 
originalmente tenían vocación forestal o pastoral. Otra de las estrategias para la expansión es el arrendamiento masivo de pequeños terrenos a agricultores con propiedades medianas, que incide en la cultura tradicional de sostenimiento de las familias campesinas, impidiendo la continuidad de cultivos básicos. Se crea una forma de mercadeo de la tierra que no está regulada ni amparada en estamentos legales y reproduce transacciones caóticas y desordenadas que exacerban las fluctuaciones sobre el precio de la tierra. ${ }^{12}$ Este fenómeno ocurre también en Colombia, donde el catastro y los procesos de titulación de tierras están dominados por los intereses políticos y económicos de las élites. El arrendamiento de la tierra lleva consigo efectos que repercuten en los parámetros de ocupación de la población rural: por un lado, el modelo de alquiler de las tierras implica el vínculo de los campesinos con las actividades de la agroindustria, lo que cambia esencialmente los cultivos pancoger o los tradicionales de las regiones, $y$, por otro lado, el cambio del rol del campesino, pues de ser propietario o productor pasa a ser asalariado, lo que transforma la dinámica del carácter agrícola y la identidad comunitaria de las asociaciones campesinas.

Otro aspecto de gran controversia es la estipulación sobre el tipo de tierras que se destinan para los cultivos de agricultura extensiva. Los gobiernos se refieren a tierras marginales en términos de su fertilidad y también señalan los territorios como espacios baldíos. Sea cual sea la denominación, existen grandes divergencias en cuanto al efecto que produce esa categorización y las repercusiones que causan en los habitantes del campo. En este sentido, nuevamente la clarificación sobre la titulación de tierras, sea individual o colectiva, vuelve a tener una importancia vital, especialmente porque el despojo es una de las características que se aprecia en muchos de los países productores. En Colombia ese aspecto tiene un precedente histórico por el conflicto armado, pero las prácticas agroindustriales han agudizado tanto el conflicto por la tierra como el desplazamiento forzado. En este sentido, la incidencia se observa no solo en el desplazamiento forzado, sino en la migración estructural o cíclica:

12. Según datos revelados por el Ministério da Agricultura Pecuária e Abastecimiento de Brasil (MAPA), se produjo un aumento del $10 \%$ de los valores sobre la tierra entre los años de 2000 y 2006 a causa de los agrocombustibles (Monsalve, 2008). 
migración-colonización-conflicto-migración, hipótesis trabajada por Fals Borda y retomada por Fajardo (2006). La expulsión de la población rural hacia las zonas urbanas sigue ese esquema y se constata como tendencia en el plano nacional y también en el continente.

\section{Tendencias energéticas en América Latina}

\section{Articulación Geopolítica}

Si bien las realidades energéticas en América Latina se configuran desde escenarios diferentes a los de las demandas energéticas de los países de la Europa Central y de Estados Unidos, la mayoría de los proyectos emprendidos se orientan a atender los requerimientos de las economías industrializadas y desestiman las implicaciones y repercusiones en el plano regional-local. De acuerdo con algunos autores, las fuentes en recursos naturales que posee el continente latinoamericano están altamente concentradas en unos países.

En el caso específico de la producción de petróleo, seis países la lideran, a la cabeza, Venezuela y México. La región se abastece de los exportadores regionales y los excedentes van hacia los Estados Unidos. En los últimos diez años se han vivido procesos continentales que muestran una clara conciencia de los recursos naturales que posee la región y su uso. Esa concientización ha estado presente de manera latente y se ha manifestado de forma más clara en los escenarios políticos nacionales, específicamente a través de los gobiernos, en cuyas administraciones se han acogido posturas de centro-izquierda e izquierda. Desde hace unas dos décadas, el tema medioambiental, no solamente el energético, ha pasado a ocupar un lugar preponderante en las relaciones interestatales, Sur-Sur y Norte-Sur.

Tendencias en asuntos Energéticos: ¿inTEgración Regional?

Según los planteamientos de Diego F. Otero Prada, la dinámica en los asuntos energéticos en el continente muestra un cambio fundamental a partir de 2007, año en el que se "delinean dos grupos: por un 
lado, los Estados Unidos, México, Perú y Colombia y, por otra parte, Venezuela, Ecuador, Bolivia, Cuba, Nicaragua, Uruguay, Brasil y Argentina con el resto de los países de Sur América en posición variable” (2009: 168). En la década de los noventa, los proyectos energéticos estuvieron impulsados especialmente por compañías trasnacionales y la participación de los gobiernos era mucho más reducida. El tema de la integración continental sobre proyectos energéticos ha formado parte de las agendas incluso desde los años sesenta, sin embargo, el matiz que ha tomado esa idea, en el marco de gobiernos progresistas, parece estar más inclinado hacia la administración de los recursos naturales.

La integración regional que se había venido gestando desde comienzos del presente siglo parece estar determinada en gran parte por el tema energético y el uso de los recursos naturales. Iniciativas como la Alternativa Bolivariana para América Latina y el Caribe (ALBA) parecían mostrar un cambio en el paradigma integrativo del continente y competían en el escenario regional junto con agrupaciones ya establecidas, como la Comunidad Andina (CAN) y el Mercado Común del Sur (MERCOSUR), que difieren en sus principios constitutivos. Observemos que las tres áreas de integración energética que se vislumbran con mayor claridad en el continente son la eléctrica, la del gas natural y la de los combustibles líquidos.

Los procesos nacientes de interacción en el bloque regional indican que en América Latina existen dos tendencias de integración energética. Una está promovida por los Estados Unidos y la Unión Europea y apoyada por México y Colombia. Esta tendencia ve las transnacionales como agentes centrales para ejecutar proyectos de explotación de recursos naturales, y el sector privado juega un papel vertebral para la integración. Los proyectos de las empresas transnacionales estarían favorecidos por mecanismos como los Tratados de Libre Comercio (TLC) bilaterales. El proyecto Plan Puebla Panamá, ${ }^{13}$ que expresa de manera concreta esta visión en sus argumentos, afirma que busca "desarrollar la infraestructura de Centroamérica con el fin de facilitar la operación de

13. Los países integrantes del acuerdo Plan Puebla Panamá son Belice, Colombia, Costa Rica, Nicaragua, El Salvador, Guatemala, Honduras, México, Panamá y República Dominicana. 
las transnacionales" (Otero Prada 2009: 172). Se trata de un acuerdo del 1994, año en el cual se lanzó el proyecto de la creación del Área de Libre Comercio de las Américas (ALCA) el con propósito de dotar de una infraestructura vial que conectase Centroamérica con México, construir allí una refinería y lograr la conexión eléctrica a través de gaseoductos. ${ }^{14}$

La segunda visión de integración está impulsada por países progresistas como Venezuela, Bolivia, Cuba y Ecuador, entre otros, y su propósito principal fue durante algún tiempo integrarse a través de los proyectos ejecutados por empresas estatales, con miras a buscar un desarrollo a partir de la complementariedad en materia energética. Mecanismos como la renacionalización de empresas y el liderazgo estatal tuvieron un carácter central. La creación del plan Iniciativa para la Integración de la Infraestructura Regional Suramericana ${ }^{15}$ representa un proyecto acogido por varios países de la región y ha sido apoyado por una serie de pactos que se concretizan a través de entidades como PetroCaribe, PetroAndina, PetroSur, el Gaseoducto del Sur, el Gasoducto Andino y la Unión de Naciones Suramericanas (UNASUR). El marco de entendimiento de estos pactos está respaldado a través de las declaraciones realizadas en Montevideo y en Caracas, expedidas por la Organización Latinoamericana de Energía (OLADE) en 2004. En ese mismo año surgió una propuesta de integración energética para Latinoamericana y el Caribe, la cual buscaba ser una alternativa regional que intensificara el desarrollo Sur-Sur. Su principio fundacional está basado en la integración a través de una plataforma energética común y pretendía convertirse, especialmente, en un intento de interconexión. Según algunos gobiernos del continente, el criterio de interconexión ha primado en los grupos de integración ya existentes en la región. Las redes eléctricas regionales han empezado a ser una realidad, ya que su construcción se inició en el 2006 y están desarrollándose en subgrupos geográficamente determinados: Centroamérica, la región Andina y MERCOSUR.

14. Las empresas multinacionales que han estado liderando en el sector energético en Latinoamérica desde la década de los noventa son Endesa, Repsol, Gas Natural, Unión Fenosa, Redes Eléctricas e Iberdrol, todas ellas de origen español.

15. Una de las críticas que se hace a esta iniciativa es que parece haber un interés mayor por el desarrollo de megaproyectos de grandes compañías regionales, mientras los objetivos de desarrollo social adquieren poco alcance. 
No solamente el tema de la electricidad, sino también la integración gasífera — que se inició con acuerdos para conexiones binacionales a partir del 2005-, ha seguido una estrategia de extensión regional. Se dieron algunos pactos intergubernamentales, como el caso Chávez-Kirchner para el Gaseoducto del Sur, proyecto integrado por Argentina, Brasil y Venezuela, pero en 2007 se congeló su planificación. Por su parte, MERCOSUR también ha diseñado planes de interconexión binacionales y enlaces para completar planes adicionales a nivel nacional. Tras los intentos de integración en el tema petrolífero en América Latina, en la actualidad las empresas más grandes del continente en este sector (Pemex, Petrobras y PDVSA) pasan por graves crisis financieras.

Como se ha presentado grosso modo, el tema energético, en el escenario global está estrechamente vinculado con la seguridad e influye en los paradigmas de integración regional latinoamericana. En el espacio continental, el tópico energético ha encauzado procesos tanto de integración como de disgregación. Estas dos visiones integrativas antes expuestas llevan consigo transformaciones esenciales en los escenarios nacionales. La promoción de los agrocombustibles en el continente podría ser considerada como uno de esos mecanismos de ejecución apoyado especialmente por bloques extra regionales, es decir, la Unión Europea y los Estados Unidos a nivel global, pues también países asiáticos y africanos están participando en el negocio de los agrocombustibles. En Latinoamérica, Brasil tiene un liderazgo especial y en algunos temas específicos, su actuación en asuntos internacionales e interregionales permitiría deducir que promueve la producción de agrocombustibles como matriz principal de su actividad energética.

La producción de sembrados para agrocombustibles es un fenómeno que se puede observar en todo el continente. Así como lo especifican Borras y Franco (2012), en la evolución del crecimiento de los monocultivos se puede registrar un aumento gigantesco para las últimas cuatro décadas en Suramérica y en Centroamérica. Argentina y Brasil no solo aumentaron la producción de soja y cańa de azúcar, sino que a nivel mundial participan en el comercio de alimentos de manera significativa, gracias también a la demanda de China. Los pronósticos indicados respecto a los agrocombustibles en el informe de la CEPAL "Perspectivas de la agricultura y del desarrollo rural en las Américas: 
Una mirada hacia América Latina y el Caribe" (2013) estiman que su crecimiento seguirá en ascenso. De todos modos, consideran que se darán algunos cambios. Uno de ellos es la preferencia del etanol respecto al biodiésel, pues un estudio reciente afirma que es más eficiente el primero que el segundo. Otro aspecto es la orientación hacia el uso de las segundas generaciones extraídas de residuos de biomasa, aunque este cambio parece ser menos prometedor.

\section{La palma de aceite y los agrocombustibles en Colombia}

\section{Política agrícola en el CONTEXTo de los agrocombustibles}

La producción de los agrocombustibles en Colombia, su impacto y repercusiones, requieren ser abordados desde una perspectiva diacrónica. Aunque es una actividad de la industria agrícola que se intensificó hace pocas décadas, su gran auge se inscribe dentro de la lógica derivada de las políticas agrarias iniciadas en décadas anteriores. En Colombia, el sistema de manejo de tierras está caracterizado aún por mecanismos heredados de la época colonial: los latifundios, junto con el minifundio, siguen siendo los modelos para administrar la pobreza para los campesinos y la riqueza para los terratenientes (Jaramillo 2010).

\section{REFORMAS AGRARIAS}

La primera reforma agraria que se llevó a cabo en Colombia data del año 1936 y sus directrices se centraron en la repartición de baldíos y en la distribución de terrenos dentro de la frontera agrícola, ocasionando conflictos entre terratenientes, colonos y pequeńos propietarios. ${ }^{16}$ La década de los treinta se caracterizó por la gran

16. Durante las dos primeras décadas del siglo $\mathrm{xx}$, los colonos migraron a regiones en las que se suponía que había abundancia de tierras, pero encontraron que muchos de esos territorios estaban ocupados por terratenientes y agricultores a gran escala, quienes los expulsaron y contrataron trabajadores asalariados (Ibáńez 2008: 22). 
expulsión de campesinos e indígenas, quienes buscaron — de alguna forma - la adherencia partidista como estrategia de protección para asegurar sus propiedades. Esa ley de reforma agraria ya se mostraba sesgada, porque favorecía los intereses de los grandes terratenientes.

La nueva reforma agraria, realizada en 1961, tenía el propósito de apaciguar los enfrentamientos violentos generados por las disputas sobre tierra heredadas de décadas anteriores, y, para ello, se puso en marcha el mecanismo de cabildeo y se promovieron programas tributarios y crediticios que desembocaron en una mayor concentración de la propiedad agrícola. El fracaso de esa nueva reforma estuvo relacionado con la asignación de tierras desde una lógica mercantilista, que desfavoreció a muchas familias campesinas y exacerbó la violencia en el entorno rural. Más tarde, en el año 1994, la ley 160 pretendió ser una salvaguardia a las anteriores reformas e impulsó un programa agresivo de desarrollo rural y legalización de terrenos baldíos. La redistribución de territorios y las hectáreas asignadas durante la última década del siglo pasado no cambiaron en lo fundamental la dinámica que se había impuesto en la primera mitad del siglo, pues no hubo variaciones importantes en la concentración territorial.

La introducción de la agroindustria, específicamente en el caso de la palma de aceite, ha logrado consolidarse con ímpetu a lo largo del territorio nacional, pero no muestra modificaciones orientadas hacia la equidad en la distribución de tierras, por el contrario, es uno de los monocultivos que mantiene la alta concentración de tierra en unas pocas manos. Uno de los casos más conocidos es la situación en la región de los Montes de María, departamento del Bolívar: de acuerdo con las declaraciones de la población campesina afrodescendiente que habita en la zona, en el estudio que realizaron Luis Sánchez-Ayala y Cindia Arango-López (2015), la incursión de cultivos de palma ha estado acompańado de una excesiva intensidad en la adquisición de predios, ya sea la compra y venta o la invasión de los territorios. Según la investigación que llevó a cabo Iván Cépeda, ${ }^{17}$ representante del Polo democrático,

17. Iván Cepeda es representante del partido político Polo Democrático. 
los estudios hechos con títulos de propiedad por el Representante a la Cámara Iván Cepeda, por un lado, y la Superintendencia de Notariado y Registro, por otro, auguran que un grupo pequeño de empresarios que hoy en día tienen la mayoría de las tierras en esta zona argumentará que las compraron legalmente. Compraron, sin embargo, en una zona donde fueron desplazados más de 120.000 campesinos por la guerrilla y los paramilitares (Osorio 2011).

De acuerdo con las cifras que suministró el Instituto Geográfico Agustín Codazzi (IGAC) en el 2012, "en el sector predominan las unidades productivas la pequeña escala, en donde el $67,6 \%$ de los propietarios tienen parcelas inferiores a 5 ha (un $4,2 \%$ de la tierra agrícola) mientras que un $0,4 \%$ de los propietarios es dueño de extensiones de terreno superiores a 500 ha (lo cual representa el 46,5\% del suelo) (IGAC 2012). La gráfica que aparece a continuación, realizada por Darío Fajardo en su estudio "Conflicto armado y proyección en el campo" (2004), muestra la estructura de la tenencia de la tierra en Colombia. Este autor señala que la posesión de la tierra en pocas manos sigue aumentando la concentración territorial y económica. Los modelos introducidos no han contemplado las prácticas locales y en su mayoría han seguido las fórmulas de los organismos internacionales. La adquisición de créditos desemboca, muchas veces, en la pérdida de los terrenos, pues los campesinos no alcanzan a devolver las deudas adquiridas y son ellos quienes tienen que afrontar los imprevistos del temporal para sus cosechas.

Respecto a los mecanismos de empoderamiento para los pobladores rurales, en la reforma constitucional de 1991 se han logrado algunos avances. Por ejemplo, en el nuevo documento de la Constitución se incorpora la dimensión ambiental en relación a las actividades económicas en diferentes niveles, ya que se habla del valor de los costos ambientales y se insiste en la función ecológica de la propiedad individual y colectiva. La introducción de lo ambiental parece haber tenido incidencia en el giro del discurso y la legitimidad de los actores, así lo señala Liliana Díaz (1999): "Son casi ochenta los artículos que establecen criterios y normas para el manejo de la conservación de los recursos naturales y el ambiente" (366). Esta autora afirma que la ambientalización extendió una visión de perspectiva sobre los conflictos ya existentes y catalogados como políticos, sociales o de otra índole. 


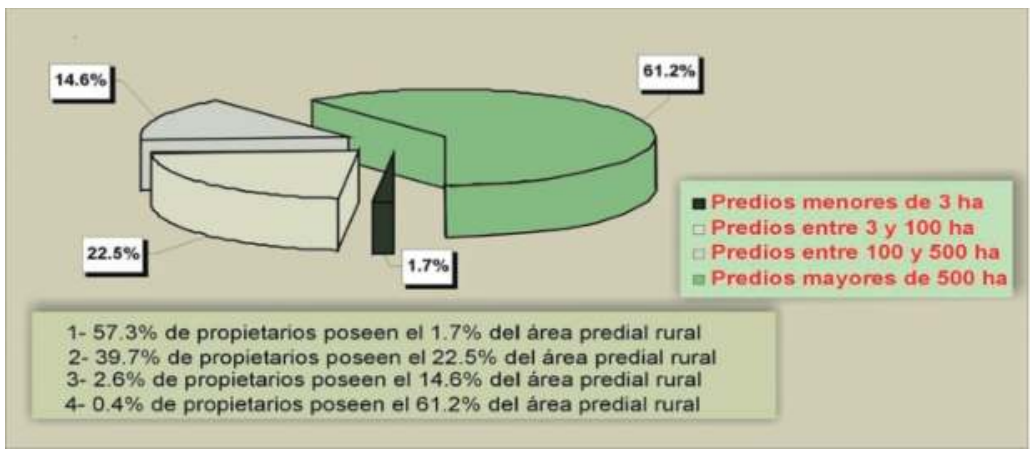

6. Estructura de tenencia de la tierra en Colombia

Fuente: Darío Fajardo (2004) a partir de datos del Instituto Geográfico Agustín Codazzi (IGAC) ${ }^{18}$

La transformación en la normativa también favoreció a grupos minoritarios en la lucha legal por sus territorios en términos ambientales. Uno de los mecanismos de acción jurídica que se introdujo es la tutela y otro es el cumplimiento, que permite que toda persona pueda acudir ante un juez para denunciar el incumplimiento de cualquiera de las instancias gubernamentales. Según Liliana Díaz, las normas en materia ambiental están orientadas a darle visibilidad al conflicto por la tierra, lo que puede desencadenar en mayores disputas, pero, al mismo tiempo, habilita espacios de acción política para las comunidades rurales.

\section{El cultivo de palma de aceite en Colombia}

La palma de aceite es uno de los cultivos bandera que ha logrado extenderse en casi todas las regiones del territorio nacional; en los últimos diez años, se ha elevado de manera vertiginosa y sigue en ascenso. Los escenarios en los que se da la producción son tan variados como las particularidades de las mismas regiones, por esta razón no se puede presentar un solo escenario nacional sobre los impactos que generan

18. Gráfico suministrado por la página ADITAL, noticias de América Latina y el Caribe. 
los monocultivos en la población rural colombiana. En el mapa que se ve a continuación, se presenta la producción por zonas y se distingue entre el aceite de palma crudo y el aceite de almendra de palma:

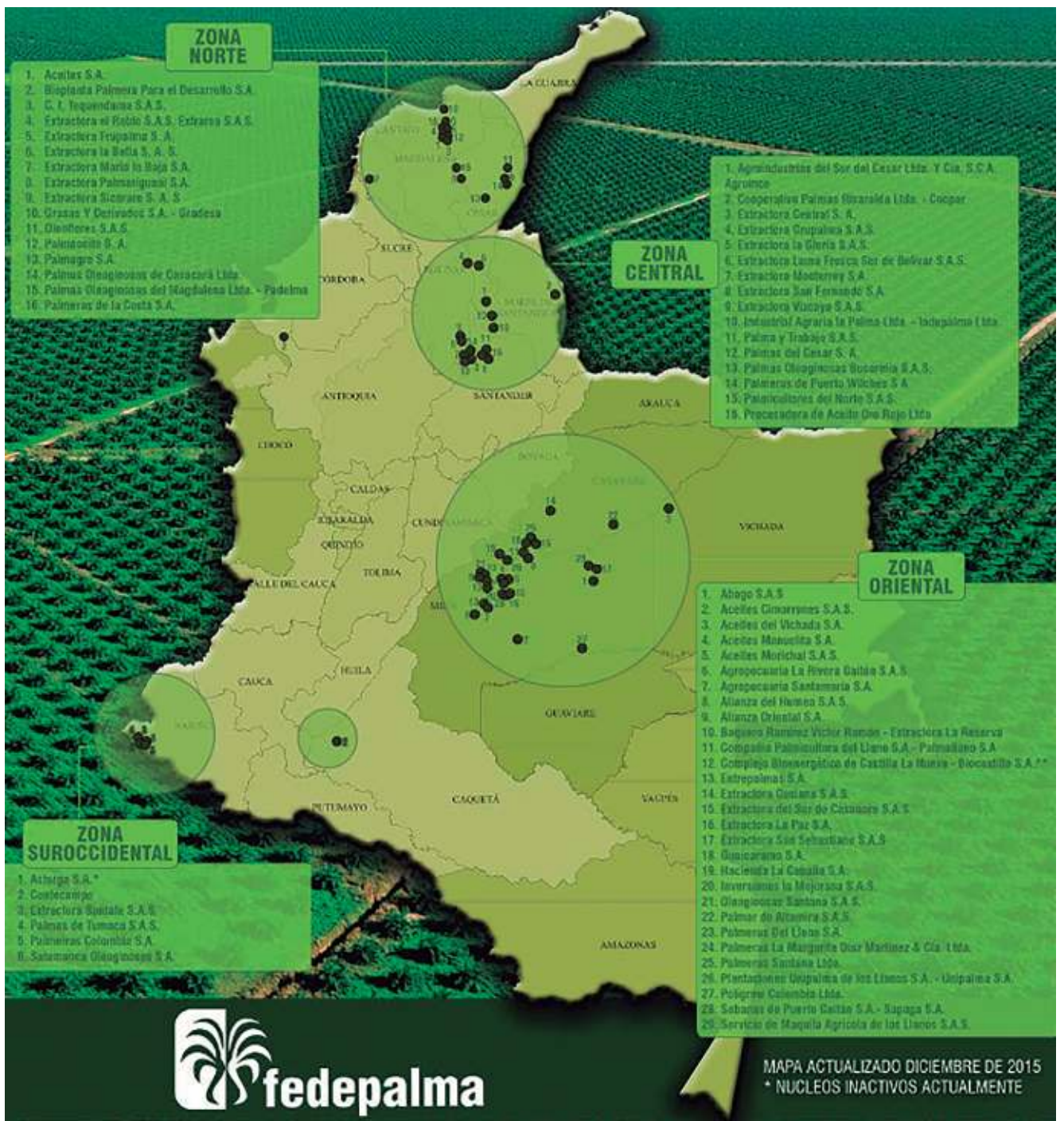

7. Regiones palmeras de Colombia. Fuente: Fedepalma (2018a: 4) 
Regiones palmeras en Colombia

La extensión del cultivo de palma está abarcando cada vez más una mayor parte del territorio colombiano. Las estadísticas para el año 2018 reveladas por FEDEPALMA indicaban que la zona oriental ocupa actualmente el mayor número de hectáreas para el cultivo con 106317 ha, le siguen la zona norte, con 97861 ha, la central, con 77594 ha, y la occidental, con 34610 ha. Esa enorme expansión se puede apreciar en el número de municipios en los que está presente este cultivo: mientras que en 1970 se extendían en diecisiete, para el año 2012 ya abarcaba ciento cinco. ${ }^{19}$ Los balances que hacía el gremio FEDEPALMA en febrero de 2016 señalaban que la zona oriental había alcanzado un mayor rendimiento en la producción, como se puede observar en la tabla que se encuentra a continuación:

Tabla 1. Colombia. Producción de aceite de palma crudo por zonas. Enero-junio, 2015-2018 (Miles de toneladas)
\begin{tabular}{|c|c|c|c|c|c|c|}
\hline \multicolumn{7}{|c|}{ Enero - Junio } \\
\hline Zona & 2015 & 2016 & 2017 & 2018 & Abs & $\%$ \\
\hline Oriental & 293,0 & 282,5 & 393,9 & 357,2 & $-36,7$ & $-9,3 \%$ \\
\hline Central & 172,6 & 180,5 & 264,3 & 253,6 & $-10,7$ & $-4,1 \%$ \\
\hline Norte & 178,8 & 142,7 & 203,6 & 209,3 & 5,6 & $2,8 \%$ \\
\hline Suroccidental & 10,5 & 12,0 & 16,5 & 19,1 & 2,6 & $15,7 \%$ \\
\hline Total & 655,1 & 617,8 & 878,5 & 839,3 & $-39,2$ & $-4,5 \%$ \\
\hline
\end{tabular}

- Cifras con corte al 31 de julio de 2018 / Fuente: Fedepalma - Sistema de Información Estadistica del Sector Palmero, Sispa

\begin{tabular}{|c|c|c|c|c|c|c|}
\hline \multirow{2}{*}{ Zona } & \multicolumn{4}{|c|}{ Enero-junio } & \multicolumn{2}{|c|}{ Variación $17 / 18$} \\
\hline & 2015 & 2016 & 2017 & 2018 & Abs & $\%$ \\
\hline Oriental & 56,0 & 52,2 & 69,4 & 61,5 & $-7,8$ & $-11,3 \%$ \\
\hline Central & 40,5 & 42,9 & 60,6 & 56,6 & $-4,0$ & $-6,6 \%$ \\
\hline Norte & 44,4 & 36,3 & 48,8 & 50,9 & 2,1 & $4,2 \%$ \\
\hline Suroccidental & 0,5 & 0,6 & 1,1 & 0,9 & $-0,2$ & $-15,5 \%$ \\
\hline Total & 141,4 & 132,1 & 180,0 & 170,0 & $-9,9$ & $-5,5 \%$ \\
\hline
\end{tabular}

- Cifras con corte al 31 de julio de 2018 / Fuente: Fedepaima - Sistema de Información Estadistica del Sector Palmero, Sispa

8. Producción de aceite de palma crudo por zonas Fuente: FEDEPALMA (2018b: 2).

19. Datos suministrados por FEDEPALMA: <http://www.sispa.fedepalma.org/sispaweb/>. 
En el orden mundial, Colombia ocupa actualmente el cuarto lugar en los países productores de palma de aceite y, en el contexto continental, el primero. Tanto la incursión del monocultivo como sus características y especificidades respecto a los impactos ambientales y sociales presentan variaciones en cada una de las zonas. Esto está relacionado con diversos factores, entre otros, las particularidades regionales en relación con la densidad de la población, el tipo de asentamientos que haya precedido al monocultivo, etc. Los palmicultores consideran que el incremento de las cifras en extensión del cultivo es un indicador de que la industria colombiana ha logrado incursionar en el mercado internacional posicionándose y mostrando competitividad.

No solo el cultivo como tal, sino también los mecanismos utilizados antes de iniciar la expansión de la industria agrícola —o justo para habilitar el espacio territorial con esos propósitos - causan repercusiones que afectan y transforman de manera drástica el escenario rural. Algunos de los estudios y de las investigaciones que se han hecho sobre la afectación de los monocultivos de palma de aceite a nivel nacional analizan los impactos sociales y medioambientales que se derivan de ese negocio (Roa 2007; Hildebrando Vélez 2008; Irene Vélez 2008 Vargas 2008; Mejía 2008; Pérez Rincón 2008; Goebertus 2008; Coronado y Dietz 2013; Castiblanco 2015). La mayoría de estos análisis proporciona elementos de reflexión sobre los efectos directos e indirectos causados por los monocultivos de producción de palma de aceite y algunos otros tematizan también el cultivo de caña de azúcar.

Las reflexiones aportadas por Hildebrando Vélez e Irene Vélez indican que en el contexto colombiano existe una situación diferenciada en torno al uso de la tierra en relación con la agroenergía y señalan, de manera especial, dos aspectos singulares en comparación con otros países del continente. El primero es el cambio de la orientación de los terratenientes vinculados a la industria de la cańa y la palma aceitera: estos se enfocan cada vez más en una producción agrícola que atienda de forma exclusiva las necesidades de la industria de carburantes. Existe una creciente tendencia a vincular a pequeńos y medianos propietarios con capital transnacional. Un segundo aspecto se refiere a la ocupación de las tierras calificadas por el Gobierno como terrenos baldíos, predios que en muchos casos aún son objeto de litigio por ser tierras que 
reclaman las comunidades campesinas o indígenas. Estos terrenos son adjudicados a empresarios para llevar a cabo diversos megaproyectos, como es el caso de las comunidades que se analizan en este estudio.

En torno a los impactos medioambientales que han venido ocasionando los monocultivos de palma aceite en el territorio colombiano, como la deforestación, la reducción de la biodiversidad y la reducción y la precarización de las fuentes hídricas, el Instituto de Hidrología, Meteorología y Estudios Ambientales (IDEAM) presentó en noviembre de 2018 un avance de los estudios que está realizando con apoyo de imágenes satelitales de la NASA para determinar la totalidad de la palma cultivada en el país, que ayudarán a determinar la incidencia de los monocultivos de palma en la pérdida de bosque. ${ }^{20}$ De acuerdo con los resultados preliminares del estudio, para noviembre de 2018 se tenía un área sembrada de 551810 ha en todo el territorio colombiano.

Mecanismos de PRomoción

\section{Instituciones de la agroindustria palmera}

El proyecto de monocultivo de la palma de aceite ha estado liderado a nivel nacional por el gremio palmero, representado en la institución FEDEPALMA. El Estado colombiano ha intervenido a través de diferentes políticas gubernamentales para la promoción de este cultivo. Dependiendo de la administración de turno se ha fomentado con mayor o menor intensidad la agroindustria palmera. La gran mayoría de cultivadores de palma son miembros de FEDEPALMA y, de acuerdo con las estimaciones de uno de los miembros de la junta directiva, ${ }^{21}$ el gremio aglutina aproximadamente un $70 \%$ de los productores de palma en el país; no todos son miembros de FEDEPALMA, pero todos deben poseer un registro que los acredite como palmeros, como se consigna en el siguiente fragmento:

20. Para ampliar información al respecto, se puede consultar la siguiente fuente en internet: <https:/www.sostenibilidad.semana.com/medio-ambiente/articulo/colombia-conocera-que-tanta-palma-de-aceite-alberga-en-su-territorio/42244>.

21. Entrevista concedida por un ex miembro de la junta directiva de FEDEPALMA, realizada en Bogotá en agosto de 2013 (archivo de entrevistas: visitas de campo, la autora). 
El Registro nacional de palmicultores (RNP) es el instrumento mediante el cual se acredita la condición de "palmicultor" de las personas naturales o jurídicas que, dentro del territorio nacional, se dedican al cultivo de la palma de aceite o a su beneficio. Constituye una herramienta invaluable para identificar a los distintos actores de la agroindustria palmera, al igual que a los beneficiarios de la inversión de los recursos del Fondo de Fomento Palmero. ${ }^{22}$

Dentro del marco organizativo se encuentra FEDEPALMA como gremio principal y entidad administradora en la que se articulan otras instancias, como la corporación Centro de Investigación en Palma de Aceite (CENIPALMA), gestada en 1991 y que se ocupa especialmente de la "generación y transferencia de tecnologías, procesos y productos de interés para el sector palmero colombiano". ${ }^{23}$ CENIPALMA desarrolla proyectos de investigación en cooperación con el Departamento Administrativo de Ciencia y Tecnología e Innovación (Colciencias) y el Servicio Nacional de Aprendizaje (SENA). También está el Fondo de Fomento Palmero, que es una cuenta especial para recaudar fondos destinados a las necesidades de investigación y fomento de la agroindustria palmera en Colombia.

FEDEPALMA funciona como una entidad corporativa que lleva a cabo actividades junto con CENIPALMA y la comercializadora internacional ACEPALMA. La agremiación tiene claros lineamientos estratégicos para impulsar el negocio de la palma en Colombia, articula sus actividades de manera sectorial y recomienda a todos sus afiliados seguir normas que cumplan con los requisitos en materia medioambiental y social. Sin embargo, su carácter gremial no la habilita para exigir que todos sus afiliados ejecuten efectivamente sus exigencias. De acuerdo con las conversaciones sostenidas con uno de los miembros de la junta directiva de FEDEPALMA, ${ }^{24}$ la mayoría de los asociados

22. El RNP fue creado y reglamentado mediante el Acuerdo no 001/95 de la junta directiva de FEDEPALMA para atender los compromisos y las obligaciones que señala la ley 138 de 1994 y demás normas que regulan su fondo.

23. Véase Bandeja de entra de la Corporación Centro de Investigación en Palma de Aceite, CENIPALMA. Para mayor información se puede consultar la siguiente página: <https://sibcolombia.net/socios/cenipalma/>.

24. Entrevista concedida por un empresario de Inparme SA; efectuada en agosto de 2013 (archivo entrevistas: visitas de campo, la autora). 
conocen los lineamientos y la filosofía del gremio y actualmente está en proceso una sistematización sobre su gestión y ejecución para que cada miembro pueda mostrarlo públicamente de forma escrita.

En otra entrevista realizada a un miembro de la Unidad de Gestión Comercial de FEDEPALMA, este señaló que su labor como gremio se centra en fomentar la industria palmera en Colombia a través de la investigación y las diversas informaciones en materia técnica, ambiental y laboral para que los palmicultores dispongan de las herramientas necesarias para llevar a cabo las labores de forma eficaz. Al parecer, las competencias del gremio se concentran en actividades para impulsar el crecimiento de la industria de palma de aceite, pero no contraen responsabilidades de las actuaciones irregulares de las personas jurídicas o naturales asociadas a su entidad. Al rastrear las declaraciones que aparecen en los estatutos del gremio, las disposiciones se ciñen explícitamente a la importancia del cumplimiento como miembros afiliados y a las estipulaciones señaladas por el Gobierno. Existe un manual sobre el código de ética y buen gobierno, en el cual se menciona que la Federación actuará como veedor ante conflictos de interés:

La Junta Directiva Nacional de FEDEPALMA, determinará el conducto regular para la declaratoria de conflictos de interés. Una vez identificados posibles conflictos de intereses, la Federación deberá implementar los mecanismos conducentes para realizar periódicamente el seguimiento de estas situaciones. [...] La Junta Directiva Nacional de FEDEPALMA y la Administración de la Federación actuarán como veedores permanentes (FEDEPALMA 2010: 9).

En algunos de los apartados se hace mención a la sanción del afiliado que no cumpla con las normas judiciales, pero el gremio como entidad no dispone de los mecanismos para determinar las falencias en el cumplimiento pleno de sus socios. En ese mismo documento se menciona que lo establecido en la Mesa Redonda de Aceite de Palma Sostenible, RSPO (por sus siglas en inglés), es la guía para la Federación: "El sector se ha fijado como objetivo el avance hacia el cumplimiento de los principios y criterios del desarrollo sostenible consagrados en el documento de la [...] RSPO” (FEDEPALMA 2010: 1). 


\section{Normativas para la promoción}

Como lo señalan Irene Vélez et al. (2010), la implementación de un marco legal que favorece la producción y el consumo de los agrocombustibles en Colombia busca sentar disposiciones legales para dar vía libre a las subvenciones y preferencias fiscales para el gremio palmero. Algunas de las estipulaciones en materia legal son las siguientes:

\begin{tabular}{|c|c|}
\hline LEYES & DECRETOS \\
\hline $\begin{array}{l}\text { Ley } 101 \text { de 1993, a través de la cual se } \\
\text { crea el Incentivo de Capitalización } \\
\text { Rural (ICR), definido como un } \\
\text { "aporte en dinero". }\end{array}$ & $\begin{array}{l}\text { Decreto } 1970 \text { de } 2005 \text {, por el cual se } \\
\text { exime de la renta líquida gravable a } \\
\text { los cultivos de tardío rendimiento por } \\
\text { diez ańos. }\end{array}$ \\
\hline $\begin{array}{l}\text { Ley } 939 \text { de } 2004 \text {, por la cual se estimula } \\
\text { la producción y comercialización de } \\
\text { agrocombustibles de origen vegetal o } \\
\text { animal para uso en motores diésel. }\end{array}$ & $\begin{array}{l}\text { Decreto } 2629 \text { de } 2007 \text {, por medio del } \\
\text { cual se dictan disposiciones para } \\
\text { promover el uso de agrocombustibles } \\
\text { en el país, así como medidas aplicables } \\
\text { a los vehículos y demás artefactos a } \\
\text { motor que utilicen combustibles para } \\
\text { su funcionamiento. }\end{array}$ \\
\hline $\begin{array}{l}\text { Ley } 1111 \text { de } 2006 \text {, que establece una } \\
\text { deducción del impuesto de renta del } \\
40 \% \text { de las inversiones en activos } \\
\text { fijos reales productivos en proyectos } \\
\text { agroindustriales, incluyendo leasing } \\
\text { financiero. }\end{array}$ & \multirow{2}{*}{$\begin{array}{l}\text { Decreto } 383 \text { de } 2007 \text {, modificado } \\
\text { parcialmente por el Decreto } 4051 \text { de } \\
2007 \text {, que establece estímulos para } \\
\text { la implementación de zonas francas } \\
\text { para proyectos agroindustriales en } \\
\text { materia de agrocombustibles. Renta } \\
\text { de } 15 \% \text { (vs. } 34 \% \text { ) e introducción de } \\
\text { equipos libres de arancel e IVA cuando } \\
\text { la inversión sea superior a } 1.775 .000 \\
\text { (USD dieciocho millones) o genere } \\
\text { quinientos empleos. }\end{array}$} \\
\hline $\begin{array}{l}\text { Ley } 1133 \text { de } 2007 \text {, por medio de la cual } \\
\text { se crea e implementa el programa } \\
\text { Agro Ingreso Seguro (AIS), que busca } \\
\text { mejorar la competitividad del sector } \\
\text { agropecuario colombiano en un } 16 \% \text {. }\end{array}$ & \\
\hline
\end{tabular}

El programa de Agro Ingreso Seguro que se llevó a cabo durante la presidencia de Álvaro Uribe y bajo la administración del ministro Andrés Felipe Arias ha sido uno de los casos más conocidos de corrupción, ya que las adjudicaciones del dinero fueron a parar en manos 
de terratenientes y reinas de la belleza, así como se documenta en el fragmento de un artículo en la revista Semana:

Como lo señala el ex ministro de Hacienda Rudolf Hommes, el programa, que apenas ahora se convierte en escándalo de medios de comunicación, ya había sido criticado en foros académicos "por sus efectos nocivos sobre la distribución del ingreso y porque, en lugar de fomentar inversión productiva, desconoce principios básicos de justicia distributiva y de eficiencia en el gasto” (Semana 2009).

\section{Diacronía DE LA industria DE PALMA DE ACEiTe}

Aunque las versiones sobre la introducción de la palma de aceite en el territorio colombiano difieren entre sí, lo que parece estar claro es que desde sus inicios no ha habido un programa uniforme a nivel nacional que articule el cultivo con políticas de desarrollo rural. Para comprender los impactos que genera la producción de palma de aceite en Colombia, es necesario conocer las fases por las que ha atravesado el desarrollo del cultivo. Veamos su evolución.

Hacia finales de los años cuarenta, la introducción del cultivo de palma de aceite para fines comerciales fue promovida a través de una política de fomento de la agricultura comercial en el marco de la sustitución de importaciones. Varios factores marcaron de manera fundamental el derrotero que seguiría la incursión de ese nuevo cultivo en el país, algunos de ellos son los siguientes:

- La gestión emprendida por el Instituto de Fomento Algodonero (IFA) para aventurarse hacia la promoción de algodón y otras oleaginosas.

- El programa fue dirigido como proyecto gubernamental proporcionando condiciones en el campo técnico y financiero para su consolidación; es decir, se trataba de un decidido trabajo conjunto entre Gobierno y empresa privada. Este proyecto buscaba suplir las necesidades nacionales en materia de aceites y grasas a través del fomento de la producción nacional.

- En el marco de esa política de sustitución de importaciones se creó el Programa de Fomento para el Cultivo de la Palma y se establecieron sociedades entre el Gobierno y la empresa privada. De esta 
forma se introdujo una plataforma para incentivar el desarrollo de lo que empezaba a ser una industria. De acuerdo con Martha Ospina y Doris Ochoa, el estímulo financiero por parte del Gobierno "trataba de adecuar la financiación a las características del ciclo productivo [...] concediéndole créditos con tasas preferenciales" (1998: 64).

Durante esa década se iniciaron los cultivos de palma de diferentes variedades como parte de la política de fomento a las oleaginosas. El Instituto de Fomento Algodonero gestionó el cultivo de semillas para la producción, seleccionando y distribuyendo el material y realizando cruzamientos para obtener mejor calidad en las plantaciones. Durante este mismo tiempo se encargó a la hacienda Patuca, departamento del Magdalena, la administración de la plantación. En ese mismo lugar, la United Fruit Company había iniciado este cultivo a inicios de la década de los años cuarenta y había introducido la primera plantación de palma en Colombia tras haber comenzado ya con cultivos en Honduras, Guatemala y Costa Rica. Ante la coyuntura de la Segunda Guerra Mundial, la United Fruit Company retomó los cultivos de banano bajo el nombre Magdalena Fruit Company y además introdujo las plantaciones de palma con un objetivo comercial: "Esta escasez de grasas y aceites en Europa y América debió mostrar a la United Fruit nuevas oportunidades de hacer negocios", así lo señalan Ospina y Ochoa (1998: 1). Como lo sugiere Fajardo (2006), la introducción de los cultivos del banano y de la palma africana fueron simultáneas, primero en el Urabá y luego extendiéndose hacia otras zonas del país. En el estudio que hace Goebertus (2008), no se refiere a una simultaneidad, sino a una transición del banano a la palma y trata de establecer algunas trayectorias de estos cultivos en relación al desplazamiento forzado.

En 1962 las plantaciones de palma se iniciaron en zonas apartadas del país, lo que se llamó "colonización con base en palma africana”. El cultivo inicial era de 2000 hectáreas sembradas en cinco regiones definidas: Norte de Santander; Magdalena, en la zona sur; Cauca; Nariño, en la zona de la costa; y Caquetá, (Ospina y Ochoa 1998:70) y ríos o aluviones importantes de cada región. Las hectáreas se debían extender de manera paulatina de acuerdo con las posibilidades. En cuanto a la distribución de la tierra, se estableció localizar en cada región ochenta parcelas de 25 ha cada una, dentro de las cuales 10 ha se dispondrían 
para el sembrado y las otras 15 para la reserva de la extensión prevista. Las tierras se darían para el trabajo de campesinos en unidades agrícolas familiares (UAF), a quienes se les otorgaría créditos para pagar las tierras durante un periodo de doce años. El trabajo en cooperativas de colonización también fue uno de los mecanismos que se utilizó para garantizar la compra del fruto a los colonos sin intermediarios. No hay mucha información detallada ni sobre la estructura de las cooperativas ni tampoco sobre su funcionamiento durante esa fase inicial. Tampoco se encuentra documentación sobre los impactos o beneficios para las poblaciones locales. Las cooperativas son un mecanismo que se ha mantenido a lo largo de la historia de la palma de aceite en Colombia, como lo veremos posteriormente.

La palma de aceite es catalogada como un cultivo de carácter permanente (o semipermanente), junto con el café, la caña de azúcar, la cańa panelera, el plátano, el banano y los cultivos ilícitos, y es el que mayor crecimiento ha representado en los últimos años en el territorio colombiano. Su dinámica va en ascenso y seguirá la misma tendencia, comprometiendo cada vez más áreas, extendiendo la frontera agrícola e invadiendo la diversidad del paisaje agrario nacional. Los pronósticos se basan en la serie de proyectos que están en marcha para ampliar los cultivos de palma de aceite y de cańa de azúcar, que son los productos destinados a la energía carburante:

Se podría decir que a futuro el área de ocupación del territorio en este tipo de sistemas productivos va a ser el de mayor crecimiento [...] en proceso de investigación y desarrollo para los mismos fines se tienen cultivos de maíz, jathropa, sorgo dulce, higuerilla, girasol, soja, maní, aguacate y cocotero entre otros (Agencia Presidencial para la Acción Social y la Cooperación Internacional 2010: 94).

Se han empezado a explorar proyectos agrícolas con la remolacha y la yuca como productos alternativos para las materias orgánicas de los carburantes. En mi visita en agosto del 2013 recorrí parte de la región Oriental y pude apreciar cómo gran parte de los campos que tradicionalmente estuvieron dedicados a la ganadería se han convertido en enormes extensiones ocupadas por el cultivo de palma. En mis conversaciones con miembros del gremio de FEDEPALMA se evidenció que el cambio de vocación de las tierras para usos agrícolas es visto como 
un desarrollo en el país. Sin embargo, la transición de un uso a otro no puede ser vista de manera parcial. La concentración de tierras muestra la aguda asimetría en las actividades agrícolas y tiene serias influencias en la seguridad alimentaria de las poblaciones rurales. Por otra parte, la relación entre los cultivos permanentes y semipermanentes muestra una ventajosa extensión de los segundos: en un área de 24,56\% de tierras aptas para cultivos agrícolas en el país, aquella destinada para los cultivos semipermanentes ocupa menos porcentaje (1,56\%), mientras que a los cultivos permanentes se les asigna un 2,20\% del total (Agencia Presidencial para la Acción Social y la Cooperación Internacional 2010: 45).

\section{EsTRATEGIAS DE PRODUCCióN}

Las dos estrategias que se ponen en práctica a nivel global para promover la industria de los agrocombustibles se implementan también en Colombia. Por un lado, existen los grandes complejos palmeros que organizan todo el engranaje de la infraestructura y adquieren territorios en propiedad (o en alquiler) para llevar a cabo la cadena productiva. La otra forma es vincular y comprometer a los agricultores de pequeños y medianos terrenos para incentivarles a incursionar en el cultivo. La demanda de tierras requerida para la agricultura extensiva reproduce escenarios de contención en los cuales se aplican mecanismos de hostigamiento hacia las poblaciones rurales. En diversos contextos se usan procedimientos irregulares para hacer legítimas las adquisiciones de grandes predios. La segunda modalidad funciona bajo lo que se conoce como las alianzas estratégicas.

\section{Cadena productiva}

Las zonas más aptas para la producción de palma son aquellas de climas cálidos, característicos de sitios cercanos a la franja ecuatorial. La cadena productiva en Colombia estaría compuesta por tres fases principales, según señala Mingorance: "La agroindustria de la palma 
de aceite, las industrias de transformación del aceite y los procesos de comercialización" (2006: 11). La extracción del aceite proviene del fruto prensado, y, dependiendo de la parte que sea procesada, se pueden obtener cuatro productos distintos: el aceite de palma crudo, la almendra de palma, el aceite crudo de palmiste y la torta de palmiste. Los escenarios de conflictividad están relacionados con lo que Pérez Rincón llama "el ciclo agrícola, el cual corresponde a la siembra, cultivo y cosecha de la planta el ciclo industrial o de transformación de la materia prima en etanol o biodiésel " (2008: 84), es decir, la primera fase de la cadena, que es la que involucra y afecta directamente a las comunidades rurales. En esta fase es donde se han implementado las alianzas estratégicas como parte del concepto de desarrollo rural.

\section{Alianzas productivas estratégicas}

Las alianzas productivas estratégicas son un modelo que se introdujo en Colombia y que ya se había desarrollado en Malasia, Costa Rica y Venezuela a finales del siglo pasado. Se cambió el modelo de producción a gran escala para introducir uno a pequeña escala, vinculando a pequeños agricultores. Este concepto se fundamenta en la práctica de negocio inclusivo, que profetiza supuestos beneficios para los campesinos, para que se atrevan a convertirse en empresarios. Volveré a este tema más adelante para contrastarlo con las experiencias de los campesinos en sus composiciones líricas. Existen dos tipos de alianzas productivas estratégicas: organizaciones de productores, vinculadas directamente a la comercialización con las empresas extractoras, y organizaciones de productores cuyo nexo es indirecto. De acuerdo con una evaluación de consultoría, "Alianzas productivas estratégicas en palma de aceite", llevada a cabo en el 2010, las organizaciones con vinculación directa tienen mejores resultados. En ese informe se evalúan cuatro dimensiones: organizacional, productiva/ambiental, comercial/financiera y administrativa. La conclusión a la que llega el reporte de evaluación indica que el desempeño depende más de las empresas y menos de los vinculados en la alianza, como lo expresa el siguiente fragmento: 
Las Alianzas con mejor desempeño son aquellas donde las organizaciones de productores tienen vínculos comerciales y de otros servicios con las empresas extractoras (Tipología 1), aunque la estrategia de interacción de cada empresa palmera con los productores con los que establecen Alianzas es particular y heterogénea, y depende en buena parte de las características gerenciales de las empresas. (Alianza SNV y CECODES 2010: 11) ${ }^{25}$

Sin embargo, no hay detalles sobre el efecto real en términos de empoderamiento para las pequeńas organizaciones. El desarrollo de las alianzas se ha dado de forma diferente en las regiones, ya que se han asociado pequeños agricultores, algunos propietarios y otros sin propiedades. Algunas de esas alianzas han sido un instrumento utilizado para la erradicación de cultivos ilícitos, que se implementó especialmente durante el Gobierno de Álvaro Uribe (2002-2010). Las alianzas productivas estratégicas son formas de organización vertical en las que los pequeños agricultores están vinculados a la producción mediante el otorgamiento de un crédito. Para la compañía se trataba de engrosar "la capacidad empresarial, incrementado los rendimientos del negocio" (Rangel, Ramírez y Betancourt 2009: 56). Para el gremio, las alianzas productivas estratégicas cumplen con la demanda de responsabilidad social que tienen las compañías hoy en día. Sin embargo, los criterios y gestiones de responsabilidad social son muy controvertidos, pues gran parte de su gestión se enfoca hacia la construcción de un discurso retórico que muestre los supuestos beneficios que aportan las compañías. En términos prácticos, los CSR (por sus siglas en inglés) son sistemas para proteger y favorecer los intereses de las compañías.

En la conversación que sostuve con los empresarios palmeros, una de las preocupaciones actuales es que las empresas afiliadas a FEDEPALMA deben obtener las certificaciones requeridas para poder comercializar en el mercado de la industria de palma. De acuerdo con los datos revelados por ese gremio en el año 2018, 11 empresas contaban con la certificación de la RSPO y 24 estaban en proceso de evaluación para obtener la certificación en 2020 (La Opinión, 2018) en la que se contempla no solo el cumplimiento de lineamientos y códigos a nivel medioambiental

25. La evaluación es realizada por una empresa holandesa SNV y el Consejo Empresarial Colombiano para el Desarrollo Sostenible CECODES. 
y social, sino también las transformaciones reales que transfiere el negocio de los agrocombustibles a los pequeños productores. Muchas de las compañías señalan la generación de empleo, la construcción de escuelas o carreteras y las viviendas como indicadores del mejoramiento en las zonas rurales. El índice de la creación de empleo directo e indirecto entre banano y palma de aceite calculado por Joaquín Virola de Hoz (2008) muestra que la palma genera el 0,16\%, mientras el banano el 0,83\% (43) por hectárea. Además, las plantaciones de palma tienen una repercusión negativa en la generación de empleos indirectos, mientras que el banano tiene un comportamiento positivo en este sentido. La sustitución del cultivo de banano por el de palma de aceite ha causado fuertes impactos en la generación de empleo en la Zona Bananera del Departamento del Magdalena.

Si bien se garantizan aportes al desarrollo en la infraestructura, la adquisición de terrenos en los contextos agrarios en los que se cultiva palma queda fuera del tema de la responsabilidad social. Por otra parte, las certificaciones deberían tener en cuenta las dinámicas de la tenencia de la tierra, atendiendo a mitigar la concentración o el acaparamiento territorial. Contemplar esas dinámicas ayudaría a determinar parámetros para medir el impacto en términos de sustentabilidad de los sembrados de palma en relación con el ordenamiento territorial.

Es un hecho que las áreas con presencia de alianzas productivas estratégicas se han extendido y, al respecto, Rangel, Ramírez y Betancourt (2009) indican que "para el ańo 2005, el 25\% del área nueva sembrada desde 1998 pertenecía a 83 Alianzas Estratégicas. [...] distribuidas mayoritariamente en las zonas palmeras Norte central del país con 45.379 hectáreas" (56). Los testimonios de campesinos de las regiones en las que se lleva a cabo la expansión de los monocultivos tanto de caña de azúcar como de palma de aceite reportan que hay demandas interpuestas a las empresas por diversas razones, entre ellas están las siguientes:

Uso y propiedad de la tierra, paramilitarismo, desplazamiento forzado, la flexibilización laboral y las condiciones infrahumanas del trabajo, pérdida de la soberanía alimentaria, violación de derechos colectivos de pueblos indígenas y afrodescendientes (H. Vélez 2008: 20). 
SEgunda Parte 



\section{Capítulo v}

\section{Casos de estudio}

Comunidades de enfoque para el análisis

En este capítulo, se aborda cada uno de los casos de estudio, es decir, cada una de las comunidades, de forma individual. La parte inicial se abre con un preámbulo introductorio en el que se cita una o varias estrofas para ilustrar la creación lírica comunitaria en relación a las confrontaciones ocasionadas por los cultivos de palma de aceite. El propósito es analizar en las letras la construcción discursiva y temática que hacen las comunidades como consecuencia de la usurpación de las tierras, el desplazamiento y el despojo, que no solo se da a nivel del capital material, representado a través de las hectáreas de tierra, sino que ocasiona un resquebrajamiento de los bienes culturales que han cultivado ancestralmente las comunidades. Es de vital importancia reconocer que desde el lenguaje de las comunidades, la naturaleza y su diversidad no representan solamente recursos, sino, sobre todo, representan bienes comunitarios. De ahí que el valor que se les otorga no está en relación con la acumulación. En este sentido es útil el concepto del intercambio que Foucault (2010) propone, pues considera que los análisis de los utilitaristas y los fisiócratas se acercan y son complementarios cuando se trata de asignar un valor: "Los unos se preguntan en 
qué condiciones - y a qué precio - puede un bien convertirse en un valor dentro de un sistema de intercambios; los otros, en qué condiciones puede transformarse un juicio de apreciación en un precio dentro de este mismo sistema de intercambios" (Foucault 2010: 213). Los juicios de apreciación sobre la tierra en términos de necesidad y utilidad son dos aspectos fundamentales que se revelan tanto en el discurso lírico de las composiciones como en las acciones emprendidas por las comunidades.

Después de ilustrar la lírica musical, se analizan los diferentes factores contextuales que han dado lugar a las tensiones entre comunidades e industria palmera. En esta sección se elabora un diagnóstico del conflicto: cronología, actores, temas, intereses, motivaciones y desarrollo de las disputas, entre otros. A efectos metodológicos se utiliza el modelo de análisis propuesto por Grundmann y Stahl (2002), el cual integra diferentes aspectos que contribuyen a determinar las especificidades que caracterizan cada uno de los casos. Además, este instrumento de valoración tiene como propósito central buscar los elementos invisibles ${ }^{1}$ que no se pueden detectar desde la observación exclusiva en un solo plano. Estos factores también se pueden rastrear a través del repertorio sociocultural almacenado en los cantos, en donde se combinan diferentes niveles narrativos que están representados en el texto lírico.

1. Johan Galtung (1998) se refiere a los factores invisibles latentes en los conflictos. En este estudio, parte de esos factores invisibles se examinan a través de la creación lírica. 


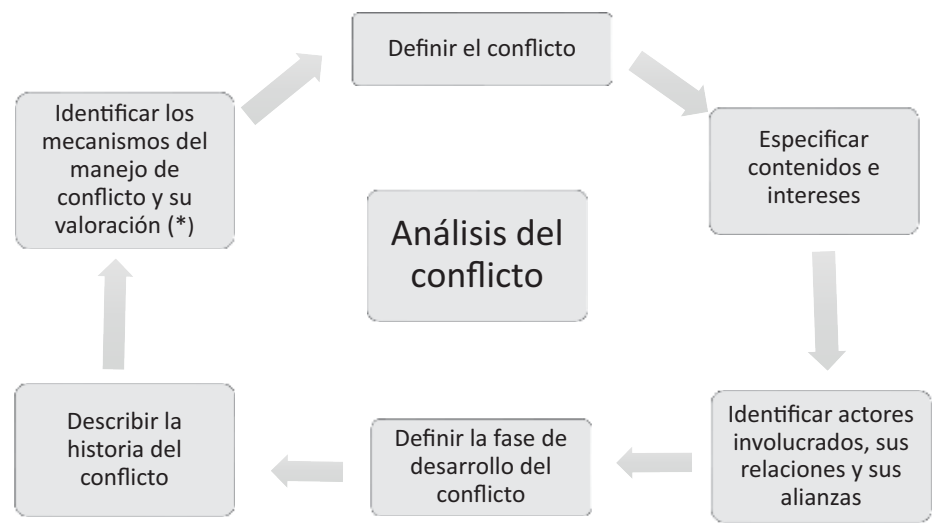

9. Instrumentos de diagnóstico y análisis

Fuente: modelo tomado de Grundmann y Stahl (2002:118)

(*) Modificado por la autora

\section{Comunidad de Las Pavas}

Diversas organizaciones de acompañamiento a las comunidades rurales coinciden en que la de Las Pavas representa el caso emblemático de tierras en la actualidad en Colombia. En el informe presentado por La Clínica Jurídica de Derecho y Territorio de la Facultad de Ciencias Jurídicas de la Universidad Javeriana considera, además, que es un "caso difícil" no solo en términos jurídicos, sino que "podía servir de base para el diseño de una dogmática jurídica para el proceso de restitución de tierras" (4) en Colombia.

Las imágenes que aparecen a continuación ilustran el trabajo y los anhelos comunitarios. En la foto de la izquierda aparece una de las consignas que suele ambientar la entrada de la hacienda de donde han sido desplazados los paveros. La mayor parte de la hacienda está invadida por los monocultivos de la empresa palmera. En la otra parte que aún no ha sido ocupada es donde se asientan algunos integrantes de la 
comunidad, que son parte de la Asociación de Campesinos de Buenos Aires (ASOCAB). En la imagen de la derecha, se encuentra el logo que ha adoptado la comunidad tras haber iniciado su proceso de nuevo retorno: "Regresando a la tierra prometida".

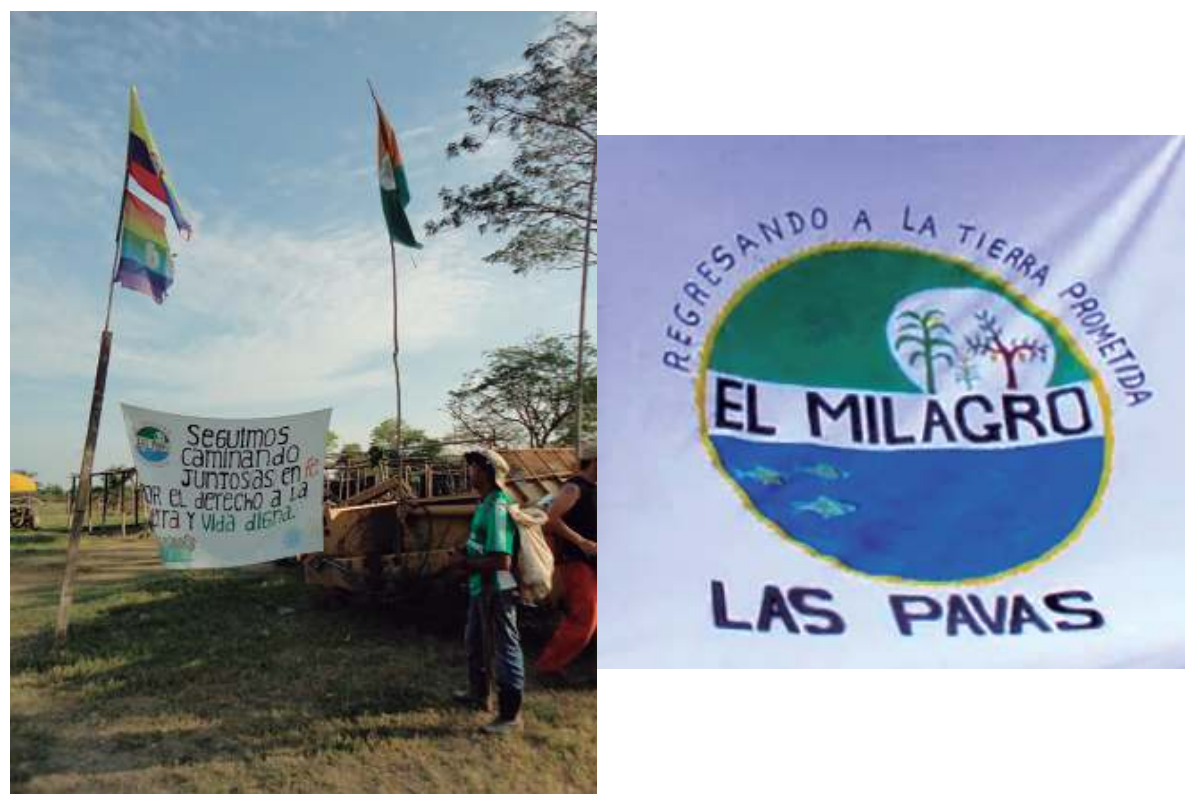

10. Comunidad Las Pavas

Fuente: archivo propio de la autora, visita al terreno, febrero de 2012

Fuente: página virtual Retorno a Las Pavas

(<https://www.retornoalaspavas.wordpress.com/>)

MÚSICA Y TERRITORIO

Desarraigo y retorno

El desarraigo marca una ruptura abrupta e involuntaria con el presente, es decir, con la existencia de una contemporaneidad que se retroalimenta de experiencias, convicciones y rituales conectados con las raíces de la tradición. Una de las primeras premisas que se manifiesta 
en los cantos es la relación entre bienes naturales y ser humano. El valor fundamental del sentido de pertenencia en las composiciones de esta comunidad reside en la máxima "El campesinado pertenece a la tierra, así como la tierra pertenece al campesino". Esa noción de pertenencia se fundamenta en la racionalidad que se explicó en el segundo capítulo y contiene en su significado una dualidad conceptual formada por los principios de reciprocidad y complementariedad, a partir de los cuales se construye una idea central sobre la necesidad del retorno. La prioridad de la subsistencia representa lo más inmediato, pero está conectada con el cuidado de valores culturales, la organización cultural y social que se adapta y respeta los ciclos naturales, las interacciones con los mundos espirituales y demás fundamentos de la subjetividad campesina.

La noción de pertenencia se ubica en un orden arquetípico y fundacional del origen mítico, que es expresado en los cantos, en lo que me detendré en detalle más adelante. Existe una correlación entre la naturaleza y el campesinado, no como idea romántica, sino como uno de los juicios sobre los que se funda la existencia misma, así como también las lógicas de organización social, política y económica de los habitantes rurales. No solo las comunidades desplazadas en Colombia se pronuncian sobre la soberanía territorial y acuífera, los procesos de migración forzada se están viviendo en muchas otras partes del hemisferio sur. En Malasia e Indonesia también se puede identificar una resistencia por la usurpación de territorios campesinos en favor de la industria palmera, como se documentó en el capítulo anterior.

La producción del CD Les voy a cantar la historia, de la comunidad de Las Pavas, retrata en su creación musical el fenómeno del desplazamiento y resalta las acciones comunitarias por el retorno, el cual construirá el programa lírico de los cantos, como lo vemos en lo que expresa Etni Torres, cantautor de la comunidad, en esta estrofa:

Llegó la hora de regresar a mi tierra

Donde pienso plasmar mis proyectos

De donde nos sacaron a precio de guerra

Y nos humillaron en aquellos tiempos.

(Etni Torres, "Llegó la hora”) 
Retomemos la idea del retorno con relación a un concepto fundacional mencionado antes. El deseo de retornar, en el caso específico del desplazado, no solamente está relacionado con la conexión natural y la necesidad biológica de la tierra como dadora de vida, sino que expresa la necesidad de "plasmar [sus] proyectos", sociales, económicos y políticos.

La expulsión como eje central desencadena dos motivos que se encuentran descritos en las composiciones: por un lado, el proyecto fundamental en la noción de retorno, porque se vincula al concepto de lo utópico-alcanzable, y, por otro, la modificación del statu quo. Es importante y necesario reiterar que estas composiciones se gestan dentro del desplazamiento forzado, ocurrido en espacios de alta tensión y enfrentamientos armados, por ello, la relación de pertenencia y filiación presente en la lírica comunitaria tiene componentes diferentes de los que pudiera tener una composición lírica proveniente de un contexto de migración no forzada. En realidad, los flujos migratorios voluntarios, que debaten varios de los representantes de los estudios culturales, tienen otra caracterización. La alusión a la expulsión — forzada — se aprecia en la expresión "nos sacaron a precio de guerra". Esta frase no solo hace referencia a la situación singular de esta comunidad, sino que ilustra el fenómeno del desplazamiento forzado en Colombia dentro del marco de una estrategia de guerra, concebida en términos de valor monetario. Respecto a la situación de la migración involuntaria Ibáñez (2008), Fajardo (2002) y otros expertos consideran que la relación entre conflicto y desplazamiento no es una relación de causa y efecto respectivamente, sino que en el caso colombiano se da de manera inversa: se crea el desplazamiento forzado para dar lugar al conflicto y así tener el control de la tierra. ${ }^{2}$ Incluso la frase "precio de guerra", escrita por Etni, cantautor pavero, confirma lo que estos investigadores sugieren sobre la relación inversa al producirse los desplazamientos forzados como estrategia.

El último verso de la estrofa antes citada expresa un mecanismo de interacción entre los campesinos y los expulsores. La "humillación" como acción de degradación y desprecio empieza a dar cuenta de las relaciones de poder que marcan la disputa, y este aspecto es reiterativo

2. Un excelente estudio sobre la evolución del desplazamiento forzado se puede consultar en César Rodríguez Garavito (2010). 
en varios cantos. La asimetría en las relaciones de poder enfrenta al campesino a la búsqueda de instrumentos de sobrevivencia. Uno de esos elementos, inherentes a su entorno cultural y que le permite explicarse su situación de desplazado, se representa a través de la figura de lo sagrado. No se trata solo de retornar, sino de poder hacerlo para vincularse esencialmente a lo vital e integrarse a lo mítico-original, como se recoge en el siguiente fragmento del canto:

\section{Primera estrofa}

Me puse a contemplar los Dioses

Con ese Dios tan grande que es el de Israel

Allí yo pude comprender

Que él que tiene la fuerza y también tiene la gloria

Es el que profesa Eliud y Misael

\section{$\underline{\text { Tercera estrofa }}$}

Mi Cristo está cumpliendo la promesa Porque de la tierra, él es dueño también Aunque estas palmeras tengan mucha fuerza

Pero no tienen más fuerza

Que el Dios de Israel.

(Edwin Torres, "Los dioses de la tierra")

\section{Significados de lo sagrado}

En esta y muchas otras composiciones se observa que, con frecuencia, se integran los nombres propios de los miembros de la comunidad, como aparece en el primer fragmento de la primera estrofa. Mencionar en el canto a Eliud y a Misael, dos líderes de la Asociación de Campesinos de Buenos Aires (ASOCAB), es una estrategia discursiva empleada para reafirmar en el relato lírico el profundo significado que tiene la filiación comunitaria para dicha asociación. Estas dos personalidades profesan confesiones religiosas diferentes, $y$, aunque eso podría representar un obstáculo, no lo es, por el contrario, este hecho se convierte en una fuente de mayor vinculación para la acción pública de la colectividad.

Por otra parte, se representa un poder que esos personajes reciben a través de su acervo religioso, lo que se expresa como una conexión entre quien tiene la fuerza y la gloria, que en el canto es Dios, y los personajes que están en el compromiso de mostrarse como testimonio y portan esos mismos atributos. Pero el tema de la fuerza y el poder no se expresa exclusivamente en un dominio supranatural y humano, $y$ 
este es uno de los aspectos que resulta más interesante en la construcción cognitiva y perceptiva de la lírica campesina. Se trata de un poder expresado por la naturaleza, en el que esta es partícipe del mensaje del mundo espiritual. Entonces, en este sentido, la fuerza de la naturaleza no es solamente una percepción sensorial que se manifiesta a través de la degradación material, sino que se instaura como conocimiento entre dos entidades: una humana, el campesino, y otra no humana, la naturaleza. El conocimiento se inscribe en la experiencia plena de relación actancial expresada en "yo pude comprender". Ahora tenemos una tríada - conocimiento, fuerza y poder- que se interconecta de una forma especial y que relaciona a los dos actantes o personajes de los cantos, pero siempre se inserta dentro de un dador o creador de quien emana ese poder. Por ello, el poder se muestra como un estímulo de acciones armónicas o como una energía que sacude y castiga.

En el pasaje de las estrofas antes citadas, no hay amonestación, pero más adelante en otros fragmentos, se manifiesta un antagonismo de poderes, como se observa en la segunda estrofa. Allí se aprecia también cómo la fuerza de la divinidad tiene mayor alcance y su poderío se contrapone a la fuerza de la planta de palma de aceite, que a su vez se compara con la industria palmera. El término las palmeras puede tener una doble connotación: por un lado, se reconstruye como una metáfora que representa la incursión del negocio industrial y, por el otro, la planta misma, cuyo monocultivo ha invadido los territorios comunitarios.

El tema del campesino- tierra es recurrente como motivo de la composición en diferentes estilos musicales. Jorge Artel (2002), un poeta de antaño, consigna en sus versos la búsqueda campesina por el asentamiento. Sus versos están inspirados en las sabanas del Sinú, en el departamento de Córdoba (la misma Región Atlántica en la que se encuentra ubicada la comunidad de Las Pavas), y consignan el éxodo de campesinos a finales del siglo XIX tras haber sido expulsados por franceses y norteamericanos, que habían llegado para establecer enclaves y plantaciones de cacao con fines de exportación, como se observa en el siguiente fragmento:

¿Adónde va el pensamiento

Por tres calles solitarias, 


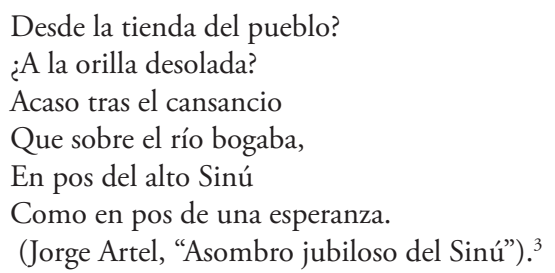

La poesía de Artel y los cantos de la comunidad de Las Pavas coinciden en retratar la experiencia del habitante rural a través de la trashumancia, ámbito en el que se articula la relación campesino-tierra. Esta dualidad ha estado presente en la narrativa rural y persiste aún en la tradición lírica. Sin embargo, existe una diferencia en la construcción discursiva: en la lírica y la narrativa oral campesina contemporánea, la fuerza ilocutiva de la reclamación revela la inequidad sistémica. No solo se expresa un lamento, sino que se construye la afirmación sobre la necesidad de transformación estructural. El matiz comunitario se manifiesta e insiste en contrarrestar los mecanismos que sostienen las estructuras señoriales, manteniendo relaciones de tierra-jornalero, tierra-arrendatario y tierra-peón, entre otras. De acuerdo con los planteamientos de Fals Borda (2009), lo que se dio a finales del siglo xviII fue "una transición de las relaciones sociales de producción coloniales (señoriales, esclavistas) a las capitalistas" (68). ${ }^{4}$ En la lírica reciente aparece de forma más pronunciada un tono crítico, pero, a su vez, se incluye en la construcción discursiva el quehacer político y la inclusión sociopolítica como derroteros para la transformación; concretamente, se expresa un claro rechazo a la exclusión y el despojo territorial.

En las tres estrofas presentadas previamente encontramos una relación de fuerzas triangular entre campesino-palmera (agroindustria)-Dios en la que existen alianzas y disputas. En el lenguaje del manejo del conflicto, el término alianza es importante para poder referirse también a la negociación. Más adelante veremos en qué consisten las alianzas

3. Citado por Fals Borda (2009: 82).

4. Mecanismos como la libertad de vientre, la matrícula, el concierto remunerado y el concierto forzoso, entre otros, fomentaron la dependencia y la desigualdad. Para mayor información, consultar Fals Borda (2009). 
y qué papel juegan en el marco de la transformación del conflicto. En el contenido lírico que presenta el fragmento citado, esa alianza se refiere a la idea judeocristiana de la tierra prometida: Dios establece una alianza con el pueblo. Sin embargo, esa fuerza divina no actúa por sí sola. Aunque en el canto no se exprese explícitamente, profesar, lo que hacen Eliud y Misael, líderes de la comunidad, es justamente poner en práctica ese vínculo entre el campesino y esa instancia superior, Dios, que los impulsa a continuar la lucha por la tierra prometida.

Si vemos detenidamente la construcción del relato en los cantos, su retórica recurre poco al uso de las metáforas, el discurso está constituido en su mayoría por figuras simbólicas que se ocupan de entregar al oyente un sentido y un significado que va más allá de la semejanza. Los símbolos se convierten en agentes que reviven atributos de lo sagrado, especialmente en lo relacionado a lo mítico-poderoso. Como lo plantea Ricoeur (2011), "los símbolos tienen raíces. Los símbolos nos hunden en la sombreada experiencia de lo que es poderoso" (82). En los cantos la noción de 'tierra' aparece como un símbolo que contiene — como lo llama Ricoeur - un "excedente de sentido", que está relacionado con la idea fundacional del origen, tanto del inicio como del final que vuelve al origen. En ese sentido, la tierra como símbolo en el texto lírico recrea nuevamente esa proposición de experiencia sagrada que conecta la experiencia campesina con un carácter preverbal. No se trata de un enlace metafórico que apela a la lógica semántica, sino de un discurso que trasciende la lógica lingüística y se instaura en la simbología de lo sagrado. Adicionalmente, a través de la tierra como símbolo se expresa el resultado de una significación intersubjetiva que no solo ha tenido lugar en las comunidades en cuestión, sino en la diacronía campesina colombiana y latinoamericana.

\section{Simbolismos}

El simbolismo de lo sagrado se representa en la figura de la tierra, no como instancia suprema, sino como parte fundamental del engranaje de un todo. En las entrevistas realizadas durante mi visita a las comunidades, se pudo constatar que, para la mayoría de los campesinos 
desplazados, la tierra significa el todo: aun cuando en las composiciones se representa como un agente natural y mediador entre un poder supranatural, los pobladores rurales le atribuyen esa razón absoluta de su existencia. El nivel de integración campesino-tierra genera vínculos de filiación casi únicos entre ellos, de tal manera que se recrea una dialéctica complementaria en la que estos dos agentes se retroalimentan entre sí, casi hasta llegar a ser idénticos. La reivindicación de esa identificación se expresa en la necesidad que reclaman los campesinos de poseer sus tierras y de que esos reconocimientos estén respaldados por procesos legítimos y de legalización de títulos de propiedad. La situación actual de muchas comunidades campesinas es justamente el limbo de la no titulación de sus territorios, lo que les impide ejercer la autodeterminación territorial y tener plenos derechos sobre los terrenos. Muy a su pesar, permanece viva la esperanza del campesino por una situación mejor. La posibilidad de obtener la propiedad legal sobre los territorios en los que han trabajado y habitado por mucho tiempo alienta su lucha cotidiana y la realización de sus proyectos en un futuro próximo, como lo ilustra este canto:

\author{
Pero yo no me preocupo \\ Porque sé que un día es mañana \\ Viene la peste cogollera \\ Para la palma africana \\ Como yo no tengo fuerza \\ Para hacer una venganza \\ Se la dejo a Dios del cielo \\ Que es el dueño de mi alma. \\ (Edwin Torres, "Algún día es mañana")
}

En la representación simbólica están contenidas dos posibilidades del poder natural: la tierra, en su comprensión mayor, naturaleza, como dadora y portadora de vida, pero también con un poder punitivo; es decir, que es la naturaleza en su papel de agente quien recibe la facultad de sancionar, como se relata en la estrofa anterior, sobre la peste cogollera, enfermedad que le cae a la palma africana y que atacó duramente los sembrados del Chocó, acabando con gran parte de las plantaciones. Estas dos manifestaciones de la fuerza y el poder son cruciales al tratar de entender qué conceptos guían los procesos de interacción de las comunidades en 
conflicto por la tierra. En esta simbología se asume la sanción como parte del poderío natural que se vuelve cómplice del campesino desplazado. En otras palabras, estaríamos refiriéndonos a la venganza como mecanismo de interacción, pero aquí se trata de un resarcimiento que procede de un poder superior y emana desde lo sagrado. La misma acción de retornar y la reterritorialización material de las comunidades desplazadas adquiere en algunas composiciones un matiz de vindicación. Esto significa que el poder sobrenatural que se manifiesta en las entidades naturales se interpreta como una complicidad que surge de esa unión de binarios campesino-tierra. La naturaleza convoca, favorece y anima la lucha campesina.

Las comunidades campesinas contempladas en este estudio no le atribuyen a la tierra un estatus de deidad, no establecen una relación transcendental con la materia natural. Este aspecto se constituye como una de las diferencias esenciales respecto a la construcción conceptual entre los agentes naturales y los agentes humanos, pues muchas comunidades indígenas sacralizan y reconocen como deidades a entidades naturales —o que están habitadas por espíritus o dioses - como las montańas, los ríos, la tierra y otros elementos de la naturaleza.

Esta introducción sobre las composiciones líricas de la comunidad Las Pavas ilustra cómo en el potencial figurativo de los pasajes presentados se consignan algunas de las temáticas de confrontación entre el campesinado y la agroindustria. A continuación, veremos aspectos sobre el contexto ambiental, social y político de la zona donde se ubica la comunidad para poder comprender mejor las características contextuales en las que emerge el conflicto. Con apoyo del esquema propuesto al inicio, se hace un diagnóstico del contexto de las disputas en torno a la producción de palma de aceite en el territorio de Las Pavas.

CONTEXTO LOCAL Y CONFLICTO

\section{Contexto histórico}

Las Pavas es quizá uno de los casos de conflicto por tierras en Colombia que ha tenido mayor difusión tanto a nivel nacional como internacional. Este proceso lleva más de una década sin ser resuelto por 
las instituciones pertinentes. En el tiempo que se culmina este escrito, se publicó el auto del 25 de agosto de 2017 para resolver la solicitud de medidas cautelares que había solicitado ASOCAB. En ese documento se confirma que los actos de extinción de dominio se encuentran en firme y tienen plena ejecutoriedad. Asimismo, se le reconoce la función administrativa del caso a la Agencia Nacional de Tierras.

La finca Las Pavas está ubicada en el municipio de San Martín de Loba, departamento de Bolívar. De acuerdo con Shawn Van (s. p.), al territorio de San Martín de Loba llegaron los mormones a inicios del siglo xx para trabajar en agricultura, ganadería y minería. Tiene una extensión de 2.842 hectáreas y se compone de una agregación territorial conformada a mediados de la década de los sesenta en la que se distinguen cuatro predios: Si Dios Quiere (42 ha), No Te Canses (473 ha), Peñaloza (198 ha) y Las Pavas (471 ha). Esta comunidad desarrolla uno de los procesos más admirables de construcción de paz desde hace más de quince años y ha seguido pasos muy consecuentes en el contexto comunitario por la reivindicación del territorio. La comunidad, y, en representación suya, la Asociación de Campesinos de Buenos Aires (ASOCAB), se ha enfrentado a procesos legales que les han costado serias amenazas a sus miembros, amenazas que provienen de diversos actores, tanto grupos armados como otros, no armados. En ese proceso, el acontecimiento más reciente tiene que ver con la detención el 10 de noviembre del 2016 de un hombre de los grupos paramilitares que "dirigió la expulsión y desplazamiento de la comunidad de La Pavas en el año 2003". 5 Este mapa de la hacienda Las Pavas fue realizado por la Clínica Jurídica sobre Derecho y Territorio de la Pontificia Universidad Javeriana gracias a la información de Efraín Alvear Olivares, uno de los cantautores y miembro de la comunidad:

5. El artículo, que se reveló justo el 10 de noviembre de 2016, confirma esa información. Se puede consultar en el diario Vanguardia: <http://www.vanguardia.com/ colombia/379476-capturan-a-alias-rapidito-por-el-desplazamiento-de-123-familias-de-las-pavas>. 
La redistribución de tierras se remonta a la década de los años veinte, época en la cual los habitantes del corregimiento de Buenos Aires vivían de las actividades pesquera y maderera principalmente. El flujo de migraciones que se origina en el interior de los departamentos de la región, en especial del de Sucre, modificó la ocupación de los pobladores, así que la actividad agrícola y la ganadera se convirtieron en actividades fundamentales para los habitantes de esa región. La producción agrícola se concentra en el cultivo de productos tradicionales de pancoger ${ }^{6}$ como la yuca, el plátano, la batata, el arroz y el maíz. Los habitantes de estas zonas han mantenido una cultura anfibia, en tanto que son habitantes ribereńos y agricultores a la vez. En noviembre de 2013, la comunidad Las Pavas fue galardonada con el premio Nacional de Paz que otorgan el diario El Tiempo, Caracol Radio, Caracol Televisión, Proantioquia, FESCOL y el PNUD.

\section{Características ambientales de la región}

La hacienda Las Pavas está ubicada en la depresión Momposina, una de las áreas de mayor riqueza hídrica en el país. Geográficamente está situada en la isla de Papayal, que se compone de dos brazos: Río Viejo y Río Morales, procedentes del río Magdalena. Esta zona es una de las más cenagosas de la nación y está conformada por tres islas: la isla de Papayal, la isla de Mompox y la isla de Morales. En toda la depresión Momposina abundan caños, ciénagas y pantanos, que están interconectados entre sí y comparten torrentes hídricos con los tres ríos que atraviesan la región: Magdalena, Cauca y San Jorge.

6. Se llaman productos pancoger a los alimentos cultivados tradicionalmente por las comunidades campesinas y que forman parte de su cultura alimentaria. 


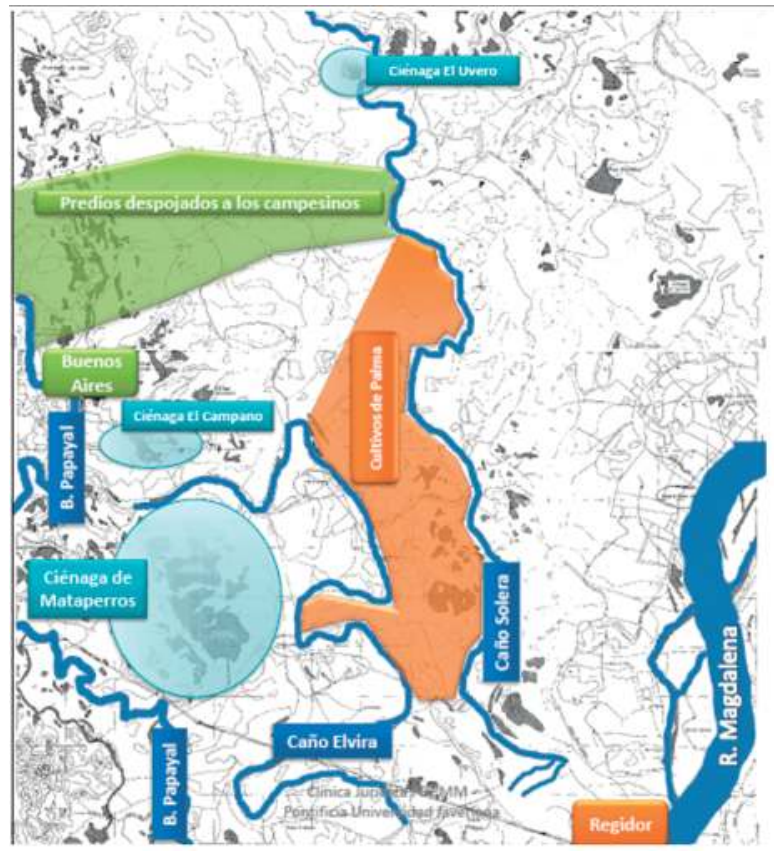

12. Cuerpos de agua de la región y los cultivos de palma Fuente: Clínica Jurídica sobre Derecho y Territorio (Pontificia Universidad Javeriana) 
De acuerdo con un informe realizado por la Comisión Independiente que fue contratada por Body-Shop y Christian Aid para analizar las disputas por tierras en el caso de la hacienda Las Pavas (Vargas et al. 2010), Bolívar es el departamento con mayor número de humedales ${ }^{7}$ si se toma el conjunto de los departamentos del país. Tiene seiscientas cuarenta y cinco ciénagas con nombre, lo cual corresponde al 34\% de las ciénagas plenamente identificadas de todo el país (mil novecientas). ${ }^{8}$ Su localización en la parte sur del departamento de Bolívar hace que sea un área importante de flujo hídrico, ya que está justamente en la parte baja del río Magdalena. Su conformación sistémica ambiental es muy variada debido a la riqueza mineral de los suelos, la abundante cuenca hidrográfica y la gran diversidad de flora y fauna. Estos atributos ecológicos son de categórica importancia porque convierten a esa región en una zona estratégica para la sostenibilidad del ecosistema regional. De acuerdo con los especialistas, en esa área se producen importantes procesos hidrológicos, de filtración y almacenamiento del agua, así como la reproducción de diferentes especies. Además, la gran diversidad que posee la región proporciona un aporte esencial para la formación de nutrientes y sedimentos que actúan contra la contaminación del río. Adicionalmente, tiene funciones reguladoras para evitar inundaciones y mitigar la contaminación por el carbono; también contribuye a la formación de su microclima. En otras palabras, la hacienda Las Pavas se encuentra en una zona vital para proteger al ecosistema y aportar en términos de sostenibilidad medioambiental al equilibro del entorno regional.

De acuerdo a estas especificidades regionales, el agua (más que la tierra) es un elemento esencial para la convivencia de la flora y la fauna,

7. En un estudio sobre los humedales en Colombia publicado en el año 2015 por el Instituto Humboldt, se hace una evaluación de sus beneficios, incluyendo la identidad cultural y el sentido de pertenencia que representan. En todas las áreas estudiadas, los resultados muestran una importancia muy alta en la matriz de valores (Jaramillo Villa, Cortés-Duque y Flórez-Ayala 2015: 26).

8. Estas cubren una superficie de $113.736 \mathrm{~m}^{2}$ y 3.549 ciénagas sin nombre, correspondientes al 26,6\% sin identificar de todo el país (13.334), las cuales cubren una superficie superior a los $35.000 \mathrm{~m}^{2}$. La depresión Momposina es la parte de mayor concentración de ciénagas, alcanzando el 80\% del área (Vargas et al. 2010: 21). 
para las actividades agrícolas y para la misma autorregulación del ecosistema. La estructura hídrica determina el funcionamiento de otras actividades como el sembrado y la pesca artesanal. La isla se encuentra en un perímetro territorial en el cual convergen varios departamentos, ${ }^{9}$ lo que hace de ella un lugar estratégico para el intercambio económico. La composición boscosa es también fundamental en la isla del Papayal: de acuerdo a las estimaciones realizadas por el mismo informe mencionado anteriormente, es una zona catalogada como un bosque secundario, y en las extensiones de la hacienda Las Pavas se encuentra el $30 \%$ de su extensión total, de 500 ha. En otro estudio realizado en el 2008, citado en el informe elaborado por Soler y León (2009), ${ }^{10}$ los bosques secundarios son zonas escasas de encontrar, caracterizadas por su alta capacidad de transformación y que actúan como bancos genéticos in situ con una función altamente reguladora. Otro aspecto de la composición ecológica de estos bosques son las zonas de rastrojo: los humedales y la vegetación lacustre son primordiales para la preservación de las funciones reguladoras que se articulan en ese ecosistema regional. De acuerdo con normas establecidas en el Convenio RAM$\mathrm{SAR},{ }^{11}$ los humedales son espacios de dominio público y, por su gran importancia en la constitución sistémica ambiental, deben ser zonas sumamente protegidas y conservadas. ${ }^{12}$

9. Los límites son los siguientes: hacia el norte, el municipio El Banco, correspondiente al departamento de Magdalena; al oriente, Tamalameque, en el departamento de Cesar, y, al occidente, San Martín de Loba, ubicada en el departamento de Bolívar.

10. Evaluación Ambiental Estratégica del Ministerio de Ambiente, Vivienda y Desarrollo Territorial y el Instituto de Biodiversidad.

11. La Convención sobre los Humedales (Ramsar, Irán, 1971) —llamada Convención de Ramsar- es un tratado intergubernamental en el que se consagran los compromisos contraídos por sus países miembros para mantener las características ecológicas de sus Humedales de Importancia Internacional y planificar su uso racional y sostenible.

12. El informe sobre impactos ambientales de la expansión de la palma aceitera en el Magdalena Medio, elaborado en 2009, describe de manera detallada las afectaciones en los ecosistemas en el caso de Las Pavas. 


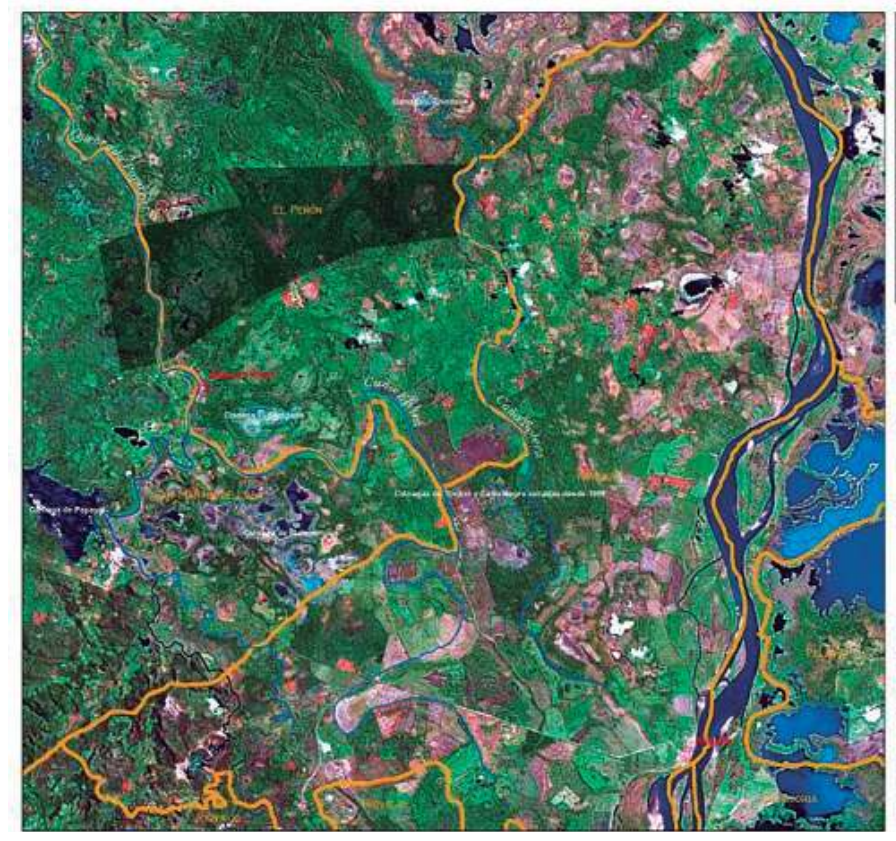

\section{Convenciones}

क Centros poblados

Quebradas y caños

Limites municipales

Ciénagas

Englobe predios

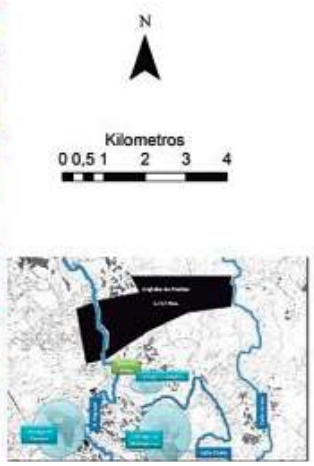

13. Mapa detallado de las características geográficas de Las Pavas Fuente: página virtual Retorno a Las Pavas. Tomado de Clínica Jurídica sobre Derecho y Territorio (Pontificia Universidad Javeriana)

\section{Cronología del conflicto}

En los años cuarenta los terrenos de la hacienda Las Pavas fueron poblados por campesinos que procedían de la región norte de la depresión Momposina. A finales de la década de los setenta, la instancia gubernamental que se ocupaba de los asuntos agrícolas, el Instituto Colombiano de la Reforma Agraria (INCORA), llevó a cabo un proceso de adjudicación de terrenos baldíos cuyos instrumentos de implementación no fueron eficaces en el establecimiento de contratos, sino que produjeron el efecto contrario. Las tierras fueron adquiridas por personas ajenas a la comunidad, quienes las destinaron al pastoreo de ganado vacuno. De acuerdo con el informe final sobre Derecho y 
Territorio de 2015, "entre 1966 y 1969, en desarrollo de la ley 135 de 1961, el INCORA titula a pequeños ganaderos foráneos un total de 1.184 hectáreas de predios baldíos" (Clínica Jurídica: 5). No están claros los procedimientos realizados ni sobre el manejo del proceso, así como tampoco por qué razones los cuatro predios nombrados anteriormente (Si Dios Quiere, No Te Canses, Peñaloza y Las Pavas) terminaron siendo propiedad de Jesús Emilio Escobar en la década de los ochenta. Según diversas fuentes, esta persona, considerada el testaferro de Pablo Escobar, permaneció en los predios y dispuso la vocación del terreno para la ganadería.

Se impuso entonces la ganadería extensiva en la zona de 1983 a 1993. De acuerdo con la cronología que se presenta en la página virtual que narra la historia de la comunidad, el aparente propietario de la finca unificó los cuatro predios y compró mejoras en predios vecinos. Posteriormente, la isla del Papayal, la zona que rodea los predios, empezó a convertirse en zona de influencia de la guerrilla Ejército de Liberación Nacional (ELN). En los inicios de los años noventa, el entonces propietario abandona los predios de Las Pavas. Este hecho parece guardar una relación con el desmantelamiento del cartel de Medellín. Sin embargo, desde 1998 se instala un grupo de paramilitares en el pueblo del Papayal para ejercer el control sobre las poblaciones aledañas y sus respectivos territorios, sembrando el terror en la región y asesinando campesinos. Durante el año 2003 se empiezan a presentar situaciones de amenaza que atemorizan a los pobladores y se les ordena desalojar los predios, ocasionando un desplazamiento masivo, que es registrado oficialmente en el municipio del Peñón.

En el ańo 2005, cuando los paramilitares salen de la zona, ante la situación de abandono de esos terrenos, la comunidad decide hacer uso de ellos y retorna a los predios, cultivando cacao y maíz. Además del desplazamiento de la población, se habían destruido los sembrados que tenía la comunidad. Para el año 2006, la Asociación de Campesinos de Buenos Aires (ASOCAB) buscó los medios para adquirir legalmente los predios y establecer contacto con el supuesto propietario, pero no tuvo éxito en su propósito. Para ese entonces, esta organización había crecido y contaba con doscientos miembros, quienes decidieron emprender una estrategia de recuperación de los predios a través de 
un proyecto de producción de maíz y para ello recurrieron a la financiación del Fondo para el Financiamiento del Sector Agropecuario (FINAGRO). Además, esta Asociación creó una filial, la Asociación de Productores de Cacao (ASOPRODCACAO), para sembrar cacao certificado en la hacienda. Sin embargo, ni la producción de maíz ni el sembrado de cacao lograron consolidarse, pues las inundaciones afectaron las cosechas. Además, FINAGRO no depositó el segundo reembolso para los insumos necesarios. ASOCAB diseñó un bosquejo de parcelación a través del reconocimiento del área total que corresponde a 2678 ha, en las que se parcelan ciento veintinueve predios (como se ve en la ilustración 15). Tras esta gestión, ASOCAB, en nombre de su representante legal Misael Payares, radicó una petición de extinción del derecho de dominio en el año 2007 sobre la hacienda Las Pavas ante el Instituto Colombiano de Desarrollo Rural (INCODER). ${ }^{13}$

Jesús Emilio Escobar, supuesto anterior propietario, regresa a la zona y amenaza a la comunidad; en marzo de 2007, realiza una compraventa de los predios y estos pasan a manos del consorcio El Labrador, formado por C. I. San Isidro y C. I. Tequendama (Grupo Daabon). El consorcio tenía como objetivo los sembrados de palma de aceite en ese territorio. Hacia finales del año 2008 se confirma que se han ocupado 70 ha del terreno con sembrados de palma a cargo de la empresa Aportes San Isidro. En ese mismo año, ASOCAB reclama formalmente de nuevo la extinción del dominio de los predios ante la Unidad Nacional de Tierras Rurales. En enero del 2009, los campesinos de Buenos Aires ingresaron al terreno para hacer un reclamo pacífico sobre la usurpación de los territorios, ocupación respaldada por una carta que envió el INCODER a la alcaldía del Peñón, en la cual se reconocía la posesión de las familias y se advertía que el proceso de extinción del dominio se encontraba en curso. El consorcio reaccionó ante este reclamo y se profirió una orden policiva, de tal manera que la

13. La petición se realizó el 13 de junio del 2006. La ley 160 de 1994 señala que se puede establecer la extinción del dominio por la no explotación económica. En este documento se reconoció la posesión de los predios de parte de ciento doce familias en los predios de Peñaloza y Si Dios Quiere. La comunidad puso una tutela, que fue registrada bajo la sentencia T267/11. 
población fue nuevamente expulsada del territorio. Los representantes legales de ASOCAB se manifestaron esta vez ante el Parlamento Europeo. Tras repetidos desplazamientos, los campesinos paveros lograron retornar en el año 2009, pero no pudieron asentarse nuevamente en sus territorios ni tampoco hacer uso de ellos para la actividad agrícola. Por esta razón, establecieron cambuches $^{14}$ — disposiciones en forma de refugios improvisados- (como se ve en la ilustración 14) contiguos a la casa de administración de las empresas palmeras. Adicionalmente, organizaron grupos de relevos para mantenerse en el terreno. En 2010, INCODER cambió la decisión antes manifestada y declaró nulo el proceso de extinción del dominio; en consecuencia, decidió iniciar un nuevo proceso. La comunidad emprendió entonces un retorno pacífico a la hacienda las Pavas en abril de 2011 y desde entonces los hostigamientos se hicieron más intensos. Diferentes episodios, como destrucción de cultivos, quema de ranchos, amenazas y bloqueos en el acceso a la finca, son frecuentes. En 2012, el INCODER y el Instituto Agustín Codazzi realizaron una nueva visita de inspección ocular como parte del procedimiento de clarificación de la propiedad. En septiembre de ese mismo año, tras varios procedimientos para la resolución de las disputas, INCODER concluyó que diez de los lotes que son objeto de disputa entre la empresa Aportes San Isidro y ASOCAB eran baldíos de la nación con una extensión de 1338 ha.

El proceso de extinción del dominio se reanudó en octubre de 2013. En el marco del mismo, una delegación del INCODER estuvo a cargo de la inspección ocular en la hacienda Las Pavas. Durante la evolución de esas disputas surgió una asociación paralela a ASOCAB, llamada Nuevo Liderazgo Campesino, algunos de cuyos miembros pertenecían anteriormente a ASOCAB y ahora trabajaban para el consorcio. Al parecer, estas asociaciones paralelas están apoyadas por las compañías palmeras para desmentir las declaraciones de ASOCAB, incluso algunas de las personas de esa asociación llegaron a asegurar que no ha habido desplazamientos. En la siguiente imagen se puede ver la formación de los ranchos improvisados:

14. El término que aparece en el $D R A E$ es 'cambucho', que significa 'habitación muy pequeña'. 


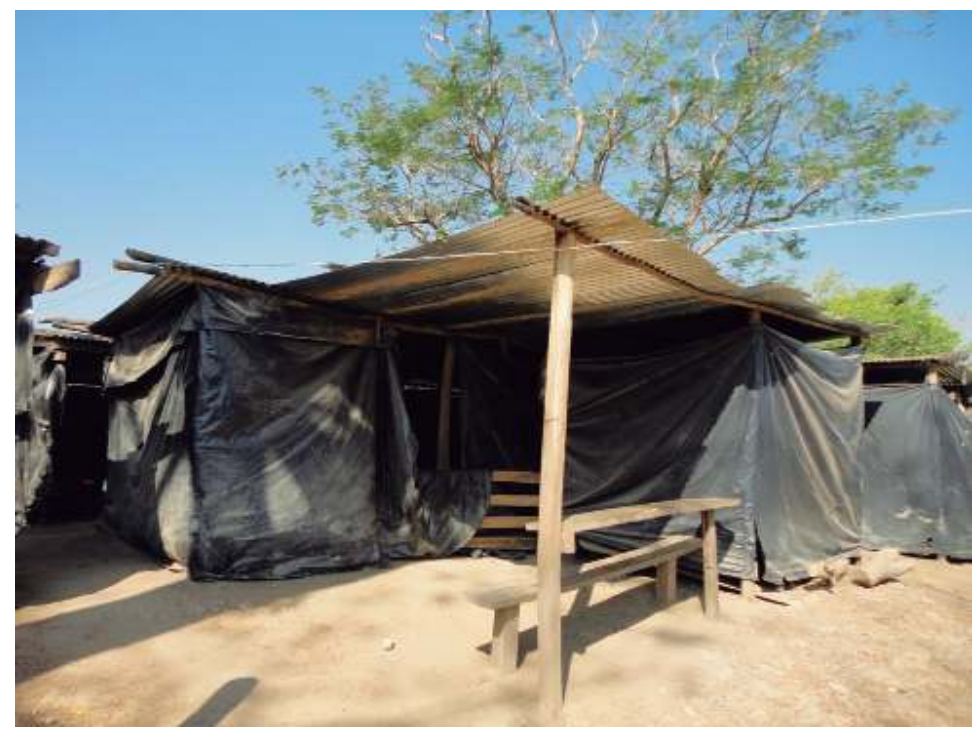

14. Cambuches fabricados por los miembros de ASOCAB Fuente: archivo propio de la autora, visita al terreno, febrero de 2012

En una entrevista, uno de los miembros de la comunidad, confirmó que, a pesar del último fallo del INCODER, se resolvió la extinción del dominio y se declaró un terreno de más de 1300 ha como baldíos de la nación. La situación de la comunidad muestra un empeoramiento severo debido a la presencia de compañías de seguridad privada contratadas por la compañía palmera, lo que quiere decir que hay hombres armados que amenazan a la población. Uno de los líderes ha tenido que salir del corregimiento por serias amenazas contra su vida. Las medidas de seguridad que ha proporcionado el Gobierno son guardaespaldas y chalecos antibalas para los líderes. Esa decisión significa que se revoca la petición del consorcio y se confirma la validez de la extinción del dominio de los predios que había adquirido la empresa a través de las compraventas ilícitas, de manera tal que los miembros de la comunidad recibieron nuevamente, y de manera formal, el reconocimiento como víctimas del desplazamiento forzado por la Unidad de Atención y Reparación Integral de Víctimas. 
En términos prácticos este reconocimiento se debería haber traducido en "dar cumplimiento a la sentencia T-267 de 2011 de la Corte Constitucional" y proceder a la restitución de tierras a la comunidad, lo que no ha sucedido. Los campesinos se han manifestado a través de diversos medios: dirigiéndole una carta al entonces presidente, Juan Manuel Santos, haciendo denuncias en su página web emitiendo comunicados mediante las organizaciones que los acompañan. El único reconocimiento al proceso de resistencia pacífica que lleva la comunidad ha sido simbólico: se les ha otorgado un galardón en el año 2013 por la producción del CD Les voy a contar la historia como una de las mejores producciones musicales.

En esa ocasión varios representantes de la comunidad viajaron a la capital a hacer la presentación de sus cantos en el marco del Festival Internacional de Teatro. En un análisis jurídico que realizó Pablo Gómez Pinilla sobre el caso de Las Pavas para su tesis de grado aparece que "el grupo de Protección de Tierras y Patrimonio de Acción Social, realizó un ejercicio de cartografía social en el cual las familias de ASOCAB dividieron y delimitaron los predios de la hacienda, según la forma en la cual se ubicaban las familias, para que estas pudieran (posiblemente) ser incluidas en el Registro Único de Predios y Territorios Abandonados RUPTA” (2014: 8). A continuación, se puede observar el resultado de ese ejercicio en el mapa que la comunidad realizó con el acompañamiento institucional de la distribución cartográfica de los terrenos de Las Pavas: 


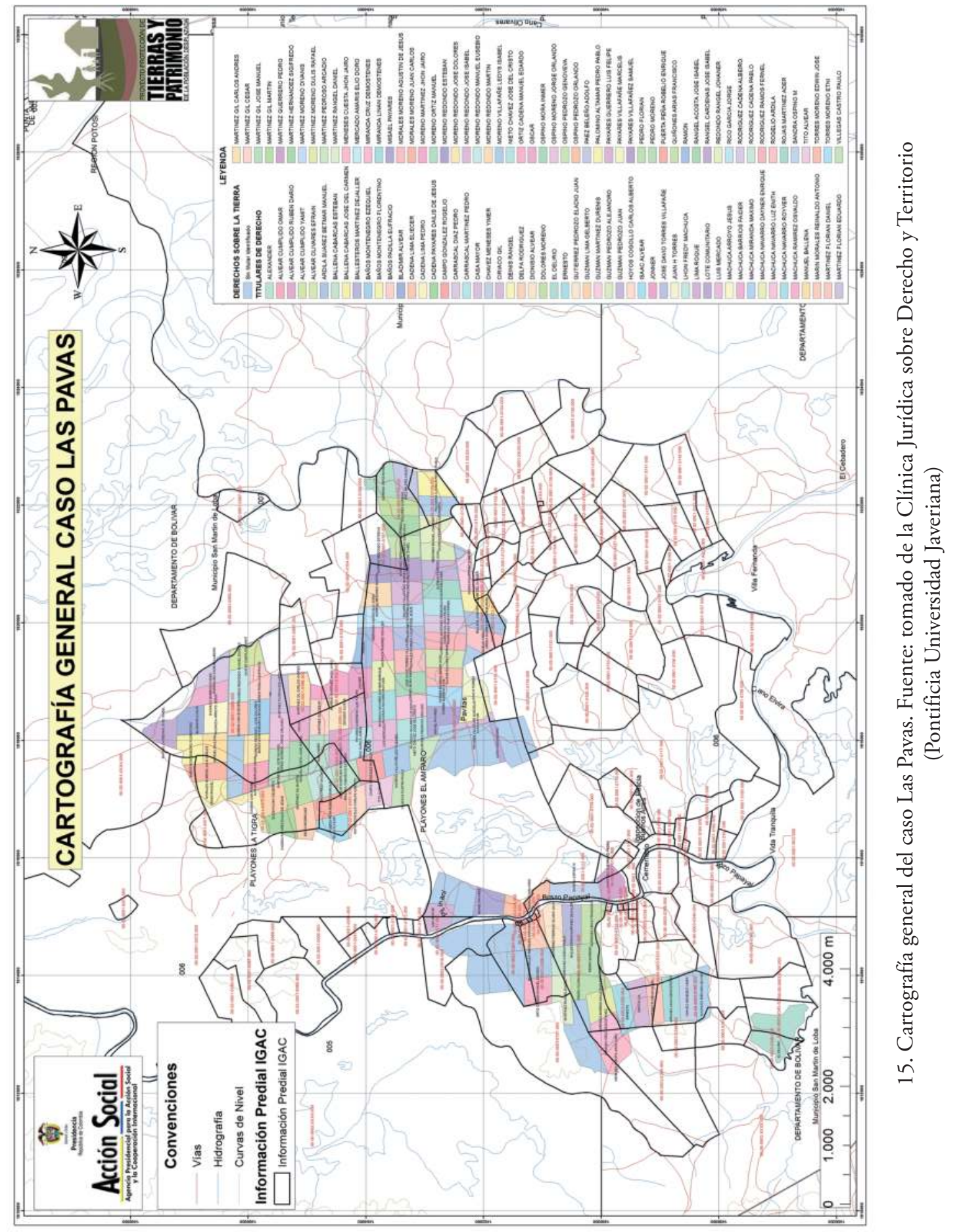


El 2 de septiembre de 2017, se le comunica a ASOCAB que se hizo público el auto "mediante el que se resuelven medidas cautelares que había solicitado ASOCAB en el proceso de extinción de dominio de los tres predios en disputa. Queda en manos de la Agencia Nacional de Tierras el papel de administrar los predios para que no sean ocupados indebidamente los baldíos por parte de Aportes San Isidro y defender el derecho de fundamental de retorno para la población desplazada". ${ }^{15}$

\section{Actores en disputa}

Al pensar en los actores en disputa es preciso preguntarse si el Estado es uno de ellos. En realidad, en el caso de la hacienda Las Pavas, no se puede afirmar que sea un agente que esté en litigio con los otros dos actores. Aunque las actuaciones del Estado han sido ambiguas y poco eficaces, de acuerdo con el informe de la Clínica Jurídica sobre Derecho y Territorio, la comunidad "tiene un alto grado de confianza [...] en la resolución de conflictos por medio de la intervención del Estado" (Informe Clínica Jurídica: 3). Según ese mismo estudio jurídico realizado por Pablo Gómez Pinilla, el tratamiento que se le dio a la extinción del dominio mostró serios fallos por parte de los organismos estatales. INCODER tuvo que reiniciar nuevamente el caso después de que la fiscal presentara la nulidad del mismo. Esta decisión tenía implicaciones en el proceso probatorio para la comunidad, pues se omitía la historia de despojos y de uso de las tierras por parte de los campesinos; es decir, los procesos jurídicos y legales han sido cuestionados y las diferentes instancias estatales que han asumido la responsabilidad del proceso, en sus diferentes etapas, han optado por dilatar los procedimientos y hacerlos más engorrosos.

Asociación de Campesinos de Buenos Aires (ASOCAB): a partir del año 1994, las mujeres del corregimiento de Buenos Aires se organizan en la Asociación Mujeres en Acción y promueven el sembrado de diversos productos. Durante el tiempo que pudieron ocupar los predios, los campesinos del corregimiento trabajaban en los predios y

15. Documento 46699, medidas cautelares 
se autoabastecían con los cultivos de pancoger. En 1998 surge la Asociación de Campesinos de Buenos Aires (ASOCAB) y se llevan a cabo proyectos agrícolas, así como también de salubridad y organización comunitaria. Actualmente ASOCAB es la agrupación que representa el proceso, se ha consolidado y sigue llevando el liderazgo. Se compone de ciento trece miembros cabeza de familia y un total de cuatrocientas cincuenta y ocho personas. ${ }^{16}$

Aportes San Isidro (empresas palmera): esta empresa realiza la compraventa de un conjunto de terrenos que había entrado en proceso de extinción de dominio tras haberse establecido nexos con el propietario Jesús Emilio Escobar. Aportes San Isidro compra esos terrenos aun sabiendo que sobre ellos existía un litigio. La adquisición de los predios fue un proceso dudoso de compraventa. ${ }^{17}$ En el transcurso del año 2004, ASOCAB constató que la empresa palmera Aportes San Isidro realizaba visitas a la hacienda Las Pavas, donde comprobó que los predios estaban inhabitados y utilizó ese argumento para realizar gestiones de la compra del sembrado de palma aceitera. Aportes San Isidro forma parte del consorcio El Labrador junto con C. I. Tequendama, quienes a su vez participan con el grupo empresarial Daabon. Miembros de las familias propietarias del grupo empresarial han participado en el cuerpo directivo de FEDEPALMA. Paradójicamente, el grupo empresarial Daabon aparece como una de las cincuenta empresas productoras de aceite de palma más sostenibles a nivel mundial. ${ }^{18}$

\section{Aspectos de incidencia y repercusión}

La población de la hacienda Las Pavas ha estado enfrentada durante varias décadas a las disputas por la tierra. Los procesos jurídicos en materia agraria demuestran que el acceso a la tierra es claramente la

16. Datos que provee el informe del año 2015 realizado por la Clínica Jurídica sobre Derecho y Territorio.

17. Jerez (2002: 210, 211).

18. Para mayor información al respecto, se puede consultar en la página virtual de Fedepalma: <http://www.web.fedepalma.org/grupo-daabon-recibe-reconocimientomundial>. 
temática principal, sin embargo, hay otros temas de conflicto que subyacen en el plano latente: penales, de lavado de activos, de corrupción en la administración pública, ilegalidad grupos armados, de títulos de propiedad y de violación de los derechos humanos.

Acceso y usos de la tierra: espacios productivos

Titulación: la titulación de los predios garantiza a las familias campesinas poder cultivar sus territorios, tener el sustento alimentario y volver a emprender proyectos productivos en la región.

Los cultivos pancoger: la población de Buenos Aires, compuesta fundamentalmente por campesinos y pescadores, tiene una dependencia directa de los territorios para el abastecimiento y consumo requerido de los alimentos que se producen. La carencia de territorio significa una reducción significativa sobre el aporte nutricional de los pobladores y, por ende, el detrimento de su bienestar.

Las áreas de reserva: la cosmovisión campesina asume como parte vital de su existencia la convivencia en zonas de recuperación para la naturaleza en las que se pueden regenerar los suelos que contribuyen a la fertilidad de las cosechas. Además, las áreas protegidas son indispensables para la supervivencia de la fauna y la flora. La conservación de los ecosistemas, antes de ser un discurso verde es una necesidad imperante para el campesinado que trabaja permanente en el agro y experimenta en su labor diaria los efectos medioambientales que causan los monocultivos. A esto se le suma el estrés hídrico que ocasionan los monocultivos: no solo el cambio en el uso de la tierra, sino la densidad e intensidad de la actividad agraria tienen impactos en la irrigación de los suelos y en la distribución acuífera de las zonas aledañas a los cultivos. Los monocultivos como la palma de aceite se convierten en sembrados perennes que ocasionan fuertes cambios en el comportamiento hídrico local y regional. 
Vida comunitaria: espacios socioculturales

Disgregación comunitaria: el desplazamiento forzado y violento produce rupturas importantes en el tejido social y cultural de la comunidad. Los integrantes que forman parte de ASOCAB pertenecen al corregimiento de Buenos Aires, pero no todos los habitantes del mismo son miembros de la asociación, aunque no solo la participación en la misma es importante, sino también el apoyo de la comunidad. Algunos campesinos han sido captados por las empresas palmeras para trabajar como jornaleros. Las disidencias entre la asociación y la vida comunitaria afectan gravemente el desarrollo del capital social comunitario y el debilitamiento interno de la comunidad.

\section{Gobernabilidad y cultura}

Gestión y manejo de los recursos: impedir el acceso a la tierra y al manejo de los recursos naturales a través de desplazamientos forzados, hostigamientos, amenazas y otras formas de violencia socava los espacios de participación, decisión y gestión de los recursos naturales. Además, se les niega sus derechos como grupo social y se han dado manejos ilegítimos por parte de las instituciones.

\section{Comunidad El Garzal}

\section{Música Y TERRITORIO}

Las composiciones musicales de la comunidad El Garzal surgen de la adhesión religiosa a la que pertenece una buena parte de su población. Otros cantos son interpretados por uno de sus habitantes, pero no han alcanzado tanta difusión intracomunitaria. La producción lírica y la interpretación musical, en este caso, están en función de la filiación religiosa en primera instancia. Aunque aparecen también temas sobre el despojo, la unificación colectiva y la negociación con otros actores, la 
intensidad del contenido lírico se dirige al sentimiento religioso, como se observa en los siguientes fragmentos:

\author{
Este gozo que tenemos \\ Nadie más lo puede dar \\ Tan sólo mi Jesús Cristo \\ Porque él sí nos sabe amar. \\ (Daniel Retamoza, sin título) \\ Con todas las fuerzas \\ Que me dan \\ Quiero gritar para que vivamos felices \\ Porque tú eres mi seguridad \\ Mi solución a lo que yo necesite. \\ (Samuel Mendoza, "Cuán grande eres")
}

En estos versos el discurso apologético es predominante, la experiencia de interacción con el mundo que rodea al ser humano emana de una conexión idílica con Dios. Se puede ver que el regocijo manifestado en las expresiones "gozo que nadie más lo puede dar" y "porque tú eres mi seguridad" excluyen un deslinde entre el sentimiento humano y la revelación divina. En la representación lírica, la experiencia de vida guiada por esa conexión mística constituye la fuente principal de resolución ante las carencias del yo lírico, es decir, la vinculación creador-ser humano se convierte en el axioma que estructura lo natural-cultural. El espacio interior se impone sobre el exterior, de tal modo que la comunicación individual con Dios es un puente catalizador que amortigua la intensidad de los avatares del mundo de afuera, la conflictividad.

\title{
CONTEXTO LOGAL Y CONFLICTO
}

El Garzal está ubicado en la parte norte de Colombia, departamento de Bolívar, en el municipio de Simití, en la región geográfica del Magdalena Medio. Su extensión abarca cerca de las 25.000 hectáreas. La población asentada en este municipio procede de diferentes departamentos, especialmente de la región Atlántica, entre ellos Bolívar, 
Cesar, Córdoba y Santander. El asentamiento, desde los ańos sesenta, está relacionado con las situaciones de expulsión y violencia por las que los pobladores abandonaron sus lugares de origen. Durante esa década, la guerrilla del ELN fue la primera que hizo incursión en esos territorios. Unos años después, también se instaló en el Magdalena Medio la guerrilla de las FARC, y ambos grupos empezaron a disputarse los territorios. En los inicios de la colonización de estos territorios, la economía de la región estuvo dominada especialmente por la extracción de maderas para el comercio y la actividad pesquera.

El Garzal es un corregimiento que se compone de trescientas sesenta y siete familias, de acuerdo con los datos proporcionados por William Plata y Sergio Cáceres (2015), integradas por setecientas ochenta y ocho personas, que están vinculadas a la Asociación de Productores Alternativos de Simití (ASPROAS). El corregimiento se compone de cuatro veredas: Tierra Firme, El Garzal, Belén y Nueva Esperanza, que en conjunto comprenden una extensión de aproximadamente unas 11.000 hectáreas. Estas comunidades están orientadas esencialmente a la producción agrícola de maíz, cacao, arroz y plátano, entre otros sembrados, que constituyen su mayor fuente de abastecimiento.

Los territorios pertenecientes a este corregimiento se han visto afectados por litigios de tierras que se caracterizan por la intervención de diferentes actores, tanto armados como no armados. Se han presentado irregularidades que afectan decisivamente el tejido social y que no están relacionadas solamente con la utilización de tierras o las repercusiones sobre el subsuelo en términos medioambientales. El control territorial de los actores armados pone a los habitantes de esta zona en un inminente riesgo de desplazamiento. De acuerdo con un estudio realizado por la Defensoría del Pueblo en 2012, en el que se determina la localización geográfica de riesgo ${ }^{19}$ y se detectan Sistemas de Alerta Tempranas, se describe que las poblaciones de los municipios de San Pablo, Simití y Santa Rosa del Sur están dentro de los posibles escenarios de riesgo que se diferencian en relación a la ofensiva de los actores armados.

19. Informe de riesgo número 008-12A.I. Defensoría del Pueblo. Defensoría delegada para la prevención del riesgo de violaciones a los derechos humanos y DIH. 


\section{Características ambientales de la región}

La región del sur del departamento de Bolívar es una zona de articulación tanto de áreas políticamente establecidas como de áreas que conforman ecosistemas importantes. Está compuesta por las poblaciones de Cantagallo, San Pablo y Santa Rosa. Las dos regiones Andina y Caribe se encuentran en esos territorios y en sus límites político-administrativos hay cinco departamentos: Santander, Antioquia, Boyacá, Bolívar y Cesar. Su ubicación se conoce geográficamente como el Magdalena Medio. Esta zona cuenta con gran abundancia de recursos hídricos, puesto que allí se encuentra un importante drenaje natural hacia el Atlántico y está en articulación con las irrigaciones del río Magdalena. Se estima que el $40 \%$ de los territorios son baldíos de propiedad de la nación y un $60 \%$ de ellos está conformado por los nichos hídricos en los que se sitúan ciénagas y humedales (SUIPPCOL 2011: 2). Sábanas y playones también hacen parte de ese ecosistema, que está protegido legalmente por la nación.

En una composición de aproximadamente treinta municipios, Barrancabermeja es la única ciudad reconocida como tal en la región. El Garzal y Nueva Esperanza son las veredas con mayor extensión de superficie, mientras las otras dos, Tierra Firme y Belén, tienen menor extensión y los usos del suelo están compartidos entre la actividad agrícola y la ganadera extensiva. Por otra parte, la configuración sistémica de esta zona ofrece una gran riqueza en recursos naturales, puesto que se pueden extraer oro y petróleo, especialmente en la parte de San Lucas, donde se ha comprobado la existencia de reservas del hidrocarburo que son explotadas de forma rudimentaria y artesanal por los habitantes del lugar y vendidas a compañías multinacionales como Anglo Gold Ashanti. El comportamiento climático de la región se caracteriza por altas temperaturas, de más de $30^{\circ} \mathrm{C}$ y con altos rangos de humedad. Se localiza en un valle circundado por el río Magdalena, que se convierte en vía casi exclusiva de acceso al corregimiento. 


\section{Cronología del conflicto}

Para comprender la historia de la comunidad, es importante tener en cuenta que, en El Garzal, los predios están organizados de manera tal que se componen de unidades agrícolas familiares (UAF). De acuerdo con las estipulaciones del INCODER, una UAF

es la empresa básica de producción agrícola, pecuaria, acuícola o forestal, cuya extensión permite, con su proyecto productivo y tecnología adecuada, generar como mínimo dos salarios mínimos legales mensuales vigentes. Además, permite a la familia remunerar su trabajo y disponer de un capital que contribuya a la formación de su patrimonio (INCODER: s. p.).

Este mecanismo, introducido en el año 1961 en el marco de la reforma agrícola llevada a cabo en el territorio colombiano, ha sido concebido desde un interrogante fundamental: ¿cuánta tierra necesita una familia campesina para vivir dignamente? En otras palabras, ¿cuánta porción de tierra debe ser otorgada a una familia en el programa de titulación? En el caso del Garzal, más de 5.000 hectáreas son terrenos baldíos y 6.000 corresponden a humedales. ${ }^{20}$

La población que actualmente forma parte de estas cuatro veredas procede de departamentos vecinos o de otras zonas del mismo departamento. En la década de los años sesenta, habitantes de diversas poblaciones se asentaron en esa zona a raíz de procesos de desplazamiento de sus zonas de origen. Dos décadas después se experimenta una oleada de violencia y, en la vereda la Nueva Esperanza, se constató que un hombre llamado Manuel Enrique Barreto había adquirido parte de los predios con procedimientos fraudulentos, instaurando una finca llamada La Carolina. Las tierras se adquirieron a la fuerza, así que muchos campesinos fueron asesinados si se resistían a su venta. Al parecer, en esa finca se almacenaba la producción de coca proveniente de otras partes de los municipios de Santa Rosa y Simití. Hoy en día está ocupada con 100 hectáreas de sembrados de palma africana. De

20. Caracterización del caso El Garzal (SUIPPCOL 2011). 
acuerdo con el informe "Caracterización del caso el Garzal", del Programa Suizo para la Promoción de la Paz en Colombia:

La expansión regional de la palma africana, que debe alcanzar el monto en el Magdalena Medio de 200.000 hectáreas para el 2012 según las proyecciones del Ministerio de Agricultura, incluye las Sabanas de Simití y por supuesto el corregimiento El Garzal, áreas que ya han sido identificadas para la implementación del cultivo según estudios del Observatorio de Paz Integral del Programa de Desarrollo y Paz del Magdalena Medio (Figueroa 2011: 12).

La utilización de esa finca como almacenamiento de un producto ilícito generó en la población un ambiente de fuerte tensión porque no correspondía con las prácticas productivas iniciadas por los campesinos y porque el uso del territorio no conservaba la vocación agrícola que les había caracterizado en esa área. Hacia finales de esa misma década, exactamente en el año 1989, la fuerza pública desmontó el centro de acopio, que había sido utilizado, hasta entonces, como sitio de tránsito de la producción de coca. A consecuencia de esa acción, los predios fueron abandonados por los supuestos propietarios. A inicios de la década de los noventa, la situación no cambió fundamentalmente, pues el área siguió siendo usada como sitio de enlace para la movilización de la producción del alcaloide. Todo este proceso estuvo acompañado de fuertes amenazas a los campesinos y de la constitución de bloques armados de la paramilicia para controlar la zona. Hacia finales de los años 90, se da una segunda oleada de violencia, pues el Bloque Central Bolívar de las Autodefensas Unidas de Colombia fue comisionada por el supuesto propietario para recobrar las tierras. Así volvieron también los hostigamientos a los habitantes del corregimiento con el propósito de expulsarlos de la región. La parte sur del departamento de Bolívar ha experimentado una dinámica agitada y se ha visto enfrentada a diferentes formas de conflicto. Sin duda, la tierra sigue siendo la causa fundamental de las disputas; la agroindustria ha transformado sus usos y ha involucrado nuevos actores. El Garzal se sitúa en una especie de corredor topográfico que permite enlazar vías terrestres y fluviales, en las cuales los actores armados 
han creado rutas que son utilizadas especialmente para la circulación de drogas ilícitas. ${ }^{21}$

En el año 1997 se crea la Asociación de Productores Alternativos del Simití (ASPROAS), que obtiene representación legal con proyectos de soberanía alimentaria y solicita la adjudicación de terrenos baldíos. Ante las amenazas y el miedo a ser expulsados de los campesinos, el señor Salvador Alcántara, pastor y líder comunitario del Garzal, asumió la vocería y el proceso de resistencia para defender la comunidad y sus territorios. No fue una decisión propia, él mismo lo relató —en la entrevista que mantuve con él en el año 2012- como un llamado que le hizo Dios, que se manifestó en la profunda necesidad que sentía de entrar a un templo y después iniciar un camino de total compromiso con su comunidad por la defensa del territorio. La situación en la zona del Magdalena Medio se tornó más tensa tras el retorno de Manuel E. Barreto al Garzal, pues su presencia estuvo acompañada por grupos paramilitares que cometían crímenes, lanzaban amenazas y hostigaban a la población. En medio de ese ambiente de tensión, la comunidad El Garzal decidió pedir al Estado la verificación de la propiedad de esos terrenos y solicitó también la titulación de algunos de los predios que habían sido ocupados por los campesinos por más de tres décadas. Ese proceso fue lento y engorroso, y mientras esa verificación se sumía en una plena parálisis, la situación para la comunidad era de total angustia. El anuncio que hizo Manuel E. Barreto de regresar para obtener sus tierras contenía una táctica de intimidación con la amenaza del posible exterminio de la comunidad que habitaba en ellas.

Salvador Alcántara tomó la decisión de hablar con Manuel E. Barreto, a quien había conocido previamente, con el fin de discutir las amenazas a la comunidad y persuadirlo para que cesaran. Este encuentro tuvo lugar con el supuesto propietario, quien le propuso a Salvador Alcántara ocuparse de sus propios beneficios, induciéndolo a obtener

21. La Oficina de las Naciones Unidas Contra la Droga y el Delito —UNODC por sus siglas en inglés - lleva una serie anual sobre los registros del censo de cultivos ilícitos en Colombia. De acuerdo con el último monitoreo de finales del 2012, se muestra una reducción. Para una información detallada al respecto, véase $<$ http:// www.reliefweb.int/sites/reliefweb.int/files/resources/Colombia_Monitoreo_de_ Cultivos_de_Coca_2012_web.pdf >. 
títulos de propiedad para su familia, en tanto el resto de las familias de la comunidad deberían abandonar los terrenos. La decisión de Salvador fue contundente, no aceptó dichos sobornos y continuó el proceso comunitario de defensa por el territorio, bajo las más fuertes amenazas contra su vida, pero con una profundísima convicción de seguir el camino que le había indicado esa revelación divina. En consecuencia, convocó a la comunidad a una junta de acción comunal para hablarles con franqueza sobre la situación en la que se encontraban. Gracias a su liderazgo y al fortalecimiento a través de los principios religiosos, animó a la comunidad a resistir pacíficamente y a buscar apoyo de organizaciones de acompańamiento para poder continuar en el territorio. La comunidad emprendió diferentes acciones de movilización comunitaria, cuya base fundamental ha sido la fe. En esa búsqueda de apoyo, contaban con la Iglesia Cuadrangular, de la que hacían parte, pero esa filiación tal vez no tendría alcance suficiente para proporcionarles las herramientas en pro de una resistencia ante actores armados. Por otra parte, en las actividades económicas, la comunidad participaba de la asociación ASPROAS, que sí sería uno de los vínculos que les beneficiaría. Salvador contactó también con el Programa de Desarrollo y Paz del Magdalena Medio y a través de ASPROAS tuvo acceso a la organización Swissaid, que más adelante le proporcionaría un gran apoyo en su lucha.

Otra manifestación divina que fue decisiva para asumir su liderazgo fue la revelación que hizo Dios a través de su esposa en el año 2004. En una especie de sueño revelador, una voz divina le hizo saber que él había sido escogido para predicar la palabra de Jesús y para asumir las riendas de ese proceso comunitario. Unos años atrás, había iniciado su formación en la Iglesia y por sus cualidades personales se destacó y fue enviado al Garzal en 1995. En el mensaje se anunciaba previamente la elección de Salvador como pastor, pero también que tendría la protección de Dios durante su camino, para que no tuviera temor. Además, le fue revelado que su proceso estaría acompañado por mucha gente que aparecería de otras partes del mundo para darlo a conocer y visibilizarlo.

En lo concerniente a la titulación irregular, las comunidades han realizado trámites de revocatoria de la adjudicación de los predios 
otorgados a Manuel Enrique Barreto. Se han adelantado varias inspecciones judiciales, cuyos procesos no fueron resueltos, sino que se dilataron y se ignoraron las adjudicaciones de baldíos realizados en 1994 y 1995 por el INCODER. En el año 2006, las Autodefensas Unidas de Colombia se desmovilizaron y con ello parecía que la figura de Manuel E. Barreto había desaparecido, pero sus herederos y sucesores siguieron ejerciendo presión en la comunidad y acusando a los habitantes del Garzal de ser guerrilleros. En el año 2004, se habían imputado cargos de posesión a la comunidad El Garzal a través de demandas a algunos de sus habitantes. Las irregularidades en la titulación muestran cómo los títulos han sido expandidos nominalmente, aunque el área material no corresponda con la extensión del corregimiento. De acuerdo con Alfredo Molano (2012),

la superficie demandada por los Barreto-Esguerra fue aumentando y hoy reclaman un terreno mucho mayor que el original y que engloba casi todo El Garzal. Más claro: los linderos del corregimiento se traslapan con los demandados por los terratenientes.

Adicionalmente, en un artículo de prensa titulado "Campesinos, narcos y humedales”, publicado en 2011, Alfredo Molano, gran investigador sobre el desplazamiento forzado en Colombia, asegura:

Y mientras ocurrían las amenazas y las masacres, las tierras del corregimiento se movían. De un momento a otro, Barreto se hizo de los títulos de estos predios. Títulos que sumados dan más de las 11 mil hectáreas del corregimiento, incluyendo incluso las ciénagas, humedales y playones. Hoy El Garzal está dividido en 14 títulos, todos a nombre de la familia Barreto Esguerra.

En el año 2011, el veredicto de un juez de Simití fue la revocación de las titulaciones que ya habían obtenido los campesinos, adjudicándolas a los familiares del señor Manuel E. Barreto, primero vinculado a las actividades del narcotráfico y después comandante del paramilitarismo. La actuación organizada y estratégica de la comunidad y, sin duda, el inmenso apoyo de diversos organismos en el ámbito jurídico tuvo efectos en ese dictamen y logró que, en 2013, el INCODER revocara esa decisión, mientras que de forma simultánea se anunciaba que 
la asignación de títulos de propiedad para los campesinos del Garzal estaba adelantándose en las instancias del INCODER.

Durante mi segunda visita de campo a las comunidades en agosto de 2013, me encontré en Bogotá con Salvador y me confirmó que tuvo que abandonar su casa en El Garzal a causa de las amenazas, relacionadas con el hecho de que, en abril de ese mismo año, el INCODER había realizado una misión de verificación. Sin embargo, Salvador consideraba exitosa esa visita porque la comunidad logró demostrar que no eran invasores y se había entregado formalmente la titulación de predios a sesenta y cuatro familias. Fue una noticia alentadora, aunque esa titulación carecía de planos y con ello se dificultaba el registro en el catastro. Esos trámites de adjudicación ya habían sido expedidos en 1999 por esa misma institución. No obstante, aún quedan por resolver las demás solicitudes de titulación. El acompañamiento de las diferentes organizaciones tanto nacionales como internacionales le ha aportado a la comunidad herramientas para actuar jurídicamente y le ha dado respaldo en el proceso. Por otra parte, el rol de liderazgo de Salvador siguió puliéndose a través de cursos de formación que le permitieron desarrollar más habilidades a ese respecto. Se sabe que la demanda que se le había hecho a la comunidad carece de argumentos que la sustenten. Salvador ha tenido que seguir ausentándose del Garzal transitoriamente por las amenazas, ya que, aunque tenía guardaespaldas, su preocupación era que brindaran protección colectiva a toda la comunidad.

\section{Actores en disputa}

El Garzal ha sido diagnosticado como una zona de alarma de desplazamiento. La tensión es latente y creciente en la población. Retomando la historia de décadas atrás, en las que el conflicto por la tierra se había recrudecido, se puede observar el ambiente de tensión debido a la restitución y titulación durante ese largo periodo. Para el presente análisis se retoman principalmente los actores que han estado involucrados en el conflicto por las tierras y aquellos que tienen una coparticipación en el mismo. 
La comunidad El Garzal está representada a través de la organización campesina Asociación de Productores Alternativos de Simití (ASPROAS), establecida desde 1997. De acuerdo con lo expuesto por el vicepresidente de esa asociación en el marco del seminario internacional "Las configuraciones de los territorios rurales en el siglo XxI. Eje temático: La reconfiguración productiva de los territorios rurales" $\left(2008,{ }^{22}\right.$ la Asociación representa diez veredas de Simití y Puerto Wilches. Según las entrevistas realizadas durante mi visita de campo en febrero de 2012, los habitantes confirmaron que los primeros habitantes que poblaron El Garzal fueron ciento diez familias (quince de ellas eran fundadoras desde la década de los años setenta), pues la comunidad logró demostrar que no eran invasores y que el supuesto propietario quería quitarles las tierras. La organización campesina ha iniciado sus actividades centrándose en el cultivo de plátano y maíz. Su abastecimiento era fundamentalmente con enfoque regional y alcanzaba los trescientos bultos de plátano y las trescientas treinta toneladas de maíz por cosecha. A causa de las fuertes inundaciones ocurridas durante el año 2004, la producción de estos dos alimentos se redujo considerablemente, ya que para ese tiempo se había introducido el cultivo de cacao. De acuerdo con el estudio realizado por Plata y Cáceres (2105), el cacao es el cultivo que más prosperidad ha brindado a la comunidad:

El cacao surgió como una alternativa consistente; por medio de Asproas se solicitaron semillas y financiación internacional para este cultivo, con muy buenos resultados. De esta manera, el cacao de El Garzal ha llegado a ser reconocido como uno de los mejores de Colombia. (516)

Esta organización agrupa tanto a campesinos como a pescadores, quienes, según ASPROAS, están interesados en reivindicar la dignidad del trabajo del campo y al campesino. La asociación está constituida dentro de la comunidad campesina y pesquera por cuatrocientos sesenta y cuatro miembros y se organiza en veintitrés comités de mujeres y doce de hombres. Trabajan en el sembrado de productos como

22. El seminario se realizó por la Facultad de Estudios Ambientales y Rurales de la Universidad Javeriana en Bogotá, Colombia, 26 de marzo de 2008. 
el maíz y el cacao y además se ocupan de actividades de agricultura orgánica, piscicultura, ganadería y cultivo de productos menores. En ese mismo documento se reconoce en primera instancia el saber y el conocimiento campesino como base fundamental de la organización y su funcionamiento: "Nuestras mayores fortalezas están en nuestra propia gente, nuestros conocimientos, nuestras semillas y los aprendizajes que hemos ganado." (ASPROAS). Dentro de sus principales objetivos, están los siguientes:

Ganar en el manejo y la gestión del territorio y de nuestras formas propias de gobierno campesino. 2. Promover y practicar la agroecología y el buen manejo de los recursos naturales. 3. Estimular la participación, decisión y vinculación de las mujeres y los jóvenes en los asuntos claves de nuestra sociedad. 4. Fortalecernos institucionalmente para ser una alternativa y un actor de la región. 5. Procurarnos nuestra seguridad y soberanía alimentaria y contribuir a la economía local. (ASPROAS).

En este proceso, el papel que han tenido las mujeres en la organización de los proyectos económicos ha sido destacado. Las situaciones de amenaza y vulnerabilidad en la que se encuentran muchas comunidades exigen que estas tomen las riendas de la casa en todos los ámbitos, en muchos casos porque sus compañeros han sido víctimas de la violencia. En el caso del Garzal, las mujeres han asumido un liderazgo fundamental para coordinar actividades de comercialización de los productos, especialmente del cacao. De acuerdo con las entrevistas que Salvador me concedió para el estudio del año 2015, resalta la importante labor femenina en la sostenibilidad económica de la comunidad. Nidia, la esposa de Salvador, ha liderado una asociación femenina llamada El Porvenir para contribuir en la adquisición de productos de mercado. Las mujeres también se han organizado para sacar adelante una panadería y gestionar proyectos de siembra.

Las empresas palmicultoras, especialmente Yarima SA, que está ubicada en la parte sur del corregimiento, han ejercido presión sobre los campesinos para poder adquirir las tierras. Otras, como la companía Agricolombia SA, han extendido sus cultivos de palma de aceite en la zona usando la modalidad del arrendamiento para involucrar a los campesinos en las actividades de los cultivos de palma de aceite. Esta compañía ha realizado contratos de usufructo en los que los pobladores 
alquilan sus terrenos por treinta ańos. Esas tierras son reclamadas por los hijos del supuesto propietario, quienes manejan la compañía Equipos y Soluciones Logísticas y trabajan como contratistas de empresas petroleras y del Ministerio de Defensa. De acuerdo con los relatos de la población, otra de las palmicultoras interesadas en los terrenos de las veredas es Alianza Palmicultora. La compañía La Carolina ha utilizado métodos de presión y de cohesión que ponen en riesgo la integridad de las comunidades, es decir, que de forma camuflada, algunas empresas de la industria palmera han sido utilizadas como medio para desplazar a las comunidades con métodos aparentemente legales, pero con estrategias de usurpación de tierras.

\section{Aspectos de incidencia y repercusión}

La comunidad logró consolidar su cohesión a través de la profunda fe religiosa y de la estrategia de los cultivos para la subsistencia alimentaria. Lograron tal nivel de unidad que decidieron quedarse en el territorio a pesar de las amenazas, los hostigamientos e incluso las presiones para sembrar palma africana en sus territorios y mantuvieron sigilosamente vigilancia para cuidarse mutuamente.

Acceso y usos de la tierra

Titulación: la titulación de los predios a 278 familias de la comunidad para poder tener dominio territorial y así continuar con sus actividades como asociación campesina.

Cultivos pancoger y productividad agrícola: la comunidad del Garzal no ha logrado ser desplazada de sus territorios. Su decidida permanencia en la tierra a través del sembrado de diversos cultivos les permite aún seguir plantando para su sustento.

Preservación de ecosistemas: la ubicación geográfica de la comunidad coincide con la localización de humedales. La población recalca la importancia de tener en cuenta la composición topográfica de la zona y de preservar el ecosistema. 
Sustentabilidad: en la última década se ha podido observar que los cultivos de gran extensión con carácter perenne constituyen una fuente de confrontación entre un discurso sostenible y uno sustentable, pues el cultivo de este tipo de palma tiene una proyección de décadas. Si su cultivo sigue invadiendo los terrenos aledaños a la comunidad, sus miembros pronostican un escenario de esterilidad que afectará a sus descendientes. ${ }^{23}$

\section{Gestión local}

Asociación y consolidación comunitaria: la oferta que hacen las empresas de adherirse como trabajadores o socios pone en riesgo el proyecto de asociación campesina. Algunos ven en ello una retribución atractiva, y esto puede volverse en contra de los intereses colectivos.

Durante mi primera estadía en la comunidad pude presenciar la visita de una empresa delegada por una compañía petrolera para determinar si la zona disponía también de recursos naturales como el petróleo. Convocó a toda la comunidad del Garzal y les ofreció prebendas para que permitieran el acceso al terreno para realizar estudios de factibilidad dentro de sus linderos. La negociación estuvo acompañada de una presentación sesgada sobre las ventajas que traería para sus habitantes el yacimiento petrolífero. Ante las inquietudes planteadas por la comunidad, inquiriendo sobre cuáles serían las implicaciones y sus derechos en caso de encontrar petróleo, la empresa no tuvo respuesta alguna: su responsabilidad no cubría estos propósitos y se dispondrían solamente a explorar la zona. Finalmente, al año siguiente se llevó a cabo la búsqueda y se le dio a la comunidad un modesto agradecimiento monetario.

23. Las dudas sobre lo que pasará con los terrenos después de tres décadas de cultivo de palma es una preocupación general expresada por los líderes locales y por los demás habitantes de todas las comunidades. 
Gobernabilidad y cultura ecológica

Manejo de recursos naturales: en especial, las cooperativas llevan a cabo los proyectos de cultivo de cacao para comercializarlos local y regionalmente, lo que implica poder decidir sobre qué tipo de cultivos son agroecológicos, cómo pueden desarrollar y consolidar sus sistemas de producción y estipular colectivamente formas de organización para el cultivo, la producción y la comercialización de sus cosechas.

\section{Comunidades de las cuencas del Curvaradó \\ y Jiguamiandó, región del Pacífico colombiano}

\section{MúsICA Y TERRITORIO}

"Los cantos deben ser como huellas de la historia, para que los niños los conserven en su memoria": fueron las palabras de Erasmo durante la conversación que sostuvimos en mi visita a la región, en febrero de 2012. He tenido la fortuna de compartir con muchas personas de las zonas humanitarias sus historias de vida, sus miedos, sus experiencias y sus inquietudes por la construcción de la paz. Esos diálogos a media tarde en tierra tropical estaban acompañados de un armonioso sonido, pero no como acorde agregado o como telón de fondo ameno de la charla, sino como una melodía impetuosa y reposada a la vez, vestida de palabras, de cantos y de cuentos que se intercalaban indistintamente en nuestras conversaciones. Estos cantos son conocidos por la comunidad, y tal vez por otras poblaciones cercanas, y compuestos como parte de la vivencia del desarraigo y con la plena esperanza de un retorno en condiciones dignas. Muchos son inéditos y algunos otros han sido divulgados a través de la Comisión Eclesial de Justicia y Paz, que con mucha dedicación y eficacia ha acompañado a estas comunidades.

En la actualidad diversos procesos comunitarios que viven la recuperación y conservación del medio ambiente apelan a su capital cultural para transmitirle a las nuevas generaciones las prácticas de sostenibilidad tradicionales de las comunidades. Ese es el caso de una 
comunidad en el consejo comunitario de la cuenca del río Yurumanguí, en el Pacífico colombiano, que ha logrado preservar más de 64.000 hectáreas de bosques. Esto se ha logrado gracias a que las comunidades apelan al uso de tradiciones y costumbres haciendo conscientes los ciclos temporales y las actividades de recolección de madera. De acuerdo a lo relatado por un líder del consejo, el monitoreo en esa zona tiene una característica específica que lo diferencia de otros sistemas:

Cuando hablamos de monitoreo, estamos hablando primero de la construcción artística de la defensa del territorio", [...] recordó la erradicación que hicieron de cultivos ilícitos en 2007, en la que, mediante cantos, generaron la apropiación de los jóvenes. Aseguró que el activar esa esencia del canto, de lo que son en sus prácticas y costumbres, ha fortalecido la cultura de cuidado del entorno (Semana Sostenible 2018a).

Plasmar el dolor de agresiones violentas en la lírica musical es una forma de reconstruir una experiencia de aflicción a través del canto, es transmitir el significado del dolor, pero con sensaciones que se deslindan del sufrimiento como razón principal de la composición. Eso es lo que han intentado hacer los diferentes compositores que reconstruyen a través de la lírica las experiencias de despojo vividas por sus comunidades. Esto confirma, una vez más, que la lírica que nace en esos ambientes cumple una función testimonial que contribuye a la resignificación estética del canto. La representación de la confrontación emerge como un relato que narra un episodio de agresión en el cual se aprecian las formas de interacción o los mecanismos utilizados por algunos de los actores. El relato está estructurado en su mayoría en discursos descriptivos y reflexivos. Se narra el desarrollo de lo sucedido, pero aquí lo más impactante son los juicios que revela el cantautor, como se ve en las siguientes estrofas:

El miércoles en la mañana

A las Palomas llegaron

Disparándole a la gente

Sin tenerle compasión (bis)

Y hasta un niño asesinaron

En presencia de la gente.

(E. Cuadrado, sin título) 
En el fragmento anterior se pueden identificar dos elementos que se intercalan: por una parte, está el relato de la acción, con los verbos llegaron, atacaron, incursionaron, quemaron, tomaron y asesinaron. Por otra parte, se evoca la sensación emotiva con los sustantivos remordimiento, dolor, indignación, perplejidad y reivindicación. La expresión lírica nos permite acceder a un interludio entre lo íntimo-colectivo y lo exterior a la comunidad; en estos dos espacios enunciativos se verbalizan emociones que, en el marco de una negociación, normalmente no manifiestan las contrapartes. Esta revelación devela las percepciones de un actor con relación al otro y cumple una doble función discursiva: por una parte, contribuye al proceso de reflexión del actuar comunitario (o manifestación de la posición frente a la disputa) y, por otra parte, es una ilustración sobre cómo se asume, desde la mirada campesina, la agresión misma.

\title{
Percepción sobre otros actores
}

En diversas composiciones se narra la intervención de los demás actores involucrados en el conflicto, un conjunto de diversos agentes impulsados por motivaciones compartidas; es decir, se les describe como grupos que persiguen los mismos intereses: el poder y el control de la tierra y el territorio. Se hace referencia al sistema capitalista y a las alianzas entre Gobierno y empresa privada, como se consigna en los siguientes versos:

\author{
Por medio de los empresarios \\ Hemos sido amenazados (bis) \\ Por esos capitalistas \\ Y por parte del Estado (bis) \\ Y nosotros, el campesino \\ No podemos reclamar \\ Porque de inmediatamente \\ Nos vienen a masacrar. \\ (E. Cuadrado, "La palma").
}

Las letras no revelan mucho sobre las motivaciones individuales de cada actor, sino que dan cuenta de las acciones que estos han causado. Además, se expresa la necesidad de cuestionar tanto los juicios de valor 
como los parámetros de distribución sobre los recursos naturales que representan esos actores. Especialmente, se hace referencia a aquellos que tienen mayores mecanismos de poder, como el Estado y las empresas. La voz lírica expresa la imposibilidad de pronunciarse ante la agresión a causa de las retaliaciones por parte de otros actores, como se veía en la estrofa anterior.

La exuberancia natural en contraste con la incertidumbre ante la pérdida de su hábitat es una temática recurrente, como se ve en la siguiente estrofa de música rap:

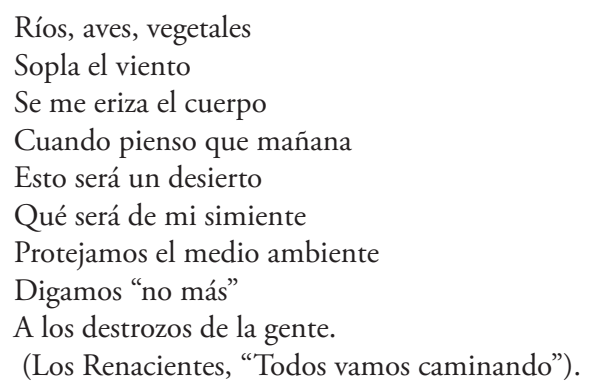

En la primera parte del fragmento, la composición entre ríos, aves y viento introduce la idea de movimiento libre en el ambiente natural-rural. Lo etéreo y lo sensorial se confabulan en una dimensión sin gravitación, indicando un flujo horizontal plano. La sonoridad entra en el entorno, complementando un paisaje que pareciera ser armónico, pero no lo es, porque la simultaneidad entre razón y sensación detienen ese fluir a través de la inquietud corporal del yo lírico al erizarse. Se revela allí un antagonismo entre estoicismo y desasosiego y se recurre a una antítesis para construir una imagen visual que aporta la perspectiva vertical del espacio, en tanto que se recalca la autoconciencia de la corporalidad humana.

En la segunda parte, es la inquietud del yo lírico la que domina el contenido textual. Esa intranquilidad se genera por la pérdida del paisaje armonioso, con su sonido y su cadencia llana. La voz lírica sitúa la idea del tiempo "mañana" y la posibilidad de encontrarse en un hábitat desértico. Esta noción de desierto, de soledad y de extinción agudiza la inquietud de su existencia misma: “¿Qué será de mi simiente?”. Ese 
interrogante constituye el núcleo temático de todo el canto, no solo en el verso citado, ya que la "simiente" da cuenta de una simbología dual de la cultura comunitaria y de la cultura ecológica de los habitantes de esa región. La semilla dadora de vida debe ser conservada y preservada por su origen ancestral, por ello surge la voz que transita hacia un nosotros lírico en "digamos no". Asimismo, esa voz insta a proteger la simiente y a pronunciarse ante los destrozos de la "gente", es decir, la comunidad como portadora de fecundidad.

\title{
Percepciones respecto al conflicto
}

Algunos cantos aluden claramente al conflicto por los territorios, pero integran la perspectiva histórica y étnica. También hay claras referencias a las pocas respuestas del Estado para resolver las disputas; junto con ello, se denuncian las prácticas erróneas de un sistema de supuesta "transparencia". En algunos pasajes se manifiestan las percepciones y las prácticas institucionales que causan fuertes impactos en la clase campesina, como se ilustra en este pasaje:

\author{
Y ahora me pregunto yo \\ Lleno de remordimiento: \\ ¿Dónde está la transparencia \\ Del gobierno nacional? \\ (E. Cuadrado, sin título) \\ Fija, gobierno corrupto \\ Lo que hoy día estás haciendo \\ Con tantos niños ya huérfanos \\ Que de hambre están muriendo. \\ (E. Cuadrado "Un 2 de junio").
}

Presencia y ausencia: lugar y espacio locales

La narrativa de los cantos hace referencia tanto a las relaciones de poder como al ejercicio del poder, como lo hemos visto antes. Las letras reivindican la comprensión de la práctica cultural desde dos aspectos 
importantes: por un lado, se manifiesta la deconstrucción del concepto de dominación en contraposición a los valores que se han cultivado en el acervo étnico-comunitario y, por el otro, se recupera el concepto de espacio-tierra como parte de la vitalidad local, con atributos de abundancia y diversidad, en los cuales está implícito el concepto de autogestión territorial.

El territorio está representado en la lírica como espacio de ausencias, bien sea porque ya no lo habita el campesino afrodescendiente o porque las actividades extractivistas han degradado el hábitat natural. Se hace referencia al territorio arrebatado, es decir, a la ausencia del mismo. Muchas alusiones que encontramos en los cantos están relacionadas con los rasgos que recrean el imaginario rural étnico-campesino: vida, agua, vitalidad, hábitat y acción pública:

\author{
¡Ay! el territorio nuestro \\ Tiene una riqueza inmensa (bis) \\ Minerales flora y fauna \\ Embellecen nuestras cuencas (bis) \\ De las penas que yo tengo \\ Algunas les he contado. \\ (E. Cuadrado, "La palma")
}

En esta estrofa, se manifiesta una de las ausencias concretas sobre lo que requiere el campesino. No hay escasez de recursos naturales, sino que hay una situación estructural de crisis. Los versos siguientes, si bien hacen referencia a la "crisis", no permiten determinar con exactitud lo que denota ese término en concreto, pero por el contenido del canto se puede deducir que su referente es un sistema de ausencias que le impiden al campesino trabajar la tierra:

\author{
Con esta crisis tan dura \\ ¿Dónde iremos a parar? \\ Aunque vivamos en el campo \\ No podremos trabajar (bis). \\ (E. Cuadrado, "El 2 de junio")
}

Concebir la palma como cultivo ilegal, como lo vemos en la estrofa siguiente, es un acto trasgresor y deliberado de la voz lírica. El 
campesino utiliza una formulación impetuosa en su composición para reivindicar su posición como actor social desfavorecido. A su vez, pone en tela de juicio el concepto mismo de legitimidad y cuestiona también la instancia que otorga legalidad a la palma de aceite. Además, el relato lírico emite un juicio de valor que objeta profundamente los cambios en el uso de las tierras; es decir, la proposición que subyace en esta estrofa cuestiona con vehemencia tanto el cambio drástico de la producción agrícola campesina como también a los ejecutores de ese cambio. La siembra de palma como cultivo "maldito" puede aludir tanto a un castigo o a un elemento perverso en el contexto de la cultura agrícola:

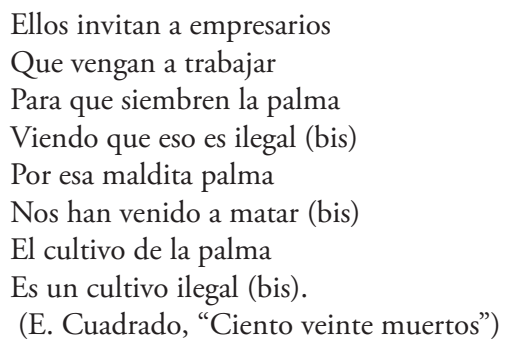

Algunos cantos contienen un preámbulo que sitúa primero las interacciones de los actores en contienda y luego da cuenta de la legitimidad de la acción comunitaria. En ese esquema narrativo, esta surge como reacción a la agresión y se sitúa como obra compensatoria en el marco de las ausencias estructurales que se acumulan en diferentes niveles. Se encuentran cantos en los que en la primera parte se narra el mundo circunstancial de privaciones y en la segunda se manifiesta la interacción de las comunidades, como lo vemos en estos versos:

Por eso los campesinos

Allá fuimos a mochar (bis).

Congregarse para "mochar" (que quiere decir 'cortar') parte de la plantación es una acción que fue llevada a cabo por algunos de los miembros de las comunidades que emprendieron el retorno para fundar las zonas humanitarias. Se trata de un acto acordado colectivamente para reclamar las tierras usurpadas e instaurar un precedente 
para situar la autogestión territorial como parte esencial de la vida comunitaria. La esencia de esta estética desde lo rural ${ }^{24}$ revela un uso del capital cultural mediante el cual se comunica la cosmovisión de lo colectivo.

La segunda perspectiva de representación del espacio se ilustra como un universo colectivo conectado a través de múltiples intersecciones. Esta idea de conexión se contrapone a la de fragmentación. El concepto de la relación espacial es análogo a la relación social. Allí la querella y la denuncia manifiestan la reivindicación de un espacio de participación inclusivo y en cierta medida se pronuncia ante las relaciones de poder ancladas en la configuración sistémica de inequidad.

En estas dos nociones de espacialidad antes referidas se combina una dualidad pendular entre el espacio físico, que está representado por la tierra, y el espacio ficcionalizado, que es la convivencia armónica en la tríada tierra-campesino-comunidad. La imagen del lugar físico-material aparece con mayor intensidad y cobra vida a través de la representación figurada de las ausencias. Sin embargo, el retorno a la tierra - propósito que persigue la comunidad - aparece con menos frecuencia en la representación temática de estos cantos. Ese asunto del regreso se inserta en la temática de la despedida sin partida, que se explicará posteriormente. Sería pertinente explorar muchas otras composiciones de literatura oral que reconstruyan los contextos del retorno, ya que esto podría arrojar datos interesantes sobre cómo se articulan esas dos temáticas de desplazamiento y regreso a la tierra, así como también qué simbologías se representan en los textos.

\section{ConteXto LOCAL Y CONFLicto}

En el selvático territorio de la zona del Bajo Atrato han convivido por mucho tiempo comunidades de indígenas, afrodescendientes y cimarrones practicando una agricultura poco extensiva, caza y pesca. Esa zona fue habitada más tarde por campesinos cordobeses, quienes

24. Héctor D. Fernández L’Hoeste analiza “un fenómeno de marcada empatía con el ser urbano: el llamado 'rock nacional' argentino" (1998: 115). 
fueron despojados de sus tierras, y por colonos que huyeron a causa de la violencia política. Estos colonos mestizos, llamados chilapos, se acogieron a las costumbres de los otros grupos y formaron un entramado pluriétnico en la región. Las comunidades de la región del Pacífico colombiano son poblaciones esencialmente ribereñas, cuya vida es acuática. En los relatos del video La libélula ${ }^{25}$ un mestizo afirma: "Yo me siento negro porque verdaderamente, tengo toda la cultura negra".

La Nueva Esperanza es una pequeñísima población compuesta por cuarenta y siete familias que se han reasentado en las zonas de la cuenca de Jiguamiandó, después de una larga historia de despojos, una Zona Humanitaria en la cuenca del Jiguamiandó, Urabá chocoano, en el Bajo Atrato (región del Pacífico). Sus habitantes han sufrido más de catorce desplazamientos masivos a manos de los grupos armados, según lo revela Erasmo Cuadrado. ${ }^{26}$ La cuenca comprende una extensión territorial de $46.530 \mathrm{~km}^{2}$. Es una zona de alta diversidad ecológica y biogeográfica, considerada bosque húmedo tropical, y ha sido declarada Reserva Forestal en 1957, "para conservación de los suelos de las aguas y la vida silvestre" (Consejo Nacional de Política Económica y Social: 6). Un $82,68 \%$ de su población se compone de afrodescendientes, el 11,9\% son comunidades indígenas (waunanas, emberas, kunas y calimas) y el 6\% restante son mestizos (Vélez et al. 2010: 67). ${ }^{27}$

Entre 1996-1997 ${ }^{28}$ se efectuaron diferentes operaciones militares; la peor de ellas fue la Operación Génesis, que violentó a la mayor parte de la población. Además, las continuas desapariciones, masacres y

25. La libélula es el título de un video que forma parte de los archivos de la Comisión Intereclesial de Justicia y Paz. El material se me suministro durante las entrevistas que realicé a los coordinadores y acompañantes de los procesos de resistencia y de las zonas humanitarias. Archivo de la Comisión.

26. Entrevista concedida por Erasmo Cuadrado (febrero de 2002), cuencas de Curvaradó y Jiguamiandó (archivo entrevistas: visitas de campo, la autora). Erasmo Cuadrado es uno de los líderes de la organización comunal de las zonas humanitarias.

27. La editora del texto es Irene Vélez, pero la investigación fue realizada por diferentes organizaciones que elaboran el informe sobre llamado Misión Internacional para la verificación del impacto de los agrocombustibles.

28. Por orden del comandante Rito Alejo del Río durante la administración de Álvaro Uribe Vélez como gobernador de Antioquia. 
desplazamientos forzados dieron origen a más de cinco mil refugiados en Pavarandó. Entre 1998 y 2001, los pobladores se reagruparon y una parte de los habitantes emprendió el retorno. Se organizaron en comités, se establecieron comunidades de paz, y posteriormente se articularon a través de una estructura más sólida, los consejos comunitarios mayores. ${ }^{29}$

Durante el año 2001, el clima de violencia se intensificó y las confrontaciones entre los grupos armados (guerrilla, paramilitares y ejército) se recrudecieron. Los testimonios de los desplazados y los informes de Justicia y Paz señalan que el éxodo de las familias coincidió con la usurpación de territorios pertenecientes a las comunidades autóctonas. Sus derechos de propiedad colectiva habían sido ya reconocidos por el Estado colombiano a través del Instituto Colombiano de Reforma Agraria (INCORA), "en consideración a lo preceptuado en el artículo 55, numeral T de la Constitución Nacional, la ley 70 de 1993 y el Decreto 1745 de 1995" (Comisión Intereclesial de Justicia y Paz 2005: 95). De acuerdo con esa ley, se contempla que "en cada comunidad, la parte de la tierra de la comunidad negra ${ }^{30}$ destinada a su uso es inalienable, imprescindible e inembargable (artículo III, reconocimiento del derecho a la propiedad colectiva). El informe "Caracterización de las tierras rurales", elaborado por la Agencia Presidencial para la Acción Social y la Cooperación Internacional (2010), indica que la titulación colectiva de comunidades negras corresponde a un 4,6\% del territorio nacional, cuya área cartográfica es de 5.231.883,31 hectáreas.

29. Los consejos comunitarios son formas de organización de las comunidades. Se definen como entidad "administrativa interna" [...] para "delimitar y asignar áreas al interior de las tierras adjudicadas, velar por la conservación y preservación de los derechos de la propiedad colectiva, la preservación de la identidad cultural, el aprovechamiento y conservación de los recursos naturales, escoger al representante legal de cada comunidad en tanto persona jurídica y hacer de amigables componedores en los conflictos internos factibles de conciliación" (ley 70 de 1993, capítulo III, artículo 5).

30. En la Constitución, "comunidad negra" se define como el conjunto de familias de ascendencia afrocolombiana que poseen una cultura propia, comparten una historia y tienen las mismas tradiciones y costumbres dentro de la relación campo-poblado, y revelan y conservan una consciencia de identidad que las distingue de otros grupos étnicos (ley 70 de 1993, capítulo I, artículo 2). 
Las comunidades negras cuentan con ciento cincuenta y cinco títulos colectivos que se localizan en la región del Pacífico, departamentos de Chocó, Cauca, Valle del Cauca y Nariño (34). A continuación, vemos en los mapas la ubicación de las zonas humanitarias analizadas en este estudio:

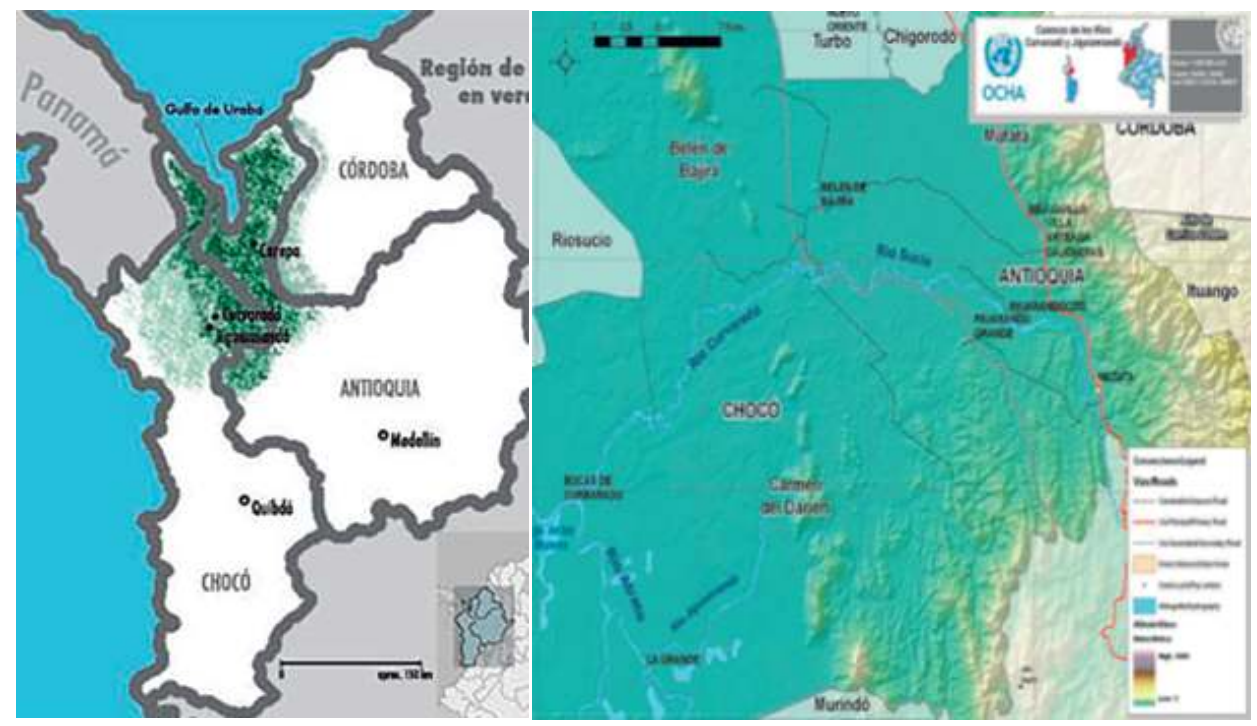

17. Ubicación geográfica de las zonas humanitarias

Fuente: OCHA

\section{Características ambientales de la región}

El área del bajo Atrato es un ecosistema frágil de selva húmeda tropical, considerado una de las zonas con mayor biodiversidad del mundo. En algunos estudios se ha detectado que en un metro cuadrado del Chocó biogeográfico ${ }^{31}$ hay mayor variedad biológica que en un kilómetro cuadrado de un país templado. El clima tropical de la región favorece

31. El Chocó biogeográfico está compuesto por Chocó, Valle del Cauca, Cauca, Nariño $y$, en menor proporción, Antioquia. 
la confluencia exuberante de agua, luz y aire. Además, su localización, alejada de las tierras bajas y rodeada por la cordillera de los Andes, le proporciona una barrera natural a la que se deben sus endemismos. Se estima que cerca del $25 \%$ de las especies de aves, mariposas y plantas que habitan en el Chocó biogeográfico no se encuentra en ningún otro lugar del planeta. La alta capacidad de pluviosidad lo convierte en una de las zonas de mayor reserva hídrica en el mundo.

De acuerdo con recientes investigaciones, esta región presenta el mayor valor de precipitaciones que se mantiene en una selva lluviosa tropical $\left(8,494\right.$ a 13,670 $\left.\mathrm{m}^{3}\right)$. La cuenca hidrográfica la forman varios ríos el Atrato, el San Juan y el Patía, entre otros, y se caracteriza por tener afluentes de corto alcance, pero de corriente intensa. De acuerdo con el informe "Caracterización de las tierras rurales" (Agencia Presidencial para la Acción Social y la Cooperación Internacional 2010), la mayoría del territorio de la región pacífica es Área Protegida de orden nacional o Reservas (ley 2 de 1959); el 18,32\% del total de zonas forestales comparte una fracción de su extensión con las Áreas Protegidas (38) y el 71,97\% de los territorios colectivos se encuentran en esas zonas de Reserva Forestal (42).

\section{Cronología del conflicto}

La dimensión territorial de las áreas respectivas de titulación colectiva comprende 43.700 hectáreas en la cuenca del Curvaradó y 54.973 hectáreas en la cuenca de Jiguamiandó. Como se indicó antes, desde inicios de la segunda mitad de los años noventa, las poblaciones de la zona empezaron a ser blanco de ataques armados, bombardeos y otras formas de agresión. En el ańo 2001, cuando las comunidades emprendieron un nuevo retorno, encontraron gran parte de sus territorios ocupados con cultivos de palma. De acuerdo con la comisión de verificación compuesta por el INCODER y la Defensoría del Pueblo, 22.022 ha de los territorios de las dos cuencas fueron invadidas. ${ }^{32}$ Las

32. Defensoría del Pueblo. Resolución Defensorial N. 39. 
empresas palmeras ${ }^{33}$ efectuaron diferentes tipos de contratos fraudulentos para legitimar sus actividades y utilizaron varios mecanismos para desplazar a las comunidades de sus territorios. Los habitantes de estas zonas tenían gran temor de sucumbir en los ataques armados o de ser víctimas de torturas, casos que ya habían sucedido con algunos de sus miembros, por ello, vivieron durante largo tiempo en completa inestabilidad, ocultándose en el monte o trasladándose a otras veredas cercanas.

Los testimonios que aparecen en el informe "La Tramoya" (Comisión Intereclesial de Justicia y Paz 2005) relatan las incursiones de los paramilitares y de los militares, quienes acusaban a los campesinos de ser guerrilleros o de colaborar con ese actor armado. En el año 2000, una parte de las comunidades logra reagruparse y se organiza en comités de diferente índole. Aunque no consiguen retornar al territorio, se mantienen en las proximidades de su región. Además, denuncian los atropellos a través de comunicados y cartas al Gobierno. Las movilizaciones por causa del desplazamiento tienen lugar principalmente en las áreas cercanas a las dos cuencas.

Entre los años 1996 y 2001 se presentaron más de doce incursiones armadas en contra de la población. A finales de 2001, las comunidades reúnen pruebas y verificaciones sobre los cultivos de palma en sus territorios y llevan el caso a la Corte Interamericana de Derechos Humanos $(\mathrm{CIDH})$ para pedir protección. La consolidación comunitaria se debe a los procesos de organización y resistencia. La formación de la Asociación de Campesinos del Atrato (ACAT) fue fundamental para tener cohesión, resistir en los territorios y movilizar diferentes medios de protección. En el ańo 2003, la Corte adopta medidas provisionales para las comunidades y se pronuncia ante el Estado colombiano. Durante esos años de continuos hostigamientos y violencia, tanto por parte de los actores armados como por parte de las actividades neoextractivistas, la comunidad, con el acompańamiento de Justicia y Paz,

33. Algunas de las empresas que realizan negocios de palma y tienen proyectos de ganadería en la región son Urapalma S.A., Palmas de Curvaradó, Inversiones Fregni Ochoa, Empresa La Tukeka, Palmera del Curvaradó, Palmadó Ltda. entre otras (Comisión Intereclesial de Justicia y Paz, 2005, p. 13). 
decide habilitar un espacio de neutralidad para la población civil: las zonas humanitarias. Tras continuas agresiones de forma consecutiva en los ańos 2004, 2005, 2008 y nuevamente en 2010, se dictamina un pronunciamiento de la $\mathrm{CIDH}$ :

En el Derecho Internacional de los Derechos Humanos las medidas provisionales tienen un carácter no sólo cautelar, en el sentido de que preservan una situación jurídica, sino fundamentalmente tutelar, por cuanto protegen derechos humanos, en la medida en que buscan evitar daños irreparables a las personas. (Corte Interamericana de Derechos Humanos 2010: 3)

De acuerdo con el informe sobre la verificación del impacto, Irene Vélez et al. (2010) señalan que se calcula que el área de territorios colectivos ocupados con palma equivale a unas 7.000 hectáreas. El INCODER también había señalado que cerca del 95\% de la palma sembrada en la región se encontraba en territorios colectivos. Ante esta constatación, la Corte Constitucional de Colombia dictó tres órdenes judiciales en los años 2009, 2010 y 2011 para garantizar el derecho de la restitución material de los territorios. El Gobierno había presentado una resolución en favor de las industrias palmeras que estaban en pleito, pero fue revocada por la Notaría de Superintendencia y Registro en el año 2009. Ya dos años antes, se había iniciado un proceso jurídico contra algunos empresarios de la industria de palma. Después de varias reclamaciones por usurpación de tierras, falsedad en documentos, delitos contra el medio ambiente, desplazamientos, amenazas y hostigamientos, la Fiscalía General inició el proceso de investigación 3.856 contra veintitrés empresarios; algunos de ellos fueron encarcelados y otros fueron investigados por apropiación de los territorios colectivos.

En 2010, el Consejo de Estado volvió a ordenar la expulsión de los ocupantes de mala fe, como se ha hecho en repetidas ocasiones. ${ }^{34}$ Aunque las arremetidas continuaban, la población resistía en las zonas humanitarias que habían establecido. Según los relatos de los pobladores,

34. En el capítulo III, artículo 15 de la ley 70 de 1993, se establece que las ocupaciones que se realicen por personas no pertenecientes a las comunidades negras en propiedades colectivas, no darán derecho al interesado, ni tendrán efectos legales y serán considerados como "poseedor de mala fe" (Ley 70 de 1993). 
las fuerzas militares y los paramilitares tienen objetivos muy similares: expulsar a las poblaciones de sus territorios. El proceso de retorno se inició en 2006, volviendo a reubicarse en una extensión de 5 hectáreas cedida por uno de los campesinos —el de mayor antigüedad en la región- para constituir la primera Zona Humanitaria en Curvaradó. Los otros pobladores llegaron posteriormente y trabajaron de forma mancomunada para habilitar zonas de biodiversidad. De acuerdo con Catherina Bouley y Danilo Rueda (2009), estos espacios surgen como mecanismos de protección para defender el derecho a la vida y la paz. $\mathrm{Su}$ concepción se funda sobre "el principio humanitario de distinción entre combatientes y no combatientes y exigen la protección que cobija a la población civil cuando se presentan conflictos armados sin carácter internacional" (15).

A pesar del respaldo de la Comisión Eclesial de Justicia y Paz, la presencia de organizaciones internacionales y el acompañamiento local, los hostigamientos persisten. Además, no se respetan los derechos humanos y se desatienden las peticiones de las comunidades, tal como lo confirman la organización Peace Brigades International, que sigue acompańando las poblaciones en la región. Sin embargo, los pobladores de las zonas humanitarias continúan resistiendo pacíficamente. En la actualidad hay ocho zonas humanitarias y más de cincuenta zonas de biodiversidad. No solamente la agroindustria de la palma ha usurpado territorios colectivos, también lo ha hecho la industria bananera, a través de Banacol. ${ }^{35} \mathrm{Al}$ respecto, Fajardo (2006) considera que se da un proceso de expropiación territorial que persigue "no solamente controlar la tierra sino también controlar la población” (30).

Un nuevo actor que hace parte de este rompecabezas son las empresas de seguridad, integradas por ex miembros de las desarticuladas Autodefensas Unidas de Colombia. Las poblaciones ya han hecho públicos los intentos de apropiación de sus tierras para siembra de banano y señalan que se repite la misma estrategia: las empresas llevan gente de otros lugares para que ocupen los territorios. En el mes de octubre de

35. Un informe realizado por la FIAN en mayo del 2012 provee información más detallada sobre los acontecimientos respecto a las actividades de Banacol en la zona de los territorios colectivos (Comisión Intereclesial de Justicia y paz 2012) 
2013, los miembros de algunas comunidades se reunieron para discutir la decisión que tomó el Comité ad hoc en la que se niega a los afromesti$z o s$ voz y voto en la elección de las directivas de los territorios. ${ }^{36}$

\section{Actores en disputa}

La experiencia de desalojo causó fisuras en el interior de la misma comunidad. Algunos de sus miembros, como se mencionó antes, cedieron ante la presión o ante las ofertas de venta o alquiler de la tierra. Estos hechos tuvieron incidencia en los alcances de la titulación colectiva y complejizaron aún más los escenarios de fragmentación comunitaria en el conflicto. La figura política representativa de las comunidades en las zonas humanitarias son los consejos comunitarios mayores y los consejos comunitarios menores.

Las empresas de la industria de la palma están implicadas directamente en las disputas por la usurpación de terrenos. Los palmicultores locales han aprovechado la coyuntura de desarticulación comunitaria o tienen alguna responsabilidad en la segregación en las poblaciones, ya que utilizaron prebendas y beneficios especiales para tener algunos miembros a su favor. También han involucrado a grupos ilegales armados o han camuflado su participación a través de las llamadas empresas de seguridad para apropiarse de algunas áreas, causar desplazamientos forzados y ejercer el control sobre parte de los territorios colectivos. Además, cometieron prevaricación para falsificar documentos públicos.

\section{Aspectos de incidencia y repercusión}

\section{Usurpación territorial}

Invasión y uso de territorios colectivos: la invasión y el saqueo de los pobladores y el uso de los terrenos colectivos es una fuerte violación a la

36. Corte Constitucional, sala especial de seguimiento. Sentencia T-025 de 2004, magistrado presidente: Luis Ernesto Vargas Silva, auto 096 de 2013. 
reglamentación de las comunidades negras sobre los títulos colectivos y su carácter "inalienable, imprescindible e inembargable", así como el uso de los territorios para cultivos de palma de aceite cuyos beneficios son industriales y no comunales.

Aspecto ambiental: se cambia la vocación agraria en los territorios, la transición de cultivos semestrales a cultivos perennes agota la fertilidad de los suelos, lo que causa erosión y produce una carga hídrica adicional —estrés hídrico- L La presión de los subsistemas, tanto por la cantidad de agua requerida como por la cantidad de tierra utilizada, genera fuertes impactos en los ecosistemas.

Cultivos pancoger los cultivos de pancoger son el fundamento alimenticio para las poblaciones. Se trata de cultivos tradicionales que garantizan su autoabastecimiento y que al desaparecer ponen en riesgo la existencia de diversas poblaciones.

Cultura ecológica y gobernanza: la usurpación y apropiación de los territorios lacera las formas de organización tradicionales que han preservado las comunidades afrodescendientes en el Pacífico colombiano. La posibilidad de gestionar y autodeterminar los usos, el manejo y la producción territorial queda anulada y, además, desdibuja las funciones de las figuras políticas locales, como los consejos mayores y menores.

Cultura étnica: este aspecto tiene incidencia no solo en las fracturas que causa en el tejido social-comunitario, sino también en la tradición y la cultura étnica. Se violentan las prácticas ancestrales, se desestructuran los intercambios intra e intercomunitarios y se socavan las prácticas y los significados de territorialidad que caracterizan a las culturas afrodescendientes. 


\section{Capítulo vi}

\section{Manejo del conflicto}

\section{Acciones comunitarias, convivencia y construcción de paz. Análisis comparativo}

Como se ha señalado en el capítulo segundo, los conflictos relacionados con el medio ambiente se caracterizan por presentar estructuras complejas debido a que abarcan varias dimensiones. La mayoría de las veces, dichos conflictos emergen con una apariencia distinta a lo medioambiental, pero en su núcleo causal aparece siempre la confrontación por los recursos naturales. En los casos que aquí se analizan, las comunidades no están reclamando las ganancias o dividendos de las actividades productivas de la tierra. Por un lado, los conflictos se dan en relación con la restitución y la titulación de tierras, lo que entraría dentro del dominio jurídico. Por el otro, las diferencias se dan en relación a la disposición de uso y autodeterminación de bienes naturales, lo que se encuadraría en el ámbito sociocultural y político. Un elemento central es que las luchas por la tierra llevan a las comunidades a determinar acciones conjuntas que van más allá de reclamar lo estrictamente material. La tenencia de la tierra es el principal elemento de confrontación, pero no es el único. El desplazamiento forzado, que 
afecta a muchos habitantes rurales, no desplaza solo seres humanos, sino también culturas, racionalidades comunitarias, formas de organización, tradiciones, visiones del mundo, formas de convivencia y construcciones arquetípicas del pasado y del futuro; es decir, con todo ello, se pone en peligro también la posibilidad de cultivar procesos locales que han construido las comunidades rurales por la paz.

Si bien los tres casos elegidos para este estudio comparten similitudes en la composición de su perfil comunitario, se puede apreciar que, respecto a las estrategias usadas para el manejo del conflicto, hay algunos rasgos singulares. En este capítulo se analizan, de forma comparativa, las que ponen en práctica las comunidades afectadas por el despojo, o ante la amenaza del mismo, ocasionado por la agroindustria palmera. Se examinan los procedimientos que emplean las comunidades para retornar a sus lugares de origen y, asimismo, se estudian los fundamentos que subyacen en la cultura política, social, ecológica y económica de estas comunidades y que conforman la base y los fundamentos filosóficos de las acciones colectivas.

Ese procedimiento está guiado por la búsqueda de un cambio sistemático en el manejo del conflicto enfocado en el caso y no en la variable. ${ }^{1}$ Existen dos puntos de partida para observar alternativas en las relaciones que desencadena un fenómeno en diferentes contextos. Los dos diseños que se suelen utilizar para la comparación de estudios de caso son most similar systems y most different systems. ${ }^{2}$

1. Charles Ragin (1987) distingue entre dos estrategias de comparación: la que se centra en los casos y la que se enfoca en la variable, es decir, el fenómeno. Este autor propone un método de análisis conocido como qualitative comparative analysis. Aunque este estudio parte de la búsqueda de la variación a partir de una relación multicausal, considero que el método sugerido por Ragin no es lo suficientemente adecuado para este análisis debido a la rigidez de la codificación de las variables: solo pueden tener dos valores. Esta rigidez no aportaría mucho para analizar la relación de intensidad que alguna de las variables pueda mostrar respecto al manejo del conflicto.

2. Adam Przworski y Henry Teune, en su libro The Logic of Comparative Social Inquiry (1970), señalan varios análisis sobre movilidad social y votaciones electorales (entre otros) que utilizan este diseño e indican que los diseños most similar "se basan en la idea de que los sistemas que son lo más posiblemente semejantes entre sí, con respecto a la mayoría de rasgos posibles constituyen el muestreo óptimo 
En nuestro estudio la comparación entre diferencias y similitudes se realizará a través de dos planos. En primer lugar, el de la realidad contextual, al cual se dedica este capítulo. Allí se identifican las estrategias de acción de las comunidades, el papel de los intermediarios y las relaciones de poder estructurales. En segundo lugar, en el plano representado, que será objeto de análisis del capítulo séptimo, se analizan las composiciones líricas y la representación de las temáticas relacionadas con las disputas, es decir, los significados y las simbologías contenidos en los cantos.

Metodológicamente es pertinente y necesario realizar esta comparación. Por un lado, porque podemos indagar contenidos explícitos y subyacentes del conflicto. Por el otro, porque es posible ahondar en la comprensión de cuáles son los significados más relevantes de la cultura campesina y comunitaria que pueden revelar las prácticas locales para manejar el conflicto. Estas reflexiones permiten distinguir qué acciones se podrían catalogar como mayormente efectivas en la construcción de la paz y de qué manera se pueden vislumbrar como estrategias con incidencia en la transformación del conflicto. Si bien la restitución de tierras es uno de los temas fundamentales en el marco del postconflicto, y se ha avanzado mucho en el dominio jurídico dentro del marco de la justicia transicional, es importante considerar qué otros ámbitos estarían ligados a un desarrollo apropiado para que la restitución responda a las necesidades locales. Revisar esos otros ámbitos es una de las contribuciones que este estudio busca aportar.

\section{Consideraciones preliminares en el contexto del postconflicto}

Indagar cómo perciben y experimentan las comunidades rurales los desafíos de la confrontación es de vital importancia, por una parte, porque se hace urgente contemplar qué transferencias y transacciones tienen lugar en el contexto de las disputas a nivel intracomunitario y extracomunitario y, por otra parte, porque es ineludible reconocer la

para el análisis comparativo [...]. Tanto las similitudes como las diferencias intersistémicas son el centro del estudio de los sistemas más semejantes” (32). 
transformación como un proceso de microcambios en la estructura de confrontación. Además, con el propósito de conocer las culturas campesinas es necesario comprender que, tras una historia de marginalización de los pobladores rurales en Colombia, se han marginado también su memoria y sus identidades. Paralelos a los escenarios de guerra, se han venido cultivando espacios por la paz en el ámbito rural colombiano. El despojo, como estrategia utilizada por diversos actores, se ha encargado de silenciar esos procesos o esas culturas de convivencia; sin embargo, las comunidades han buscado siempre formas creativas para organizarse y concebir escenarios de vida en común. Esas culturas de convivencia comunitaria siguen vivas, aunque no hayan tenido voz en el concierto nacional. Por ello, volcar la mirada hacia ellas para empezar a descubrir y a recuperar escenarios locales y pacíficos que funcionan a escala micro brinda la posibilidad de ver con otros lentes pasos efectivos hacia la transformación del conflicto y la construcción de paz. Quienes usurpan los territorios quieren comprar y vender no solo las tierras, sino también ideas, acordes a las estrategias de mercado con aparentes legalidades y en las que domina una estética mercantil. Las medialidades y los medios son sumamente proclives a difundir esas estéticas moldeando los imaginarios de progreso y desarrollo que se acomoden a modelos netamente utilitaristas. En consecuencia, es necesario acceder a otros discursos, si se quiere, subalternos o alternos. De igual modo, es imprescindible acceder y conocer estéticas nacientes, emergentes, que muestran las cartografías de insostenibilidad y vulnerabilidad que crea el llamado desarrollo. Por ello, es de vital importancia considerar el poder del canto y de las literaturas orales rurales y visualizar el trabajo de los campesinos, a quienes las estrategias del mercado neoliberal los están desdibujando del mapa nacional. En el informe "El campo colombiano: un camino hacia el bienestar y la paz. Misión para la transformación del campo" (2015), se formula esa problemática de la siguiente manera:

Por lo general la solución a los conflictos por intereses se basa en sistemas de poder económico y político, sin tener en cuenta en muchos casos la vocación del territorio. Este tipo de procesos dan origen a la subutilización y sobreutilización del suelo y a la generación de condiciones de insostenibilidad del desarrollo de las actividades tanto rurales como urbanas y en otros casos a situaciones de riesgo (Departamento Nacional de Planeación 2015: 233). 
La necesidad urgente de reconocer las voces y las huellas de quienes han soportado con tenacidad el despojo nos exige admitir que, en la praxis rural, existen otras formas y otros modos de relación social, económica, ecológica y política que emergen desde la comunidad y las prácticas de convivencia comunitaria. Justamente esos modelos de los poderes económicos y políticos a los que se refiere la cita anterior han promovido estrategias neocolonizadoras de extracción. Además, se han impuesto en el sistema de transacciones políticas y económicas no solo impidiendo la transformación de los conflictos por la tierra, sino agudizando esos mismos escenarios. Las graves disputas por la tierra no pueden ser superadas si se siguen utilizando los mismos mecanismos para contrarrestarlos: reformas inocuas, participaciones no vinculantes, economías en completa ilegalidad y muchos otros más. En la implementación de dichos mecanismos, no se han contemplado las experiencias ni los conocimientos locales comunitarios, no se han incluido sus saberes sobre la naturaleza, sobre la administración de los recursos, sobre agricultura, etc. Conocer esos procesos comunitarios de fondo en todos sus ámbitos es uno de los primeros pasos para poder entablar una conversación descolonizadora y auténtica sobre lo que se podría entender como la paz en el campo. El estudio de Forero, Rodríguez y León (2015) sobre la agricultura familiar en la altillanura colombiana muestra diez familias que han recibido terrenos del INCODER y que han estado trabajando en proyectos a pequeña escala con resultados económicos muy favorables, como lo expresa el siguiente fragmento:

Los ingresos por hectárea mes oscilan entre $\$ 36,922$ y $\$ 152,467$. Esto es aproximadamente entre 3,7 y 15,2 veces lo que obtendrían por arrendar sus tierras a los agricultores empresariales de la región. A la fecha del estudio, estos agricultores empresariales principalmente de soya y maíz, pagaban aproximadamente $\$ 10,000$ pesos por hectárea mes (50).

En el contexto actual de Colombia existen muchas razones por las cuales se amerita optar por análisis académicos con enfoque de base o de abajo hacia arriba (bottom-up). Dos de esas razones tienen un carácter excepcional. La primera corresponde a un proceso social de reconciliación que se ha venido cultivando desde hace casi un lustro y que finalmente se cristalizó en las negociaciones y en el Acuerdo Final 
de paz que fue refrendado por el Congreso en diciembre de 2016. Reiterar que es un proceso social de construcción de paz es reconocer que la sociedad colombiana se ha encaminado hacia la búsqueda de transformaciones sociales desde diferentes segmentos de la sociedad — la academia, la escuela, la familia, la Iglesia - y desde muchos otros ámbitos en donde se teje la vida cotidiana. En este sentido, el Acuerdo, que actualmente está en el curso de su implementación, brinda un marco de principios guía que se consignan en el papel, pero que en la práctica deben ir encontrando espacios, modos y posiciones para que se hagan efectivas las transformaciones hacia una paz con equidad. La segunda razón, igual de importante que la anterior, es que existen formas de determinación comunitaria que deben ser consideradas, incluidas e implementadas como parte de las prácticas políticas del intercambio social. Las racionalidades comunitarias y sus fundamentos para administrar la tierra y para relacionarse con el ambiente son propuestas conceptuales sobre cómo convivir de manera sustentable.

\section{Espacialidad rural}

En el contexto colombiano, las relaciones entre el espacio rural y el espacio urbano se han agravado por la dinámica de la guerra. Los usos y las formas de distribución de los ámbitos agrarios muestran cada vez mayores desequilibrios en las relaciones población/territorio. Los procesos de urbanización y la saturación de las periferias citadinas parecen ser un fenómeno paralelo a la desolación paulatina del campo. En los paisajes urbanos, los efectos del desplazamiento forzado exacerban las condiciones infrahumanas de las poblaciones vulnerables que llegan a habitar en los sectores con amplios márgenes de pobreza. De acuerdo con Jesús Bejarano (1998), países como Argentina, Brasil y Ecuador han necesitado más de tres décadas para reducir los niveles de participación de la mano de obra agrícola del $50 \%$ al $30 \%$ en sus economías. En el caso colombiano, esto ocurrió en el término de dieciocho ańos. Es lo que se conoce como desagriculturización del empleo. De acuerdo con Bejarano (1998), citado por Fajardo (2004): "En 1938 la población rural representaba el 69,1\% y en 1951 el 57\% pero en 1973 la 
población localizada en los medios rurales había descendido al 40.7\% y en 1993 al 31,0\%", y actualmente, según el Informe detallado de la Misión para la transformación del campo del 2014, coordinado por T. Ángel Y G. Llinas para el Departamento Nacional de Planeación, el 30\% de la población colombiana, que en cifras reales corresponde a cuarenta y siete millones de personas, habita en el campo (2015: 68). En ese mismo Informe, se señala que "de acuerdo con el IGAC, el índice Gini de la propiedad de la tierra se ha mantenido en niveles de 0,86 con una ligera tendencia a aumentar y se ve reflejado en que el $63 \%$ de los predios del país son microfundios con menos de 3 hectáreas (UPRA)" (2015: 241).

Pero ¿qué pasa con la gente que aún permanece en el campo? A pesar de las grandes tensiones, buena parte de la población rural que habita en la ciudad (la gran mayoría de ellos en condiciones de desplazamiento forzado) quiere regresar a su terruño. De igual manera, la mayoría de la escasa población que permanece en el campo reivindica su derecho a la tierra, a la gestión territorial, a la soberanía alimentaria y a la inclusión en un desarrollo sustentable. Si seguimos las cifras que nos muestran los movimientos migratorios entre campo-ciudad, como lo indica Bejarano (1998), podríamos advertir que el grupo social campesino es una franja cada vez más minoritaria de las sociedades latinoamericanas y que, en especial en Colombia, tiende a desaparecer.

Orlando Fals Borda (2009) había planteado ya hace algunas décadas la "descomposición del campesinado". Esta idea estaba basada especialmente en una reflexión sobre la tierra y su tenencia en torno a los mecanismos que se introdujeron a finales de la colonia. En los últimos treinta años, la clase campesina muestra mayores rasgos de exclusión social y se ve amenazada por mecanismos de desterritorialización provenientes de distintos actores. Fals Borda indica que su composición ha estado afectada por diferentes factores, que varían con mayor o menor intensidad en la historia colombiana. Los megaproyectos en áreas rurales, la ganadería extensiva, los cultivos ilícitos y, en últimas, el control de las áreas rurales han agudizado drásticamente los procesos de la migración campesina, dando origen al desplazamiento forzado. Es necesario conocer los procesos de las comunidades que optan por economías agrícolas de pequeńa escala, que, pese a la escasez 
de recursos económicos y a la poca asistencia técnica que reciben, desarrollan competencias significativas, como es el caso de familias campesinas en la altillanura colombiana:

Estas familias han implementado en sus predios sistemas de producción campesina, caracterizada por la baja inversión monetaria y la maximización de la utilización de la mano de obra familiar disponible, el uso de los recursos existentes en el entorno natural y el intercambio entre vecinos de trabajo, conocimientos y materiales genéticos (Forero, Rodríguez y León 2015: 25).

\section{Comparación distintiva por roles y causas}

El informe "El campo colombiano" (2015) del Departamento Nacional de Planeación ofrece una tipología de los conflictos por uso de tierras e indica que los llamados proyectos de desarrollo agrario tienen corresponsabilidad en esa situación, como se indica en la siguiente nota:

El segundo tipo de conflicto territorial está relacionado con la definición de prioridades para la explotación del territorio, sin tener en cuenta los modelos de territorio regionales ni la existencia de reglas claras sobre prioridades de uso. Esta situación genera tensiones sociales entre diversos actores nacionales y locales. Por ejemplo, la construcción de obras de infraestructura como vías, represas, puertos, desarrollos agroindustriales, etc. por lo general contrasta con los modelos de territorio definidos por las comunidades que habitan estos territorios (235) (las cursivas son mías).

En el capítulo IV se hizo referencia en detalle a las estrategias de promoción que utiliza la industria palmera para acrecentar su negocio. A continuación, observamos un esquema aproximativo a la propuesta que hace Bächler (1999) para distinguir qué roles puede adoptar una misma causa en los actores. En este caso, me detendré de especial manera a puntualizar las estrategias que utilizan las comunidades rurales enfrentadas a la problemática de tierras por la agroindustria palmera. Veremos de forma comparativa en la siguiente tabla las categorías propuestas por Dessler (1994) y reelaboradas por Bächler (1999) para analizar los aspectos del manejo de conflicto en cuanto a la dinámica y el contenido. En la primera parte se brindan algunas reflexiones sobre las categorías que aparecen propuestas en la tabla. Posteriormente, se 
analizarán la interlocución y el diálogo entre actores, las estrategias de acción y las relaciones de poder estructural, observando el trabajo en redes. Después se estudiará el contenido del conflicto, haciendo referencia en concreto a los paradigmas contrapuestos.

\begin{tabular}{|c|c|c|c|c|c|c|}
\hline & \multirow[t]{2}{*}{ Objetivos } & \multicolumn{2}{|l|}{ Razones } & \multirow[t]{2}{*}{ Desencadenantes* } & \multirow[t]{2}{*}{ Catalizador } & \multirow[t]{2}{*}{ Canales } \\
\hline & & Causa histórica & Causa contextual & & & \\
\hline \multirow{3}{*}{ 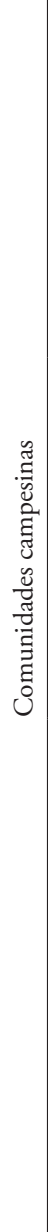 } & $\begin{array}{l}\text { Las Pavas } \\
\text { Consolidarse } \\
\text { como asociación } \\
\text { campesina con } \\
\text { titulación territorial. } \\
\text { Desarrollar acciones } \\
\text { de productividad y } \\
\text { comercio regional }\end{array}$ & $\begin{array}{l}\text { Asentamiento, } \\
\text { posesión de } \\
\text { territorios: } \\
\text { agricultura local } \\
\text { para elevar su } \\
\text { producción } \\
\text { y mejorar } \\
\text { su situación } \\
\text { económica }\end{array}$ & $\begin{array}{l}\text { — Desplazamiento } \\
\text { forzado } \\
\text { — Acción } \\
\text { comunitaria: } \\
\text { permanencia en la } \\
\text { hacienda y retornos } \\
\text { - Plantaciones de } \\
\text { palma de aceite }\end{array}$ & $\begin{array}{l}\text { — Desalojo } \\
\text { por parte del } \\
\text { Consorcio } \\
\text { — Amenazas y } \\
\text { hostigamientos } \\
\text { — Fragmentación } \\
\text { comunitaria }\end{array}$ & $\begin{array}{l}\text { — Acciones } \\
\text { jurídicas } \\
\text { - Acciones } \\
\text { públicas } \\
\text { — Decisiones del } \\
\text { INCODER } \\
\text { - Resignificación } \\
\text { en el arte musical }\end{array}$ & $\begin{array}{l}\text { —Red de paz } \\
\text { — Asociación } \\
\text { campesina } \\
\text { local: ASOCAB }\end{array}$ \\
\hline & \begin{tabular}{|l} 
El Garzal \\
Consolidarse \\
como comunidad \\
campesina \\
con titulación \\
territorial. Llevar \\
a cabo actividades \\
de producción \\
cooperativa y \\
productiva \\
\end{tabular} & $\begin{array}{l}\text { Posesión de } \\
\text { territorios: } \\
\text { agricultura local } \\
\text { para elevar su } \\
\text { producción } \\
\text { y mejorar } \\
\text { su situación } \\
\text { económica }\end{array}$ & $\begin{array}{l}\text { - Amenaza de } \\
\text { desplazamientos } \\
\text { y expulsión de las } \\
\text { tierras } \\
\text { - Reclamación } \\
\text { de territorios por } \\
\text { parte de empresas } \\
\text { palmeras }\end{array}$ & $\begin{array}{l}\text { Exigencia y } \\
\text { negociación para } \\
\text { titulación }\end{array}$ & $\begin{array}{l}\text { - Cooperativas: } \\
\text { producción de } \\
\text { cacao } \\
\text { — Acciones } \\
\text { jurídicas } \\
\text { - Adhesión a } \\
\text { la congregación } \\
\text { religiosa local }\end{array}$ & $\begin{array}{l}\text { — Red de paz } \\
\text { — Asociación } \\
\text { campesina } \\
\text { Regional: } \\
\text { ASPROAS }\end{array}$ \\
\hline & $\begin{array}{l}\text { Comunidades } \\
\text { de las cuencas } \\
\text { Jiguamiandó y } \\
\text { Curvaradó } \\
\text { Consolidarse como } \\
\text { comunidades } \\
\text { afrocolombianas } \\
\text { y campesinas con } \\
\text { derechos sobre } \\
\text { su territorio y } \\
\text { autogestión local }\end{array}$ & $\begin{array}{l}\text { Hábitat ancestral: } \\
\text { identidad étnica }\end{array}$ & $\begin{array}{l}\text { - Invasión de } \\
\text { los territorios con } \\
\text { sembrado de palma } \\
\text { de aceite } \\
\text { - Violación de } \\
\text { titulación colectiva }\end{array}$ & $\begin{array}{l}\text { A partir de la } \\
\text { titulación: } \\
\text { desplazamientos y } \\
\text { hostigamientos a la } \\
\text { comunidad }\end{array}$ & $\begin{array}{l}\text { - Constitución } \\
\text { de los consejos } \\
\text { locales } \\
\text { — Intervención } \\
\text { de la } \\
\text { Corte } \\
\text { Constitucional y } \\
\text { La Corte } \\
\text { Interamericana } \\
\text { de Derechos } \\
\text { Humanos } \\
\text { - Resignificación } \\
\text { en diferentes tipos } \\
\text { de arte }\end{array}$ & $\begin{array}{l}\text { — CAVIDA } \\
\text { - Zonas } \\
\text { humanitarias } \\
\text { - Trabajo en } \\
\text { redes } \\
\text { - Asociación } \\
\text { de Campesinos } \\
\text { del Atrato, } \\
\text { ACAT }\end{array}$ \\
\hline
\end{tabular}

18. Roles de una misma causa: desplazamiento forzado para producción de palma de aceite en tres comunidades rurales en Colombia Fuente: elaboración propia, basado en Baechler (1999) 
OBjetivos

Restitución y titulación: la titulación de los territorios corresponde al marco legal. La titulación en los casos de Las Pavas y el Garzal es la prioridad apremiante, mientras que en las comunidades del Pacífico lo es la restitución. Reclaman la devolución de los territorios que han sido invadidos y adquiridos por los empresarios con procesos fraudulentos. Sin embargo, no solo existen irregularidades en cuanto a los procedimientos de la titulación de tierras, sino que la titulación misma se ha convertido en un detonante de conflicto, como se observa en el caso de las comunidades de las cuencas del Pacífico y de El Garzal, que recibieron en el 2013 algunas titulaciones. De acuerdo con el informe "Colombia rural. Razones para la esperanza" (uno de los más completos sobre la distribución de las tierras en Colombia), elaborado por el Programa de Naciones Unidas para el Desarrollo (PNUD), se señala que la carencia de un sistema de titulación ha estado también influenciada por las burguesías, el tráfico de tierras dentro de la lógica del narcotráfico y por la alta concentración de tierra que existe en Colombia:

El país y los poderes constituidos nunca han optado por una decisión política de modificar sustancialmente la estructura de tenencia de la tierra. Cuando se han intentado reformas agrarias redistributivas, la oposición abierta o velada ha estado presente por parte de gremios y élites agrarias (2011: 207).

El informe presenta una descripción sobre la evolución de la concentración de tierra en el país. Además, allí se indica que la consecución de la paz en Colombia pasa por la solución de conflictos por la tierra como una condición necesaria pero no suficiente. Como se mencionó antes, en los procesos de titulación en los que se ha restituido la tierra a los campesinos se han desencadenado situaciones de mayor tensión para la población, como en El Garzal. Incluso, en algunos casos, los habitantes se han visto forzados nuevamente a ausentarse del territorio por los hostigamientos y las amenazas.

Gestión territorial y autodeterminación: este objetivo correspondería a la gobernanza territorial. Existe una historia de despojo que ha sido causada por diferentes actores y actividades para controlar los 
territorios colectivos, algunos para cultivos ilícitos y otros para proyectos agroindustriales. Como hemos visto en los tres casos, la gestión territorial no ha podido darse de hecho: las comunidades que se establecen en las demarcaciones geográficas específicas han huido de otros entornos similares. Lograr la gestión y la autodeterminación significa empoderarse como culturas comunitarias, consolidar prácticas colectivas en diferentes ámbitos, establecer economías productivas y coparticipar en decisiones político-administrativas, en especial las que tienen que ver con el uso de los recursos naturales.

\section{RAZONES}

Desplazamiento y usurpación de territorios: como se aprecia en la tabla anterior, tanto las razones contextuales como las causas históricas son semejantes en las tres comunidades. Históricamente, el desplazamiento de la población rural — ya sea forzado o semiforzado- ha sido una constante en la historia nacional. ${ }^{3}$ La usurpación territorial se da a causa de las irregularidades en la titulación, lo que impide a las poblaciones ejercer los derechos de propiedad, pero se da incluso teniendo títulos de propiedad, como en el caso de las comunidades de las cuencas del Curvaradó y Jiguamiandó. Diferentes autores han afirmado que el desplazamiento o el despojo es una estrategia para controlar las tierras. En realidad, muchos de los proyectos agroindustriales y extractivos se convierten en cadenas de acaparamiento rural y se presentan modelos económicos de alta rentabilidad donde la participación de las comunidades es irrisoria. Una de las problemáticas es el espacio temporal que prevén muchos de esos proyectos. En el caso de la minería, las empresas firman contratos que permiten hasta treinta años de beneficios para las compañías, de tal manera que no existen marcos temporales para cambiar el curso de esos proyectos. El caso de la industria de aceite de palma es similar porque la producción prevé dividendos recién después de los cinco años y se contemplan cultivos

3. De acuerdo con el informe del PNUD sobre la situación rural en Colombia (elaborado en el 2011), esta posee un sistema de catastro sumamente desactualizado. 
que permanecen unos veinticinco ańos produciendo ganancias para los empresarios.

Negligencia institucional: esta razón tiene incidencias en la intensidad y la duración de las disputas. En los casos de este estudio, las instancias institucionales han mostrado descuido y han postergado la resolución y la terminación de los litigios. No se les ha dado curso a procesos judiciales como el de la extinción de dominio y se han detectado procedimientos irregulares que favorecen a los empresarios $y$, por ende, la usurpación de territorios. Se potencia el uso del poder de los actores con mayores recursos para utilizar la violencia. Se puede ver en la corresponsabilidad de las instituciones que representan, como el INCODER, o las amonestaciones que le ha hecho la Corte Interamericana de Derechos Humanos al Estado colombiano, entre otros muchos ejemplos.

\section{Canales}

Los canales, como los entienden Bächler y Dessler, son líneas políticas, sociales, económicas o nacionales. Estos autores indican las causas que han llevado a que se conformen los grupos (en disputa) existentes. Los canales de agrupación que son visibles en este estudio se aglutinan en la filiación, la identidad étnica y la subjetividad campesina.

Identificación étnica: los símbolos y significados de la identidad étnica están codeterminados por la autodeterminación territorial. Aunque algunos estudios argumenten que la etnicidad se convierte en un instrumento para reclamar el dominio territorial, las comunidades afrodescendientes buscan emplazar su identidad como actores sociopolíticos, ese emplazamiento está materializado en su hábitat: el territorio.

La religión: un canal para aunarse como agrupación. Se convierte en un mecanismo de cohesión entre las diferentes confesiones. Muchas de las comunidades campesinas tienen la religión como bastión para lidiar con las circunstancias del conflicto que los aqueja. En el caso del Garzal, su pertenencia a la Iglesia Internacional del Evangelio Cuadrangular ha sido fundamental para que la comunidad lleve a cabo 
acciones de resistencia contra el despojo territorial. En este sentido, en general, en los estudios sobre el conflicto, su manejo y su transformación, se subestima la influencia que puede alcanzar la religión en términos de acción política.

Subjetividad comunitaria: la construcción de una subjetividad comunitaria se ve influenciada por dos procesos y figuras de organización: por un lado, la asociación campesina, que aparece como ente aglutinador en todos los casos, y, por el otro, el trabajo en red que llevan a cabo las comunidades campesinas de diferentes regiones del país.

Las asociaciones campesinas: las asociaciones no son solamente agentes que asumen funciones diversas en los ámbitos políticos, sociales y económicos, muchas de ellas se han convertido en verdaderos núcleos y focos vertebrales da la cultura de convivencia y de las prácticas de la equidad. En la dinámica paralela al conflicto, se erigen vigorosas alternativas por la construcción de la paz que tienen muy poca divulgación en los medios. Algunos de ellos son movimientos de obreros, de mujeres, de artistas, de vendedores ambulantes y de estudiantes. Respecto a los movimientos campesinos, Héctor Mondragón, en su ensayo "Movimientos sociales: una alternativa democrática al conflicto", señala que estos movimientos aparecen en Colombia a inicios del siglo Xx a través de organizaciones locales que logran ser apoyadas por las plataformas políticas y se consolidan a nivel nacional en la Confederación Campesina e Indígena, la cual fue aniquilada de 1946 a 1958. Mondragón anota lo siguiente:

Un nuevo proceso de organización campesina ha surgido en las últimas dos décadas, pero en medio de la dispersión organizativa. La mayoría de las organizaciones campesinas, tanto las que conformaban entonces el Consejo Nacional Campesino, como la ANUC y otras de índole regional y/o local, aprobaron el 8 de abril de 2003, un programa común con los indígenas y afrocolombianos: El Mandato Agrario, por vida digna, tierra, territorialidad y soberanía alimentaria (2006: 17).

Redes desde la base: las comunidades, no solo campesinas, sino también afrodescendientes e indígenas, se congregan en un trabajo de red llamado Red de Iniciativas y Comunidades de Paz desde la Base. Esa red y sus objetivos reiteran el trabajo de construcción de la paz, es decir, que coexisten diferentes grupos que trabajan articulados por 
motivos sumamente afines. En este caso, podríamos decir que los canales son motivos de convocatoria local que conforman un supracanal de expresión e interlocución entre los grupos más débiles para interactuar ante la sociedad civil y los actores armados. Más adelante, en el apartado "Relaciones de poder estructurales" de este capítulo, veremos en detalle los roles de las redes en relación a las relaciones de poder estructural.

\section{Detonantes}

El establecimiento de los monocultivos de la palma de aceite y el desplazamiento forzado: los monocultivos de palma aparecen en la casilla de las causas contextuales. La dimensión de los cultivos y el surgimiento de una nueva estructura en la cultura agrícola, centrada en la extracción, es un detonante que desata nuevos conflictos. Hay dos aspectos relevantes en relación a las causas contextuales. En primera instancia, una relación sistémica global agrava la disposición de la distribución regional económica que caracteriza al país. Esto quiere decir que las regiones que estaban al servicio de la producción nacional para los centros desarrollados pasan al servicio de la producción global. Como se presentó en el capítulo IV, los proyectos agroindustriales tienen una conexión con las demandas de los países que mayor energía consumen, que son los que imponen gran parte de las políticas energéticas a nivel mundial. Con esta dinámica se exacerba la concentración del poder no solo en términos productivos, sino también financieros y administrativos. En cuanto al espacio productivo, eso significa que determinadas localidades han sido sobreexplotadas exclusivamente para el mercado internacional. El Departamento de Planeación Nacional indica que un estudio realizado por el Instituto Geográfico Agustín Codazzi (IGAC) en el 2012 señala que en el país existe un 13\% de tierras con vocación agrícola que es subutilizada para otros usos, mientras que el 15\% del territorio colombiano es sobreutilizado. Justo en esos desequilibrios de los usos es en donde mayor conflictividad se presenta.

En segunda instancia, en el plano nacional se distinguen dos ejes: uno, netamente económico, la inserción de Colombia en el mercado 
global de las oleaginosas, y otro maquillado con la política de seguridad nacional, la consolidación como proyecto agrario para combatir la erradicación de cultivos ilícitos, que empezó a ser impulsado en la administración de Álvaro Uribe (2002-2010). Rangel, Ramírez y Betancourt (2009) señalan al respecto que "la nueva etapa de cultivo de la palma africana empieza en 2002 con las políticas de sustitución de cultivos ilícitos, implementadas por el Gobierno nacional de la región (zona Central) a través del Plan Colombia" (60). ${ }^{4}$ En realidad, ese plan fue fallido, porque su efecto en la reducción de cultivos ilícitos no mostró resultados significativos. En la mayoría de las regiones se pueden encontrar ejemplos en los cuales la sustitución de estos por cultivos de palma desencadena confrontaciones adicionales y, además, exacerba las brechas de desigualdad en la distribución territorial. Entre otros, está el caso de los Montes de María. Como lo señalan Bouley y Rueda:

El "desarrollo" del campo en este caso consiste en reemplazar los pequeños campesinos que resultan improductivos para la lógica del mercado global por "empresarios" del campo, o sea grandes empresas que manejan plantaciones extensivas de monocultivo a las cuales la población campesina se habrá de vincular como obreros del campo (2009: 7).

Existen experiencias interesantes e innovadoras en algunas de las zonas de mayor conflictividad, entre otras por la presencia de cultivos ilícitos, como es la región de Tumaco. Los consejos comunitarios de algunas de las poblaciones de Tumaco, como Alto Mira y Frontea, han iniciado proyectos de sustitución con cultivos tradicionales como el cacao, el coco y el plátano. Los líderes ambientalistas y sociales han impulsado esas iniciativas, que han derivado en economías productivas con un efecto positivo también en la conservación del medio ambiente. Esos proyectos están apoyados por el Programa Nacional Integral de Sustitución de Cultivos de Uso Ilícito (PNIS) del gobierno. Estos modelos de producción son diferentes al modelo de la cadena de valor

4. El Plan Colombia fue un programa cuya apariencia mostraba un proyecto de desarrollo para el país, pero en realidad su orientación estuvo basada en la lucha contra el narcotráfico, desafortunadamente, sin una verdadera propuesta de desarrollo rural. 
que caracteriza al cultivo de palma de aceite a larga escala. Por otra parte, al darle vía a los cultivos tradicionales, se activan posibilidades que fortalecen las culturas agrícola regionales y tienen efectos en el bienestar familiar y comunitario.

\section{Modalidades de ingreso de la industria palmera a nivel local}

En el caso específico de la región geográfica del Magdalena Medio, en donde están ubicadas las comunidades Las Pavas y El Garzal, se dan características muy similares de la incursión de la industria de palma de aceite: ninguna de las dos comunidades quiere involucrarse en el negocio de la agroindustria de palma. La incursión de la palma en el municipio de Simití es posterior a los sembrados de cultivos ilícitos y se pueden distinguir tres procedimientos simultáneos y diferentes, de acuerdo con Astrid Álvarez y Fernando Castrillón (2007):

— La modalidad que vinculó a las familias campesinas en el proceso de sembrado. — La modalidad que vinculó a los pequeños y medianos agricultores en el cultivo de la palma.

- La modalidad que implantó la palma como un cultivo a gran escala, aprovechando para ello, los contextos de violencia y las diferentes formas de desplazamiento. (84)

Estas tres modalidades se han ido adoptando en la región - y también en diversas zonas del país- y son parte de las estrategias utilizadas por los consorcios palmeros. La vinculación de los campesinos y los pescadores con las actividades de cultivo se hace desde el concepto de arrendatarios de tierras, prestadores de servicios y como asalariados. Los procesos de implantación de monocultivos de palma - a menor o mayor escala— han influido de manera drástica sobre los patrones de la cultura local. Algunos de los aspectos que señalan Álvarez y Castrillón (2007) sobre la expansión de la palma en Simití son los siguientes: 
- Seis de cada diez familias no tiene tierra. El caso más extremo se presentó en Ánimas, población en la que el $90 \%$ de sus habitantes quedaron sin acceso a la tierra.

- Del 40\% de los habitantes que poseen tierra, sólo el 15\% de ellos tiene una titulación que los acredite como propietarios.

- De ese mismo 40\%, solamente un $29 \%$ cuenta con una extensión de tierra suficiente para realizar los sembrados, es decir 37 hectáreas.

- De las familias que tienen acceso a la tierra, el promedio por familia es de 8.4 hectáreas lo que indica que es una cantidad menor a la que necesita una familia para sobrevivir dignamente (86).

De acuerdo con los relatos de los campesinos, el sembrado de dos tipos de palma en la región, la palma mangué y la palma amarga, había formado parte de los cultivos utilizados para los bienes de consumo: eran utilizadas especialmente para la construcción de los techos de las casas. Ninguno de esos otros tipos de palma ha sido contemplado para el cultivo ni tomado en cuenta por los gremios que promueven la industria de palma de aceite en Colombia para conservar la cultura agrícola de las regiones.

En la zona del Pacífico colombiano, en donde se ubican las cuencas del Curvaradó y Jiguamiandó, el ingreso del agronegocio estuvo vinculado a la utilización de territorios colectivos, aun teniendo estas superficies carácter "inalienable, imprescindible e inembargable", como se estipula en la Constitución colombiana de 1991. El ingreso de la palma como monocultivo ocurre durante la última década de los ańos noventa; en la apropiación de los territorios para realizar proyectos de agricultura industrial de palma de aceite se distinguen varias modalidades:

- Compraventa de mejoras: las empresas le compraron las tierras a personas particulares que alegan la ocupación de los territorios antes de la expedición de la titulación.

- Contratos de usufructo: las empresas realizaron contratos con personas que actúan en nombre de varios consejos comunitarios, pero que no los representan legalmente.

- Actas de compromiso: Las empresas han firmado actas de compromiso con miembros de las comunidades sin autorización de la Asamblea; es decir, eran miembros de la comunidad sin tener las facultades jurídicas. 
Siendo la vocación agrícola de esta región especialmente la de las palmas, la industria palmicultora ha optado exclusivamente por el monocultivo del tipo palma africana, desconociendo otros tipos que crecen tradicionalmente en la región Pacífica y la variedad de usos que les dan los pobladores locales, así como lo documentan R. Bernal y G. Galeano:

Una gran parte de la vida del hombre del Pacífico está ligada a las palmas. Al igual que en otras áreas del trópico, las palmas cubren numerosas necesidades de la vida diaria, que incluyen alimento, vivienda, herramientas, utensilios, juguetes y adornos. Otras especies están ligadas a las ceremonias y otras más hacen parte de la mitología. Por lo menos, cuarenta y seis de las ciento seis especies de palmas del Pacífico tienen algún uso reconocido y algunas de ellas tienen gran potencial económico. Ningún otro grupo de plantas presta al hombre tantos y tan diversos servicios como las palmas (1993: 229). ${ }^{5}$

\section{Composición de actores}

En la siguiente figura se puede observar la composición de los actores ${ }^{6}$ y los grupos en su interior. Esa primera distinción nos permite acercarnos al potencial participativo de los actores en la estructura del conflicto. Allí se muestran dos tipos de relación: la primera, directa, actores en confrontación; la segunda, indirecta, actores que guardan un nexo por las alianzas o por su interacción en el conflicto.

5. Se puede encontrar también al mismo documento en el siguiente enlace: <https:// www.academia.edu/11569202/Las_palmas_del_and\%C3\%A9n_Pac\%C3\%ADfico>.

6. Aunque en el lenguaje del análisis del conflicto se llaman actores, es necesario entender que las instancias involucradas en una disputa se transforman, se articulan y desarticulan de acuerdo con la constelación de acciones que se dé en la marcha. Algunos académicos como Röling y Wagemakers (1998) prefieren utilizar el término interesados, porque esa denominación integra una amplia gama de personas naturales, jurídicas, individuales o colectivas. 


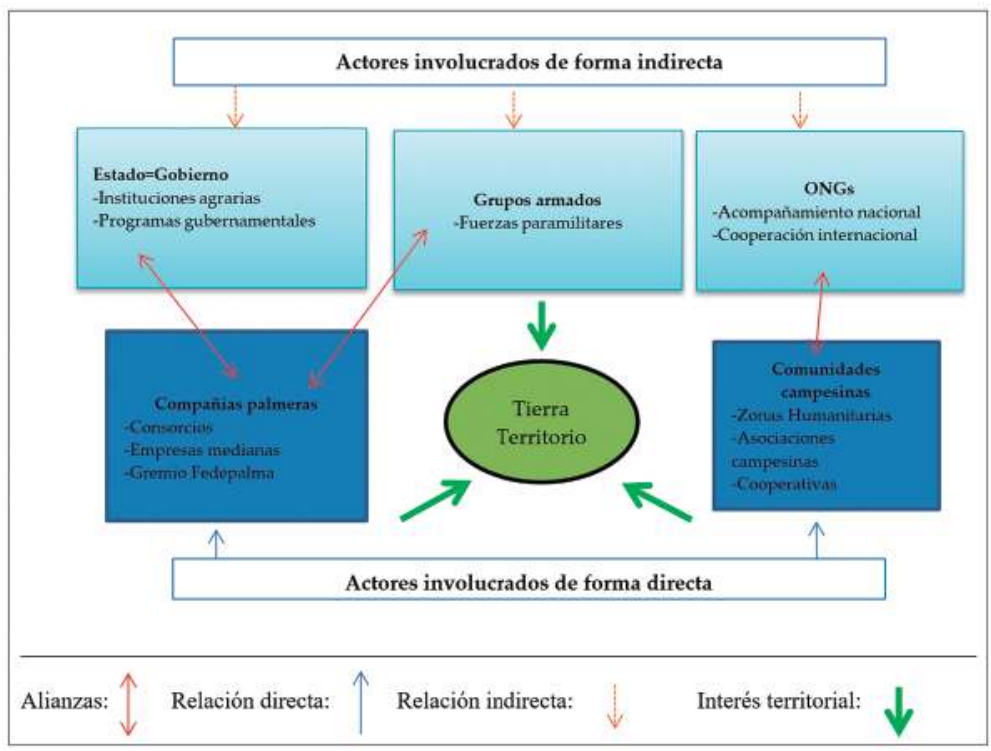

19. Relación de actores en el conflicto

Fuente: elaboración propia

Asociaciones campesinas: la estrategia que utilizan las comunidades se orienta, en primer lugar, a organizarse como una agrupación rural. En el caso de la comunidad de Las Pavas, el mantenerse en la asociación campesina ASOCAB es un mecanismo dentro del cual existen funciones regulatorias y normativas. Está creada en el ámbito rural, que ha dotado de sentido la lucha campesina en comunidad. La institucionalización de la actividad campesina y su constitución como persona jurídica será de vital importancia tanto en la acción intracomunitaria como en la interacción e interlocución con los actores en disputa.

La constitución y el empoderamiento a través de una asociación campesina se observa especialmente en dos comunidades. En el caso del Garzal, la aglutinación de las poblaciones se da en torno a la constitución de una cooperativa que cultiva y comercializa cacao. 
La adherencia a la Iglesia pentecostal influye notablemente en la acción social, pero en términos de representatividad es la Asociación de Productores Alternativos de Simití (ASPROAS) el núcleo organizativo regional. En las conversaciones con uno de los líderes del Garzal, este expresaba tres elementos que han sido definitivos en la permanencia en el territorio: " $\mathrm{La}$ fe, la visibilización, acompañamiento y el cultivo de cacao coordinado a través de la cooperativa". ${ }^{7}$

En el caso de las comunidades de las cuencas de Curvaradó y Jiguamiandó, si bien la Asociación de Campesinos del Atrato es una estructura que animó y motivó el retorno a los territorios, la constitución oficial se da a través de la figura de los consejos comunitarios, divididos en consejos mayores y consejos menores. La constitución de las zonas humanitarias y zonas de biodiversidad tiene una incidencia en la deconstrucción discursiva sobre el derecho a la tierra, los bienes y los recursos naturales. Además, estas son dos figuras que incorporan estratégicamente elementos jurídicos del Estado en defensa por la cosmología y la cultura de los pueblos ancestrales que habitan en la región de estas cuencas.

Compañías palmeras: por compañías palmeras debe entenderse las empresas que operan en los predios que habían estado en litigio previamente y de los cuales hacen uso para cultivar palma. En algunos casos se trata de representación de consorcios y en otros de compañías independientes que pertenecen al gremio palmicultor y que pueden ser medianas o grandes. A este respecto, es importante tener presente que las que realizan la producción de la palma de aceite están asociadas en el gremio FEDEPALMA. Los nexos corporativos de los miembros se determinan en mayor medida por el beneficio empresarial que el gremio les brinda; más específicamente, se trata de una plataforma para la comercialización y exportación de los productos que se extraen de la palma. De acuerdo con las descripciones de FEDEPALMA, estos son los motivos de su existencia:

Apoyar a los palmicultores en la defensa de sus intereses y el logro de la competitividad de una agroindustria de una oleaginosa que transforma la calidad de vida

7. Archivo de entrevistas realizadas por la autora en las visitas de campo. 
de las comunidades que la acogen y promueve el progreso y el bienestar. Representa fielmente los intereses de sus asociados como es su papel irrenunciable, y está orientado a satisfacer sus necesidades inclusive más allá de sus expectativas (Fedepalma). ${ }^{8}$

En cada uno de los tres casos, el conflicto se ha presentado con las compañías palmeras que tienen interés en las tierras que habían sido ocupadas o con compañías que han ocupado territorios de las comunidades campesinas para extender su actividad agroindustrial. En los perfiles de las empresas o de los empresarios hay también algunas diferencias en relación a sus características. En el caso de la comunidad de Las Pavas se trata del consorcio El Labrador y la empresa Aportes San Isidro (que forman parte del grupo Daabon), la cual adquirió los predios de propiedades supuestamente privadas con procedimientos poco claros. En la compraventa que se realizó con Jesús Emilio Escobar se adquirieron cuatro terrenos definidos, como se mostró en la cronología del caso, en el capítulo V. En el caso de las zonas humanitarias, la empresa Urapalma SA se apropió del territorio colectivo perteneciente, por orden legal, a las comunidades. En el caso de la comunidad El Garzal, se trata de la compañía Equipos y Soluciones Logísticas, que, de acuerdo con los reportajes de Alfredo Molano, les pertenece a familiares o a los hijos del presunto propietario Manuel Enrique Barreto. ${ }^{9}$

Aunque no todas las empresas de la industria palmera en Colombia están involucradas en conflictos de tierra, las reclamaciones desde diferentes zonas del país salen cada vez más a la luz pública. El despojo lo denuncian también otras poblaciones, uno en la zona atlántica (el caso de Montes de María) y otro en la zona sur-occidental, región del Pacífico (Tumaco y poblaciones de Bajo Mira y Alto Mira). De acuerdo con Sergio Coronado y Cristina Dietz (2013), en la zona atlántica las alianzas estratégicas que promueven las compañías utilizan

8. Este fragmento aparece en la página de Fedepalma y describe la institución. Se encuentra disponible en <http://web.fedepalma.org/quienes-somos-fedepalma>.

9. Recientes investigaciones sobre las dinámicas de apropiación de tierras en la zona norte de Colombia indican que los propietarios de esta empresa son herederos de una de las personas que estuvo involucrada en actividades de cultivos ilícitos (Molano 2012). 
mecanismos excluyentes, las posibilidades de participación están vetadas para campesinos que no tienen acceso a las tierras. Además, a quienes han optado por no vincularse al negocio de la palma, se les restringe el uso del distrito de riego, priorizando, de manera casi exclusiva, su utilización para las plantaciones de palma. En el caso de las comunidades de Alto Mira y Bajo Mira, la expansión de este cultivo amenaza las comunidades afrocolombianas, constituidas en sus territorios colectivos. Un reporte realizado por Mark James Maughan (2011) indica que el costo económico, social y político no muestra una opción de sostenibilidad. Este autor afirma que las empresas utilizan un trasfondo neocolonial para la introducción de los monocultivos.

\section{Narrativas de la industria palmera}

En un análisis sobre la expansión de monocultivos de palma de aceite para la producción de agrocombustibles Giampietro y Mayumi (2009) hacen una aproximación diferente al debate, tanto académico como social, sobre la agroindustria de los hidrocarburos. Estos autores reflexionan sobre cómo diferentes segmentos de la sociedad, los gobiernos, la academia, las instituciones financieras y las organizaciones no gubernamentales, han construido narrativas sobre los beneficios de los agrocombustibles sin haber dado cuenta de los inminentes problemas que acarrearían. En su estudio ilustran diversas narrativas que se encuentran en contraposición con los diferentes preceptos de valoración sobre los recursos naturales. Estos autores señalan que "cuando se tratan análisis cuantitativos aplicados a la sostenibilidad, el énfasis del debate debe estar en la calidad de las narrativas seleccionadas para hacer esos cálculos y no en los resultados numéricos" (Giampietro y Mayumi 2009: 12).

A continuación, veremos dos aspectos que son parte importante en la filosofía del gremio FEDEPALMA y que guardan una relación con los efectos de la industria palmera en las comunidades rurales. Como ya se ha visto en el capítulo IV, la industria de la palma de aceite en Colombia funciona bajo el liderazgo de este gremio. De acuerdo con las conversaciones sostenidas con sus directivos, está comprometido en la búsqueda del bienestar de sus afiliados, pero se pueden identificar 
prácticas empresariales que van en detrimento de la clase campesina. Por ello, es indispensable conocer cuál es la filosofía y cuáles son las líneas directrices que guían el concepto empresarial de la producción de palma de aceite.

En los documentos publicados en la página virtual de FEDEPALMA y en material impreso, la construcción narrativa del gremio se centra, especialmente, en la productividad agrícola que provee el cultivo de palma de aceite. Asimismo, se resaltan los beneficios que los campesinos (o potenciales asociados) tendrán si se adhieren al proyecto palmero que ofrecen las empresas. La construcción de esos dos ejes, beneficio y productividad, sostiene el discurso agroindustrial de la palma como motor para la transformación de la ruralidad en Colombia. Este gremio ilustra la magnitud que ha alcanzado la industria palmera colombiana en los últimos cincuenta años: se documenta el desarrollo tecnológico, la producción ecológicamente limpia, los aportes fiscales a la nación, la generación de contratación, la construcción de infraestructuras a nivel local y regional y el aumento de las exportaciones. Un aspecto vertebral de su discurso es el concepto de 'asociatividad'.

Asociatividad: el carácter asociativo promueve la composición de nuevas instancias de comercio dentro de un sistema de producción propio. Ser socio de la industria palmera significa agregarse a la cultura de la palma, que se estimula desde dos enfoques: por un lado, la introducción y familiarización con las labores del cultivo, que varían dependiendo de las que se realicen y de la fase de la cadena productiva en la que participen o a la que se vinculen los campesinos, ${ }^{10} \mathrm{y}$, por otro lado, se promociona la asociatividad como un elemento simbólico de heredad: "El mayor patrimonio de la agroindustria en Colombia es uno de los argumentos que aportan a considerar la asociatividad como beneficio" (Ospina 2007: 41). Esto no es exclusivo de este gremio, de hecho, la vinculación de miembros es lo que un gremio, una asociación o una fundación, entre otras formas de organización, promueve. En este caso, se trata más de qué tipo de valoraciones

10. Para quienes se involucran en labores agrícolas, implica adquirir un conocimiento técnico y tecnológico para lograr éxito en las cosechas, conocer las características del cultivo, sus malezas, los tipos de producción y los procedimientos de poda y recolección, entre otros. 
y juicios se derivan de la noción de asociatividad. Es importante tener en cuenta que esta representa beneficios en la medida en que se den utilidades al gremio, y el gremio, por su parte, estimula la idea de convertir al agricultor en un campesino empresario. Sin embargo, no es lo mismo asociarse a un gremio como miembro que dispone de un capital económico para la inversión que como un miembro que cuenta con pocos recursos financieros; esta es la situación de muchos campesinos. Si bien la mayoría de los agricultores no tienen recursos monetarios, algunos de ellos cuentan aún con tierras, un bien capital.

Casa vs. tierra-territorio: en el perfil de asociatividad que promueve el gremio, las ideas de bienestar y progreso forman parte central de ese concepto. Adquirir una propiedad, es decir, tener casa propia, es un aspecto esencial que las empresas presentan como indicador de éxito para los campesinos. Entre los documentos de FEDEPALMA, la publicación Habitando el lugar. Una mirada a la vivienda desde el arte y la arquitectura, elaborado por María Eugenia Nińo y Santiago Pradilla (2010), muestra especial interés por el tema de la vivienda. Se ilustran los resultados de un taller realizado en el marco del programa cultural "Diálogos de las regiones palmeras", que ha sido desarrollado en varias de estas regiones y concebido como diseño participativo para imaginar la arquitectura de la vivienda propia, aunque en el documento se especifica que "en los talleres, los participantes no llegan a la ejecución de un proyecto, pero marcan un punto de partida" (9). Se promueve la adquisición de vivienda como eje central del desarrollo comunitario, una las prioridades que presenta ese documento, y dentro de sus objetivos aparece "encontrar el punto donde los imaginarios de progreso se articulen de la mejor manera con lo ambiental, lo cultural y lo social" (9). Este programa cultural está orientado a crear y reforzar la idea de que la posibilidad de adquirir vivienda propia se logra, con mayor probabilidad, a través de la participación y adhesión a la cultura de la palma. La noción de "construcción de identidad" que se promueve en la agroindustria está directamente relacionada con la creación de una comunidad palmera, lo que significa ser empleado o trabajar para las empresas de palma. El concepto de comunidad y, en especial, la identificación comunitaria se comprende a través de la adhesión a las empresas palmeras y a los beneficios que de estas puedan derivarse. Lo que determina la identidad comunitaria, 
desde la narrativa del gremio, es la asociatividad; mientras que para las comunidades que han sido desplazadas forzadamente está vinculada a la idea de territorialidad y no exclusivamente a la posesión de una vivienda, como lo veremos más adelante.

Si bien la posesión de una vivienda es importante para cualquier familia, ya sea urbana o campesina, este aspecto se toma como argumento para justificar discursivamente su adquisición y otorgarle un valor mayor. En las condiciones de precariedad en las que viven las comunidades rurales, este tipo de estímulos refuerza la racionalidad de la optimización individual, no solo la idea de la vivienda propia, sino también muchos otros elementos. Esta forma de construir la narrativa sobre los beneficios que ofrecen las empresas de la industria palmera tiene repercusiones en el tejido social y la cohesión de las comunidades porque, tras la ilusión de poseer una casa moderna y lograr beneficios individuales, se da un deslinde del trabajo comunitario y se tienden a romper los nexos con las asociaciones campesinas originarias. El taller que se mencionó antes se ha realizado con diferentes tipos de población: niños, jóvenes y adultos. La imagen que aparece a continuación es el resultado de "las conclusiones a aportes de los participantes de las comunidades palmeras", según el arquitecto y tallerista que ha elaborado el boceto del diseño de vivienda:

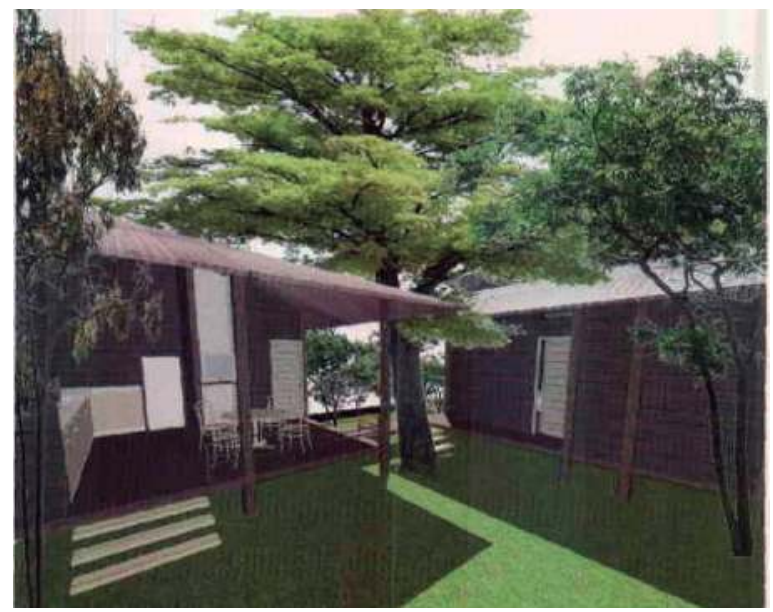

20. Prospecto de casa para trabajadores de la industria palmera Fuente: Habitando el lugar (Niño y Pradilla 2010: 41) 
Las construcciones discursivas sobre el lugar representan posiciones y principios contradictorios entre los actores involucrados en las disputas. La vivienda, en su connotación de casa como motivo esencial del concepto lugar, aparece con relevancia en los documentos del gremio. Dicho concepto, que promueve la agroindustria en su estrategia de asociatividad, difiere substancialmente del significado que las comunidades rurales le confieren a la noción asociarse: dentro de la dimensión territorial, la vivienda — casa— es para las comunidades un elemento integrativo del hábitat, se comprende como parte importante del territorio, pero no es el territorio mismo. Esta idea de la casa que promueven las empresas podría resultar un arma de doble filo porque la compra de una casa no asegura el bienestar familiar o comunitario, sino que está también ligada a la responsabilidad de la deuda que los campesinos adquieren y que, en la mayoría de casos, no son capaces de afrontar con la retribución monetaria que reciben. Al dejar sus territorios, muchas familias campesinas aceptan condiciones de pago por una vivienda que los pone en una situación económica difícil y que están conectadas con la única salida de ser obreros en las empresas palmeras.

\section{ACTORES INVOLUCRADOS DE FORMA INDIRECTA}

Grupos armados: los grupos armados, aunque no son actores directamente involucrados en las disputas por la tierra, tienen gran interés en mantener el control de algunas zonas estratégicas. Entre estos aparecen las antes llamadas Autodefensas de Colombia, que, tras la desmovilización en el año 2006, han creado otras estructuras. De acuerdo con Rangel, Ramírez y Betancourt (2009), "en el centro y norte del departamento del Cesar —zona norte—, después de las desmovilizaciones se han registrado varias estructuras de bandas emergentes. Una está conformada por desmovilizados del Bloque Norte de las AUC, [...] otra es la de las Águilas Negras, [...] otra más la de los Mellizos que cubren varias partes del departamento de sur a norte" (82-83). Llama la atención que muchos de los proyectos de palma de aceite se encuentran precisamente en zonas de mayor conflictividad y donde hay presencia de esas bandas. En los casos específicos de las zonas 
humanitarias y de Las Pavas, las alianzas, al parecer, se dan entre grupos paramilitares y compañías palmeras; especialmente, en las zonas humanitarias ha habido varias denuncias por la actuación conjunta de los empresarios y los grupos armados o empresas de seguridad. La operación de los grupos desmovilizados pasó de ser centralizada —en la antigua estructura- a formar diferentes células que están presentes en diversas regiones del país y siguen imponiendo el terror y atemorizando a la población rural. Las vinculaciones entre estos dos grupos han sido corroboradas por la Corte Interamericana de Derechos Humanos, citadas en el informe "La Tramoya" (Comisión Intereclesial de Justicia y Paz 2005). En el caso de los otros actores, tanto el Estado como las compañías, se constituyen alianzas con el propósito de incrementar el dominio económico a través del control territorial y desplazar a la población de sus hogares. Sin embargo, esas alianzas no se dan solamente entre los actores que ostentan el poder de forma legítima:

Desde el año 2001 la empresa Urapalma S.A. ha promovido la siembra de palma aceitera en aproximadamente 1.500 hectáreas de la zona del territorio colectivo de estas comunidades, con ayuda de la protección armada perimetral y concéntrica de la Brigada XVII del Ejército y de civiles armados en sus factorías y bancos de semillas. Los operativos e incursiones armados en estos territorios has tenido el objetivo de intimidar a los miembros de las Comunidades (114).

Organizaciones de apoyo y asistencia: Existe otro grupo de actores, las organizaciones no gubernamentales. Estos grupos están acompañando a la población campesina de la región, algunas de los cuales forman parte de SUIPPCOL. ${ }^{11}$ Trabajan en una red coordinada con

11. El programa SUIPPCOL surge en 2001, guardando coherencia y complementariedad con los esfuerzos que el gobierno suizo realiza por la paz sostenible y justa en el marco de la política exterior para Colombia, tanto por la vía diplomática, manteniendo la disponibilidad de buenos oficios para las eventuales conversaciones y procesos de paz como por la cooperación al desarrollo llevada a cabo desde hace muchos años por sus organizaciones especializadas: Grupo de Trabajo Suiza-Colombia ASK!, Cáritas Schweiz, Acción Cuaresmal, HEKS/EPER, Terre des Hommes Schweiz, Peace Brigades International Schweiz, Swissaid, Amnistía Internacional Schweiz, E-changer, Bethlehem Mission Immensee BMI y Peace Watch Switzerland. SUIPPCOL. 
organizaciones internacionales, que les brindan apoyo financiero y promueven algunas de las acciones que emprenden las comunidades. El acompańamiento está reforzado en algunos casos con la presencia permanente en las zonas donde se encuentra asentada la población, es decir, que visitan las zonas con regularidad y, en el caso de las comunidades El Garzal y Las Pavas, existe un convenio con la ONG Peace Watchers para enviar observadores por un tiempo definido a la región. Las zonas humanitarias están acompañadas especialmente por la Comisión Intereclesial de Justicia y Paz, también presentes en la región. Las organizaciones acompañantes de las comunidades se podrían definir como una filiación en red que incide en su empoderamiento y en la construcción de su interacción social.

\section{Aspectos del manejo del conflicto}

Los estudios sobre el manejo del conflicto por recursos naturales en América Latina se han iniciado como una búsqueda de herramientas que atendieran a necesidades inmediatas y poco a poco se han extendido hacia el análisis de temas estructurales con perspectivas desde lo global, lo regional y lo local, es decir, se ha pasado de la comprensión exclusiva del manejo hacia el entendimiento sobre la transformación de estructuras. Borel (2005) plantea la necesidad de reconstruir un marco teórico sobre el manejo del conflicto y hace énfasis en el camino recorrido. Junto con otros investigadores regionales, hace parte de un colectivo de reflexión continental que está inscrito en el marco de la construcción del Observatorio Latinoamericano de Conflictos Ambientales (OLCA). Este colectivo empezó a elaborar un marco conceptual y metodológico que se concentra en la temática del manejo de los conflictos socioambientales y reflexiona también acerca de su transformación y su incidencia en los contextos sociales. Uno de los planteamientos principales que guían esos estudios es la concepción de lo ambiental como un "universo enmarcado culturalmente", en palabras de Rodríguez y Correa (2005): 
La cultura se asume como síntesis de procesos biológicos y conductuales; y el desarrollo sostenible como política desde lo deseable localmente; lo natural y lo social integrado y autorregulado, con vínculos entre la base físico-natural, la economía y la sociedad local. (366)

El conflicto se considera, dentro de la acción pública, como una transferencia a la vez positiva y negativa de valores entre las partes en contienda (Ortiz 1999). ${ }^{12}$ En ese sentido, esta transferencia no solo ocurre entre los actores involucrados, sino que busca tener claras incidencias en la regulación de un marco sociocultural en el contexto nacional. Además, a largo plazo esos procesos derivan en marcos de transformación basados en valoraciones que den validez a las concepciones locales y de los actores menos favorecidos, como lo recalcan Rodríguez y Correa (2005). Veremos a continuación algunos elementos, técnicas y estrategias de manejo del conflicto que son identificables en los procesos de estas tres comunidades.

\section{INTERLOCUCIÓN Y DIÁLOGO}

Diferentes actores, especialmente regionales, han buscado espacios de interlocución para tematizar las repercusiones e incidencias de los monocultivos de la palma aceitera en la región: ad hoc y encuentros para el diálogo directo entre las partes involucradas. En el caso de Las Pavas, el consorcio El Labrador ha expresado el interés de participar en un espacio de diálogo para conversar sobre la palma y, en especial, sobre las alianzas estratégicas: la mesa de diálogo organizada por el Programa de Desarrollo y Paz del Magdalena Medio (PDPMM). En lo relacionado con el conflicto entre ASOCAB y el consorcio El Labrador, FEDEPALMA fue invitado como instancia mediadora a la reunión a la que

12. Ortiz anota que las formulaciones sobre el manejo del conflicto socioambiental emergen del trabajo que se ha llevado con comunidades rurales en el continente latinoamericano, especialmente, y sugiere cinco aspectos fundamentales que las comunidades deben tener en cuenta: 1. origen del conflicto; 2 . identificar incompatibilidades reales, no solo posiciones; 3 . análisis de la transferencia de valores en lo conductual; 4. análisis serio sobre incompatibilidades; y 5. diseño de estrategias de manejo del conflicto en torno a los recursos naturales. 
no asistieron varias entidades invitadas porque percibían un manejo parcializado de la convocatoria y la mediación. La Corporación Autónoma Regional anunció sanciones a los palmicultores por sus errados procedimientos con el medio ambiente y FEDEPALMA argumentó que "las empresas no estaban incumpliendo, porque la ley no exigía planes de manejo" (Vargas et al. 2010: 15).

Los diálogos se iniciaron después de que el consorcio hubiera adquirido los predios, es decir, este conocía el litigio por las tierras. Las conversaciones en la mesa de diálogo tuvieron lugar en dos ocasiones. La oferta del consorcio fue devolver gradualmente 200 ha de tierra, 100 al inicio y 100 a su discreción, dependiendo del uso que les diera ASOCAB. Esta propuesta estaba sustentada en la inseguridad alimentaria ocasionada por el cultivo de palma en el corregimiento, pero fue rechazada por ASOCAB. De acuerdo con el informe, el PDPMM tenía fundadas sospechas sobre la dudosa actuación del consorcio afuera de la mesa de diálogo, por lo cual desistió de seguir participando, Pero los diálogos se restablecieron posteriormente con su presencia. Para reiniciar las conversaciones, el consorcio pidió que los campesinos abandonaran los predios que estaban ocupando, propuesta que no fue aceptada por ASOCAB ni por el PDPMM.

En el caso del Garzal, la comunidad ha tomado la decisión de permanecer en el territorio, lo cual ha obligado a una gran coordinación de las juntas de acción comunal que trabajan unidas. La persuasión ha sido utilizada como estrategia: la comunidad ha recibido enviados de las empresas con propuestas para que las familias campesinas se adhieran a sus proyectos. En los relatos, uno de los líderes comunitarios afirma que el proyecto campesino comunitario difiere totalmente de la propuesta que hacen las palmeras: "Es un proyecto ambicioso por treinta años [...], pero después ¿qué nos espera? Porque la tierra donde se cultiva palma queda improductiva. Y nosotros tenemos que pensar en una tierra para nosotros y para los que vienen detrás de nosotros" ${ }^{13}$ Algunas de las familias que recibieron las recientes titulaciones ya tenían previamente una forma de título, así que el proceso fue en realidad su legalización y no su otorgamiento. Además, la región

13. Archivo de entrevistas realizadas por la autora. 
es geoestratégicamente importante, como se ha señalado antes, y por ello es codiciada por distintos actores, Algunos de los cuales ejercen presión con medios violentos, ocasionando desplazamientos individuales y familiares.

\section{Papel de los intermediarios o actores de influencia}

Las organizaciones acompañantes de los procesos de las comunidades de estudio conforman un grupo diverso en el cual se pueden identificar organizaciones no gubernamentales, eclesiales, seculares y jurídicas, entre otras. En cada uno de los procesos, el acompańamiento ha aportado conocimientos y reflexiones sobre el manejo y la transformación del conflicto con las empresas palmeras. La autorreflexión ha vislumbrado posibilidades de acción, movilización y aprovechamiento de los recursos propios de las comunidades para diseñar opciones de cambio. Algunas herramientas como talleres, capacitaciones, encuentros interregionales, trabajos en red, socialización de experiencias y otros han posibilitado que las comunidades conozcan más y mejor sus derechos, así como también sus marcos de legalidad y los de otros actores involucrados. Identificar los perfiles de los actores y sus niveles de legitimidad ha sido valioso, sobre todo, para estimar los límites de una acción y las posibilidades de acercamiento y negociación. En este sentido, se puede decir que se ha aplicado la técnica de investigación-acción, que explora de forma crítica y reflexiva las herramientas que tienen los actores para hacer efectivas sus demandas. Además, esos análisis han sido de gran importancia para la identificación de las fortalezas y debilidades en el interior de las comunidades; así como también para el fortalecimiento de sus formas de organización a partir de sus historias comunitarias y sus capacidades de negociación en el contexto de la industria palmera. La planeación de las acciones y los procedimientos para realizarlas ha sido evaluada en el marco de los talleres y los encuentros intercomunitarios, por ejemplo, en el Programa Acción Social (PAS), que acompaña a las comunidades del Magdalena Medio, y Justicia y Paz, en el caso de las comunidades de las cuencas de Curvaradó y Jiguamiandó. La técnica mapa de conflicto, por ejemplo, se ha utilizado en El Garzal 
por la Clínica Jurídica sobre Derecho y Territorio. De la misma manera, en El Garzal y en las cuencas se ha mapeado geográficamente el territorio de las comunidades, lo que ha tenido efectos tanto en el manejo de la información como en los planes sobre ordenamiento territorial que proponen las comunidades. Pero, sobre todo, el acompañamiento jurídico ha tenido alcances más decisivos, como se verá más adelante, en las acciones jurídicas. En las estrategias de acción, veremos de manera detallada cómo las comunidades reterritorializan los espacios para reconstruir la vitalidad comunitaria y su concepto territorial.

El acompañamiento de los diferentes actores ha sido fundamental en los procesos de resistencia y defensa de la tierra y del territorio. Si bien me he referido antes a las incidencias en el interior de las comunidades, este acompañamiento es perceptible también a otras escalas: en los tres casos, se puede confirmar que las comunidades han ido desarrollando una mayor capacidad para habilitar espacios de negociación a nivel institucional y a nivel jurídico La percepción y la valoración respecto a los diferentes organismos que han brindado su apoyo han sido definitivas para la reconstrucción del tejido comunitario. Sin embargo, en unas de las entrevistas que realicé a miembros de las organizaciones de acompañantes, la sensación de algunos representantes era que la coparticipación de diferentes organismos de forma simultánea podría ocasionar confusión en las comunidades en relación a las decisiones a largo plazo, así como también a inquietudes relacionadas con la pertinencia de acciones comunitarias para abordar asuntos específicos en la dinámica del manejo del conflicto. En relación a esto, es preciso mencionar que la lucha por el territorio es un proceso de larga duración: las comunidades llevan más de una década sufriendo los despojos y otras formas de violencia. Esto ha ocasionado que esas poblaciones hagan uso de esa experiencia y puedan responder así ante situaciones que parezcan desbordarlas o que otros perciban como inmanejables. 


\section{Estrategias de acción autónoma: convivencia territorial}

Hemos visto cómo el marco contextual político y económico en el que se dan los conflictos por el territorio y los recursos naturales se caracteriza por la gran asimetría de poderes y por incompatibilidades sobre juicios de valoración. Las comunidades locales se enfrentan no solo a un actor, sino a un engranaje que maneja y regula, en gran parte, los aparatos de poder y de distribución de poderes. Por ello, no resulta sorprendente que, en los casos aquí presentados, así como en muchos otros en América Latina, Asia y África, los Estados y sus instancias representantes actúen en pro de mantener y favorecer ese engranaje. Las realidades de los procesos de litigio revelan que, aunque las comunidades pongan en práctica las herramientas para la negociación y el consenso, sus intereses comunitarios seguirán socavados. Existen formas de dominación que se han legitimado en un sistema de intercambios y transacciones sociales y políticas ante las cuales las comunidades campesinas están en gran desventaja. Por ello, la búsqueda de estas poblaciones se orienta a transformar, más que el marco del conflicto, los marcos de dominación estructural. La construcción de la subjetividad comunitaria, que es el fundamento conductor de muchas de las acciones colectivas, se inscribe dentro del quehacer político transformador y la acción política participativa. Desde esa perspectiva, las acciones emprendidas por las comunidades están concebidas como estrategias de construcción de paz que se consolidan en el proceso de resistencia pacífica ante el despojo y el conflicto.

Pablo Ortiz (1999) sugiere que el diseño de estrategias de manejo del conflicto debe considerar escenarios tanto de agudización como de colaboración. A este respecto es preciso considerar que la situación de las comunidades está determinada por historias de muerte, no solo de agresión. Ese ambiente de violencia desgasta el tejido colectivo con una intensidad tal que la prioridad más apremiante es el fortalecimiento de la comunidad para poder recuperarse como actor social. Esto quiere decir que los escenarios de colaboración se vuelcan, en primer lugar, en la restitución del actor colectivo, que es la comunidad o la asociación como instancia representativa y, posteriormente, se emprenden 
acciones en búsqueda de espacios de equidad para recuperar sus territorios y su hábitat.

Cuando hablamos de conflicto podemos pensar que la situación de muchas comunidades rurales en Colombia tiene que ver no solo con manejar las disputas por el territorio y los recursos naturales, sino también con enfrentar el conflicto armado. Por esa razón, el diálogo y los acercamientos no son siempre opciones posibles y viables, cuando se está interactuando con actores que han tomado las armas para violentar y asesinar a los campesinos. El desafío es mucho mayor cuando la vida de poblaciones enteras está comprometida y los hechos horrendos tienen implicaciones en todos los ámbitos de la vida comunitaria rural. La tenacidad y la determinación de los pobladores campesinos que emprenden acciones por la defensa del territorio no pueden ser subestimadas: "La tierra es la vida y la vida no se vende, se ama y se defiende" es una de las consignas que se escuchan en las manifestaciones para recuperar el territorio. Como veremos, las acciones directas para reterritorializar los espacios del destierro pueden concebirse como actos de construcción de la convivencia territorial.

En la siguiente tabla, se pueden diferenciar algunas de las acciones que han sido emprendidas por las tres comunidades. Este listado nos permite visualizar las diferencias y las similitudes respecto a las acciones entre los casos elegidos: se puede observar de manera más específica las estrategias de cada comunidad y posteriormente se presenta un análisis sobre los diferentes niveles en los que se interconectan esas acciones. 


\begin{tabular}{|c|c|c|c|c|}
\hline Comunidades & Acciones directas & Acciones en los medios & Acciones legales & Alianzas \\
\hline Las Pavas & $\begin{array}{l}\text { - Retorno } \\
\text { — Construcción de } \\
\text { cambuches } \\
\text { — Sembrados maíz y } \\
\text { pancoger }\end{array}$ & $\begin{array}{l}\text { — Declaraciones en la } \\
\text { prensa } \\
\text {-Declaraciones en } \\
\text { televisión } \\
\text { — Producción musical }\end{array}$ & $\begin{array}{l}\text { - Tutelas } \\
\text { - Denuncias } \\
\text { - Peticiones }\end{array}$ & $\begin{array}{l}\text { - Trabajo en redes } \\
\text { campesinas } \\
\text { - Trabajo con ONG } \\
\text { nacionales } \\
\text { - Trabajo con ONG } \\
\text { internacionales. }\end{array}$ \\
\hline El Garzal & $\begin{array}{l}\text { - Incrementar cultivos } \\
\text { - Permanecer en el } \\
\text { territorio }\end{array}$ & Reportajes escritos & $\begin{array}{l}\text { - Denuncias } \\
\text { — Tutelas } \\
\text { — Trámites de } \\
\text { representación directa }\end{array}$ & $\begin{array}{l}\text { — Trabajo en redes } \\
\text { nacionales } \\
\text { - Acompañamiento de } \\
\text { ONG internacionales }\end{array}$ \\
\hline $\begin{array}{l}\text { Zonas } \\
\text { humanitarias }\end{array}$ & $\begin{array}{l}\text { - Retorno } \\
\text { - Tumbar plantaciones } \\
\text { - Construcción de } \\
\text { zonas humanitarias } \\
\text { y zonas de biodiversidad }\end{array}$ & $\begin{array}{l}\text { - Declaraciones } \\
\text { - Difusión en la redes } \\
\text { virtuales } \\
\text { - Comunicados } \\
\text { - Producción musical }\end{array}$ & $\begin{array}{l}\text { - Tutelas } \\
\text { - Querella en la } \\
\text { Corte Interamericana } \\
\text { - Verificación de } \\
\text { cultivos ilegales }\end{array}$ & $\begin{array}{l}\text { - Trabajo en redes } \\
\text { campesinas indígenas a } \\
\text { nivel continental } \\
\text { — Trabajo con ONG } \\
\text { nacionales } \\
\text { - Trabajo con ONG } \\
\text { internacionales }\end{array}$ \\
\hline
\end{tabular}

21. Acciones comunitarias específicas en cada comunidad Fuente: elaboración propia.

\section{Acciones DiREctas}

De acuerdo a lo que plantea Carlos Crespo, una acción directa es

cualquier método de lucha inmediata de las organizaciones u otros sectores, [...] parte del principio de la actuación autónoma. [...] Su rasgo principal da cuenta de una acción organizada por gente común para lograr cambios por sus propios esfuerzos, sin intermediarios (Crespo 2005: 253).

Señala que algunas de las acciones directas pueden ser entendidas como "iniciativas locales proactivas", es decir, con acción propositiva. Estas acciones se mueven entre la esfera de lo privado, porque nacen como propuestas de personas, y la esfera de lo público, porque tienen una incidencia en el ejercicio del derecho público. A este tipo de iniciativas se las ha llamado también lo privado-comunitario, por guardar relación tanto con el Estado como con el mercado. Ramón 
Galo (1999) considera que el surgimiento de esas iniciativas es una respuesta a la implementación fallida de los sistemas democráticos en los países del Sur.

El retorno: este es uno de los mecanismos comunitarios que implica un alto grado de trabajo y de consciencia intracomunitarios. En realidad, pocas comunidades logran retornos colectivos. Detrás de una acción de esta envergadura, y contemplando los escenarios de agresión en los que han sido expulsadas estas comunidades, se evidencia que en esas poblaciones existe un capital humano, comunitario y social robusto y muy sólido. De acuerdo con un artículo publicado en el periódico nacional El Mundo en 2016, "es un mito que los campesinos desplazados no quieran retornar a sus tierras, así lo evidenció la Primera encuesta nacional [en marzo del año 2016] sobre restitución de tierras y retorno, realizada por la Consultoría para los Derechos Humanos y Desplazamiento (Codhes)" (Rendón Marulanda 2016). El retorno se puede catalogar como una acción directa. Es un mecanismo estratégico que utilizan dos de las tres comunidades de este estudio para reclamar los territorios que les han sido arrebatados por empresas de la industria de palma de aceite. Los campesinos me relataron que en la zona humanitaria de Nueva Esperanza, tras los innumerables desplazamientos, han tenido que refugiarse en el monte. Los testimonios que aparecen recopilados en "La Tramoya" (Comisión Intereclesial de Justicia y Paz 2005) narran la muerte de niños a causa de la ingesta de aguas contaminadas. Todas las zonas humanitarias se declaran, abiertamente y de forma escrita, lugares exclusivos para la población civil no vinculada con los actores armados, como se puede apreciar en la siguiente imagen: 


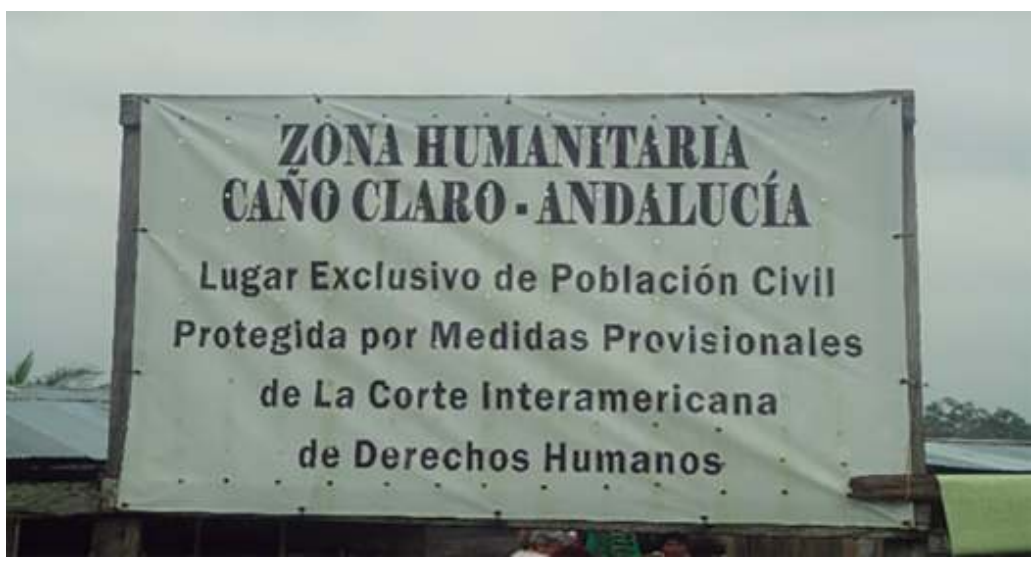

22. Zonas humanitarias

Fuente: archivo propio de la autora, visita al terreno, febrero de 2012

Las poblaciones en el Pacífico colombiano ${ }^{14}$ tienen, lamentablemente, una historia de abandono más intensa que la de otras regiones del país, aunque también en la región Atlántica existen varios conflictos irresueltos por la tenencia y concentración de tierras utilizadas tradicionalmente para la ganadería, además de los usos para cultivos ilícitos. Tanto las comunidades de las zonas humanitarias como la comunidad de Las Pavas se empeñan en un retorno definitivo y emprenden también acciones legales y de difusión en los medios, como lo veremos más adelante. A continuación, se caracteriza en detalle la acción directa del retorno de dos comunidades:

14. Las cifras proporcionadas por el Departamento Administrativo Nacional de Estadística (DANE) respecto al indicador Necesidades Básicas Insatisfechas son del $81,94 \%$ para el Chocó y la población en cabecera y de un 76,11\% en el resto del departamento (Fuente: DANE. Último censo, realizado en el año 2005). 


\begin{tabular}{|c|c|}
\hline Zonas humanitarias & Las Pavas \\
\hline \multicolumn{2}{|c|}{$\begin{array}{l}\text { Las condiciones del retorno se dan en situaciones de alta conflictividad por parte de los actores armados, con } \\
\text { profunda ausencia del Estado. Las garantías del retorno son casi nulas y la ley de restitución de tierras muestra } \\
\text { serias falencias }\end{array}$} \\
\hline $\begin{array}{l}\text { Primero: el regreso estaba sustentado como } \\
\text { propuesta política de reordenamiento territorial. } \\
\text { Segundo: el apelar a una instancia jurídica } \\
\text { continental tuvo y sigue teniendo efectos legales que } \\
\text { amonestan al Estado colombiano. } \\
\text { Tercero: la titulación colectiva promulgada en } 1993 \\
\text { respaldaba la acción misma. } \\
\text { Cuarto: las comunidades, si bien habían } \\
\text { sufrido graves pérdidas por la multiplicidad de } \\
\text { desplazamientos, mostraban fuerte cohesión por la } \\
\text { historia de construcción étnica-comunitaria. } \\
\text { Quinto: los integrantes de las comunidades estaban } \\
\text { informados sobre los procesos jurídicos, las leyes de } \\
\text { titulación y las acciones de las demás zonas. } \\
\text { Sexto: la constitución de consejos comunitarios } \\
\text { mayores y menores funcionaba como canal de } \\
\text { procesamiento y órgano de retroalimentación y } \\
\text { consulta comunitaria. } \\
\text { Séptimo: el factor étnico fue fundamental para la } \\
\text { reivindicación del espacio territorial en la reafirmación } \\
\text { cultural y del patrimonio natural. } \\
\text { Octavo: se llevaron -y se siguen llevando-a cabo } \\
\text { acciones de verificación y denuncia de cultivos ilícitos } \\
\text { y cultivos ilegales de palma en los territorios colectivos } \\
\text { una vez retornados. } \\
\text { Noveno: la zona del Chocó dejó de ser un área } \\
\text { estratégica para el programa nacional y gremial de } \\
\text { sembrado de palma aceitera. }\end{array}$ & $\begin{array}{l}\text { Primero: el reasentamiento estaba fundamentado en } \\
\text { el derecho por la posesión de los predios de manera } \\
\text { pacífica y se quería continuar sin interrupción. } \\
\text { Segundo: el retorno fue una decisión planeada por la } \\
\text { comunidad y apoyada por la mesa de interlocución. } \\
\text { Tercero: las inconsistencias institucionales de manejo } \\
\text { entre instancias jurídicas locales y regionales se } \\
\text { hicieron visibles con el retorno, aunque se prolongó el } \\
\text { tiempo de duración para la comunidad. } \\
\text { Cuarto: el retorno se da como un proyecto de } \\
\text { reclamación territorial, pero, por la falta de recursos } \\
\text { y por los hostigamientos sufridos, las condiciones de } \\
\text { permanencia en la hacienda son aún muy inestables. } \\
\text { Quinto: la acción de retorno ha estado liderada } \\
\text { por ASOCAB, aunque hay fracturas importantes en } \\
\text { el tejido comunitario generadas en gran parte por el } \\
\text { consorcio El Labrador, lo que derivó en la formación } \\
\text { de una asociación campesina paralela. } \\
\text { Sexto: se ha gestado una discusión nacional en torno } \\
\text { a los impactos de la palma en regiones específicas, } \\
\text { como la zona de Bolívar, uno de los departamentos de } \\
\text { mayor importancia en la zona norte del país. }\end{array}$ \\
\hline \multicolumn{2}{|c|}{ Transformación: incidencias de transformación en ámbitos específicos } \\
\hline $\begin{array}{l}\text { Muestra incidencia en el ámbito político, código } \\
\text { jurídico. }\end{array}$ & $\begin{array}{l}\text { Muestra incidencia en el ámbito social, político y } \\
\text { jurídico. }\end{array}$ \\
\hline
\end{tabular}

\section{Circunstancias del retorno}

Fuente: elaboración propia 
En las circunstancias que han enfrentado las poblaciones objeto de este estudio, el retorno es un proceso traumático, especialmente cuando existe el precedente de la migración forzada. Existen diversos factores que inciden en la decisión para retornar al lugar de origen. En el contexto de expulsión en el conflicto armado, las comunidades han tenido que sopesar el valor de regresar: la pérdida de seres queridos antes, durante y después del retorno ha sido una de las más duras experiencias para estos colectivos y las garantías de seguridad representan uno de los factores que más influye en la decisión. A este respecto, Ana María Ibáñez (2008) afirma lo siguiente:

El retorno de población desplazada debe, además, estar enmarcado en el Derecho Internacional Humanitario y contemplar las dinámicas que provocaron el desplazamiento inicial. En primer lugar, el retorno [... no no ni siquiera una alternativa cuando persisten las condiciones de violencia y conflicto que causaron el desplazamiento. (216)

Como indica esta autora, no hay unas buenas condiciones estructurales para el retorno, pero, aun así, las comunidades de este estudio regresan a sus lugares de origen. Retornar es una acción que ejerce presión en las instancias gubernamentales para que cumplan con las demandas de la población civil. En la misma encuesta realizada por la Consultoría para los Derechos Humanos y Desplazamiento (Codhes) en el ańo 2016 sobre los procesos de retorno y recogida en el artículo de El Mundo citado anteriormente, los resultados arrojan que "cerca del $72,6 \%$ de las personas que reciben una sentencia con la restitución material efectivamente retorna a sus tierras, el $12,8 \%$ realiza una explotación económica pero no vive en él y el 1,5\% permite que familiares vivan en el predio o lo exploten económicamente" (Rendón Marulanda 2016). Además, Ricardo Sabogal Urrego, director de la Unidad de Restitución de Tierras, afirma en este mismo artículo que "lo que muestra esta encuesta del Codhes es que la gente sí quiere regresar si se le da los incentivos para que vuelvan, si se le da tierra, proyecto productivo, vivienda y seguridad" (Rendón Marulanda 2016).

Los relatos de los campesinos de las comunidades de este estudio indican que, efectivamente, no toda la población logró o quiso retornar: en algunos casos, el trauma sufrido sobrepasaba la intención o 
las ganas de hacer efectivo el regreso y, en otros, las amenazas fueron decisivas para quedarse en el sitio en el que habían migrado. Ana María Ibáñez (2008) señala también que los retornos que se han dado en Colombia son pocos y se carece de datos de los retornantes, por esta razón no está claro qué políticas públicas son más efectivas para promover el regreso con garantías. Esta autora considera que "llevar a cabo un análisis para explorar estos interrogantes, no es posible" (24). Si bien existen dificultades para obtener información en los lugares de retorno, una primera exploración debería apelar a otras fuentes, como son las diferentes acciones comunitarias. Este estudio quiere ser una contribución también en ese sentido.

En el modelo que realizó Ana María Ibáñez sobre el deseo de retornar, se estima que hay dos variables que influyen de manera importante respecto a esta decisión: por un lado, ser víctima de nuevas agresiones $y$, por el otro, el porcentaje del predio que puede ser recuperado. Sin embargo, en las comunidades de este estudio hay otros elementos relevantes que tienen influencia, como, por ejemplo, la filiación étnica, las prácticas socioculturales y las acciones políticas en miras de la gobernanza territorial. Un retorno sostenible es lo que buscan las comunidades que regresan, sean campesinas, indígenas o afrocolombianas; estas dos últimas son quienes muestran procesos de regreso más exitosos. Si bien esas categorías dan una idea de la composición comunitaria, esta puede aparecer sesgada porque existen diversas identidades entrecruzadas, ya que muchas comunidades indígenas son también campesinas, y viceversa. Del mismo modo, buena parte de las comunidades afrocolombianas están asentadas en ambientes rurales y conservan la cultura agrícola. En el marco jurídico, la ley 387 de 1997 (modificada en los años 1999, 2000 y 2005) presenta el retorno como una medida de estabilización económica y un derecho de la población expulsada de su territorio. La Corte Constitucional, por su parte, redimensiona las implicaciones y aduce que dicho retorno debe estar enmarcado dentro de un contexto de reparación integral a la población afectada. En el año 2009, surgió uno de los mayores aportes que ha hecho este organismo a los planteamientos sobre el retorno: el goce efectivo de derechos, para lo cual las políticas públicas estipularon estos doce componentes: 
i) acceso a programas de subsidio de vivienda; (ii) acceso a tierras productivas a través de la recuperación de tierras abandonadas y la formalización legal de la propiedad; (iii) inclusión de la población en el sistema de salud pública; (iv) educación para los niños menores de 15 años; (v) rehabilitación de las rutas de acceso a los lugares de retorno; (vi) facilitación del acceso a la justicia para hacer efectivo los derechos de verdad, justicia y reparación; (vii) servicios básicos como electricidad, agua y alcantarillado; (viii) acceso a una alimentación suficiente y adecuada; (ix) acceso a fuentes de ingreso y trabajo; (x) seguimiento humanitario, que es considerado como una garantía para el ejercicio de los derechos de la población en retorno; (xi) apoyo a la organización social; y (xii) ayuda psicológica a las comunidades que retornan (Ley 387 de 1997).

En el actual Acuerdo Final de paz, el retorno es contemplado como una de las estrategias que se favorecerán y estimularán en el marco de la creación de una jurisdicción especial para la paz. El texto del Acuerdo señala que se pondrán en marcha retornos colectivos con un enfoque territorial y de género y se emprenderán retornos acompañados que contemplan programas de reparación colectiva y restitución de tierras y otros elementos acordes a la reparación de las víctimas. De acuerdo con las declaraciones del ex magistrado Manuel José Cepeda, la creación de esa jurisdicción especial para la paz (JEP) tiene el propósito de "administrar justicia, ejercer funciones judiciales. No tendrá ni funciones constituyentes ni facultades supraconstitucionales. Las normas mediante las cuales sea creada la JEP, como es usual en Colombia, serán sujetas al control de la Corte Constitucional" (El Tiempo 2016). Existen aún diversas críticas respecto al Tribunal para la Paz y a los procedimientos de Justicia Transicional que tienen que ver con los procesos de investigación, restauración y reparación de las víctimas.

\section{La comunidad El Garzal: la ética religiosa}

Esta comunidad es la única de las tres que no logró ser desplazada de forma colectiva, ya que ha trabajado mancomunadamente con las demás veredas que fueron varias veces amenazadas y hostigadas tanto para vender las tierras como para salir de los territorios. La decisión que tomó la comunidad El Garzal fue un no rotundo a abandonar el territorio. De acuerdo con los relatos, la vigilia y la fe, rasgos afines a 
todos los integrantes de la comunidad, contribuyeron a mantenerlos unidos. Además, se construyó un proceso de confianza mutua basado en el proyecto campesino comunitario fundamentado en la convicción religiosa: "Se hacían vigilias y ayunos y las alabanzas a Dios en las celebraciones eran formas de pedirle protección".

En las conversaciones que sostenían los miembros del Garzal sobre las propuestas que recibían de las empresas, establecían puntos de contraste entre los planes agroindustriales y los proyectos agrícolas de la comunidad. Mencionan que una figura política de la localidad fue persuadida por algunos empresarios, pero, gracias a la unidad basada en la fe, los miembros de la comunidad dialogaban periódicamente y se mantuvo finalmente la cohesión comunitaria y la membresía de ese importante líder dentro del proyecto comunitario. No solo las empresas, sino también familias pudientes de la región han tratado de ingresar a la comunidad para incitar las ventas de los terrenos. Los líderes y las organizaciones de mujeres han sido fundamentales para la permanencia, pues han sido figuras centrales para la movilización colectiva.

Como se explicó en la narración cronológica del conflicto, el carácter religioso ha sido el motor para emprender y mantener la acción comunitaria. En este proceso es interesante observar que las acciones siguen una corriente diferente a lo que suelen ser los preceptos religiosos que guían a las iglesias evangélicas. Mientras la tradición eclesial tiende a recalcar la importancia de profesar una profunda fe que se aísla o quiere aislarse casi por completo del orden social o político establecido, la comunidad El Garzal logra una enorme transformación en esos dos ámbitos, pues sus miembros — como lo indican Plata y Cáceres (2015) — han sabido resignificar esos preceptos y trasladarlos a sus contextos locales, en los que se requerían acciones concretas para negociar, planear, etc. Algunos de los rasgos que indican estos actores están enmarcados también en lo que John Paul Lederach denomina los procesos de "sanación social": una nueva interpretación de la fe, una fe que permite trasladar el lenguaje y la simbología religiosos para hacerlos análogos en las acciones comunitarias políticas. Sentirse una comunidad de fe les proporcionó - y les sigue proporcionando- a los miembros de la comunidad la persistencia y el valor necesarios para resistir pacíficamente. Además, la certeza de que Dios los protege y 
apoya la causa de permanecer en su territorio les fortaleció y fortalece. Así, dentro de un marco que vincula las acciones sociales y políticas con la cultura religiosa y las consagra en lo espiritual, ha sido posible persistir y no abandonar el territorio. Compartir los temores y los aciertos e intercambiar informaciones relevantes que se daban durante las reuniones semanales contribuyó a la cohesión del colectivo. Salvador Alcántara afirma que "no tomar decisiones individuales era una de las máximas previas a cualquier decisión o acción que pudiera afectar a la comunidad" (entrevista) ${ }^{15}$. Esto surtió efecto en todos los líderes de las comunidades que hacían parte de la planeación, evaluación e implementación de las decisiones acordadas. Otro de los líderes precisó que cuando no encontraron consenso entre ellos se abstuvieron de orientarse por una de las resoluciones propuestas y optaron por someterla a consideración de toda la comunidad, convocando a la población a asambleas extraordinarias.

El retorno en dos de las tres comunidades analizadas no es un hecho singular ni completamente aislado en el contexto actual en Colombia. La Defensoría Delegada para los Derechos de la Población Desplazada, en su informe de agosto del año 2012 "Análisis y valoración de la política pública de retornos y reubicaciones", describe los alcances de la respuesta institucional ante el fenómeno del desplazamiento masivo y se señalan los logros y las falencias. Se describen treinta y tres casos de retorno y siete reubicaciones en treinta y dos municipios de Colombia. Volver al territorio supone la planeación de una nueva vida que brinde las condiciones para poder rehacer la cotidianidad, la institucionalidad y el tejido social. El uso del espacio territorial, en los casos en que es posible efectuar el retorno, es uno de los puntos centrales para reconstruir una comunidad rural en los territorios de origen. Es necesario documentar más y mejor los procesos de retorno en el país, ese podría ser un primer paso para empezar a comprender los mecanismos utilizados por las comunidades en sus procesos de reconstrucción social.

15. La entrevista realizada a Salvador Alcántara es parte del material del archivo obtenido en el trabajo de campo en 2013. 


\section{Reapropiación del espacio local: el significado del lugar}

Las comunidades se han reasentado en sus lugares de origen, instalándose en condiciones realmente precarias. En el caso de las zonas humanitarias, la reterritorialización estuvo concebida como práctica de reafirmación del espacio que les pertenece, cuyo reconocimiento jurídico prevalecía y la comunidad de Las Pavas ha logrado el reasentamiento en medio de serias disputas por la titulación de los predios. Permanecer en el territorio se convierte en una amenaza debido a la presencia y el hostigamiento de los actores armados y a la gran incertidumbre respecto a la legalización.

El lugar como referencia cultural existe a través de espacios materialmente definidos. La necesidad de pertenencia y la representación social y política están estrechamente vinculadas a unos sitios concretos. La construcción de la experiencia vital, natural y social se aferra a la existencia de un espacio real. Respecto al lugar como concepto, Arturo Escobar (2000) plantea que, en el contexto de la globalización, en la que se relativiza la espacialidad, se construyen una cantidad de metáforas para asignarle significados a la movilidad, lo que crea un efecto mayor en la concientización sobre el concepto del espacio. Esa consciencia se traduce en la inquietud por discernir los cambios de las dinámicas culturales, siendo muchas de ellas consecuencia de la desterritorialización en varios ámbitos. Este autor lo expresa así:

Existe un sentimiento de pertenencia que es más importante de lo que queremos admitir, lo cual hace que uno considere si la idea de "regresar al lugar" — para usar la expresión de Casey_ o la defensa del lugar como proyecto — en el caso de Dirlik — no son cuestiones tan irrelevantes después de todo (2000: 113).

Observemos estos aspectos en cada una de las comunidades en la siguiente tabla: 


\begin{tabular}{|c|c|c|}
\hline Zonas humanitarias & Las Pavas & El Garzal \\
\hline $\begin{array}{l}\text { Constitución de zonas humanita- } \\
\text { rias y zonas de biodiversidad }\end{array}$ & Construcción de cambuches & Finca campesina \\
\hline $\begin{array}{l}\text { - La constitución de zonas } \\
\text { humanitarias y zonas de biodiver- } \\
\text { sidad que están amparadas por la } \\
\text { Corte Interamericana posibilita un } \\
\text { marco de acción para la población } \\
\text { y es un medio de protección por la } \\
\text { presencia de grupos armados en la } \\
\text { zona y sus constantes amenazas. } \\
\text { — Es un instrumento de afirma- } \\
\text { ción jurídica y constitucional. } \\
\text { — Las zonas humanitarias } \\
\text { están organizadas en torno a un } \\
\text { concepto de red, en el cual existe } \\
\text { una distribución del espacio para } \\
\text { diferentes labores. De este modo } \\
\text { se cristaliza la reafirmación de la } \\
\text { comunidad y su concepto interac- } \\
\text { tivo de paz. } \\
\text { — Es un instrumento para } \\
\text { reconstruir nuevas formas de go- } \\
\text { bernabilidad tanto en la práctica } \\
\text { comunitaria como de los recursos } \\
\text { naturales; esto último, especial- } \\
\text { mente a través de las zonas de } \\
\text { biodiversidad. } \\
\text { — Recupera el trauma y el dolor } \\
\text { como dispositivo de reconstruc- } \\
\text { ción histórica y da continuidad a } \\
\text { la historia colectiva y ancestral. }\end{array}$ & $\begin{array}{l}\text { — La construcción de cambuches } \\
\text { es un mecanismo de presión que } \\
\text { alerta tanto a las empresas como } \\
\text { a la opinión pública respecto al } \\
\text { tema de la tierra. } \\
\text { — Las circunstancias de titulación } \\
\text { irresuelta son sin duda la mayor } \\
\text { desventaja para la población. } \\
\text { — La instalación de cambuches se } \\
\text { hace de manera pacífica y mani- } \\
\text { fiesta la recuperación del espacio } \\
\text { para la defensa del territorio. } \\
\text { — Es un instrumento para hacer } \\
\text { un llamado a la alta concentración } \\
\text { de tierras que se ha venido dando } \\
\text { en la región a través de diferentes } \\
\text { formas, en este caso, la siembra de } \\
\text { palma de aceite a larga escala. }\end{array}$ & $\begin{array}{l}\text { - Cuenta con varios espa- } \\
\text { cios de producción: } \\
\text { - } \quad \text { parcela agroforestal } \\
\text { sembrado de cacao, } \\
\text { plátano, frutales } \\
\text { el patio productivo } \\
\text { diversificado } \\
\text { — Espacios menores, horta- } \\
\text { lizas, plantas medicinales } \\
\text { — Parcelas de cultivos de } \\
\text { maíz, arroz, rastrojos y } \\
\text { potreros. } \\
\text { - Juntas de acción comu- } \\
\text { nal, con carácter autóctono, } \\
\text { han coorganizado esta } \\
\text { estructura de las fincas. }\end{array}$ \\
\hline
\end{tabular}

24. Reapropiación del espacio local Fuente: elaboración propia 
Las acciones que emprenden estas tres comunidades están justamente encaminadas a defender el territorio para la construcción cultural de su colectivo: en el caso de las zonas humanitarias, ese propósito está estrechamente ligado a una historia ancestral de cohesión étnica y en el caso de Las Pavas y El Garzal, su canal es el carácter campesino. Aunque la defensa del lugar se refiera en primera instancia a la tierra, es preciso recordar que las comunidades de enfoque son esencialmente ribereñas, por lo que una dimensión integral de los recursos naturales para garantizar la vida y las condiciones dignas de las poblaciones es preponderante. Algunos de los planteamientos de los estudios culturales sobre los procesos de migración se centran sobre todo en analizar los flujos migratorios internacionales y prestan poca atención a los del interior de los territorios nacionales, flujos que se siguen dando aún entre los escenarios urbanos y rurales. Los planteamientos de Néstor García Canclini (2001), por ejemplo, sobre la pérdida de la relación entre el territorio geográfico y la construcción cultural son pertinentes para comprender los procesos de las migraciones voluntarias, pero en el contexto de la migración forzada, como es el caso de estas comunidades, pierden su validez. Las comunidades afrodescendientes, indígenas y campesinas, no solo en el territorio nacional, sino en muchos países del hemisferio sur, abogan por sus derechos territoriales y ven en la tierra la materia de legitimación de sus culturas ancestrales.

Por otra parte, la reflexión de Homi K. Bhabha (2004 sobre las zonas intervienes (in-between spaces) como lugares de negociación y articulación de la diferencia señala con más énfasis el desenvolvimiento del sujeto colonial — ahora postcolonial—, pero le confieren poca importancia a las nuevas formas de poder que se gestan en esos espacios. Mientras desde la perspectiva de los flujos migratorios se crean zonas intermedias que son figurativas y no necesariamente materiales, en los contextos de migración forzada y en los casos del conflicto por la tierra, existe una necesidad urgente de recuperar zonas con claros límites materiales y geográficos, territorios que han sido usurpados y vetados de la reproducción cultural campesina y comunitaria. La materialidad representa esa parte física, que es fundamental, del concepto de territorio, en concreto los recursos naturales, las fuentes hídricas, las zonas de cultivo y la diversidad de los ecosistemas. Sin embargo, 
esa construcción del territorio sería incompleta si no existieran otros espacios a través de los cuales se retroalimentan las significaciones de lo material: aquellos espacios dinámicos de reconstrucción y cruce entre las dimensiones materiales, humanas y espirituales en los que se cultivan discursos, se recrean semánticas y se regeneran las simbologías que componen el entramado territorial. Este es un aspecto determinante para comprender cómo las prácticas comunitarias cultivan espacios de convivencia con la naturaleza, con lo humano y con lo inmaterial y proveen un potencial social para construir relaciones de justicia y paz, además de convertirse en creación factual de la representación heterocultural. Por ello, más que advertir la creación de los espacios de intervalo, resulta necesario poner en consideración qué términos, qué paradigmas, qué ideologías y qué estéticas guían las negociaciones y las transformaciones que puedan tener lugar en los espacios intermedios.

La constitución de las zonas humanitarias y la instalación de los cambuches representan intentos de reterritorializar el espacio que les ha sido arrebatado a las poblaciones afrodescendientes. Estas acciones son mecanismos de protección y resistencia ante los procesos de usurpación de las tierras. Si revisamos la simbología de lo fronterizo, sugerida por Bhabha (2004), cambia de la noción de división lineal a una idea de conexión: se trata de un espacio de transición que comunica las realidades en contacto, lo que implicaría la convergencia de prácticas, saberes y conocimientos. Esta noción de conectividad, que sería perceptible en los flujos migratorios, se desdibuja en el contexto de la migración forzada, con lo que surge la idea de lo limítrofe como reacción al destierro físico.

En la situación concreta del conflicto por la tierra podríamos visualizar la noción fronteriza desde dos ángulos: las fronteras del espacio material y de lo inmaterial y las alianzas y la hibridación. Respecto al primero, la frontera en el espacio material no se difumina, sino que, por el contrario, adquiere mucha más relevancia porque la demarcación territorial de lo que ha sido usurpado es fundamental para restablecer los derechos del hábitat territorial y porque la negociación en el terreno de lo ambiguo tiende a tornar el camino de la resolución mucho más complejo. La construcción de las zonas humanitarias es una clara muestra de la frontera como instrumento de contención ante 
la agresión y de validación de lo cultural-local. Tal vez sea necesario recurrir a la noción de frontera para recuperar la idea de equidad en la diferencia, que se ha diluido en el discurso simbólico y de hibridación y que se reproduce con inequidad y crudeza en las relaciones de poder.

El segundo ángulo es el de las alianzas y lo híbrido. Desde esa comprensión, podríamos decir que, efectivamente, la formación de espacios intertextuales entre lo regional, lo nacional y lo internacional ha posibilitado el renacimiento de estas comunidades y la refundación de los espacios colectivos. Los espacios de reformulación que sugiere Bhabha (2004) se simbolizan en las comunidades a través de la creación de inter-redes. En el caso de las poblaciones rurales de enfoque, esas intersecciones de intercambio han dado lugar a la creación de nuevos lugares culturales y de nuevas formas de representar la diversidad cultural que emergen desde la pluralidad étnica, cultural, confesional, etc. Las articulaciones y los flujos sociales que se plantean como espacios híbridos y como representaciones con cruces de elementos de diferente naturaleza no se dan como una mezcla: si hay creación cultural, esta emerge en el marco de lo que representa la diferencia o la singularidad dentro de un marco de unidad colectiva. En ese sentido sería más apropiado usar el término abigarramiento propuesto por René Zavaleta Mercado (1986) para referirse a procesos culturales cuyas singularidades son visibles y forman un conjunto heterogéneo, pero no son necesariamente híbridos. En la representación territorial existen ejes de conexión y ejes de deslinde, por ejemplo, si observamos cómo las comunidades afrodescendientes y las indígenas representan o se relacionan con la Pachamama, puede existir el rito del chayar en unas etnias y en otras no, sin embargo, la figura común de representación reseguirá siendo la misma.

\section{LA CASA DE LA MEMORIA (ZONAS HUMANITARIAS)}

La reconstrucción del espacio interior de las zonas humanitarias se simboliza en forma de red — como la de una telarańa- y aparece dibujada como orientación cartográfica al ingresar al área donde se localizan estas. En el centro de la Nueva Esperanza se encuentra situada la casa de la memoria, que es el sitio de encuentro de la comunidad y 
el lugar de recuperación de la memoria histórica. Allí cada una de las paredes está reservada para un motivo especial: en una de ellas se encuentra una lista con los nombres de diferentes personas de las comunidades que han fallecido de forma violenta; en otra, aparecen diversas informaciones sobre los cultivos que se producen, el tiempo de las cosechas y demás prácticas agrícolas. En las siguientes imágenes se ve esta casa de la memoria, la primera muestra el perfil exterior y las otras dos, el ambiente interior:

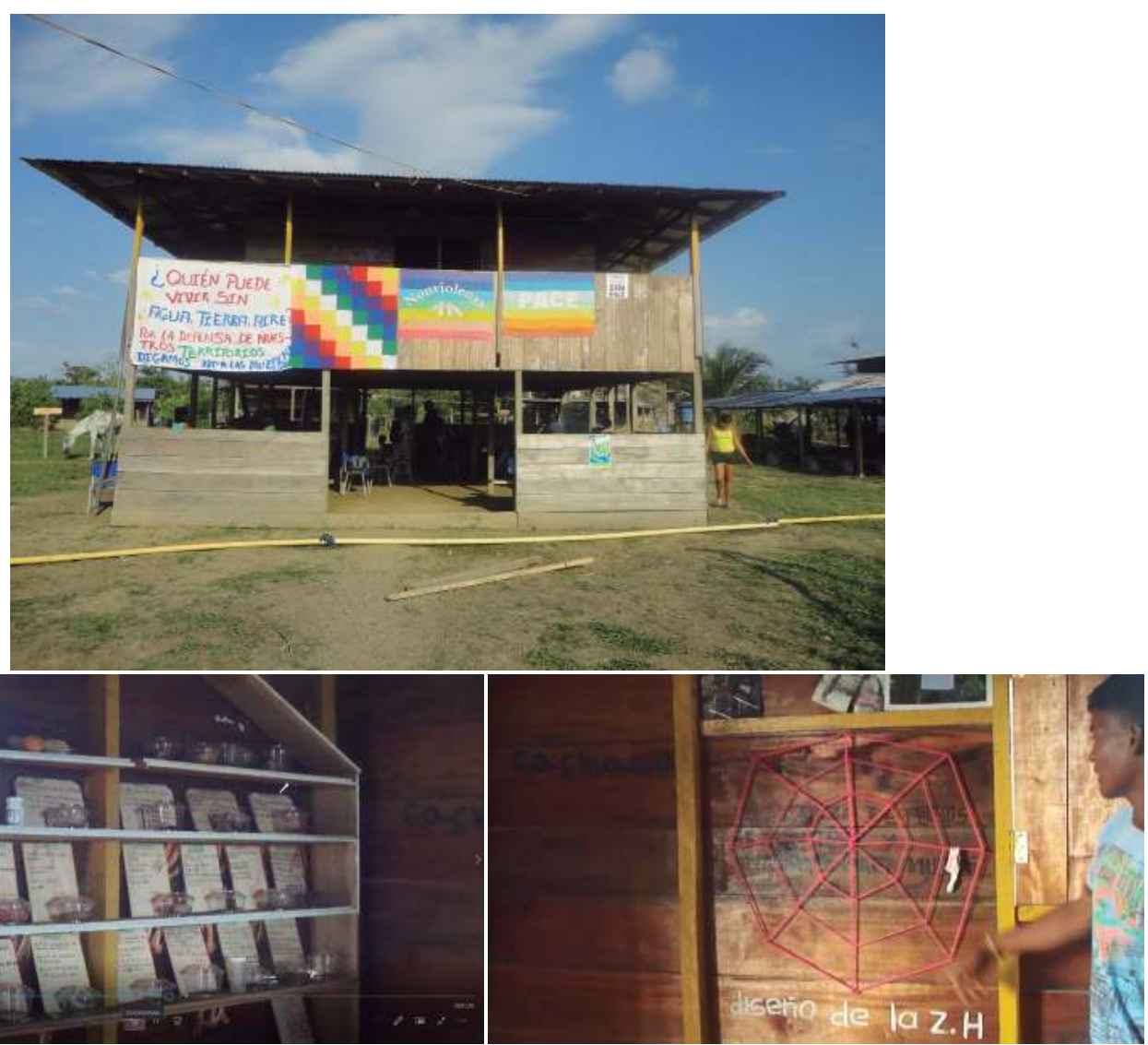

25. La casa de la memoria

Fuente: archivo propio de la autora, visita al terreno, febrero de 2012 

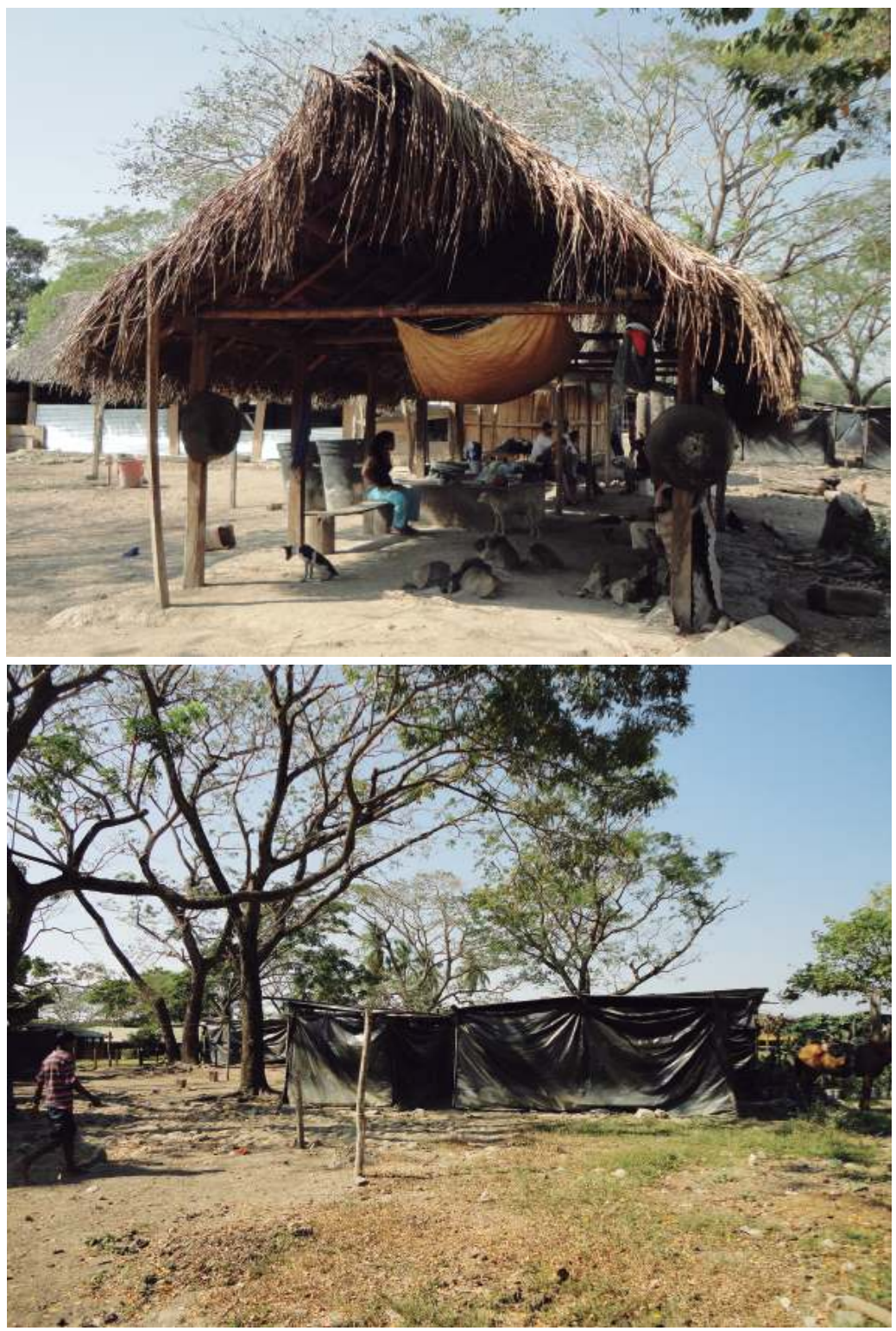

26a y 26b. Reterritorialización ASOCAB Fuente: archivo propio de la autora, visita al terreno, febrero de 2012 
Cambuches (hacienda Las Pavas)

Los procesos de retorno son experiencias sumamente complejas que demandan cohesión, confianza, unión y mucha fortaleza comunitaria. Las estrategias de reterritorialización que ha emprendido ASOCAB han sido planeadas para lograr sostenibilidad en la hacienda. El propósito de recuperar las tierras y habilitarlas nuevamente para actividades de subsistencia a través del cultivo ha tenido sus altas y bajas: las condiciones de hábitat para las familias son precarias, pues no cuentan con servicios públicos ni de agua ni de electricidad, y el terreno donde están los cambuches está vigilado por la empresa de seguridad de la compañía palmera. En diferentes ocasiones, los paveros han encontrado los sembrados destruidos y, de acuerdo con las últimas declaraciones de los líderes de la comunidad, siguen los hostigamientos a los miembros de ASOCAB por parte de hombres armados. En la ilustración 26a se puede ver las construcciones improvisadas de la comunidad, y en la $26 \mathrm{~b}$ las instalaciones ocupadas por la administración de la empresa.

\section{Resistencia y permanencia: usos del espacio común}

Como se ha mencionado anteriormente, el acceso a la tierra per se no es suficiente para garantizar el desarrollo rural ni tampoco el bienestar comunitario. La tierra como recurso material y económico está ligada de forma inherente a la consecución y el incremento de otros recursos inmateriales y simbólicos, como la dignificación de la vida y su hábitat, la participación en la toma de decisiones, la reproducción de repertorios culturales y la formación de filiaciones colectivas, entre muchos otros. Un aspecto central en el proceso de autogestión comunitaria es la recuperación de la actividad agrícola como base fundamental de la independencia económica y el autodesarrollo. Los cultivos de maíz, en el caso de las comunidades de Las Pavas y El Garzal, han sido estratégicos para reafirmarse en el territorio. En los dos casos, las inundaciones les han destruido los sembrados, causando grandes pérdidas. Después de estos episodios, las comunidades han tenido muchas dificultades para volver a reanudar las cosechas. Uno de los grandes obstáculos con 
los que se enfrentan son las carencias en la financiación para desarrollar proyectos que fomenten la agricultura campesina y fortalezcan las propuestas de desarrollo comunitario. Asimismo, las ayudas tecnológicas del Gobierno han sido precarias o incluso nulas. Muchas de las comunidades deben afrontar los riesgos, sean climáticos o del mercado, por sus propios medios, es decir, deben asumir las llamadas externalidades del sistema a las que se refiere Martínez Alier (2011). En la tabla que se ve a continuación, se especifican los usos que le han dado las comunidades a sus territorios:

\begin{tabular}{|l|l|l|}
\hline \multicolumn{1}{|c|}{$\begin{array}{c}\text { Zonas humanitarias/ } \\
\text { zonas de biodiversidad }\end{array}$} & \multicolumn{1}{|c|}{ Las Pavas } & \multicolumn{1}{c|}{ El Garzal } \\
\hline $\begin{array}{l}\text { Tumbar parte de las } \\
\text { plantaciones y sembrar } \\
\text { productos de pancoger. }\end{array}$ & Cultivar las tierras. & $\begin{array}{l}\text { Cultivar las tierras como } \\
\text { estrategia de resistencia. }\end{array}$ \\
\hline $\begin{array}{l}\text { - Derribar las } \\
\text { plantaciones que estaban } \\
\text { ocupando sus territorios. } \\
\text { - Instalar zonas de } \\
\text { biodiversidad para } \\
\text { reactivar la producción } \\
\text { agrícola y ecológica. }\end{array}$ & $\begin{array}{l}\text { Los sembrados de maíz } \\
\text { fueron dispuestos para } \\
\text { restablecer las labores } \\
\text { agrarias de la comunidad } \\
\text { y poder así reactivar sus } \\
\text { economías. }\end{array}$ & $\begin{array}{l}\text { - Cultivos de maíz. } \\
\text { - Cultivos de cacao: } \\
\text { fortalecimiento para la } \\
\text { - Organidad. } \\
\text { cooperativa para la la venta } \\
\text { de cacao. }\end{array}$ \\
\hline
\end{tabular}

27. Habilitar las tierras: permanencia y resistencia Fuente: elaboración propia

Las acciones de permanencia en el terreno no son un capricho, están fundamentadas en un paradigma de participación productiva horizontal. En primer lugar, las localidades aledañas se suplen de la generación de alimentos que se produce en la zona: las asociaciones y cooperativas no trabajan solamente para sí mismas, sino que desarrollan actividades de comercio productivo regional para distribuir sus productos. Un ejemplo es la cooperativa de cacao de la comunidad El Garzal. La asociación decidió diversificar la producción agrícola para afrontar mejor los reveses climáticos y propuso a los miembros realizar una distribución de los espacios de producción en cada una de sus 
fincas, como se aprecia en la primera imagen; en la segunda imagen se ve la recolección de cacao en la cooperativa y en la tercera se ilustra una finca en la comunidad El Garzal:
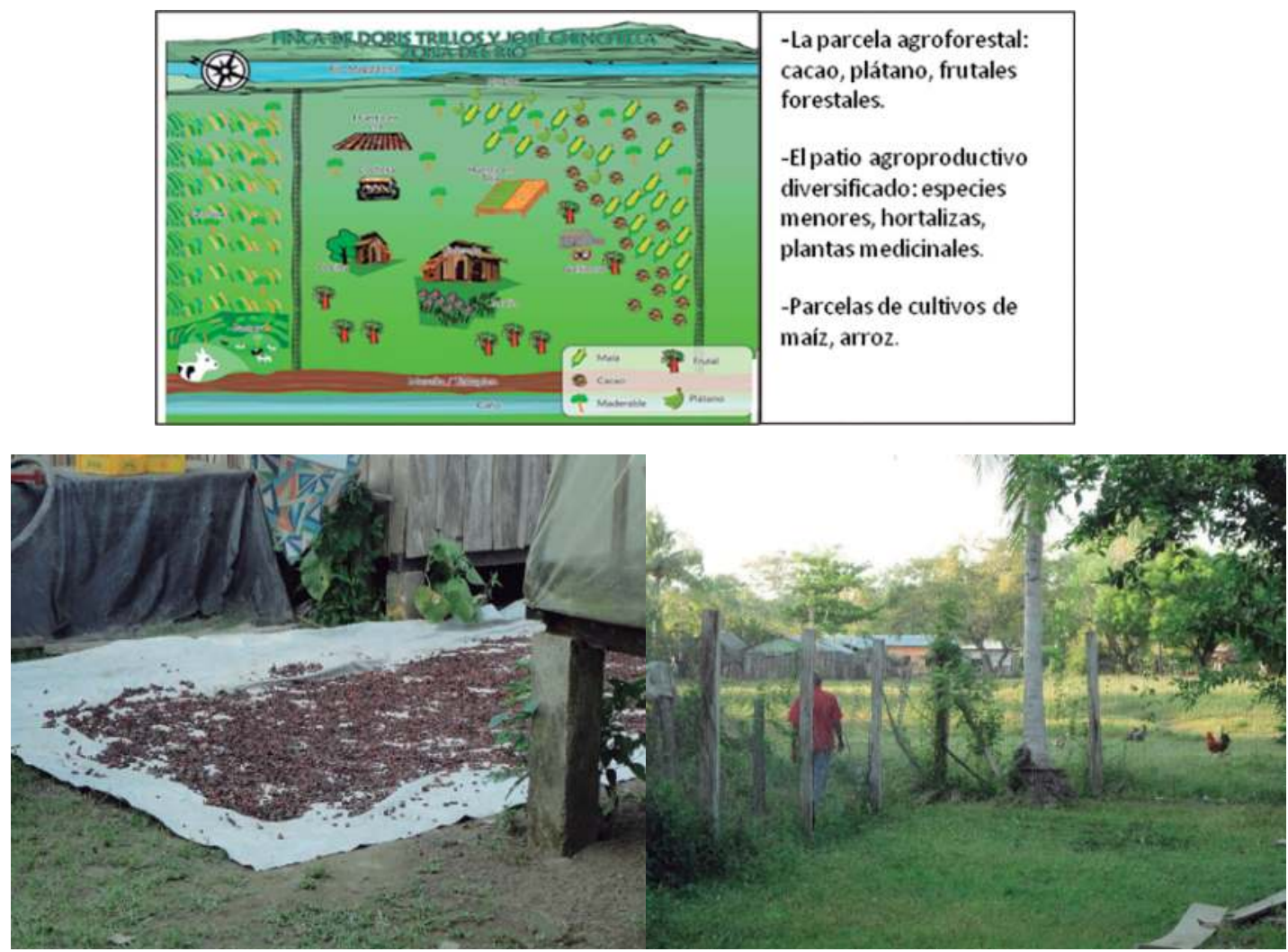

28. Distribución de una finca campesina en El Garzal Arriba, fuente: tomado de Alcántara (2008: 11) Abajo, fuente: archivo propio. Visita al terreno, 2012 
En algunos momentos del conflicto, el manejo de la disputa entre las comunidades y las compañías ha posibilitado llegar al diálogo para escuchar las propuestas de estas últimas. La búsqueda de compatibilidades es una de las estrategias que señala Ortiz (1999); sin embargo, ese intento se hace más difícil si se trata de valoraciones que se sitúan en paradigmas diferentes. Una de las grandes incompatibilidades en los procesos de manejo del conflicto vividos por estas comunidades radica en el uso de los territorios: la industria palmera quiere destinarlos cultivos para las plantaciones industriales, mientras que las asociaciones campesinas quieren realizar proyectos agrícolas para suplirse y comercializar en la región. Este es un punto esencial que muestra la diversidad en la utilización de las tierras. En primer lugar, el sembrado de palma cambia drásticamente la práctica agrícola comunitaria, por tratarse de un producto perenne. Además, excluye a muchos campesinos de la comercialización diversificada, pues la distribución de los frutos de la palma se da en una estructura vertical, en la que una sola instancia compra las cosechas, que son procesadas en la destiladora más cercana, lo que implica una mayor dependencia de los campesinos de una parte de la cadena de mercado. Adicionalmente, los productos de la palma requieren un procesamiento tecnológico al que no tienen acceso todos los integrantes de la cadena productiva. A estos factores se suma la categorización que se le da al campesino como asociado (el aspecto de la asociatividad se especifica previamente en este estudio al referirse a la narrativa de la industria palmera). En esta misma línea, es preciso recordar que los cultivos de palma de aceite estuvieron contemplados dentro del Plan Colombia como parte de los mecanismos para la sustitución de los cultivos ilícitos y también fueron concebidos desde una perspectiva de desarrollo alternativo que no se hizo efectivo para los pequeños agricultores y en la que no hubo adjudicaciones de créditos para estimular las dinámicas de producción agrícola campesina. 


\section{Acciones legales}

Respecto a las acciones legales que emprendieron las tres comunidades, no existen grandes diferencias: las zonas humanitarias apelaron a la Corte Constitucional y, posteriormente, a la Corte Interamericana de Derechos Humanos; la comunidad Las Pavas acudió al Parlamento Europeo para conseguir la solidaridad internacional como víctimas del conflicto y en condición de desplazados, y El Garzal recurrió a la protección de seguridad para la defensa de la vida y de sus familias.

Las acciones legales llevadas a cabo por las tres comunidades han tenido consecuencias en el ámbito jurídico y político. De acuerdo con Liliana Díaz (1999), la introducción del código ambiental, con mecanismos y espacios de participación concretos, ha tenido un efecto positivo para las comunidades rurales porque, entre otras cosas, les permite argumentar desde lo ambiental situaciones que ya habían sido expuestas desde otros términos; es decir, son marcos que dan legitimidad para argumentar una situación preexistente e incuestionable. A su vez, hacen posible deslegitimar acciones que antes se consideraban inocuas por la inexistencia de normas adecuadas o la insuficiencia en la aplicación de las mismas. Liliana Díaz (1999) y Fernando Cepeda (2013) coinciden en afirmar que la Carta Constitucional contiene numerosas normas sobre la participación ciudadana y comunitaria. Lo que se debería reforzar es la interpretación y la aplicación de alternativas de las normas y del derecho para que incidan de manera efectiva como instrumentos legales en el fortalecimiento de las comunidades; en otras palabras, poner la normatividad al servicio de los procesos de participación y crear mecanismos de una acción vinculante de cara a la toma de decisiones.

En relación al manejo jurídico y legal en el marco del conflicto de Las Pavas, existe una intervención por parte de la Clínica Jurídica sobre Derecho y Territorio: un "modelo de intervención social" enfocado a aumentar los instrumentos jurídicos para que la comunidad pudiera enfrentar mejor la situación de conflicto. De acuerdo con el informe de la Clínica Jurídica (2015), se pueden observar tres resultados que están en consonancia con los objetivos a conseguir —como se especifican a continuación - y cada uno de los cuales deriva en efectos jurídicos concretos: 
- Diseño y ejecución de estrategia de la obligación por parte del Estado para persecución de los delitos cometidos en la Hacienda de Las Pavas.

- Diseño y ejecución de estrategias para activar herramientas de verdad, justicia y reparación en el marco de la justicia transicional.

- Diseño y ejecución de estrategias para la garantía de los derechos sobre el uso.

Es preciso mencionar que ese modelo de intervención les proporciona a las comunidades la posibilidad de contar con un actor que ejerce el rol de interlocutor con el Estado. De la misma manera, se constata que la participación de este tiene un peso simbólico, independientemente de su intervención per se. Al parecer, "sólo los actores de un poder análogo, al menos en un nivel simbólico, logran construir un equilibrio en disputas jurídicas y políticas que parecieran perdidas, incluso para los campesinos mismos" (Clínica Jurídica 2015: 14).

\section{Acciones en los medios}

Todas las comunidades han emprendido acciones para difundir su situación y darse a conocer a nivel nacional o incluso internacional: con el apoyo de las diversas organizaciones de acompańamiento han creado canales de difusión para divulgar los procesos colectivos. Las Pavas cuenta con un blog en la red, en el cual se pueden seguir paso a paso los acontecimientos y las interacciones con otros actores; un reportaje sobre su retorno, que se ha convertido en documental y se ha empezado a difundir en Suiza, entre otros; un CD con los cantos compuestos por miembros de la comunidad en donde narran su historia, las percepciones sobre el conflicto y sus proyectos comunitarios, entre otros temas. Además, Las Pavas y El Garzal también forman parte de la Red de Iniciativas y Comunidades de Paz desde la Base. Las comunidades de las zonas humanitarias cuentan también con un espacio virtual en la página de la Comisión Intereclesial de Justicia y Paz, en el cual se va consignando la historia del proceso. El grupo musical Los Renacientes — quienes pertenecen a la comunidad del Cacarica — han grabado tres $\mathrm{CD}$, con los cuales han dado a conocer su experiencia de despojo del territorio y a su vez han difundido la existencia de otras 
comunidades del departamento del Chocó que se enfrentan a condiciones de destierro similares.

Respecto a la presencia de estos casos en los medios, hay quienes consideran que las grandes controversias tienden a polarizar aún más el terreno, ya tenso, entre los actores en disputa. Si bien este argumento puede contribuir a la captación de grupos a favor y en contra, lo definitivo es el efecto que tenga en la sociedad civil. La visibilización de los procesos comunitarios es más que necesaria en la sociedad colombiana. Además, la pluralidad de versiones permite juzgar desde diversos ángulos un mismo evento. Por otra parte, los procesos de representación de las realidades y su difusión conducen a una mayor concientización en relación a temas fundamentales de la convivencia social. En Colombia, esas informaciones y su divulgación contribuyen a que diferentes segmentos de la sociedad se formen una opinión sobre los procesos rurales, de tal manera que logre transcender el propósito sensacionalista que persigue gran parte de la información de los medios masivos.

\section{Relaciones de poder estructurales}

Trabajo en Red y gobernanza

Las prácticas de cooperación interna de las comunidades estudiadas ${ }^{16}$ y la organización de una Red de Iniciativas y Comunidades de Paz desde la Base son propuestas que aplican principios de participación democrática y articulación comunitaria. En Latinoamérica se vienen dando procesos de articulación entre grupos de base en los que colaboran principalmente campesinos, indígenas y afrodescendientes. Los movimientos que han surgido en estos países persiguen objetivos muy similares en relación al manejo de los recursos naturales y a los sistemas de participación y administración institucional y política. Boaventura de Sousa Santos (2010) los llamaría procesos para "democratizar la

16. Las comunidades que hacen parte de esa Red tienen entre sus principios de acción la concertación consensuada entre sus miembros y la participación equitativa en la diferencia. 
democracia". Afirma que en el contexto de América Latina se viven dos tipos de lucha: "La coexistencia de luchas defensivas y luchas ofensivas, que distinguen la región en este momento, produce una turbulencia muy específica en el cuadro político democrático" (65). Las luchas defensivas son las que llevan a cabo los grupos marginados y vetados de participación sociopolítica, quienes sienten con mayor vehemencia los estragos de los modelos económicos. Estas luchas se orientan hacia la defensa de los bienes naturales y de las prácticas del lugar. En ese sentido, De Sousa Santos señala que

las luchas de vocación se manifiestan en los procesos [...] de la democracia participativa, comunitaria e intercultural; la democratización del acceso a la tierra; de la redistribución de las rentas de explotación de los recursos naturales; de la promoción de alternativas de desarrollo, como lo son el buen vivir (sumak kawasay o suma qamaña) o de la negación de la separación entre sociedad y naturaleza, concebida como Madre Tierra (la Pachamama) (2010: 65).

En el caso de los ambientes rurales en Colombia, se deben contrarrestar las asimetrías de poder tanto en la administración como en el uso de recursos naturales. Los consejos comunitarios de las cuencas de Curvaradó y Jiguamiandó, la Asociación Campesina de Buenos Aires y la Asociación Productora Alternativa del Simití son organizaciones cuyo funcionamiento parte de la consultación directa a los miembros para la toma de decisiones, es decir, apelan a prácticas de democracia directa en sus contextos locales, en las que se fomentan marcos de discusión y aquiescencia comunitaria. Las estrategias sobre cómo tratar las desavenencias y los desacuerdos con otros actores en el interior de la red funcionan en una perspectiva del manejo conjunto del conflicto. Al respecto, Chevalier y Buckles (2010) indican que la presencia de conflictos en las comunidades les alerta para reconocer singularidades, pero actuando por el bien común. Estos autores resaltan la distinción entre iguales como punto de adherencia al colectivo: la acción comunitaria está determinada por las diferencias que las comunidades de una red tengan con "el mundo exterior", representado en la estructura social. Existe una conciencia comunitaria muy clara de la diferencia, la equidad y la complementariedad, lo que se expresa con relaciones recíprocas de mutualidad en la búsqueda de intereses que favorecen a todos los miembros 
de la red. Como lo afirma uno de los líderes del Garzal, la comunidad logró permanecer en el lugar gracias a la participación, la información y el intercambio de todos los integrantes de la misma.

El trabajo en red, como hacen las comunidades de este estudio, se caracteriza por la implementación de mecanismos de interacción y de representación actoral para movilizar los recursos políticos y de poder. Al respecto, Kooiman (2003) plantea que las disputas que surjan de la interacción entre diversos actores tienen que ser solucionadas también con respuestas de esa misma diversidad y no de un grupo exclusivo. La interacción en redes es también una estrategia para ajustar las disparidades que se producen en el flujo de diferencias entre actores distintos (Cerrillo Martínez 2005). Si bien Agustí Cerrillo se refiere a la formación de redes en el contexto europeo, en donde estas están constituidas por actores públicos y privados, para nuestros casos es pertinente analizar las incidencias con relación a la red misma. Hay diversos planteamientos acerca de la red como concepto en los estudios políticos que son pertinentes a cualquier organización que emplee ese sistema. Algunos autores denominan las redes como "comunidades políticas" y otros apelan a la noción de "redes sectoriales", estableciendo diferencias en los niveles de cohesión. Más allá de la denominación, me importa observar la relación en términos de gobernanza y su incidencia en el ejercicio de la democracia en el contexto rural.

En el marco del conflicto, la Red de Iniciativas surge como un mecanismo de interacción y trabajo entre actores que han quedado al margen de los procesos de decisión y que son apoyados por organizaciones no gubernamentales como SUIPPCOL. Todos ellos son procesos que están articulados en torno al derecho a la tierra y al territorio. Treinta comunidades, entre comunidades de afrodescendientes, comunidades indígenas y comunidades campesinas mestizas, jóvenes y mujeres, conforman la Red. En su concepto, la paz es inherente al equilibrio natural territorial y se especifica en el documento Enfoque y propuesta de paz desde la base (Ruta Pacífica de las Mujeres et al. 2007) ${ }^{17}$ :

17. El documento "Enfoque y propuestas de paz desde la base" forma parte de los documentos del programa suizo SUIPPCOL que apoyó procesos locales de construcción de paz. Ese documento no se encuentra en la red. 
La paz para las comunidades la entendemos como la cohesión equilibrada y armónica con la madre naturaleza; y el escenario del territorio como espacio de creación y procreación de la vida como el todo integral y como el reconocimiento a la tenencia de la tierra, en donde libremente y de diferentes maneras se construye el proyecto de vida individual y/o colectivo. Donde se fortalece la cultura social, política y espiritual, desarrollada en un país pluriétnico y multicultural de las comunidades y organizaciones sociales rurales y urbanas de Colombia (8).

Se trata de una diversidad de actores que funcionan en el entorno regional y local y se constituyen en ejes de articulación. Los principios base de su trabajo se fundamentan en el respeto a la singularidad y la diferencia entre sus miembros, así como en los ejes temáticos que articulan el proyecto colectivo. El carácter pluriétnico redimensiona la construcción en el significado de equidad participativa y a través del enfoque específico que cada comunidad atribuye al concepto de territorialidad. La puesta en marcha de las acciones emprendidas por las comunidades tiene efectos en la conquista de espacios de gobernabilidad que pueden tener incidencia en la transformación del conflicto en diferentes niveles, por ejemplo, los siguientes.

Capacidad de generar propuestas o iniciativas: esto implica el conocimiento de los temas de conflicto, de su posicionamiento como actor y los instrumentos que puede habilitar para la negociación y el manejo. En consecuencia, se deben conocer o, como mínimo, informarse sobre las competencias de sus adversarios y los recursos e instrumentos con los que cuentan los diversos actores. La concientización sobre los puntos compatibles puede aportar a la transformación de las percepciones negativas sobre los oponentes.

Fortaleza de grupos sociales y ejercicio de la democracia: el trabajo en red posibilita una retroalimentación entre las debilidades y las fortalezas que posee una organización y la participación proactiva en el diseño de políticas públicas.

Reconfigurar los espacios y el ejercicio de gobierno: la redefinición de lo local-territorial, la distinción entre tierra-territorio, la integración de las diversas dimensiones, como la espiritual y la cultural, inciden en la reconfiguración de espacios rurales, así como en el uso y la administración de los recursos naturales. 
Nuevas dimensiones políticas sobre lo público y lo privado: el territorio como espacio de creación y de reproducción de conocimientos trascienden la perspectiva mercantil que le asignan otros actores a los recursos naturales. La valoración del dominio público se redimensiona y reconstruye la participación de los actores sociales y los poderes públicos respecto a sus derechos y también a sus responsabilidades.

Valor de legitimidad: las comunidades campesinas encuentran una plataforma para reconstruir sus capacidades de acción y función como actores sociales. El trabajo en red fortalece el ejercicio de sus derechos.

\section{Contenidos inconmensurables: paradigmas contrapuestos}

\section{TIERRA-TERRITORIO: CONCEPTOS}

Dentro del marco de las negociaciones para el Acuerdo Final de paz, se consideran para el primer punto, titulado "Hacia un nuevo campo colombiano. Reforma integral rural", catorce principios, de los cuales seis están estrictamente relacionados con los casos de las comunidades de este estudio: transformación estructural, desarrollo integral del campo, restablecimiento y regulación de la propiedad, derecho a la alimentación, participación, democratización del acceso y uso adecuado de la tierra (Nuevo Acuerdo Final). El concepto 'tierra-territorio' es una dualidad que prevalece para las culturas rurales, sean estas indígenas, afrodescendientes o campesinas, y es un fundamento que motiva el manejo del conflicto - tal y como lo han hecho las comunidades antes referidas - hacia la búsqueda de acciones transformativas para equilibrar las asimetrías de poder. En esa línea, los Programas de Desarrollo con Enfoque Territorial (PDET), concebidos en el Acuerdo de Paz (2016), pueden ser un instrumento que aporte a la inclusión y al diseño del ordenamiento territorial que proponen los distintos actores. Es indispensable tener claro que es necesario fomentar el desarrollo regional diferenciado según las necesidades y características de cada región.

Para las comunidades indígenas, la díada tierra-territorio está determinada por el ámbito sociocultural y jurídico-político. Respecto a lo sociocultural, el territorio es el espacio que fue proporcionado para 
habitar y allí están interconectadas la historia, la tradición, la espiritualidad y la comunidad. En lo jurídico-político, la figura del resguardo cumple la función de delimitar el territorio habitado, es decir, es la entidad territorial que goza de autonomía. La tierra es la gestora de un poder trascendental y una cultura propia que con el hombre-comunidad forma vínculos inquebrantables. La ruptura de ese lazo ancestral significaría la desaparición de la existencia comunitaria indígena. De acuerdo con el documento Enfoque y propuesta de paz desde la base elaborado por Ruta Pacífica de las Mujeres et al. (2007), "el Consejo Nacional Indígena de Paz considera importante distinguir entre tierra y territorio: la tierra es la Madre; el territorio es el espacio de vida, de relaciones con lo social, lo cultural y lo espiritual" (11).

Para las comunidades afrodescendientes, el territorio está compuesto por los mismos ámbitos. Respecto al primero, se refieren a la organización social y cultural y el aprovechamiento del entorno, que son el núcleo de su existencia y su permanencia como comunidad. Este ámbito sociocultural está conformado por elementos materiales, como el agua, la tierra y la fauna, e inmateriales, como el conocimiento y las costumbres. "Lo étnico-cultural orienta los procesos de apropiación territorial y constituye el eje conductor de la construcción de la paz, a través de sus planes de etno-desarrollo" (Ruta Pacífica de las Mujeres et al. 2007: 13). Este concepto está ligado a la asimilación de los recursos y a las formas de organización a través de la construcción social. Para las demás comunidades campesinas, el territorio significa

un espacio y escenario de cohesión, movilización y transformación social. Alrededor de ocho principios se construye y defiende el territorio campesino: integración, autonomía, vocería, movilización, democracia, identidad, historia y lenguaje (12).

El territorio permite la vida digna de las comunidades porque es el medio de trabajo, sustento y alimento y es el espacio en el cual se vivencian las prácticas campesinas que se constituyen en identidad y tradición de los pueblos rurales. El Mandato Agrario del 2003, que surgió en el Congreso Nacional Agrario y en el que participaron más de setenta y cinco organizaciones campesinas, se pronuncia contra la 
crisis nacional en el agro y la negativa al Área de Libre Comercio de las Américas (ALCA) y a los Tratados de Libre Comercio (TLC). En ese documento se estipulan el derecho a la tierra y el territorio:

El derecho a la tierra y el territorio es parte fundamental de la vida y la cultura de los pueblos y las comunidades rurales. Se garantizará este derecho a las comunidades afrocolombianas e indígenas y a los campesinos que han carecido de tierra o la tienen en cantidad insuficiente, así como a quienes la han perdido o a quienes teniéndola estén amenazados de perderla como consecuencia de la violencia, el latifundio o la quiebra de los productores. (Mandato Agrario 2003: 5)

En ese mismo documento, con relación al derecho a la territorialidad, se anota lo siguiente:

- Se reconocerá la diversidad e identidad cultural regional, local, étnica y la relación con la naturaleza y el ambiente como partes esenciales de la territorialidad. - La territorialidad no es solamente un concepto que hace referencia a lo local y propio, sino que incluye las relaciones con otros sectores y la capacidad de unidad con y entre las diferentes comunidades, pueblos y sectores sociales (8).

De acuerdo con un informe de la Comisión Nacional de Reparación y Reconciliación, la figura jurídico-política de la díada tierra-territorio está representada en las zonas de reserva campesina, ${ }^{18}$ promulgadas en la ley 160 de 1994. En el año 1996 se formalizó el establecimiento de estas zonas con el decreto 1777, cuyas áreas de delimitación serían fijadas por el INCORA. Posteriormente, se introdujo una modificación en el año 2007, limitándolas solo a las áreas de la frontera agrícola. En el actual Acuerdo Final de paz se estipula el uso de las zonas de reserva campesina para lograr la formalización masiva de la pequeña y la mediana propiedad rural. En términos de

18. Son zonas de reserva campesina las áreas geográficas seleccionadas por la junta directiva del INCORA teniendo en cuenta las características agroecológicas y socioeconómicas regionales. En los reglamentos respectivos se indicarán las extensiones mínimas y máximas que podrán adjudicarse, determinadas en unidades agrícolas familiares, el número de estas que podrá darse o tenerse en propiedad, los requisitos, las condiciones y las obligaciones que deberán acreditar y cumplir los ocupantes de los terrenos. 
formalidad constitucional, existen diversos artículos que definen esta figura de ordenamiento territorial y en donde no solo se les reconoce una función en las economías campesinas, sino también se describen como medida de conservación del medio ambiente y como elemento social porque preservan la cultura de las comunidades rurales. Estas zonas han sido creadas para contener o "cultivar las economías campesinas" y la concentración de tierras y ponerle freno al latifundio. Esta figura de ordenamiento territorial rural contempla la conservación y el uso de los recursos naturales dentro de la sostenibilidad. Su incorporación en el marco jurídico de la Constitución fue el resultado de las reivindicaciones campesinas por la tierra a mediados de los años ochenta para atender a los cuestionamientos de ordenamiento territorial y a la expansión de la frontera agrícola. La Asociación Nacional de Zonas de Reserva Campesina (ANZORC), que surgió en los años noventa y se reactivó a partir de 2011, lleva un proceso organizativo que muestra la eficacia de la gestión campesina. La zona de reserva campesina del valle del río Cimitarra es un modelo ejemplar, pues tiene un plan de desarrollo sostenible planeado para el año 2022 y contempla la conservación de la serranía de San Lucas.

Existe una figura casi paralela que son las zonas de interés de desarrollo rural, económico y social (ZIDRES). De acuerdo con la misma ley 160 de 1994, se hará un deslinde de los baldíos y no todos serán destinados a las zonas de reserva campesina, sino que serán utilizados como zonas de desarrollo empresarial en las diferentes regiones con el propósito de

permitir la incorporación de sistemas sustentables de producción en áreas ya intervenidas, conservando un equilibrio entre la oferta ambiental y el aumento de la producción agropecuaria, a través de la inversión de capital, dentro de criterios de racionalidad y eficiencia y conforme a las políticas que adopten los Ministerios de Agricultura y del Medio Ambiente. (Ley 160 de 1994, artículo 82) 


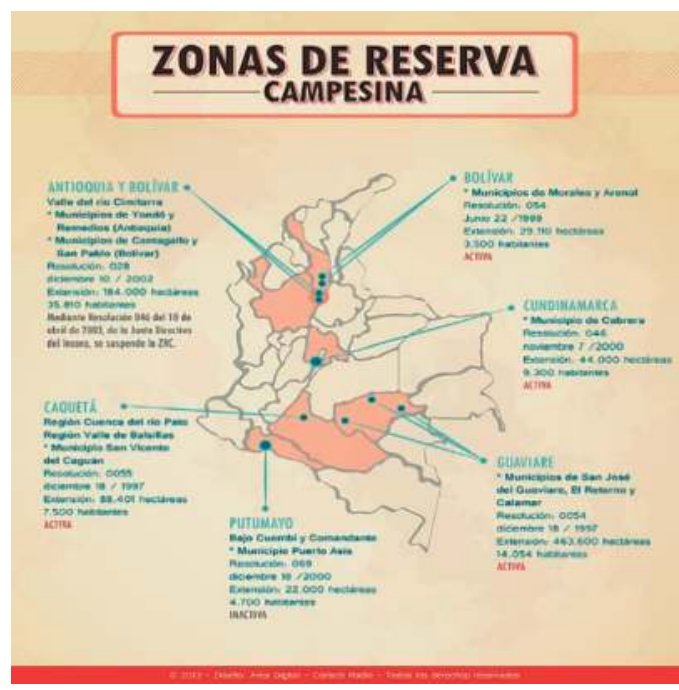

29. Zonas de reserva campesina

Fuente: tomado de Caracol Radio (2013) ${ }^{19}$

Según la descripción del decreto anterior, la zonas de reserva campesina tienen como propósito "superar las causas de los conflictos sociales que las afecten y, en general, crear las condiciones para el logro de la paz y la justicia social en las áreas respectivas", es decir, si los procesos de titulación de baldíos toman algunos conceptos de esta figura territorial, favorecerán no solo de la terminación del conflicto, sino la productividad y el bienestar locales con incidencia regional. Por el contrario, lo que ha sucedido hasta el momento es que el Gobierno ha favorecido el uso y el abuso de los terrenos baldíos para sembrados no sustentables y sin criterios de racionalidad, como se estipula en dicho artículo.

En el marco general del Acuerdo Final de paz, aparecen diferentes formulaciones que reiteran la necesidad de atender a las poblaciones rurales, que han sido las mayormente afectadas por el conflicto. Las

19. <http://www.caracol.com.co/radio/2013/07/16/media/1373986020_933902. html>. 
disputas por la tierra no se reducen exclusivamente a los actores en combate. La terminación del conflicto ayudará, sin duda, a liberar grandes extensiones del territorio colombiano que los grupos armados han controlado por mucho tiempo, pero el desafío que se plantea es cómo dar vía a proyectos que generen productividad y bienestar para las comunidades rurales y cómo recuperar esos territorios para actividades legales, que no vuelvan a caer bajo el dominio de grupos que controlen poblaciones y sus economías. El conflicto por la tierra no termina en el momento en que los actores armados entregan las armas: se empieza a transformar verdaderamente cuando se negocian salidas concretas con pautas vinculantes de participación y que favorezcan los intereses de los habitantes del campo. La restitución de tierras y el sistema legal de titulaciones en el marco de una paz sostenible solo serán posibles si se restablecen los saberes, los modos de vida y las relaciones comunitarias que le han dado sentido y significado a la tierra. Las estrategias de reterritorialización deben concebir la tríada campesinotierra-vida comunitaria como fundamento base de la implementación en el trabajo de restitución territorial. En los últimos tiempos, tras la firma del Acuerdo Final de paz (2016) con la guerrilla de las FARC, se han registrado un gran número de muertes de líderes campesinos y de organizaciones rurales. ${ }^{20} \mathrm{El}$ control territorial lo quieren seguir ejerciendo las bandas organizadas, sea de origen paramilitar o aquellas que quieren permanecer en economías ilegales, especialmente vinculadas al sector de la extracción minera.

Para hacer efectivos esos procesos de restitución, tienen que ponerse en marcha investigaciones de esclarecimiento de la verdad y de la no repetición. Si bien estos son misiones controvertidas de la Jurisprudencia Especial para la Paz (JEP) y están enfocadas a tratar los crímenes de lesa humanidad, no está claro el procedimiento ante la responsabilidad de algunas industrias de la usurpación por parte de territorios que han pertenecido a las comunidades.

20. Para más detalles, se puede consultar la siguiente dirección: $<$ http://www.resumenlatinoamericano.org/2017/02/09/lista-de-lideres-comunales-asesinados-en-colombia-desde-la-firma-del-acuerdo-de-paz/>. 
Segmentos de la industria y de la extracción minera que son promotores de esas dinámicas aprovechan en muchas ocasiones la ilegalidad o la legalidad disfrazada y utilizan empresas de seguridad para continuar con el despojo. En la Colombia rural se han introducido medidas llamadas reformas, cuando lo único que han ocasionado es la conservación del modelo latifundista y la concentración territorial en manos de unos pocos. Sin ser un caso aislado en América Latina, se puede constatar que las llamadas reformas agrarias no se han sido efectivas. En Venezuela, en 1960, se distribuyeron parte de los terrenos baldíos, pero no se tocó a los latifundistas. En Brasil, en 1964, en el contexto de la dictadura, restituyeron más tierras a los terratenientes, a quienes gobiernos anteriores les habían expropiado las tierras, que a los campesinos. También en 1964, en Ecuador, el Gobierno distribuyó las tierras más improductivas y facilitó así que los grandes terratenientes se quedaran con las mejores. En Argentina, los intentos de reforma del Gobierno de Juan Domingo Perón fueron anulados por la oligarquía, así que no tuvieron consecuencias en la transformación estructural del campo argentino.

En ese gris panorama de reformas, las fórmulas de los paquetes económicos, que parecen ser la solución al sistema asimétrico de distribución territorial, resultan fallidos: los créditos para que los campesinos tengan mejores condiciones de vida son una ilusión. Incluso la introducción de nuevas y mejores tecnologías para la agricultura no serán efectivas si permanecen intocables los regímenes de propiedad actuales: no sería un problema si existiera la voluntad empresarial y política para apostar por el verdadero bienestar campesino. Esas voluntades han estado ausentes en la historia agrícola, y en el acuerdo actual de paz no aparece suficientemente explícito cómo se va a confrontar el modelo del latifundio. Las alternativas de modificar la distribución territorial, que pueden generar nichos de convivencia en el país y productividad en el campo y frenar la excesiva importación de alimentos, pueden ser parcialmente viables si se parte de las propuestas que hacen las comunidades y las figuras que fortalecen los procesos locales, entre ellos las zonas de reserva campesina. 
TERRITORIOS, ESPACIOS Y GOBERNANZA: ¿LOCALES VS. GLOBALES?

En los estudios culturales, las reflexiones sobre espacialidad y movilidad dirigen su atención a los procesos y las dinámicas que tienen lugar en el espacio urbano y a la migración entre naciones. Algunos análisis exploran las relaciones que se establecen entre campo y ciudad, pero pocos se dedican a examinar exclusivamente el espacio rural. En Colombia y en otros países de Latinoamérica, desde hace ya más de dos décadas, gran parte de las problemáticas nacionales guardan alguna relación con los escenarios económicos y políticos que se crean en los ambientes rurales. Muchos estudios examinan las transferencias de valores y prácticas entre lo global y lo local: las circunstancias del contexto rural en el hemisferio sur ameritan efectuar ese mismo análisis, pero cambiando el punto de partida, es decir, observando qué transferencias se producen desde lo local hacia lo global. Esto significa indagar qué visiones del mundo emergen desde los espacios locales y qué contenidos discursivos representan la pluralidad y la particularidad culturales. Es importante tener en cuenta que muchas especificidades locales surgen no como resultado de impactos en la relación de fuerzas y las tendencias de unificación globalizantes (Martin Barbero y Herlinghaus 2000), sino como prácticas y saberes distintos que reclaman legitimidad y representación en los sistemas sociopolíticos y en la economía.

El manejo de los recursos naturales parece estar suspendido en la tensión entre prácticas globales y locales. Hemos identificado anteriormente los actores locales — comunidades campesinas-, con sus características específicas. Las empresas palmeras de origen nacional son actores que tienen el dominio económico para incidir en las decisiones respecto de la administración de los recursos naturales. El Estado, representado en sus diferentes instancias gubernamentales, ostenta el poder político que determina el manejo de los recursos, incluyendo los naturales. Las estrategias de la economía global han reformulado el papel del Estado en el escenario de los mercados internacionales. Comparto la idea de algunos analistas respecto a que el Estado no ha perdido poder, sino que ha cambiado las prácticas del mismo. Desde esa perspectiva, los preceptos democráticos, fundamentos del principio 
republicano, reproducen modelos de libertad, orden y justicia basados en la maximización de los bienes individuales. El papel regulador del Estado, que debería garantizar el derecho para la sociedad civil y nacional, queda cada vez más en la penumbra; por lo menos, en gran parte de las realidades del hemisferio del sur se puede constatar esa tendencia.

Las prácticas que emergen de grupos específicos y que se han vendido como globales se apoyan especialmente en un sistema que regula las economías de mercado a nivel internacional, es decir, la internacionalización de políticas económicas. Para adoptar estos ajustes, la mayoría de los Estados introduce reformas que se orientan hacia el paradigma de economía neoliberal, aplicadas en diferentes ámbitos. Uno de los puntos neurálgicos son los procesos de decisión política que tienen lugar en los espacios nacionales: los grupos de influencia económica, tanto a nivel nacional como a nivel internacional, mantienen las fronteras de los acuerdos casi de manera exclusiva con el aparato estatal. Las discusiones democráticas en torno a la economía de mercado quedan reducidas a estos dos actores, con lo cual el resto del capital social nacional, grupos sindicales, asociaciones campesinas e indígenas, entre otros, queda al margen de esos procesos, aunque exista reglamentación jurídica que estipule mecanismos de consulta para desarrollar proyectos a las localidades rurales; es decir, se produce un efecto de despolitización de los medios, de los recursos y, en general, del fuero económico de la sociedad civil. Es más, la tendencia es deslocalizar, cada vez más, esas discusiones, lo que significa sacarlas del ámbito nacional. Ese hecho tiene repercusiones directas en los actores de la sociedad civil y en la creciente disminución de sus competencias en el contrato social.

El nuevo orden económico global supone un ordenamiento local que dispone los espacios de concentración de recursos en función de los órganos de poder. Solo en el seno de ese marco es posible entender que el índice de gobernanza de los recursos naturales, ${ }^{21}$ en el cual

21. En un reciente estudio realizado por la agencia Revenue Watch Institute, se evalúa la gobernanza usando el índice de gobernanza de los recursos naturales (Revenue Watch Index RGI9), donde se estudia la calidad de cuatro componentes: marco 
Colombia ocupa el noveno lugar, incorpore elementos de validación que desconocen los impactos locales en términos sociales. En este escenario, la gobernabilidad, lejos de ser un discurso en construcción por las fuerzas sociales públicas y privadas, se convierte en un discurso exclusivo de actores que dominan el poder público y el poder económico. El informe "Colombia rural. Razones para la esperanza" (PNUD 2011) indica que "el poder político está sobrerrepresentado por los terratenientes y los propietarios en las instancias legislativas y normativas [...]. El Estado colombiano por acción y omisión ha sido cómplice de esos deberes y no ha tomado decisiones políticas que posibiliten el cambio de la tenencia y distribución de la tierra" (195).

La participación es uno de los principios fundamentales de la gobernanza, que en el marco de ese contexto queda socavada, y no podemos contemplarla sin el poder de decisión y la incorporación de actores directamente implicados, como lo son, en este caso, las comunidades rurales. Si se dan procesos de participación en el manejo de los recursos naturales (sea en monocultivos, actividades extracción u otros), estos se limitan a usar mecanismos de adhesión, lo que quiere decir que las comunidades estarían casi obligadas a incorporarse a procesos de acción ya puestos en marcha, no a procesos de decisión y consulta previa, como está estipulado por la ley. Incluso las consultas populares, si bien tienen el poder de veto, no les permiten a las pequeñas poblaciones tener pleno derecho sobre los recursos naturales de sus territorios.

Se trata de un flujo de transferencias, que, de acuerdo con Bruno Latour (2016), se constituyen en parte de una invención —europeapara la dominación conocida como globalización, de tal manera que los modelos económicos se imponen con carácter homogéneo en latitudes y territorios geográfica y culturalmente diferentes. Como se ha documentado en el caso de las plantaciones de palma, la participación de las comunidades se entiende como su vinculación a las cooperativas ya establecidas o las alianzas estratégicas propuestas por las empresas. En las zonas humanitarias, incluso el mecanismo de consulta estipulado en la ley no fue utilizado ni respetado por las empresas y,

legal institucional, prácticas de reporte, controles de calidad y de salvaguarda y ambiente favorable. 
en Las Pavas, el consorcio El Labrador no contempló los litigios sobre la tierra previos a la compra de los terrenos; por tanto, el contacto con la comunidad se buscó solo para concretar los costos y los beneficios económicos que sus miembros podrían recibir y acordar si se vinculaban a la empresa como trabajadores o socios. En las zonas humanitarias no hubo ni siquiera ese tipo de participación. Las comunidades que hemos examinado en este estudio proporcionan elementos concretos para reconstruir los conceptos de gobernanza y democracia a partir de valores, normas y estructuras definidas con características locales y regionales, formuladas en el ejercicio de las acciones que las poblaciones mismas han emprendido. Sus conceptos de espacialidad y continuidad comunitarias contemplan el uso de la tierra en la multidimensionalidad que vincula la tríada tierra-campesino-comunidad de relaciones recíprocas, en la que se expresa lo sustancial a través del valor étnico, cultural, social, organizativo y colectivo. Eso no implica que las poblaciones rurales no quieran los beneficios que pueda representar para la agricultura el avance tecnológico y el acceso a otros conocimientos sobre el manejo, la producción, el sembrado y la comercialización, entre otros aspectos. Esa es, paradójicamente, una de las razones por las cuales las comunidades se manifiestan, pues los beneficios de ese progreso no están puestos al servicio de la cultura agrícola campesina, sino exclusivamente de la industria agrícola. 



\section{Capítulo VII}

\section{Representación en la lírica musical: contenidos y dinámicas del conflicto}

Este capítulo final se orienta a indagar qué se representa en los cantos y cómo responde a la imperante necesidad de comprender los significados y las proposiciones que plantean las comunidades a través del arte. Gran parte de la tradición oral recopila vivencias individuales y colectivas que interconectan dos universos: el fáctico-contextual y el lírico-narrativo. A diferencia de muchos análisis en los cuales el texto - entiéndase, texto lírico- es el centro en sí, el presente estudio integra también el contexto de elaboración, el proceso de recepción y la interpretación de los cantos compuestos en las comunidades. Esa integración constituye una parte importante de la acción comunicativa del texto lírico. En la categorización que se presenta en la ilustración 18 se observa que dentro de los catalizadores del conflicto aparece en la lista "la resignificación en el arte musical o en otros tipos de arte". La producción de material artístico es uno de los elementos que permite comprender cómo los actores del conflicto viven, afrontan y producen significados para reconstruir sus vidas tras el desplazamiento forzado. 
En este capítulo veremos en detalle cómo las composiciones construyen una lírica que narra el antes, el durante y el después del conflicto. En los cantos encontraremos proposiciones subyacentes que manifiestan percepciones sobre las interacciones de los actores, experiencias sobre lo divino y lo supranatural, significados de la territorialidad, etc. La composición lírica, como se ha explicado en el capítulo sobre música y conflicto, es un instrumento para lidiar con el duelo, reconstruir la memoria colectiva, mitigar las pérdidas, comunicar niveles cognitivos y emotivos, estimular acciones e iniciar procesos de construcción del retorno. La música representa en Colombia una de las estrategias de convivencia para crear melodías para la paz.

\section{¿Quién canta?}

Una obra artística, sea individual o comunitaria, posee vínculos con un contexto referencial. Manuel Alberca sugiere que "la obra literaria no puede ser un espejo fiel, sino un complejo juego de espejos que se reflejan unos a otros, sometidos a las más extrañas deformaciones" (2007: 63). Si nos trasladamos al terreno de lo musical, vemos que el canto difiere del texto escrito en cuanto a las formas de recepción y el origen de su naturaleza; es decir, se trata de otro género. El autor, como lo manifiestan los textos líricos del corpus, es la figura que canta lo vivido y que puede testimoniar los acontecimientos, una instancia donde se reelabora y se resignifica la experiencia de la comunidad y se expresa a través del canto; es decir, no hay un deslinde total entre la voz lírica y el cantautor. La autoría en estos cantos posee matices culturales que difieren de los paradigmas en los cuales se producen los textos escritos de la tradición moderna: rebasa la figura del autor individual porque la creación de sentido y el significado de lo experimentado se vincula con una concepción arquetípica de lo colectivo, en donde se funden el yo y el nosotros.

En los cantos de vallenato (que son aproximadamente veinticinco de un repertorio de treinta y siete) se puede observar que el yo representa una colectividad: "nosotros el campesinado". Es posible identificar en esa voz lírica un cambio de roles, ya sea en la voz de un campesino 
— "campesino bonaerense", "mi pueblo"-; en el nombre propio de un campesino - "Martín Valiente" —; en la naturaleza — "la voz en la montańa", "el mico desplazado", "la guartinaja"—; en la voz de la comunidad — "mi pueblo", "pueblito"—; en la condición actual — "desplazado"—, o en el artista — "cantor" -

En las poblaciones rurales con identidad comunitaria, el canto es un bien común. En estas composiciones líricas se constata también lo que señala Antonio Sánchez Romeralo (1989) sobre el mérito de la poesía oral: "Su funcionamiento en el contexto propio de la poesía oral tiende a hacer de esta un bien común, de grupo, res ómnium, cosa de todos, no apropiable por ninguno. La voz une y exalta el sentido de la comunidad, lo que en el acto vital de la dicción o el canto se siente como común y propio" (20). El canto es un patrimonio estratégico para revelar el destierro del hábitat y el anhelo del retorno al lugar, el profundo sentido de pertenencia y la unión con el territorio. En las composiciones de las zonas humanitarias, la voz lírica transita entre la segunda persona del plural — "nosotros campesinos" - , la tercera del singular — "él", "ella"— y la primera del singular —el "yo" testigo—. En su rol de testigo, ese "yo" evalúa la situación del desplazamiento, contrapone la historia y su presente y proyecta la acción comunitaria hacia un futuro que es el retorno.

El acto comunicativo en el que se configura la composición vallenata adopta una pluralidad de voces que cuentan y cantan, expresan una relación de la vocería con su entorno. Las relaciones se refieren a lo que define a la comunidad como cultura medioambiental: "Chocó", "la tierra", "los ríos", "las montañas", "cuencas", "campesino de verdad". Los impactos hacia la cultura campesina se ven en expresiones como "todos los desplazados hermanos", "a mi pueblo desplazado", "lo que hay es desplazados", "vienen matando campesinos", "yo soy un campesino desplazado" o "compraron las tierras del campesino". Esas expresiones no solo pretenden revelar lo que está sucediendo en el campo, sino que se concentran en una reflexión acerca de los medios que se utilizan y de las relaciones de poder de quienes intervienen, como se aprecia en las siguientes frases: "Por esa maldita palma, que nos han venido a matar", "yo creo que el hambre los va a matar" o "por medio de los empresarios hemos sido amenazados”. La voz lírica se manifiesta 
a sí misma como metáfora de representación, pues existe una profunda necesidad de ser escuchado ante la experiencia de despojo. En relación a las sensaciones sobre el desplazamiento, John Paul Lederach (2010) anota: "Muchas víctimas de la violencia experimentan un profundo sentido de impotencia [...]. La voz como metáfora tiene una asociación con términos como inclusión, poder y con significado" (65). ${ }^{1}$

\section{Lírica testimonial}

En la mayoría de los cantos vallenatos y de rap que se han recolectado en este corpus se pueden identificar rasgos muy similares a los que posee la literatura testimonial. ${ }^{2}$ Sin embargo, existe una diferencia fundamental: mientras en la literatura testimonial siempre hay una figura mediadora que se encarga de reunir la información contenida en el texto, en el canto no se requiere de esa figura. Lo que hace más fidedigna la construcción del relato, porque aquí quien canta es la misma persona que ha creado la letra de la composición. Como lo hemos visto en la tipología que se presentó en el capítulo III, las letras se refieren a temáticas sociales, reiterando la función política del canto: se revelan datos como fechas de los acontecimientos o nombres de los sitios en donde estos han tenido lugar. El relato cantado recurre a las marcas testimoniales para aportar veracidad, contando lo que se ha visto o escuchado: "Lo que aquí nos sucedió", "lo que pasó en la cuenca del Jiguamiandó", "el martes treinta de marzo", "son ciento veinte personas las que han asesinado", "Martín Valiente se encuentra muy tiste porque el 14 de julio la palmera lo desplazó", etc.

1. La traducción es mía. El texto original en inglés es el siguiente: "Many victims of violence experience a profound sense of powerlessness [...]. Voice as metaphor has association with terms like inclusion, power and meaningfulness".

2. Renato Prada Oropeza (1986) distingue cuatro características para identificar los textos testimoniales. Si bien en los cantos hay algunos de estos elementos, no existe un mediador que haya transformado los textos para llevarlos a la escritura, por lo tanto, no los catalogo como literatura testimonial, pero sugiero la expresión lírica testimonial. 
En las entrevistas que realicé a varios miembros de estas comunidades, muchos relatos se centraban en la necesidad de resignificar lo que en la sociedad colombiana denota y connota ser campesino. Los relatores contaban con pesadumbre cómo las actividades del campo ocupan un lugar residual en el imaginario nacional, como ya se hizo referencia previamente. Existe una preocupación de fondo de la población rural por encontrar una interlocución, especialmente en el interior de otras narrativas nacionales. El canto opera como un espejo en el que se refleja la naturaleza del habitante rural, pues existe un trayecto narrativo del sentimiento en el cual canto y vida se retroalimentan. La composición lírica le permite al campesinado representar sus realidades y se convierte en parte del proceso mismo de transformación ante el conflicto. Al respecto, Martín-Barbero y Herlinghaus (2000) se refieren a lo que permanece en el cambio y a lo que cambia en la permanencia. En esa mutación existe, definitivamente, un dinamismo trasformador que no altera lo tradicional, sino que, por el contrario, lo enriquece.

Plasmar en el canto la posibilidad de reelaborar y superar el trauma es uno de los cometidos con los que cumplen estas composiciones. Sin embargo, no basta considerar la creación artística como terapia del dolor, pues en ella subyace un terreno en el cual se entrelazan relaciones espacio-temporales y acontecimientos de la construcción sociocolectiva. Los cantos muestran las tensiones dentro de una estructura de fragmentación en la que el imaginario comunal campesino interactúa, busca rearticularse y quiere ser representado dentro de la diversidad de la cultural nacional.

\section{¿A quién se le canta?}

La voz lírica del canto busca un "encuentro con un destinatario implícito o explícito al que se quiere afectar mediante un mensaje elaborado literariamente" (Castillo 2010: 112). No siempre aparecen de forma explícita los destinatarios a quienes va dirigido el relato lírico, algunas veces va destinado a una persona específica y en otras ocasiones a un oyente implícito. Pero lo interesante es, en efecto, el contrato discursivo presupuesto en la canción vallenata, melodía en la cual están 
compuestos la mayoría de estos cantos. A este respecto, Escamilla, Morales y Grandfield (1993) señalan: "El contrato discursivo de la canción vallenata no es más que ese 'ritual sociolingüístico' relacionado con las prácticas sociales propias de la comunidad en que surge” (40). La mayoría de los cantos del corpus seleccionado contiene en su relato uno o varios destinatarios. Esta gran pluralidad de oyentes manifiesta la apertura de diálogo e interlocución que entablan las voces de las comunidades con los diferentes actores sociales. Muchas veces se trata de una forma de conversación que establece el intérprete con su audiencia, pero se pueden encontrar también formulaciones en imperativo o inquisiciones sobre actos realizados por esos oyentes: el universo lírico se construye de exhortaciones y querellas.

Uno de los destinatarios que aparece especialmente en los cantos de las zonas humanitarias es el Gobierno, que está algunas veces representado por la figura del poder ejecutivo — "señor presidente" - o se apela al nombre propio - "doctor Samper", "doctor Uribe"-. En algunos pasajes se hace referencia al Estado, no al Gobierno. Uno de los cantos toma como título el programa presidencial "El gobierno de la gente", del ex presidente Ernesto Samper (1994-1998) durante su mandato. Otros destinatarios a los que se hace referencia son "los empresarios", "el campesino", "el labriego", "el pueblo", "el niño", "los animales", "las organizaciones", "el proceso", "los actores armados", "Chocó", "hermanos míos", "la gente que no valora al campesino" y "Dios". En la mayoría de cantos existe más de un destinatario.

En la comunidad El Garzal, la composición musical está vinculada a la práctica religiosa: todos los cantos tienen como destinatario principal a Dios. Este hecho no es sorprendente porque, por un lado, el carácter religioso se manifiesta en el repertorio narrativo del vallenato y, por otra parte, la dimensión espiritual está presente en las líricas populares, especialmente en las más autóctonas. Un aspecto importante con relación a la dimensión religiosa es que, en la práctica de la fe, el canto es entendido también como una forma de comunicación de lo supranatural con lo humano y construye un simbolismo que expresa la relación entre esas dos entidades.

Como hemos visto en la tipología propuesta en el tercer capítulo, las temáticas se dirigen hacia distintos personajes en el texto lírico, 
construyendo y ordenando el discurso de forma diferente. Si pensamos en la composición de algunos de los cantos, aquellos que se refieren a los adversarios inician el relato señalando sus acciones de agresión. Las composiciones que siguen este esquema están elaboradas como discursos retóricos que apelan a una sentencia. El género judicial pertenece a la práctica retórica y, como lo anotan Antonio Azaustre y Juan Casas, "está encarnado básicamente por los discursos pronunciados ante el juez; el objetivo del orador es acusar o defender en torno a la alternativa justicia vs. injusticia” (2006: 14).

Los cantos cuyo destinatario es la comunidad se enmarcan en un discurso demostrativo que exalta su proceso y los diferentes mecanismos que emplean para afrontar el conflicto sobre la tierra. Las composiciones en las que se enfatiza el objeto de contienda tienden a reconstruir el relato lírico a partir de la deliberación: abundan las proposiciones reflexivas, por lo cual es posible encontrar ideas opuestas sobre lo que es útil y perjudicial para las comunidades en relación a los usos y el manejo de los recursos naturales. Nuevamente la voz, como metáfora de interlocución, sirve de conexión en términos de tiempo y de espacio. Al presentar un destinatario, la voz lírica dibuja reciprocidades que rompen la idea de soledad y desamparo. En palabras de John Paul Lederach:

La voz se organiza alrededor de una metáfora fonética y auditiva. Es interesante que el sonido es multidimensional y multidireccional. Él envuelve y puede crear una sensación de ser captado. [...] Cuando la gente habla de la voz como conexión de cambio a nivel comunitario, ellos usan el lenguaje del eco: la sensación de sentir que el sonido emerge desde dentro y toma la forma de palabras que entran a un espacio compartido [...]. En este proceso la gente participa en la creación de resonancia (2010: 67). ${ }^{3}$

3. La traducción es mía. El texto original en inglés es el siguiente: "Voice organises around an aural, sound-based metaphor. Sound, interestingly, is multidimensional and multidirectional. It surrounds and can create a sensation of being held. [...] When people speak of voice as having connection to change at the community level they use the language of echo: the sensation of feeling sound rise from within and take the form of words that enter a shared space [...]. In this process people participate in creating resonance". 


\section{Contenidos transversales}

Podemos identificar ejes temáticos de los cantos, en los cuales hay subtemas e ideas específicas que son seleccionadas por los cantautores para construir su mensaje. En la parte introductoria a cada comunidad, he realizado una primera aproximación a las temáticas de los cantos que han compuesto algunos de sus miembros, ahora veremos cuáles son los tres temas transversales y las relaciones que los agrupan:, como se observa en la ilustración 29.

Los temas se distribuyen de esa manera porque es la articulación que se encuentra presente en el corpus. Esa conexión no es unívoca, sino que se intercambian y matizan los discursos dando mayor expresión a una de las tres tipologías que se describen previamente en el capítulo tercero:

\begin{tabular}{|c|c|c|}
\hline Cultura agrícola & $\begin{array}{c}\text { Desterritorialización } \\
\text { y retorno }\end{array}$ & Clase campesina \\
\hline El trabajo & El desplazamiento & El saber \\
La memoria & La naturaleza & La lucha \\
El sembrado & La etnicidad & El dolor \\
El futuro local & El territorio & El proceso campesino \\
El proyecto comunitario & La tierra & La resistencia \\
La lucha en el campo & El retorno & La experiencia \\
El monocultivo & El poder & La espiritualidad \\
El territorio & & Valor y antivalor \\
& & La agresión \\
& & Las creencias \\
\hline
\end{tabular}

30. Temas transversales en los cantos Fuente: elaboración propia 
Sistema de equivalencias: nuevos significados del agro y los agricultores

Es pertinente iniciar este análisis refiriéndonos a la estrategia metadiscursiva recurrente en todo el corpus. La memoria se almacena a través del registro cantado y contado. El ejercicio lírico se toma como objeto de interlocución y de acción de forma simultánea. La reiteración de la misma acción sugiere la personificación de la voz en el canto, como lo ha señalado John Paul Lederach (2010): la voz, en los cantos, parece ser una metáfora de sí misma. Observemos el siguiente fragmento:

\author{
Es aquí donde tengo la oportunidad \\ De hacer las canciones y cantarle a mi pueblo. \\ (Monchi Pavero, "Campesino de verdad") \\ Cantándole sigo yo \\ A mi pueblo desplazado \\ Debemos vivir unidos \\ Para volver al Chocó \\ Porque esa tierra querida \\ Nos la dio nuestro Dios \\ (Augusto Gómez, "Cómo fue”).
}

Como se observa en los dos fragmentos anteriores, el canto se convierte en el vehículo que tiene la facultad de mantener viva la cultura agraria, el instrumento de interacción intracomunitario ante la adversidad. La situación de desplazamiento se pondera como metadiscurso lírico a la vez: el "aqui" reactualiza la necesidad de darle continuidad a la ruptura que ha causado el desarraigo, pero también se manifiesta como voz-sonido y posibilidad, tanto de expresión como de interlocución. La convergencia de voz y práctica agrícola se reitera en diferentes pasajes. El inicio del segundo fragmento, citado anteriormente, utiliza el hipérbaton para invertir el orden sintáctico de la frase y así enfatizar la acción — "cantándole sigo yo"-, de tal manera que se refuerza el cantar como acción alternativa para enfatizar la preservación de la cultura agrícola en "aquí". 
El yo lírico se compone de una voz que se articula entre esos dos espacios: canta contando y cuenta cantando. El cuento contiene una fuerza constitutiva en lo generacional, por lo que "aquî" aparece no solo como testimonio - como se señaló antes—, sino que cumple una función adicional de enlace temporal. Este hecho indica que la oralidad, como parte de la construcción histórica propia y significativa de la vida rural, se revitaliza a través de la música.

Con respecto a la transmisión de la historia, se pueden encontrar dos estilos de composición que organizan la construcción semántico-lógica de estos cantos: en algunos, corresponde a un relato estructurado temporalmente, así que cada parte estructura un razonamiento propio y autónomo, mientras que en otros predomina un estilo suelto en el que se suman diferentes ideas que se coordinan entre sí. El primer estilo predomina en composiciones que focalizan el relato de la agresión y el segundo es habitual en los otros tipos de relato lírico. En algunas ocasiones, la historia se condensa en una especie de microrrelato:

Les vengo a contar la historia

De nuestro desplazamiento.

(Augusto Gómez, "Cómo fue")

Les voy a contar la historia que ha pasado aquí en mi pueblo Me quemaron la casita que tenía yo en Las Pavas

Por culpa de las palmeras he quedado a la deriva Por culpa de las palmeras tengo un dolor en el alma.

(Monchi Pavero, "Algún día es mañana")

En este fragmento, el recurso metadiscursivo — "les voy a contar"tiene la intención de involucrar al oyente y lograr su atención. De los cuatro versos que componen este microrrelato, dos condensan el hecho histórico y los otros dos recogen actores y sentimientos que forman parte del universo lírico. Estos microcuentos construyen el principio y el fin del universo lírico en unas pocas líneas. Allí aparece no solo la dimensión espacial del contenido factual, sino la dimensión temporal que vincula la duración y el momento de lo sucedido. Respecto a la brevedad de estos relatos, no solo en el discurso lírico, sino en general, Lauro Zavala señala: "Hoy en día, la brevedad es una virtud. Y en la 
escritura contemporánea algunas formas de ficción ultracorta alcanzan una riqueza y una complejidad extremas" (2007: 129).

\section{La cultura agrícola campesina}

Una de las macroproposiciones que se encuentra al rastrear el material del corpus es la oposición cultura agrícola versus industria agrícola: la agricultura concebida como actividad industrial extractivista destruye la cultura agrícola campesina.

En los fragmentos anteriores, la voz lírica focaliza su mensaje en el tópico de la destrucción. En los dos últimos versos, se repite "por culpa de las palmeras" para reiterar la responsabilidad del causante del conflicto; se distingue su sensación de tristeza: "un dolor en el alma" y la pesadumbre por la pérdida del terruño: "he quedado a la deriva", es decir, sin orientación ni rumbo. La expresión de dolor confirma la ruptura del entorno agrícola en la hacienda: "Las Pavas". El destrozo no solo está presente en la separación de la díada campesino-tierra, sino también en actos de agresión concretos: "me quemaron la casita que tenía yo en Las Pavas".

En algunos de los pasajes se nombran explícitamente los actores involucrados, mientras que en otros se tematiza la actividad del monocultivo. Las proposiciones que se construyen en estas dos estrofas representan un discurso declarativo en el que subyace la lógica de contrarios: la presencia del monocultivo equivale a la ausencia (despojo y muerte) de los campesinos y, por lo tanto, la muerte también para la cultura agrícola. Estas lógicas no son coexistentes, sino excluyentes, su formulación se hace a través de la antítesis de valores contrarios. Esa oposición remite al valor que se le da a tierra: en el caso de los agricultores, es útil porque representa diversas dimensiones de su cosmovisión, a las que las comunidades denominan territorio, y el agricultor se sitúa en un marco de utilidades recíprocas donde él también interactúa y crea utilidad; en el caso de la industria extractiva, la valoración se reduce a la rentabilidad que se deriva de la producción agrícola. Mientras los agricultores adaptan sus estilos de vida y patrones de subsistencia a los ciclos naturales, la industria quiere adaptar la naturaleza a sus necesidades, orientadas al 
excesivo consumo y a la generación de riqueza. Si analizamos esta representación lírica en relación al manejo del conflicto y las posibilidades de negociación, encontramos que estas dos lógicas son opuestas, pues sus juicios de valoración surgen de epistemes diferentes.

\author{
Por esa maldita palma \\ Nos han venido a matar (bis) \\ El cultivo de la palma \\ Es un cultivo ilegal. \\ (Erasmo Cuadrado, "La palma”)
}

La consideración del cultivo de palma como ilegal, que plantea el cantante lírico en el ejemplo anterior, introduce una nueva dimensión: resalta la diferencia entre la cultura agrícola y el uso de la industria foránea, desligada de los contextos locales. El acto de deslegitimación se refiere a los procedimientos del sistema político y jurídico que legalizan aquellas prácticas que descomponen grupos sociales, especialmente en el entorno rural. Es justo allí en donde la significación de lo local interactúa a través de la voz lírica para manifestar y reivindicar un panorama alternativo que les dé validez a los fundamentos de la ontología campesina.

El despojo y el desplazamiento forzado subyacen como temas principales en el entramado lírico y están entrelazados con los efectos que estos causan en el quehacer agrario: la defunción de la práctica agrícola, que es la base del sustento alimentario y uno de los mayores bienes culturales. Muchas comunidades rurales subsisten gracias a los cultivos de pancoger. El cambio del uso agrícola al industrial quebranta la relación entre recursos naturales y campesinado y se vuelve incompatible con los preceptos recogidos por la memoria cultural agrícola, como se expresa en las siguientes estrofas:

\footnotetext{
Me arrancaron el mafufo, el cacao y también la ahuyama

Todo eso lo destruyeron pa' sembrar palma africana

En el tiempo que cultivaba, me sentía muy contento

La comida me sobraba y también el bastimento

Pobrecita de mi vida y hoy no tengo que comer

No tengo pa' la panela y me hace falta el café

(Orlando Ospino, "Historia de mi vida").
} 
Explorar más en profundidad las representaciones de la memoria agrícola significa descubrir distintos grados y dimensiones de la incidencia entre las prácticas globales y las locales. Los nuevos usos del agro manifiestan una afectación en diferentes niveles: el tema de la soberanía alimentaria es un tópico que se expresa claramente en varias composiciones. Nuevamente encontramos aquí una relación de opuestos; en este pasaje se contrapone la idea de abundancia a la de escasez: "la comida me sobraba"/ "hoy no tengo que comer". La escasez se sitúa en la espacialidad agrícola del territorio: "todo eso destruyeron". En ese proceso de destrucción, el espacio agrícola, que antes era de la comunidad, ha sido invadido pues se le da otro uso: "pa' sembrar palma africana”. Los impactos en el ámbito nutricional y alimentario se están dando en muchos países del continente. La devastación del panorama agrícola es análoga a la del hábitat local, entre un pasado sosegado y un presente yermo, como se observa en el pasaje anterior y en los primeros dos versos del siguiente fragmento:

\author{
Aquí solo ahora se pueden ver \\ Colegios sin niños y casas sin mujer \\ Razón del destino marcado ayer \\ Por las palmeras, el nuevo cartel \\ (Efraín Alvear, "Lamento por mi pueblo").
}

En la primera parte de la estrofa anterior, la voz lírica ilustra la desolación que ha traído consigo la agroindustria: a través de "colegios sin niños y casas sin mujer". La primera parte expone la idea de vacío, en donde existe la materia, "casa", "colegio"; pero ha desaparecido la esencia humana y, por lo tanto, la vida. En el verso posterior, "razón del destino, marcado de ayer", se recupera la perspectiva temporal, dando la idea de un tránsito progresivo hacia lo inerte y reforzando la idea del vacío antes introducida.

"Cartel" se plasma como figura a través de la cual la voz lírica denota la irrupción de prácticas mercantiles autoprotegidas que regulan la distribución, el uso y el funcionamiento de su territorio: una nueva composición de empresas que disponen de los bienes territoriales para el monocultivo de palma. La connotación de ilícito se hace presente una vez más en el canto, es decir, se pone en cuestión lo que está visto 
en el sistema económico como algo legal. Ese carácter legal que se les da las actividades extractivistas atenta contra la integridad y existencia comunitaria de los habitantes rurales. La noción del cartel sugiere una serie de informaciones implícitas: la existencia de una red de actores y factores que favorecen una gobernanza foránea y que ocasionan desequilibrios en los aquí locales y transforman las fuentes de producción de sembrados para un allá,. referido este a la práctica global que se apropia de los recursos naturales e impone el modelo neoextractivista que ya se ha mencionado anteriormente.

Los relatos líricos describen relaciones antagónicas entre un "nosotros" y un "ellos", como la incompatibilidad entre destrucción y trabajo. El trabajo en la tierra, con la tierra y por la tierra aparece de forma reiterativa en la mayoría de los cantos. La imposibilidad de trabajar a consecuencia del despojo no se expresa como una insuficiencia de recursos naturales, sino como una carencia de oportunidades: "Ya no dejan trabajar al pueblo campesinado" o "mis hijos también se fueron, no había donde trabajar". El trabajo en torno a la tierra es expresión de la acción comunitaria: este es uno de los planteamientos preponderantes que, en el caso de la comunidad del Garzal, aparece como estrategia para evitar el desplazamiento, como lo presenta el siguiente fragmento:

\author{
Muchachos a trabajar \\ Pongámosle fin a esto \\ Todos juntos hay que sembrar \\ Para reforzar el proceso \\ Porque si no trabajamos \\ No podemos ayudar \\ A Rafa y a Salvador \\ Y a la demás entidad. \\ (Daniel Mendoza, "Los veinte años de lucha”)
}

\title{
La desterritorialización
}

La relación entre campesino y naturaleza —entendida como territorio- está lejos de ser idílica y armónica, como se pudiera pensar: los cantos revelan ese vínculo como una interacción de fuerzas en las que el campesino es puesto a prueba. Las inclemencias climáticas se suman 
a la precariedad de instrumentos tecnológicos para enfrentar dichas adversidades. Esa valentía con la que se autodescribe el campesino se contempla como resultado/consecuencia de los conocimientos trasmitidos y adquiridos de generación en generación y como fruto de la experiencia de la población rural al compenetrarse profundamente para interpretar el lenguaje de la naturaleza y adaptarse al entorno agreste, como se observa en el siguiente fragmento:

\author{
Martín Valiente era un campesino bravo \\ Que a las montańas de Las Pavas se le midió \\ No le importaba que el tigre lo asechara \\ Y en su matica de caña Martín se refugió \\ (Monchi Pavero, "Martín Valiente").
}

Se podría decir que es una relación de sometimiento mutuo, ya que la naturaleza tiene esa característica dual de ser depredadora y protectora a la vez, por eso el hablante lírico nos canta que Martín puede refugiarse en "la matica". El uso del diminutivo también se presenta con frecuencia en las composiciones; aquí muestra afecto.

El lenguaje cotidiano y regional está presente en todas las composiciones. La actitud del campesino Martín implica tanto riesgo como valentía para sortear lo inesperado, lo que expresa la habilidad de la población rural para afrontar los desafíos de la naturaleza, como las inundaciones - "porque es que el bendito, río no nos deja trabajar"-, que aparecen en la siguiente estrofa:

\footnotetext{
Aquí veinte ańos de lucha

De lucha, pero con paz

Porque es que el bendito río

No nos deja trabajar
}

(Daniel Mendoza, "Los veinte ańos de lucha").

El río se presenta como símbolo de alerta para el campesino, la denotación semántica del caudal y la inundación juegan un doble papel respecto al contenido discursivo: por un lado, representan la dimensión propiamente ambiental en las consecuencias que sufren las poblaciones rurales y, por el otro, la simbología del tiempo y el caudal del río componen una imagen que ilustra el desbordamiento en una 
doble vía, la climática y la social. Las imágenes con las que se asocia el río son múltiples y pueden aparecer relacionadas con la cadencia de palabras, de dimensiones temporales o espaciales.

En los cantos, el impacto de la agroindustria denota un poder destructivo que se compara con la fuerza de la naturaleza: esta puede ser amenazadora y también protectora, pero la agroindustria palmera solo tiene poder destructor, lo cual no le permite al campesino interactuar con esa entidad; es decir, los monocultivos son implacables y devastadores, como lo relata Efraín en estos versos:

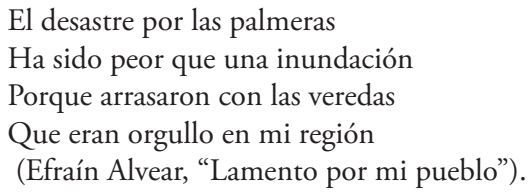

El marcador temporal entre el pasado y el presente es reiterativo en la revelación del yo lírico para seńalar los diferentes significados que otorgan las comunidades a la concepción sobre tierra-territorio en los cantos. Las descripciones sobre la abundancia y la exuberancia naturales y ecológicas están acompańadas de indicadores que se refieren a la dificultad para la construcción comunitaria, sea por la agresión armada o por la insuficiencia de recursos. La descripción de la abundancia se conecta con el contexto del trabajo del campesino y se retratan actividades campesinas que involucran a los diferentes ecosistemas, la pesca, la caza, la convivencia con animales domésticos y una serie de prácticas de la economía tradicional. Todas ellas hacen referencia al uso del territorio, no solo de la tierra. El uso del tiempo pasado "salíamos" hace énfasis en las prácticas cotidianas que han sido fracturadas por el despojo, como lo muestra este fragmento:

Playones libres con muchas crías

A donde salíamos en algarabía

Aquí se tenía todo lo que se quería

Cerdos y burros y vacas a montón

El que no pescaba, salía a cacería

Trayendo chigüiro y patos del playón

(Efraín Alvear, "Lamento por mi pueblo"). 
Como hemos podido ver a través de las ilustraciones, el tópico de la naturaleza converge en el universo lírico de estos cantos de dos formas: como un motivo de remembranza o como motivo de lucha. Para introducir el tema de la naturaleza, la voz lírica apela a la digresión como recurso que dinamiza la estructura textual: su propósito es aportar al relato discursivo un efecto sinestésico. En la estructura textual del canto esas digresiones representan un oasis de traslación de discursos, convocan la simultaneidad sentipensante, situándose en un oasis de sosiego, en contraposición a la carga semántica llena de tópicos de agresión. Esta representación no tiene que ser interpretada como mímesis de la realidad, sino como reconstrucción de sentido ante el sinsentido que causa la violencia tanto armada como estructural en las poblaciones rurales.

\section{Tierra, territorio y etnicidad}

La tierra es un concepto inherente a la construcción social y comunitaria de los habitantes de las zonas rurales, pero en él están contenidos diferentes matices. En los cantos se pueden identificar distintas connotaciones asociadas con ese tópico: las interrelaciones con la tierra, los usos, la distribución, la conservación, las propiedades y su manejo. $\mathrm{Al}$ indagar sobre la problemática de la tierra, es indispensable concebir cada uno de esos matices como componentes fundamentales que se revelan a través del potencial figurativo y simbólico del canto. Las composiciones que emergen en el contexto del conflicto por la tierra revelan discursos en disputa y permiten escudriñar la composición de los actores invisibles que se deben tomar en consideración para el análisis de su manejo y su transformación.

Una meta-proposición primaria que subyace en la información y está implícita en todas las composiciones es la siguiente: la tierra y el territorio constituyen bienes (no riquezas) no transferibles y proveen un beneficio comunitario. El carácter inalienable es un principio de la historia cultural y comunitaria de muchas poblaciones rurales, en especial, de las afrocolombianas. En los cantos, la voz lírica expone el dolor ante la problemática de la tierra con la intención de trasladar al oyente 
al plano local y referencial para establecer una mayor complicidad con el relato lírico, como se observa en estas estrofas:

Que aquí en el Sur de Bolívar Hay tierra pa'trabajar. Aquí se encuentra un pueblito Que se llama El Garzal.

(Daniel Retamoza, "Los veinte años de lucha”)
¡Óyeme, Chocó!

¡Oye, por favor!

Tú no tienes por qué estar sufriendo así.

(Deyanira Mosquera, "Óyeme, Chocó")
Campesino bonaerense, tú que quieres trabajar Tienes que tener primero la tierra pa' cultivar.

(Orlando Ospino, "Historia de mi vida")

En cada uno de estos fragmentos, la voz lírica se dirige a un destinatario: el pueblo o la región. En estas letras, la colectividad es un constituyente fundamental en el concepto asociado con la tierra. La expresión de afecto se reconoce en el uso del diminutivo "pueblito" y en la perspectiva de pertenencia en "campesino bonaerense". Mientras en la primera estrofa se afirma que hay tierra, en las otras dos se expresa el dolor y la carencia. En la segunda, la deprecación aparece como estrategia para implorar por la transformación ante el dolor: “¡Óyeme, Chocó!, ¡Oye, por favor!”. En la primera estrofa, se menciona el nombre de la comunidad El Garzal, que estuvo en riesgo de desplazamiento colectivo, evitado a través de la oración y el sembrado de pancoger, como se mencionó anteriormente. En las otras dos se hace alusión al sufrimiento por la carencia de la tierra a causa del destierro: esta se expresa en los cantos como resultado de las fuerzas y los mecanismos de poder empleados por otros actores y no por el deterioro natural. Un asunto relacionado con esto es la titulación de tierras:

\begin{tabular}{|c|c|c|}
\hline Estas son tierras baldías & Con esta crisis tan dura & Compraron las tierras del campesino \\
\hline Hoy son tierras del Estado & ¿A dónde iremos a parar? & Diciendo que en ellas podían quedar \\
\hline Propias para los campesinos & Aunque vivamos en el campo & Así les marcaron a todos camino \\
\hline Que somos muy maltratados. & no podremos trabajar. & Por donde tuvieron todo que dejar. \\
\hline $\begin{array}{l}\text { (Daniel Retamoza, } \\
\text { "Los veinte años de lucha") }\end{array}$ & $\begin{array}{l}\text { (Erasmo Cuadrado, } \\
\text { "2 de Junio") }\end{array}$ & $\begin{array}{l}\text { (Efraín Alvear, } \\
\text { "Lamento por mi pueblo") }\end{array}$ \\
\hline
\end{tabular}

En estas tres estrofas, el yo lírico expresa el acontecer circunstancial como resultado de determinaciones exógenas que afectan a su entorno. En la primera estrofa, el uso del vocablo "propias" aglutina tres 
acepciones diferentes relacionadas con la tierra. Por una parte, propio es sinónimo de natural, adecuado. En este sentido, hay una proposición conceptual, no solo deontológica, sino también fundacional: se sugiere, con sutileza, la necesidad del equilibrio de poderes tras una historia campesina de desarraigo semipermanente, es decir, la voz lírica insta a la redistribución de las tierras con equidad. Por otra parte, propio sugiere pertenencia: en este sentido, se alude al marco de la legalidad en el que deberían ser asignadas las tierras a la comunidad. El debería como posibilidad futura es omitido por la voz lírica, pero se infiere en el curso semántico-temporal, y vendría después de la primera parte: "tierras baldías / hoy son tierras del Estado / propias". En la segunda estrofa se insiste en la imposibilidad de usar las tierras para el trabajo agrario de la comunidad. En el relato previo a esta estrofa, el yo lírico ilustra la incursión de las fuerzas militares y describe cómo se produjo el desplazamiento. Se documenta en primer lugar la crisis rural como resultado de la confrontación, no al contrario: pone de relieve la interdependencia de las estructuras sociales y los pocos instrumentos de poder de los que disponen los campesinos, lo que la voz lírica expresa a través de la incertidumbre: "¿A dónde iremos a parar?".

La misma macroproposición esbozada anteriormente se hace más enfática en el marco de la reivindicación étnica. En los cantos vallenatos de Las Pavas y El Garzal, la identificación campesino-tierra representa la díada que aglutina una pluralidad de relaciones, mientras que en las composiciones de las zonas humanitarias el carácter étnico aparece con mayor énfasis: la etnicidad es sin duda uno de los componentes importantes en la lucha de la defensa por la tierra y se convierte en un canal de filiación en el caso de estas zonas. En los cantos recopilados en "Óyeme, Chocó" — vallenato—, como también en los del grupo Los Renacientes — rap-, la temática de la tierra está estrechamente vinculada a los principios étnicos y, desde esa perspectiva, la voz lírica construye el relato. En el siguiente fragmento se retrata el sentido de pertenencia y nuevamente se localiza topográficamente la región:

Yo tengo una tierra

Una tierra allá

¿Y cuál es esa tierra? (bis) 


\author{
Es la tierra natal \\ ¿Y dónde es esa tierra? (bis) \\ Es el Chocó \\ ¿Y dónde es el Chocó? \\ Donde somos desplazados. \\ (Los Renacientes, "Tierra querida”)
}

En estas letras se incorpora la dialéctica ausencia-presencia como elemento que insta a una mayor cohesión con la tierra: la ausencia está marcada por la situación de desplazamiento forzado en el que se encuentra el yo-nosotros de la voz lírica y la presencia se introduce ya con el indicativo tener. La noción de pertenencia a la tierra se amplifica en la estrofa contigua, "tierra natal", a través de la cual el "nosotros" lírico plasma la adhesión. Luego se hace una transición hacia lo topográfico-local: "El Chocó". Posteriormente, la voz utiliza hábilmente una construcción declaratoria para dar una respuesta que rompe la posible banalidad de la pregunta: “¿Dónde es el Chocó? Donde somos desplazados". Esa respuesta alude nuevamente a la relación ausencia-presencia: la actualización temporal "somos" da cuenta de la situación de destierro y la voz lírica se pronuncia desde esa condición, la de su presencia misma. El siguiente fragmento del canto "Llanto" integra la historia del origen africano como parte de la identificación de las comunidades chocoanas:

Soy chocoano, colombiano

Origen africano

La melancolía me envuelve a recordar mi pasado

Pero aquel que lo olvida

Él mismo se ha condenado

Seguiremos luchando por el sendero sońado

Desde atrás los negros hemos sido golpeados

Recordar mi pasado, un pueblo encadenado

Seguiremos luchando por lo que están pensando

Porque con otros medios nos están esclavizando

Diremos ¡no! a lo planeado

Carretera Panamericana

Para destruir nuestra tierra amada:

¡Cacarica!

(Los Renacientes, "Llanto") 
En este fragmento hay una mutación de la voz lírica — aparece en un yo y se transforma en un nosotros-, lo que es propio en el universo lírico de las composiciones sobre la reafirmación de la tierra y, en especial, en aquellas que se refieren al proceso comunitario de lucha. Aquí se utiliza la metáfora "el sendero sońado", en la que se manifiestan varios temas que aparecen en otros elementos del canto. En primer lugar, la noción de sendero está asociada a un desplazamiento y a una dinámica de movimiento. Ese vaivén lo expresa la voz lírica a partir de una visión diacrónica de desigualdad y sometimiento: "Desde atrás los negros hemos sido golpeados". A través de ello, se manifiesta la historia de dominación sobre los afrocolombianos en el contexto nacional: las poblaciones del Pacífico han estado subyugadas a un proyecto de país impuesto por otros grupos nacionales, la conformación de zonas y regiones se ha gestado desde epicentros de poder que han captado los recursos y la distribución de los mismos y, para ello, han sectorializado el espacio nacional, como afirma Fajardo:

En el proceso de formación del mercado nacional tienden a definirse relaciones jerarquizadas entre las regiones ("sistemas regionales"), que expresan la espacialidad de la división social del trabajo. La comprensión de estas y de sus dinámicas dentro del proceso general de la producción y, más concretamente, "dentro de la teoría del capital". Es a partir de los procesos de división social del trabajo y de espacialidad, al igual que de las tendencias hacia la acumulación (también en términos espaciales) que se propone la comprensión de la existencia de regiones o epicentros que "acumulan y concentran funciones productivas financieras y administrativas" (1993: 24).

La dimensión étnica tiene un efecto en la concepción de lo regional y lo nacional a partir de una constitución heterogénea. La voz lírica expresa la necesidad de romper con esa jerarquización y muestra su lucha en contra de propósitos ajenos a su estructura organizacional, de ahí, la negativa a una "carretera panamericana"; es decir, en la espacialidad y la territorialidad locales se afirma una propuesta diferente de usos de la tierra dentro de la nación. La lírica se convierte en un proyecto cultural. A este respecto, Fajardo (1993) considera que

la heterogeneidad social que se configura en el interior de las regiones tiene manifestaciones étnico-culturales y también políticas; estas últimas expresan la 
diversidad de intereses en torno a la apropiación de recursos excedentes y alrededor del acceso al control del poder, entre muchas otras motivaciones. (26)

En las composiciones se manifiesta la identificación regional, que se refuerza en el aspecto étnico. Esa etnicidad se instaura como proyecto político que recoge una decisión colectiva que la voz lírica expresa así: "Recordar mi pasado, un pueblo encadenado / Seguiremos luchando por lo que están pensando”. Esta consigna reitera el firme propósito de distinguirse como población afrocolombiana y renegociar en el marco nacional tanto las formas como los mecanismos de participación en las decisiones políticas, sociales y económicas del país.

En los cantos del rap se puede apreciar que en casi todas las letras la tierra aparece como concepto integral del universo y es codestinataria del relato lírico. Aquí la designación se compone del término aimara y quechua Pachamama y de la palabra castellana tierra, que contiene un eco fonético que se alimenta de dos orígenes lingüísticos diferentes pero que, semánticamente, son semejantes. La expresión "Pacha tierra mama” reitera ese vínculo semántico para darle una connotación pragmalingüística, de manera que enfatiza en una relación entre lo ancestral que conecta lo inmaterial y lo suprahumano, creando lazos filiales y míticos, como se ilustra en el siguiente fragmento:

¡Oh! Pacha tierra mama no vamos a callar.

Aquí están los renacientes que de ti cuidarán

¡Aquí están los renacientes!

(Los Renacientes, "Llanto")

\section{Otros actores: las palmeras y el Estado}

La voz lírica configura el escenario de los desacuerdos constatando la participación de diferentes actores, pero también revelando las transferencias de valores y juicios que emanan de sus acciones. El empleo de los sujetos tácitos en los cantos, por un lado, podría indicar la percepción de la voz lírica respecto a la corresponsabilidad de diferentes grupos sociales, pero, por otro, esa omisión puede estar construida en lo que no se dice, pero se significa. 
LAS PALMERAS

La referencia a las palmeras en el texto lírico tiene dos connotaciones: las empresas palmeras y las plantas de palma africana. Respecto a las empresas palmeras, aparecen en los cantos como actores que establecen alianzas con el Gobierno. En todos los cantos, este actor aparece en relación con el desplazamiento y la usurpación de tierras, pero no como interlocutor de la voz lírica, como se observa en los siguientes fragmentos:

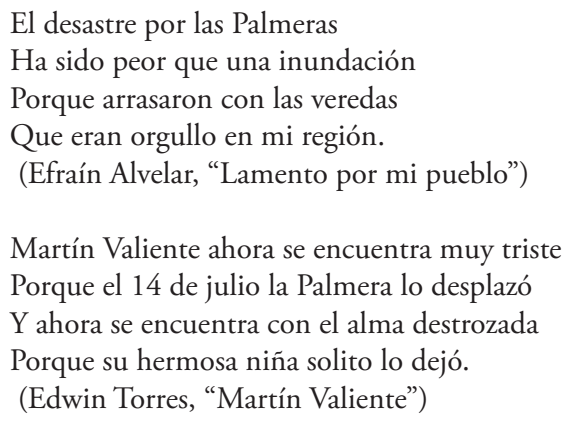

Las diferentes acciones que se significan en la lírica cuando la voz que canta se refiere a las palmeras pueden connotar tanto las empresas como la planta. En sus efectos, se pueden identificar dos categorías: por un lado, las acciones adversas, donde aparecen los hechos o bien ejecutados o bien propiciados por las palmeras y que tienen efectos nocivos para las comunidades, y. por otro lado, aparecen algunas acciones, de forma más bien aislada, que se podrían catalogar como colaborativas. Este tipo de acciones se refieren exclusivamente a las plantas de palma africana, lo que se podría interpretar como una expresión de complicidad de la naturaleza con los campesinos. En la siguiente tabla se deslindan las connotaciones representadas a través de la voz lírica: ${ }^{4}$

4. El programa "Conflicto y colaboración en el manejo de recursos naturales", referido en Rodríguez y Correa (2005), las llama "estrategias adversariales" y "estrategias colaborativas". Aquí se toman los calificativos exclusivamente para llamar 


\begin{tabular}{|c|c|c|}
\hline Acciones adversas & & $\begin{array}{c}\text { Acciones } \\
\text { colaborativas }\end{array}$ \\
\hline $\begin{array}{l}\text { - Causa dolor al campesino } \\
\text { - Explota oro y siembra palma } \\
\text { - Desplazó al campesino } \\
\text { - Causan desastre } \\
\text { - Arrasaron las veredas } \\
\text { - Compraron las tierras del campesino } \\
\text { con engaño } \\
\text { - Marcaron el camino de partida } \\
\text { - Desplaza la fauna: Guartinaja y el mico }\end{array}$ & $\begin{array}{l}\text { Palmeras } \\
\text { (Empresas) }\end{array}$ & \\
\hline Acciones adversas & \multirow[b]{2}{*}{$\begin{array}{l}\text { Palmera } \\
\text { (planta) }\end{array}$} & $\begin{array}{c}\text { Acciones } \\
\text { colaborativas }\end{array}$ \\
\hline $\begin{array}{l}\text { - Cortaron los frutos } \\
\text { - Secaron las aguas } \\
\text { - No se encuentra comida } \\
\text { - Envenenan la semilla }\end{array}$ & & Peste cogollera \\
\hline
\end{tabular}

31. Resignificación del actor: las palmeras. Fuente: elaboración propia

\section{El Estado}

En la representación lírica, el Estado aparece de dos formas. En las composiciones cuyo programa narrativo focaliza la acción campesina, el interlocutor a quien se dirige el canto es el Gobierno o el presidente. Esta forma de diálogo cantado es también característica de algunas de las composiciones que muestra Juan Manuel Echavarría en su exposición Bocas de ceniza, donde aparecen rostros cantando y contando la historia sucedida en la masacre de Bojayá, en el Chocó, Región Pacífico, el 2 de mayo de 2002. ${ }^{5}$ Por otra parte, en los cantos cuyo programa

la atención sobre las percepciones que tiene el campesinado. Además, se optó por llamarlas acciones y no estrategias porque no todas son premeditadas.

5. Juan Manuel Echavarría es un artista colombiano que ha tematizado en sus exposiciones el desplazamiento. 
lírico lo constituye el episodio de violencia, el Gobierno aparece como actor aliado de la violencia, tanto física como estructural y se le imputa una corresponsabilidad en la violencia hacia la clase campesina, comparándolo con los actores armados en varias de las canciones.

Muchos de los cantos interpelan en sus letras querellas sobre la marginación y el sometimiento de la clase campesina, sugiriendo que el Gobierno actúa a través de la omisión o de la prolongación estructural de la inequidad. Este aparece también en muchos de las canciones como promotor que impulsa las grandes empresas y los consorcios, omitiendo las necesidades populares en el área rural.

\author{
Mientras que los pobres nińos \\ Son los que se están muriendo \\ Allá están los asesinos \\ En el palacio nacional \\ (Erasmo Cuadrado: sin título)
}

Se recurre al simbolismo de lo espacial para ilustrar las asimetrías: "el palacio", sitio de reunión de los gobernantes, en contraposición al sin lugar de los campesinos. Las composiciones incorporan la denuncia, haciendo uso de la fuerza ilocutiva, como en "¡Oiga, señor presidente!", "el gobierno de la gente", de denuncias, como en "gobierno corrupto", o sencillamente expresando la desconfianza ante los gobernantes, como lo observamos en la siguiente estrofa:

Hay un proceso en el Sur de Bolívar
Donde tratamos de arreglar muchas cosas
Y hay un gobierno que dice mentiras
Y hasta nos mata pa'callarnos la boca.
(Etni Torres, "De aquí no nos vamos a ir")

Siguiendo la misma idea de cómo pueden influir los actores en el desarrollo del conflicto, se pueden distinguir las siguientes acciones. 


\begin{tabular}{|c|c|c|}
\hline Acciones adversas & \multirow{4}{*}{$\begin{array}{c}\text { Acciones colaborativas } \\
\begin{array}{c}\text { - Cuida al de la plata } \\
\text { - Desplaza al pobre }\end{array}\end{array}$} & $\begin{array}{l}\text { - Gobierno que crea } \\
\text { esperanzas }\end{array}$ \\
$\begin{array}{c}\text { - Quitan las tierras } \\
\text { - El campesino no vale } \\
\text { nada para el Gobierno } \\
\text { El Gobierno que dice } \\
\text { mentiras }\end{array}$ & \multirow{4}{*}{ Estado } & $\begin{array}{l}\text { Expectativas: que el } \\
\text { Gobierno los pueda } \\
\text { escuchar }\end{array}$ \\
& & \\
\hline
\end{tabular}

32. Resignificación del Estado. Fuente: elaboración propia

\section{El retorno en el relato lírico}

La vida agrícola como camino y destino está retratada en varios pasajes de los cantos. La voz lírica reconstruye la ontología campesina, atribuyéndole su destino a la mano divina, que configura las circunstancias de la vida del hombre, ya sea marcado por la fuerza suprema de Dios o como construcción entre hombre-naturaleza y deidad. La experiencia del desarraigo impone un camino de destierro y, de forma paralela a esa idea, se reconstruye en el relato lírico la noción del retorno. Este es el camino simbólico que une al hombre con su entorno y, ante todo, con la esencia arquetípica de la existencia humana: Dios, como se observa en el siguiente pasaje:

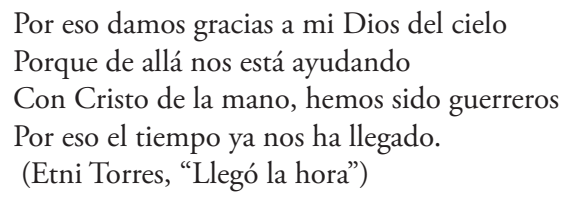

\section{La despedida}

La despedida es un tema que aparece de manera iterativa a lo largo de todo el corpus. Expresada a través de un sentimiento de pesar o de una reminiscencia, es tanto un motivo principal en las composiciones 
como un tema secundario que está anclado a la concepción transitoria del desplazamiento y el retorno. Sea expresión de despedida o partida, de ruptura o de alguna otra forma temporalmente ubicada, se establece una conexión entre el yo lírico y su entorno. Mientras en las canciones románticas esta partida está estrechamente vinculada con el distanciamiento de un ser amado, sea hombre o mujer, en este tipo de composiciones ese sujeto amoroso está constituido por la relación del campesino con la tierra y el territorio. Ese hábitat territorial comparte los sentimientos de despojo que brotan en el yo lírico campesino, que se manifiesta a través de figuras del reino animal, como, por ejemplo, la guartinaja, que establece un diálogo con un mico narrando su tristeza por el destierro en el siguiente fragmento:

\author{
En una mata de monte hay una guartinaja oculta \\ Ella vio venir de lejos a un mico y su familia \\ Ella le preguntó: "Amigo, ¿para dónde viaja?” \\ El mico contestó: "Miren qué cipote vaina" \\ El hombre me desplazó, con grandes maquinarias \\ Tumbaron las montañas, tierra donde yo habitaba \\ Entonces ella le dijo: "Yo también soy desplazada [...] \\ Entre los animales, sola he quedado yo" \\ (Edwin Torres, "El mico desplazado").
}

Muchas de las composiciones del vallenato tradicional se refieren a las relaciones que se tejen en el entorno local y natural. Las historias que se derivan de la construcción social están enmarcadas en escenarios de desavenencias o de complicidad. Los temas vallenatos que emergen de un contexto de desplazamiento forzado están matizados por dos aspectos: la profunda pesadumbre por el despojo y la expresión de impotencia del yo lírico en lograr el retorno a su territorio. Respecto al primer aspecto, la mayoría de cantos cuyo contenido emotivo está más focalizado hacia la tristeza profunda narran la incursión o el ataque de un actor armado a su población, mientras que aquellos cuyo núcleo expresivo-emotivo se concentran en la impotencia tienden a relatar en mayor grado las relaciones de poder y sometimiento a las que está expuesta la población rural. 
La despedida como negación de la negación: uno de los primeros matices de la temática de la despedida está concebido desde una dialéctica en la que esta se deconstruye como alternativa para el sujeto lírico: se considera como espacio transitorio que se niega a sí mismo, con el propósito de construir un preámbulo semántico que retrata el retorno. Cada referencia a la despedida como negación sugiere un estadio en transición que recupera la construcción temporal del futuro y se aleja de la mera noción de la despedida en relación con el pasado, como se expresa en los siguientes versos:

\author{
Después de tanta amargura \\ De dolor y de pensar \\ Por fin unidos \\ Lograremos retornar \\ Esta historia sucedida \\ No quisiera recordar \\ Mis hermanos asesinados \\ Y hoy vamos a retornar. \\ (Deyanira Mosquera, “Óyeme, Chocó)
}

El olvido como opción para mitigar el dolor de la despedida, que, en este caso, no está solo causado por dejar la tierra, sino también los compañeros, es una opción para el desterrado. Sin embargo, en estos versos anteriores, se formula una antítesis que hace posible la coexistencia del no recordar con el acto del recuerdo: "No quisiera recordar / Mis hermanos asesinados". Además, la elipsis verbal en el segundo verso refuerza el deseo de ese olvido voluntario y remeda la expresión del contenido en la estructura misma del relato, aunque justamente esa es la dialéctica en la que se reconstruye la idea del regreso. El dolor, la muerte, el despojo, la zozobra y las ausencias no pueden ser olvidadas, por lo que el retorno es la posibilidad de transformar la "historia sucedida".

Desde esta dialéctica el canto no es una oda del distanciamiento, sino una composición transversal propuesta en la continuidad hacia el retorno. El razonamiento del retorno se reconstruye en la posibilidad de crear en el discurso una despedida sin despedida, es decir, se niega la ruptura como parte ontológica de la esencia campesina porque la despedida de la tierra, que es elemento fundamental de la naturaleza 
rural, significaría la negación del mismo campesino y de su colectivo. En consecuencia, la temática de la despedida no es el tema de la composición, sino que sirve como instrumento para construir la posibilidad de retorno en el relato lírico:

\author{
Llegó la hora de regresar a mi tierra \\ Donde pienso plasmar mis proyectos \\ De donde nos sacaron a peso de guerra \\ Y nos humillaron en aquellos tiempos. \\ (Etni Torres, "Llegó la hora")
}

La idea de regreso está construida en un tiempo arquetípico, es expresado en los cantos como una acción del presente, más que como una opción futura. En los fragmentos anteriores el retorno se menciona en la culminación del relato lírico, lo cual podría relacionarse con el objetivo máximo al que llega la voz lírica. En la estrofa anterior, por el contrario, el regreso no es un punto de llegada, sino de partida y la voz lírica pone de manifiesto la intención que lo motiva a retornar.

El retorno también se expresa como posibilidad futura. En la estrofa anterior, el dolor como referencia previa a la despedida es superado por un estado de no preocupación que aparece directamente asociado con una utopía cercana, expresada a través de "un día es mañana”. La idea del futuro que emerge desde la experiencia interior del hablante lírico se construye usando una coexistencia temporal entre el uso sintáctico del tiempo verbal ser y la referencia semántica del adverbio mañana. Esto quiere decir que, dentro de la permanencia y la trayectoria de la confrontación, la expectativa mayor es la transformación, específicamente, el cambio de las circunstancias de despojo, y la imposibilidad del dominio territorial que expresa el yo lírico. El regreso también se vislumbra con un proyecto futuro que guía el presente, así como lo muestra la estrofa siguiente:

\author{
Tenemos en mente \\ Que seremos un municipio \\ En la isla de Papayal \\ Partiendo de este principio \\ Que seremos la despensa territorial \\ (Efraín Alvear, "Sentimiento de mi pueblo").
}


El retorno como transición hacia la nueva ruralidad en estas composiciones apela a una axiología en la que se propone y, al mismo tiempo, se reivindica la necesidad de un estatuto constitutivo campesino: me refiero tanto a las directrices de las políticas agrarias como a los atributos que componen dicho imaginario. Estos dos aspectos están contemplados dentro de los escenarios de globalización en los que suceden profundas transformaciones de las identidades. Las propuestas gubernamentales de una nueva ruralidad contemplan un campesino que esté en plena coherencia con los desarrollos tecnológicos que demandan los intercambios globales, sin repensar los reajustes de los proyectos regionales que surgen desde las estructuras populares. Los movimientos y las traslaciones entre los espacios urbanos y los rurales son entendidos, desde esta nueva perspectiva, como piezas complementarias de un desarrollo global. Esta nueva ruralidad articula discursos de lo global a partir de conceptos de desarrollo mercantilista $y$, por ende, pondera valoraciones de la tierra y, en general, de los recursos naturales basadas exclusivamente en el comercio y la producción. Estos supuestos no incluyen funciones sociales, ecológicas y culturales en las relaciones entre recursos naturales y recursos humanos. En este canto esta relación se expresa de la siguiente manera:

\author{
Falta nobleza con los campesinos (bis) \\ Porque al campo quieren retornar \\ A trabajar sin temor ninguno \\ Así podemos vivir en paz. \\ (Efraín Ávila, "El sufrimiento”)
}

El yo lírico usa el concepto de nobleza para expresar un valor transferido por otros actores del conflicto como reacción al deseo del retorno. Es posible identificar esa percepción a través de dos acepciones: una de ellas, "falta nobleza" en relación a la carencia de valoración por parte de la sociedad y el Gobierno de la clase campesina en cuanto a su aportación en el capital económico, en el ámbito ecológico, sus saberes y su importancia como grupo social y como capital humano nacional - la voz lírica sugiere que el desdén es la forma de trato a los pobladores de las áreas rurales — y, por otra parte, "falta nobleza" entendida 
como ausencia de honestidad y de lealtad en las interacciones con el Gobierno. $^{6}$

\section{Resignificación del campesino y acciones comunitarias}

En algunos textos líricos, la constitución orgánica de la asociación se convierte en motivo de la narración: se hace referencia a la instancia campesino-campesinado con el propósito de reconstruir los atributos de la población rural y redefinir ese concepto. Esa redefinición se articula en las nociones sobre la acción y determinación comunitarias. Si bien hay dos canales de filiación entre los miembros de las comunidades (lo étnico y lo regional), el elemento de mayor cohesión es la identificación como campesinos. La representación del actor campesino/campesinado pasa por un proceso de deconstrucción que intenta desmontar una arquitectura natural que ha dominado por largo tiempo el imaginario nacional. A continuación, presentamos una síntesis de los términos que se usan en los cantos para representar la gestión y la autodefinición campesinas:

\begin{tabular}{|c|c|c|}
\hline Gestión campesina & \multirow{3}{*}{ Campesino } & Autodefinición campesina \\
\hline $\begin{array}{l}\text { - Organización comunitaria } \\
\text { - Federación }\end{array}$ & & $\begin{array}{l}\text { Atributos: bravo, valiente, } \\
\text { luchador, orgulloso de sí, } \\
\text { no es empresario, con historia }\end{array}$ \\
\hline Unión & & $\begin{array}{l}\text { Sentimientos: tristeza, pérdida, } \\
\text { soledad, amargura, silencio }\end{array}$ \\
\hline Liderazgo & \multirow{4}{*}{$\begin{array}{l}\text { Paralelismos: } \\
\text { — La guartinaja } \\
\text { — El mico }\end{array}$} & $\begin{array}{l}\text { Condición: desplazado, sin tierras, } \\
\text { ruptura, a la deriva }\end{array}$ \\
\hline Reclamación de derechos & & $\begin{array}{l}\text { Espacio: anhelado, tierra, } \\
\text { montaña, pueblo Buenos Aires, } \\
\text { región, vereda, sur de Bolívar }\end{array}$ \\
\hline Retorno & & $\begin{array}{l}\text { Tiempo: sin agricultura, sin casas, } \\
\text { sin frutos }\end{array}$ \\
\hline $\begin{array}{l}\text { - Alianzas } \\
\text { - Resistencia }\end{array}$ & & $\begin{array}{l}\text { Instrumentos: experiencia, fe, } \\
\text { memoria, canción }\end{array}$ \\
\hline
\end{tabular}

33. Resignificación del concepto campesino-campesinado Fuente: elaboración propia

6. En las dos estrofas previas a este fragmento, el canto "El sufrimiento" de Efraín Ávila menciona que el actor es el Gobierno. 
En las composiciones es perceptible esa profunda intención de resignificar el concepto de campesino, integrando dimensiones hasta entonces no pertenecientes a esa categoría. Los relatos contados por los campesinos durante la jornada ecuménica y ecológica en febrero de 2012 también expresan la necesidad de rehacer y desmitificar el significado del término. Este hecho pone al descubierto el desatino de las políticas agrarias, que han conducido a la descomposición de la clase campesina, reduciendo su acción a tareas específicas - labrador, cultivador, labriego o peón-. Es de crucial importancia comprender que el discurso lírico tiene como propósito edificar una semántica renovadora y autónoma que hace parte del proceso de la construcción de la paz.

En la canción "Campesino embejucao", 7 aunque no pertenece a las comunidades de este estudio, la voz lírica se pronuncia en contra de una sobrecarga de identidades que se le dan al campesino. Esta composición, referida a un contexto histórico anterior, refleja un hastío acerca los múltiples interrogantes a los que están expuestos los trabajadores del campo respecto a sus filiaciones partidistas o ideológicas, especialmente en el marco del conflicto armado:

\footnotetext{
Me tienen arrecho con tanta juepuerca preguntadera

Que qué color tiene mi bandera que si yo soy godo o soy liberal

Me tienen verraco con tanta juepuerca averiguadera

Que si soy eleno que pelo si quiera, apoyo a las AUC o soy de las FARC

Me tienen mamao con tanta juepuerca interrogadera

Que si yo a la tropa le abro las cercas y les doy el agua de mi manantial

Que si soy comunista, de ANAPO, de la izquierda, o de la derecha

Que si imperialista, que joda arrecha resulta querer vivir uno en paz

Yo soy campesino trabajador, pobre, muy honrao

Vivía muy alegre, pero me tienen embejucao.

(Óscar Humberto Gómez, "Campesino embejucao")
}

En las diferentes composiciones se da una resignficación de lo que es el sujeto campesino y la labor campesina: una propuesta desde un sistema de equivalencias cultivadas en el acervo rural y que quiere ser

7. Óscar Humberto Gómez, "Campesino embejucado"; véase <https://www.youtube.com/watch?v=j2QN6MDLHzEfxM>. 
alternativa en las consideraciones de la reforma integral. Se tiene la tendencia a considerar reforma a un paquete de medidas económicas que debería significar las estrategias de superávit en el tema agrario; erróneamente, insisto en ello, porque esa reforma debe primero considerar el sistema de equivalencias que hacen del campo y del campesino justamente espacios rurales. El sistema de intercambio que establece el campesino con la tierra no está mediado solo por el excedente económico que la producción le proporciona, sino por la plusvalía física y no física, pues, en situaciones de ausencia de conflicto y si las condiciones del terreno no han llegado a la degradación, por lo general, la tierra que se trabaja provee una cantidad de productos superior a lo que consume el campesino.

En cuanto a las acciones comunitarias emprendidas por las colectividades campesinas, la lucha como idea de cohesión aparece en todos los cantos: "hay motivos de luchar", "lucha y defiende tu honor", "luchemos con más amor", "luchando por nuestro deber", "por nuestro derecho a seguir luchando, "gente valiente que no cesa de luchar", "aquí veinte años de lucha, de lucha, pero con paz", entre otras.

\author{
Lucha pueblito ancestral \\ Lucha y defiende tu herencia (bis) \\ Lucha por lo de tus hijos \\ Y no olvides tus creencias (bis) \\ Creencias de esos ancestros \\ Ay, que luchaban como hermanos (bis) \\ Qué cultura tan hermosa \\ Que tenía nuestra gente. \\ (Isidro Omaña, "Negros en Palenque”)
}

En estos versos se muestra no solo la acción, sino los elementos sustantivos con los que la voz lírica reconstruye la esencia comunitaria: la valentía de continuar para perseverar en la lucha; el amor como sinónimo de la unión colectiva y en un sentido de convicción y de compromiso ante la paz; la lucha como herramienta de trascendencia, no como instrumento mediático y cortoplacista, y como fuente dinámica de la transformación gradual de la conflictividad; la unión como 
valor fundamental para la acción social y la cohesión comunitaria. En el pasaje anterior podemos ver que esa cohesión comunitaria se expresa como parte de la herencia cultural y ancestral que ha sido transmitida durante generaciones. La permanencia en el territorio como forma de resistencia tiene incidencias tanto en el dominio social como en el político. Observemos la siguiente composición:

\author{
De aquí no nos vamos a ir \\ Aquí nos vamos a quedar \\ Y aquí nos toca luchar \\ Pa’ poder sobrevivir \\ Pertenecemos a la Federación \\ $\mathrm{Y}$ allí luchamos toditos unidos \\ Tenemos mesa de interlocución \\ Y ahí nos sentamos con muchos amigos. \\ (Etni Torres, "De aquí no nos vamos a ir")
}

La permanencia en el "aquí", referido al territorio comunitario, es una de las estrategias de lucha pacífica que manifiestan los relatos líricos. Este fragmento del canto ilustra la lucha decidida de la comunidad de Las Pavas: "sobrevivir" significa actuar conjuntamente. Como se expone en la segunda estrofa, las alianzas son parte de esa lucha. La mesa de interlocución es el espacio de encuentro con "los amigos" (las organizaciones que les acompañan), el cual les posibilita reflexionar sobre las formas de actuar y las decisiones que deben tomar. Esas alianzas son atribuidas atribuyen a la conexión con una instancia superior, el poder divino:

\footnotetext{
Por eso damos gracias a mi Dios del cielo

Porque de allá muchas estrellas bajaron

A alumbrar el camino como aquel lucero

Para que el triunfo se quede en nuestras manos (bis)

(Etni Torres, "Llegó la hora").
}

A través de los símiles "estrella" y "lucero" se consigna la aportación que percibe el yo-nosotros lírico de los acompañantes en el proceso de desplazamiento y retorno. En las dos estrofas, como en muchos 
otros fragmentos de los cantos, el camino es el símbolo fundamental del dinamismo comunitario: en él se consagra la dimensión espacial y temporal y se recorre el proceso y los aprendizajes recibidos:

Y hemos conocido muchas organizaciones

Que nos van mostrando el camino

Nos dieron apoyo y nos enseñaron

Por nuestros derechos a seguir luchando

(Etni Torres, "Llegó la hora").

El camino de retorno que han trazado estas comunidades es un sendero en construcción que une circuitos temporales, espaciales y materiales y articula vínculos entre grupos humanos a diferentes escalas y en diferentes latitudes. El camino del canto se fusiona con él y juntos emprenden la ruta de vuelta al territorio. 



\section{Capítulo VIII}

\section{Conclusiones}

Gran parte de los conflictos relacionados con el acceso a y el uso de bienes naturales en América Latina se enmarcan en una matriz cuyas relaciones de poder son profundamente asimétricas. El Sur Global está enfrentándose a una dinámica de adquisición de tierras que, a través de tácticas de usurpación para la expansión de monocultivos de palma de aceite y otras plantaciones extensivas, repercute severamente en la reconfiguración espacial y temporal de las cartografías nacionales. Los mayores impactos los afrontan las poblaciones locales, pues no solo se les despoja de sus tierras, sino que se desplazan sus modos de vida, sus formas de organización, sus economías, sus patrones de relación y, en general, su cultura campesina o étnica.

Los impactos del desplazamiento forzado en la ruralidad colombiana han venido retando a las comunidades afectadas a buscar estrategias de resiliencia para actuar ante las asimétricas configuraciones de poder, dominio y concentración de tierras. El desplazamiento forzado ha sido usado como estrategia sistemática por actores armados y no armados para ejercer control territorial en diversas regiones del país. Si bien la agroindustria ha sido presentada como uno de los caminos para promover el desarrollo del campo, sus efectos y beneficios en la sostenibilidad ambiental y social de las comunidades involucradas son altamente controvertidos. En específico, los cultivos de palma de aceite 
a larga escala han exacerbado las dinámicas de desplazamiento forzado y han conducido a profundas transformaciones en detrimento de las poblaciones campesinas, afectando no solamente a los ecosistemas, sino causando fisuras en las estructuras del tejido social y comunitario. $\mathrm{Si}$ bien estos cambios no se presentan de forma homogénea en todas las regiones, se evidencian afectaciones importantes en los sistemas productivos locales, la soberanía alimentaria de las comunidades, la explotación de la mano de obra entre otros.

Los procesos de transformación de conflictos están estrechamente vinculados a los espacios de construcción de paz, pues juntos emergen paralelamente a través de diversos mecanismos que tienen efectos en la mitigación de las disputas y, a su vez, permiten reconfigurar la dinámica de la confrontación. Para comprender la complejidad de los procesos y las experiencias en la transformación del conflicto y en la construcción de paz es necesario alejarse del enfoque lineal que ha dominado en el análisis académico. En consecuencia, es indispensable reconsiderar esa complejidad en el marco de una estructura de naturaleza multifacética, en la que el cambio y la reconstrucción no siguen una dirección secuencial, sino que están incorporados y relacionados entre sí en diferentes intensidades y niveles. La evolución de estos procesos se hace mucho más perceptible a escala local, dado que allí se configura una simultaneidad espacio-temporal en la que se vinculan diferentes elementos, pero que tiene un fluir concatenado a escala nacional. La memoria cultural, las visiones de mundo, las acciones colectivas, entre otros, se convierten en catalizadores que inciden en la transformación de las realidades que ha generado el conflicto prolongado, aportando las simientes para la reconstrucción de la estructura social, comunitaria e institucional.

Antes de diseñar mecanismos para abordar las confrontaciones con los actores en disputa, las comunidades inician procesos organizativos para restaurar el tejido comunitario que ha sido fracturado. La asociación campesina se convierte en una figura vertebral, a través de la cual se reedifican las posibilidades de acción comunitaria, cumplen diferentes funciones en lo político, lo social, lo jurídico y lo cultural. Estas poblaciones se concentran en la autogeneración de potencialidades y la selección de elementos del repertorio sociocultural para reconstituirse 
como actores sociales nuevamente. Ese repertorio está fundamentado en la cohesión, la identificación y la movilización de la subjetividad comunitaria, que se basa en principios de reciprocidad y complementariedad con entidades humanas, materiales, inmateriales y espirituales. Es importante observar que la fase de reconstrucción comunitaria surge como estadio previo al manejo de la confrontación con las empresas de industria palmera, pero va aconteciendo de forma simultánea en el marco del manejo del conflicto. Cada una de las asociaciones campesinas ASOCAB, ASPROAS y ACAT que han sido analizadas en este estudio han tenido roles fundamentales en la reconstrucción de la vida comunitaria y su representación en diversos ámbitos y, por lo tanto, indiscutibles efectos en la transformación del conflicto y la construcción de paz.

Para restablecer el tejido comunitario, las comunidades apelan a rescatar la noción de lo pasado como pieza fundamental para la proyección futura. Por ello, más que narrar la conflictividad del presente, las comunidades inician un rescate de la memoria colectiva en sus diferentes matices: lo agrario, lo étnico, lo religioso y lo organizativo, entre otros. El volver al pasado mitiga la fractura del tejido comunitario y abre la posibilidad de recrear nuevas realidades que se orientan hacia la idea del futuro, concretizado en el retorno a la tierra. En este proceso de recuperación colectiva se activan un cúmulo de lenguajes que han servido de vehículo para la transmisión de saberes, cosmologías, experiencias, sentidos y todo aquello que une a los miembros y los identifica como comunidad. La constitución comunitaria integra diferentes tipos de lenguaje y los convierte en signos de representación, $y$, para estas comunidades estudiadas, el lenguaje musical es poderosamente vital e imprescindible. Tal vez no podemos afirmar que este lenguaje que usan para reconstruir circuitos espaciales y temporales de lo colectivo sea nuevo, pero lo que sí se puede constatar es que se trata de un lenguaje musical renovado. El lenguaje musical regional tiene una importancia preponderante, por ello el ritmo vallenato, propio de la Región Caribe de Colombia, es una de las melodías predilectas para recomponer la memoria colectiva en sus distintos matices. Esa renovación del lenguaje musical se puede identificar tanto en el significante como en el significado; pues, por un lado, la composición vallenata se 
compromete a seguir ese ritual sociolingüistico que la identifica con su origen local, como a su discurso narrativo y propositivo, alejándose de un carácter estereotipado. Además, si bien retoma la esencia original del cantar vallenato, no se asemeja a la lírica tradicional antigua, sino que sigue el estilo de la canción popular moderna, en tanto que contiene una denuncia hacia los usos y abusos de la agroindustria de la palmera, que ocasiona serios impactos al ambiente colectivo. Los cancioneros populares antiguos no reflejaban en sus versos la tensión de la relación entre amo y trabajadores sino que retrataban un entorno afable e idílico del campo.

Los procesos que están teniendo lugar en el espacio rural contra el despojo de tierras son también perceptibles en los ambientes urbanos, aunque con otros matices. Podríamos sugerir que se trata de la reconstrucción de la memoria histórica desde otras racionalidades y con otros lenguajes. El espacio rural en Colombia viene dando pasos determinantes hacia la reafirmación de marcos de pensamiento y de acción que consoliden la subjetividad comunitaria y refuercen la gobernanza ambiental y social fuera de los parámetros utilitaristas y mercantiles en los que se conciben actualmente el manejo de la naturaleza y los recursos naturales. Desde hace varias décadas, se ha venido revelando un dinamismo social y organizativo desde la base y, aunque las condiciones estructurales existentes han querido truncar esas dinámicas, estos procesos, al parecer, siguen tomando mayor fuerza.

El uso de los bienes culturales al que apelan las comunidades locales tiene eco a nivel nacional, porque la afectación que causa el despojo es un fenómeno que por un lado, es recurrente en varias regiones de la Colombia rural, y por otra parte, tiene efectos en la institucionalidad tanto en el campo como en la ciudad. La recomposición del tejido comunitario emerge de la naturaleza del campo que está emparentada con la naturaleza del canto; este, la lírica y la oralidad pertenecen a esos bienes comunes que permiten no solo reconstruir la voz comunitaria, sino también constituir la epistemología del ethos comunitario. En ese proceso de restauración, las comunidades recrean y negocian nuevos significados en el contexto de la violencia que se materializan a través de la composición musical. Se manifiesta una polifonía de voces que ha sido desplazada y que reconstruye en la sonoridad, la melodía y el 
canto los fundamentos de la cultura agrícola. En este sentido, hay dos procesos de reterritorialización que ocurren de forma paralela y que se retroalimentan entre sí. Por un lado, el poder del canto: el repertorio de la oralidad se instaura con determinación en el territorio de los discursos para reafirmar su validez y ampliar los significados en lo verbal y no verbal. Por el otro lado, el empoderamiento comunitario: la voz cantora recobra presencia para interpelar por la comunidad y rescatar su validez como actor social e interlocutor. Así, se podría afirmar que esa dualidad de reterritorializaciones constituye una plataforma que formaría parte de los factores invisibles que contribuyen a la transformación simétrica de las relaciones estructurales de poder.

Una vez que las comunidades logran reafirmarse con la fuerza de la melodía, el poder del lenguaje musical transciende el ámbito comunitario y se convierte en instrumento de comunicación e interlocución ante otros actores. En este sentido, el empoderamiento a través de la voz melódica incide también en los factores visibles del manejo y la transformación del conflicto. En realidad, no es solo el canto como voz lo que aporta un nuevo lenguaje en estos procesos, sino que sus profundos aportes se pueden evidenciar en la significación textual y contextual, ya que es portador de los significados tanto cognitivos como emotivos de la experiencia comunitaria campesina y étnica.

Los textos de los cantos tematizan la reconstrucción de sus estilos de vida, sus valoraciones sobre la naturaleza, sus relaciones con los ciclos de cultivo y sus interacciones con los mundos espirituales, materiales y no materiales; es decir, en ellos se plasma la recuperación de esa cosmología campesina y étnica que sitúa las temporalidades y enlaza las continuidades de la vida rural. El proceso de producción en el que surgen esas composiciones debe ser entendido como una movilización de los bienes socioculturales para recuperar la vida territorial y, al mismo tiempo, el poder explicar el sinsentido causado por la violencia del destierro. Esa movilización tiene claras incidencias tanto en la dinámica como en el desarrollo del conflicto, pues, si bien las acciones que emprenden las comunidades no dependen directamente de la gestación del canto ni de su proceso de producción, el material sonoro y lírico sí actúa dentro de un conjunto semiótico y se convierte en signo que refuerza y motiva los significados comunitarios. Desde 
esa perspectiva, la producción, el consumo y la difusión de la lírica campesina testimonial generan significados de relación que influyen en las acciones comunitarias y en el quehacer político, ya que a través de ellos se resguardan las semillas de lo que se traduce en acciones políticas, jurídicas y de resiliencia, entre otras.

El proceso de producción musical supone un lugar de reflexión sobre los valores fundamentales y las racionalidades que caracterizan a las comunidades. Asimismo, la creación oral implica deliberar cuáles son los pilares sobre los que se diseña el retorno al territorio del que fueron desplazados forzadamente, por eso los cantos ponen en consideración la gestión y la gobernanza de lo territorial, la labor agrícola, el rol del campesino, la soberanía alimentaria, la sustentabilidad, la economía agrícola, etcétera. Estos panoramas de continuidad temporal son el fruto de las reflexiones sobre cómo proceder, qué comunicar y cómo interactuar en los contextos de la confrontación. No es preciso deslindar el texto lírico del contexto comunitario: la naturaleza de la producción musical emana del contexto extra-artístico.

El texto lírico recrea un marco conceptual donde se representan nuevas equivalencias en torno a las valoraciones sobre la naturaleza, la tierra, el campesinado y la paz que germinan desde la racionalidad de la unidad-común o comunitaria. Se trata de la resignificación de las temáticas que han ocasionado la confrontación. Esas equivalencias deconstruyen los postulados de la agroindustria respecto al uso y el acceso de los bienes naturales y a la subjetividad comunitaria de la identidad campesina; es decir, a través de la producción del discurso lírico se reconfiguran categorías de valoración de la tierra y el territorio que cuestionan los términos de intercambio mercantil que han convertido los recursos naturales en riquezas individuales. Se reafirman los significados de la territorialidad situando al agricultor, a los bienes naturales y a los bienes inmateriales como piezas de un circuito de reciprocidades y complementos. Esta concepción devuelve los recursos naturales a la condición de sujetos y los libera de la función puramente utilitarista que les ha dado la agroindustria. Esas equivalencias y su resignificación aportan una comprensión de la naturaleza como ser no dominable, no cuantificable. 
La creación lírico-musical actúa en la reconstrucción de significados no solo de la razón, sino de la emoción. Por un lado, es un dispositivo de recepción del dolor social y, por el otro, es un artefacto que va a incidir en la motivación colectiva. La relación entre producir y consumir los cantos, que es lo que sucede en las poblaciones de estudio, acontece en el marco de un cúmulo de sentidos, asociaciones y sensaciones. Esto es evidente en la idea de resistencia y resiliencia comunitarias, de tal manera que la reiteración de esos actos musicales hace que se conviertan en referentes culturales comunitarios asociados con la lucha pacífica. En esa medida, algunas de estas composiciones se vuelven fuentes líricas con un alto contenido visual que evocan al campesino, la tierra, el territorio, lo ancestral, lo étnico, el origen, etc., y que tienen incidencia porque estimulan la acción y la interacción en la búsqueda de la equidad y la construcción de la paz. En las acciones de retorno, el acompańamiento de las melodías compuestas por la comunidad de Las Pavas, por ejemplo, es representativa: se refuerza la evocación visual del regreso y en muchos cantos hay una imbricación entre presente y futuro que contribuye a esas asociaciones entre la razón y la emoción.

En la práctica cotidiana de las comunidades el manejo del conflicto no corresponde a un acto aislado en la evolución y desarrollo para solventar las disputas, sino que está incorporado en las estrategias de resiliencia. A pesar de los ambientes de hostilidad y violencia abierta, las comunidades han propiciado procesos de mediación y encuentro dentro de en un marco estructural creado para la concertación; algunas veces con participación de actores externos y otras, dentro de las alianzas en red de la que forman parte los colectivos. Es preciso resaltar que se percibe un giro importante en los paradigmas sobre los que se basa la negociación del conflicto. Mientras algunas comunidades afectadas por la usurpación de territorios negocian en la distribución de los dividendos que pueda generar un sistema productivo agrícola, las comunidades objeto de enfoque de este estudio no negocian la relación, tenencia y gobernanza de la tierra dentro de los parámetros mercantilistas, sino dentro de los parámetros de una ecología cultural que integra otras dimensiones y posibilidades de relación entre seres humanos y naturaleza basados en principios de reciprocidad y complemento. 
Por eso, sus acuerdos no están orientados a la distribución de la plusvalía o los dividendos provenientes de los recursos naturales, sino a la creación y reproducción de sistemas que favorezcan los modos de vida comunitarios y locales, el acervo cultural campesino y el ethos campesino y étnico. De ahí que los conceptos de espacialidad, lugar y pertenencia constituyan matrices sustanciales en los mecanismos utilizados por estas comunidades. Una particularidad en el proceso del manejo del conflicto es que se distingue la búsqueda de la paz en el marco de un cambio estructural, en contraposición a un pacifismo sin fruto. En este sentido, las acciones que llevan a cabo las comunidades podrían ser catalogadas como actos provocativos o renuentes, pero, desde la perspectiva de transformación del conflicto, son precisamente esas acciones las que puede tener mayor incidencia en las modificaciones estructurales que conducen a la equidad. No siempre las acciones de cooperación entre actores desembocan en equilibrio de poder. Por el contrario, la aparente cooperación lleva a que los actores con mayor poder obliguen a los actores más vulnerables a alinearse con sus objetivos. En este orden de ideas, la no cooperación bajo esas circunstancias potencializará la exacerbación del conflicto. Las comunidades de este estudio, no son casos aislados, sino que son representativas para una amplia franja de colectivos en el territorio nacional que buscan la resolución del conflicto apelando a los parámetros ecológico-culturales para encontrar marcos de concertación. Las acciones de retorno al territorio emprendidas por algunas de las comunidades aquí estudiadas son actos que han demandado mayor cohesión y fuerza comunitarias. Los retornos están concebidos como una búsqueda de espacios de convivencia y diseńados como parte de las acciones de resiliencia, por lo tanto, pueden ser entendidos como parte del proceso de construcción de la paz.

Aunque en el contexto del postconflicto se hable de una transición y de una justicia transicional, sería casi más acertado hablar de procesos de transmutación. Este concepto se acerca más a la noción de cambio en las formas y las prácticas y se aleja de la idea lineal de un orden progresivo. Si concebimos las acciones autónomas de las comunidades, las estrategias de movilización para tener presencia en los medios y los mecanismos para emprender acciones jurídicas entre 
otras, podemos afirmar que estas formas del manejo del conflicto han cultivado espacios de resistencia pacífica en sus diversas expresiones y han erigido, paralelamente, lugares simbólicos y físicos para impulsar prácticas de convivencia. Las culturas de convivencia son interludios en los que se administran la distribución de la equidad y las correspondencias entre las dimensiones de la cosmología comunitaria; pueden ser de naturaleza material o inmaterial y su razón de ser es la búsqueda del bienestar común, y sus elementos constitutivos son multitemporales o multiespaciales; se encuentran interconectados entre sí pero no son híbridos, sino heterogéneos y abigarrados.

$\mathrm{El}$ acto de retornar a las regiones de origen, les permite a las comunidades desplazadas situar cartográficamente esos espacios y darles vida plena. Las comunidades de las zonas humanitarias, la comunidad de Las Pavas, la comunidad de El Garzal y muchas otras que no han sido estudiadas aquí, al volver a sus territorios logran recomponer el espacio físico y adecuarlo con sus funcionalidades que corresponden a su cultura étnica y campesina. En el caso de las zonas humanitarias, el diseńo de organización espacial en forma de telarańa ilustra de forma grandiosa cómo la construcción de espacios de convivencia es análoga a las relaciones de reciprocidad y de complemento. Así como hay una relación de equidad, se busca una relación donde se reconoce la diferencia. De igual manera, La diferencia es resignificada y entendida como punto de confluencia y no de divergencia. Los múltiples lugares, espacios, interludios, sitios de la convivencia que han protegido las culturas comunitarias, tanto en Colombia como en otros puntos del Sur Global, en medio del despojo territorial, están aún por ser explorados. Lo importante es que, por lo menos, sepamos que existen y que haya razones que despierten nuestra curiosidad para conocerlos. Lo que necesitaríamos, definitivamente, con profunda urgencia como sociedad, en tiempo transformación es tener la capacidad de despojarnos de la racionalidad individualista y permitir que las melodías comunitarias por la paz se conviertan en sonidos polifónicos de nuestra cotidianidad. 



\section{Discografía y bibliografía}

\section{Discografía}

Cuadrado, Erasmo. Archivo de cantos inéditos de las zonas humanitarias recopilados en 2013 por la autora.

GómEz, Óscar Humberto. "El campesino embejucao", disponible en <https:// www.youtube.com/watch? $v=\mathrm{j} 2 \mathrm{QN} 6 \mathrm{MDLHzE}>$.

Les voy a cantar la historia. Fundación Chasquis, 2013. Disco compacto (comunidad Las Pavas).

Los Renacientes 97. Los Renacientes. Ayara EsTuDios, 2008. Disco compacto (zona humanitaria Cacarica).

Óyeme Chocó. Melodías de la esperanza, comunidades en retorno al Cacarica, Chocó. CAVIDA. Disco compacto, Disponible en <https://www.youtube. $\mathrm{com} /$ watch?v=R2aFCSaNFY8>.

Retamoza, Daniel. Cantos inéditos de la comunidad El Garzal

Tocó cantar. Travesía contra el olvido. Centro Nacional de Memoria Histórica, 2014. Disco compacto.

\section{Bibliografía}

Acevedo, Gloria Inés et al. (2009): Conflictos socioambientales y recurso hidrico una aproximación para su identificación y análisis. Bogotá: Pontificia Universidad Javeriana.

Adorno, Theodor W. y Bielsa, Esperanza (2002): "Sobre la música popular", en Guaraguao 6, 15, 163-201. 
Agencia Presidencial para la Acción Social y la Cooperación InterNACIONAL (coord.) (2010): Caracterización de las tierras rurales y su correlación con el desplazamiento forzado en Colombia. Bogotá: Editorial Sevioffset. AíNSA, Fernando (2003): Narrativa hispanoamericana del siglo XX: del espacio vivido al espacio del texto. Zaragoza: Prensas Universitaria de Zaragoza.

Alape, Arturo (1997): El Bogotazo: memorias del olvido. Bogotá: Editorial Planeta.

AlberCA, Manuel (2007): El pacto ambiguo. De la novela autobiográfica a la autoficción. Madrid: Biblioteca Nueva.

Alcántara, Salvador (2008): "Campesinos sin tierra somos como peces sin agua”, en Fabio Lozano y Juan Guillermo Ferro (eds.), Las configuraciones de los territorios rurales en el siglo XXI. Bogotá: Facultad de Estudios Ambientales y Rurales-Pontificia Universidad Javeriana, 225-230.

Álvarez, Astrid y Castrillón, Fernando (2007): "Agrocombustibles: una vía para el despojo de las tierras y la inseguridad alimentaria de los campesinos del centro-oriente de Colombia (Sur de Bolívar)", en Revista Semillas 34/35, 83-88.

Álvarez GardeazÁbal, Gustavo (2003): Las mujeres de la muerte. Bogotá: Mondadori.

Anderson, Benedict (1991): Comunidades imaginadas. Reflexiones sobre el origen y la difusión del nacionalismo. Ciudad de México: Fondo de Cultura Económica.

ÁNGel, Tatiana y LLINAS, Guillermo (2015): EL campo colombiano: un camino hacia el bienestar y la paz. Informe detallado de la misión para la transformación del campo. Bogotá: Departamento Nacional de Planeación/ Nuevas Ediciones.

Arendt, Hannah (1970): On Violence. San Diego: Harvest Book.

Árquez VAN-STrahlen, Óscar (1998): "El carnaval en la región momposina”, en Boletin Historial LVI, 29-30.

Artel, Jorge (2002): Sinú. Riberas de asombro jubiloso. Córdoba: Gobernación de Córdoba.

Atteslander, Peter (2010): Methoden der empirischen Sozialforschung. Berlin: Erich Schmidt.

Azaustre, Antonio y Casas, Juan (2006): Manual de retórica española. Barcelona: Ariel.

BARTHES, Roland (1977): "Introducción al análisis estructural de los relatos", en Silvia Niccolini (comp.), El análisis estructural. Buenos Aires: Centro Editor de América Latina.

- (2005): Das Rauschen der Sprache. Frankfurt am Main: Suhrkamp. 
Bautista S. Rafael (2004): La descolonización de la politica: introducción a una política comunitaria. La Paz: Agruco.

BäCHLER, Günther (1999): "Environmental Degradation and Violent Conflict: Hypothesis, Research Agenda and Theory-Building", en Mohamed Suliman (ed.), Ecology Politics and Violent Conflict. London/New York: Zed Books, 76-112.

BÄCHLER, Günther et al. (1996): Kriegsursache Umweltzerstörung: Ökologische Konflikte in der Dritten Welt und Wege ihrer friedlichen Bearbeitung. Band I. Chur. Zürich: Ruegger.

Bejarano, Jesús (1998): Economía de la agricultura. Bogotá: Tercer-Mundo/ Universidad Nacional.

Bermúdez, Egberto (2004): “¿Qué es el vallenato? Una aproximación musicológica”, en Ensayos historia y teoría del arte IX, 9, 21. Bogotá: Universidad Nacional.

- (2009): "Jacques Gilard y la música popular colombiana”, en Caravelle 93, 19-40.

Bernal, Rodrigo y Galeano, Gloria (1993): "Las palmas del andén Pacífico", en Pablo Leyva (ed.), Colombia Pacífico. Bogotá: Fondo FEN-Colombia, tomo I, 220-231.

Beutler, Gisela (1985): El romancero español en Colombia. Bogotá: Instituto Caro y Cuervo.

Bнавна, Homi K. (1998): “The Commitment to Theory”, en New Formations 5, 3-23.

- (2004): The Location of Culture. London/New York: Routledge.

Buum, Winfried. E. H. et al. (2010): "Ecological Consequences of Biofuels", en Rattan Lal y B. A. Stewart (eds.), Soil Quality and Biofuel Production. Boca Raton: CRC Press, 63-92.

Blumer, Herbert (1969): Symbolic Interactionism: Perspective and Method. Berkeley/Los Angeles: University of California Presss.

Bonacker, Thorsten (ed.) (2005): Sozialwissenschaftliche Konflikttheorien. Eine Einführung. Wiesbaden: Vs-Verlag für Sozialwissensschaften.

Borel, Rolain (2005): "Conflictos ambientales en América Latina: una reflexión en el camino”, en Iokiñe Rodríguez y Hernán Darío Correa (eds.), Encrucijadas ambientales en América Latina. Entre el manejo y la transformación de conflictos por recursos naturales. Santiago de Chile: Andros, 13-22.

Borras, Saturnino et al. (2011): "Land Grabbing in Latin America and the Caribean Viewed from Broader International Perspectives", Seminario "Dinámicas en el mercado de la tierra en América Latina y el Caribe", FAO, 14-15 de noviembre, Santiago de Chile. 
- (2012): "Land grabbing in Latin America and the Caribbean", en The Journal of Peasant Studies 39 (3/4), 845-872, disponible en <https://doi. org/10.1080/03066150.2012.679931>.

Borras, Saturnino y Franco, Jennifer (2012): "Global Land Grabbing and Trajectories of Agrarian Change: A Preliminary Analysis", en Journal of Agrarian Change, 12 (1), 34-59, disponible en <https://doi.org/10.1111 /j.1471-0366.2011.00339.x>.

Budde, Heinz (1995): “Die Rekonstruktion kultureller Sinnsysteme”, en Uwe Flick et al. (eds.), Handbuch Qualitative Sozialforschung. München: Psychologie Verlags Union.

Carballo, Marita e Inglehart, Ronald (1997): "Does Latin America Exist? (And there is a Confucian Culture?): A Global Analysis of Cross-Cultural Differences", en Political Science and Politics 30(1), 34-47, disponible en $<$ https://doi.org/10.2307/420668>.

CÁrdenas, Felipe y Montes, Mónica (2009): "Narrativas del paisaje andino colombiano: visión ecológica en la música carranguera de Jorge Velosa", en AIRB. Revista de Antropología Iberoamericana 4(2), mayo-agosto, 263293.

Castiblanco, Carmenza y Rojas Bustos, Juan Carlos (2016): "Intervención ciudadana en el proceso de constitucionalidad (Expediente D-11275) contra algunas disposiciones de la Ley 1776 de 2016, por la cual se crean y se desarrollan las Zonas de Interés de Desarrollo Rural, Económico y Social, ZIDRES".

Castillo, Ariel (1986): "La canción vallenata", en Huellas 17, 49-54.

- (2010): "Literatura y lucidez creadora en los cantos de Adolfo Pacheco", en Cuadernos de Literatura del Caribe e Hispanoamérica 12, 103-133.

Cepeda, Fernando (2013): "Participación política para la competitividad regional”, en Afro el Periódico 3,8, edición especial.

Cerrillo Martínez, Agustí (2005): La gobernanza hoy. Madrid: Instituto Nacional de Administración Pública.

Chevalier, Jacques M. y Buckles, Daniel (2010): "El manejo de los conflictos: Una perspectiva heterocultural”, en Daniel Buckles (ed.), Cultivar la paz: conflicto y colaboración en el manejo de los recursos naturales. Ottawa: Centro Internacional de Investigaciones para el Desarrollo, 15-48.

Collier, Paul y Hoeffler, Anke (1998): "On economic causes of civil war", en Oxford Economic Papers, 50, 563-573.

Comisión Intereclesial de Justicia y Paz (2005): La Tramoya. Derechos Humanos y Palma aceitera. Curvaradó y Jiguamiandó. Caso Tipo 6. Bogotá: Comisión Intereclesial de Justicia y Paz. 
Coronado, Sergio y Dietz, Kristina (2013): “Controlando territorios, reestructurando relaciones socio-ecológicas: La globalización de agrocombustibles y sus efectos locales, el caso de Montes de María en Colombia”, en Iberoamericana 49, 93-116.

Correa, Gabriel (2002): "El rock argentino como generador de espacios de resistencia”, en Huellas 2, 40-54.

Coser, Lewis (1972): Theorie Sozialer Konflikte. Berlin: Neuwied.

Cotula, Lorenzo, Dyer, Nat y Vermeulen, Sonja (2008): Fuelling exclusion? The Biofuels Boom and Poor People's Access to Land. London: FAO/IIED.

Crespo, Carlos (2005): "La negociación como dispositivo para reducir relaciones de dominación: aspectos conceptuales y teóricos”, en Iokiñe Rodríguez y Hernán Darío Correa (eds.), Encrucijadas ambientales en América Latina. Entre el manejo y la transformación de conflictos por recursos naturales. Santiago de Chile: Andros, 237-256.

Cruse, Richard, Cruse Michael J. y Reicosky, Don C. (2010): “Soil Impacts of Residue Removal for Biofuel Feedstock”, en Rattan Lal y B. A. Stewart (eds.), Soil Quality and Biofuel Production. Boca Raton: CRC Press, 45-62.

Curle, Adam (1971): Making Peace. London: Tavistock Publications.

De Sousa Santos, Boaventura (2010): Refundación del Estado en América Latina. Perspectivas desde una epistemología del Sur. Bogotá: Siglo del Hombre Editores.

- (2012): De la mano de Alicia. Lo social y lo político en la postmodernidad. Bogotá: Siglo del Hombre Editores.

Deleuze, Gilles (2001): Short Cuts 4. Frankfurt am Main: Zweitausendeins Verlag.

Derrida, Jacques (1971): De la gramatología. Buenos Aires: Siglo XXI.

- (1978): Writing and Difference. London: Routledge/Kegan Paul.

Dessler, David (1994): "How to Sort Causes in the Study of Environmental Change and Violent Conflict”, en Nina Graeger y Dan Smith (eds.), Environment, Poverty, Conflict. PRIO Report 2. Oslo: International Peace Research Institute, 91-112.

DíAz, Liliana (1999): "Mecanismos legales y alternativos para el manejo de conflictos ambientales", en Pablo Ortiz (ed.), Comunidades y conflictos socioambientales. Experiencias y desafios en América Latina. Quito: Abya-Yala, 369-382.

Dietz, Kristina (2018): "Consultas populares mineras en Colombia: Condiciones de su realización y significados políticos. El caso de La Colosa”, en 
Colombia Internacional 93, 93-117, DOI <https://dx.doi.org/10.7440/ colombiaint93.2018.04>.

Dworack, Thomas et al. (2008): "A Review of the Possible Impact of Biomass Production from Agriculture on Water". Background paper for the conference "WFD meets CAP-Looking for a consistent approach". Background paper for the European conference "Water Framework Directive and Agriculture", 21-22 September 2007, Paris.

Eagleton, Terry (1994): Ästhetik. Der Geschichte der Ideologie. Stuttgart: Verlag J. B. Metzler.

- (2000): The idea of culture. Oxford: Blackwell.

Engel, Sven (2001): Vom Elend der Postmoderne in der Dritten Welt. Eine Kritik des Post-Development-Ansatzes. Stuttgart: Ibidem-Verlag.

Escamilla, Julio, Morales, Efraín y Grandfield, Henry (1993): "El lirismo y la narrativa como proyectos discursivos de la canción vallenata", en Huellas 38, 40-50.

Escobar, Arturo (1984): "Discourse and Power in Development. Michael Foucault and the Relevance of his Work to the Third World", en Alternatives $10,377-400$.

- (1988): "Power and Visibility. Development and the Intervention and Management of the Third World", en Cultural Anthropology 3, 31-41.

- (1995a): Encountering Development. The Making and Unmaking of the Third World. Princetown: Princeton University Press.

- (1995b): "Imagining a Post-Development Era", en Johnatan Crush (ed.), Power of Development. London/New York: Routledge, 211-227.

- (2000): "El lugar de la naturaleza y la naturaleza del lugar: ¿globalización o postdesarrollo?", en Edgardo Lander (comp.), La colonialidad del saber: Eurocentrismo y ciencias sociales. Perspectivas Latinoamericanas. Buenos Aires: Concejo Latinoamericano de Ciencias Sociales (CLACSO), 113-143.

- (2006): "An Ecology of difference: Equality and conflict in a glocalized world", en Focaal-European Journal of Anthropology 47, 120-137.

Escobar, Arturo y Paulson, Susan (2005): "The emergence of Collective Ethnic Identities and Alternative Political Ecologies in the Pacific Rainforest”, en Susan Paulson y Lisa Gezon L. (eds.), Political Ecology across Spaces, Scales and Social Groups. New Brunswick: Rutgers University Press, 257-278.

Escobar, Augusto (1996): "La violencia: ¿̇generadora de una tradición literaria?”, en Revista Gaceta 37, 21-29.

Eтте, Ottmar (2016): Writing between Words. Transarea Studies and the Literatures without-a-fix-above. Berlin/Boston: Walter de Gruyter. 
Fajardo, Darío (1993): Espacio y sociedad. Formación de las regiones agrarias en Colombia. Bogotá: Corporación Colombiana para la Amazonía-Araracuara (COA).

- (2001): "Notas para la formulación de un programa de desarrollo rural para la paz", en Instituto Colombiano de la Reforma Agraria (INCORA): Colombia, tierra y paz: experiencias y caminos para la reforma agraria Alternativas para el siglo XXI. Bogotá: Incora, 14-37.

- (2002): "Tierra, poder político y reformas agraria y rural", en Cuadernos Tierra y Justicia 1, 3-48.

- (2004): "Conflicto armado y su proyección en el campo", en Martha Cárdenas y Manuel Rodríguez (eds.), Guerra, sociedad y medio ambiente. Bogotá: Foro Nacional Ambiental, 67-106.

- (2006): "Desplazamientos forzados en el desarrollo de la agricultura comercial colombiana", en IV Jornadas Abiertas "Tierra y desplazamiento en Colombia. Crisis humanitaria por el control del territorio”. Bogotá: Taula Catalana per la Pau i els Drets Humans a Colòmbia, 21-46.

FAls Borda, Orlando (2009): Una sociología sentipensante para América Latina. Orlando Fals Borda. Antología. Bogotá: Siglo del Hombre Editores/ CLACSO.

FAYAD, Luis (2008): Los parientes de Ester. Cieza: Alfaqueque.

FERNÁNDEZ, Héctor D. (1998): Narrativas de representación urbana. Un estudio de expresiones culturales de la modernidad latinoamericana. New York: Peter Lang.

Figueredo, María L. (2002): "El eterno retorno entre la poesía y el canto popular: Uruguay, 1960-1985”, en Revista Canadiense de Estudios Hispánicos 26, 299-321.

FigueroA, José Antonio (2009): Realismo mágico, vallenato y violencia política en el Caribe colombiano. Bogotá: Instituto Colombiano de Antropología e Historia.

Fischer, Günther y Schrattenholzer, Leo (2001): "Global Bioenergy Potentials through 2050", en Biomass and Bioenergy 20, 151-159.

FLICK, Uwe (2010): Qualitative Forschung. Eine Einführung. Berlin: Rowohlts Enzyklopädie.

Fontaine, Guillame (2004): "Enfoques conceptuales y metodológicos para una sociología de los conflictos ambientales”, en Martha Cárdenas y Manuel Rodríguez (eds.), Guerra, sociedad y medio ambiente. Bogotá: Foro Nacional Ambiental, 503-531.

- (2005): "Del manejo de conflictos ambientales a la institucionalización de arreglos: el aporte de las teorías de la gobernanza”, en Sergio Florencio 
Abreu (comp.), Integración, equidad y desarrollo. Quito: FLACSO, 131148.

Forero, Jaime et al. (2015). La viabilidad de la agricultura familiar en la altillanura. Análisis de su eficiencia económica-productiva y su dinámica ecosistémica en comunidades de Puerto López. Bogotá: Oxfam/Universidad Javeriana/Unillanos/Crece.

Forumo, Paul y Aide, Mitchell (2017): "Characterizing Commercial Oil Palm Expansion in Latin America: Land Use Change and Trade", en Environmental Research Letters 12 (2), 1-12, <https://iopscience.iop.org/article/10.1088/1748-9326/aa5892>.

Foucault, Michael (2010): Las palabras y las cosas: una arqueología de las ciencias humanas. Ciudad de México: Siglo XXI.

Franco, Jennifer et al. (2010): "Assumptions in the European Union Biofuels Policy: Frictions with Experiences in Germany, Brazil and Mozambique", en Journal of Peasant Studies 37(4), 661-698.

Frazão, Almeida; Cenciani, Karina y Barbosa, Marília (2010): "Land Use in Production of Raw Materials for Biofuels", en Rattan Lal y B. A. Stewart (eds.), Soil Quality and Biofuel Production. Boca Raton: CRC Press, 93-118.

Freja De LA Hoz, Adrián F. (2012): Romances, coplas y décimas en el Pacífico y el Caribe colombiano: poética de una literatura oral en Colombia. Bogotá: Universidad Nacional de Colombia. Tesis de Magister, disponible en <http:// www.bdigital.unal.edu.co/6612/1/adrianfaridfrejadelahoz.2012.pdf>.

- (2015): La literatura oral en Colombia. Romances, coplas y décimas en el Pacifico y el Caribe colombianos. Bogotá: Universidad Nacional de Colombia.

Friedman, Susana (1989): "Estrategias orales y transmisión musical del romance en las tierras bajas de Colombia", en Pedro Piñero et al. (eds.): El Romancero. Tradición y pervivencia a fines del siglo XX. Cádiz: Fundación Machado, 701-715.

FriTz, Thomas (2008): Agroenergie in Lateinamerika. Fallstudie anhand vier ausgewählter Länder: Brasilien, Argentinien, Paraguay und Kolumbien. Berlin: Diakonisches Werk der EKD e. V. für die Aktion "Brot für die Welt".

Funtowicz, Silvio y Ravetz, Jerome (1993): "Science for the Post-normal Age", en Futures 25 (7), 739-755.

Galeano, Eduardo (2003): Las venas abiertas de América Latina. Barcelona: Siglo XXI.

GaLO, Ramón (1999): "Introducción a las metodologías participativas", en Pablo Ortiz (ed.), Comunidades y conflictos socioambientales. Experiencias y desafios en América Latina. Quito: Abya-Yala, 433-450. 
Galtung, Johan (1996): Peace by Peaceful Means. Oslo: International Peace Research Institute.

- (1998): Tras la violencia, 3R: reconstrucción, reconciliación, resolución. Afrontando los efectos visibles e invisibles de la guerra y la violencia. Bilbao: Gernika Gogoratuz.

García Canclini, Néstor (1995): Culturas híbridas. Estrategias para salir y entrar de la modernidad. Buenos Aires: Sudamericana.

- (2001): Consumer and Citizens. Globalization and Multicultural Conflicts. Minneapolis: University of Minnesota Press.

García Márquez, Gabriel (1986): El coronel no tiene quien le escriba. Barcelona: Bruguera.

- (1994): Cien años de soledad. Bogotá: Editorial Oveja Negra.

Garfinkel, Harold (1996): "Ethnomethodology's Program”, en Social Psychology Quarterly 59 (1), 5-21.

Giampietro, Mario y Mayumi, Kozo (2009): The Biofuel Delusion: The Fallacy of Large-scale Agro-biofuel Production. London: Earthscan.

Gilard, Jacques (1986): "Emergence et récupération d'une contre-culture dans la Colombie contemporaine", en Cahiers du Monde Hispanique et Luso-brésilien 46, 109-121.

- (1993): "Crescencio o don Toba. Falsos interrogantes y verdaderas respuestas sobre el vallenato", en Huellas 37, 28-34.

Greiff, Carlos de (2009): "Geoestrategia de la energía para un planeta limpio y con hidrógeno y electricidad”, en Edgar Viera Posada (ed.), Tendencias mundiales y latinoamericanas en el uso de recursos energéticos. Bogotá: Editorial Javeriana, 29-65.

Goebertus, Juanita (2008): "Palma de aceite y desplazamiento forzado en zona bananera: 'trayectorias' entre recursos naturales y conflicto", en Colombia International 67, 152-175.

Gómez Pinilla, Pablo (2014): Informe práctica social (proyecto tierras-PDPMM, clinica juridica, Pontificia Universidad Javeriana, 2010), trabajo de grado, disponible en <https:/www.repository.javeriana.edu. co/handle/10554/10080>.

Grundmann, Gesa y Stahl, Joachim (2002): Como la sal en la sopa. Conceptos, métodos y técnicas para profesionalizar el trabajo de las organizaciones de desarrollo. Quito: Abya-Yala.

Gudynas, Eduardo (2012): "Der neue Progressive Neo Extraktivismus in Südamerika”, en Der Neue Extraktivismus - Eine Debatte über die Grenzen des Rohstoffmodells Lateinamerika. Berlin: Forschungs-und Dokumentationszentrum Chile-Lateinamerika \& Rosa-Luxemburg-Stiftung, 46-62, 
disponible en <http://www.gudynas.com/publicaciones/capitulos/GudynasNeueProgressiveExtractivismus12.pdf>.

Hall, D. O. y Scrase, James I. (1998): "Will Biomass be the Environmentally Friendly Fuel of the Future?", en Biomass and Bioenergy 15 (4/5), 357-367, disponible en <https://doi.org/10.1016/S0961-9534(98)00030-0>.

Hall, Peter y Taylor, Rosemary (1996): "Political Science and the Three Institutionalismus", en Political Studies 44, 936-957.

Hall, Stuart (2002): "Wann gab es ,das Postkoloniale? Denken an der Grenze", en Sebastian Conrad (coord.): Jenseits des Eurozentrismus. Postkoloniale Perspektiven in der Geschichts- und Kulturwissenschaft. Frankfurt am Main: Campus Verlag, 219-246

- (2007): "Through the Prism of an Intelectual Life", en Brian Meeks (ed.), Culture, Politics, Race and Diaspora. The thought of Stuart Hall. Miami/ London: Ian Randle Publishers/Lawrence and Wishart, 269-291.

Hall, Stuart y Mellino, Miguel (2011): La cultura y el poder. Conversaciones sobre los Cultural Studies. Buenos Aires: Amorrortu Editores.

Hall, Stuart y Whannel, Paddy (1965): The Popular Arts. New York: Pantheon Books.

Haller, Tobias; Breu, Thomas; De Moor, Tine; Rohr, Christian y ZnoJ, Heinzpeter (2019): The Commons in a Glocal world. Global Connections and Local Responses. London: Roulegde.

Hazell, Peter y Pachauri, Rajendra P. (2006): "Bioenergy and Agriculture: Promises and Challenges. Overview", en Peter Hazell y Rajendra P. Pachuari (eds.): Bioenergy and Agriculture: Promises and Challenges 2020 Focus 14, 1-3.

Hebebrand, Charlotte y Laney, Kara (2007): "An Examination of US and EU Government Support to Biofuels", en International Food and Agricultural Trade Policy Council, Issue Brief 26, 1-36, disponible en <http:// www.agritrade.org/Publications/documents/biofuels_Final5.pdf>.

Herlinghaus, Hermann (2009): Violence without Guilt. New York: Palgrave McMillan.

Hernández Salgar, Óscar (2007): "Colonialidad y poscolonialidad musical en Colombia”, en Latin American Music Review 2, 242-270.

- (2016): Los mitos de la música nacional. Poder y emoción en las músicas populares colombianas 1930-1960. Bogotá: Pontificia Universidad Javeriana.

Hill, Jason et al. (2006): "Environmental, Economic, and Energetic Cost and Benefits of Biodiesel an Ethanol Biofuels", en Proceedings of the $\mathrm{Na}$ tional Academy of Sciences of the United States of America 103(30), 1120611210. 
Hoggart, Richard (1967): The Uses of Literacy. Aspects of Working-class Life, with Special References to Publications and Entertainments. London: Chattus.

Homer-Dixon, Thomas (1999): Environment, Scarcity and Violence. Princeton: Princeton University Press.

Howard, Keith (2010): "Music across the DMZ", en John O'Connell y Salwa El Shawan Castelo-Branco (eds.), Music and Conflict. Urbana: University of Illinois Press, 67-88.

Hurtado, Monica; Pereira-Villa, Catherine y Villa, Edgar (2017): "Oil Palm Development and Forced Displacement in Colombia: Causal or Spurious?", Cuadernos de Economía, 36 (71), 441-468.

IвÁŃEZ, Ana María (2008): El desplazamiento forzado en Colombia. Un camino sin retorno hacia la pobreza. Bogotá: Ediciones Uniandes.

IgLesias, Ana María (2011): "La canción francesa como transmisora de ideología: análisis lingüístico de la canción 'La bête' de Zebda”, en Synergies Espagne 4, 77-84.

IngLeHART, Ronald (1977): The Silent Revolution: changing values and political styles among western publics. Princeton: Princeton University Press.

Jaramillo Villa, Úrsula; Cortés-Duque, Jimena y Flórez-Ayala, Carlos (2015): Colombia Anfibia. Un pais de humedales. Vol. I. Bogotá: Instituto de Investigación de Recursos Biológicos Alexander von Humboldt.

Jerez, César (2002): "Neoliberalismo, cuestión agraria, desarrollo regional, derechos humanos y conflicto: La lucha por el derecho a la tierra en el Magdalena Medio", en Plataforma Colombiana de Derechos Humanos, Democracia y Desarrollo: Por el derecho a la tierra. Bogotá: Ediciones Antropos.

Johnson, Jane y Papiernik, Sharon (2010): "Soil Processes and Residue Harvest Management”, en Rattan Lal y B. A. Stewart (eds.), Soil Quality and Biofuel Production. Boca Raton: CRC Press, 1-44.

Koolman, Jan (2003): Governing and Governance. London: Sage.

Kuper, Adam (1999): Culture: The Anthropologists' Account. Cambridge: Harvard University Press.

Lat, Rattan y Stewart, B. A. (eds.) (2010): Soil Quality and Biofuel Production. Boca Raton: CRC Press.

Latour, Bruno (2016): "Onus Orbis Terrarum: About a Possible Shift in the Definition of Sovereignty", en Millennium: Journal of International Studies 44 (3), 305-320.

Lederach, John Paul (1995): Preparing for Peace: Conflict Transformation Across Cultures. Syracuse: Syracuse University Press. 
- (1999): The Journey toward Reconciliation. Scottdale: Herald Press.

- (2003): The Little Book of Conflict Transformation. Intercourse: Good Books.

- (2005): The Moral Imagination: The Art and Soul of Building Peace. New York: Oxford University Press.

- (2010): Building Peace: Sustainable Reconciliation in Divided Societies. Washington D.C.: United States Institute of Peace Press.

Lederach, John Paul y Lederach, Angela Jill (2010): When Blood and Bones Cry Out. Journeys through the Soundscape of Healing \& Reconciliation. New York: Oxford University Press.

Libiszewski, Stephan (1992): What is an Environmental Conflict? Vol. I, Environment and Conflict Project (ENCOP). Bern/Zürich: Swiss Peace Foundation/Center for Security Studies and Conflict Research.

Lienhard, Martin (2003): La voz y su huella. Escritura y conflicto étnico-cultural en América Latina 1942-1988. Lima: Editorial Horizonte.

LisT, George (1973): "A comparison of Certain Aspects of Colombian and Spanish Folksong", en Yearbook of the International Folk Music Council 5 , 72-84.

López, Ángela (1998): "El arte de la calle”, en Reis. Monográfico sobre Sociología del Arte 84, 173-194.

López Baquero, Constanza (2012): Trauma, memoria y cuerpo. El testimonio femenino en Colombia (1985-2000). Tempe: Asociación Internacional de Literatura y Cultura Femenina Hispánica (AILCFH).

Lypovetsky, Gilles (1986): La era del vacío. Ensayos sobre el individualismo contemporáneo. Barcelona: Anagrama.

Mason, Simon (2004): From Conflict to Cooperation in the Nile Basin. Zürich: Swiss Federal Institute of Technology.

Maughan, Mark James (2011): "Land Grab and Palm Oil in Colombia". International Conference on Global Grab and Grabbing. Institute of Development Studies, University of Sussex, Brighton, 6-8 April.

Martín-Barbero, Jesús (1991): De los medios a las mediaciones: comunicación, cultura y hegemonía. Barcelona: Gili.

- (2001): El sur de la modernidad: comunicación, globalización y multiculturalidad. Pittsburgh: Instituto Internacional de Literatura Iberoamericana

Martín-Barbero, Jesús et al. (2005): América Latina. Otras visiones desde la cultura. Bogotá: Convenio Andrés Bello.

Martín-Barbero, Jesús y Herlinghaus, Hermann (2000): Contemporaneidad latinoamericana y Análisis cultural. Conversaciones al encuentro de Walter Benjamin. Madrid/Frankfurt am Main: Iberoamericana/Vervuert. 
Martínez Alier, Joan (2011): El ecologismo de los pobres. Barcelona: Icaria. Martínez Alier, Joan y Røpke, Inge (2008): Recent Developments in Ecologial Economics. Cheltenham: Edward Elgar.

Mayntz, Renate (2005): "Nuevos desafíos de la Teoría de la Gobernanza", en Agustín Cerrillo Martínez (ed.), La gobernanza hoy. Madrid: Instituto Nacional de Administración Pública, 83-98.

Medina Lima, Ismael (2003): Vallenatos en su tinta: una aproximación literaria a los cantos narrativos de Rafael Escalona. Cali: Feriva.

Mejía, Mario (2008): "Monocultivos y sustentabilidad en megaproyectos agrícolas”, en Irene Vélez (ed.): Agrocombustibles. Llenando tanques, vaciando territorios. Bogotá: Censat Agua Viva/PCN (El Proceso de Comunidades Negras en Colombia), 74-82.

Melo, Marluce y Albuquerque, Renata (2010): "Mulheres Canavieiras", en Maria Luisa Mendoça (ed.), Monopolio da Terra no Brasil: Impactos da expansão de monocultivos para a producão de agrocombustiveis. São Paulo: Rede Social de Justiça e Direitos Humanos, 29-32.

Miall, Hugh (2001): "Conflict Transformation: A Multi-dimensional Task", en A. Austin y N. Ropers (eds.), Berghof Handbook for Conflict Transformation. Berlin: Berghof Research Center for Constructive Conflict Management, 1-7.

Mingorance, Fidel; Minelli, Flaminia y Le Du, Hélenè (2004): El cultivo de la palma africana en el Chocó: legalidad ambiental, territorial y derechos humanos. Quibdó: SUIPPCOL.

Miñana Blanco, Carlos (2009): "Investigación sobre músicas indígenas en Colombia. Primera parte: un panorama regional”, en A contratiempo. Música en la Cultura 13, 1-50, disponible en <http://www.danzaenred.com/ articulo/el-concepto-musica-en-los-pueblos-indigenas-de-colombia-documento>.

Molano, Alfredo (2005): Desterrados: Crónicas del desarraigo. Bogotá: Punto de Lectura.

Mondragón, Héctor (2006): Movimientos sociales: una alternativa democrática al conflicto. Barcelona: Colectivo Maloka/Justícia i Pau.

Monsalve, Sofía (ed.). (2008): Os Agocombustiveis no Brasil. Heidelberg: FIAN International.

Morgan, James Luker (2010): “The Managers, the Managed, and the Unmanageable: Negotiation Values at the Buenos Aires International Music Fair", en Ehtnomusicology Forum 19 (1), 89-113.

Moscovisci, Serge (1973): "Foreword", en C. Herzlich, Health and Illnes: A Social Psychological Analysis. London: Academic Press. 
Niño, Eugenia María y Pradilla, Santiago (2010): Habitando el lugar. Una mirada a la vivienda desde el arte y la arquitectura. Bogotá: Arte Dos Gráfico.

Ocampo Valencia, Sebastián (2009): "Agroindustria y conflicto armado. El caso de la palma de aceite", en Colombia Internacional 70, julio-diciembre, 169-190.

O'Connell, John y Castelo-Branco, Salwa el Shawan (2010): Music and Conflict. Urbana: University of Illinois Press.

Oosterkamp, Jan; De Bruin, Irene y Barrón, Guelly (2007): "Oil Palm: Comparing Chocó West Kalimantan (Indonesia)", en Coraid, 1-67.

Ong, Walter J. (1982): Orality and Literacy. The Technologizing of the Word. London: Methuen \& Co.

Ortiz, Pablo (ed.): (1999): Comunidades y conflictos socioambientales. Experiencias y desafios en América Latina. Quito: Abya-Yala.

Ortiz, Pablo y Ernsrt, Lizi (2007): Tratamiento Comunitario de conflictos socioambientales. Manual Introductorio. Quito: PLASA/Fundación Futuro Latinoamericano.

Ospina, Martha (2007): Los rostros de la palma. Bogotá: FEDEPALMA.

Ospina, Martha y OсноA, Doris (1998): La palma africana en Colombia: Apuntes y memorias. Vol. 1. Bogotá: FEDEPALMA.

Ostrom, Elinor y Walker, James (2003): Trust and Reciprocity. Interdisciplinary Lessons from Experimental Research. New York: Russell Sage Foundation.

Otero Prada, Diego F. (2009): "La integración energética latinoamericana: dos visiones", en Edgar Viera Posada (ed.), Tendencias mundiales y latinoamericanas en el uso de recursos energéticos. Bogotá: Editorial Javeriana, 167-202.

Pardue, Derek (2004): “Writing in the Margins': Brazilian Hip-Hop as an Educational Project", en Anthropology \& Education Quarterly 35 (4), 411432.

Pérez Rincón, Mario (2008): "Los agrocombustibles: sólo canto de sirenas", en Irene Vélez (ed.), Agrocombustibles. Llenando tanques, vaciando territorios. Bogotá: Censat Agua Viva/PCN (El Proceso de Comunidades Negras en Colombia), 83- 95.

Peskett, Leo et al. (2007): "Biofuel Agriculture and Poverty Reduction", en Natural Resource Perspectives 107, 1-6.

Pettan, Svanibor (2010): "Music in War, Music for Peace: Experiences in Applied Ehtnomusicology”, en John O'Connell y Salwa El Shawan Castelo-Branco (eds.), Music and Conflict. Urbana: University of Illinois Press, 177-192. 
Piñero Ramírez, Pedro (2010): La niña y el mar. Formas temas y motivos tradicionales en el cancionero popular. Madrid/Frankfurt am Main: Iberoamericana/Vervuert, 2010.

Plata, William Elvis, Cáceres Mateus, Sergio (2015): "Resistir a los violentos y tejer sociedad desde la fe: El Garzal (Colombia)”, en Theologica Xaveriana, 65, 180, julio-diciembre, 497-525.

Posada, Consuelo (2002): "Canción vallenata: entre la tradición y los intereses comerciales”, en Estudios de Literatura Colombiana 10, 70-79.

Prada Oropeza, Renato (1968): "De lo testimonial al testimonio. Notas para un deslinde del discurso-testimonio.”, en René Jara y Hernán Vidal (eds.), Testimonio y literatura. Minneapolis: Institute for the Study of Ideologies and Literatures.

PratT, Mary Louise (1992): Imperial Eyes: Travel Writing and Transculturation. London/New York: Routledge.

- (2000): "La modernidad desde las Américas", en Revista Iberoamericana LXVI (193), 831-840

Przworski, Adam y Teune, Henry (1970): The Logic of Comparative Social Inquiry. New York: Wiley-Interscience.

Quilis, Antonio (1985): Métrica española. Barcelona: Ariel.

Ragin, Charles (1987): The Comparative Method. Moving beyond Qualitative and Quantitative Strategies. Berkeley: University of California Press.

Rajagopal, Deepak. et al. (2007): "Challenge of Biofuel: Filling the Tank without Emptying the Stomach?", en Environmental Research Letters 2, $1-9$.

Ramírez Barrados, Herlinda (2000): "La transformación de un héroe de corrido a través del tiempo", en Hispania 83, 189-197.

Ramos, Silvia (2006): "Brazilian Responses to Violence and New Forms of Mediation: the Case of the Grupo Cultural AfroReggae and the Experience of the Project 'Youth and the Police"', en Ciencia \& Saude Colectiva 11(2), 419-428.

Rangel, Alfredo; Ramírez, William y Betancourt, Paola (2009): La palma africana: Mitos y realidades del conflicto. Bogotá: Fundación Seguridad y Democracia.

Rasmussen, Anne K. (2010): "Performing Religious Politics: Islamic Musical Arts in Indonesia”, en John O'Connell y Salwa El Shawan Castelo-Branco (eds.), Music and Conflict. Urbana: University of Illinois Press, 155-176.

Red de la Diversidad-Fundación Wayna Tambo (2016): Procesos educativos para la crianza de lo comunitario. Experiencias de la Red de la Diversidad. Cuaderno de Conversaciones 3. La Paz: Arte Punto Gráfico. 
Restrepo, Eduardo (s. f.): "Estudios culturales en América Latina”, Revista de Estudos Culturais 1, <http://www.each.usp.br/revistaec/?q=revista/1/ estudios-culturales-en-am\%C3\%A9rica-latina>.

Restrepo, Laura (2001): La multitud errante. Bogotá: Editorial Planeta.

Rey Sabobal, Camilo (2013): Análisis espacial de la correlación entre cultivo de palma de aceite y desplazamiento forzado en Colombia”, en Cuadernos de Economía 32, (61) 683-719.

Reyes, P. Alejandro (2016): Guerreros y campesinos. Despojo y restitución de tierras en Colombia. Bogotá: Ariel

Ricoeur, Paul (2001): La metáfora viva. Madrid: Cristiandad/Trotta.

- (2011): Teoría de la interpretación. Discurso y excedente de sentido. Ciudad de México: Siglo XXI Editores.

Rincón G., John J. (2011): "Desplazamiento forzado. Despojo de tierra y territorios en Colombia" documento". Investigación del Centro Nacional de Memoria Histórica.

Rist, Stephan et al. (2007): "Moving from Sustainable Management to Sustainable Governance of Natural Resources: The Role of Social Learning Processes in Rural India, Bolivia and Mali”, en Journal of Rural Studies 23, 23-37.

RoA, Tatiana (2007): “Colombia's Palm Oil Biodiesel Push”. Research report for IRC Americas Program, February 2. Silver City: International Relations Center.

Ross, Michael (2003): "Oil, Drugs and Diamonds: The Varying Role of Natural Resources in Civil War", en K. Ballentine y J. Sherman (eds.), The political economy of armed conflict: Beyond greed and grievance. Boulder: Lynne Rienner, 47-70

- (2004): "What Do We Know About Natural Resources And Civil War?", en Journal of Peace Research 41(3), 337-356

Röling N. G. y Wagemakers M. A. E. (1998): Facilitating Sustainable Agriculture: Participatory Learning and Adaptive Management in Times of Environmental Uncertainty. Cambridge: Cambridge University Press.

Rodríguez, Diana (2011): Desplazados: narrativas de identidad y espacio de la Colombia contemporánea. Tesis doctoral. Universidad de Toronto, Canadá.

Rodríguez, Iokiñe y Correa, Hernán (eds.) (2005): Encrucijadas ambientales en América Latina. Entre el manejo y la transformación de conflictos por recursos naturales. Santiago de Chile: Andros.

Rodríguez Garavito, César (2010): Más allá del desplazamiento: Políticas, derechos y superación del desplazamiento forzado en Colombia. Bogotá: Ediciones Uniandes. 
Roundtable on Sustainable Biofuels (2009): RSB Land Rights Guidelines. Lausanne: École Polytechnique Fédérale de Lausanne (EPFL).

Ruta Pacífica de las Mujeres, Red de Comunidades e Iniciativas de Paz desde la Base y Consejo Nacional de Indígenas de Paz (2007): Documento enfoque y propuesta de Paz desde la base. SUIPPCOL.

SAID, Eduard (1994): Culture and Imperialism. London: Vintage.

- (1996): "Kultur und Identität - Europas Selbstfindung aus der Einverleibung der Welt", en Lettre International 34, 21-25.

Sánchez Ayala, Luis y Arango López, Cindia (2015): "Contra viento y marea, aquí estoy”, en Latin American Research Review 50 (3), 203-224.

SÁnchez, Tomás y Acosta, Alejandro (2008): "Música popular campesina. Usos sociales, inclusión en escenarios escolares y apropiación por los niños y niñas: la propuesta musical de Velosa y Los Carrangueros", en Revista Latinoamericana de Ciencias Sociales 6, 111-146.

SÁnchez Romeralo, Antonio (1989): "Presencia de la voz en la poesía oral", en Pedro Piñero et al. (eds.), El Romancero. Tradición y pervivencia a fines del siglo XX. Cádiz: Fundación Machado, 11-24.

SASSON, Albert (2011): Bioenergía y agrocombustibles. Su relevancia más allá de la polémica. Bogotá: Universidad Javeriana.

SCHARPF, Fritz (2006): Interaktionsformen. akteurzentrierter Institutionalismus in der Politikforschung. Wiesbaden: Verlag für Sozialwissenschaften.

Sнонат, Ella (1991): "Gender and Culture of Empire: Toward a Feminist Ethnography of the Cinema", en Quarterly Review of Film and Video 13, Issue 1-3, 45-84.

Szurmuk, Mónica y Mckee, Robert (2009): Diccionario de Estudios Culturales latinoamericanos. Ciudad de México: Siglo del Veintiuno.

Speight, James (2011): The Biofuels Handbook. Cambridge: Royal Society of Chemistry.

Storey, John (2001): Cultural Theory and Popular Culture. An Introduction. Edinburgh: Pearson Education.

- (2003): Cultural Studies and the Study of Popular Culture. Athens: University of Georgia Press.

SUIPPCOL (2011): Comisión mixta de verificación 2011. Examen in situ de la situación humanitaria.

TAYlor, Steven J. y Bogdan, Robert (1987): Introducción a los métodos cualitativos de investigación: La buisqueda de significados. Barcelona: Editorial Paidós.

Thompson, Krista (2009): "The Sound of Light: Reflections on Art History in the Visual Culture of Hip-Hop", en The Art Bulletin 4, 481-505. 
Tickner, Arlene (2008): "Aquí en el Ghetto: Hip-Hop in Colombia, Cuba, and México", en Latin American Politics and Society 3, 121-146.

ToAsa, José (2009): Colombia. A new Ethanol Producer on the Rise? Washington, D.C.: USDA Economic Research Service.

Torres, Héctor (2017): "En peligro la consulta popular y la Consulta Previa por la anti-democracia del Gobierno Santos, y su completa solidaridad con las multinacionales", en Redes Cristianas, disponible en <http://www. redescristianas.net/en-peligro-la-consulta-popular-y-la-consulta-previa-por-la-anti-democracia-del-gobierno-santos-y-su-completa-solidaridad-con-las-multinacionaleshector-alfonso-torres-rojas-sociologo/>.

Torres, Roberto (2005): “'Canción de protesta': definición de un nuevo concepto historiográfico”, en Cuadernos de Historia Contemporánea 27, 223-246.

Urrea Danilo (2013): "Manejo público-comunitario del agua. Recuperación social del horizonte común en el contexto colombiano”, en Ecología politica 45, 71-74.

VAN, Shawn (s. a.): "Mormon Land Grabbing in a Colombian 'Fairyland': the American-Colombian Corporation Fiasco, 1909-1960".

VArgas, Mónica (2008): "La deuda ecológica de los agrocombustibles", en Irene Vélez (ed.), Agrocombustibles. Llenando tanques, vaciando territorios. Bogotá: Censat Agua Viva/PCN (El Proceso de Comunidades Negras en Colombia), 57-74.

Vélez, Hildebrando (2007): Political Ecology of Energy. Ideas to stride a Path towards Sustainable Societies. Bogotá: Censat Agua Viva.

- (2008): "Los espejismos de los agrocombustibles", en Irene Vélez (ed.), Agrocombustibles. Llenando tanques, vaciando territorios. Bogotá: Censat Agua Viva/PCN (El Proceso de Comunidades Negras en Colombia), 13-50.

Vélez, Irene (ed.) (2008): Agrocombustibles. Llenando tanques, vaciando territorios. Bogotá: Censat Agua Viva/PCN (El Proceso de Comunidades Negras en Colombia).

Virola de Hoz, Joaquín (2008): Banano y revaluación en el Departamento del Magdalena, 1997-2007. Cartagena de Indias: Banco de la República/ Centro de Estudios Económicos Regionales.

Von Haldenwang, Christian (2005): "Gobernanza sistémica y desarrollo en América Latina”, en Revista CEPAL 85, 35-52.

Wade, Peter (1998): "Blackness and National Identity: Three Moments in Colombian History”, en Popular Music 17, 1-19. 
- (2003): “Compreendendo a 'África' e a 'negritude' na Colombia: a música e a política da cultura”, en Estudos Afro-Asiátios 25, 1, 145-178.

- (2005): Understanding Africa and Blackness in Colombia. Music and politics of culture", en K. Yelvington (ed.), Afro-Atlantic Dialogues: Anthropology in the Diaspora. Santa Fe: School of American Research Press, 351-378.

Walker, Gregg y Daniels, Steven (1997): "Foundations of Natural Resource Conflict. Conflict Theory and Public Policy", en Birger Solberg y Saija Miina (eds.), Conflict Management and Public Participation in Land Management. Proceedings of the International Conference, Joensuu, Finland, 17-19 June 1996. Joensuu: European Forest Institute, 13-36.

Walter, Mariana (2009): "Conflictos ambientales, socioambientales, ecológico, distributivos de contenido ambiental... Reflexionando sobre enfoques y definiciones", en Boletín ECOS 6, 1-9.

- (2011): "Conflictos ambientales: enfoques y clasificaciones", en Santiago Álvarez Cantalapiedra (coord.), Convivir para perdurar. Conflictos ecosociales y sabidurías ecológicas. Barcelona: Icaria, 37-50.

Weller, Wivian (2000): "A Construção de identidades através do Hip Hop: uma análise comparativa entre rappers negros em Sáo Paulo e rappers turcos-alemães em Berlim”, en Cuaderno CRH, Salvador 32, 213-232.

Williams, Raymod (1966): The long Revolution 1921-1988. New York: Harper \& Row.

- (1991): The Colombian Novel, 1844-1987. Austin: University of Texas Press

Zavala, Lauro (2007): Ironías de la ficción y la metaficción en cine y literatura. Ciudad de México: Universidad Nacional Autónoma de México.

Zavaleta Mercado, René: (1986). Lo Nacional-popular en Bolivia. Ciudad de México: Siglo Veintiuno.

ZnOJ, Heinzpeter; Jud, Rahel y BaKhriokTora, Yudi (2018): "Rain Forest Anomy. National parks, REDD+ implementation and the run to the forest in Jambi, Indonesia”.

REFERENCIAS DE INTERNET

AliAnZa SNV y CECODES (2010): “Las Alianzas productivas estratégicas en palma de aceite", disponible en <http://www.web.fedepalma.org/bigdata/ fedepalma/pdf/lasalianzasproductivasestrategicasenpalmadeaceite.pdf $>$.

Asociación de Productores Alternativos de Simití (ASPROAS). Paz desde la base. Disponible en <https://www.icbf.gov.co/sites/default/files/ bolivar-_asociaciones_productoras.pdf> [consultado 14.9.2019]. 
Arango, Ana María y Valencia, Leónidas (2009): "La Chirimía chocoana: asimilación y reafirmación”, en Revista Digital A contratiempo 13, disponible en <http://www.acontratiempo.bibliotecanacional.gov.co/?ediciones/ revista-13/articulos/chirimia.html> [consultado 24-9-2013].

Bouley, Catherine y Rueda, Danilo (2009): "Zonas humanitarias y Zonas de biodiversidad: Espacios de dignidad para la población desplazada en Colombia”. Disponible en <http://www.justiciaypazcolombia.com/Zonas-Humanitarias-y-Zonas-de> [consultado 10-8-2012].

Centro de Monitoreo de los Agrocumbustibles (2008): "El Brasil de los agrocombustibles. Los impactos sobre la tierra, el medio ambiente y la sociedad", disponible en <http://www.reporterbrasil.org.br/documentos/ brasil_de_los_agrocombustibles_v1.pdf> [consultado 11-7-2012].

Clínica Jurídica, Facultad de Ciencias Jurídicas, Universidad JaveriaNA (2015): "Intervención de la Clínica Jurídica sobre Derecho y Territorio en el caso de los campesinos de la hacienda de las pavas", informe final, disponible en <https://www.javeriana.edu.co/documents/15838/6479586/ Intervenci $\% \mathrm{C} 3 \% \mathrm{~B} 3 \mathrm{n}+\mathrm{de}+\mathrm{la}+\mathrm{Cl} \% \mathrm{C} 3 \% \mathrm{ADnica}+\mathrm{Jur} \% \mathrm{C} 3 \% \mathrm{ADdica}+$ sobre+Derecho+y+Territorio+en+el+caso+de+los+campesinos+de+la+hacienda+Las+Pavas/226d0a64-136b-4e42-be09-4f8c5120b6a3> [consultado 23.4.2016].

Comisión Económica para América latina y el Caribe CEPAL (2013): "Perspectivas de la agricultura y el desarrollo rural en las Américas. Una mirada hacia América Latina y el Caribe 2013", 44, disponible en <http:// www.rlc.fao.org/es/publicaciones/perspectivas-2013/> [Consultado 11-92013].

Comisión Intereclesial de Justicia y Paz (2012): "Banacol. Empresa implicada en paramilitarismo y acaparamiento de tierras. Hands of the Land", disponible en <http://www.biodiversidadla.org/Objetos_Relacionados/ Banacol._Empresa_implicada_en_paramilitarismo_y_acaparamiento_de_ tierras_en_Curvarado_y_Jiguamiando> [consultado 25-8-2013].

Departamento Administrativo Nacional de Estadística, disponible en $<$ http://www.dane.gov.co/index.php/estadisticas-sociales/necesidades-basicas-insatisfechas-nbi> [consultado 10-1-2014].

Departamento Nacional de Planeación (2015): "El campo colombiano: un camino hacia el bienestar y la paz. Misión para la transformación del campo (2015)", disponible en <https://www.colaboracion.dnp.gov.co/CDT/Agriculturapecuarioforestal $\% 20 \mathrm{y} \% 20 \mathrm{pesca} / \mathrm{El} \% 20 \mathrm{CAMPO} \% 20 \mathrm{COLOMBIA-}$ NO\%20UN\%20CAMINIO\%20HACIA\%20EL\%20BIENESTAR\%20 Y\%20LA\%20PAZ\%20MTC.pdf> [consultado 13-4-2016]. 
EChavarría, Juan Manuel (2003-2004): “Bocas de ceniza”, disponible en < https:// hambrecine.com/2014/08/10/bocas-de-ceniza/> [consultado 14.9.2019].

El Mundo (2016): "Refutan críticas de Andrés Pastrana a acuerdo con las Farc”, 28 de febrero de 2016, disponible en <https://www.eltiempo.com/ archivo/documento/CMS-16523285>.

Escobar, Melva (2016): "Afros: lo que viene después de la paz", en Semana, Disponible en <https://www.semana.com/nacion/articulo/el-poder-de-lasrazas-afros-retos-en-el-posconflicto/478249>.

Fedepalma (2010): "Código de ética y buen gobierno", disponible en <http:// www.web.fedepalma.org/sites/default/files/files/Fedepalma/CODIGO_ ETICA_FEDEPALMA.pdf> [consultado 10-9-2012].

- (2018): "Qué es el Fondo de Fomento Palmero", disponible en <https://web. fedepalma.org/que-es-el-fondo-de-fomento-palmero> [consultado 14.9.2019].

- (2018a): Boletín Económico 2, disponible en <http://www.web.fedepalma. org/sites/default/files/files/Fedepalma/BET_julio_2018_baja.pdf>.

- (2018b): Boletín Económico 4, disponible en <http://www.web.fedepalma. org/sites/default/files/files/Fedepalma/BET_OCTUBRE_2018.pdf>.

Ferrari, Sergio (2010): "La tierra semilla de paz en Colombia”, en Swissinfo.ch, disponible en <https://www.swissinfo.ch/spa/la-tierra—semilla-de-paz-en-colombia/28525356> [consultado 5.7.2012].

Finnegan, Ruth (2002): “¿Por qué estudiar la música? Reflexiones de una antropóloga desde el campo", en Revista Transcultural de Música 6, disponible en <http://www.sibetrans.com/trans/articulo/224/por-que-estudiar-la-musica-reflexiones-de-una-antropologa-desde-el-campo> [consultado: 15-10-2013].

Fundación Festival de la Leyenda Vallenata (2014): "Las colitas", disponible en <https://www.festivalvallenato.com/colitas/> [consultado: 124-2015].

García, Alfredo (2015): "Colombia importa el 28\% de sus alimentos: presidente de la SAC”, en El Pais, 25 de mayo, disponible en <http://www. elpais.com.co/economia/colombia-importa-el-28-de-sus-alimentos-presidente-de-la-sac.html>, [consultado 15-4-2016].

Global Renewable Fuels Alliance (2014): "Global Ethanol Consumption to Reduce GHGs by Over 106 Million Tonnes in 2014”, disponible en <http://www.globalrfa.org/news-media/global-ethanol-consumptionto-reduce-ghgs-by-over-106-million-tonnes-in-2014> [consultado 23-52014].

GonzÁlez, Héctor (2014): "La música vallenata según Gabriel García Márquez", en Panorama Cultural, 19 de mayo, disponible en <http://www. 
panoramacultural.com.co/index.php?option=com_content\&view=article\&id=2513:la-musica-vallenata-segun-gabriel-garcia-marquez\&cati$\mathrm{d}=3$ \&Itemid $=160>$ [consultado 25-10-2015].

Grain (2016): "El acaparamiento global de tierras en el 2016. Sigue creciendo y sigue siendo malo", disponible en <https://www.grain.org/ media/W1siZiIsIjIwMTYvMTEvMjkvMjBfMjJfNDZfNzk1X0FUR19MYW5kX0dyYWJfRGVhbHNfRVNfZmluYWwucGRmIl1d> [consultado 24.11.2017].

Incoder (Agencia Nacional de Tierras), <https://www.google.com/search?client=firefox-b-d\&q=agencia+nacional+de+tierras+colombia $>$ [consultado 13.9.2019].

INDEXMUNDI, <http://www.indexmundi.com/agriculture/?commodity=palm-oi1\&graph=production>, [consultado 7-11-2013].

LifeMosaic (s. a.): "Palma de aceite", disponible en <http://www.lifemosaic. net/esp/proyectos/palma-de-aceite/> [consultado 11-12-2013; 12-8-2013].

Mandato Agrario (2003): "Congreso Nacional Agrario Por vida digna, soberanía alimentaria, derecho a la tierra y a la territorialidad. ¡No al ALCA!", disponible en <http://www.mamacoca.org/FSMT_sept_2003/ es/lat/mandato_agrario.htm> [consultado 25.5.2015]

Mingorance, Fidel (2006): "El flujo del aceite de palma Colombia-Bélgical Europa. Acercamiento desde una perspectiva de derechos humanos". Bruselas: Human Rights Everywhere, disponible en <http://www.collectifs. net/cbc/doc/informe_es_v3-1.pdf> [consultado 22-5- 2011].

Molano, Alfredo (2011): “Campesinos, narcos y humedales", en El Espectador, 17 de diciembre, disponible en <http://www.elespectador.com/impreso/nacional/articulo-368762-caso-el-garzal> [consultado 10-10-2012].

- (2012): "Caso el Garzal. Viaje al pasado y presente de un corregimiento del sur de Bolívar donde narcos y paramilitares han atemorizado a las comunidades", disponible en <https:/www.swissaid.ch/sites/default/files/ Caso-El-Garzal_es.pdf>.

Nuevo Acuerdo Final para la Terminación del Conflicto y la Construcción de una Paz Estable y Duradera, disponible en <https://www. mesadeconversaciones.com.co/sites/default/files/12-1479102292.11-1479 102292.2016nuevoacuerdofinal-1479102292.pdf> [12-11-2016].

OCHA, United Nations Office for the Coordination of HumanitaRIAN AfFaIRs, <http://www.colombiassh.org/site/IMG/png/Choco_A3_ sin.png> [consultado 13-4-2013].

OchoA A., María (2002): "El desplazamiento de los discursos de autenticidad: Una mirada desde la música", en Revista Transcultural de Música, 
disponible en <http://www.sibetrans.com/trans/articulo/231/el-desplazamiento-de-los-discursos-de-autenticidad-una-mirada-desde-la-musica> [consultado 12-5-2012].

- (2006): "A manera de introducción: La materialidad de lo musical y su relación con la violencia", en Revista Transcultural de Música, disponible en <http://www.redalyc.org/pdf/822/82201001.pdf> [consultado 29-52012].

Osorio, Camila (2011): "Así se concentró la tierra en los Montes de María", en La silla vacía, 4 de julio, disponible en <https://www.lasillavacia.com/ historia/asi-se-concentro-la-tierra-en-los-montes-de-maria-25534>.

Peace Brigades Colombia (20i6): "Democracia y ciudadanía en Guamocó", en PBI Colombia, disponible en <https://www.pbicolombiablog. org/2016/12/11/democracia-y-ciudadania-en-guamoco/>.

Pendzich, Christine, Thomas, Garry y Wohigent, Tim (1994): The Role of Alternative Conflict Management in Community forestry. Roma: FAO, disponible en <http://www.fao.org/docrep/005/x2102e/X2102E00.Htm> [consultado 12-9-2011].

Perspectivas de un Programa de Biocombustibles en América Central (2004): "Proyecto Uso Sustentable de Hidrocarburos (Convenio CEPAL)", disponible en <https://www.cepal.org/es/publicaciones/25669-perspectivas-un-programa-biocombustibles-america-central-proyecto-uso> [consultado 12-9- 2013].

Programa de Naciones Unidas para el Desarrollo (PNUD) (2011): "Colombia rural. Razones para la esperanza. Informe Nacional de Desarrollo Humano 2011". Bogotá: INDH, PNUD, disponible en <http://www. pnud.org.co/sitio.shtml\#.UvFI1NhbC71> [consultado 25-9-2012].

Programa Suizo para la Paz en Colombia SUIPPCOL, <http://www.pas. org.co/\#!suippcol> [consultado 1-8-2013].

RAmírez LasCarro, Luis Carlos (2017): "Vallenato, ¿etiqueta para una moda?", en Portal Vallenato, 17 de mayo, disponible en <https://www. portalvallenato.net/2017/05/17/vallenato-etiqueta-para-una-moda/\#more-96589> [consultado 21.05. 2017].

Real Academia Española (2001): Diccionario de la Real Academia de la Lengua Española, 22a edición, disponible en <https://www.rae.es/recursos/ diccionarios/diccionarios-anteriores-1726-2001/diccionario-de-la-lengua-espanola-2001>.

Rendón Marulanda, Olga Patricia (2016): "Los desplazados sí quieren retornar", en $E l$ Mundo, 22 de diciembre, disponible en <http://www. elmundo.com/portal/pagina.general.impresion.php?idx=271640>. 
Retorno a Las Pavas, <https://retornoalaspavas.wordpress.com/>.

Reyes Posada, Alejandro (2015): "Dos demagogias enfrentadas en el agro", en El Espectador, 20 de junio, disponible en <http://www.elespectador. com/opinion/dos-demagogias-enfrentadas-en-el-agro-columna-567501> [consultado 10-5-2017].

Rodríguez, Carlos: "La tradición oral en el Pacífico sur colombiano", en El Decimarrón, disponible en <http://www.eldecimarron.blogspot.ch/p/ la-tradicion-oral-en-el-pacifico-sur.html $>$ [consultado 10-10-2013].

Semana (2009): "Agro escándalo seguro", disponible en <http://www.semana.com/nacion/articulo/agro-escandalo-seguro/108603-3>.

Semana Sostenible (2018a): "El monitoreo comunitario ya probó que puede frenar la deforestación", 28-11, disponible en <https://www.sostenibilidad.semana.com/medio-ambiente/articulo/el-monitoreo-comunitario-ya-probo-que-puede-frenar-la-deforestacion/42226> [consultado 12-6-2019].

- (2018b): "Colombia conocerá qué tanta palma de aceite alberga en su territorio", 30-11, disponible en <https://www.sostenibilidad.semana.com/ medio-ambiente/articulo/colombia-conocera-que-tanta-palma-de-aceite-alberga-en-su-territorio/42244> [consultado 12-6-2019].

Soler, Juan Pablo y León, Daniel (2009): "Impactos ambientales de la expansión de palma aceitera en el Magdalena Medio, hablan los pobladores. Estudio de Caso. Las Pavas, Municipio El Peñón, Departamento de Bolívar, Colombia", disponible en <http://prensarural.org/spip/IMG/pdf/ Informe_de_Impactos_Ambientales_Version_FINAL._1_.pdf> [consultado 15-4-2012].

VArGas, Ricardo et al. (2010): "Informe Comisión Independiente Conflicto de Tierras Las Pavas-Bolívar, Colombia”, Body-Shop y Christian Aid, disponible en <http://www.setianworks.net/indepazHome/attachments/601_ Las\%20Pavas\%20PUBLICACION\%20FINAL.pdf> [consultado 21-42012].

VÉLEZ, Irene et al. (2010): "Misión Internacional para la verificación del impacto de agrocombustibles en 5 zonas afectadas por los monocultivos de palma aceitera y caña de azúcar en Colombia", disponible en $<$ http://detenerelacaparamientodetierras.files.wordpress.com/2011/11/informe-mision-internacionl-agrocombustibles1.pdf> [consultado 12-5-2011].

VALdÉs, Constanza (2011): "Can Brazil Meet the World's Growing Need for Ethanol?”, disponible en <https://www.ers.usda.gov/amber-waves/2011/ december/can-brazil-meet-the-world-s-growing-need-for-ethanol/> [consultado 17-5-. 2012]. 
Villamizar, Katherine (2018): “Colombia tendrá 24 empresas de palma certificadas en dos años”, en La Opinión, 8 de junio, <https://www.laopinion.com.co/economia/colombia-tendra-24-empresas-de-palma-certificadas-en-dos-anos-155939\#OP> [consultado 23 agosto 2018].

Wilson, David (ed.) (2012): “Gobernanza de la tierra en Brasil. Estudio geo-histórico de la gobernanza de la tierra en Brasil”, disponible en <https:// www.landcoalition.org/es/resources/gobernanza-de-la-tierra-en-brasil>, [consultado 13-4-2013].

\section{REFERENCIAS LEGISLATIVAS}

Corte Interamericana de Derechos Humanos (CIDH) (2010): "Medidas Provisionales Respecto de la República de Colombia asuntó Comunidades Jiguamiandó y Curvaradó”,

LEY 2 DE I959, "Por la cual se dictan normas sobre economía forestal de la Nación y conservación de recursos naturales renovables", 16 de diciembre de 1959, Congreso de Colombia.

LEY 70 DE I 993, "Por la cual se desarrolla el artículo transitorio 55 de la Constitución Política”, del 27 de agosto de 1993, Diario Oficial no 41.013 del 31 de agosto de 1993.

LeY I60 DE I 994, "Por la cual se crea el Sistema Nacional de Reforma Agraria y Desarrollo Rural Campesino, se establece un subsidio para la adquisición de tierras, se reforma el Instituto Colombiano de la Reforma Agraria y se dictan otras disposiciones", 3 de agosto de 1994, Diario Oficial n. ${ }^{\circ}$ 41.479 del 5 de agosto de 1994.

LEY I3 8 DE I994, "Por la cual se establece la cuota para el fomento de la Agroindustria de la Palma de Aceite y se crea el Fondo del Fomento Palmero", 9 de junio de 1994, Diario Oficial 41.389.

LEY 387 DE I997, "Por la cual se adoptan medidas para la prevención del desplazamiento forzado; la atención, protección, consolidación y estabilización socioeconómica de los desplazados internos por la violencia en la república de Colombia”, 18 de julio de 1997, Diario Oficial n. 43.091 del 24 de julio de 1997.

LEY I 448 DE 20I I, "Ley de Víctimas y Restitución de Tierras", Unidad de Restitución de Tierras, Ministerio de Agricultura y Desarrollo Rural.

Sentencia T-025/2004, (magistrado presidente Luis Ernesto Vargas Silva), Corte Constitucional Sala Especial de Seguimiento, Auto 096 de 2013. 
Sentencia T-267/i i "Acción de Tutela contra las actuaciones de autoridades de policía", 8 de abril de 2011, Corte Constitucional de Colombia.

OTROS DOCUMENTOS OFICIALES

Comisión de las Comunidades Europeas (200I): Libro blanco sobre la gobernanza, disponible en <https://eur-lex.europa.eu/legal-content/ES/ TXT/?uri=LEGISSUM\%3Al10109>.

Consejo Nacional de Política Económica y Social (CONPES) 3491: "Política de Estado para el Pacífico Colombiano".

Defensoría del pueblo: Defensoría delegada para la prevención del riesgo de violaciones a los Derechos Humanos y DIH. Sistema de Alarmas Tempranas. Informe de Riesgo número 008-12A.I, 22 de junio de 2012.

Defensoría del pueblo: Resolución Defensorial no 39, "Violación de los Derechos Humanos por siembras de palma africana en territorios colectivos de Jiguamiandó y Curvaradó/Chocó”, 2 de junio de 2005.

Departamento Administrativo Nacional de Estadística (DANE): Documento Necesidades Básicas Insatisfechas (NB), por total, cabecera y resto, según departamento y nacional. Resultados Censo General 2005.

Evaluación Ambiental Estratégica del Ministerio de Ambiente, Vivienda y Desarrollo Territorial y el Instituto de Biodiversidad, 2008.

Fiscalía General de la Nación: Proceso 3856, Indagatoria a palmeros, 23 de diciembre de 2007. 


\title{
Anexo. Corpus de cantos recopilados
}

\author{
Cantos de las zonas humanitarias \\ Cacarica y Nueva Esperanza
}

Canto 1

Título: Sin título

Cantautor: Erasmo Cuadrado

Pongan cuidado señores

Lo que aquí nos sucedió

El martes treinta de marzo

En la cuenca del Jiguamiandó (bis)

Llegaron los militares

Y de sorpresa nos cogió.

Entraron por todas partes

Metiendo miedo y terror (bis)

El miércoles en la mañana

A las Palomas llegaron

Disparándole a la gente

Sin tenerle compasión (bis)

Y hasta un niño asesinaron

En presencia de la gente

Y después pa' disculparse

Dijeron que era un error (bis)

Y después pa' subsanar
El error que cometieron

Se llevaron al cadáver

Y a sus padres también (bis)

Pensando que con dinero

Iban a recuperar

La vida de un ser humano

Que nada tiene que ver (bis)

$\mathrm{Y}$ ahora me pregunto yo

Lleno de remordimiento:

¿Dónde está la transparencia

Del gobierno nacional? (bis)

Mientras que los pobres niños

Son los que se están muriendo

Allá están los asesinos

En el palacio nacional (bis)

Haciendo su comitiva

Invitando a celebrar

La vida de un campesino

Que acá vienen a matar (bis) 


\section{Canto 2}

Título: "El dos de Junio" Cantautor: Erasmo Cuadrado

Me acuerdo aquel dos de junio

Cuando al campo salí a jugar

Que nos atacó el gobierno

Vestido de paramilitar (bis)

Le damos gracias a un labriego

Que salió a trabajar

Que cuando el vio este grupo

Al pueblo corrió a avisar (bis)

Cuando ellos incursionaron

Que no nos pudieron matar,

Solo para desquitarse

Quemaron nuestro hábitat (bis)

Y ellos son como la rata

Donde pueden atacar

Lo que no llevan lo dañan

Es su forma de actuar (bis)

Fija, gobierno corrupto

Lo que hoy día estás haciendo

Con tantos niños ya huérfanos

Que de hambre están muriendo (bis)

Y ellos son como la rata

Donde pueden atacar

Lo que no llevan lo dañan

Es su forma de actuar (bis)

Con esta crisis tan dura

Dónde iremos a parar

Aunque vivamos en el campo

No podremos trabajar (bis)

Y ellos son como la rata

Donde pueden atacar

Lo que no llevan lo dańan

Es su forma de actuar (bis)

\section{Canto 3}

Título: "Ciento veinte muertos" Cantautor: Erasmo Cuadrado

Tengo el corazón herido Y lleno de remordimiento Y esto es culpa del gobierno Que ha causado tanto muertos (bis)

Son ciento veinte personas

Las que han asesinado

Y esto ha sido con la cara del

Gobierno ParaEstado (bis)

Por eso el Jiguamiandó se imita

Diciéndole al mundo entero

Que estos ciento veinte muertos

Es por causa del dinero (bis)

Ellos invitan a empresarios

Que vengan a trabajar

Para que siembren la palma

Viendo que eso es ilegal (bis)

Y nosotros el campesino

No podemos reclamar

Porque de inmediatamente

Nos vienen a masacrar (bis)

Canto 4

Título: "La palma"

Cantautor: Erasmo Cuadrado

Póngame cuidado amigo(h)

Lo que les voy a contar (bis)

Por esa maldita palma

Nos han venido a matar (bis)

El cultivo de la palma

Es un cultivo ilegal (bis)

Por eso los campesinos

Allá fuimos a mochar (bis) 
Por medio de los empresarios

Hemos sido amenazados (bis)

Por esos capitalistas

Y por parte del Estado (bis)

¡Ay! el territorio nuestro

Tiene una riqueza inmensa (bis)

Minerales flora y fauna

Embellecen nuestras cuencas (bis)

De las penas que yo tengo

Algunas les he contado (bis)

En todos estos problemas

Ha estado metido el Estado (bis)

Y ha estado metido el Estado

Mis penas no han terminado (bis)

Mis penas no han terminado

Y ha estado metido el Estado (bis)

\section{Canto 5}

Título: "Negros en Palenque"

CANTAUTOR: Isidro Romańa

Miren el tiempo que estamos

Que todos estamos sufriendo (bis)

Hay motivos de luchar

Unidos y organizados (bis)

Si hay fracaso en el camino Luchemos con más amor (bis)

Ay, que morimos es por el pueblo Y por darle la solución (bis)

No nos quedemos atrás

Ay, luchemos con más amor (bis)

Que morimos es por el pueblo

Por darle la solución

Que abogados ya tenemos

En el tribunal de Dios (bis)

Investigando los casos

Que a todos nos sucedió (bis)

Lucha pueblito ancestral

Lucha y defiende tu herencia (bis)
Lucha por lo de tus hijos

Y no olvides tus creencias (bis)

Creencias de esos ancestros

Ay, que luchaban como hermanos (bis)

Qué cultura tan hermosa

Que tenía nuestra gente

Lucha y defiende su honor

Como negros de Palenque

\section{Canto 6}

Título: Sin título

\section{CANTAUtor: Erasmo Cuadrado}

Tengo una pena en el corazón

Que me lastima los sentimientos (bis)

$\mathrm{Al}$ ver los niños en un sufrimiento

Sin poder darle una solución (bis)

Ellos hoy no cuentan con recreación

Tampoco pueden ir a estudiar (bis)

Viven sufriendo desnutrición

Yo creo que el hambre los va a matar

(bis)

Ya hoy los dineros de Bienestar

Ya bien están en otros bolsillos (bis)

Entre caimanes y caimancillos

Que siempre logran acaparar (bis)

Ay, la población infantil

Que es el futuro de nuestra patria

Hoy, la población infantil

Que es el futuro de nuestra patria

Está condenado es a sufrir

$\mathrm{Y}$ a vivir sin una esperanza

Ay, ya los niños de esta región

Siempre reciben tratos infames

Viven sufriendo desnutrición

$\mathrm{Y}$ ya se mueren en los hospitales 


\section{Canto 7}

Título: "Óyeme Chocó”

Cantautora: Deyanira Mosquera,

\section{CD Óyeme Chocó}

¡Óyeme Chocó!

Te quiero besar

Era un sueño y se hizo realidad

Coro

¡Óyeme Chocó!

¡Oye por favor!

Tú no tienes por qué estar sufriendo así

La resignación

De tu corazón

Algún día llegará la redención (bis)

Después de tanta amargura

De dolor y de pensar

Por fin unidos

Lograremos retornar

Coro

Esta historia sucedida

No quisiera recordar

Mis hermanos asesinado(h)

Y hoy vamos a retornar

Coro (bis)

\section{Canto 8}

Título: "El sofoco"

\section{Cantautora: Julia Valdemar, CD Óyeme Chocó}

La gente salió del Chocó

No con gusto ni ganas tampoco (bis)

A nosotros no nos mataron

Pero sí mataron un poco (bis)

Yo le doy gracias a Dios

Que a mí nada me sucedió (bis)
Pero lo que si más me duele

Fue que allá todo se perdió (bis)

Le exigimos al presidente

Todos los desplazados hermanos (bis)

Que nos dé una reubicación

En el casco urbano e Turbo (bis)

Nosotros no somos perezosos

Y nos gusta de trabajar (bis)

Con qué cara volvemos allá

Con semejante corretear (bis)

\section{Hablado:}

Pedimos una reubicación digna.

$\mathrm{Y}$ esto es para que lo escuche Colombia y el mundo entero.

\section{Canto 9}

Título: "El sufrimiento"

CANTAUTOR: Efraín Ávila, CD Óyeme

\section{Chocó}

El sufrimiento que hay en mi pueblo

Lo estoy sufriendo con mucho dolor

(bis)

Lo digo porque esta situación

No la había vivido en esta región (bis)

Lo digo porque esta situación

Me tiene muy triste con mucho dolor (bis)

Ellos salieron de su ranchito

Dejando todo tirado a perder (bis)

Unos salieron acompaños

Con los hijitos y la mujer (bis)

Más sin embargo vivo hacinado

Luchando por nuestro deber (bis) 
Porque el gobierno ha hecho cosas Que nunca en la vida debería de hacer Matando los hombres y las mujeres Dejando niños sin parecer (bis)

A quién le importa la guerra en Colombia Ya no se vive con tranquilidad Los hombres lloran pidiéndole a Cristo Dios mío esta guerra dónde irá a parar

Porque el sonido de estas metralletas

No hacen silencio en el Urabá

No hacen silencio en el Urabá

Porque el sonido de las metralletas

No hacen silencio en el Urabá

Falta nobleza con los campesinos (bis)

Porque al campo quieren retornar

A trabajar sin temor ninguno

Así podemos vivir en paz

\section{Canto 10}

\section{Título: "Violencia Brava"}

CANTAUTOR: Javier Ávila, CD Óyeme

Chocó

Yo voy a contarles lo que nos pasó Con toda mi gente en la tierra del Chocó (bis)

Y las mujeres gritaban

Y los niños que lloraban

Y los actores armados, ellos no reflexionaban (bis)

Hace treinta años que vivíamos es esa tierra Los patriarcas aquí la (...) son los que refieren de ella

Oiga señor Presidente

Usted qué es lo que le pasa

Con esta violencia brava

Que cometió la desgracia
Vivimos soñado en esa bonita tierra

Y también contamos con esos recursos de ella

Oiga Doctor Samper

Con fusiles y metrallas

Dejaste quitar la tierra con esa violencia brava

\section{Canto 11}

Título: "Cómo fue"

Cantautor: Augusto Gómez

Les vengo a contar la historia

De nuestro desplazamiento

Como fue que sucedió

Estando allá en el Chocó

Este es un caso muy moro

Para que el mundo lo sepa

Nos sacaron a la fuerza

Con bombas y metralleta (bis)

Con bombas y metralleta

Y fue la pública fuerza

El 24 de febrero del año 97

Un lunes de mañanita

Estando allá en montañita

La gente se levantaba

Pa' su tarea cotidiana

Cuando en el cielo escuchamos

Unos grandísimos ruidos

De los pájaros cristales

Que venían a su destino

Que venían a su destino

A sacar el campesino

Ya siendo la hora siete

Esto si me dolió a mí

De seguido allá explotaban

Las bombas en el Salaquí 
De los aviones safir

Que allá rápido volaban

Cumpliendo con su misión

Pa’ cabar la población

Cumpliendo con su misión

Pa' cabar la población

De esa bella región

Como a las seis de la tarde

El caso nos preocupaba

Allá en la comunidad

La fuerza también se entraba

Con ráfagas de metralla

Y bombas también tiraban

Cuando salimos corriendo

Huyendo pa' la montaña

$\mathrm{Y}$ en mis brazos yo cargaba

Una niña que lloraba

Una niña que lloraba

Su madre desesperada

\section{Canto 12}

\section{Título: "El gobierno de la gente" Cantautor: Augusto Gómez}

En el gobierno de la gente

Ahora sí estamos fregados

Ya no dejan trabajar el pueblo

campesinado

Ya no dejan trabajar a este pueblo

chocoano

Nos sacan de nuestra tierra

Porque es zona guerrillera

$\mathrm{Y}$ eso todo lo hacen para quedarse con ella

Para quedarse con ella, con nuestra

querida tierra

Cantando le sigo yo

A mi pueblo desplazado

Debemos vivir unidos

Para volver a Chocó
Porque esa tierra querida

Nos la dio fue nuestro Dios

Ella nos da nuestro pan

para darle a nuestra familia (bis)

Póngame mucho cuidado

Usted señor Presidente (bis)

En su gobierno e la gente

Lo que hay es desplazados

Nos tiene aguantando hambre

Siendo todos colombianos

Y estamos decepcionados

Con su gobierno tan malo (bis)

\section{Canto 13}

Título: El señalamiento

Cantautor: Augusto Gómez

Me siento muy preocupado

En mi país

Y porque somos de aquí

No podemos vivir

Es por la tanta injusticia

Con el pueblo campesinado

Porque somos seńalados

Objetivo militar

De los gobiernos de turno

Pa' podernos asesinar

Por lo que me he dado cuenta

Ya está comprobado

Cuando entramos a denunciar

El atropello social (bis)

Esos actores armados

Que nunca quieren la paz

Por eso que es que están violando

Aquellos grandes tratados

Del derecho humanitario

Y los derechos humanos 
Otro caso sucedido el 7 de junio En el año 2001 llegó otra invasión De ejército irregular

Con su paramilitar

Allí otra vez fue violado

El territorio de vida

Por sus actores armados

En el pliego de petición

\section{Cantos DE LA ZONA HUMANITARIA \\ CACARICA}

\section{Canto 14}

Título: "Llanto"

\section{CANTAUTOR: Los Renacientes}

Soy chocoano, colombiano

Origen africano

La melancolía me envuelve a recordar mi pasado

Pero aquel que lo olvida

El mismo se ha condenado

Seguiremos luchando por el sendero sońado

Soy hermano te sueño lo que están burlando

Aquellos leones que lo están devorando

Desde atrás los negros hemos sido

golpeados

Recordar mi pasado

Un pueblo encadenado

Seguiremos luchando por lo que están

pensando

Porque con otros medios nos están

esclavizando

Diremos no a lo planeado

Carretera panamericana

Para destruir nuestra tierra amada

Cacarica

Estas ratas podridas

Imponen nuestras vidas

Que nos prepara el destino

Le pregunto al de arriba
Sólo le pido una cosa

Que me de valentía

Para seguir luchando por el resto de mis

días

Llanto el que vive mi gente

No sé qué vamos a hacer con estos

dementes

Y son los planes que incrementan a la guerra

Siembras de monocultivos que dañan a la tierra

Por otro lado la carretera amenazando

Un sector pobre que la tierra está cui-

dando

Como lo hicieron también nuestros

ancestros

Teniendo en cuenta que la tierra no tiene precio

Ellos murieron, hoy no están con

nosotros

Pero en nuestra mente se reflejan sus

rostros

Lucha civil,

Con la pacha tierra linda que nos da el vivir

(...) Hermano que nos han matado

Por luchar en contra de vivir encadenado

La gente pobre es la que siempre matan

Los asesinos felices en hoteles con buena plata

Esta es la enseñanza del maldito sistema La gente que lo rechaza la tratan como el problema

Oh pacha tierra mama

No vamos a callar

Aquí están Los Renacientes

Que de ti cuidarán (bis)

Llanto el que vive mi gente

No sé qué vamos a hacer con estos

dementes 


\section{Canto 15}

Título: "Vaguay"

\section{CANTAUTOR: Los Renacientes}

Oye, Vaguay ¿qué te está pasando?

Los Rena vienen rompiendo cadenas

Oye Vaguay ¿qué te está pasando?

La historia de nuestros negros, que nos quedan

No estamos felices en esta puta nación Que persiguen y humillan

A la gente sin razón

La tierra es nuestra madre

La madre de la vida

Los indígenas vivían

Con la madre en la armonía

No queremos lo(s) que se deleiten

Con el dedo metido dentro de la gente

Como un tierno cordero

Malvado hijueputas

Que atropellan nuestro pueblo

Ya estoy fatigado

Que se vayan al infierno

Oye Vaguay, ¿qué te está pasando?

Los Rena vienen rompiendo cadenas

Oye Vaguay ¿qué te está pasando?

La historia de estos negros es que nos

quedan

Humillando a mi gente

De miles maneras

No le des mente a eso

Lucha hasta que puedas

Aquí nos invadieron

Se robaron todo el oro

De la tierra se adueñaron

Muchos negros maltrataron

En esta madre tierra nadie se va a quedar

Y mi Dios tu cuenta no se las va perdonar

Aquellos que oprimen

Y nos siembran la miseria

Ya estoy cansado

Que se vayan a la mierda

Oye Vaguay, ¿qué te está pasando?

Los Rena vienen rompiendo cadenas

Oye Vaguay ¿qué te está pasando?

La historia de estos negros es que nos quedan

Humillando a mi gente

De miles maneras

No le des mente a eso

Lucha hasta que puedas

Penas cobrará

Una a una, diferentes maneras

Meterte con mi gente

Que nada malo de ella espera

Arranca al negro

Del África madre tierra

Lo traen como esclavo

A laborar (...) sin tierra

El negro utilizado

Como una herramienta

No tiene valor

Interesa es su fuerza

Por eso nos maltratan

Y nos tratan por las duras

Pa’ desintegrarnos de nuestras culturas

Oye Vaguay, ¿qué te está pasando?

Los Rena vienen rompiendo cadenas

Oye Vaguay, ¿qué te está pasando?

La historia de estos negros es que nos quedan 
Parece que algunos afros

Se olvidaron del ayer

Sirviendo a ciertos ricos

Que nos quieren es joder

Vienen del norte

Con plata y tecnología

A robar nuestros recursos

$\mathrm{Y}$ a acabar con nuestras vidas

Nosotros no comemos

De amenazas de oligarcas

Por eso nos persiguen como si fuéramos ratas

Ratas, ¿por qué? por cuidar nuestra tierra $\mathrm{Y}$ así nuestros niños puedan vivir en ella

\section{Canto 16}

\section{Título: "Tierra querida"}

\section{CANTAUTOR: Los Renacientes}

Yo tengo una tierra

Una tierra allá

¿Y cuál es esa tierra? (bis)

Es la tierra natal

¿Y dónde es esa tierra? (bis)

Es el Chocó

¿Y dónde es el Chocó?

Donde somos desplazados

Oiga pues mi amigo

Lo que le voy a contar (bis)

Que ahora sí es verdad que vamos a retornar (bis)

Coro

Oiga pues mi hermano

Óigame mi señor

Que ahora si nos vamos

Para el Chocó

Porque esa es la tierra que nuestro Dios nos dejó (tres veces)
Cuánto soñamos con retornar

Ahora sí este sueño se nos hizo realidad

Yo les cantaré y también les rapearé

Cuando estemos en la Cuenca

Nos vamos a sentir muy bien

Porque esa es la tierra que nos vio nacer

¿Por qué?, ¿por qué? ¿Por qué?, ¿por qué?

Porque esa es la tierra que nuestro Dios

nos dejó (tres veces)

Oiga pues mi hermano

Óigame mi señor

Que ahora si nos vamos

Para el Chocó

\section{Canto 17}

Título: "Homenaje a nuestros

mártires"

\section{Cantautor: Los Renacientes}

Coro

Llora mi pueblo al recordar los hermanos que hoy no están

(bis)

Tierra santa y bendita la cual habitamos Sońar vivir en comunidad amando a su hermano

La gente se levantaba a sus áreas cotidianas

Y no morirse de hambre acostado en la cama

Un pueblo que es feliz rodeado de la

fauna

Que en el mundo no es nada sin nuestra pacha mama

Pero ha llegado el día más inesperado

La mańana gris y aún en verano

Fecha inolvidable como el 97

Donde mataron hermanos con

motosierra y machete 
Es triste recordar tanta gente que corría Mujeres embarazadas y nińos que nacieron ese día

Pero algo doloroso en nuestras mentes se quedó

Ver como masacraban tanta gente en el Chocó

De forma inhumana un hermano mataron Cortándole la cabeza y con ella jugaron Hermano Marino López has regresado a tu tierra

Lo triste que son tus restos esto es producto de la guerra

Tú y otros hermanos que la tierra cobijó El culpable es el gobierno y Rito Alejo porque ordenó

Que porquería desgraciado que al senado se lanzó

Haciéndose el inocente después que el pueblo sangró

Vimos que desunidos no se puede seguir. Entonces nos organizamos para poder resistir

\section{Coro}

Queremos decirle al mundo todo lo que está pasando

Con estos proyectos que nos están perjudicando

Hoy le decimos al pueblo que siga luchando

Para que estos ricos cabrones no nos sigan esclavizando. Con dolor la frontera muchos hermanos cruzaron

Al llegar a Cúpica, allí se refugiaron

Días interminables de dolor y amargura

Donde mataron hermanos, las fosas eran sepulturas

Coro

Con el dolor en el alma por lo que nos pasó

Regresamos a Cacarica a resistir con amor
Situaciones injustas hemos vivido Por defender los derechos de este pueblo sufrido

Empresas que arrasan nuestra

biodiversidad

Una vez más afirmamos en este tribunal Hoy dejamos bien claro lo que nos está pasando

Que las multinacionales nos están masacrando

Apoyando con recursos al

paramilitarismo

Para que vayan al campo a masacrar

campesinos

Momentos difíciles nos tocó pasar

En el coliseo de Turbo para poder

retornar

Toda la gente lloraba de la persecución

Del mismo gobierno que nos desplazó

Con metralletas y bombas nos sacaron

de aquí

Pruebas palpables están en el Salaquí

Donde existe una bomba que no explotó

Díganme si eso justicia, lo que se vivió

en el Chocó

Fecha inolvidable la de Curvaradó

Donde destrozaron una niña porque por

miedo corrió

Con la memoria de Marino queremos

recordar

Nuestros mártires burlados en esta guerra sin piedad

Planes sobre planes, en mi territorio

Hoy estamos aquí para defender el patrimonio

\section{Coro}

Malhechores inoportunos que nos siembran la miseria

Engańando al pueblo y quedarse con la tierra

Que desgracia que viven estos pueblos

colombianos

Unifiquemos propuestas y luchemos 
como hermanos

Hoy recordamos Orlando en el Jiguamiandó

Que luchar por su gente la vida le costó

Su cuerpo no se encuentra, su espíritu nos apoya

Aquí estamos los renacientes que conservamos su memoria

\section{Canto 18}

\section{Título: Sin título}

\section{CANTAUTOR: Los Renacientes}

\section{Coro}

Todos vamos caminando

Y las cosas van pasando

Hasta cuándo/dónde este silencio

Yo te pregunto mi hermano (bis)

Renaciente, presente

Uno más sobreviviente

De la cual expresa

Lo que en su corazón se siente.

Tenlo presente

Representando

Toda mi gente

Que camina con claridad

Tranquilidad, justicia y solidaridad.

Nuestro rap como objetivo es

Construcción de paz.

Agarrados de la mano

No nos matemos

Que todos somos seres humanos.

Toma conciencia

Pueblo maltratado

Yo represento al campesinado

Con talento y rimas

Brotadas desde adentro

Tierra fértil

Y productora maíz, plátanos y arroz

Es una parte de la economía en el

Choco.

Oh, así es como rimo yo
Con paciencia

No queremos más sevicia

Por poca conciencia

Coro

Todos vamos caminando...

Ríos, aves, vegetales

Sopla el viento

Se me eriza el cuerpo

Cuando pienso que mańana

Esto será un desierto

¿Qué será de mi cimiente?

Protejamos el medio ambiente

Digamos "no más"

A los destrozos de la gente

Entro en ambiente

Rápidamente,

Con este calor

Que pica como serpiente

¿Cuándo vamos a vivir feliz, mi gente?

Una mańana lluviosa

Y muy espesa

Como cae la lluvia

Sobre la naturaleza

Los micos jugando

Las aves volando

Los niños contentos

Con su aire sao

Si tú eres consciente

No lo destruyamos

Te brinda amor y mucha fortaleza

Coro

Yo te pregunto mi hermano...

Desde el Chocó

Vengo caliente

Pegao, con armonía

Resistiendo un nuevo día

Con melodía

En la sevicia

Que se ve todos los días, hermano

Ten conciencia 
Y no apoyes la delincuencia

No más violencia, despojo

$\mathrm{Ni}$ discriminaciones sin consciencia

Que atropellan estos pueblos

De las forma más dura

Con desplazamientos, masacres y

torturas

Golpeado por el capitalismo y el Estado enmascarado que...

Coro

Desde Chocó, Colombia Cacarica, Renacientes

\section{Cantos}

de la comunidad de Las Pavas

\section{Canto 19}

Título: "Algún día es mañana"

CANTAUTOR: Edwin Torres

Les voy a contar la historia

Les voy a contar la historia

Que ha pasado aquí en mi pueblo

Me quemaron la casita

Que tenía yo en Las Pavas

Por culpa de las palmeras

He quedado a la deriva

Por culpa de las palmeras

Tengo un dolor en el alma

Coro

Pero yo no me preocupo

Porque sé que un día es mañana

Viene la peste cogollera

Para la palma africana

Como yo no tengo fuerza

Para hacer una venganza

Se la dejo a Dios del cielo

Que es el dueño de mi alma

Yo vivía esperanzado

En este bendito gobierno
Y ahora les digo cantando

Que esto no sirvió de nada

Cuidan es al de la plata

Y al pobre si lo desplazan

Para quitarle las tierras

Y sembrar palma africana

Coro

Pero yo no me preocupo

Porque sé que un día es mañana

Viene la peste cogollera

Para la palma africana

Como yo no tengo fuerza

Para hacer una venganza

Se la dejo a Dios del cielo

Que es el dueño de mi alma

\section{Canto 20}

Título: "Bonaerenses de ASOCAB"

CANTAUTOR: Efraín Alvear

Bonaerenses campesinos

Agricultores asociados

Que en seis letras se dice

$\mathrm{Y}$ es la empresa de ASOCAB

Es un arma poderosa

En manos de un abogado

$Y$ también es una fuerza

Que nadie puede aguantar

\section{Coro}

Ay Buenos Aires, te queremos invitar

Que no te apartes de la empresa

de ASOCAB

Que estando unidos

Es como podemos lograr

El objetivo, que queremos alcanzar

ASOCAB es una empresa

De un mil de agricultores

Que sólo tienen machete

Y también un barretón 
Pero tienen honestidad

Y también otros valores

Garantía que te invitan

A hacer en ella inversión (coro)

Siendo solidarios

Es cómo tenemos la paz

Entre hermanos y amigos

Esta es nuestra gran unión

Abiertos al conocimiento,

Fuente de la libertad

Y esto ha hecho al pequeño

Grande en nuestra gran asociación

Coro

De los grandes poderosos,

ASOCAB rescata tierra

Para darlas a los pobres

Y campesinos en posesión

No derrama sangre,

Tampoco hace guerra

ASOCAB es laboratorio

De paz en nuestra región

Coro (bis)

Canto 21

\section{Título: "Historia de mi vida"}

Cantautor: Orlando Ospino

Campesino bonaerense

Tú que quieres trabajar

Tienes que tener primero

La tierra pa' cultivar

Lo digo por experiencia

Que tengo una edad avanzada (bis)

Me sacaron de Las Pavas

Tierra donde cultivaba

Sembraba maíz y yuca,

Patilla y ajonjolí (bis)
Estos eran los cultivos

Con que yo podía vivir (bis)

Me arrancaron el mafufo

El cacao y también la ahuyama

Todo eso lo destruyeron

Pa' sembrar palma africana (bis)

El tiempo que cultivaba

Me sentía muy contento

La comida me sobraba

Y también el bastimento (bis)

Pobrecita de mi vida

Y hoy no tengo que comer (bis)

No tengo pa' la panela

Y me hace falta el café (bis)

Mis hijos también se fueron

No había donde trabajar (bis)

Uno se fue para Arauca

y otros para Bogotá

Como allá el sueldo es muy poco

A mí no me mandan nada (bis)

Mi esposa se quiere ir

Yo sé que se desespera (bis)

Le digo que hay que esperar

Que nos regresen la tierra (bis)

Pobrecita de mi vida

Y hoy no tengo que comer (bis)

No tengo pa' la panela

Y me hace falta el café (bis)

Yo duermo es en un cambuche

Entre tablas que saqué (bis)

Con mi compañero Pedro

Un hombre de mucha fe (bis) 
Canto 22

Tí́tulo: "Llegó la hora"

Cantautor: Etni Torres

Llegó la hora de regresar a mi tierra

Donde pienso plasmar mis proyectos

De donde nos sacaron a peso de guerra

Y nos humillaron en aquellos tiempos

(bis)

Por el riachuelo, pasaban los cadáveres

Para atemorizar, a mi pueblo

Y haciendo disparos por las calles

Arruinando, hasta los cantineros

Y eso ha quedado grabado en nuestra memoria

Que no lo hemos olvidado (bis)

Para sacarnos de nuestras tierras

Mataron a nuestros hermanos (bis)

Y así robando y matando mi pueblo

Todo quedó desolado

Pero nos fuimos uniendo

Para luchar organizados (bis)

Y aprendimos a defender nuestros

derechos

Con las otras comunidades

Con los hermanos de Río Viejo

Tiquicio, Arenal y Morales (bis)

Por eso damos gracias a mi Dios del cielo

Porque de allá muchas estrellas bajaron

A alumbrar el camino como aquel lucero

Para que el triunfo se quede en nuestras manos (bis)

\section{CANTO 23}

Título: "Los Dioses de la Tierra" Cantautor: Edwin Torres

Me puse a contemplar los Dioses

Los Dioses de la tierra con este dios tan grande que es el de Israel

Allí yo pude comprender

Que él que tiene la fuerza y también

tiene la gloria

Es el que profesa Eliud y Misael

Coro

Y como yo he creído en su promesa

Así como Eliud y Misael

Y si alguno no lo tiene en cuenta

Tarde o temprano se tendrá que convencer

Ahora me siento seguro

Que en él tengo mi futuro

Pues eso no lo dudo, me pude convencer

Que él que no[h] ha dado el triunfo

Eso es tan solo uno porque él tiene el poder

Mi Cristo está cumpliendo la promesa

Porque de la tierra, él es dueño también

Aunque estas palmeras tengan mucha

fuerza

Pero no tienen más fuerza

Que el Dios temible de Israel

\section{Canto 24}

Título: "Martin Valiente y Su Mata de Caña”

\section{Cantautor: Edwin Torres}

Martín Valiente era un campesino bravo

Que a las montańas de Las Pavas se le midió

No le importaba que el tigre lo asechara

Y en su matica de cańa Martín se refugió 


\section{Coro}

Martín Valiente ahora se encuentra muy triste

Porque el catorce de Julio, la palmera lo desplazó

$\mathrm{Y}$ ahora se encuentra con el alma destrozada

Por su matica'e caña que a Martín se le perdió

Martín Valiente se encontraba muy contento

Porque el doctor Uribe era su legislador Pero cuando se dio cuenta que lo desplazaba

Martín Valiente de Uribe renegó

Coro

Yo he contado todo y no he contado lo más triste

Que a Martín Valiente después le sucedió Se le enfermó una de sus hijas Y por no tener dinero, la niña falleció

\section{Coro}

Martín Valiente ahora se encuentra muy triste

Porque el 14 de Julio la palmera lo desplazó

Y ahora se encuentra con el alma destrozada

Porque su hermosa niña solito lo dejó

\section{Canto 25}

\section{Título: "Palo de letras"}

CANTAUTOR: Etni Torres

Yo subí a la montaña

En el sur de Bolívar

De Palo de letra

Y encontré una tristeza

$\mathrm{Y}$ un silencio muy grande
Empecé a preguntarle

Para que me dijeran

Y empecé a preguntarle

Pero no me respondió

Y minero pajarito

En el camino me contó

Lo que viene sucediendo

Por toda la región

Vienen matando campesinos

A los negros y a los indios

Para robar su región

Y un minero pajarito

En el camino me contó

Lo que viene sucediendo

En las tierras del Chocó

Vienen matando campesinos

A los negros y a los indios

Para robar su honor

Y esto es injusto, pero es la realidad

Que otros países nos manden a matar (bis)

Que otros países nos vengan a robar

$\mathrm{Y}$ esto es injusto, pero es la realidad

Y esto es algo tan bello

Que no encuentro palabras

Un tesoro tan grande

Que mi dios nos regaló (bis)

Sur de Bolívar dispuesto a movilizarse A defendernos para así vivir en paz

$Y$ esto es injusto, pero es la realidad Que otros países nos manden a matar Y esto es injusto pero es la realidad Que otros países nos vengan a robar Y esto es injusto pero es la realidad Las trasversal para podernos saquear 


\section{Canto 26}

Título: "Pueblito bello"

Cantautor: Efraín Alvear

Tengo que inspirarme

Para hacerle una canción

Al pueblo de Buenos Aires

Que llevo en mi corazón

Recuerdo inolvidable

Para aquella institución

Adonde quiero educarme

Para un mańana mejor

Coro

Pueblito mío

Pueblito bello

Ahora yo quiero

Dedicarte mi canción

Si un día me muero

Aunque no quiero

Pero me toca

Porque así dispuso Dios

Hace más de ochenta años

Que Luciano lo fundó

Con machete y hacha

Pepe Torres trabajó

Con un cariño sincero

Y con el más profundo amor

Para que fundaran

Esta gran institución

Coro

Es un pueblo sencillo

Humilde y trabajador

Donde vive el cosechero

Y también el pescador

Donde todas las mañanas

Se paran con la ilusión

De ver crecer un pueblo

Orgullo de la región

Coro (bis)

\section{CANTO 27}

Título: "Lamento por mi pueblo"

CANTAutor: Efraín Alvear

En Buenos Aires todo lo había

Pesca, madera y también cacería

Playones libres con muchas crías

Donde salíamos en algarabía

Aquí se tenía todo lo que se quería

Cerdos y burros, vacas a montón

El que no pescaba, salía a cacería

Trayendo chigüiro y patos del playón

Guadalajara, Mataperro y El Cerro

Por el Peñón, Buenos Aires perdió

Y por los cadáveres en el brazuelo

En mi pueblo, la tienda se acabó

Ahora les toca a muchos vender

Los cerdos, los burros y la vacas también

Dejar su casita aunque esa de zinc

Marcharse a otra parte para no morir

Porque en mi pueblo

No hay nada que hacer

No hay la agricultura

Como en el ayer

El desastre por las palmeras

Ha sido peor que una inundación

Porque arrasaron con las veredas

Que eran orgullo de mi región

Esperanza de Dios y mi Solera

De sus muchos caminos ni rastro quedó

Aquí no hay quien vaya

Tampoco quien venga

Porque la palmera todo despojó

Compraron las tierras del campesino

Diciendo que en ellas se podía quedar

Así le marcaron a todos el camino

Por donde tuvieron todo que dejar 
Cortaron los frutos y secaron las aguas Aquí no se encuentra nada que comer Por eso no hay niños que acudan las aulas No están las familias que había ayer

Aquí ahora sólo se pueden ver Colegios sin nińos y casas sin mujer Razón del destino, marcado ayer Por las Palmeras, el nuevo cartel

\section{Canto 28 \\ Título: "Sentimiento de mi pueblo" CANTAUTOR: Efraín Alvear}

En este canto

Yo quiero declarar

El sentimiento

Que en mi pueblo puedo ver

Gente valiente

Que no cesa de luchar

Por un mañana

Que será mejor que el ayer

Tenemos en mente

Que seremos un municipio

En la Isla de Papayal

Partiendo de este principio

Que seremos la despensa territorial

Teniendo agricultura

Y también ganadería

Llegaremos a ser

Una zona industrial

Porque transformaremos

Con la eléctrica energía

La materia prima

Hasta ponerla a comerciar

\section{Canto 29}

Título: "El mico desplazado"

Cantautor: Edwin Torres

En una mata de monte

Hay una guartinaja oculta

Ella vio venir de lejos

A un mico y su familia

Ella le preguntó:

"Amigo, ¿para dónde viaja?

Y el mico le contesto:

"Miren, que cipote vaina:

El hombre me desplazó

Con grandes maquinarias

Tumbaron las montañas

Tierra donde yo habitaba

Tumbaron las montañas

De Solera y Las Pavas"

Entonces, ella le dijo:

"Yo también soy desplazada,

Mataron a mi padre

Y mi madre falleció

Y sola he quedado,

Yo entre los animales

Entre los animales,

Sola he quedado yo

Sola he quedado yo

Entre los matorrales

Entre los matorrales

Sola he quedado yo

\section{Canto 30}

Título: "Una voz en la montaña"

Cantautor: Edwin Torres

Si se escucha una voz dentro de la montaña

Es el Monchi Pavero que va cantando

Le canta con amor a las mujeres

$\mathrm{Y}$ al proceso de Las Pavas 
Yo soy un campesino desplazado

Aunque pa' mucha gente no valgo nada Yo soy un campesino desplazado

Aunque para el gobierno no valgo nada

Porque no soy un empresario

Que explota oro y siembra palma

Yo tengo mucha gente que me critica

Que por qué mis derechos yo reclamo

Y esto es lo digno de un ser humano Por eso mis derechos yo los reclamo

Y esto es lo digno de un colombiano

Por eso mis derechos yo reclamo

\section{Canto 31}

Título: "De aquí no nos vamos a ir" CANTAUtor: Etni Torres

Hay un proceso en el sur de Bolívar

Donde tratamos de arreglar las cosas

$Y$ hay un gobierno que dice mentiras

Y hasta nos mata pa' callarnos la boca

De aquí no nos vamos a ir

Aquí nos vamos a quedar

$\mathrm{Y}$ aquí nos toca luchar

Pa' poder sobrevivir

Pertenecemos a la Federación

Y allí luchamos toditos unidos

Tenemos mesa de interlocución

$\mathrm{Y}$ ahí nos sentamos con muchos amigos

Ahí presentamos todos los problemas

Pa' que el gobierno nos pueda escuchar

Estamos cansados de tanta guerra

Llego el momento de buscar la paz

Si conocieran lo que hemos vivido

En esta historia les voy a contar

Ahí han matado muchos amigos

Y la semilla terminó envenenada

\section{CANTO 32}

Título: "Campesino de verdad" Cantautor: Edwin Torres

Soy campesino, un campesino de verdad Orgullosamente yo soy un buen Pavero Es aquí donde tengo la oportunidad De hace canciones y cantarle a mi pueblo

Soy bonaerense, nunca lo podré negar Porque he crecido en las calles de pueblo Ay Buenos Aires, ¿cómo te voy a olvidar? Fuiste la cuna donde me criaron mis viejos

Desde muy niño yo aprendí a valorar Esa cultura que tiene mi bello pueblo Ay Buenos Aires que es tierra de paz A donde nacen muchos hombres buenos

De aquellos hombres que yo les quiero hablar

De aquellos hombres que les dicen cambucheros

Yo los admiro por su capacidad

De resistencia y se ser buenos obreros

\section{Canto 33}

Título: Digamos sí al plebiscito

Cantautor: Etni Torres

Digamos Sí al plebiscito

Sé que mañana sale un sol distinto

La nueva luz a mi país yo veo llegar

Feliz me siento al ver correr mis hijos

Y que una mina, no escuche explotar (bis)

Toda mi gente tiene la esperanza

Que ahora las cosas sí pueden cambiar

Solo pongamos un poco de confianza

$\mathrm{Y}$ al plebiscito sí hay que votar 
Allá en Las Pavas hay un grano de arena Por esa paz que ha luchado ASOCAB Hay acabemos esta bendita guerra Llegó el momento de perdonar $\mathrm{Y}$ al plebiscito sí hay que votar

Ay mi país ya se encuentra cansado De esta guerra que tocó librar Pero si hay unos que han aprovechado Y a los del campo nos toca llorar $\mathrm{Al}$ plebiscito sí hay que votar

\section{Cantos Comunidad El Garzal}

\section{Canto 34}

Título: "Los veinte años de Lucha" Cantautor: Daniel Retamoza

Pongan cuidado muchachos

Lo que les vengo a cantar Que aquí en el Sur de Bolívar Hay tierra pa'trabajar.

Aquí se encuentra un pueblito

Que se llama Garzal

Garzal es corregimiento

Y está cerca de Vijagual

Vivimos en la parcela

Para poder comprobar

Que somos dueños de la tierra

Y que queremos trabajar (bis)

Estas son tierras baldías Hoy son tierras del Estado Propias para los campesinos Que somos muy maltratados Aquí veinte años de lucha De lucha, pero con paz Porque es que el bendito río No nos deja trabajar

Y ahora ha aparecido un capo Que no la quiere quitar Tiene documentos falsos
Y la justicia comprada Por eso no da la cara Para poder comprobar Que son dueños de esta tierra Y que hay que desocupar

Muchachos a trabajar Pongámosle fin a esto Todos juntos hay que sembrar Para reforzar el proceso

Porque si no trabajamos

No podemos ayudar A Rafa y a Salvador Y a la demás entidad Que ellos pelean por nosotros Para este pleito ganar

Hay unos que trabajamos Y otros nada más que ven Viven pendientes de los títulos Yo no sé porque será Sea por mal o sea por bien Pero es la pura verdad

Habiendo buenos trabajos Nada nos preocupará Que llegue la Comisión De inspección ocular Porque así de esa manera Los títulos puedan dar (bis)

\section{Canto 35}

Título: Sin título

CANTAUTOR: Daniel Retamoza

Escuchen hermanos míos

Lo que a mí me sucedió

En este mundo perdido

En el cual andaba yo

Y le doy gracias a Dios

Porque él de allí me saco 
Y yo alabo a mi Cristo

Porque mi alma alimentó

Y al espíritu santo

Que de gozo me llenó

Por eso yo siento gozo

Gozo es lo que siento yo

Gozo sentimos nosotros

Cuando alabamos a mi Dios

Este gozo que tenemos

Nadie más lo puede dar

Tan sólo mi Jesús Cristo

Porque él sí nos sabe amar

Él es nuestro padre amado

Que nos ha dado el perdón

El murió crucificado

Por darnos la salvación

Por eso mi amado hermano

No vamos a desmayar

Porque pasito adelante

A la meta hay que llegar

No le vamos a abofetear

Ni le causemos dolores

Porque con Cristo Jesús

Somos más que vencedores

\section{Canto 36}

Título: "Los comentarios"

\section{CANTAUTOR: Daniel Retamoza}

Yo compuse esta canción Y aquí la vengo a cantar Ahora que ha llegado el juez Esto lo vamos a arreglar

La tierra donde trabajamos Ya nos la quieren quitar Y en esta tierra partida Y lo podemos comprobar
Porque esto cuando

Esto era hacienda

Aquí nadie podía entrar

Porque si se descuidaba

$\mathrm{Al}$ (...) iba a dar

Para que allí descansara

Por toda su eternidad

Hablado:

O sino que lo diga mi amigo Juaco

Que lo andaban buscando para mostrar el camino y prefirió

Tirarse al rio

Dos horas hundiendo y saliendo

Que nada más se le veía el sombrero

Para no dejarse mostrar el camino

El gobierno se enteró

El gobierno se enteró

Porque hasta allá llegó el rumor

$\mathrm{Y}$ fue cuando bombardearon

La pista en el Totumo

Porque había mucho ganado

Mucho ganado escogido

Y de aquí lo transportaban

A los Estados Unidos

Hablado:

$Y$ ese kilo de carne

Valía era dólares

Porque era pura novilla fina

De Arauca traían la hoja (bis)

A la hacienda a procesar

Porque la Hacienda dizque era (bis)

De Gacha y Pablo Escobar

Yo que todo lo creía,

Yo no me podía creer esto

Que él que les administraba

Era Luis Enrique Barreto.

$\mathrm{Y}$ entonces porque carajos

Él puede ser dueño de' sto 
Miren lo que sucedió (bis)

Esto tenía que pasar

Primero matan a Gacha

Y después a Pablo Escobar

Y Luis Enrique Barreto

A Simití fue a pararse

Para arreglar los papeles

Y con la hacienda quedarse

Y él que arregló los papeles

Mejor que se vaya huyendo

Hablado: Si es que está vivo

Porque todos los corruptos

A la cárcel 'tán cayendo.

Y él que se encuentre empolvado

Que se vaya sacudiendo

Lo dicho del presidente

Hasta ahorita lo están cumpliendo

Y él que se encuentre embarrado

Pues que se vaya limpiando

Porque es que la fiscalía

Ahora sí está investigando.

\section{Canto 37}

\section{Título: "Don Carmelo"}

Cantautor: Samuel Mendoza y Ovidio

Aguilar

Don Carmelo camina por la ciudad

Con su esposa y sus tres hijos

Pero se sienten extrańos

Don Carmelo extraña todo lo de allá

Las montańas, los cultivos,

La brisa cerca del campo

El primero de enero

Estrenando Año Nuevo

Don Carmelo estaba alegre

Pues fue muy buena la cosecha en

diciembre

Y estaba dándole gracias a Dios
Pero en ese momento de la nada salieron Hombres extraños

Con un tono imponente

Hoy don Carmelo está triste

Camina a su lado en la calle

Una moneda que alguno le regale

Como un salario para poder vivir

Hoy don Carmelo está triste

Entre personas que lo miran muy raro

No como víctima sino como el malo

Acá tampoco lo quieren recibir

Don Carmelo no hizo nada malo

Él solo quería vivir en paz

Don Carmelo pertenece al campo

Porque allá es tierra feliz

De allá lo echaron pero allá no lo reciben

Tres días tienen los niños sin comer

Uno se encuentra enfermo

Y don Carmelo está llorando

Pobrecito ya no encuentra ni que hacer

Cuando lo quiere poner

Ay, Don Carmelo está llorando

Don Carmelo regresa

Como una gran princesa

Se encuentra su mujer en el suelo

llorando

El pequeñito los había abandonado

\section{Canto 38}

Título: "Creación Universal”

Cantautor: Canto eclesiástico

Siento que te quiero más y más

Que no te puedo olvidar

Olvidarte es imposible

Eres la razón de mi cantar

Fundamento de mi andar

Esperanza que se vive 
$[\ldots]$

Con todas las fuerzas

Que me dan

Quiero gritar para que vivamos felices

Porque tú eres mi seguridad

Mi solución a lo que yo necesite

Mi dicha, mi felicidad

Eres todo lo que mi corazón te brinde

Eres mi felicidad

Eres todo lo que mi corazón te brinde

Mi pensamiento, al caminar

Mi ocupación al trabajar

Mi mejor canción y mi baluarte

Mi pensamiento, mi ansiedad

El aroma fresco al despertar

En un día lleno, de deberes

[...]

Te doy las gracias para contemplar

La creación universal ya tornada de arco

iris
Va una sonrisa tan natural

Del vaivén del ancho mar

De los cerros o jardines

Pero no puedo comparar el amor que tú me das

No lo encuentro, ¿dónde existe?

Solo al pensar que un día estaré

Arrullado en tus brazos padre querido

Siento que el calor corre en mi ser

Que solo siento y no puedo decirlo

Explicarlo yo no podre

Lo que sí sé es que por tu amor yo vivo

Es mi amor que llevo en mi ser

Me fortaleció y me dio el poder

Para vencer el enemigo

No sé cómo agradecer

No encuentro palabras, callaré

Que mi corazón hable contigo. 

